

\section{A Business Ecology Perspective on Community-Driven Open Source}

The Case of the Free and Open Source Content Management System Joomla

Markus Radits

2019

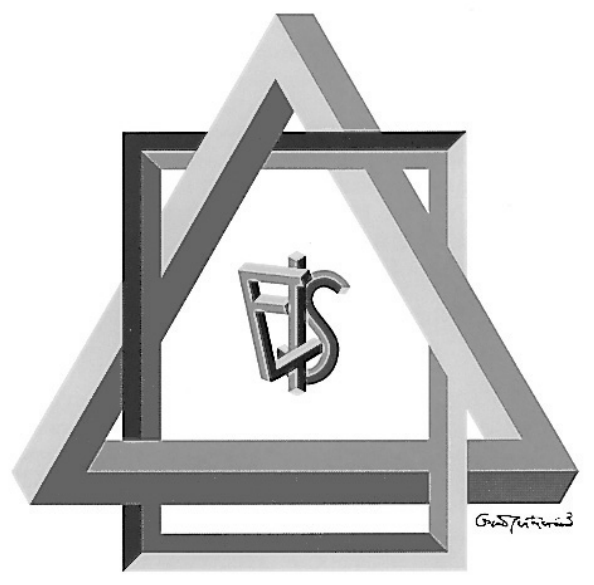

Economic Information Systems

Department of Management and Engineering

Linköping University, 58183 Linköping

www.liu.se 
(C) Markus Radits 2019

A Business Ecology Perspective on Community-Driven Open Source: The Case of the Free and Open Source Content Management System Joomla

Linköping Studies in Science and Technology

Both the cover image and the tree image used in this thesis were acquired from $123 r$ stock content agency. The right to use these images in this thesis is secured through the standard licence from $123 \mathrm{rf}$.

Dissertation No. 1937

ISBN: 978-91-7685-305-4

ISSN: 0345-7524

Printed by LiU-Tryck, Linköping 2019

Distributed by Linköping University

Department of Management and Engineering

SE-581 83 Linköping 


\section{Abstract}

This thesis approaches the phenomenon of open source software (OSS) from a managerial and organisational point of view. In a slightly narrower sense, this thesis studies commercialisation aspects around community-driven open source. The term 'community-driven' signifies open source projects that are managed, steered, and controlled by communities of volunteers, as opposed to those that are managed, steered, and controlled by single corporate sponsors.

By adopting a business ecology perspective, this thesis places emphasis on the larger context within which the commercialisation of OSS is embedded (e.g., global and collaborative production regimes, ideological foundations, market characteristics, and diffuse boundary conditions). Because many business benefits arise as a consequence of the activities taking place in the communities and ecosystems around open source projects, a business ecology perspective may be a useful analytical guide for understanding the opportunities, challenges, and risks that firms face in commercialising OSS.

There are two overarching themes guiding this thesis. The first theme concerns the challenges that firms face in commercialising communitydriven OSS. There is a tendency in the literature on business ecosystems and open source to emphasise the benefits, opportunities, and positive aspects of behaviour, at the expense of the challenges that firms face. However, business ecosystems are not only spaces of opportunity, they may also pose a variety of challenges that firms need to overcome in order to be successful. To help rectify this imbalance in the literature, the first theme particularly focuses on the challenges that firms face in commercialising communitydriven OSS. The underlying ambition is to facilitate a more balanced and holistic understanding of the collaborative and competitive dynamics in ecosystems around open source projects.

The other theme concerns the complex intertwining of community engagement and profit-oriented venturing. As is acknowledged in the literature, the subject of firm-community interaction has become increasingly important because the survival, success, and sustainability of peer production communities has become of strategic relevance to many organisations. However, while many strategic benefits may arise as a consequence of firm-community interaction, there is a lack of research studying how the value-creating logics of firm-community interaction are embedded within the bigger picture in which they occur. Bearing this bigger picture in mind, this thesis explores the intertwining of volunteer community engagement and profit-oriented venturing by focusing on four aspects that 
are theorised in the literature: reinforcement, complementarity, synergy, and reciprocity.

This thesis is designed as a qualitative exploratory single-case study. The empirical case is Joomla, a popular open source content management system. In a nutshell, the Joomla case in this thesis comprises the interactions in the Joomla community and the commercial activities around the Joomla platform (e.g., web development, consulting, marketing, customisation, extensions). In order to achieve greater analytical depth, the business ecology perspective is complemented with ideas and propositions from other theoretical areas, such as stakeholder theory, community governance, organisational identity, motivation theory, pricing, and bundling.

The findings show that the common challenges in commercialising community-driven OSS revolve around nine distinct factors that roughly cluster into three domains: the ecosystem, the community, and the firm. In short, the domain of the ecosystem comprises the global operating environment, the pace of change, and the cannibalisation of ideas. The domain of the community comprises the platform policy, platform image, and the voluntary nature of the open source project. And finally, the domain of the firm comprises the blurring boundaries between private and professional lives, the difficulty of estimating costs, and firm dependencies. Based on these insights, a framework for analysing community-based value creation in business ecosystems is proposed. This framework integrates collective innovation, community engagement, and value capture into a unified model of value creation in contexts of firm-community interaction.

Furthermore, the findings reveal demonstrable effects of reinforcement, complementarity, synergy, and reciprocity in the intertwining of volunteer community engagement and profit-oriented venturing. By showing that this intertwining can be strong in empirical cases where commercial activities are often implicitly assumed to be absent, this thesis provides a more nuanced understanding of firm involvement in the realm of open source.

Based on the empirical and analytical insights, a number of further theoretical implications are discussed, such as the role of intersubjective trust in relation to the uncertainties that commercial actors face, an alternative way of classifying community types, the metaphor of superorganisms in the context of open source, issues pertaining to the wellbeing of community participants, and issues in relation to the transitioning of open source developers from a community-based to an entrepreneurial self-identity when commercialising an open source solution. Furthermore, this thesis builds on six sub-studies that make individual contributions of their own. 
In a broad sense, this thesis contributes to the literature streams on the commercialisation of OSS, the business value and strategic aspects of open source, the interrelationships between community forms of organising and entrepreneurial activities, and the nascent research on ecology perspectives on peer-production communities. A variety of opportunities for future research are highlighted.

Keywords: open source software, open source community, business ecology, business ecosystem, firm-community interaction, community stakeholders, community governance, organisational identity, collective identities, motivation theory, participation patterns, pricing, bundling, Joomla 


\section{Sammanfattning}

Denna avhandling undersöker fenomenet öppen källkod, 'open source', ur ett lednings- och styrningsperspektiv. Mer konkret studeras aspekter på kommersialisering av ett community-drivet open source projekt (OSS, open source software). Uttrycket 'community-drivet' hänvisar till open source projekt som drivs och styrs av volontärgrupper, till skillnad från open source projekt som drivs och styrs av enskilda företag.

Genom att tillämpa ett affärsekologiperspektiv fokuserar denna avhandling på det vidare sammanhang som karaktäriserar kommersialisering av OSS, såsom globala och kollaborativa produktionssystem, värderingarna öppenhet och samarbete, marknadsstrukturer, och diffusa organisationsgränser. Aktiviteterna i open source communityn och dess kringliggande ekosystem kan bidra till många fördelar för företag, och därför kan ett affärsekologiperspektiv vara en användbar analytisk lins för att förstå de möjligheter, utmaningar och risker som företag står inför när de kommersialiserar OSS.

Två övergripande teman lyfts fram i denna avhandling. Det första temat handlar om de utmaningar som företag står inför när de kommersialiserar community-driven OSS. Det finns i litteraturen om affärsekologier och open source en tendens att betona fördelar, möjligheter och positiva aspekter på beteende på bekostnad av att undersöka utmaningar som företag står inför. Affärsekologier innebär dock inte enbart möjligheter för företag, utan kan också orsaka en rad utmaningar som företag behöver hantera för att lyckas. Med utgångspunkt i denna obalans i litteraturen fokuserar det första temat på de utmaningar med kommersialisering av community-driven OSS. Detta görs för att bidra till en mer balanserad och holistisk förståelse av den på samma gång kollaborativa och konkurrerande dynamiken i affärsekologin runt ett open source projekt.

Det andra temat handlar om sammanflätningen (intertwining) mellan community-deltagande och vinstdrivande verksamhet. Såsom det framgår i litteraturen har frågan om samverkan mellan företag och communities blivit allt viktigare, eftersom communityernas överlevnad, framgång och hållbarhet har blivit strategiskt viktiga för många organisationer. Även om många strategiska fördelar kan uppstå som en följd av samverkan mellan företag och communities saknas forskning om hur värdeskapande uppstår i en vidare kontext. Med ett bredare perspektiv i åtanke undersöker denna avhandling sammanflätningen av frivilligt community-deltagande och en vinstdrivande verksamhet genom att fokusera på fyra aspekter av sammanflätning som förekommer i litteraturen: förstärkning, komplementaritet, synergi, och ömsesidighet. 
Denna avhandling är utformad som en kvalitativ utforskande fallstudie. Det empiriska fallet är Joomla, ett innehållshanteringssystem som bygger på open source. Inom ramen för avhandlingen undersöks fallet i termer av samspel inom Joomla-communityn och de kommersiella aktiviteterna som sker runt Joomla-plattformen (t.ex., webbutveckling, rådgivning, marknadsföring, anpassningar, och extensions). För att uppnå ett analytiskt djup kompletteras affärsekologiperspektivet med idéer och förslag från andra teoretiska områden, såsom intressentmodellen, community-styrning, företagsidentitet, motivationsteori, prissättning, och buntning.

Resultaten visar att utmaningarna med kommersialisering av community-driven OSS kretsar kring nio olika faktorer som kan grupperas i tre områden: ekosystemet, communityn, och företaget. Ekosystemsfaktorerna innefattar den globala verksamma miljön, förändringshastigheten och kannibalisering av idéer. Community-faktorerna innefattar plattformspolicy, plattformsimage, och att deltagandet i open source projektet sker på frivillig basis. Slutligen innefattar företagsfaktorerna suddiga gränser mellan privatliv och arbetsliv, svårigheten att uppskatta kostnader samt beroendeförhållanden mellan företag. Baserat på dessa insikter föreslås en modell för att analysera community-baserad värdeskapande i affärsekologier. Modellen integrerar kollektiv innovation, community-deltagande, och value capture i en holistisk modell för community-baserad värdeskapande i kontexten samverkan mellan företag och communities.

Vidare beskrivs effekterna av sammanflätningen av frivilligt communitydeltagande och vinstdrivande verksamhet i termer av förstärkning, komplementaritet, synergi, och ömsesidighet. Genom att visa att sammanflätningen av frivilligt community-deltagande och vinstdrivande verksamhet kan vara stark i fall där det ofta antas implicit att kommersiella aktiviteter inte förekommer ger denna avhandling en mer nyanserad förståelse av företags roll i kontexten open source.

Baserat på empiriska och analytiska insikter diskuterar denna avhandling ett antal teoretiska konsekvenser, såsom rollen som intersubjektiv tillit spelar i förhållande till den ovisshet som kommersiella aktörer står inför, ett alternativt sätt att klassificera community-typer, metaforen superorganismer i kontexten open source, community-deltagares välbefinnande, samt hur open source utvecklare hanterar övergången från en community-baserad självidentitet till en entreprenöriell självidentitet vid kommersialisering av OSS. Dessutom ger de sex delstudier som avhandlingen bygger på egna bidrag som presenteras i respektive delstudie.

I stora drag bidrar denna avhandling till litteraturen om kommersialisering av OSS, affärsmässiga och strategiska aspekter på open 
source, samspelet mellan community-driven entreprenörsverksamhet samt den framväxande forskning som använder ett affärsekologiperspektiv för att studera kollegial produktion baserad på allmännytta. En mängd olika möjligheter för framtida forskning lyfts fram. 


\section{Preface}

In Economic Information Systems, our main focus is where management and IT meet, not least the new, fast-growing, IT-intense organisations. More specifically, we deal with how information is transferred from, between and to people, and with the potential in and consequences of digitisation. The area includes research on business development, management control, and knowledge and competence development, especially in organisations where use of IT plays an important role.

We study the roles that strategies and information systems play in the collaboration between people in organisations in different sectors (public, private and non-profit), networks and coalitions, and the interaction with the surrounding ecologies. Perspectives management - perceiving and handling the perspectives of different stakeholders - is an important part in the striving for a deeper and more nuanced understanding of the phenomena we study.

Our PhD students also participate in the Swedish Research School of Management and Information Technology, a collaboration between a dozen Swedish universities and university colleges. In line with its name, the research school organises courses, $\mathrm{PhD}$ conferences and supports $\mathrm{PhD}$ candidates within management and IT, thus providing a wide network.

The present thesis, A Business Ecology Perspective on CommunityDriven Open Source - The Case of the Free and Open Source Content Management System Joomla, is written by Markus Radits. He presents it as his doctoral thesis in Economic Information Systems at the Department of Management and Engineering, Linköping University.

Linköping, November 2018

Alf Westelius

Professor,

Economic Information Systems 


\section{Acknowledgements}

This work would not have been possible without the help and support of many people. First and foremost, I want to thank the three seniors at our division, Alf, Nils-Göran, and Carl-Johan, whose ideas and thoughts had a great impact on my work.

Alf, my supervisor, was an incredible source of inspiration and a great intellectual guide. While he gave me a lot of freedom to pursue my research interests, he also encouraged my ability to reflect critically and make informed decisions as a researcher. Without Alf's support and mentoring, this thesis would not exist in its present form. I want to thank him, not only for his constructive and elaborate feedback, but also for all his sympathy and compassion when I faced challenging and difficult times.

Further, I want to thank Nils-Göran, my co-supervisor. He often stimulated interesting and enlightening discussions during our divisioninternal seminars. During my thesis work, I benefited greatly from his experience, feedback, and advice. In particular, I want to thank him for the time and efforts that he gave in reading, commenting upon, and critiquing my work and my writing. Now that he has officially retired from his duties at LiU, I wish him all the best with his further projects.

I also benefited greatly from the involvement and presence (and telepresence) of Carl-Johan, my second co-supervisor. I want to thank him for all the thought-provoking discussions and suggestions, and for backing me in my teaching at LiU. Carl-Johan often brought in new perspectives into my thinking. Through his initiative, I had the opportunity to co-author a book chapter on the pricing of digital products together with Einar Iveroth. This was yet another exciting opportunity for me to learn.

Moreover, I want to thank my PhD colleagues and three more seniors at EIS who have accompanied me throughout these years. In alphabetical order, these are: Emelie, Erik, Fredrik, Margaret, Mathias, Özgün, Susanne, and Thomas. Although some of them have left EIS in the meantime, I want to thank everyone for criticising and scrutinising my work from so many different angles. They have helped me to challenge my own assumptions, thereby helping me to broaden my intellectual horizons. I want to say a special thanks to Emelie who edited the Swedish summary of this thesis (Sammanfattning).

I also want to thank my colleagues and friends on our division's corridor, those in other corners of the campus, and those who have left the campus in the meantime whom I had the pleasure of getting to know. You made working at the campus much more lively, fun, and inspiring. 
Furthermore, I want to thank Kevin Crowston, professor at Syracuse University, for acting as a discussant during my pre-final seminar. For me, Kevin's involvement was another exciting opportunity to have my work exposed to the scrutiny of an experienced and knowledgeable scholar within the field. I want to thank Kevin for the time that he spent on reading and discussing my work. We had an interesting and productive seminar, which gave me lots of valuable input for improving my thesis. I cannot thank him enough for this.

I also want to thank my colleagues at our Sweden-wide research school, 'Management and $\mathrm{IT}^{\prime}$. The two annual conferences organised by our research school provided us, the PhD students, with the opportunity to expose our research to a wider academic audience, beyond the confines of our divisions. Much of the critique and feedback that I received from my colleagues at these conferences translated into improvements of the texts that I was working on. In particular, I want to thank the reviewers, discussants, and session participants for their engagement and constructive critique.

Funding for my PhD program was provided by Linköping University and the research school 'Management and $\mathrm{IT}^{\mathrm{T}}$. I am grateful for the financial and organisational backing that I received from these institutions. I also want to thank Johan, our division's head, and Alf for their understanding and support, enabling me to continue working on my thesis over an extended period of time. Moreover, I want to thank Karin, Görel, and Erika for all the help in administrative and organisational matters.

My further sincere thanks go to all the people who agreed to be interviewed by me during the course of this thesis project. I am very grateful that they shared their experiences, thoughts, and insights with me so openly. Thanks to them I have been able to draw on rich and interesting data while conducting my studies.

Finally, I want to thank my parents and my friends for the emotional and social support during what I would call an exciting, but also tense and taxing period in my life. I owe you a great deal and will always be grateful to you.

Linköping, November 2018

Markus Radits 


\section{Table of contents}

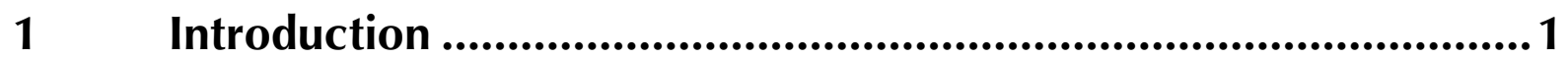

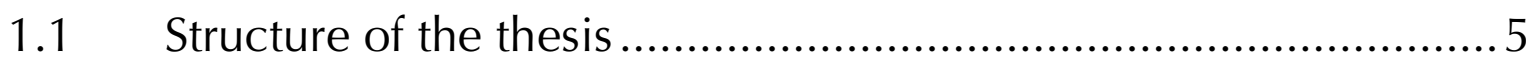

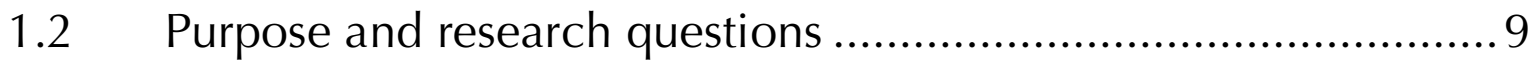

1.2.1 The challenges in commercialising community-driven OSS (Theme 1) ............................................................ 10

1.2.2 The intertwining of community engagement and profitoriented venturing (Theme 2 ) .......................................... 11

$2 \quad$ Background and literature review ............................................... 13

2.1 Historical roots of open source and its evolution .................... 13

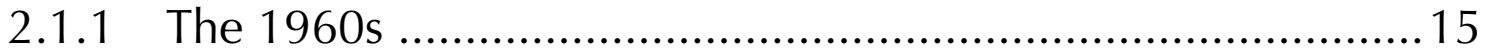

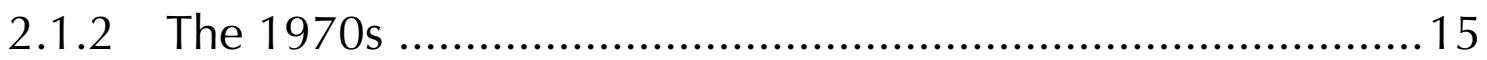

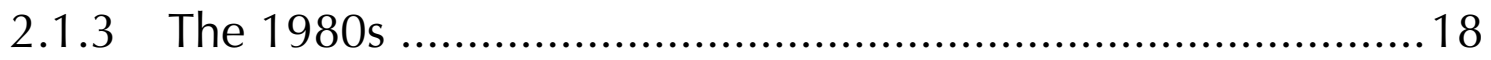

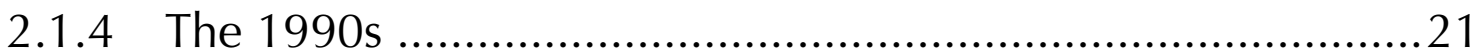

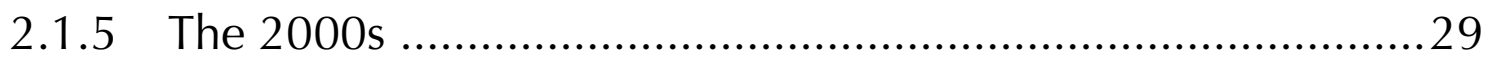

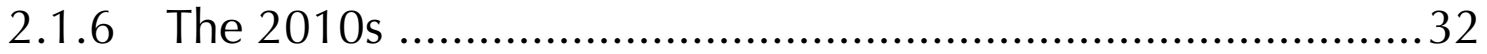

2.2 Theorising on open source in the management fields ..............37

2.2.1 General characteristics of open source..............................37

2.2.2 Salient themes from a historical point of view ......................38

2.2.3 Developer-centrism in the literature ................................. 41

2.2.4 The structure of open source communities ........................ 42

2.2.5 Business value and strategic aspects around open source .....43

2.2.6 Ecology perspectives in the realm of open source ................46

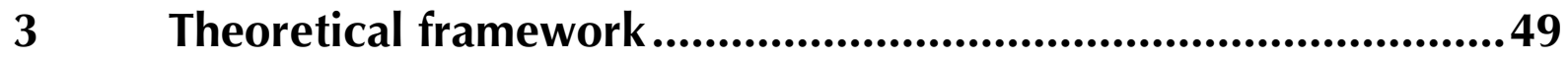


3.1 Business ecology .......................................................... 50

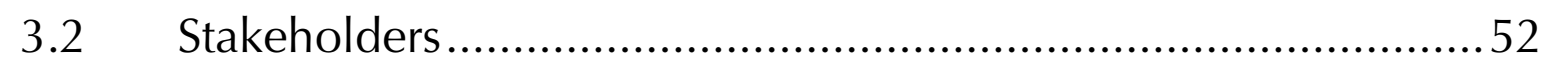

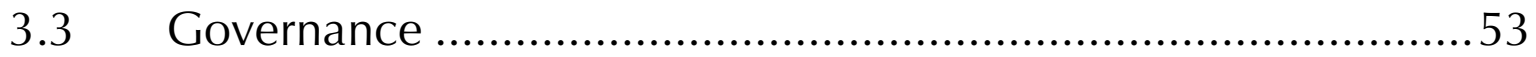

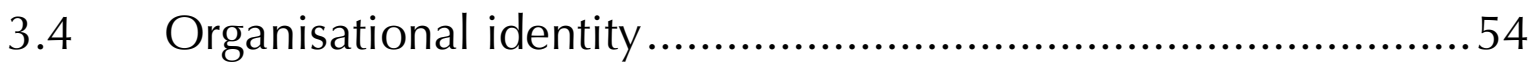

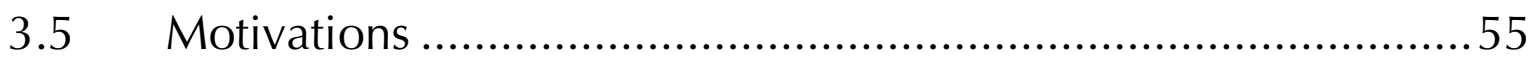

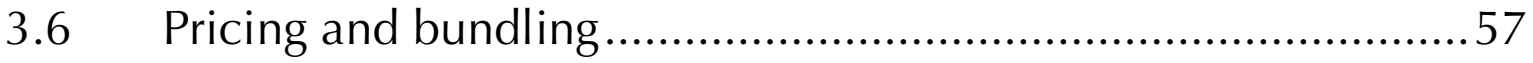

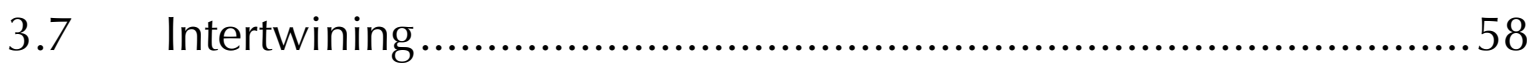

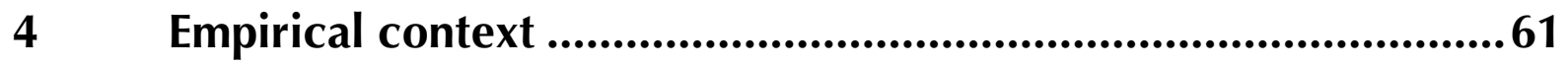

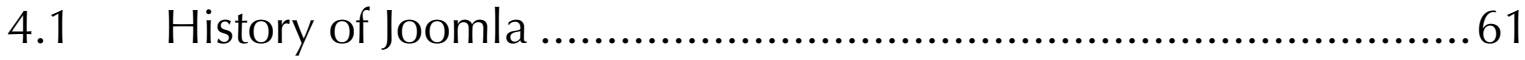

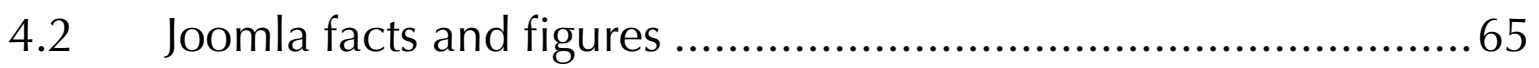

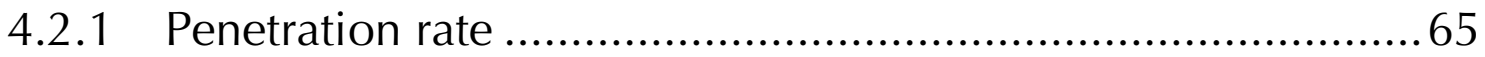

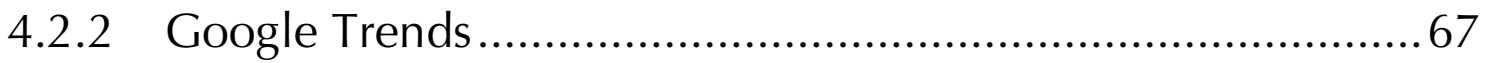

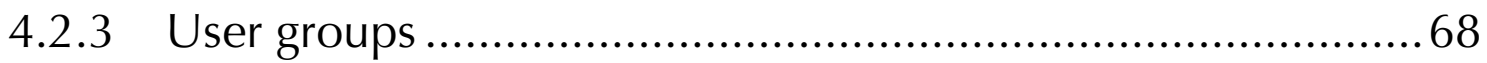

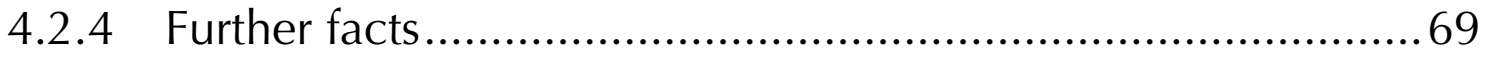

4.3 Organisational structure .................................................. 70

4.3.1 Open Source Matters ..................................................... 70

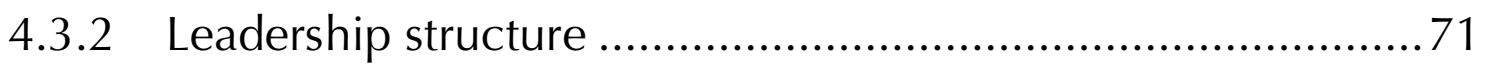

4.4 The mission, vision, and values of Joomla.............................. 75

4.5 Commercial services around Joomla ...................................... 76

$5 \quad$ Methodological approach and research design...........................77

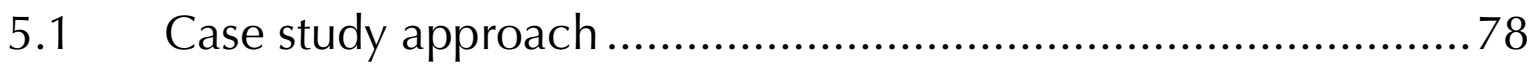

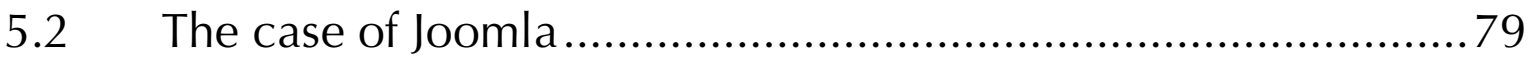

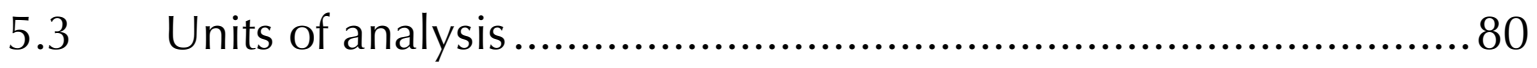




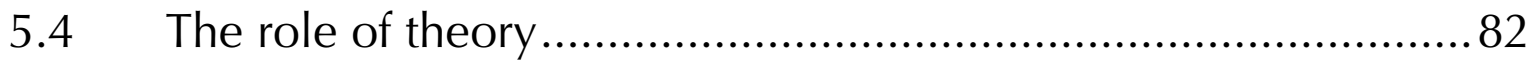

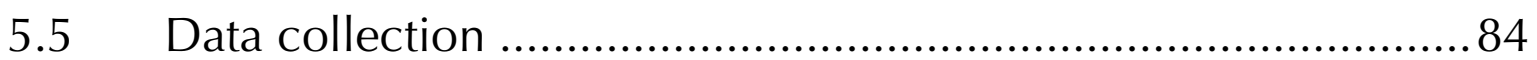

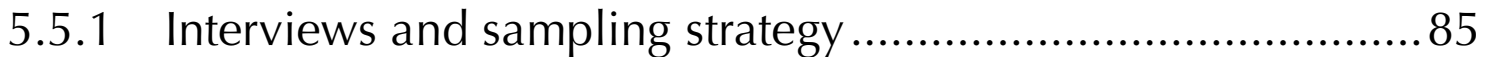

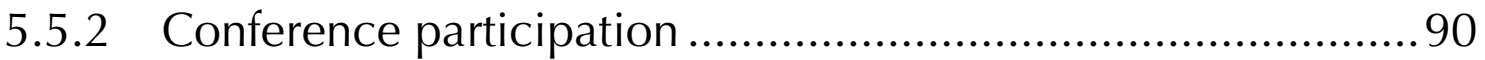

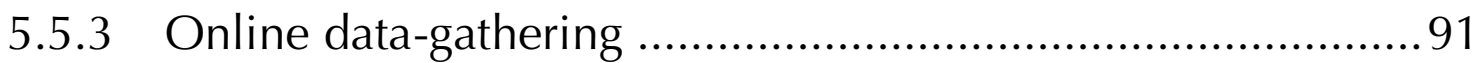

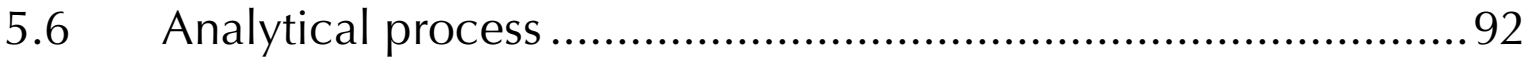

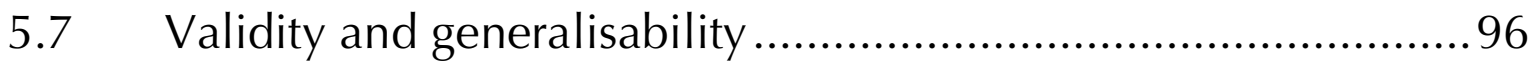

6 A multi-stakeholder perspective on community-driven open source (Study I) .....................................................................99

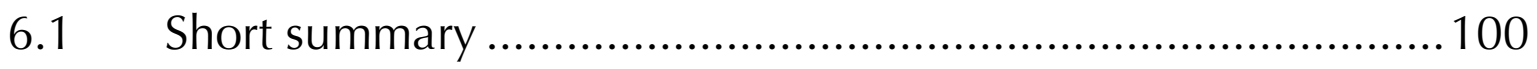

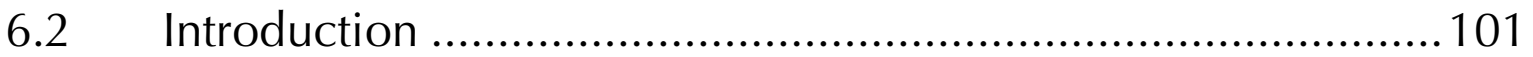

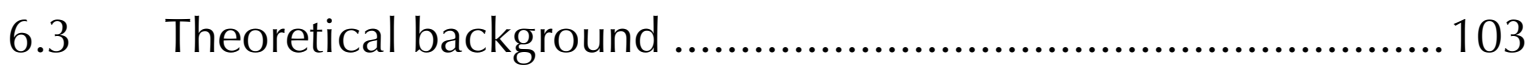

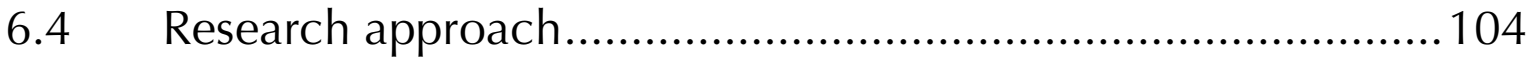

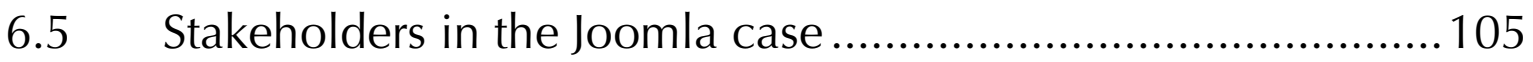

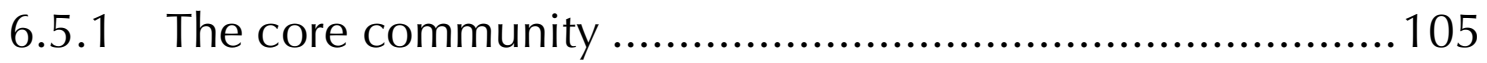

6.5.2 Domestic communities............................................... 107

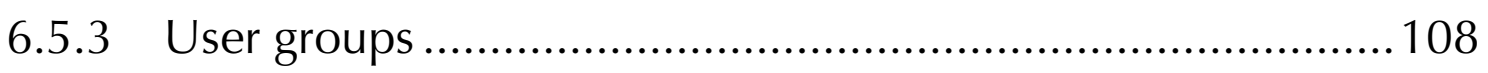

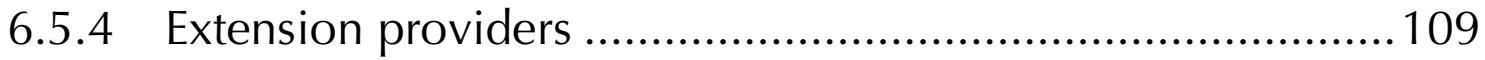

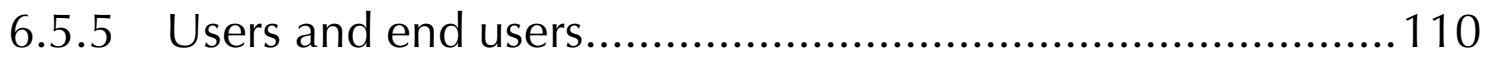

6.5.6 Providers of value-added services .................................. 111

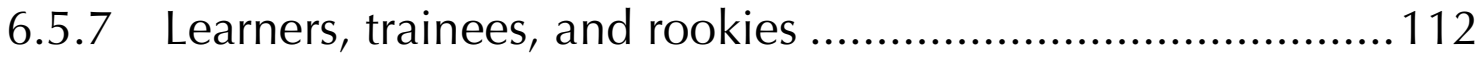

6.5.8 Sponsors, partners, and advertisers .................................. 113

6.5.9 The wider Internet community ........................................ 114

6.5.10 Policy makers and standard setters .................................117 


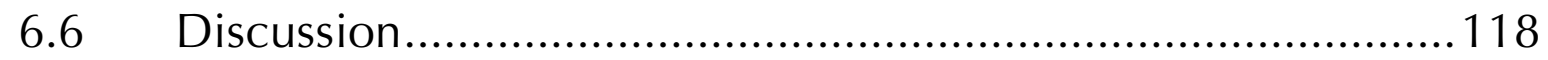

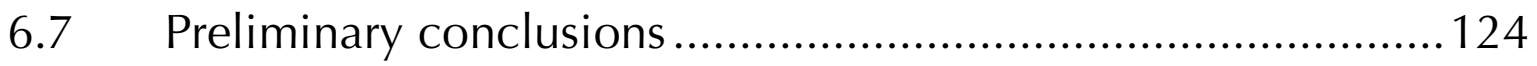

7 An integrative framework for open source governance (Study

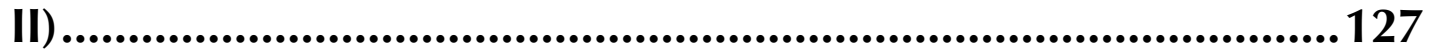

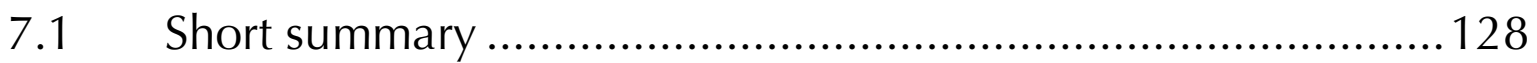

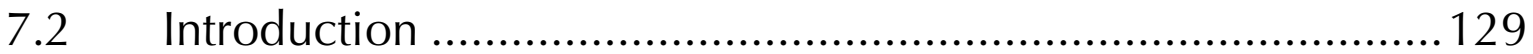

7.3 Theoretical background on open source governance..............130

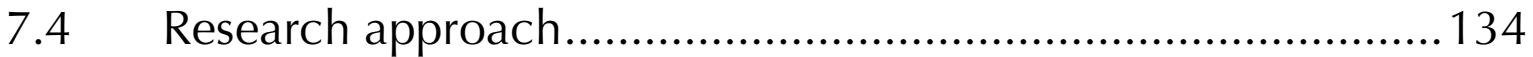

7.5 Key dimensions in open source community governance ........135

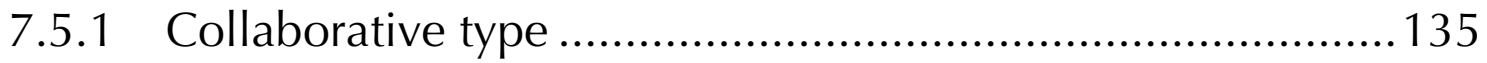

7.5.2 Patronage and sponsorship ...........................................137

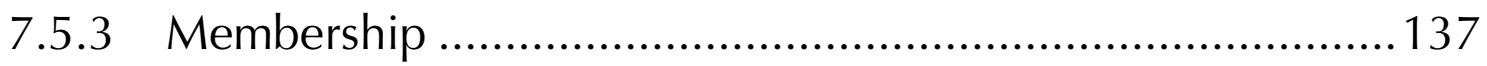

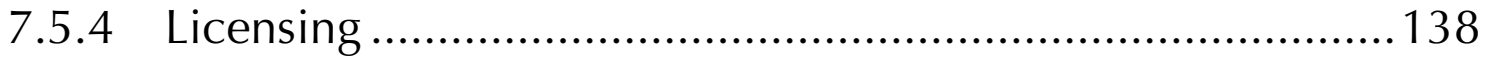

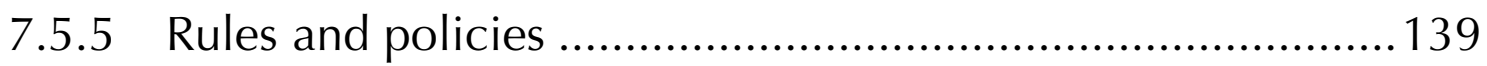

7.5.6 Decision-making and conflict resolution .......................... 141

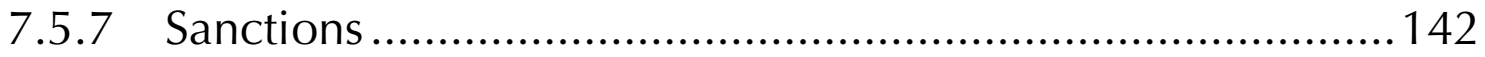

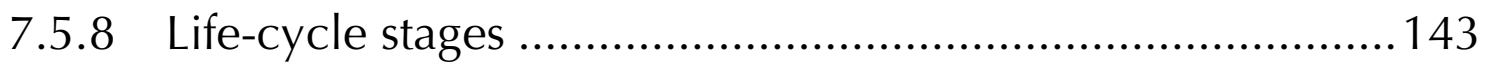

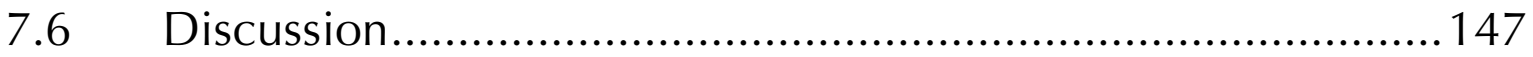

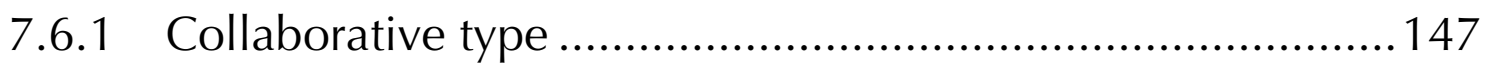

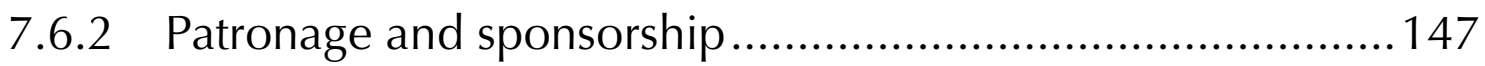

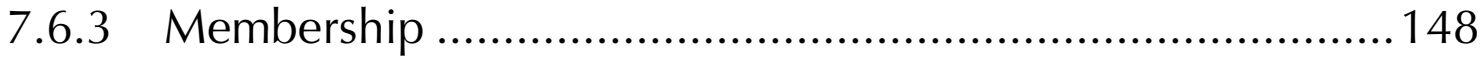

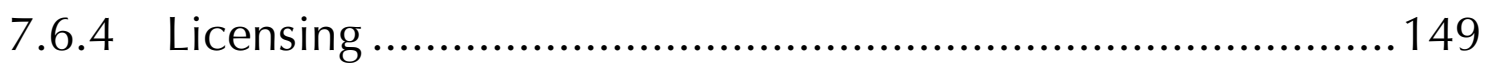

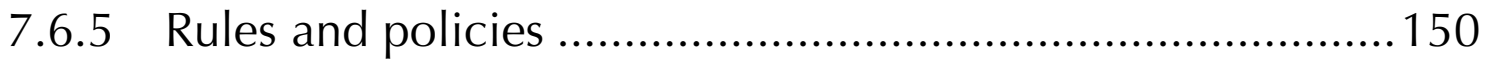

7.6.6 Decision-making and conflict resolution .......................... 152 
7.6.7 Sanctions

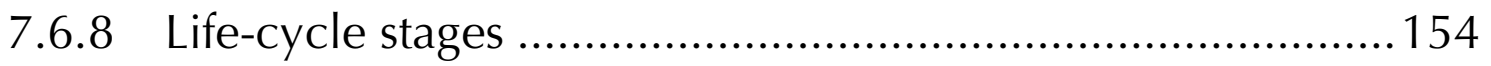

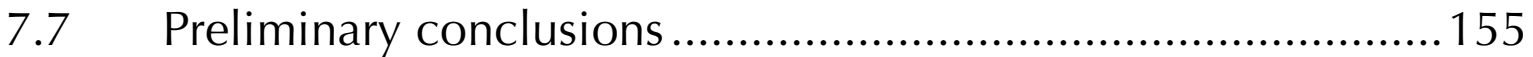

8 Collective identities and governance in the context of community-driven open source (Study III) .................................157

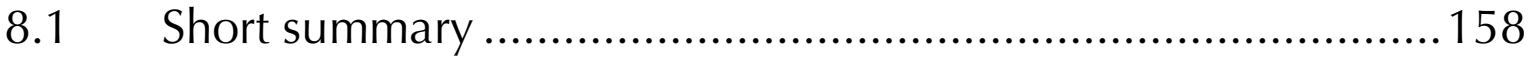

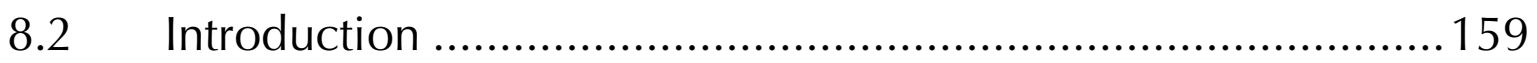

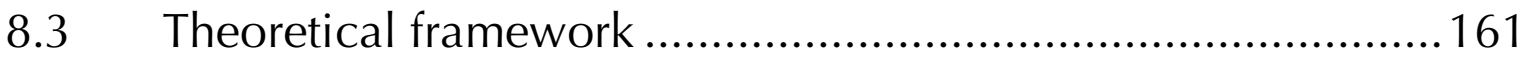

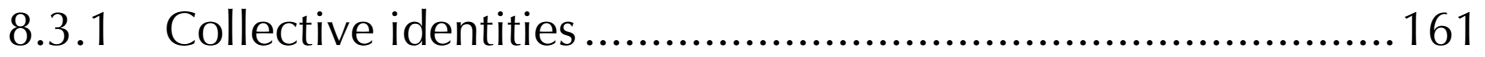

8.3.2 Open source community governance..............................163

8.3.3 Analytical model ...................................................... 163

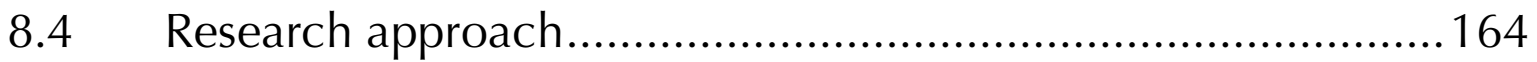

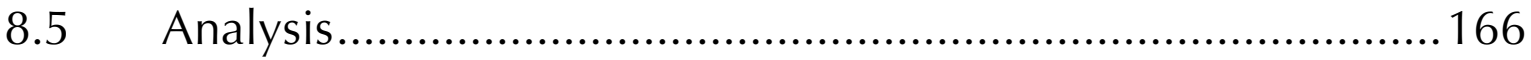

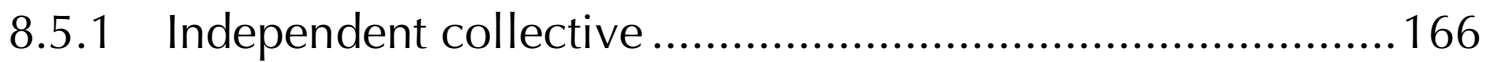

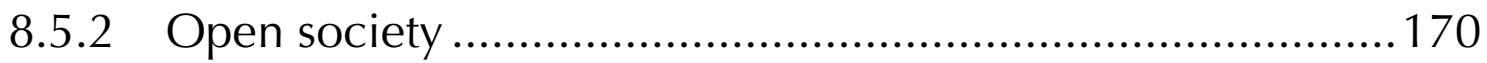

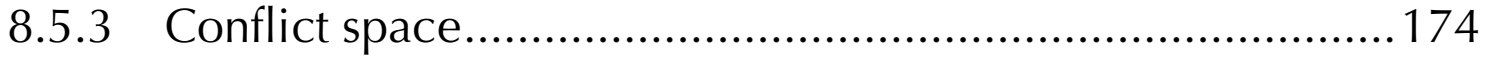

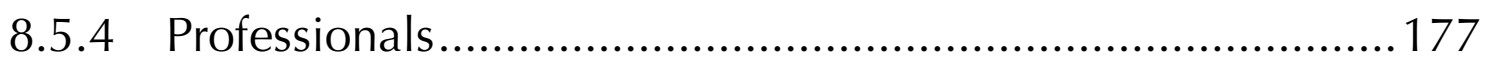

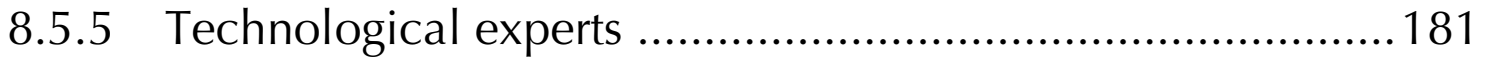

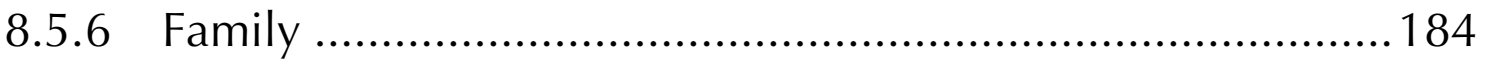

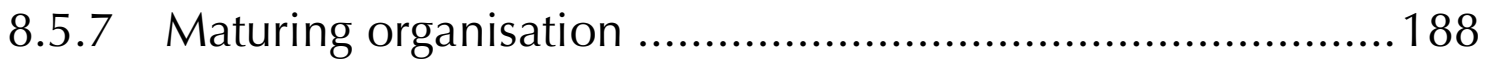

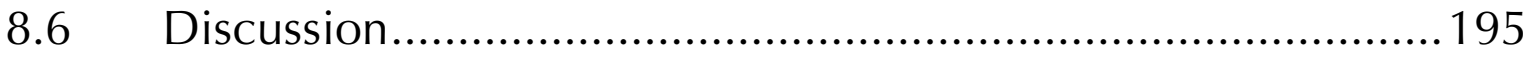

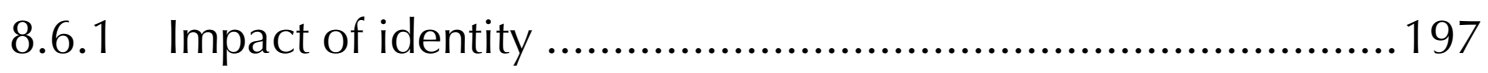

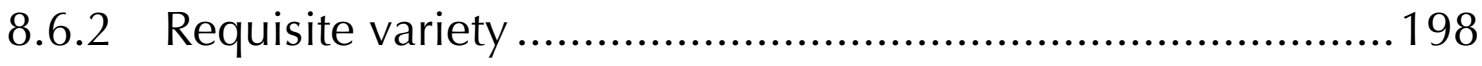

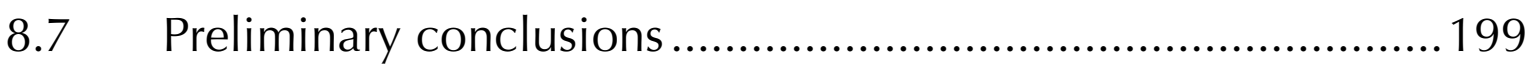


9 Relationships between volunteer work and economic interests in the context of community-driven open source (Study IV) ...................................................................................201

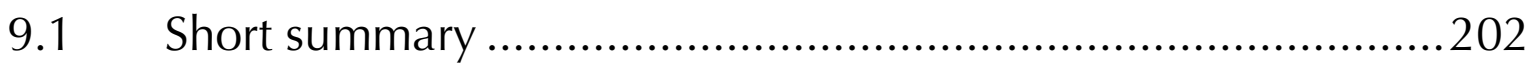

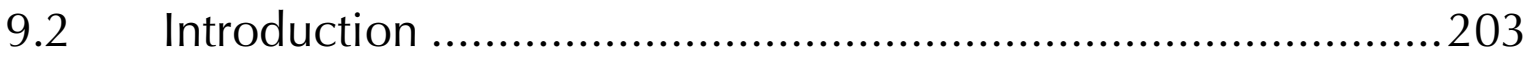

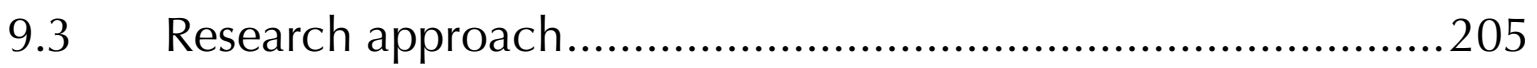

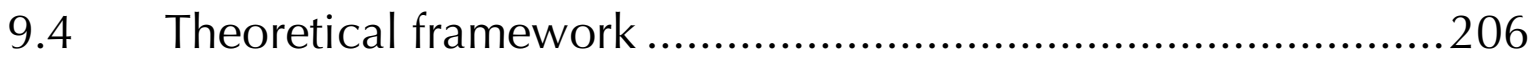

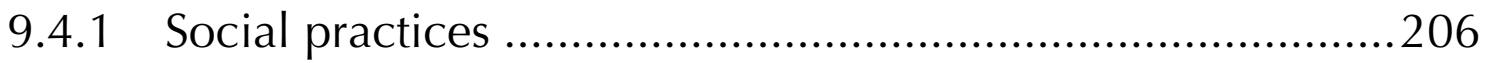

9.4.2 Basic tenets of self-determination theory ..........................207

9.4.3 Analytical model ...................................................208

9.5 Literature review on motivations for community

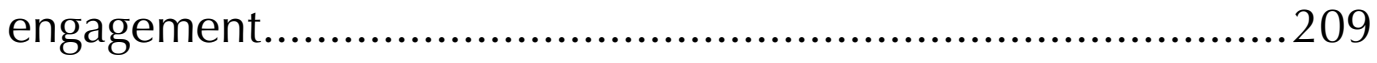

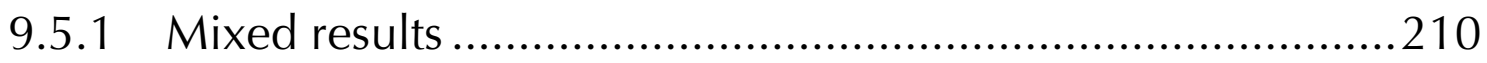

9.5.2 Complexity, plurality, and interrelatedness of motivation....210

9.5.3 Criticism towards the dichotomy of intrinsic and extrinsic motivations............................................................. 211

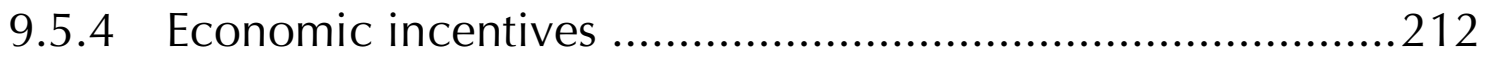

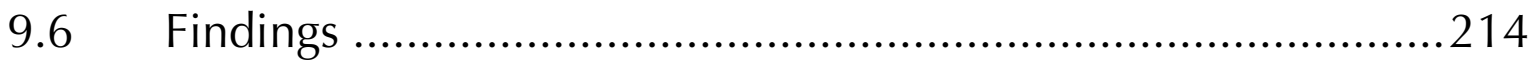

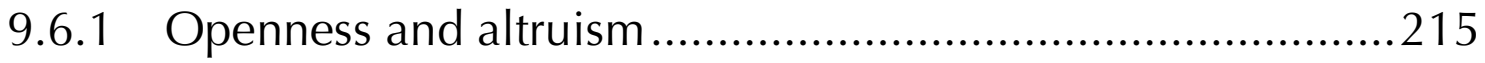

9.6.2 Supportiveness, helping behaviour, reciprocity, and social responsibility ..................................................216

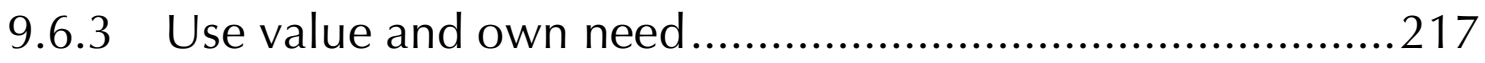

9.6.4 Influence, monitoring, and vested interests ......................218

9.6.5 Sense of community, identity, and connectedness .............220

9.6.6 Learning, knowledge exchange, and knowledgeable

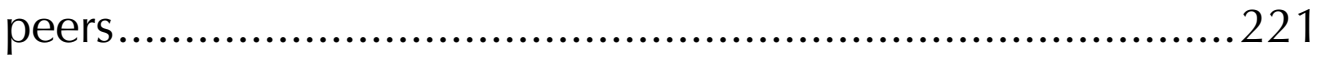

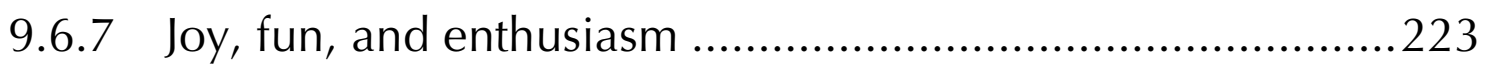


9.6.8 Reputation and status

9.6.9 Commitment and perceived switching costs ....................226

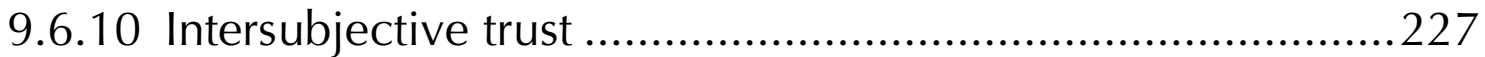

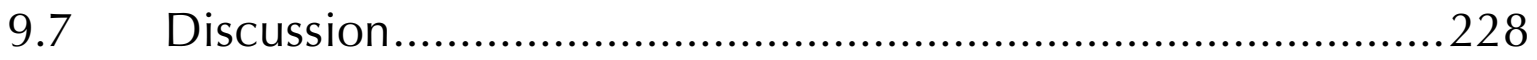

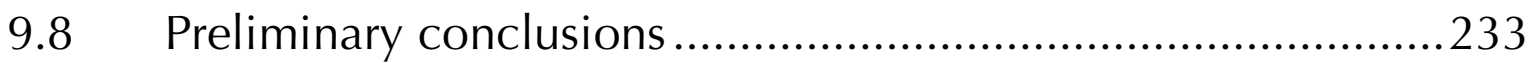

10 Pricing of open source software extensions (Study V) ...............235

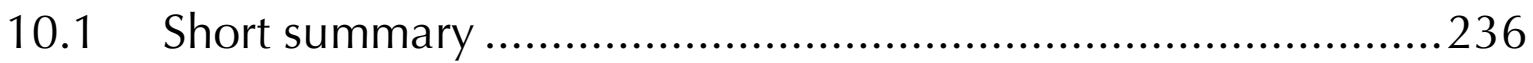

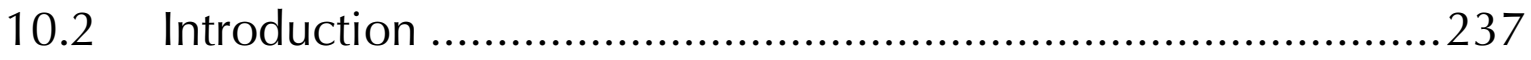

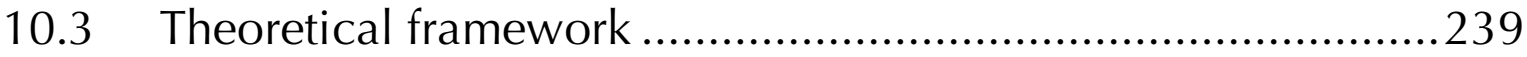

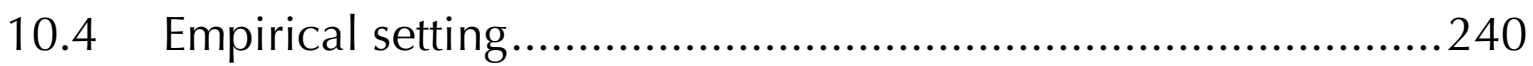

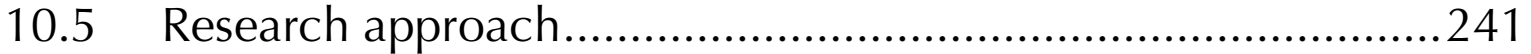

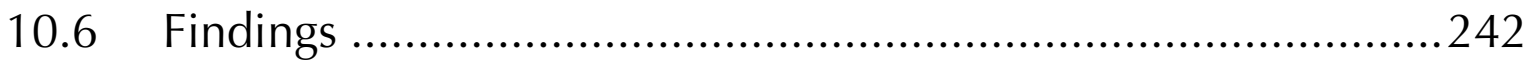

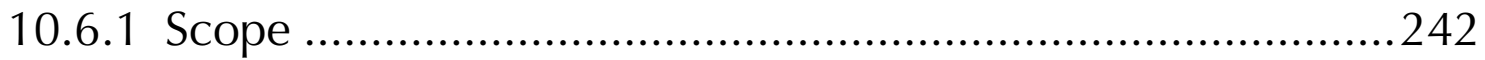

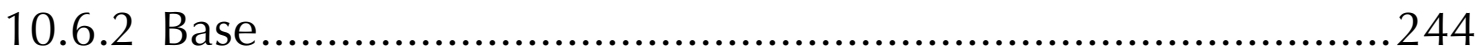

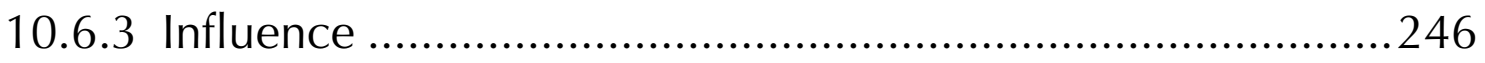

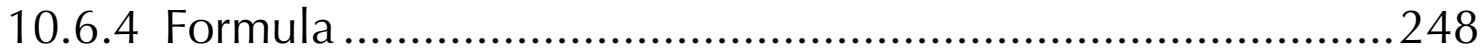

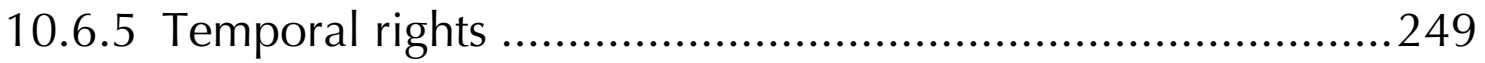

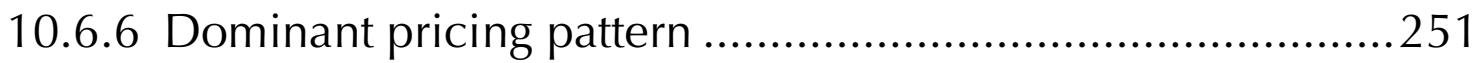

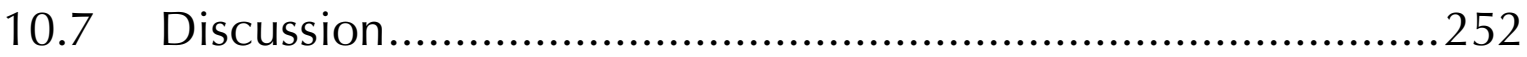

10.7.1 Dominance of value-based pricing....................................253

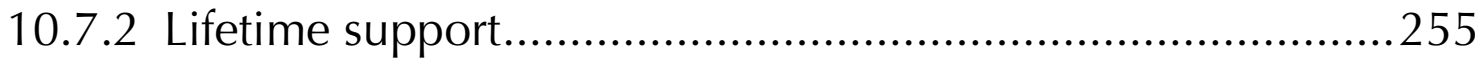

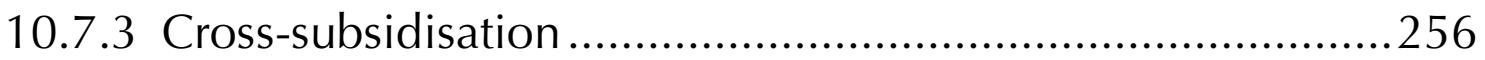

10.7.4 Software licence and the price model ............................257

10.7.5 Limitations and opportunities for further research ..............258 
10.8 Preliminary conclusions

11 Bundling and versioning of open source software extensions (Study VI)

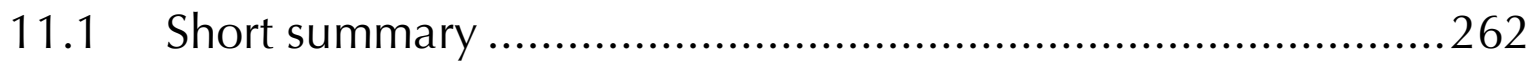

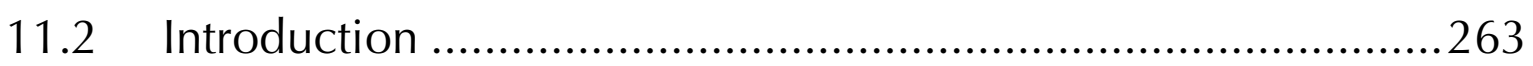

11.3 Background and strategic aspects......................................264

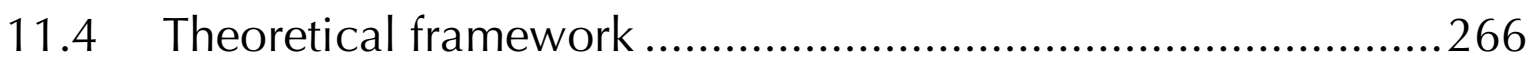

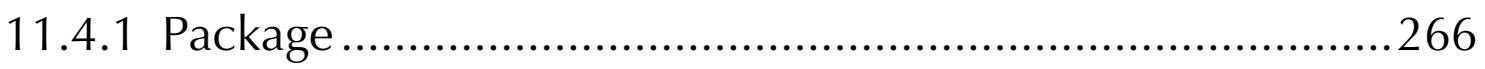

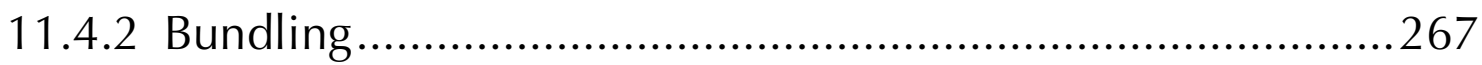

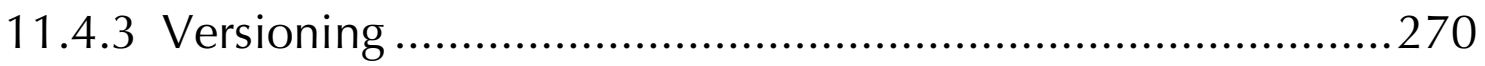

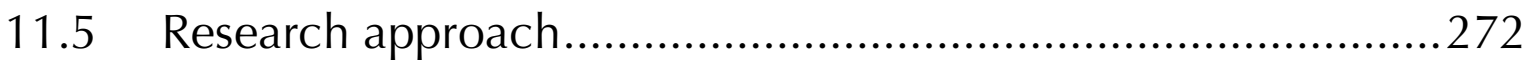

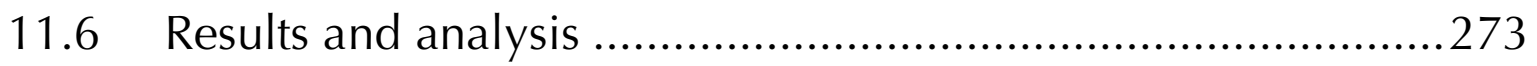

11.6.1 Motives for bundling and versioning …..........................2275

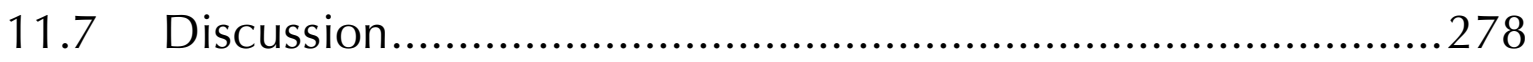

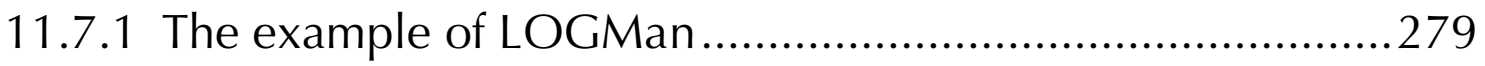

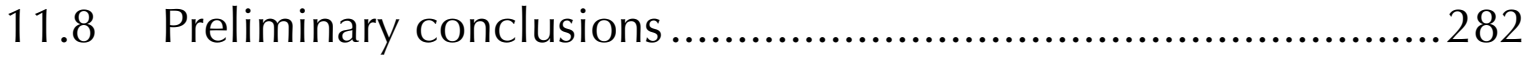

12 Findings and analysis .......................................................283

12.1 RQ1: What are the challenges in commercialising community-driven OSS and how do firms cope with them? ...283

12.1.1 Global operating environment......................................28

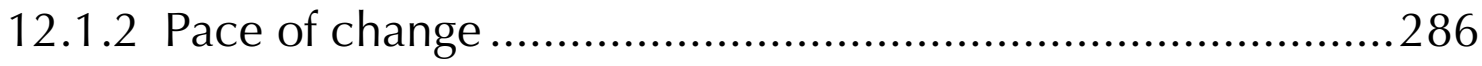

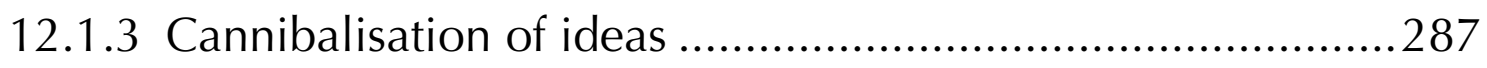

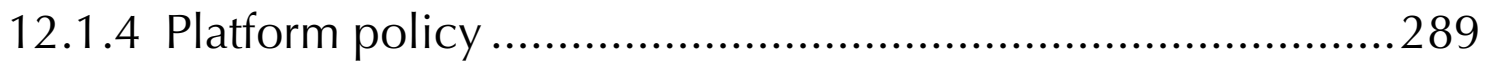

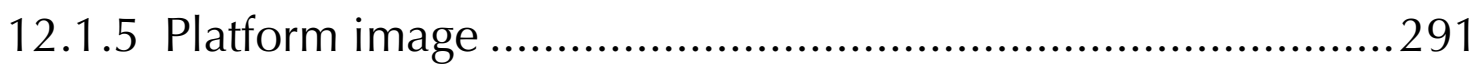


12.1.6 Voluntary nature of the open source project .....................293

12.1.7 Blurring boundary between private and professional lives ..294

12.1.8 Difficulty of estimating costs..........................................296

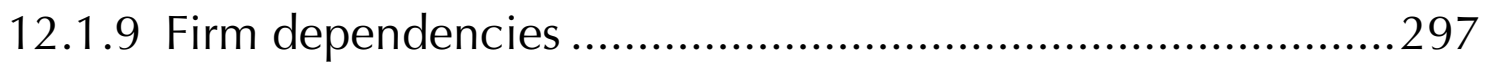

12.2 RQ2: How are volunteer community engagement and profit-oriented venturing intertwined in the context of community-driven open source? .........................................299

12.2.1 Summary statistics on the first set of interviews ..................300

12.2.2 Summary statistics on the second set of interviews ..............301

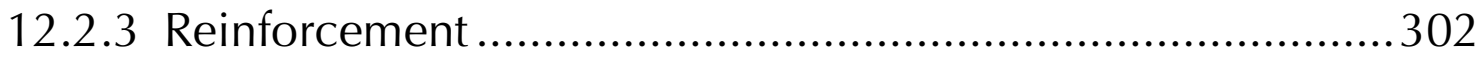

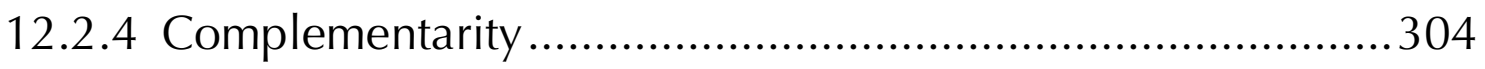

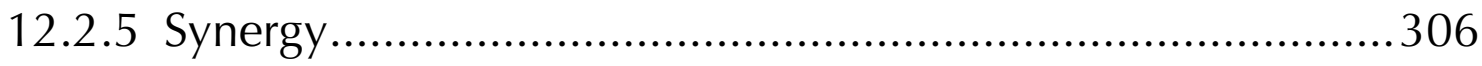

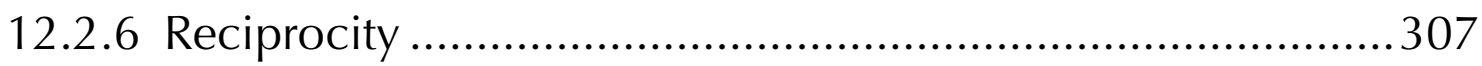

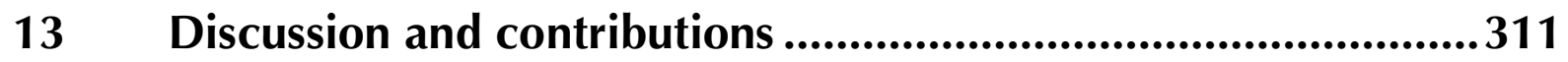

13.1 Communities as superorganisms …..................................... 311

13.2 A framework for analysing community-based value creation in business ecosystems ...................................................... 313

13.2.1 Collective innovation (ecosystem and community) ..............316

13.2.2 Community engagement (firm and community) .................316

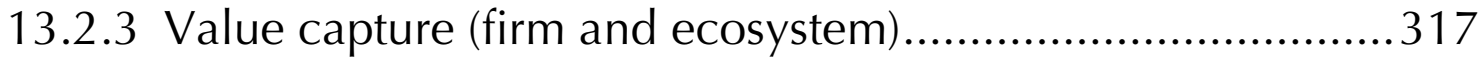

13.2.4 Community-based value creation (collective innovation, community engagement, and value capture) ......................318

13.2.5 Applying the framework to the Joomla case .......................320

13.2.6 A generic representation of community-based value creation utilising organismic metaphors .............................325

13.3 A model for classifying community types ..............................327 
13.4 Governance and strategic open source

13.5 Spiritual well-being, sense of belonging, and psychological health

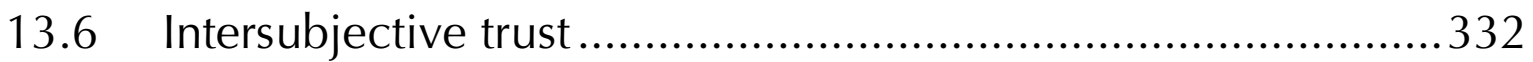

13.7 Community-based self-identity versus entrepreneurial selfidentity

13.8 Value-based, strategic, and ecology perspectives on open source

15 Limitations

16 Future work

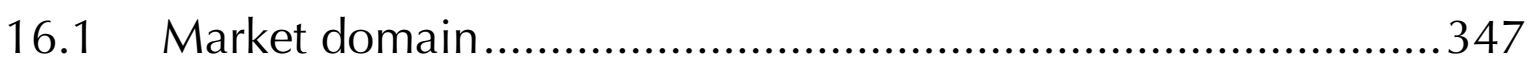

16.1.1 Intermediary market places for extensions, plugins, components, and add-ons

16.1.2 Crowdfunding and location-based pricing ........................348

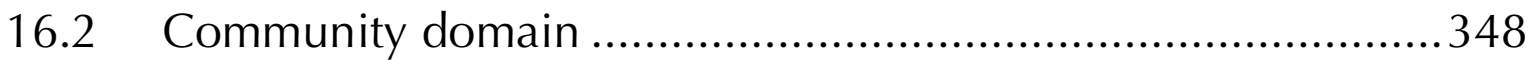

16.2.1 The fragmentation of online communication......................348

16.2.2 Free-riding and disincentives for community engagement...349

16.2.3 The transitioning from non-commercial to commercial extensions

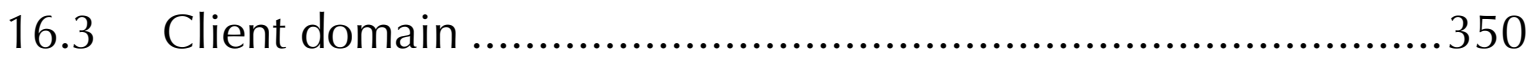

16.3.1 Focus on the clients' perspective .......................................350

16.3.2 Signalling strategies and the scoping of projects .................351

17 List of figures. 
20.1 Appendix A1 - interview guide for the first set of interviews...387

20.2 Appendix A2 - interview guide for the second set of interviews with a focus on governance and organisational identity

20.3 Appendix A3 - interview guide for the second set of interviews with a focus on business aspects.....

20.4 Appendix A4 - a review of the literature on open source community engagement with a focus on economic incentives (Study IV).

20.5 Appendix A5 - product attributes and differentiation criteria (Study VI)

20.6 Appendix A6 - package names and significations (Study VI) ..404 


\section{List of abbreviations}

AGPL Affero General Public License

BSD Berkeley Software Distribution

CMS Content Management System

CoC Code of Conduct

DARPA Defense Advanced Research Projects Agency

FLOSS Free and Open Source Software

FSF Free Software Foundation

GPL General Public License

IoT Internet of Things

JED Joomla Extension Directory

MOS Mambo Open Source

NCC Netscape Communications Corporation

OSI Open Source Initiative

OSM Open Source Matters

OSS Open Source Software

SaaS Software as a Service

SDT Self-determination theory

SFLC Software Freedom Law Centre

UCB The University of California, Berkeley

\section{Important note to the reader}

This thesis uses both a footnote and an endnote system. Footnotes are used in the usual sense, i.e., to provide details and clarifying information, whereas endnotes are specifically utilised to point to web links. Footnotes are written in Roman numbers and are attached at the bottom of each respective page. Endnotes (i.e., references to web links) are indicated by Arabic numbers and are listed at the end of this thesis in Chapter 21. 
"Human history is, in essence, a history of ideas." - H.G. Wells 


\section{Introduction}

The evolution of open source software (OSS) has accumulated a mountain of stories about its successes, conflicts, and failures over the past 50 years or so. These stories often connect to the flowering age of computing and the emergence of the Internet; they span a range from the grassroots movements and the sharing of code in the 1960s up to the now widely shared conceptions of OSS as a vital infrastructural resource and its value for scientific, social, economic, and technological development.

The popularity of OSS has continued to grow in recent years. Evidence for this continuation is not only found in the literature (Aksulu \& Wade, 2010; Carillo, Huff, \& Chawner, 2017; Crowston, 2016; Crowston, Wei, Howison, \& Wiggins, 2012; Daniel \& Stewart, 2016; Rosenfall, 2012), it is also apparent from statistics on SourceForge and GitHub, which are both popular sites providing infrastructural support for open source projects. In 2001, SourceForge hosted over 10,000 projects and had more than 100,000 registered users (von Hippel, 2001). By July 2018, these figures had risen to over 500,000 projects and about 3.7 million users ${ }^{1}$. GitHub, the world's largest host of open source code (Gousios, Vasilescu, Serebrenik, \& Zaidman, 2014), had even grown to more than 28 million users and about 85 million hosted open source projects in July 2018 since its inception in $2008^{2}$.

While only a small percentage of open source projects may be mature and stable (Fitzgerald, 2006), OSS is at the core of a wide range of business models and system solutions (Crowston, Feller, Mols, \& Wasserman, 2016). Millions of users, firms, educational institutions, and governmental and nongovernmental organisations across the globe trust in, rely on, and/or contribute to the development of OSS (Morgan \& Finnegan, 2014; von Krogh, Haefliger, Spaeth, \& Wallin, 2012).

In the spirit of H.G. Wells', the history of OSS could be seen as a history of ideas; in particular, ideas about sharing practices, intellectual property, and new forms of collaboration". These ideas have not only challenged the proprietary production paradigm - they have led to the emergence of new business models and made open source a viable sourcing strategy for a broad range of stakeholders (Carillo, Huff, et al., 2017).

"Human history is, in essence, a history of ideas." - H.G. Wells (as quoted in the epigraph of this thesis)

" E.g., mass collaboration through online means. 
However, in the literature, business, strategy, and value perspectives on open source have been accorded far less attention by scholars than software development perspectives; with the consequence that issues in relation to firms' ability to create value and competitive advantage, given the idiosyncrasies of open source, are relatively underexplored (Carillo, Huff, et al., 2017; Crowston \& Shamshurin, 2017; Daniel \& Stewart, 2016; Morgan \& Finnegan, 2014).

In particular, there have been few attempts to study the commercialisation of OSS as a phenomenon embedded in its larger context, such as the ecosystem around open source projects (Carillo, Marsan, \& Negoita, 2017). This is surprising since many benefits of open source arise as a consequence of the communities and ecosystems surrounding open source projects (Fitzgerald, 2006; Zahra \& Nambisan, 2012). With globalisation, networked economies, the increased complexity of today's products and services, and the increased interdependence of economic activities, it has become more important than ever to pay attention to the larger social and economic context (i.e., the ecosystem) within which firms' activities occur (Olve, Cöster, Iveroth, Petri, \& Westelius, 2013).

Moreover, dominant views of value creation have mainly focused on the value created for customers and firms rather than alternative targets, such as users, communities, and society at large (Morgan \& Finnegan, 2014). As is argued in the literature, the "exclusive focus on the firm level ignores the role of the 'overarching' business ecosystem that provides the social and economic context for exchanges to take place" (Borgh, Cloodt, \& Romme, 2012, p. 151).

The increasing importance of the larger social and economic context in which firms' activities occur is also reflected in the fact that firms increasingly rely on their interaction with communities in order to make their own economic contributions. The subject of firm-community interaction has become of strategic relevance to many organisations because their success increasingly depends on the sustainability of communities (Carillo, Marsan, et al., 2017).

Bearing in mind the wider context of firms' activities, the perspective of business ecology offers a fruitful and holistic alternative to the study of value creation. The perspective of business ecology has its roots in value networks and regards the ecosystem as a source of value creation and competitive advantage for firms (Clarysse, Wright, Bruneel, \& Mahajan, 2014). Management thinking has increasingly utilised the perspective of business ecology in order to cope with complex environments, diffuse boundary conditions, and the ever-present nature of change (Aarikka-Stenroos \& Ritala, 2017; Westelius \& Lind, 2016). Business ecology emphasises the 
dynamic and complex nature of the environments in which actors cooperate, collaborate, and compete, in light of diverse goals and interests, and the conditions and restrictions imposed by those environments (Olve et al., 2013). According to Thomas and Autio (2014, p. 2), the business ecology perspective generally highlights the "interdependencies between organisations and their environment". As stated by the authors, value in business ecosystems is created collectively through the interactions between its participants. Thus, value creation in business ecosystems is an emergent phenomenon.

As readers will already have noticed, the words 'ecology' and 'ecosystem' will both be used here. 'Ecology' will signify relationships and interactions between 'organisms' and the environment (emphasising dynamic, emergent, and analytical aspects), while 'ecosystem' will denote concrete manifestations of a 'living space'. Often a particular ecosystem's boundaries, structural properties, and types of 'organisms' are at the centre of attention"II. Although ecology and ecosystem are often used interchangeably, this thesis maintains this differentiation in order to emphasise their slightly different viewpoints. This is because both ecological aspects of open source communities will be discussed, and one particular such community: that formed around the software Joomlav which will be introduced presently. The case of Joomla will be studied as an ecosystem, in accordance with the distinction just made.

The realm of open source lends itself to the study of commercialisation aspects within a wider social and economic context. Open source settings also provide ample opportunities to study the interaction between for-profit entities and communities ${ }^{v}$, a topic that is enjoying increased scientific attention (Mollick, 2016). There are several reasons why business ecology can be a useful analytical guide in the context of open source. Typically, the commercialisation of OSS is embedded in fast-changing and complex environments within which diverse social entities collaborate and compete (Carillo, Marsan, et al., 2017). OSS is typically associated with globally distributed production regimes, extensive use of electronic means of communication, self-organising communities of volunteers, diffuse boundary conditions (e.g., lack of formal memberships, informal collaboration), complex technological landscapes, diverse sponsorships and industrial collaborations, idiosyncrasies of legal frameworks (e.g., licensing),

III E.g., drawing on parallels to biological ecosystems, think of a particular section of a river, its subpopulations of fish, and environmental conditions such as the weather.

IV Notice that the Joomla brand name includes an exclamation mark ("Joomla!"). For reasons of readability, it was decided to omit this exclamation mark throughout this thesis.

$\checkmark \quad$ Comprising both commercial and non-commercial actors. 
distinct ideological foundations, cultural diversity, and, not least, diverse commercialisation approaches.

By employing a business ecology perspective to explore open source, this thesis emphasises the wider context within which the production, commercialisation and use of OSS is embedded. This approach is designed to direct attention towards the interactions among key actors, the properties that characterise these interactions (e.g., goals, values, interests) and the value-generating logics that apply (Normann \& Ramirez, 1993).

Furthermore, business aspects around open source are often discussed in relation to open source projects that are backed or governed by single corporate sponsors, which neglects the challenges faced by firms in commercialising community-driven OSS. In the context of this thesis, the term 'community-driven' refers to open source projects that are governed, run, and controlled by communities of volunteers (unlike open source projects that are driven and controlled by single firms) ${ }^{\mathrm{VI}}$. This lack of research on firm involvement in the realm of community-driven open source is also expressed in the recent literature (Ciesielska \& Westenholz, 2016).

Firms that run a business based on community-driven open source may face distinct challenges. For instance, there may be greater uncertainty in terms of the community's capacity for making decisions (e.g., slow decisionmaking processes, lack of roadmaps). There may be a lack of continuity in activity levels and release cycles due to the voluntary nature of communitydriven open source. There may be a lack of task commitment because there are no contractual agreements to obligate the volunteer workforce to commit to tasks. Due to the high autonomy in task selection and the lack of hierarchical authority, these communities may also suffer from an uneven workload distribution. Furthermore, with community-driven open source, there is a lack of monetary compensation for sourcing labour and skills (unlike with open source projects that are governed and controlled by corporate sponsors).

In spite of these conditions, there are many firms that build their businesses around community-driven open source. These firms not only cope with the uncertainties that stem from the voluntary nature of the open source project, they are also exposed to a fast-changing environment, epitomised by changing business practices, evolving technological landscapes, global competition, and different stakeholder interests.

VI Previous research has proposed similar distinctions between community open source and commercial open source (Capra \& Wasserman, 2008). However, this distinction is problematic because it suggests that there are no commercial activities around community-driven open source projects. 
While the business ecology perspective serves as an overarching analytical guide, a holistic understanding of value creation requires the joint consideration of multiple theoretical dimensions (Morgan, Feller, \& Finnegan, 2013). Therefore, in order to allow for greater analytical depth, ideas and propositions from other theoretical areas are also utilised, including stakeholder theory, open source governance, organisational identity, motivation theory, pricing, and bundling. In addition, as part of the larger context, environmental factors are considered, such as economic pressure, trends, and platform competition. This holistic approach is inspired in part by the idea that the complexities of human affairs can be reasonably well understood by painting rich pictures of the multifaceted and interrelated nature of issues and problems (Checkland, 2000).

From an empirical point of view, this thesis takes a close look at the Joomla community, which is a worldwide community of volunteers that accounts for the production of a popular open source content management system (CMS) - the Joomla CMS. A detailed description of the empirical context is given in Chapter 4 . The present chapter continues by outlining the structure of this thesis.

\subsection{Structure of the thesis}

This thesis is a monograph that is inspired by ideas of a compilation thesis approach. This means that it exhibits the breadth and scope of a monograph thesis, while building upon a set of six sub-studies. In the context of this thesis, these sub-studies are referred to as Study I - Study VI.

One advantage of a monograph thesis is that it allows for a richer and more complete disclosure of the entire investigation. Thus, it allows for greater richness and breadth in communicating the empirical and analytical results. However, today, the academic world revolves around papers, which typically address problems in a narrower and more isolated, though markedly more focused, manner. However, much valuable information might be lost when conforming to the narrower formats of research papers. Therefore, consistent with the methodological and epistemological approach (see Chapter 5), and the ubiquity of the paper format in the academic world, this thesis combines ideas from both paradigms, the monograph approach and the compilation thesis approach, in order to allow for both a holistic and an in-depth examination of the subject.

Each of the six sub-studies in this thesis focuses on different theoretical perspectives; namely: stakeholder theory (Study I), open source governance (Study II), organisational identity (Study III), motivation theory (Study IV), pricing (Study V), and, finally, bundling and versioning (Study VI). The six 
sub-studies are integrated into this document as Chapters 6-11. The motivation for this choice of perspectives is explained in the theoretical framework (see Chapter 3). Table 1 provides a compressed overview of the sub-studies on which this thesis builds upon, along with a short description of their purpose and role in the context of this thesis. 


\begin{tabular}{|c|c|c|c|}
\hline Study & Title & $\begin{array}{l}\text { Theoretical } \\
\text { lens }\end{array}$ & $\begin{array}{l}\text { Purpose and role in the context of this } \\
\text { thesis }\end{array}$ \\
\hline Study I & $\begin{array}{l}\text { A multi- } \\
\text { stakeholder } \\
\text { perspective on } \\
\text { community- } \\
\text { driven open } \\
\text { source }\end{array}$ & $\begin{array}{l}\text { Stakeholder } \\
\text { theory }\end{array}$ & $\begin{array}{l}\text { Draw boundaries and identify relevant } \\
\text { sets of actors whose future is most } \\
\text { notably intertwined within the } \\
\text { ecosystem. Facilitate an understanding } \\
\text { of the larger picture within which } \\
\text { commercial activities are embedded. }\end{array}$ \\
\hline Study II & $\begin{array}{l}\text { An integrative } \\
\text { framework for } \\
\text { open source } \\
\text { governance }\end{array}$ & $\begin{array}{l}\text { Open source } \\
\text { governance }\end{array}$ & $\begin{array}{l}\text { Identify the key dimensions in open } \\
\text { source governance. Facilitate an } \\
\text { understanding of how community } \\
\text { governance affects the activities and } \\
\text { interactions within the ecosystem. }\end{array}$ \\
\hline Study III & $\begin{array}{l}\text { Collective } \\
\text { identities and } \\
\text { governance in } \\
\text { the context of } \\
\text { community- } \\
\text { driven open } \\
\text { source }\end{array}$ & $\begin{array}{l}\text { Organisational } \\
\text { identity, open } \\
\text { source } \\
\text { governance }\end{array}$ & $\begin{array}{l}\text { Examine the interplay between } \\
\text { community governance and identity in } \\
\text { the context of a worldwide community } \\
\text { of volunteers. Facilitate an } \\
\text { understanding of the diversity of values, } \\
\text { images, and worldviews with which the } \\
\text { ecosystem is charged. }\end{array}$ \\
\hline Study IV & $\begin{array}{l}\text { Relationships } \\
\text { between } \\
\text { volunteer work } \\
\text { and economic } \\
\text { interests in the } \\
\text { context of } \\
\text { community- } \\
\text { driven open } \\
\text { source }\end{array}$ & $\begin{array}{l}\text { Motivation } \\
\text { theory }\end{array}$ & $\begin{array}{l}\text { Examine how community engagement } \\
\text { supports volunteers in advancing their } \\
\text { economic goals and career concerns. } \\
\text { Facilitate an understanding of how } \\
\text { motivation patterns and economic } \\
\text { incentives affect the productivity, } \\
\text { stability, and viability of the ecosystem. }\end{array}$ \\
\hline Study V & $\begin{array}{l}\text { Pricing of open } \\
\text { source software } \\
\text { extensions }\end{array}$ & Pricing & $\begin{array}{l}\text { Examine dominant pricing practices } \\
\text { pursued by extension providers (who } \\
\text { are important actors within the } \\
\text { ecosystem). Facilitate an understanding } \\
\text { of commitments, payment flows, } \\
\text { performance agreements, and the } \\
\text { distribution of risks between actors } \\
\text { within the ecosystem. }\end{array}$ \\
\hline Study VI & $\begin{array}{l}\text { Bundling and } \\
\text { versioning of } \\
\text { open source } \\
\text { software } \\
\text { extensions }\end{array}$ & $\begin{array}{l}\text { Bundling and } \\
\text { versioning }\end{array}$ & $\begin{array}{l}\text { Examine bundling and versioning } \\
\text { practices. Facilitate an understanding } \\
\text { of how diverse sets of capabilities, } \\
\text { competencies, resources, and } \\
\text { differentiation strategies are leveraged } \\
\text { in light of the competitive dynamics } \\
\text { within the ecosystem. }\end{array}$ \\
\hline
\end{tabular}

Table 1: An overview of the sub-studies on which this thesis builds upon. 
For analytical convenience, the six sub-studies can be roughly divided into two realms. The first represents the community foundations and deals with the community's organisational capabilities for producing and maintaining the public good. Three of the sub-studies (Study I - III) deal with such issues. The second realm is about profit-oriented venturing and deals with the appropriation of returns based on OSS. The other three sub-studies (Study IV - VI) deal with issues that belong to this realm.

Figure 1 illustrates the relationships between these two realms as understood in the context of this thesis. Using the metaphor of a tree, the visual content of Figure 1 is interpreted as follows. While the community foundations are depicted as the roots of the tree, profit-oriented venturing is located amongst branches and leaves in the treetop, symbolising the shoots of the tree. The tree metaphor is intended to symbolise an organic reciprocity between these two realms. It requires stable and healthy community foundations in order for open-source-based businesses to grow and prosper. Profit-oriented venturing can really only blossom if the community foundations allow for the continuous production and maintenance of the public good. On the other hand, profit-oriented venturing can provide impulses and direction to the production of OSS. Open source vendors can supply the community with important nutrients (e.g., knowledge and expertise, feedback from their customers, voluntary work efforts) and fertilise the ground in which the community foundations root, thereby facilitating the thriving of a community. Both realms, the community foundations and profit-oriented venturing, are affected by the environment. This is comprised of factors such as trends, regulatory changes, competitive pressure, changing technological landscapes, and the availability of volunteers as a resource.

From an ecology perspective, the health of a business ecosystem is dependent upon its ability to transform inputs (e.g., labour and other resources) into productive outputs (lansiti \& Levien, 2004). For instance, communities often rely on voluntary work efforts as a nutrient in order to be able to create productive outputs, such as new software releases. Taking the ecology metaphor as a point of departure, the purpose of this thesis and the research questions are followed up. 


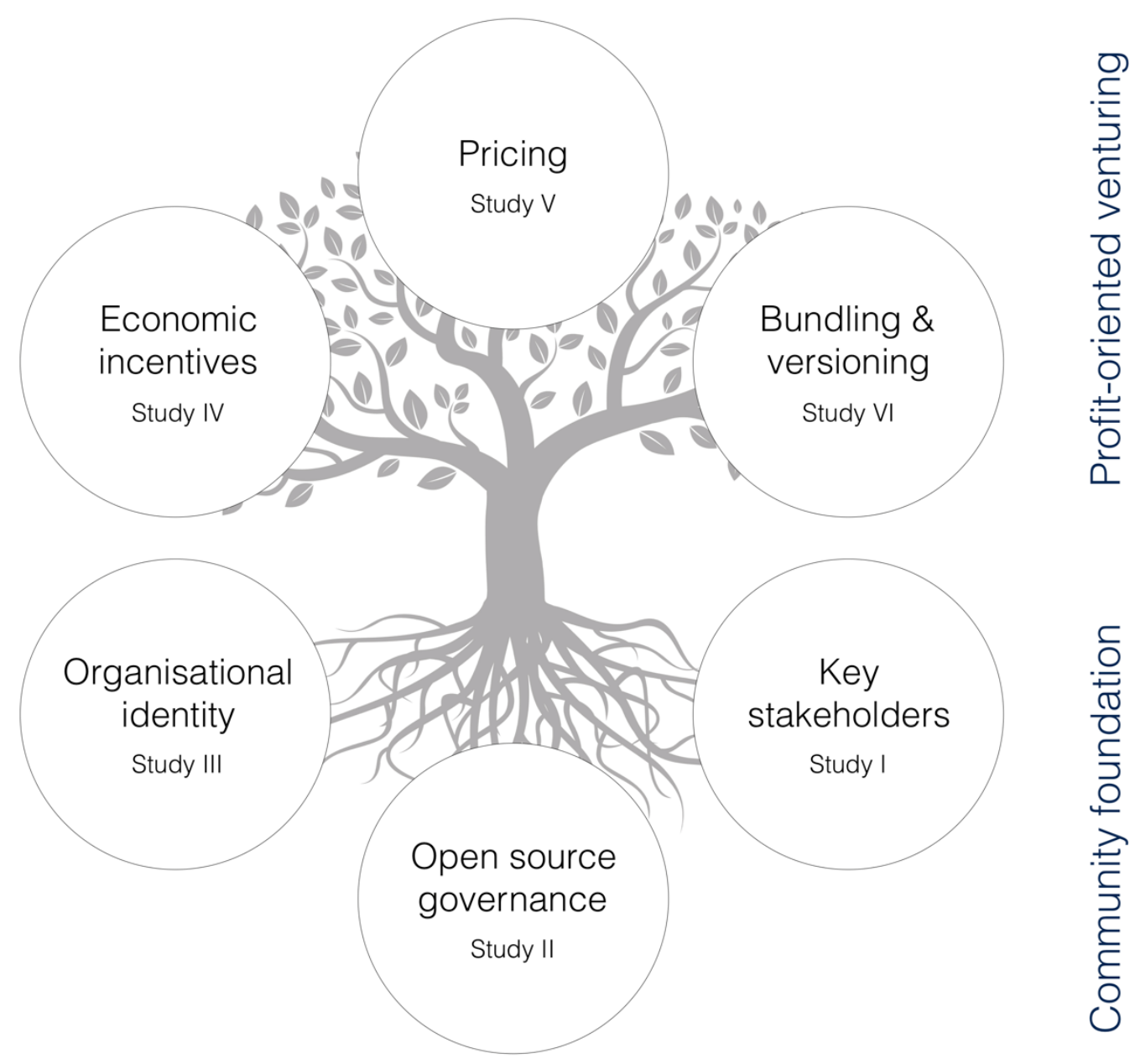

Figure 1: A structural overview of this thesis. This thesis builds on six sub-studies. For analytical convenience, the six sub-studies can be roughly divided into two realms: the realm of the community foundations and the realm of profit-oriented venturing.

\subsection{Purpose and research questions}

There are two overarching themes guiding this thesis. For each of these themes, one research question is formulated. The overall purpose of this thesis is to investigate the challenges involved in commercialising community-driven OSS (Theme 1) and to explore the connections between community engagement ${ }^{\mathrm{VII}}$ and profit-oriented venturing in the context of community-driven open source (Theme 2).

VII With 'community engagement' this thesis refers to the participation and involvement in communityrelated tasks and activities, and a commitment towards community-related goals and values. 


\subsubsection{The challenges in commercialising community-driven OSS (Theme 1)}

More broadly, Theme 1 connects with recent research exploring the business value and strategic aspects of open source (Carillo, Huff, et al., 2017; Carillo, Marsan, et al., 2017; Daniel \& Stewart, 2016; Duc, Cruzes, Hanssen, Snarby, \& Abrahamsson, 2017; Morgan et al., 2013; Morgan \& Finnegan, 2014; Teixeira, Mian, \& Hytti, 2016; Valença, Alves, Heimann, Jansen, \& Brinkkemper, 2014).

While many benefits may arise as a consequence of the communities and ecosystems around open source projects, likewise, also many challenges may arise. Naturally, collaboration and competition in business ecosystems can carry the potential for friction (Valença et al., 2014). This means that business ecosystems are not only spaces of opportunity, they also pose challenges that firms need to overcome in order to be successful. While the literature mainly depicts business ecosystems as spaces of opportunity (e.g., for sourcing skills, resources, and complementary assets), this thesis focuses on the challenges that firms face in commercialising communitydriven OSS.

Challenges are broadly understood as the major difficulties that firms need to overcome in order to be successful in commercialising communitydriven OSS. Such challenges are analysed from a business ecology perspective, in view of the characteristic environmental conditions and restrictions (e.g., global interaction, ideological foundations, governance regimes, salient values and identities, and participation patterns in the community).

In a narrower sense, Theme 1 also concerns the difficulties of appropriating returns based on OSS while adhering to platform policies and principles such as openness. It has been notoriously difficult to appropriate returns based on OSS (Dahlander, 2005; Lerner \& Tirole, 2002; Krishnamurthy, 2005; Mollick, 2016; Morgan et al., 2013; Morgan \& Finnegan, 2014; Riehle, 2009b, 2012; Rosenfall, 2012; Wasserman, 2013; Weiss, 2015). These difficulties are essentially reflected in the pricing and bundling practices employed by providers of value-added services for OSS (Petri, Radits, \& Iveroth, 2018). This is the reason why Theme 1 also touches upon dominant forms of pricing and the commitments stipulated by price models (Iveroth et al., 2013; Olve et al., 2013). The first research question (RQ1) is formulated as follows: 
RQ1: What are the challenges in commercialising community-driven OSS and how do firms cope with them?

\subsubsection{The intertwining of community engagement and profit- oriented venturing (Theme 2)}

Theme 2 concerns the intertwining of community engagement and profitoriented venturing. More broadly, Theme 2 connects with research on the relationships between community forms of organising and entrepreneurial activities (Dahlander \& Magnusson, 2005; Mollick, 2016; Rosenfall, 2012), research on sourcing strategies exploring the power of communities for creating business value (Carillo, Huff, et al., 2017; Morgan et al., 2013; Morgan \& Finnegan, 2014), and research on emergent qualities and dynamic interaction around open source projects (Androutsellis-Theotokis, Spinellis, Kechagia, \& Gousios, 2011; Carillo, Marsan, et al., 2017; Valença et al., 2014).

Following calls for more research on how the value-creating logics of firm-community interactions are embedded in the bigger picture in which they occur (Carillo, Marsan, et al., 2017; Morgan \& Finnegan, 2014; Linåker, Rempel, Regnell, \& Mäder, 2016), the intertwining of community engagement and profit-oriented venturing is viewed from a business ecology perspective, in light of the conditions and restrictions imposed by the environment. For instance, in the realm of community-driven open source, one such important condition refers to the voluntary nature of the open source project.

There may be various (yet unexplored) ways in which community engagement and profit-oriented venturing intertwine in the context of community-driven open source. Not least because interactions in business ecosystems imply a strategic interdependence among actors (Duc et al., 2017). The second research question (RQ2) is formulated as follows:

RQ2: How are volunteer community engagement and profit-oriented venturing intertwined in the context of community-driven open source?

The next section provides the necessary historical and theoretical background in order to position this thesis more thoroughly with respect to the relevant literature. 



\section{Background and literature review}

This chapter is intended to present the greater picture in which this thesis is embedded, thematically, historically, and theoretically. There are two main parts to the chapter: first, a review of the historical roots of open source and its evolution; and second, a review of theorising on open source in the management fields, with a particular focus on business, value, and strategic aspects.

Concerning the first part, in tracing the roots of open source, emphasis is placed on the organisational, collaborative, economic, and strategic aspects relating to open source, rather than on technical details and hardware (as other reviews tend to do). While many important key developments of open source took place in the realm of open source operating systems, a further emphasis is placed on the developments around open source web technologies, since the empirical focus of this thesis is an open source CMS that belongs to this particular realm. While this historical account of open source draws heavily on Weber (2004), AndroutsellisTheotokis et al. (2011), and Tozzi and Zittrain (2017), the story also incorporates many other sources of information (i.e., academic articles, different web sources) in order to render a more complete, coherent, and balanced picture. As an additional benefit, this review extends the discussion to some very recent developments in the realm of open source.

The historical account of open source is followed by a brief review of the theorising of business value, and strategic aspects of open source in the literature. The major theoretical themes around open source in the management fields are laid out in order to position this thesis accordingly. In short, ecology perspectives on open source are identified as a nascent field of endeavour in the management fields. In particular, two threads are identified as potentially fruitful research avenues: first, the challenges that firms face in participating in ecosystems around open source projects; and second, the ways in which community engagement and profit-oriented venturing are intertwined in the context of community-driven open source.

\subsection{Historical roots of open source and its evolution}

While the term 'open source' was coined and popularised in the late 1990s, the free sharing of code was already a common practice by the 1960s, starting in the 1950s, when the first commercial mainframe computer systems were released (Androutsellis-Theotokis et al., 2011; Bretthauer, 2001). In 1952, IBM released one of the first commercial scientific 
computers ${ }^{\mathrm{VIII}}$, whose users mainly consisted of people working in academic laboratories and corporate computing centres (Androutsellis-Theotokis et al., 2011; Bretthauer, 2001). In 1955, a group of IBM's corporate customers ${ }^{\text {IX }}$ launched one of the first enterprise computer user groups. This was named 'SHARE', in capital letters, with the motto: "SHARE is not an acronym; it's what we $\mathrm{do}^{\prime \prime}$. As outlined by Akera (2001), IBM's corporate customers were often dissatisfied with the quality of the programs it delivered. However, modifying these programs often proved to be an arduous task, in particular due to a lack of high-level programming languages and a lack of qualified staff (Weber, 2004).

According to Weber (2004), industry leaders decided that a joint effort was needed to overcome the problems and inflexibilities of IBM's computer systems. As he explains, the SHARE user group proved to be useful in developing libraries, standards, more efficient coding systems, and generalpurpose programs (e.g., mathematical routines, input-output utilities) that were distributed freely amongst the group's members. Rather than having to duplicate much of the development work, the corporations' collaborative pursuit enabled them to distribute the costs of coding (costs that were often underestimated). Despite corporate loyalties and competition among the participating corporations, a shared sense of identity emerged among the SHARE collaborators while working on the tools that they jointly needed but could not afford to build on their own (Akera, 2001; Weber, 2004).

The SHARE user group and its activities can be seen as one of the early origins of what is now called open source; remarkably, after 63 years, this group still exists, driving a broad agenda around IT-related topics (e.g., education, professional networking, business strategy) and IBM-centric products and services (e.g., cloud services) ${ }^{4}$. Interested readers are referred to Akera (2001), who explores the genesis, purpose, and functions of this user group in depth. Corporate customers of other systems around that time launched similar groups, such as the 'USE - Scientific Exchange' that was launched in 1956 in order to promote the development of standards, and the exchange of software and programming techniques for UNIVAC computers ${ }^{5}$.

\footnotetext{
VIII The IBM 701.

Ix Including corporations such as IBM, Boeing, General Electric, General Motors, Lockheed, and others (Akera, 2001).
} 


\subsubsection{The 1960s}

During the 1960s, computers became more affordable and attracted a broader range of potential buyers, although these were still mainly universities and corporate computing centres (Weber, 2004). Nevertheless, more people gained access to the new technologies. A hacker culture gradually began to emerge, particularly around university campuses, most notably at the MIT Artificial Intelligence Laboratory (Androutsellis-Theotokis et al., 2011; Raymond, 1999a).

As described by Weber (2004), an important development took place in the early 1960s, which was the development of the first systems for multitasking and time-sharing. Building on this, the work of Ken Thompson and Dennis Ritchie, two researchers at AT\&T's Bell Labs, culminated in the development of UNIX in 1969 (the same year Linus Torvalds was born ${ }^{6}$ ). The development and design of UNIX was seen as a significant technical contribution, celebrated for its simplicity, power, and elegance (Spinellis, 2017). UNIX would find its way into a broad range of application areas, such as supercomputing, network hardware, and personal and handheld computers, which were developments that Weber (2004, p. 26) sees as "central pillars for both the economic and cultural foundations of open source".

\subsubsection{The 1970s}

UNIX played an important role in laying the foundations for the collaborative culture upon which open source builds (Weber, 2004). UNIX went viral after its originators presented it at the ACM Symposium on Operating Systems in 1973 (Weber, 2004). Interestingly, AT\&T did not dare to pursue any major business interests with UNIX due to a settlement with the United States Department of Justice concerning antitrust issues dating back to the 1950s. This settlement (also called the Consent Decree) required AT\&T to stay out of any business except its own core business, which was the provision of common carrier communication services. This meant that AT\&T could not turn UNIX into a 'real' product'. However, AT\&T still licensed UNIX after Bell Labs received a flood of requests from universities (West \& Dedrick, 2001). In the end, AT\&T charged low fees to educational institutes (i.e., licences were sold at nominal cost), while licences were much more expensive for private companies and federal agencies ${ }^{\mathrm{Xl}}$. More

The term 'hacker' refers to technical experts and enthusiasts who engage in creative problem-solving (Lakhani \& Wolf, 2005).

$\mathrm{xI}$ For private firms, the cost for obtaining a UNIX license was 20,000 USD; for federal agencies it was 7,200 USD (McCulloch, 1981). 
importantly, in order to avoid conflicts with antitrust agencies, AT\&T did not advertise UNIX, or offer support or bug fixes for $i t^{8}$. This legal situation contributed to the spread of UNIX because it could be acquired at relatively low cost (at least for educational institutes); furthermore, it facilitated a collaborative spirit amongst UNIX users because they could not rely on AT\&T or Bell Labs for support, but had to share support and bug fixes with each other (Weber, 2004). In this regard, users were 'forced' to collaborate with each other (Androutsellis-Theotokis et al., 2011).

For universities, UNIX was attractive not only due to its low price but also because it was an appreciated research and learning tool whose source code was available for study (Weber, 2004). According to Weber (2004), during the mid-1970s, UNIX also started to spread outside the USA (e.g., to Australia, the UK, and Japan), with the effect that more and more people around the world formed user groups to share ideas and support. In 1976, a UNIX copy program was developed (called UUCP) that could send files from one UNIX machine to another over dial-up networks, which further reduced the costs of distributing the code.

Another crucial invention during the 1970s was the general-purpose programming language ' $C$ ', which was designed to be used with the 'embryonic' UNIX (Raymond, 1999a). The popularity of UNIX increased after it was rewritten in $\mathrm{C}$ because it could then be ported to any other Ccompatible machine. This meant that, for the first time, an operating system could serve as a common software environment for different types of machines, with the advantage that software and tools would not have to be redesigned or rewritten every time a new machine was released (Raymond, 1999a).

Between 1974 and 1979, a collaboration between The University of California at Berkeley (UCB) and Bell Labs further increased the popularity of UNIX; this collaboration led to the Berkeley Software Distribution (BSD), which provided a variety of improved features on top of AT\&T's version of UNIX (Androutsellis-Theotokis et al., 2011). The BSD quickly spread among research centres all around the world; however, users were still required to obtain a licence from AT\&T in order to use the UNIX that was distributed with the BSD (Androutsellis-Theotokis et al., 2011).

According to Weber (2004), around 1978, AT\&T increasingly ran into trouble with the popularity of UNIX. The demand for it grew to such an extent that AT\&T's activities could more recognisably be interpreted as a transition into the software business, potentially bringing the corporation into conflict with the antitrust agencies. Another problem for AT\&T was that UCB increasingly took the lead in cutting-edge UNIX research (Weber, 2004). 
According to Salus (1994), AT\&T had not fully realised the commercial value of UNIX in its early days; however, this changed during the late 1970s, when it became clearer that the system could serve a mass market. When AT\&T realised that there was a mass market emerging for the UNIX system, it began treating the source code as a trade secret. As a consequence, the corporation issued a new licence that prohibited universities from studying the source code in courses (which took effect with UNIX version 7 in 1979).

Subsequently, many universities entirely abandoned studying UNIX in classes and simply taught theory instead (Salus, 1994). Amongst the many people who were frustrated with AT\&T's decision to restrict the universities' licences was Andrew S. Tanenbaum, an American-Dutch computer scientist. As a testimony to his frustration, he later referred to AT\&T's decision as "one of the dumbest mistakes in all of business history" (Severance, 2014, p. 7). In order to better teach his students how an operating system works, Tanenbaum started working on a UNIX clone, with the intention of not using a single line of AT\&T code (Salus, 1994). His UNIX clone later became known as MINIX. MINIX had an extraordinary impact in the software field and crucially inspired Linus Torvalds in his work on Linux in the 1990s, which will be discussed later on.

Another important development that spurred the emergence of open source as we know it today was ARPANET (starting in 1969). ARPANET marked the dawn of networked communication, which elevated sharing practices to a new level during the following decades. Universities, research laboratories, and small isolated groups of hackers would begin to collaborate with unprecedented speed and on an unprecedented scale (Raymond, 1999a). ARPANET brought with it the first electronic email lists and enabled cooperation among special-interest groups scattered across the USA. People in these groups also increasingly began using their email lists for social and recreational purposes, which the Defense Advanced Research Projects Agency (DARPA) deliberately ignored in order to foster more interest in the computing field among young and talented people (Raymond, 1999a).

Last but not least, the 1970s brought the emergence of the proprietary software industry as an independent branch of industry, which was a consequence of the unbundling of hardware and software. Hitherto, computers had mainly been sold as vertically integrated proprietary products (West \& Dedrick, 2001). The impetus for the unbundling of hardware and software came from an antitrust suit in 1969 that forced IBM to unbundle its software from hardware sales (Androutsellis-Theotokis et al., 2011). Another factor that may have facilitated the emergence of the software industry as an independent undertaking was that it became much 
easier to port software across different types of machines, which unleashed the power of economies of scale for software producers.

In many respects, the proprietary software industry represented the ideological counterpart to open sharing practices. Increasingly, tensions built up between proponents of the proprietary software industry, epitomised by Microsoft (founded in 1975) and its co-founder Bill Gates, on the one hand, and, on the other, the proponents of the open sharing paradigm. The terms 'open source' or 'free software' did not yet exist, but the tensions with the proprietary software providers surely shaped the identity of the open source movement. One instance that serves to illustrate these tensions is a famous open letter by Bill Gates in 1976 (entitled "open letter to hobbyists") in which he accused people of stealing software when they copied and shared it (in particular Microsoft software) with others (Raymond, 1999a). Weber's (2004) explanation of the conflicts between the proponents of the proprietary and the sharing paradigms is informative and can be cited in full.

\begin{abstract}
"This [i.e., the conflict between the proponents of proprietary software and the open sharing paradigm] was not a marginal disagreement or a quarrel over how to interpret rules about intellectual property. Rather it was a clash between two distinct and incompatible cultural frames. Part of the difference was broad and philosophical, a perspective about human motivation - do people write software to make money, or to create and experiment as true artists do? Part of the difference was more mundane-a disagreement about the evolving structure of the computing industry. Where, in the chain of products that made up computing, was value being added? In either case (or in both), the differences arose from starting assumptions and thus the worldviews could not really be reconciled. Lines of conflict were drawn here, lines that would shift and reposition over the next twenty-five years but would never go away" (Weber, 2004, p. 37).
\end{abstract}

\title{
2.1.3 The 1980s
}

Drawing on Weber (2004), the key developments of the 1980s can be summarised as follows. The early 1980s marked the watershed of the collaboration between AT\&T and UCB. Perhaps the irony is that both parties increasingly benefited from their collaboration, while at the same time their interests began to diverge more recognisably, which was essentially due to AT\&T's growing commercial interests in UNIX.

The relevance and the importance of the features that the BSD provided on top of AT\&T's UNIX are evident from the fact that most commercial software vendors at that time distributed the BSD, rather than AT\&Ts 'UNIX 
system $V^{\prime}$, a commercial variant of UNIX released in 1983. In addition, in DARPA, the BSD had a weighty supporter commissioning UCB with the development of a TCP/IP integration for UNIX (Weber, 2004). In fact, much of the work on UNIX at UCB was funded by DARPA (West \& Dedrick, 2001). With UCB's activities around UNIX, AT\&T had the benefit that many of the new features and improvements that were released with the BSD could be integrated into its own commercial version of UNIX, for free (Weber, 2004).

The public perception of AT\&T's commercial activities around the development of UNIX changed markedly at the beginning of the 1980s, and this led to another antitrust suit against the corporation. The verdict of this suit ordered the divestiture of AT\&T. The breaking up of AT\&T was finalised in 1984. This meant that Bell Labs was made an autonomous entity, and AT\&T was free to enter into the software business. According to Weber (2004), as a consequence, AT\&T dramatically altered the licensing terms for UNIX, with fees skyrocketing "to around \$100,000 [USD] in 1988 and as high as \$250,000 [USD] a few years later" (Weber, 2004, p. 39). Very few universities and firms wanted to pay these sums (or could afford to pay them). These licensing terms also posed a challenge to the users of the BSD because they still had to obtain a licence from AT\&T for the UNIX system that was distributed with the BSD.

In order to mitigate this problem, the UNIX group at UCB decided to embark on a mission to disentangle the BSD code, which was written by UCB fellows, from the UNIX code that was licensed by AT\&T. The goal of UCB was to refactor the BSD and release it as a separate package, independent of UNIX. UCB started off by disentangling the TCP/IP network code and other utility functions from the UNIX code and releasing them under the package name 'Networking Release 1' in 1989. The licence for the 'Networking Release 1' was extremely liberal (known as the BSD licence). Basically, a licensee could do anything with the code, without the need to pay royalties. When the 'Networking Release 1' became popular, UCB decided to expand their project and incorporate other BSD features into its network package. Eventually, these efforts resulted in the idea of rewriting and replacing the entire AT\&T code that shipped with the BSD in order to produce a feature-complete BSD operating system that could be used without a costly AT\&T licence ${ }^{9}$.

As Weber (2004) goes on to explain, the efforts to produce a featurecomplete BSD UNIX were coordinated and designed as a public, distributed, Internet-based development process that resulted in the involvement of almost 400 volunteer developers. While this process suffered from poor Internet connections, and while the most valuable contributions often came from within $U C B$, the collaborative effort to rewrite AT\&T's 
UNIX produced an almost complete operating system by 1991, after only eight months of work. However, the emphasis is on 'almost complete' because there were six files remaining that still contained AT\&T code but which were considered too difficult to rewrite by the UCB developers at that time. Instead, the group at UCB decided to "release the slightly incomplete system and hope that someone else would finish the work" (Weber, 2004, p. 42). It would be another six months before William Jolitz, another talented UCB fellow, had finished and replaced the remaining six files. The result was a complete and bootable operating system for the Intel 80386 architecture (the architecture that ushered in the era of personal computers). This operating system became known as the 386/BSD. According to Weber (2004, p. 42), the 386/BSD system "was licensed for free redistribution and modification as long as attribution remained intact".

Alongside the BSD, there was another important development that took place during the 1980s. In 1983, Richard Stallman, a fellow at the MIT Artificial Intelligence Laboratory at that time, announced his plans to develop a UNIX-like operating system that he called the GNU operating system $^{10}$. According to Weber (2004), Stallman's motivation for writing GNU was in part rooted in the frustration of not being able to access the source code of operating systems that came with newly shipped mainframes at MIT - the researchers were even required to "sign nondisclosure agreements simply to get an executable copy" (Weber, 2004, p. 46). Facing such obstacles, Stallman became particularly outspoken about the moral dimension associated with sharing practices in the realm of software; his ideas and activities would have a great impact in the software field, which extends up until today.

Using Weber's (2004, p. 47) words, Stallman regarded software as "a manifestation of human creativity and expression", and as "a key artefact of a community", which in Stallman's thinking "existed to solve problems together for the common good". As Weber (2004) further explains, Stallman believed that the proprietary software regime did not provide the right incentives for writing good code. Stallman demanded that people should have unconstrained access to source code and should be able to use, modify, and share the code just in whatever way they see fit. In 1984, Stallman founded the Free Software Foundation (FSF) ${ }^{11}$. The FSF and Stallman accounted for the development of a number of important software tools (e.g., EMACS, GCC compiler). However, efforts to develop a kernel for the GNU operating system floundered for several years (West \& Dedrick, 2001). Stallman published the so-called GNU Manifesto ${ }^{12}$ in 1985, which laid the foundations for the so-called free software movement. With this manifesto, Stallman explained his motivations for writing the GNU 
operating system, which were rooted in his conviction of solidarity with other users and users' freedom to use software code. In Stallman's philosophy, free software referred to four essential freedoms that the users of a program should have. As published on the GNU website ${ }^{13}$, these freedoms are: the "freedom to run the program as you wish, for any purpose", the "freedom to study how the program works, and change it so it does your computing as you wish", the "freedom to redistribute copies so you can help others", and the "freedom to distribute copies of your modified versions to others".

It is important to note that the term 'free' in free software is to be interpreted as freedom or libre (e.g., liberty), and not as gratis. However, as Weber (2004) points out, the use of the term 'free' in free software created much confusion (in particular amongst business people). As will be discussed in the next section, the term 'open source' was coined mainly in an attempt to resolve the ambiguities that were conveyed with the term 'free' software. Weber (2004) further explains that, in order to prevent free code from being used in proprietary packages, Stallman came up with an intellectual property regime that would ensure the freedom of the code. Practically, this was achieved with the invention of the General Public Licence (GPL), which he released in 1989. The key idea of the GPL is that all derivates of the code must remain free, which became known as 'copyleft'. Sometimes, the GPL is also referred to as a 'viral licence' because it requires that the licence is preserved in all derivative work. Amongst the plethora of open source licences that exist today, the GPL is amongst the most popular.

\subsubsection{The 1990s}

According to Weber (2004), the developments throughout the 1990s would eventually lead to what can be seen as the "birth of the modern open source software phenomenon" (Weber, 2004, p. 38). The advent of mass Internet connectivity would act as a catalyst for this phenomenon (Raymond, 1999a; Weber, 2004).

As mentioned before, with the 386/BSD operating system, an entire royalty-free UNIX alternative became available to the masses, which clearly threatened AT\&T's UNIX business model. This was the driver for increasing commercial activity and competition around the UNIX system. As well as the commercial UNIX variants that sprang up ${ }^{\mathrm{XII}}$, several other free BSD derivatives emerged, most notably, NetBSD, FreeBSD, OpenBSD, and

XII Amongst others, Weber (2004) mentions the examples of Sun Microsystems, Hewlett-Packard, IBM, Apollo, and the Digital Equipment Corporation, who all built their commercial versions of BSD. 
Darwin (on which macOS is based) ${ }^{14}$. It could be argued that the example of UNIX shows that the publication of the source code, together with the removal of proprietary licencing, can trigger a lively differentiation process (which encourages experimentation and derivate work). However, this development also gave rise to many legal quarrels, and proliferating standards, which raised doubts about the future of UNIX (Weber, 2004). Raymond (1999a) argues that the bickering about cross-platform portability among proprietary UNIX vendors at that time enabled Microsoft to grab away a large share of the market for PC operating systems with, what he calls, an inferior operating system.

Rather unaffected by the developments around the BSD, the early 1990s brought the emergence of another (today well-known) open source operating system. In 1991, Linus Torvalds began his work on creating a free UNIX-like operating system, which he called Linux. According to Weber (2004), at this time, Torvalds was not aware that a free BSD operating system already existed. As reasons for Torvald's lack of awareness of BSD, Weber (2004) cites the infancy of the Internet, the fact that the Web did not yet exist, and that information spread unevenly on USENET newsgroups. In his work, Torvalds benefited tremendously from existing OSS that he could build upon. Using the MINIX operating system, developed by Tanenbaum, and the GNU tools, released by the FSF, Torvalds was able to make rapid progress and eventually attracted a multitude of followers who helped him in developing Linux (Raymond, 1999a). As Raymond (1999a) points out, the Linux project brought an important social innovation to software development processes. In contrast to the BSD project, which was mainly developed and coordinated within the institutional bounds of UCB (although it involved external contributions), Linux evolved in a different, more bottom-up style, involving casual hacks, the contributions of large numbers of volunteers, and fast iterations of feedback instead of rigid standards for quality control (Raymond, 1999a). As explained by Raymond (1999a, p. 9), this development model created "a sort of rapid Darwinian selection on the mutations introduced by developers". The Linux project quickly became a success. By 1993, Linux was already as stable and reliable as many commercial UNIX variants on the market (Raymond, 1999a). According to West and Dedrick (2001), Linux became the most commercially successful example of a new wave of OSS. In its early days, Linux was mainly distributed and sold via CD-ROM, which was a lucrative source of revenue due to the fact that broadband Internet connections were still a rarity.

Interestingly, Torvalds initially conceived of a licence that would prohibit anyone from charging for the distribution of the software; however, 
he quickly gave in to the large number of protesters who claimed they would otherwise lose money on copying and distributing the code - as a consequence, Torvalds decided to adopt Stallman's intellectual property regime and released Linux under the GPL terms in 1992 (Weber, 2004). As Weber (2004) points out, an important consequence of this decision was that Linux would remain free forever because of the 'viral' clause of the GPL (i.e., the idea of copyleft). The decision to license Linux under GPL terms came at a time when AT\&T and BSD were still locked in an ongoing legal battle over the ownership of UNIX, which pushed many people from BSD to Linux - many of whom were less interested in this legal dispute than in studying and writing code (Weber, 2004).

The activities around Linux proved that a large and complex system could in fact be developed and maintained through Internet-based mass collaboration amongst volunteers (Weber, 2004). As Weber (2004) points out, this mass collaboration was based on a simple but important principle: "If there is something you want and others also want it enough to help you build it, go ahead and do it" (Weber, 2004, p. 103). Raymond (1999b) referred to this development model as a babbling bazaar that allowed multiple agendas and differing approaches to emerge, coexist and compete.

From 1994 onwards, Linux became more and more of an economic phenomenon. Drawing on Weber (2004), the further key events can be summarised as follows. Linux began to flourish when it was ported from the 80386 computer architecture (for which it had been initially developed) to other platforms (e.g., Intel, Alpha, the Motorola 6800 series, Power PC, Sun SPARC, Oracle). One of the first corporations to make a commitment to Linux was the Digital Equipment Corporation, a manufacturer and provider of high-end computing systems. It was obvious that commercial companies had clearly benefited from the type of mass collaboration that spawned the Linux operating system. Based on mass collaboration, it took about three to four years to turn, what had appeared to many to be, a hobbyists' toy into "a first-class operating system for advanced computing architectures" (Weber, 2004, p. 106).

The first rudimentary business activities around Linux (e.g., selling copies via CD-ROM) evolved into more sophisticated business practices. For instance, the porting of Linux to different systems opened up a niche for system integrators who bundled and maintained Linux ports for different hardware platforms. Furthermore, services such as consulting, installation, configuration, and customisation for Linux became a profitable branch of business. A plurality of Linux distributions emerged during that time (e.g., SuSE Linux, Red Hat Linux, Debian Linux, TurboLinux, Caldera, VA Linux), each addressing slightly different needs and niches. 
As Weber (2004) argues, while Linux had become of major importance to enterprise-level computing throughout the 1990s, many of its supporters still had a hobbyist mindset, which led to tensions between those who firmly believed in Stallman's ideas of freedom, and those who took a more pragmatic stance towards licensing. The pragmatist camp had a different kind of freedom in mind, one that kept the restrictions imposed on the code to an absolute minimum, as was the case with the BSD licence. Whereas, the GPL required all modifications and derivates to be released as free code, the BSD licence was more permissive in the sense that it also allowed the code to be incorporated into closed-source proprietary software products.

For the pragmatist camp, one major source of confusion with free software was the label 'free'. 'Free' was associated by many (especially by business people) with zero price or zero cost. As Weber (2004, p. 114) states, free software (in the sense of freedom) "may have been technically desirable; but from a marketing perspective, it was a disaster, in no small part because of the name". Furthermore, the fact that most 'free software' was distributed free of charge reinforced the 'gratis' image around 'free software' (Raymond, 1999c).

In order to resolve these tensions and to make free software more appealing to commercially-oriented people, the quest for a new label began. An important step in this direction came in 1998 with the announcement by the Netscape Communications Corporation (NCC) that it would make the source code of its Netscape browser available to the public (as the Mozilla project). The executives at NCC were inspired by Raymond's ideas on Internet-based collaborative software development and in February 1998 invited him to join them on working out a source-release strategy and a licence (Raymond, 1999b). Several other known figures in the software field were involved in these strategy sessions. At the beginning, many of the discussions at these strategy sessions still revolved around the term 'free software'; however, at some point, Christine Peterson, as she claims in an article published in early 2018, came up with the term 'open source software ${ }^{\prime 15}$. As Peterson writes in her article, at that time, several other terms were also under debate, such as 'freely distributable', 'cooperatively developed', and 'sourceware'. 'Freed software' was under consideration, too (Tozzi \& Zittrain, 2017). In a nutshell, the participants at these strategy sessions liked Peterson's suggestion and continued to use and spread the label 'open source software'. For a more complete picture of how the term open source became endorsed by the leading figures in the software field, interested readers are referred to Weber (2004), and Tozzi and Zittrain (2017). 
The Netscape browser may have been the first software code that was explicitly marketed under the label of 'open source software'. By making the Netscape browser open source, NCC hoped to harness the creative potential of possibly thousands of developers in order to spur innovation ${ }^{16}$. As Tozzi and Zittrain (2017, p. 222) put it, the open-sourcing of the Netscape browser was clearly a business strategy - NCC "evinced no deep-seated ideological commitment to the FOSS [i.e., free and open source software] movement. The company was in the final stages of its losing war against Microsoft's Internet Explorer browser and hoped that opening the [Netscape] Communicator code to third-party contributions and distributing the browser free of charge would help to regain users and reduce development costs".

Moreover, according to Williams (2002), for Raymond and his followers, the strategy sessions in relation to the publication of the Netscape browser code were also an opportunity to take advantage of Netscape's decision in order to encourage other companies to follow suit (and make their software open source). Much of the marketing work for the Netscape browser was about disassociating it from the image of 'free software', which was seen to be associated by the trade press and in the corporate world with stereotypes of communism and hostility towards intellectual property (Raymond, 1999c). The intention was to rebrand the Netscape browser with more pragmatic tales and positive traits, such as cost savings and increased reliability, which would facilitate corporate buy-in, or so Raymond and his followers believed (Raymond, 1999c).

It should be mentioned that there are also disputes about who coined the term 'open source' and when exactly it was created. According to the Google Ngram Viewer, the popularity of the term 'open source' saw a steep increase from the late 1990s onwards. Before that, the term was virtually unknown (except in a rather different context in the realm of intelligence ${ }^{17}$ ). What is more important is that the term 'open source' was intended to resolve the "tension between BSD philosophy and GPL philosophy, between pragmatists and purists, between the moral arguments of Richard Stallman and the commercial desires of companies" (Weber, 2004, p. 114).

Raymond and Bruce Perens founded the Open Source Initiative (OSI) in 1998, a non-profit organisation with the purpose of promoting OSS. In 2018, the OSI celebrated its $20^{\text {th }}$ anniversary, as announced on its website ${ }^{18}$. The OSI also provides a definition of open source, along with a set of guidelines for determining whether a particular licence qualifies as an open source licence $^{19}$. These guidelines were based on the Debian Social Contract and the Debian Free Software Guidelines (Androutsellis-Theotokis et al., 2011), which take a liberal stance towards the use of free and non-free software ${ }^{20}$. 
Today (in May 2018), the OSI lists 84 different OSI-conforming open source licences on its website ${ }^{21}$. It is beyond the scope of this text to delve into open source licensing in greater depth. Interested readers are referred to the corresponding literature stream dealing with this topic (S. H. Lee, 1999; Lerner \& Tirole, 2005).

The term 'open source software' was met with (more or less) great resistance by Stallman and the supporters of the FSF (Androutsellis-Theotokis et al., 2011). Stallman saw open source as an amoral approach and ever afterwards tried to maintain a clear delineation between open source and free software. In order to make the distinction between open source and free software clearer, several solutions were proposed. As Stallman explains on the GNU website ${ }^{22}$, there are two political camps in what he refers to as the free software community (which indicates that he sees free software and open source as part of the same movement). He argues that free software emphasises the freedom of users, while open source only emphasises the practical benefits that come with free code. In order to accommodate both perspectives and to allow for a neutral stance, he champions the term 'Free/Libre and Open Source Software' (FLOSS). Alongside the term 'open source software', the term FLOSS is widely used in the literature. Another term that is sometimes used, probably to a lesser extent, is 'Free and Open Source Software' (FOSS). However, Stallman argues that the term FOSS is misleading because it represents a single point of view, rather than two differing political positions. In any case, Stallman is keen to stress that proponents of the free software camp do not use either of these terms. Rather, they use 'free' software, 'libre' software or 'free (libre)' software.

Unfortunately, this text cannot delve any further into the (partly ongoing and unresolved) debates around naming, branding and philosophical aspects of free software and open source software. In this thesis, the term 'open source software' is generally used instead of 'free software' because the thesis focuses on aspects of commercialisation around this particular type of software. Connotations such as 'gratis', 'zero price', and 'zero cost', which are potentially invoked by the phrase'free software', might render the study of commercialisation aspects around this type of software dissonant to a reader. It should be added that the OSI (the stewardship organisation for open source) recognises the GPL as an OSI-conforming licence, which can be interpreted as meaning that open source embraces the ideas of 'free' (libre) code, rather than standing in contrast to it.

As stated by Raymond (1999c), the adoption of the term 'open source' spread quickly. In Raymond's view, in essence, this meant that a name was given to a phenomenon "whose impact was already larger than anyone outside the Internet community had yet realised" (Raymond, 1999c, p. 9). 
During the 1990s, several key open source web technologies emerged. To name but a few, with the open-sourcing of Netscape the Mozilla project was brought to life (1998), the Apache Software Foundation was formed (1999), and several other important open source (Web) technologies were introduced, such as Python (1990), PHP (1994), and MySQL (1995). With Linux, the Apache web server, MySQL, and PHP, the so-called LAMP stack (the acronym for these brands) became popular in the late 1990s (Tozzi \& Zittrain, 2017). The LAMP stack provided the masses (and still does so) with a cost-free and powerful software infrastructure for operating and developing websites (Tozzi \& Zittrain, 2017).

The growth of OSS also concerned the proprietary software producers. Raymond (1999c) illustrates this point by the example of Microsoft and what became known as the so-called Halloween Documents ${ }^{23}$. These were a confidential Microsoft-internal strategy memorandum that acknowledged the success of open source models and outlined several strategies for combating it. According to Tozzi and Zittrain (2017), the documents were written by Vinod Valloppilli, a Microsoft product manager, at the request of Microsoft's senior vice president, James Allchin.

These documents were leaked in October $1998^{\mathrm{XIII}}$ and received a lot of attention after being published by Raymond. In these documents, open source is portrayed as a revenue and platform threat to Microsoft, but also as a credible development methodology that can match, if not exceed, the quality achieved through proprietary production models. The author of the documents was impressed by the "ability of the OSS process to collect and harness the collective IQ of thousands of individuals across the Internet" ${ }^{\prime 23}$. These documents outlined several strategies for how Microsoft could thwart the momentum of open source. One such strategy was called embraceextend-extinguish. According to Tozzi and Zittrain (2017), with embraceextend-extinguish, Microsoft first intended to use and extend standardsbased technologies with proprietary extensions, which would help them to attract customers. Eventually, they would use these proprietary extensions as leverage to stifle open protocols and to facilitate monopoly lock-in. In a press statement, Microsoft confirmed the authenticity of the documents, but downplayed their significance by emphasising that they did not represent Microsoft's official stance towards open source, but rather the views and assessments of an individual engineer (Tozzi \& Zittrain, 2017).

It surely cannot be ignored that the proprietary production paradigm was successful throughout the 1990s, too. For instance, Microsoft managed to gain market share in the personal computer market as well as the enterprise 
server market that was previously dominated by UNIX-like systems (Weber, 2004). As reasons for Microsoft's ability to gain market share, Weber (2004) mentiones the fragmentation of the UNIX community (i.e., as a consequence of the proliferation of UNIX derivatives), duplications of effort (leading to slower development), and poor compatibility. Looking at the Halloween Documents, one might also recognise aggressive marketing strategies as a reason for Microsoft's success.

In the late 1990s, the confrontations between proponents of proprietary software and free software intensified. Besides the quarrels with Microsoft, another such confrontation was the conflict between Troll Technology (the producer of Qt, a windowing and widget toolkit for graphical interfaces) and the open source development communities around KDE and GNOME, two graphical desktop environments for Linux. This story is illustrative of the kind of power games that were going on between the proprietary and open source worlds. Drawing on Tozzi and Zittrain (2017), this story can be summarised as follows. In the 1990s, open source developers began working on a variety of more advanced and appealing desktop environments for Linux, most notably the KDE and GNOME desktop environments. Matthias Ettrich began with the development of KDE in 1996 using the tools provided by the Qt library. Qt was a mature proprietary programming library owned by a company called Troll Technology ${ }^{\mathrm{XIV}}$. In principle, Qt's licence allowed KDE to be licensed and distributed under GPL terms, for free. However, the open source developers were still concerned about the dependence on this proprietary software framework. For instance, among the perceived risks were that Troll Technologies might cease its support for the framework or make its licence incompatible with GPL code without consulting the KDE development community. As a consequence, open source developers initiated the GNOME project in 1997, which was dedicated to producing a Linux desktop environment that was entirely based on free software, eliminating dependency on the Qt framework. At the same time, open source developers initiated the so-called Harmony project in order to reimplement and clone the Qt library as a GPL library. According to Tozzi and Zittrain (2017), both follow-up projects, GNOME and Harmony, were intended to force Troll Technologies to release the Qt framework under more liberal terms. In short, Troll Technologies relented in light of the threat of becoming irrelevant to the open source community - in 2000 it released its most recent Qt framework under GPL terms, which Tozzi and Zittrain (2017) interpret as an important victory for the proponents of the free software camp. Tozzi and Zittrain (2017, p. 182) see this incident as "an 
example of the FOSS community's ability to secure the leverage it needed to overcome proprietary software companies whose leaders chose to play by rules with which FOSS developers disagreed".

This section ends with a word on the growing importance of OSS for the business world. As argued by Tozzi and Zittrain (2017), profitable businesses based on OSS were not a novelty in the 1990s; however, the success of OSS in the late 1990s "raised the importance of FOSS within the business world to a new level" (Tozzi \& Zittrain, 2017, p. 199). The success of many flagship distributions (e.g., Red Hat, IBM, Apache) throughout the coming years illustrates this point.

\subsubsection{The 2000s}

Based on Tozzi and Zittrain (2017), the key developments throughout the 2000s can be summarised as follows. Open source continued to flourish during this decade, with the scope and range of open source applications becoming increasingly diverse and sophisticated. In the realm of open source operating systems, enhanced usability and user experience attracted a wider demographic of users, beyond the technically inclined. Both the emergence of graphical desktop environments for Linux and the evolution of productivity applications (e.g., OpenOffice, Evolution, Mozilla Thunderbird) did much towards that end.

OpenOffice is probably amongst the most popular of the open source productivity applications. It originated as StarOffice, which was a proprietary office suite first released in $1985^{24}$. StarOffice was acquired by Sun Microsystems in 1999 who were in search of a more cost-efficient office solution for their employees. Essentially, Sun Microsystems wanted to avoid having to pay expensive licence fees for Microsoft Office for thousands of their employees. In 2000, Sun Microsystems decided to make StarOffice open source in order to build a development community around it.

StarOffice was made open source as the OpenOffice project and quickly attracted many followers and users. According to Tozzi and Zittrain (2017), by 2004, OpenOffice had reached a market share of $14 \%$ in the enterprise market, which was fiercely dominated by proprietary competitors. By making OpenOffice available to the public, Sun Microsystems betted that skilled enthusiasts would jump on board and help improve the product ${ }^{25}$. However, Tozzi and Zittrain (2017) also mention that the significant investment made by Sun Microsystems into the OpenOffice project (e.g., paid development) had contributed crucially to its success. Through its engagement, Sun Microsystems may have had the benefit of being able to influence the development activities in favourable ways, such as the 
inclusion of features that the company prioritised itself. The OpenOffice project was forked later on (with the birth of LibreOffice), when Sun Microsystems was acquired by Oracle in 2010.

The differentiation process of Linux-based systems continued throughout the 2000s. A multitude of Linux distributions emerged as a consequence (e.g., Lindows, Corel Linux, Mandrake, Gentoo, Ubuntu, SUSE). According to Tozzi and Zittrain (2017, p. 172), in 2001, the "Linux User magazine estimated that about 140 distributions were in existence". Also, the history of Android, today's most popular operating system for mobile devices by far, dates back to the 2000s. Android is based on Linux and was initially developed for use with digital cameras in 2003; however, it became an operating system for phones after Google acquired the company behind Android in 2005. Officially released by Google in 2007, Android powered about $90 \%$ of all mobile devices in 2016 (Tozzi \& Zittrain, 2017).

While the desktop market was dominated by Microsoft, the story was rather different, not only for the market in mobile devices, but also for the Internet and the server market, which was dominated by diverse open source applications and open source operating systems (which is still the case today).

Tozzi and Zittrain (2017) explain the dominance of open-source-based applications and systems in the server market and the Internet as a consequence of the very fact that distributed computing (such as the Internet, cluster and grid computing) depends on open protocols in order to function. At the same time, OSS and open protocols drastically reduced the costs of building these systems and making them scalable.

According to Tozzi and Zittrain (2017), in 2000, IBM made a huge investment in Linux. Executives at IBM had frequently heard of Linux in their talks with business people and developers. After commissioning an internal study on Linux, executives at IBM became convinced that having its corporate strategy centred around the open source model of Linux would be the right thing to do. This was followed by a gigantic and unprecedented investment of one billion USD to support Linux kernel development and related applications. According to Tozzi and Zittrain (2017), executives at IBM saw open source as a mainstream culture that would come to dominate the future. The bet was that standards-based systems were the foundations upon which the next generation of Internet businesses would build. The huge investments were intended to spur innovation and improve software quality, performance, and security.

IBM was not alone in this respect; in a similar fashion, many other major corporations invested in open source technologies; to name but a few: Apple (with OS X in 2001), Dell (by selling computers that shipped with 
preinstalled Linux from 2007 on), and Google (with the Chromium OS in 2009).

The 2000s were also characterised by the perennial 'war' between Microsoft and open source. In 2001, Microsoft's CEO, Steve Ballmer, even referred to Linux as "a cancer that attaches itself in an intellectual property sense to everything it touches". Ballmer contended that open source was in no way a viable business model for commercial companies. In the early 2000s, Microsoft still regarded open source as a major threat to its business model, a stance that would change substantially throughout the next decade, as will be discussed in the next section. Meanwhile, the conflicts between Microsoft and open source companies surged.

One such conflict arose with the inception of Lindows in 2001, a Linuxbased operating system that was capable of running major Microsoft applications ${ }^{26}$. These efforts were based on and inspired by the Wine API, an open source project created in 1993 to bring Windows applications to Linux. In 2002, Microsoft sued Lindows for a violation against the Windows trademark. In short, the court rejected Microsoft's claim. However, in a settlement Microsoft paid 20 million USD for the Lindows trademark and Lindows changed its name to Linspire.

In the realm of the Web, many important developments around OSS took place throughout the 2000s. The prevalence rates of the Apache web server reached about $70 \%$ in the mid-2000s (Tozzi \& Zittrain, 2017). Today, it is still one of the most popular web servers, alongside other alternatives (e.g., NGINX, Microsoft IIS ${ }^{27}$. During the 2000s, today's most popular open source CMSs were created; namely, WordPress, Joomla, and Drupal. WordPress was created in 2003 as a fork of the 'B2/cafelog', an open source blogging tool. Joomla was created in 2005, after forking from the Mambo project. Drupal was made open source in 2001 by its founders. All three CMSs were licensed under GPL terms.

Many of the developments around open source web technologies were accompanied and inspired by the transition from Web 1.0 applications to the so-called Web 2.0 ${ }^{\mathrm{XV}}$. OSS was essential for the new types of applications and companies that emerged. For instance, Facebook (launched in 2004) made a strong commitment to open source very early on. As emphasised by a Facebook engineer, "Facebook is built on open source from top to bottom,

xv The term Web 1.0 is often used to describe the early stages of the Web when the Internet turned into a mass phenomenon, which happened in the early 1990s. The interactive aspects of online communication got more important later on. With the Web 2.0 the user and the social relations had become more central. With the Web 2.0, new types of web applications emerged, such as social media platforms (e.g., Facebook, Twitter). 
and could not exist without it" ${ }^{28}$. This commitment to open source continues today. Facebook's technology strategy comprises engagement in a broad range of open source projects. The company not only uses OSS, it actively contributes to a wide array of open source projects (e.g., MySQL, Cassandra, Hadoop, Hive, Hbase), and has repeatedly published applications and systems as open source projects that were initially developed internally. Companies such as Google, Facebook, and others embraced OSS as a major factor driving competitive advantage; these companies would not have been able to scale economically or technically without $\mathrm{OSS}^{29}$.

\subsubsection{The 2010s}

The number of open source projects grew explosively during the 2000s and has continued to do so until today. As already mentioned in the introduction to this thesis, two popular hosting providers for open source projects (i.e., GitHub and SourceForge) registered a steep rise in the number of open source projects and users on their platforms. According to Tozzi and Zittrain (2017), DistroWatch.com, a website providing statistics relating to Linux distributions, registered 800 different Linux distributions by 2015; albeit, many of these were not under active development and the bulk of users were ascribed to a minority of Linux distributions. The Apache Software Foundation became one of the most important centres for OSS, hosting flagship projects such as Hadoop, Cassandra ${ }^{\mathrm{XVI}}$ and many others, accumulating nearly 300 open source projects by 2016 (Tozzi \& Zittrain, 2017).

Open source continued to push and thrive in areas as diverse as the Web, mobile computing, embedded systems, robotics, computer graphics, gaming, virtual reality, artificial intelligence, and cloud server infrastructures. Even Microsoft, seen by many seen as the archfoe of the free and open source movement, eagerly began to embrace open source throughout the 2010s. The following discusses some recent examples of how Microsoft began incorporating open source into its own activities, strategies, brands and products.

According to an article in The Economist, in 2014, the new CEO of Microsoft, Satya Nadella used a slide in his presentation that read "Microsoft loves Linux" ${ }^{\prime 30}$, a significant change in attitude compared to Microsoft's former CEO, Steve Ballmer, who referred to it as a cancer. Microsoft had surely not discovered its love for open source after all these years, but had rather realised the necessity of allying with open source in order to remain

$\mathrm{xvI}$ Hadoop, is a collection of tools for processing massive amounts of data (big data). Cassandra is a distributed database system for managing clusters of datacentres and cloud computing infrastructures. 
competitive in a fast-changing technological landscape with trends moving towards mobile, embedded, and cloud-based computing, areas in which open source technologies excel.

In order to align with these trends, Microsoft refocused its commercial operations and technology strategy. It began placing stronger emphasis on its cloud-based operations and services, rather than on the Windows operating system for PCs. As the above-cited article in The Economist points out, with the shift towards mobile and cloud computing, Windows has gone from being one of Microsoft's most important cash cows to becoming a lossleader for pushing other Microsoft products, such as its cloud services. Events that seemed unimaginable only a decade ago illustrate how Microsoft began to incorporate the open source model into its strategy.

One important event took place in 2014, when Microsoft released its .NET framework as an open source project ${ }^{31}$. To many, Microsoft's decision came as a surprise because it went very much against its previous philosophy of protecting its own technologies ${ }^{32}$. As was communicated on the corporation's website, the motivation behind this move was to facilitate cross-platform development based on its .NET libraries, and to strengthen the ecosystem around the .NET platform. Microsoft's increasing investments in Linux-based server technology may help to explain its growing ambition to create cross-platform compatibility ${ }^{33}$.

Another significant event took place in 2016, when Microsoft introduced the so-called Windows Subsystem for Linux, which makes it possible to run Linux applications on a Windows operating system (the opposite of what the Wine project provides for Windows applications on Linux) (Tozzi \& Zittrain, 2017).

Furthermore, Microsoft itself recently began investing a considerable amount of resources into Linux development. These investments are part of a new strategy that includes collaborations with open source companies (e.g., Canonical ${ }^{\mathrm{XVII}}$ and Red Hat) and a variety of open source communities. In 2016, Microsoft became a platinum sponsor of the Linux Foundation, and also got a seat on the Linux Foundation's Board of Directors. The foundation's website lists the many benefits that platinum members can reap. For instance, it gives members the ability to "govern and create new open source projects with The Linux Foundation", and it provides access "to Linux Foundation executives for open source strategy discussions ${ }^{\prime 34}$. The list of sponsors of the Linux Foundation reads like a Who is Who of the IT industry. In May 2018, the Linux Foundation listed 13 platinum members, including corporations such as AT\&T, CISCO, IBM, ORACLE, and Intel. It

XVII Canonical is the steward of the Ubuntu project, one of the most popular Linux distributions today. 
also gave 15 Gold members and a long list of Silver members ${ }^{35}$. This shows that the Linux project has become the collaborative pursuit of an entire industry. Its new role in the Linux Foundation might bestow upon Microsoft at least some moderate influence over important decisions concerning Linux ${ }^{36}$.

Also, unusually, in March 2018, Microsoft gave the headlining keynote at one of the largest Linux conferences in the world, the Southern California Linux Expo ${ }^{37}$. One year earlier, in 2017, Microsoft had become a sponsor of the OSI, an organisation that was set up to promote OSS (the previous target of Microsoft's embrace-extend-extinguish strategy). OSI celebrated Microsoft for its participation in open source projects and its leading role as a contributor to GitHub ${ }^{38}$. Patrick Masson, the OSI General Manager, referred to Microsoft's sponsorship as "a significant milestone for the OSI and the open source software movement more broadly". He further stated that there could not be "any greater testament to the maturity, viability, interest, and success of open source software than not only Microsoft's recognition, but also their support as a sponsor ${ }^{\prime \prime 38}$.

In line with its new strategic orientation, Microsoft began developing its own Linux-based operating system (which they named Azure Cloud Switch) to power the Azure cloud server network infrastructure (Tozzi \& Zittrain, 2017). Showcased in 2015, the Azure Cloud Switch stack comprises both open source and proprietary software ${ }^{39}$. As reported in the Linux Magazine $^{40}$, Microsoft had recently announced a further Linux-based operating system, called Microsoft Azure Sphere. Azure Sphere is an operating system for Internet of things (IOT) devices. At the product presentation in April 2018 ${ }^{41}$, Microsoft's president, Brad Smith, announced the following to his audience:

"... [Azure Sphere] is a new operating system, it's based on a custom Linux kernel ... that has really been optimised for an loT environment and is reworked with security innovations pioneered in Windows. Of course, we are a Windows company, but what we have recognised is, the best solution for a computer of this size in a toy [i.e., an IoT device] is not a full-blown version of Windows, it is what we are creating here, it is a custom Linux kernel complemented by the kinds of advances that we have created in Windows itself. For anybody who has been following Microsoft, I am sure you will recognise, that after 43 years this is the first day that we are announcing that we will be distributing a custom Linux kernel. It's an important step for us".

As Klint Finley wrote in the Wired magazine, "by building on open source software, Microsoft can take advantage of improvements to the code made 
by other companies with similar problems" ${ }^{\prime 2}$. While Microsoft has become one of the most active contributors on GitHub ${ }^{43}$, there are critics who complain that the corporation contributes back to the Linux community in only a limited fashion. Basically, the GPL does not require Microsoft to disclose the modifications it has made to the Linux source code since it uses the software exclusively for internal purposes ${ }^{\mathrm{XVIII}}$. This is the reason why Microsoft's open source activities are monitored with critical eyes by some of the proponents of the free software camp, who essentially see Microsoft as a free-rider exploiting the benefits of open source without offering much in return (Tozzi \& Zittrain, 2017) ${ }^{\mathrm{XIX}}$. Microsoft might be monitored even more carefully by the proponents of open source since it acquired GitHub in June 2018. Currently, GitHub is the world's largest provider of infrastructure (e.g., hosting, version control) for open source projects. The GitHub platform brings together a vast pool of developers, which has made it an attractive target for Microsoft's activities. Already in 2017, Microsoft and GitHub collaborated in order to make Microsoft products available as open source projects on GitHub, such as the Visual Studio Code and the .NET runtime ${ }^{44}$.

However, critics fear that Microsoft's open source engagement could just be a continuation of its embrace-extend-extinguish strategy, just in a different suit ${ }^{45}$. Many developers expressed their concerns on social media channels over Microsoft's purchase of GitHub, threatening to move to alternative infrastructure providers. In exactly what ways the activities on GitHub will be affected by its new owner, Microsoft, remains to be seen.

On a final note, according to Tozzi and Zittrain (2017), Stallman sees the trend towards cloud-based computing as a threat to free software. Stallman expressed worries that with cloud solutions the users are divested of control even more than with proprietary solutions. His argument is that, with cloud services, personal data is surrendered to whoever owns the cloud, with little control over the providers' use of this data. As a further problem he recognises users' inability to access the source code that is running on servers. According to Tozzi and Zittrain (2017), the FSF tried to address this loophole in the GPL with the inception of a new licence, the socalled GNU Affero General Public Licence (AGPL). In a nutshell, the AGPL requires modified code that is operated on servers to be distributed back to the community ${ }^{46}$. This licence was first introduced in 2007, but the

XVIII The GPL requires the source code only to be disclosed to the receiver of the software. However, if the software is not distributed (e.g., to customers, partners, or the general public), the source code does not need to be disclosed.

xIx However, as von Hippel \& von Krogh (2003) observed, most users of OSS may be free-riders, only a minority contributes back. 
phenomenon that it tries to address (i.e., open source in the context of cloudbased services) might have surged more recognisably throughout the 2010 s. However, as Tozzi and Zittrain (2017) point out, the AGPL has so far seen limited adoption.

Inspired by Androutsellis-Theotokis et al. (2011), Figure 2 provides a condensed summary of the genesis and evolution of open source, with a focus on web technologies, and including some of the most significant events. The timeline in Figure 2 reflects important historical developments and trends in which the Joomla CMS (which is the empirical focus of this thesis) is embedded, such as the invention of the first high-level programming languages (e.g., Fortran, Lisp, C), the rise of modern open source operating systems (e.g., UNIX, BSD, GNU, Linux), the emergence of the Internet and the Web (e.g., Sendmail), the invention of modern open source database technology (e.g., POSTGRES, MySQL), the invention of open source licences (e.g., BSD, GPL), the inception of modern open source web browsers (e.g., Netscape, Mozilla) and JavaScript engines (a programming language for dynamically manipulating website content for increased interactivity), the invention of PHP (one of the most important open source server-side scripting languages), the rise of modern open source CMSs (e.g., Mambo, Drupal, WordPress, Joomla), the trend towards mobile computing (e.g., Android) and responsive design (e.g., Bootstrap), and more recent developments, including the use of OSS in the context of big data, cloud infrastructures (e.g., Cassandra, Hadoop), and machine learning (e.g., TensorFlow, PredictionsIO).

The business ecology metaphor aligns well with the diversity and the complexity of today's landscape of open source technologies. As mentioned in the introduction, business ecology copes with complex environments, ongoing change, and diffuse boundary conditions (Aarikka-Stenroos \& Ritala, 2017; Olve et al., 2013; Westelius \& Lind, 2016), which are characteristic of today's business practices, in particular, in the realm of open source and the Web. 


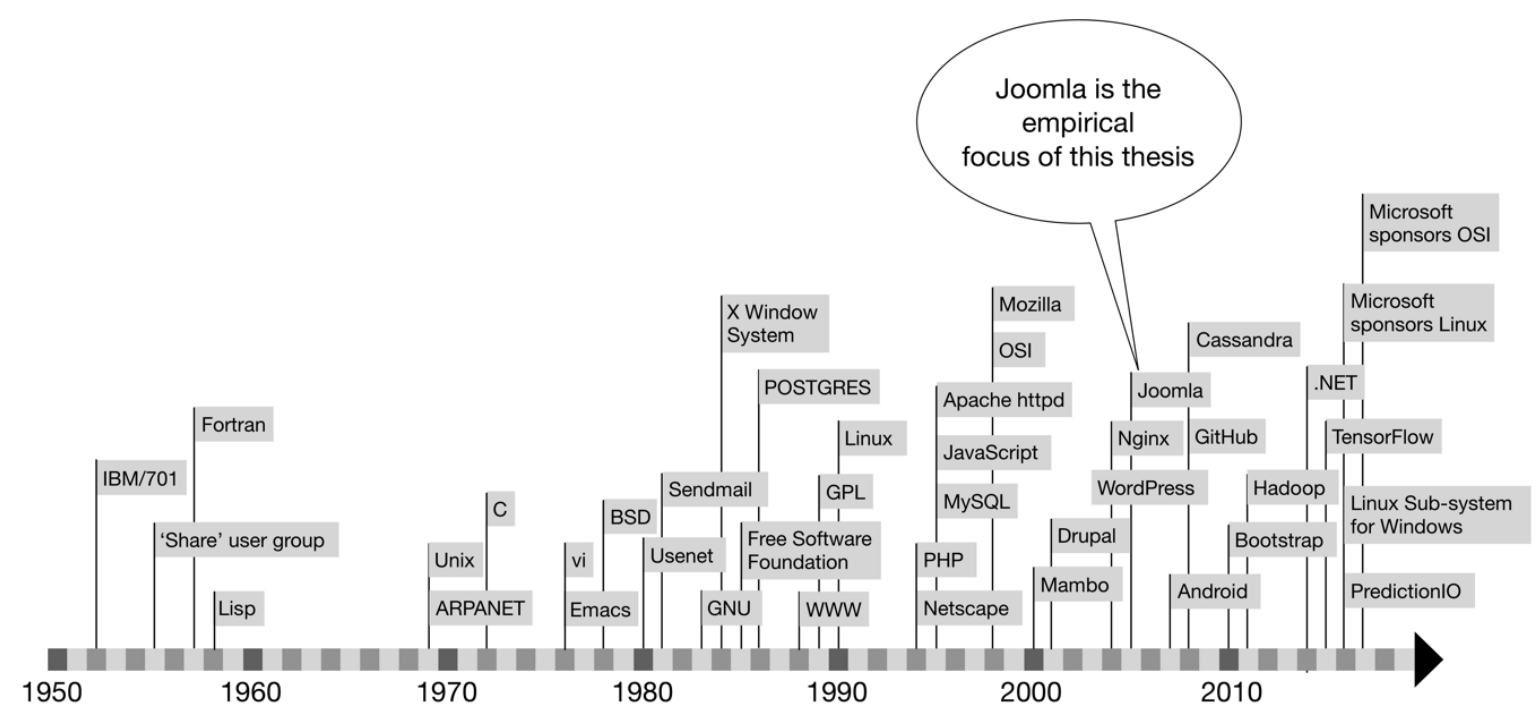

Figure 2: Inspired by Androutsellis-Theotokis et al. (2011), this timeline provides a condensed summary of the genesis and evolution of open source, with a focus on web technologies and significant events.

\subsection{Theorising on open source in the management fields}

This section briefly reviews the relevant theoretical body on open source in the management fields in order to position this thesis both thematically and theoretically. First, this review provides a description of the general characteristics of OSS, and gives definitions of the relevant key terms. Thereafter, there is a brief reflection on four salient themes identified from the historical evolution of open source. Subsequently, this review emphasises charting the business, economic, and strategic aspects of open source in the literature. Based on this review, potential gaps and trends in the literature are highlighted and the choice of theoretical perspective for this thesis is motivated accordingly.

\subsubsection{General characteristics of open source}

In contrast to contract-based, market-based, and state-based production, the social production model of open source is often referred to as commonsbased peer production, in which information gathering, authority, decisionmaking, and membership are relatively informal and decentralised (Morgan et al., 2013).

OSS has been described as a collective and public good that is non-rival in consumption (like other immaterial goods) and non-excludable (von Hippel \& von Krogh, 2003; Weber, 2004). Open source licensing can be 
seen as the institutional backbone that preserves the public good (Osterloh \& Rota, 2007). In other words, open source licensing ensures the terms under which OSS is produced, modified and shared. The copyleft regime enforced by the GPL terms (as discussed earlier) is an example of this.

Typically, OSS is freely distributed over the Internet. Users can view, study, and modify the code, and they are free to distribute their modified versions. The open source definition provided by the OSI underpins these characteristics ${ }^{47}$.

Typically, OSS is developed by organisationally and geographically distributed groups of people, referred to as open source communities (Crowston et al., 2012; Osterloh \& Rota, 2007). Complementary to that, the wider notion of an open source project can be referred to as the collective effort of producing and supporting OSS, which encompasses the community, the governance and management of the project, the technologies and infrastructure that facilitate the production processes, and the choice of open source licence (Androutsellis-Theotokis et al., 2011). The Linux project and the Joomla project are two examples (of many) for the widely-used nomenclature of 'open source projects'.

\subsubsection{Salient themes from a historical point of view}

Reflecting on the historical evolution of open source, four salient themes are highlighted; namely: open source as a collective development and innovation process, open source as the commodification of cutting-edge software technology, open source as collective ownership, and open source as an industry-sponsored and industry-managed phenomenon. The following describes these themes in more detail.

The first theme, open source as a collective development and innovation process, emphasises that code and ideas are created, maintained, and improved by communities, rather than single actors. Even when there are single actors (e.g., individuals, firms) that drive the development around an open source project, their activities are typically embedded in the larger context of a community. People in the community provide feedback, bug reports, support, and other types of contributions. Typically, the collective development and innovation process is fed by the ideas and contributions of (potentially massive numbers of) geographically distributed people. Through their joint efforts, these collaborators are not only able to distribute the costs of coding, they also avoid the duplication of effort. Open source as a collective development and innovation process is a well-documented phenomenon in the literature (Dahlander, 2005; Levine \& Prietula, 2013; West \& Bogers, 2014; West \& Gallagher, 2006a; West \& Lakhani, 2008; von 
Krogh, Spaeth, \& Lakhani, 2003; von Hippel, 2001; von Hippel \& von Krogh, 2003).

The second theme, open source as the commodification of cutting-edge software technology, emphasises the non-excludability and non-rivalry characteristics of open source. This means that the code is available to the public, or at least to an extended circle of beneficiaries. Open source, seen as a commodity, can bring cost savings to entire industries because resources are spared that would otherwise go into the replication of generalpurpose functions and systems. In particular, firms that are operating largescale and complex infrastructure are the beneficiaries of such systems. The open source development model keeps the access barriers to cutting-edge technology low, while allowing niche players to offer complementary or integrative products and services. The commodification effects of OSS are at the heart of the literature on open source business models and revenue models. In a sense, this literature revolves around the paradox of earning money based on something that is openly available and effectively comes for free (i.e., OSS as a free commodity) (Androutsellis-Theotokis et al., 2011; Lakka, Stamati, Michalakelis, \& Martakos, 2011; Okoli \& Nguyen, 2015; Riehle, 2009a; Rosenfall, 2012; Watson, Boudreau, York, Greiner, \& Wynn Jr, 2008).

The third theme concerns open source as collective ownership. This theme refers to the intellectual property regime around open source. Open source licences were developed in order to preserve open source as a public good. While the copyright ensures the attribution to the originators of the code, open source licences typically grant the rights to use and modify the source code. From a historical perspective, sharing practices in the realm of software were affected by restrictive and liberal licensing regimes, to varying degrees and at different points in time. There were periods and episodes in which intellectual property and law suits were leveraged to suppress the sharing of code, which often led to uncertainty regarding its use. However, attempts to monopolise ownership of the code (through licensing) almost inevitably provoked a backlash by those who felt unjustly excluded from its use. The counter reactions often undermined such attempts. For instance, AT\&T was challenged by both Tanenbaum's MINIX, and UCB's decision to write a free feature-complete open source operating system that could be used independently of AT\&T's costly UNIX. As mentioned earlier, the history of open source shows that the openness of the code and the removal of proprietary licensing triggers a lively differentiation process. The proliferation of forks in the past can serve as evidence for this claim. Issues around collective ownership are essentially reflected in open source licensing. While the literature on open source licensing has accumulated a 
considerable body of knowledge (S. H. Lee, 1999; Lerner \& Tirole, 2005), the subject of open source licensing is often implicit in the diversity of perspectives on open source (e.g., development perspectives, innovation perspectives, value perspectives).

Finally, the fourth theme concerns open source as an industry-sponsored and industry-managed phenomenon. While hackerdom and hobbyism have always been important drivers in the realm of open source, so have corporate and commercial interests, with a range of implications, both positive and negative. Often, corporate and commercial interests have led to bickering, disputes, conflicts, and forks. However, seemingly, the involvement of firms can also bring benefits to the development of OSS. And, in turn, as is increasingly recognised in the literature, the open source way of doing things can bring many benefits to firms (August, Shin, \& Tunca, 2018; Morgan et al., 2013; Morgan \& Finnegan, 2014). Microsoft's recent strategic U-turn towards open source illustrates this point. The theme of open source as an industry-sponsored and industry-managed phenomenon is apparent when looking at the historical evolution of open source; however, it is less pronounced in the literature. One possible reason for this could be the many conflicts that were caused by interventions from firms around open source projects, creating uncertainty about whether open source can be a credible and sustainable model for collaboration and development in commercial and professional contexts. The popularity and success of the open source phenomenon gives reason to believe that firms today might have a better idea of how to interact with open source communities in ways that are mutually beneficial. However, theoretical understanding still lags behind in terms of explaining the strategic ramifications of open-source-based business venturing. This will be discussed in more depth throughout the remaining sections within this chapter.

In summary, open source as an industry-sponsored and industrymanaged phenomenon can be regarded as an emergent theme in the literature. While there have been studies addressing firm involvement and firm-community interaction around open source projects (Dahlander \& Magnusson, 2005; Mehra, Dewan, \& Freimer, 2011; Schaarschmidt, 2012), many authors still regard this subject as a nascent field of endeavour, especially in the realm of value and ecology perspectives on open source (Carillo, Marsan, et al., 2017; Ciesielska \& Westenholz, 2016; Duc et al., 2017; Linåker et al., 2016; Mollick, 2016; Teixeira et al., 2016; Valença et al., 2014). 


\subsubsection{Developer-centrism in the literature}

One possible reason for why there is a lack of research on firm involvement and firm-community interaction around open source projects, is the developer-centrism in the literature. Research on open source tends to be developer-centric (Rozas \& Gilbert, 2015). This tendency can also be reflected in definitions of open source communities. For instance, Carillo and Okoli (2008, p. 8) defined open source communities as "groups of loosely connected programmers, who use the Internet as a medium for collaboratively developing, improving, and disseminating software".

One problem with developer-centric views on open source is that they fall somewhat short in capturing the diversity of actors and activities around open source projects. For instance, alongside software developers, there may be business people, entrepreneurs, firms, freelancers, hobbyists, students, educational institutes, and governmental and non-governmental organisations that are involved in community activities. Developer-centric perspectives on open source also tend to narrow down the broad range of activities around open source projects to the activity of coding.

In an attempt to overcome developer-centric notions of open source, this thesis emphasises actors and their activities, such that open source communities can be imagined as groups of loosely connected actors who engage in community activities. Community activities can be imagined as activities that are in one way or another related to an open source project (e.g., activities related to the Linux project, or the Joomla project).

From this perspective, there can be a broad and diverse range of community activities beyond the activity of coding. For instance, community activities can comprise the fostering of partnerships and professional networks, the development of ideas and business models, the exchange of support, help and advice, the organisation of events, marketing, the publishing of articles and books, administrative work and maintenance, financial and legal work, monitoring and accounting, official representation, lecturing, mentoring, and of course, all the activities that are more directly connected to the production of the software, such as testing, bug reporting, bug fixing, user interface design, and the writing of documentation.

Focusing on this broader conception of open source communities allows us to see beyond the confines of software development. On the one hand, this is reasonable from a theoretical point of view, given the increasing attention paid to the business value and strategic aspects around open source (Carillo, Marsan, et al., 2017; Duc et al., 2017; Morgan \& Finnegan, 2014). On the other hand, it is reasonable from an empirical point of view, given the fact that open source has always been a playground for diverse 
actors and their interests ${ }^{\mathrm{xx}}$, not just that of software developers interested in writing code. Therefore, widening the scope beyond the confines of software development does justice to the multiformity and diversity of the open source phenomenon, which seems particularly apt from a managerial point of view.

\subsubsection{The structure of open source communities}

In order to understand firm involvement and firm-community interaction around open source projects, the reader needs a notion of the structure of open source communities. The wide variety of open source projects that exists today might indicate that there is no single way of doing open source (Tozzi \& Zittrain, 2017). However, there is a widely accepted way of conceiving of the structure of open source communities, the so-called coreperiphery model (Androutsellis-Theotokis et al., 2011; Crowston \& Shamshurin, 2017; Nakakoji, Yamamoto, Nishinaka, Kishida, \& Ye, 2002). According to this model, open source communities can be imagined as loosely coupled entities that exhibit higher degrees of cohesion and involvement at the community's core than at the periphery. Typically, the community's core comprises smaller sets of actors who are more extensively committed to community-related activities, tasks, and responsibilities (e.g., core developers, leaders, official representatives, sponsors). In contrast to actors at the core, actors at the periphery are involved in and committed to community activities to a lesser extent. For instance, actors residing at the periphery may occasionally report bugs, test the software, provide feedback and support, or just use the software. The transition between core and periphery is fluid. Figure 3 provides a visualisation of the core-periphery structure along with diverse roles and activities (Androutsellis-Theotokis et al., 2011; Crowston \& Shamshurin, 2017; Nakakoji et al., 2002). The range of roles and activities in this figure is neither exhaustive nor mutually exclusive, but illustrative. As a side note, the rather confined set of roles and activities that previous literature used to explain the core-periphery structure provides further evidence for the prevalence of developer-centric views of open source in the literature.

xx As the historical roots of open source and its evolution show. 


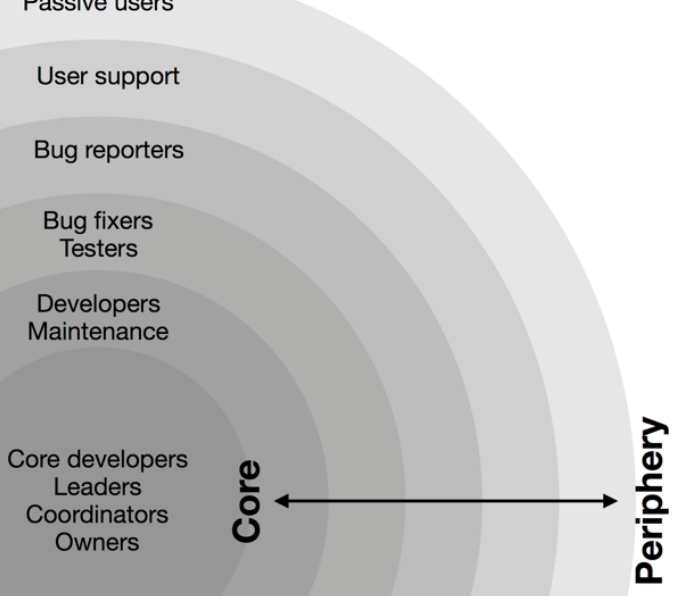

Figure 3: The core-periphery structure of open source communities, an onion-like model (Androutsellis-Theotokis et al., 2011; Crowston \& Shamshurin, 2017; Nakakoji et al., 2002).

With a wider conception of open source communities in mind, this model can be extended with additional roles and activities. For instance, firms might want to act as sponsors of an open source project in order to sustain the community and its activities. Furthermore, firms might want to occupy board positions in the foundations that provide organisational and legal backing to an open source project in order to secure a certain degree of influence over community decisions. In contrast, some firms might prefer to remain located at the periphery, merely opting to monitor the community activities in order to align their own activities with important community decisions (e.g., release cycles and different initiatives).

\subsubsection{Business value and strategic aspects around open source}

The commercialisation aspects of OSS have been studied from different theoretical angles. One such angle is the business model concept 
(Androutsellis-Theotokis et al., 2011; Lakka et al., 2011; Okoli \& Nguyen, 2015; Riehle, 2009a; Rosenfall, 2012; Watson et al., 2008).

However, discussions on open source business models have predominantly revolved around revenue models, such as dual-licensing models, open core models, freemium-type approaches to the commercialisation of OSS, the provision of value-added services for OSS (e.g., consulting, support, customisation), brand licensing (e.g., exploitation of trademarks), embedded OSS (OSS that is sold together with hardware), and software as a service (SaaS) models. While this research has helped to illuminate the different ways of earning money based on OSS, it has fallen short in attending to the breadth and scope of the organisational and strategic implications of open-source-centred business models and ventures (e.g., open source communities as a potential site for knowledge exchange, value creation, innovation, and competitive advantage).

In contrast to open source business models, the nascent literature on value and strategy perspectives on open source has broadened the scope of study to the domain of value networks (West, 2007). This research has explored how firms' networks of relationships (e.g., communities, customers, users, alliances, complementors, and partners) facilitate the creation and capture of value in open source settings (Morgan et al., 2013). Employing more unitary conceptions of value, this research went beyond studying the frequently cited organisational benefits of using OSS (such as improved software quality, greater transparency, lower costs, and decreased lock-in) in order to emphasise the role and importance of the ideas, knowledge, skills, expertise, talent, resources, capabilities, and complementary assets that reside in open source communities, discoverable outside an organisation's boundary (Lakhani \& Panetta, 2007; Morgan et al., 2013; Morgan \& Finnegan, 2014; Weber, 2004).

However, network approaches towards value creation are also challenged because they assume well-defined and clear boundaries between firms, customers, and suppliers (Bengtsson \& Kock, 2014). A further problem with network perspectives is that they tend to neglect the dynamic and changing nature of interaction among actors (e.g., between firms, partners, customers, and communities).

As an alternative to network perspectives on value creation, ecology perspectives and research on ecosystems emerged in the management fields (lansiti \& Levien, 2004; Moore, 1996, 2013; Olve et al., 2013; Teixeira et al., 2016; Westelius \& Lind, 2016). Essentially, the ecology lens in the management fields is a way of coping with today's increased complexity and the interdependence of economic activities. Economic activities are seen in the context of the bigger picture in which they occur (Olve et al., 
2013). More attention is shifted to contextual and environmental factors in order to better understand the evolving (and complex) nature of organisational life (Carillo, Marsan, et al., 2017). The value-creating logics also include the more distant areas of interaction (Westelius \& Lind, 2016).

Scholars regard ecology perspectives as a promising research territory, in particular, in the context of peer production communities (Carillo, Marsan, et al., 2017). The ecology perspective may be a suitable lens in the context of open source for several reasons. For instance, open source settings are typically characterised by complex interaction patterns, diffuse boundary conditions, diverse technological dependencies, cultural plurality, global communities, and global markets. In ecology speak, in the realm of open source, a colourful variety of 'species' collaborates, cooperates, and competes in a context of relatively fast-changing technological landscapes and business practices. The concept of 'coopetition', which is explained in more detail in the next section, stands for this form of interaction.

While the business value and strategic aspects of open source have been studied at the firm level (Morgan \& Finnegan, 2014), the strategic benefits of open source may emerge as a consequence of the dynamic interaction around open source projects (Androutsellis-Theotokis et al., 2011; Carillo, Marsan, et al., 2017; Valença et al., 2014). Given these emergent qualities, recent research has called for more attention to how the value-creating logics of firm-community interaction are embedded into the bigger picture in which they occur (Morgan \& Finnegan, 2014). Recently, Daniel and Stewart (2016) showed that participants in open source communities can benefit more from the knowledge embedded in a community's network of people when participants engage in interactive discussions with their community peers. From a strategy perspective, their results highlight the importance of interactive dialogue for effective knowledge exchange. This means that effective knowledge exchange could be seen, for example, as an emergent quality of interactive dialogue. However, the study by Daniel and Stewart (2016) is developer-centric, too. As the authors point out, they do not consider effects that might stem from the involvement of for-profit entities. Nor do the authors attend to the macro-institutional context in which interactive discussions occur, such as community or market characteristics.

Scholars have only recently begun to employ ecology perspectives in the realm of open source. The next section discusses this nascent field of endeavour in greater depth. 


\subsubsection{Ecology perspectives in the realm of open source}

While there has been much research on participation patterns and revenue models in open source settings, there is growing interest in ecology perspectives in the context of open source (Duc et al., 2017; Teixeira et al., 2016). Reviewing the field, a tentative line can be drawn between ecology perspectives on open source in the management fields and research on software ecosystems in the computing fields (Bosch, 2009; Jansen, Finkelstein, \& Brinkkemper, 2009; Joshua, Alao, Okolie, \& Awodele, 2013; Messerschmitt \& Szyperski, 2005). Research on software ecosystems tends to be more technology-oriented (e.g., ecosystem architectures, software interfaces, dependencies of software components, requirement engineering, technological infrastructures). In contrast to software ecosystems, the more sociologically-minded ecology research in the management fields (lansiti \& Levien, 2004; Moore, 2006; Olve et al., 2013; Westelius \& Lind, 2016) places emphasis on the social nature of business ecosystems. This thesis mainly subscribes to the latter category of ecology research.

In essence, ecology research in the management fields has focused on studying aspects of competition, collaboration, and conflict among actors within an ecosystem. This leads to one of the central ideas in this research: the concept of coopetition, which is a portmanteau of cooperation and competition. One recurring idea is that firms first collaborate on standards and basic solutions, and then compete over applications that build on these (Brandenburger \& Nalebuff, 1997; Olve et al., 2013).

Coopetition implies a certain degree of strategic interdependence among actors within an ecosystem (Dagnino, 2009; Duc et al., 2017). The concept of coopetition highlights that actors both cooperate and collaborate in order to create value that exceeds their individual capabilities (e.g., through joint research projects, pre-competitive collaboration, the development of a common codebase); yet, at the same time, these actors compete with complementary or integrative products and services (Duc et al., 2017; Shapiro \& Varian, 1999).

While coopetition can positively stimulate productivity, it can also carry the potential for friction stemming from differing needs (Valença et al., 2014), conflicting values (Jansen et al., 2009), and incongruent interests among actors (Duc et al., 2017).

This means that business ecosystems are not only spaces of opportunity, they also pose challenges that firms need to overcome (or deal with) in order to be successful. For instance, from an ecology perspective, congruence with the environment is a determinant of organisational survival and success (Carillo, Marsan, et al., 2017). For firms, it may be challenging to develop 
congruence with the environment. Their ability to do so might determine their faith and ability to prosper within business ecosystems. Therefore, research should consider both the opportunities and the challenges that reside in ecosystems (Linåker et al., 2016). However, ecology research has so far tended to emphasise the opportunities and benefits of participation in ecosystems. In a similar fashion, as Carillo, Marsan, et al. (2017) observe, research on open source has focused on the positive aspects of behaviours, most notably, participation, contribution and sharing practices.

In summary, the benefits, opportunities, and positive aspects of behaviours have received the majority of the attention both in ecology research and in research on open source, at the expense of the challenges that actors face. One reason for this may be that studies on coopetition in ecosystems are scarce (Bengtsson \& Kock, 2014; Linåker et al., 2016), and, even more so in the realm of community-driven open source (which is characterised by a lack of direct monetary compensation for community work) (Ciesielska \& Westenholz, 2016). In part, the predominance of opportunities in the literature may also stem from the myopic views of business networks that are mainly attentive to a more or less well-defined surrounding. In contrast, ecology thinking encourages to be attentive to opportunities, inspiration, and threats from afar, not just from an obvious surrounding (Westelius \& Lind, 2016).

Moreover, studies on open source have tended to focus on the developer and user levels, rather than on firm-community interaction (Linåker et al., 2016). However, more generally, the subject of firm-community interaction has become more important because the survival, success, and sustainability of peer production communities has become of strategic relevance to organisations (Carillo, Marsan, et al., 2017). Therefore, more concentrated efforts around these subjects (e.g., firm involvement and firm-community interaction around open source projects) are both justified and defensible.

In the context of community-driven open source, firm-community interaction broadly covers the cooperative/collaborative dimension of coopetition. Firms can engage in voluntary community work in order to support the production and maintenance of the collective good. At the same time, of course, they face competition for customers, valuable resources, and favourable positions within ecosystems.

Various challenges might arise as a consequence of both firmcommunity interaction and the characteristics of the contextual environment. For instance, in the context of community-driven open source, there may be challenges that relate to community governance and licensing, salient identities and values, diverse motivations, and dominant business practices such as pricing and bundling. 
All in all, our understanding of how actors in ecosystems around open source projects collaborate and compete remains incomplete (Teixeira et al., 2016). In particular, the challenges that firms face when participating in ecosystems around community-driven open source projects are underexposed. RQ1, presented in the introduction, addresses this particular thread.

Furthermore, theory lacks understanding about the ways in which community engagement and profit-oriented venturing are interrelated (Mollick, 2016). As mentioned earlier, coopetition implies a strategic interdependence among actors (Duc et al., 2017). This could mean that interactions between for-profit entities and communities might take a symbiotic form (Carillo, Marsan, et al., 2017). However, there may be various (as yet unexplored) connections between profit-oriented venturing and collaborative activities in the context of open source. Both these realms may intertwine in various ways. RQ2, presented in the introduction, addresses this particular thread.

The next chapter presents and discusses the theoretical framework that serves as the analytical backbone of this thesis. In order to allow for a denser examination of the subject, the lens of business ecology becomes enriched with relevant ideas and propositions from other theoretical areas, such as stakeholder theory, community governance, organisational identity, motivation theory, pricing, and bundling. The argumentation behind the choice of these theoretical areas is also presented. 


\section{Theoretical framework}

This chapter discusses the theoretical concepts that are central to this thesis, elaborates on the meanings of these concepts, and describes how they interrelate in the context of this thesis.

The metaphor of business ecology serves as the main theoretical guide. The choice of the business ecology perspective was partly motivated in the introduction and the previous chapter. Since this thesis investigates firmcommunity interactions in the context of open source, a business ecology perspective seemed an appropriate choice. This is because today's business practices have to be seen more and more in light of the larger context within which they occur (Olve et al., 2013).

In order to aim for greater analytical depth, it was decided to complement the business ecology perspective with ideas from other relevant theoretical areas, such as stakeholder theory, community governance, organisational identity, motivation theory, pricing, and bundling. These theoretical complements are regarded as dimensions under the umbrella of business ecology. The choice of these areas is motivated in the following sections.

Figure 4 depicts the overall structure of the theoretical framework as understood in the context of this thesis. The remaining sections of this chapter delve into the meanings of the concepts that are involved, and describe how the main perspective and the chosen dimensions interrelate. 


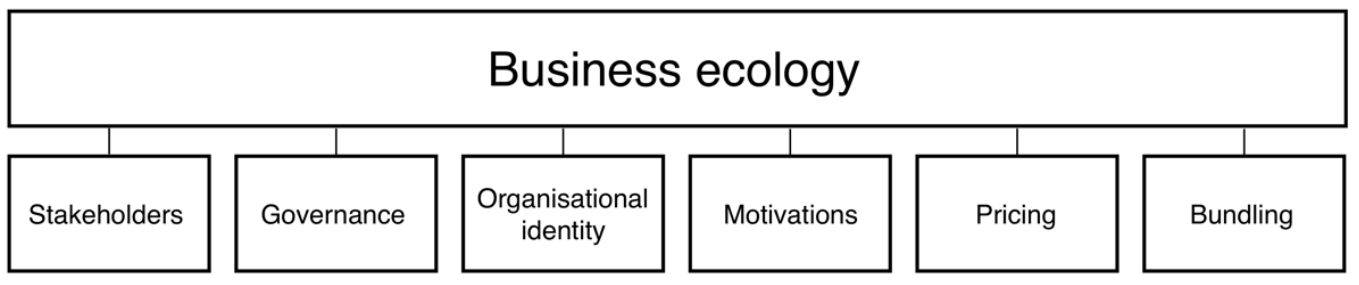

Figure 4: The structure of the theoretical framework of this thesis. The business ecology perspective is complemented with ideas from other relevant theoretical areas, such as stakeholder theory, community governance, organisational identity, motivation theory, pricing, and bundling.

\subsection{Business ecology}

More generally, ecology can be defined as the "branch of biology that deals with the relations of organisms to one another and to their physical surroundings" ${ }^{\prime 8}$. Ecology emphasises conditions under which these organisms interact. Since the term ecology derives from the Greek word 'oikos' (which refers to house, household, dwelling place, and family), ecology has also been described as the "science of the household of nature or the economy of organisms" (Schwarz \& Jax, 2011, p. 145). The term ecosystem delineates a specific region (e.g., a confined physical surrounding or living space) and its population of organisms that one wishes to study (Tansley, 1935). As already mentioned in the introduction, while the term 'ecology' more clearly signifies the study of the relationships and interactions between organisms and the environment (emphasising dynamic, emergent, and analytical aspects), the term 'ecosystem' more clearly emphasises concrete manifestations of a 'living space', including its boundaries, structural properties, and types of 'organisms' that are at the centre of attention. Although both terms are often used interchangeably, this thesis maintains this differentiation in order to emphasise these slightly different viewpoints.

The term business ecology signifies the metaphoric application and use of ecological principles in management research. The plural term 'business ecosystems' emphasises that there is an abundance of 'living spaces' that can be studied, which all breed their own types of 'organisms', orders, and characteristics. With the term business ecology, management research emphasises the complexities of today's business practices, the dynamic and 
changing nature of the environments in which firms operate, and the diffuse boundary conditions (Aarikka-Stenroos \& Ritala, 2017; Olve et al., 2013; Thomas \& Autio, 2014; Valkokari, 2015; Westelius \& Lind, 2016).

According to Olve et al. (2013), business practices have become more complex for at least two reasons. First, with IT-enabled change and ongoing trends in digitalisation, the costs of communication and business transactions have plummeted, with the consequence that firms increasingly dare to become dependent on each other. And, second, products have increasingly become more complex, which necessitates intensified knowledge sharing and long-term perspectives on collaboration among the contributors to value creation (e.g., customers, partners, competitors).

A business ecosystem can thus be conceived of as the 'living space' in which diverse 'organisms' (e.g., firms, users, customers, governmental and non-governmental organisations) collaborate and compete in order to create and capture value, in light of the environmental conditions and restrictions (Valkokari, 2015).

According to lansiti and Levien (2004), there are strong parallels between biological ecosystems and business ecosystems. As they argue, both are systems of interconnected actors that depend on each other for effectiveness and survival. However, it is worth keeping in mind that there may also be differences between biological and organisational ecosystems, as outlined by Mars, Bronstein, and Lusch (2012). Without dwelling any further upon this ${ }^{\mathrm{xxI}}$, the analogy may have its limitations, but its vivid terminology has been judged by many scholars to be useful in exploring contemporary business systems and drivers of success (Carillo, Marsan, et al., 2017; Iansiti \& Levien, 2004; Moore, 1993, 2013; Olve et al., 2013; Zahra \& Nambisan, 2012).

According to Hearn and Pace (2006), the emergence of ecological metaphors in management research can be explained as a consequence of shifts in thinking from consumers to co-creators of value, from value chains to value networks, from product value to network value, from cooperation and competition to coopetition, and, finally, from individual firm strategy to value ecology. In this sense, business ecology draws upon a variety of research fields and areas, including value chains and value constellations,

xxI It seems possible to conceive of counterexamples for the differences between biological and organisational ecosystems provided by Mars, Bronstein, and Lusch (2012). For instance, they argue that species in biological ecosystems do not implement strategies for decreasing risk. However, it could be argued that many animals have developed strategies and measures for protecting their lives, their offspring, their herds, and their access to vital resources. 
theories of economic action, value appropriation, value networks, and innovation (Thomas \& Autio, 2014).

The business ecology perspective adopted in this thesis is mainly inspired by Olve et al. (2013), and Westelius and Lind (2016). For them, business ecology refers to the dynamic interplay between actors, their motives, intentions, and goals. The field of vision is extended from a putative set of central actors to more distant areas of interaction (Westelius \& Lind, 2016). These ideas are in part inspired by Moore, (1993); however, Olve et al. (2013), and Westelius and Lind (2016) specifically note that their conception of an ecosystem differs from that of Moore (1993), in that they do not assume a central actor who controls and directs the activities within an ecosystem (although there can be powerful and influential actors nonetheless). This means that, whether actors see themselves as central or peripheral, essentially, their capacity to control other interactions is limited.

The business ecology perspective encourages holistic thinking in the sense that firms can afford to ignore neither the environment nor the population of actors whose activities facilitate their success or the stability of the ecosystem which they are part of (lansiti \& Levien, 2004). Contrasted with the more static notion of value chains, the perspective of business ecology emphasises the fluidity of value-creating logics and constellations. As Olve et al. (2013) point out, while studying a snapshot of an ecosystem can give an impression of the current value-creating logics, it is assumed that these logics are going to change and that new actors and relationships will emerge, while others may fade. Nevertheless, given the relative ephemerality of the status quo, organisations can act meaningfully in changing environments relative to their own long-term goals.

\subsection{Stakeholders}

In order to analyse the relationships within ecosystems in a meaningful way, it is necessary to draw boundaries and to select relevant sets of actors whose relationships one wishes to study (Olve et al., 2013). It may be useful advice to draw the boundaries by identifying the actors whose futures are most notably intertwined (lansiti \& Levien, 2004). However, this may not always be obvious. To some extent, ecology perspectives lack more concrete advice on how to identify relevant sets of actors.

The literature on stakeholder theory and stakeholder identification may be a valuable source of inspiration in this regard. Stakeholders can generally be defined as "any group or individual who can affect or is affected by the achievement of the organisation's objectives" (R. E. Freeman, 2010, p. 46). Both business ecology perspectives and stakeholder theory face the problem 
of having to identify relevant actors or legitimate stakeholders. Stakeholder theory considers a variety of dimensions during the identification process. Among these dimensions are key attributes such as power, legitimacy, and urgency (Mitchell, Agle, \& Wood, 1997). But social status (Perrault, 2017) and social responsibility (Mitchell, Lee, \& Agle, 2017) are also potential attributes to consider. By drawing inspiration from the literature on stakeholder theory, this thesis gained some more guidance during the identification of actors who are influential in the ecosystem (Westelius \& Lind, 2016), and those who are critical to the survival of others (Mars et al., 2012).

Compared to stakeholder theory, the business ecology perspective encourages us to draw wider boundaries. The idea is that the field of vision should not become too myopic when identifying relevant actors (Westelius \& Lind, 2016). This means that distant others may also be identified as legitimate sources or targets of influence. The inclusion of distant areas of interaction may help to disclose more hidden webs of suppliers, competitors, and their relationships (Moore, 1993).

Drawing the boundaries and selecting relevant sets of actors is intended to facilitate the understanding of the larger picture into which commercial activities are embedded. Study I (Stakeholders) is specifically concerned with the unboxing of the larger picture, including relevant actors and their relationships, in this open source setting. An understanding of the larger picture enables us to zoom in on narrower parts of the ecosystem, which then facilitates an understanding of the strategic implications from different subjective viewpoints (Olve et al., 2013).

\subsection{Governance}

Community governance is a precursor for the viability of open source communities (Morgan \& Finnegan, 2014). Because many commercial actors depend on the open source project, community governance also has implications for the ecosystem in which commercial actors collaborate and compete. Community governance in this sense can affect the development, growth, and health of an ecosystem (Mars et al., 2012; Moore, 1993).

In the context of open source, community governance has been defined as "the means of achieving the direction, control, and coordination of wholly or partially autonomous individuals and organisations on behalf of an OSS development project to which they jointly contribute" (Markus, 2007, p. 152). However, actors' capacity to control the interactions of others in ecosystems is limited. In order to emphasise this facet, the definition by 
Markus (2007) can be complemented with ideas from network governance (Sagers, McLure-Wasko, \& Dickey, 2004).

Network governance has been defined as the actions undertaken by a set of autonomous actors who are "engaged in creating products or services based on implicit and open-ended contracts to adapt to environmental contingencies and to coordinate and safeguard exchanges" (Jones, Hesterly, \& Borgatti, 1997, p. 914). Although formal contracts may well exist between some of the actors, they coordinate their activities by what Jones et al. (1997, p. 916) call "a complicated dance of mutual adjustment and communication". This perspective emphasises the role of informal (and decentralised) forms of control as a dominant force shaping activities and interactions within ecosystems.

In the context of ecosystems around open source projects, aspects of network governance may be applicable for understanding coordination and exchange. This is because coordination in open source communities is often characterised by informal ties, a lack of contractual relationships, collective sanctioning, and reputation-based authority (Sagers, 2004).

The informal social mechanisms for coordinating exchange are critical to the productivity of an open source community (Crowston et al., 2012), its performance (Crowston \& Shamshurin, 2017), and its ability to attract and retain a motivated voluntary work force (Shah, 2006). Connected to this, Study II (Governance framework) specifically explores governance aspects in the realm of open source.

\subsection{Organisational identity}

Organisational identity can be defined as "the theory that members of an organisation have about who they are" (Stimpert, Gustafson, \& Sarason, 1998, p. 87), or the set of claims about what is central, distinctive, and enduring about an organisation (Albert \& Whetten, 1985). Because ecosystems and communities are environments with diffuse boundary conditions, it can be difficult to define membership. Instead, one may resort to organisational identity and describe affiliation. Both ecosystems and open source communities could be understood as entities that are charged with identities and worldviews that provide a sense of affiliation and purpose (Mars et al., 2012).

According to Mars et al. (2012), when organisations take shape as networks of actors, or of pre-existing organisations, they do so around common cultural features; in a similar fashion, industries often come to share common logics and worldviews. This suggests that ecosystems emerge based on identities and worldviews that are common and complementary. 
According to Kim, Lee, and Han (2010), the identity and vision of an ecosystem is reflected in the contributions of its actors, who band together around a common purpose. Actors who share common or complementary features within an ecosystem are also more likely to exchange information and other resources (Mars et al., 2012).

Furthermore, identity may be important for the self-conception of commercial actors in firm-community relationships. In such relationships, identity may enable and constrain actors' ability to act and "perhaps even their ability to recognise alternative courses of action" (Westelius \& Lind, 2016, p. 70). In this sense, identities are also important signals, helping firms to decide whether and how to invest resources in open source projects (Daniel \& Stewart, 2016).

According to lansiti and Levien (2004), competition will increasingly occur between ecosystems, rather than between firms. Different ecosystems or platforms may emphasise particular sets of identities and characteristics that appeal to certain audiences, third-party developers, and firms.

lansiti and Levien (2004) argue that ecosystems should allow for a diversity of species to grow. According to them, diversity can not only increase the potential for innovation, it can also increase an ecosystem's resilience against external shocks. Connecting to this idea from an identity perspective, Pratt and Foreman (2000) argue that low diversity of identities can lead to a lack of organisational response strategies when facing turbulent times. As they argue, plurality of identities (e.g., diversity in skills, interests, and cultural backgrounds) allows for higher requisite variety when coping with environmental change. However, they also point out the potentially negative effects resulting from a plurality of identities. For instance, plurality of identities can lead to ambivalence concerning members' conception of who they are as an organisation, which can potentially cause inconsistent action or vacillation, and impede strategic decision making.

Both a diversity of identities and shared identities may be important at the same time. A shared set of specific values may hold an ecosystem together, while other identity traits may facilitate innovation, increase requisite variety and ensure resilience in the face of adverse conditions. Study III (Collective identities) specifically studies the relationships between identity and community governance in this open source setting.

\subsection{Motivations}

Voluntary work efforts could be seen as a major nutrient fuelling the production of OSS. This particularly applies to the context of communitydriven open source. Drawing on lansiti and Levien (2004), while these vital 
nutrients ensure the productivity of the open source project, they also indirectly facilitate the survival of ecosystems that are built around open source projects. Therefore, the question of what motivates individuals and firms to support open source projects (e.g., through voluntary work efforts and financial donations), is critical. In particular, for firms that are dependent on the maintenance and continuation of open source projects, this question may be of strategic relevance (Hertel, 2007; Mollick, 2016; von Krogh et al., 2012).

While individual actors may pursue their local needs and goals when contributing to open source projects, their contributions often come to benefit entire ecosystems. Arguing with lansiti and Levien (2004), this makes sense because actors have strong incentives to preserve the overall stability, health, productivity, and resilience of an ecosystem in which they participate. A further benefit reaped by firms may be that collaboration as a modus operandi may also increase the relative predictability of ecosystems (lansiti \& Levien, 2004).

The motivations to engage in open source communities may be heterogeneous and complex (Bitzer, Schrettl, \& Schröder, 2007; S. Freeman, 2007; Roberts, Hann, \& Slaughter, 2006); however, from an ecology perspective, actors may see their engagement as a valuable strategy, rather than an altruistic deed (Mars et al., 2012). Key players (or keystones) may participate in communities because they have strong incentives to preserve the ecosystem around open source projects (Mars et al., 2012). Furthermore, keystones have strong incentives to increase efficiency in order to allow others to be part of their value creation; otherwise, they run the risk of losing followers (Mars et al., 2012). In turn, communities might help keystones to improve the efficiency of their value creation processes.

Furthermore, from an ecology perspective, actors might engage in communities because they share a common fate with others in the ecosystem, regardless of differences in individual strengths (lansiti \& Levien, 2004). This might shed a different light on helping behaviour in the context of open source (i.e., complementary to altruistic motives). This is because actors have strong incentives to support others in enhancing their own performance, which in turn can strengthen the entire ecosystem (lansiti \& Levien, 2004).

On the other hand, not every one might experience a sense of shared fate equally. Some actors might see opportunities to thrive in other ecosystems, depending on how unilaterally directed at a specific ecosystemidiosyncratic aspect their particular position is, or depending on the perceived costs of occupying positions in multiple ecosystems or of transitioning into another (e.g., building know-how). While motivations can 
be complex, diverse and interrelated, Study IV particularly focuses on the direct and indirect economic benefits of community engagement in the context of community-driven open source.

\subsection{Pricing and bundling}

Pricing and bundling are closely intertwined (Iveroth et al., 2013), which is the reason why they are jointly treated under this heading. The pricing of software is generally challenging (Laatikainen, Ojala, \& Mazhelis, 2013), and even more so in the realm of open source because the software usually comes free of charge (Dahlander, 2005).

Drawing on Olve et al. (2013), the connections between business ecology and pricing can be illustrated as follows. A price model basically regulates the commitments, compensations, performance agreements, and payment flows between actors within an ecosystem, such as between a firm and its customers, between a firm and its suppliers and partners, or between platform providers and merchants. The significance of relationships with others is in part reflected in pricing and price model configurations.

From a strategic perspective, the way in which firms charge for their products and services can be seen as a source of competitive advantage in itself. For instance, seen as a strategic tool, price models can be leveraged to change customer behaviour or to spawn market opportunities that may be slumbering within an ecosystem (Iveroth et al., 2013). Depending on their strategic objectives, firms may leverage price models towards facilitating long-term relationships with other actors in the ecosystem, or favour more short-term relationships based on single transactions. Further deliberations can include the incentives provided by available bundling options, the significance of specific customer segments, and the distribution of risk between buyers and sellers.

Furthermore, price models regulate the distribution of revenue amongst the contributors to the creation of value within an ecosystem (e.g., platform providers, sellers of value-added services and complementary products, or content creators). From a cost perspective, in the context of open source, the organisational and intellectual costs of managing and developing complex software products are distributed (Weber, 2004). This allows firms to reduce costs by minimising the number of developers while retaining access to quality open source products, including the large pool of knowledge and expertise in the respective communities (Androutsellis-Theotokis et al., 2011).

From an ecology perspective, the distribution of revenue ideally protects the financial viability (or health) of the whole ecosystem. As suggested by 
Moore (1993, p. 81), a firm's value contribution to the ecosystem is important for the "whole ecosystem's continued price/performance improvement". And, finally, the financial sustainability of the ecosystem may also depend on whether actors can create value through network effects. By network effects, lansiti and Levien (2004, p. 2) are referring to the "increasing value of a product or service as the number of people using it grows". Study V (Pricing) and Study VI (Bundling and versioning) specifically focus on dominant forms of pricing and bundling in this open source setting.

\subsection{Intertwining}

In Section 1.2.2, the word 'intertwining' was introduced as central to Theme 2 in the present study. For this word, dictionary definitions ${ }^{\mathrm{XXII}}$ emphasise characteristics such as close connections among two (or several) elements, interlacing, mutual involvement, and an inextricable linkage. For Robey et al. (2003, p. 118), "intertwining literally refers to the weaving, braiding, and entangling of filaments such as silk, wool or hair", which "augments the performance of individual elements".

This thesis focuses on four aspects of intertwining that are theorised in the literature: reinforcement, complementarity, synergy, and reciprocity (Lundmark \& Westelius, 2008; Robey et al., 2003; Valiente \& Westelius, 2007). In the context of this thesis, these categories are mainly applied in relation to RQ2.

By 'reinforcement', Robey et al. (2003) are referring to the strengthening of a relationship by "adding an element that amplifies the effect of another element" (Robey et al., 2003, p. 118). To illustrate their point, the authors use the example of intertwined filaments, whose total strength increases when other filaments are added. As the authors explain, as a consequence of this additive effect, the redundancy of a system increases, which is a desirable quality in system design. From an ecology perspective, redundancy is likely to increase the resilience of an ecosystem.

By 'complementarity', Robey et al. (2003) are referring to elements that each exhibit particular weaknesses and strengths. However, combined in a complementary fashion, they can compensate for each other's weaknesses and strengths. From an ecology perspective, actors might be able to do this in various ways (e.g., through collaboration and specialisation).

By 'synergy', Robey et al. (2003) are referring to the combination of elements in ways that create new properties. Essentially, "synergistic relationships are catalytic in the sense that one element reacts with another 
to produce performance effects that surpass the effects from the individual elements" (Robey et al., 2003, p. 120). As an example, the authors mention the reengineering of business processes for enhanced performance.

By 'reciprocity', Robey et al. (2003) are referring to the interdependence of intertwined relationships. In their conception, this interdependence implies an equal partnership among the elements with no one element taking the lead. For Valiente and Westelius (2007) reciprocity is not a distinct aspect of intertwining, but is rather inherently fundamental to its other aspects. However, this thesis incorporates reciprocity nonetheless because it evokes a resemblance to mutualistic symbiotic relationships (Dahlander \& Magnusson, 2005). From an ecology perspective, such associations seem important.

While Robey et al. (2003) mainly feature the positive facets of intertwining, this thesis considers both positive and negative facets in order to aim for so-called mindful intertwining (Lundmark \& Westelius, 2008; Valiente \& Westelius, 2007). Mindful intertwining strives for a more balanced assessment of the benefits and drawbacks of intertwining (Lundmark \& Westelius, 2008; Valiente \& Westelius, 2007). Table 2 summarises the definitions of aspects of intertwining.

\begin{tabular}{|l|l|}
\hline Aspect of intertwining & Meaning \\
\hline Reinforcement & $\begin{array}{l}\text { "Each element amplifies the effect of the other element" } \\
\text { (Robey et al., 2003, p. 119). }\end{array}$ \\
\hline Complementarity & $\begin{array}{l}\text { "Each element offers unique characteristics. When combined } \\
\text { with the other, the two compensate for each other's } \\
\text { weaknesses" (Robey et al., 2003, p. 119). } \\
\text { "One element interacts with the other to produce effects that } \\
\text { Synergy }\end{array}$ \\
\hline Receed the effects from the individual elements" (Robey et al., \\
2003, p. 119). \\
\hline \\
"Elements are mutually interdependent, each depending on \\
the other" (Robey et al., 2003, p. 119).
\end{tabular}

Table 2: Four aspects of intertwining: reinforcement, complementarity, synergy, and reciprocity (Robey et al., 2003). 



\section{Empirical context}

The empirical focus of this thesis is the Joomla community. This chapter provides the reader with more detailed information about Joomla, its community, and the activities around it. Joomla is one of the most popular open source CMSs with millions of users around the world. The Joomla project started in 2005, and its origins have an interesting history. This is because Joomla was born out of differing views about its stakeholders and competing bids for governance, which connects to many of the issues around open source that were discussed earlier (see Section 2.1).

\subsection{History of Joomla}

The inception of Joomla goes back to the year 2005. It was created out of a fork of the Mambo project, which was a CMS that was initially developed by an Australian company, called Miro. Joomla basically emerged out of a dispute between the volunteer developers of the Mambo project and Miro. There is plenty of information on the Web that describes the cause and consequences of this dispute. Most of this information narrates the founding story from the perspective of the volunteer developers. The presentation of the history of Joomla in this section mainly draws on this type of information (i.e., the community perspective). However, in order to provide a more nuanced and balanced picture of the disputes and events that led to the inception of Joomla, I also found it important to incorporate the view of the former CEO of Miro, with whom I conducted an email interview.

From a community perspective, an illuminating source for getting to know more about Joomla's history is a public presentation given by Kenneth Crowder, a Joomla contributor and co-author of a book on using Joomla (Severdia \& Crowder, 2009). This presentation was given at the Joomla World Conference in Bangalore, India, in $2015^{49}$. Miro started developing Mambo at the beginning of 2000 as a closed-source proprietary CMS to build websites for the company's clients ${ }^{49}$. In 2001, Miro adopted a duallicensing approach with Mambo, releasing the software under the name "Mambo Site Server", and under the terms of the GPL. In 2002, Miro renamed the Mambo Site Server as "Mambo Open Source" (MOS) ${ }^{49}$. From a community perspective, Miro's intentions in making Mambo open source were to utilise the improvements that were being made through the community's contributions for a commercial release of the software, and to rein back on the open source project after it became popular ${ }^{50}$. In 2002, a team of (non-Miro) volunteer developers worked on the release of MOS 4.0, 
which was the development branch that eventually transitioned into Joomla ${ }^{51}$. In 2003, the MOS development team was given full responsibility for the MOS code from Miro ${ }^{52}$. According to Crowder's presentation, in 2004, a steering committee was formed with the mandate to manage the MOS project (e.g., definition of priorities, policy recommendations, resourcing, monetary expenditures). This steering committee consisted of five members, two from the open source project development team (who later became co-founders of Joomla), two Miro employees, and one legal counsel. In 2005, the project name changed from MOS to simply 'Mambo', and talks began between the volunteer developers and Miro about introducing a non-profit organisation, the Mambo Foundation, to back the Mambo project. From a community perspective, the intentions of forming a non-profit organisation were to ensure the project's legal protection and its funding ${ }^{53}$, but also to protect the Mambo project from the commercial interests of Miro. Other open source communities served as inspiration and models for ideas on the Mambo Foundation, such as the Eclipse Foundation, the Ubuntu Foundation, and the GNOME Foundation ${ }^{54}$.

However, there were differing opinions between the volunteer developers and Miro about the structure and purpose of the Mambo Foundation. People in the community suspected that Miro's intention was to design the foundation in such a way as to be granted control over the Mambo project, precluding developers' interference ${ }^{55}$. According to Crowder's presentation, the volunteer developers were displeased when Miro's CEO created the Mambo Foundation because they thought that it was not created under the terms that had previously been agreed upon between Miro and the open source development team. According to Crowder, the CEO of Miro appointed himself the Chairman of the Board, which meant that the volunteer developers saw their goal of removing the commercial interests of Miro from the Mambo project as jeopardised. For the volunteer developers, Miro's move was perceived as a 'power grab' to regain control over the Mambo project. None of the core developers were represented on the Board of the Mambo Foundation. Miro justified this decision as follows ${ }^{56}$; they argued that they wanted to have members from the industry on the Board, who, in the company's eyes, had more objective views and experience, rather than the volunteer developers. Furthermore, it argued that the obligations of serving on the Board would be too time-consuming for the volunteer developers and essentially put an end to their programming work for the Mambo project. However, in the eyes of the volunteer developers, Miro wanted to take back the control over the Mambo project after it had 
become popular and started to receive awards ${ }^{\mathrm{XXIII}}$. Eventually, the trust between the development team and Miro was broken. From the volunteer developers' point of view, the frustration and anger in dealing with what they saw as Miro's breach of faith ultimately triggered the decision to fork the Mambo project.

In August 2005, the core developers published a letter to the community $^{57}$. This letter not only reflected the distrust in Miro on the volunteer developers' side, it also emphasised important community values, such as openness, sharing, production for the benefit of others, the spirit of collaboration, fun, and the protection of users' and developers' interests. Furthermore, it emphasised that community governance should be designed in ways that would enable businesses to be confident about investing in the future development of the open source platform.

According to Crowder's presentation, the core developers consulted with Eben Moglen, a law expert with a focus on open source, and the founder of the Software Freedom Law Center (SFLC) ${ }^{58}$. The SFLC "provides legal representation and other law related services to protect and advance Free and Open Source Software ${ }^{\prime 59}$. With the help of the SFLC, the core developers created a not-for-profit organisation in New York, in September 2005, to provide organisational and legal backing for the continued development of the Mambo fork. Because Mambo was licensed under GPL terms, there were basically no legal problems in taking the code and creating a fork out of it. Still, at that time, there were fears among the core developers about lingering legal problems, but there was also the fear that people in the Mambo community would not follow. These concerns were legitimate insofar as the Mambo community was claimed to be a strong and loyal community with a broad user base. Furthermore, it was alluded to the fact that most forks actually fail.

However, it soon became clear that a critical mass of people in the community would support the core developers' move. The core developers created a website through which they communicated with their followers. According to information on Wikipedia ${ }^{60}$, there were over one thousand people who joined within a day to offer their support and words of encouragement. The name of the new project was decided to be 'Joomla!', which is an "anglicised spelling of the Swahili word jumla, meaning all together or as a whole" ${ }^{\prime \prime 0}$. Furthermore, a logo competition was launched. Figure 5 shows the winning logo from this competition, which is still Joomla's logo up today.

XXIII Such as for the best open source solution at the LinuxWorld Conference in 2005. 


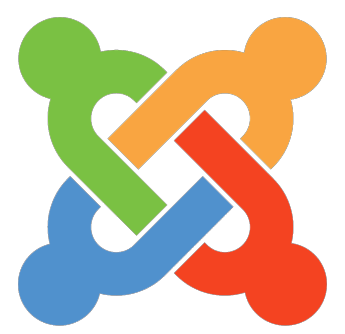

Figure 5: The Joomla logo. The Joomla logo symbolises togetherness and unity as important community values ${ }^{61}$.

To provide a complementary perspective on the events and disputes that led to Joomla's inception, the following highlights the opinions and views of the former CEO of Miro and founder of the Mambo project, Peter Lamont, as they were articulated in an email interview that was conducted as part of this work.

According to Lamont, Miro did not initially intend to commercialise Mambo, but this changed later when they started to offer a commercial version of the software with slightly different features than the community version. When Miro was approached by people offering their help in creating a community around Mambo, Miro's hope was to get input regarding the direction and robustness of the software and to create a commercial opportunity to sell templates for the Mambo CMS. However, Lamont emphasised that he never had the intention of commercialising the work of the open source community. As he argued, while both the commercial and the open source version of the software remained similar to begin with, eventually the Miro-developed Mambo was split away from the community version. According to Lamont, Miro rewrote its version of Mambo from the ground up and focused on its set of features, while the community did their own thing.

Thereafter, Lamont found himself confronted with a request from the community's side to give the Mambo project to the community in its entirety. Lamont said that this request made him feel uncomfortable because he had personally funded the development of the Mambo project for several years. As he indicated in the interview, for him, this was the underlying unrest that led to distrust between Miro and the open source community. Lamont said that he eventually assigned the intellectual property to the Mambo community in a deed of transfer for one USD, however, with great hesitation. Furthermore, he emphasised that he had formed the Mambo 
Foundation at the community's request and transferred the registered trademarks to it. Lamont said that he was fond of the idea of a foundation as a platform for ensuring that Mambo remained in the hands of the open source community. However, due to personal conflicts and out of distrust, he refused to have a key community member on the Board of the Mambo Foundation, a decision which Lamont regrets in retrospect. He thinks that this decision triggered the community backlash that resulted in the fork. Furthermore, he regrets having assembled the Board of the Mambo Foundation in stealth back then. Lamont is self-critical regarding the events that led to the fork; however, he also points out that ego and distrust were involved on both sides. In short, his understanding is that both sides could have handled things better; in particular, the manner in which the conflict was handled.

According to Crowder's presentation, eventually, in September 2005, Joomla 1.0.0. was released, which was basically a rebranded Mambo 4.5.2 with a few bug fixes. As he states, in this first Joomla release all occurrences of the word 'Mambo' got replaced with 'Joomla', except for those occurrences that were required to remain by the GPL. The Joomla project quickly gained traction and was able to garner a wide user base, eventually making it one of the world's most popular open source CMSs. The history of the major Joomla releases went from 1.0.0 in 2005 to an alpha release of Joomla 4.0 that was recently announced in $2017^{62}$. In contrast, the Mambo project lost relevance after the inception of Joomla and was discontinued in 2008.

\subsection{Joomla facts and figures}

This section provides various Joomla-related statistics in order to facilitate a better understanding of how Joomla might be ingrained into the Web at the present time. This overview is also intended to illustrate the level of activity around the Joomla platform.

\subsubsection{Penetration rate}

It is not easy to compile reliable data on CMS usage. The total number of websites in existence might have risen to well beyond of one billion at this time, and it is (currently) impossible to monitor all of them. Nevertheless, there are services that provide projections for the overall penetration rates of web technologies. As an indicator of the penetration rates of Joomla, statistics from W3Techs ${ }^{63}$ are presented. W3Techs provides surveys about usage statistics for all kinds of web technologies, including open source CMSs. Figure 6 provides an overview of the penetration rates of the three 
most popular open source CMSs. According to information on W3Techs, the bars are to be interpreted as follows. The grey bar indicates the percentage of the total number of websites that a system powers and the green bar indicates the percentage of market share within the open source CMS segment. This means that, according to these statistics, Joomla powers about $3.2 \%$ of all websites that are monitored by W3Techs. Within the segment of open source CMSs, Joomla has a market share of about $6.6 \%$.

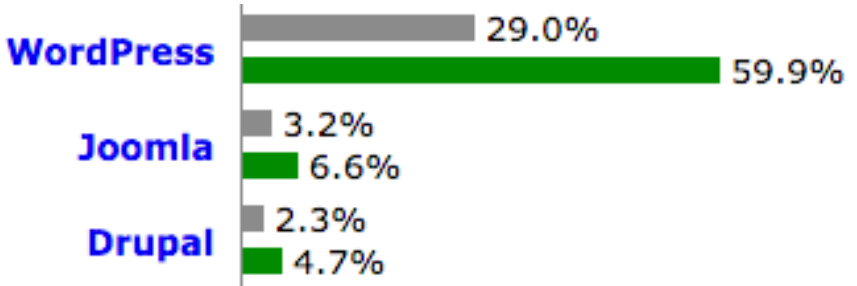

Figure 6: Penetration rates of the three most popular open source CMSs, as shown by statistics on W3Techs in December 2017.

However, the problem is that W3Techs only monitors the top ten million websites based on a website popularity ranking ${ }^{64}$. The penetration rates of Joomla might shift when looking at other segments of the Web. Joomla is known to be a popular choice among smaller clubs and businesses that are likely to have a lower popularity ranking. Therefore, the penetration rates of Joomla could be slightly higher than what the W3Techs figures suggests. When considering the entire Web, Joomla usage might even be close to $9 \%$, as reported by other sources ${ }^{65}$.

Given the problems in measuring usage, only very rough estimates of Joomla usage can be provided. The current total number of websites in existence is estimated to be over 1.2 billion $^{66}$. Projecting an estimated total share of around $3.2-9 \%$ onto the current total number of websites, Joomla powers a total number of websites that might range somewhere between 38.4-108 million. 


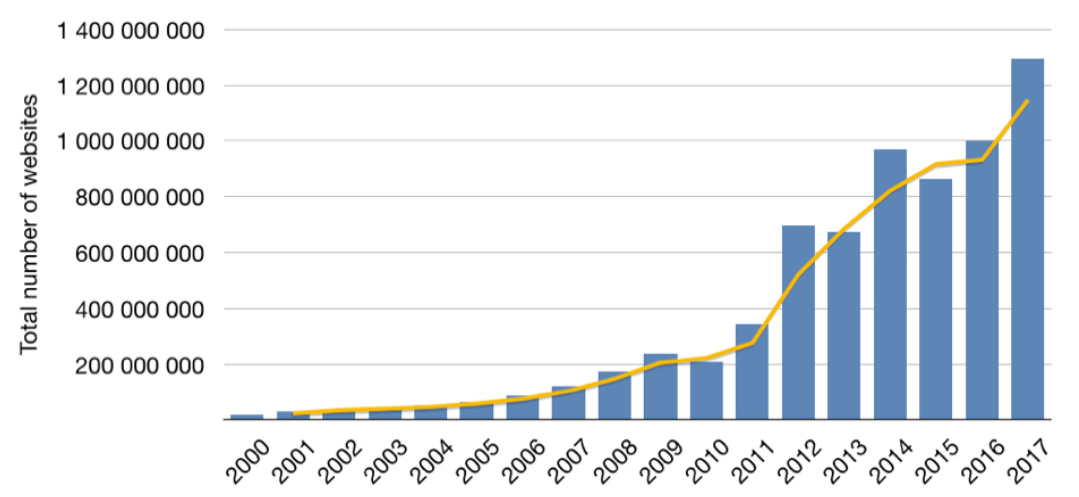

Figure 7: Total number of websites for the years 2000-2017.

Figure 7 plots the increase in the total number of websites from 2000 onwards, using data from Internet Live Stats ${ }^{66}$. An interesting facet, given the ongoing non-linear growth, might be that the total number of websites currently powered by Joomla might have grown, even if Joomla might have lost market share relative to its main competitor (i.e., WordPress) during the past few years (as was indicated by interviewees). However, this is speculative.

\subsubsection{Google Trends}

Google Trends is a service that can be used to render and compare search term frequencies for particular terms over selected periods of time. Figure 8 shows a comparison of search frequencies of the terms 'Joomla' and 'WordPress' over time. This figure was compiled in November 2017; it indicates a constant decline in search term frequencies for the term 'Joomla' relative to the term 'WordPress' from about 2009 up until November 2017. However, it is difficult to say whether this graph represents an objective account of relative popularity. There are several ways to interpret this graph. For instance, it only covers searches on the Google search engine, while searches conducted on forums, social media, and other platforms are not covered. Several interviewees suggested that the people working with Joomla are on average technologically more proficient than people working with WordPress, which could also mean that the people working with Joomla might have less need to consult the Google search engine for advice. While this is purely speculative, Study III (Collective identities) discusses the problem of how to interpret the results of this Google Trends graph in more depth. 
A further problem with Google Trends may be that the overall search interests may be skewed by the use of automated robots on the Web, which could explain the enigmatic peak of searches for the term 'WordPress' around June 2014 in Figure 8. Again, this is speculative, but it illustrates the difficulty of using data from Google Trends for inferring reasonable conclusions about the overall popularity of Joomla.

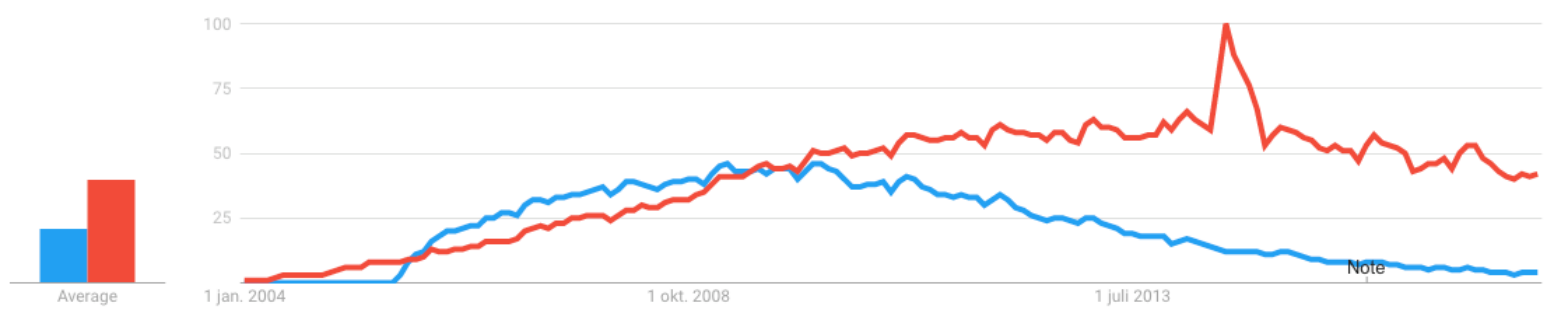

Figure 8: A comparison of Joomla (blue) with WordPress (red) on Google Trends, compiled in November $2017^{X X I V}$.

\subsubsection{User groups}

User groups are a vital part of many open source communities. They are locally managed groups. While much of the interaction in open source communities occurs online, user group meetings are opportunities for personal meetings, to network and share experiences with others in the community. User group meetings are attended by diverse audiences such as users, newcomers, administrators, developers, business people, and entrepreneurs. For newcomers, user groups are an opportunity to learn and to connect with other people in the community. For Joomla, user groups are also important in terms of recruiting new community members. Joomla hosts a directory of user groups on its website. Figure 9 shows the worldwide distribution of Joomla user groups in November 2017; the total number of user groups registered on Joomla's website was 172 .

\footnotetext{
XXIV The "Note" annotation in the bottom right-hand corner of this graph was automatically generated by the Google Trends engine. When hovering over this 'Note' with the mouse, it stated that improvements to the data collection system were applied from the beginning of 2016 onwards.
} 


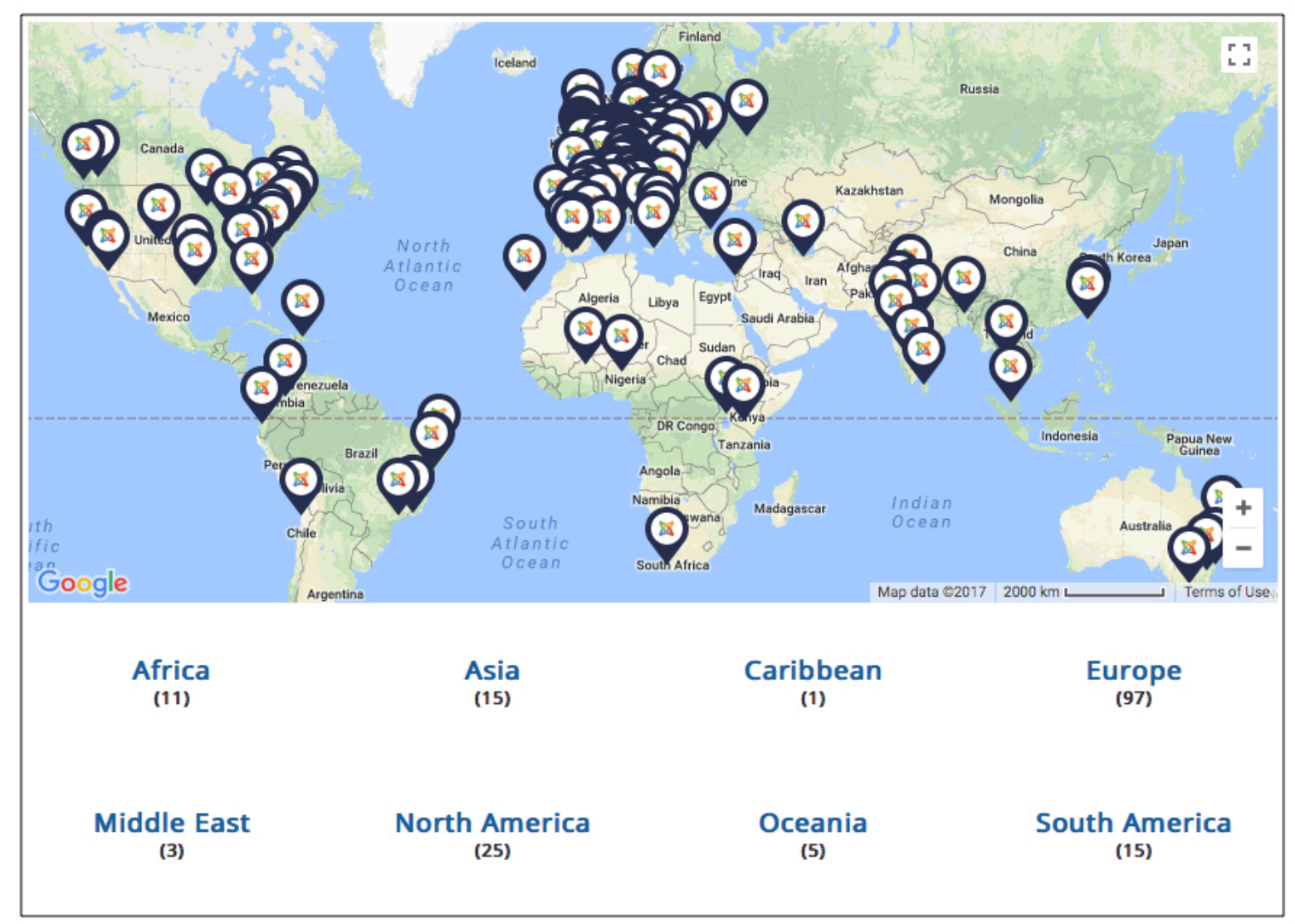

Figure 9: Worldwide distribution of Joomla user groups, as of November 2017.

\subsubsection{Further facts}

Table 3 provides an overview of further numbers and facts about the Joomla project, including the number of awards Joomla has received, an overview of important community events, the activities on the issue tracker, GitHub statistics, forum statistics, information from the Joomla extension directory (JED), the Joomla resources directory, and the number of users on the volunteer portal. Most of this information was compiled in December 2017.

\begin{tabular}{|l|l|}
\hline Reference & Description \\
\hline Awards & $\begin{array}{l}\text { According to information on Joomla's website } \\
\text { received } 17 \text { awards between } 2005 \text { and } 2017 . \text { Recently, Joomla has } \\
\text { won the CMS Critic People's Choice Awards for the Best Free CMS } \\
\text { three times in a row in 2015-2017. }\end{array}$ \\
\hline Events & $\begin{array}{l}\text { There are two big annual international Joomla conferences: the } \\
\text { 'Joomla World Conference', and the 'J and Beyond' conference. } \\
\text { Additionally, there are user group events, JoomlaDays, } \\
\text { JoomlaCamps, and Pizza, Bugs, and Fun events. The calendar on }\end{array}$ \\
\hline
\end{tabular}




\begin{tabular}{|c|c|}
\hline & $\begin{array}{l}\text { the Joomla website listed } 51 \text { community events all around the globe } \\
\text { for the year } 2017^{68} \text {. }\end{array}$ \\
\hline Forum & $\begin{array}{l}\text { According to statistics on the Joomla forum }{ }^{69} \text {, in September } 2018 \text {, } \\
\text { the forum had a total number of } 721,535 \text { members and } 3,180,940 \\
\text { posts, distributed over a total of } 757,884 \text { topics. The highest } \\
\text { number of concurrent users ever online was } 10.365 \text { (on } 29 \text { Aug in } \\
2011 \text { ). }\end{array}$ \\
\hline GitHub & $\begin{array}{l}\text { The Joomla code is hosted on GitHub, which is a Web-based } \\
\text { distributed version control system that provides infrastructural } \\
\text { support for open source projects. It also provides a variety of } \\
\text { collaborative features. According to Joomla's account on GitHub }{ }^{70} \text {, } \\
\text { in September 2018, the main CMS branch of the code showed } \\
30,304 \text { commits, } 208 \text { releases, and a total of } 582 \text { developers who } \\
\text { had contributed to the code until this time. }\end{array}$ \\
\hline Issue tracker & $\begin{array}{l}\text { In December } 2017 \text {, there were } 3,416 \text { users registered on Joomla's } \\
\text { issue tracker. It also showed that, since } 2011 \text {, a total of } 18,921 \\
\text { issues had been filed }{ }^{71} \text {. }\end{array}$ \\
\hline JED & $\begin{array}{l}\text { In December } 2017 \text {, on the JED, a total number of } 7,979 \text { extensions } \\
\text { were available, of which more than } 50 \% \text { were commercial } \\
\text { extensions. }\end{array}$ \\
\hline $\begin{array}{l}\text { Joomla resources } \\
\text { directory }\end{array}$ & $\begin{array}{l}\text { The Joomla resources directory provides a list of Joomla-registered } \\
\text { providers of professional services. In December 2017, } 306 \\
\text { companies were listed in this directory in } 15 \text { different categories } \\
\text { (e.g., creative strategy, design and development, marketing and } \\
\text { support). According to the information on the Joomla website, to } \\
\text { become listed here, a company has to have a proven track record } \\
\text { of creating Joomla-based solutions }{ }^{72} \text {. }\end{array}$ \\
\hline Volunteer portal & $\begin{array}{l}\text { In December } 2017 \text {, the volunteer portal on the Joomla website } \\
\text { had } 1,477 \text { registered users. }\end{array}$ \\
\hline
\end{tabular}

Table 3: An overview of numbers and facts about the Joomla project.

\subsection{Organisational structure}

This section gives an overview of the formal governance model of Joomla and how the community is currently structured and organised.

\subsubsection{Open Source Matters}

Joomla is legally, financially, and organisationally backed by a not-for-profit organisation, called Open Source Matters (OSM). According to US law, in a strict legal sense, OSM is not a foundation, but a non-profit organisation that is not funded or controlled by any single external entity ${ }^{74}$. 
According to information from the OSM website $^{75}$, the purpose of OSM is described as follows. OSM exists for the sole purpose and benefit of the Joomla project. OSM does not control Joomla or its community. The community is in control of Joomla; the role of OSM is to serve the community in formal matters.

OSM deals with the Joomla's finances, legal issues, the signing of contracts and agreements on behalf of the Joomla project, the management of Joomla assets (e.g., domains, trademarks, copyright), and the investigation of licensing, copyright, and trademark breaches. OSM also has formal duties that are required by US law (e.g., review of by-laws, disclosure of financial information). According to the OSM website, the organisation generates revenue through advertising on the Joomla website, sponsorships, royalties, its web shop, and Joomla.com (a hosting service, which could be seen as the Joomla equivalent to WordPress.com). The major expenses are the support of events, team meetings, accounting and legal expenses, and taxes. For the period 2017/2018, the leadership disclosed a Joomla Project Budget, calculating a total income of 583,200 USD and total expenses of 582,580 $\mathrm{USD}^{76}$.

\subsubsection{Leadership structure}

At the time of writing, Joomla had transitioned into a new leadership structure in early 2017. Prior to that, the new leadership structure was subject to community discussions for several years. The overarching purpose of the new leadership structure is to make the community management more effective. Before the transitioning, the community basically had three leadership entities: the OSM board, the community leadership team, and the production leadership team. Before 2013, there was another important entity, the community oversight committee, whose official role was to protect the Joomla project from mismanagement. As stated on the Joomla website, the community oversight committee was dissolved in 2013 on the grounds that "OSM has proven itself to be a competent and trustworthy steward of the Joomla project's legal and financial assets" ${ }^{177}$.

With the new leadership structure adopted in 2017, the community leadership team and the production leadership team were dissolved and unified into one top-level governing body, the Board of Directors. While the community's core governing body used to consist of 32 people, in the new structure this number was substantially reduced ${ }^{78}$. Figure 10 shows the new organisational structure of the Joomla project, which was decided by vote (with a required two-thirds majority) in $2015^{79}$ and which was put into effect in early 2017. 


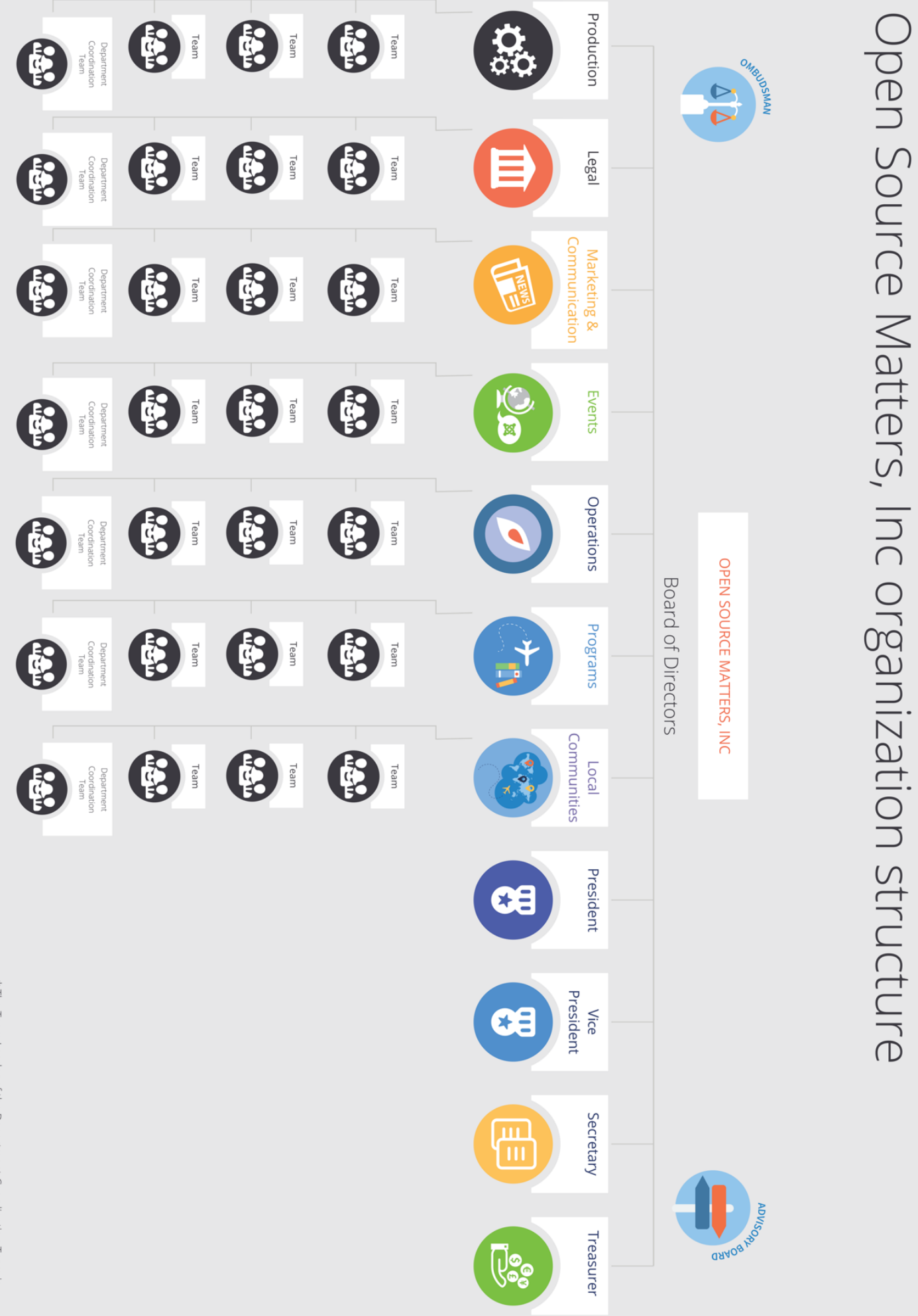

Figure 10: The top-level organisational structure of Joomla as depicted by OSM. The number of teams in this diagram is illustrative. 
As communicated on the Joomla website $^{80}$, the goals of the new organisational structure were to empower people in the community, to lower the entry barriers for volunteer workers, to make the decision-making more effective, to encourage active volunteers, to increase transparency and cross-team communication, and to make the organisational structure and the workflows more understandable.

With the new organisational structure, seven departments (Production, Legal, Marketing and Communication, Events, Operations, Program, and Local Communities) were introduced. Each of these departments consists of different teams and their Team Leaders ${ }^{81}$. At the time of writing, there was a total of 39 teams assigned to the different departments (the Local Communities Department had no team assigned at that time). Figure 11 shows the distribution of teams across the departments. The number of team members is given in brackets for each team. A total number of 231 people were assigned to the teams. 


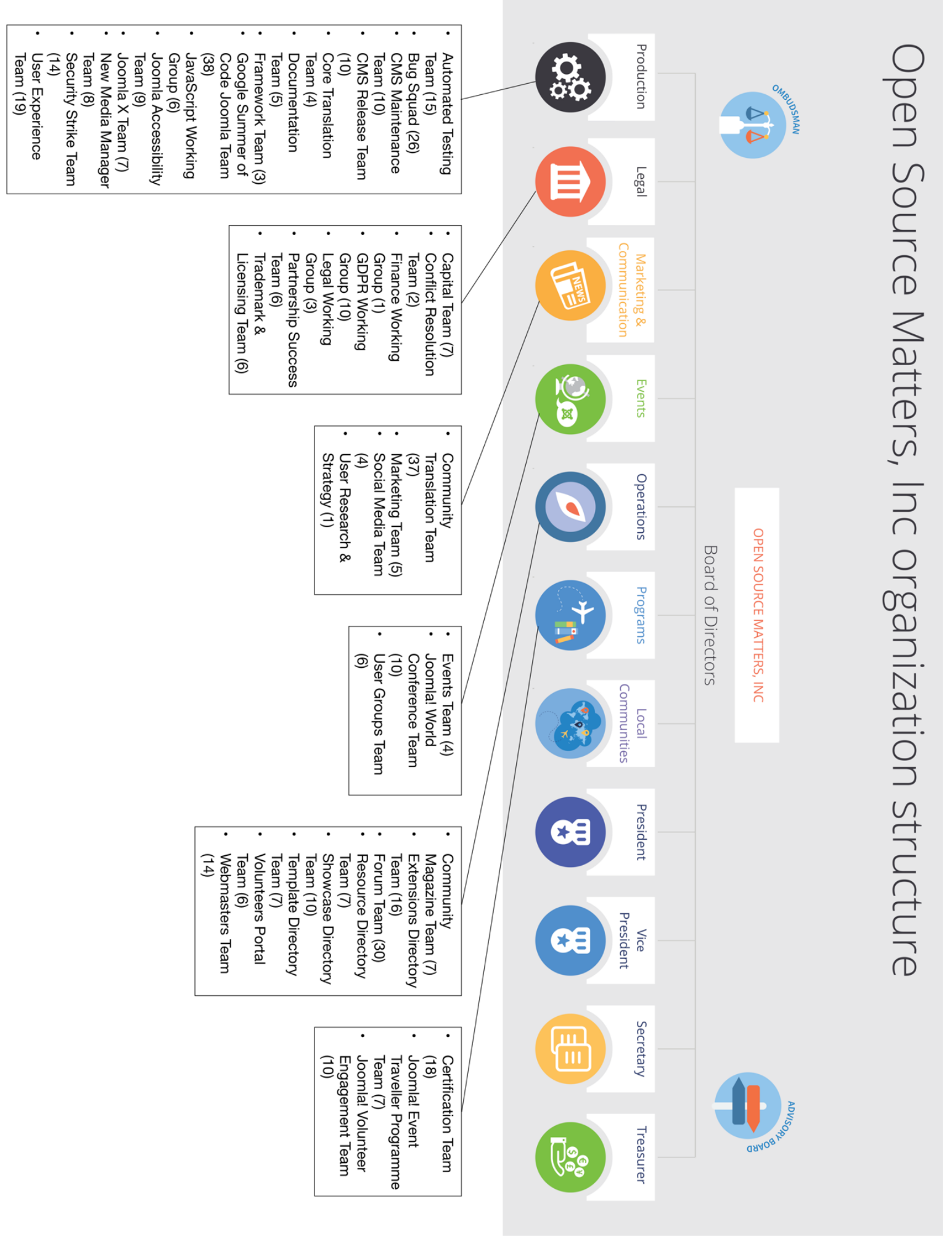

Figure 11: Departments together with an overlay of their teams, as of December 2017 (at the time of writing, there were no teams assigned to the Local Communities Department). 
However, a total number of 408 team memberships was observed, which means that there were people holding multiple team memberships. Figure 12 shows the distribution of team memberships on the volunteer portal. As can be seen, a majority of people had only one or two memberships, but a minority had three and more (up to 11) memberships.

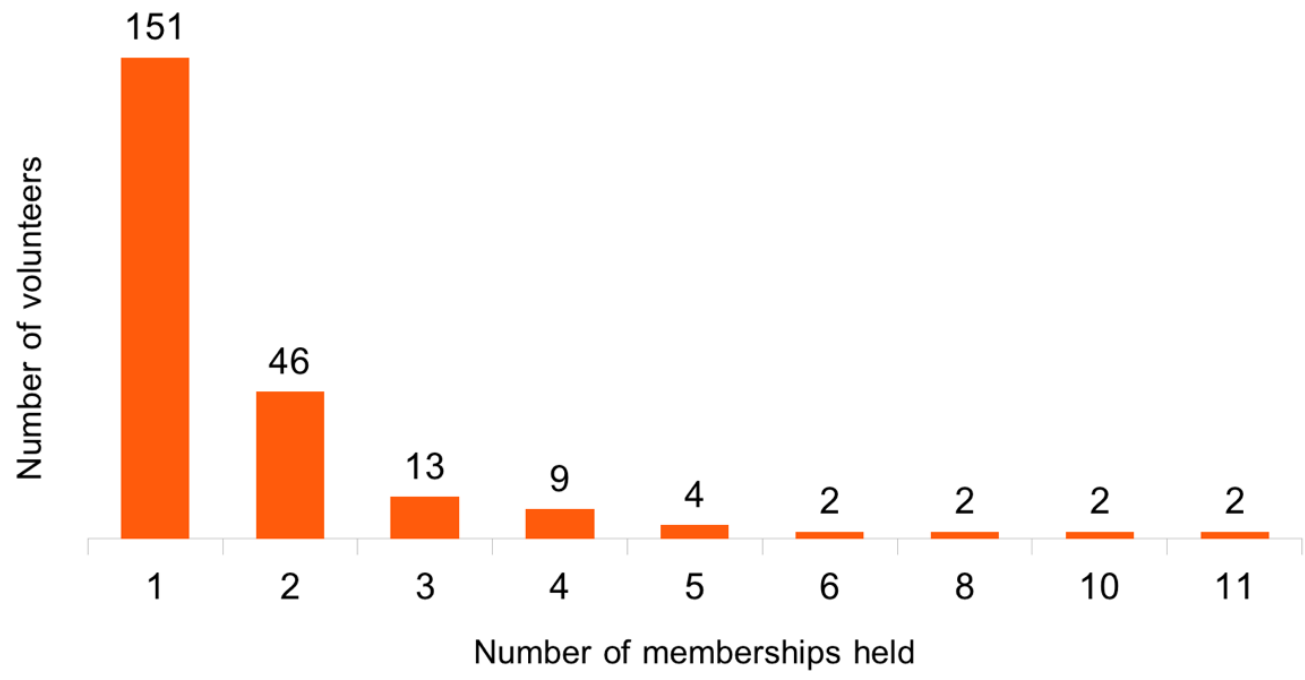

Figure 12: Distribution of team memberships among volunteers, as of December 2017.

The governance model of Joomla could be described as a blend of meritocratic and democratic elements. All official community representatives are elected, based on the rules stipulated in the bylaws ${ }^{82}$. Each department has one Department Coordinator who is elected by the Team Leaders within the respective department. The Team Leaders in turn are elected by the members of their team. However, to become a team member, one has to be accepted by the respective Team Leader. The Team Leaders, together with the Department Coordinators, and Officers vote for all the Board positions ${ }^{83}$. The Board of Directors consists of the seven Department Coordinators and the four Officers that are required by law (president, vice president, secretary, and treasurer) ${ }^{84}$.

\subsection{The mission, vision, and values of Joomla}

The mission, vision, and values of the Joomla community, as communicated on the Joomla website ${ }^{85}$, can be summarised as follows. The mission 
statement emphasises that the Joomla project is about providing a free, flexible, stable, and secure platform for digital publishing and collaboration. As the main target audience, agencies, Web-builders, small and mediumsized businesses, and non-profit organisations are mentioned. The vision statement emphasises the goal of nurturing a global and open community of volunteers, the social responsibility of the project, the autonomy of volunteers in the project, and the desired qualities of OSS (e.g., freedom and security). As the key values, freedom, equality, trust, community, collaboration, usability, and transparency are listed on the Joomla website.

\subsection{Commercial services around Joomla}

There is a range of diverse actors in and around the Joomla community. While the Joomla project is carried on the backs of volunteers, Joomla is also used by many people in their professional lives (e.g., business owners, web developers). Commercial actors offer a broad range of value-added services connected to the Joomla platform. The categories in the Joomla resources directory ${ }^{86}$, as shown in Figure 13, provide a good overview of the breadth of services that exist.
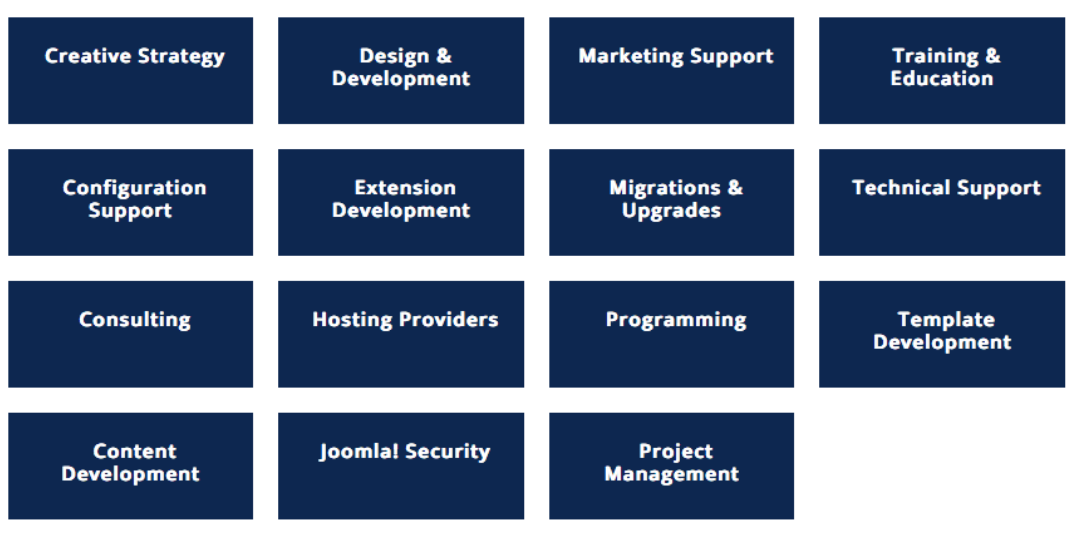

Figure 13: The categories in the Joomla resources directory provide a glimpse of the breadth of commercial services that are offered in connection with the Joomla platform. 


\section{Methodological approach and research design}

This thesis pursues a qualitative approach, grounded in an interpretive tradition of research (Klein \& Myers, 1999; Schwandt, 1998; Walsham, 1995, 2006). As mentioned in the introduction, this thesis aims to explore the challenges that are involved in commercialising community-driven OSS, how firms cope with these challenges, and how volunteer community engagement and profit-oriented venturing are intertwined in the context of community-driven open source. Subscribing to the notion that human affairs are complex, multifaceted, and interrelated (Checkland, 2000), a rich understanding of the issues and the nature of the problems that people encounter was deemed necessary. Therefore, an interpretive approach seemed most suitable.

Interpretive approaches enable detailed examinations of people's perceptions, they make the reasons for problems and conflicts more accessible, and highlight the effects of various contextual factors in relation to the research problem (Walsham, 2006; Walsham \& Sahay, 1999). People's interpretations can vary depending on their beliefs and the values to which they subscribe to (Darke, Shanks, \& Broadbent, 1998). Interpretive approaches enable us to attend to both similarities and differences in how people perceive, understand, and interpret their professional lives and business settings (Westelius, 1996).

From the perspective of interpretive research, knowledge is viewed as a socially constructed product of intersubjective meanings and human interpretation (Orlikowski \& Baroudi, 1991). In order to grasp the meanings of social phenomena, one has to interpret and make sense of them (Schwandt, 1998). In contrast to naturalistic views of social science, in which the facts are assumed to exist independently of the observer, the researcher's role in the interpretive tradition is "to understand human thought and action in social and organisational contexts" (Klein \& Myers, 1999, p. 67). Thus, the researcher offers a "construction of the constructions of the actors one studies" (Schwandt, 1998, p. 222).

While knowledge in the positivist tradition is primarily regarded as consisting of value-free (objective) facts, in the interpretive tradition, facts and values are regarded as being intertwined (Myers, 1997; Walsham, 1995). This means that knowledge and truth in the interpretive research tradition are a result of perspective seeing, which rests on the concepts and models that we invent to make sense of the world (Schwandt, 1998). For instance, business ecology, ecosystems, and the other conceptual terms 
used in this thesis do not exist out there - they are a means by which to conceive of the world (Olve et al., 2013).

According to Klein and Myers (1999, p. 71), due to the hermeneutic nature of interpretive work, "we come to understand a complex whole from preconceptions about the meanings of its parts and their interrelationship". The preconceived notions of conceptual terms (e.g., the meanings with which concepts are loaded) influence the ways in which we come to understand the world.

From an epistemological point of view, an interpretive approach matches well with the ecology perspective employed in this thesis. Business ecology is a holistic perspective that requires the interpretive work by the researcher to make the dynamics and complexities of ecosystems understandable. An understanding of issues or problems in relation to a larger and dynamic context can be stimulated and fostered through continuous iterations between the parts that are of interest and the whole (Klein \& Myers, 1999). For instance, from an ecology perspective, the positions of single actors can be better understood when considering the dynamics at the ecosystem level (e.g., technological trends, the emergence of new business models, partnerships, markets and/or customer segments).

\subsection{Case study approach}

This thesis is designed as a qualitative exploratory single-case study. Generally, case studies are well-suited to studying complex contemporary social phenomena because they allow for a meaningful and holistic assessment of real-life contexts and events (Meyer, 2001; Ponelis, 2015; Yin, 2009) ${ }^{\mathrm{XxV}}$. The case study approach is especially useful when studying 'how' and 'why' questions ${ }^{\mathrm{xxV}}$, which often require a contextual understanding of a phenomenon (Darke et al., 1998; Meyer, 2001). For instance, this thesis considers people's goals, activities, and motivations as they unfold in the context of their doing. Single-case studies can facilitate a deep understanding of phenomena or problems (Andrade, 2009). Sometimes, the results of single-case studies can serve as valuable inputs for comparative studies or for large-scale quantitative follow-up studies.

\footnotetext{
xxv While Yin's approach to case studies is considered positivist in its epistemological stance, both the interpretive and the positivist tradition in case study research agree on many points, such as the suitability of case study approaches for exploring and understanding complex phenomena, or the generalisability of case study results to theoretical propositions (Walsham, 1995).

xxvı As opposed to questions asking 'how much' or 'how many' (Andrade, 2009).
} 


\subsection{The case of Joomla}

As mentioned in the introduction and as described in more detail in the previous chapter, the empirical case is Joomla, a popular open source CMS. The case as such refers to the commercial activities around the Joomla platform, which includes factors and entities that are crucially linked to these activities, such as the Joomla community (e.g., the people who drive the Joomla project and engage in community work), the market for Joomla extensions, pricing practices by open source vendors, and the role of networks and partnerships. The technical work of community members, that is the individual and collaborative work resulting in computer code as such, is not the focus of this thesis.

For the sake of simplicity, the case can be concisely referred to as the 'Joomla case'. With this conception in mind, one could in a similar fashion take the research questions and study the WordPress case, or the Magento case, or the Drupal case, or any other open source project that seemingly exhibits comparable features (e.g., in terms of community size, penetration rates of the software, licensing, or target audiences). Given the size of the Joomla community and the ecosystem around it, the breadth and scope of the entire study seemed large. In order to cope with that, a single-case approach seemed most apt.

As alluded to earlier, there are several reasons why the Joomla case is interesting and relevant. For instance, there is no single commercial entity that owns, governs, or drives the Joomla project, unlike many other comparable open source projects. Joomla is governed and driven by a plurality of people all around the world who do not own or control the project exclusively but collectively. Furthermore, in the case of Joomla, there is no direct monetary compensation for doing community work (except for small monetary remunerations for travel expenses that apply to people who officially represent the Joomla project). Unlike other comparable open source projects, the Joomla project does not employ people for any community work (e.g., programming tasks, support, or OSMrelated duties). People can only indirectly earn money based on Joomla (e.g., by working as web developers, designers, system analysists, or marketers).

Furthermore, the Joomla project is interesting in terms of governance because of the voluntary nature of the project. The Joomla project has existed since 2005 and has seen many governance changes in order to coordinate the work efforts of its volunteers. One difficulty relates to the problem of securing continuity in development cycles and activity levels based on a purely voluntary workforce. Exploring the challenges in commercialising the community's software product(s), and the intertwining 
of volunteer community engagement and profit-oriented venturing in such a case was not only fascinating from a personal point of view but also seemed relevant from a theoretical point of view, given the increased research interest in the relationships between community forms of organising and entrepreneurial activities (Mollick, 2016; Rosenfall, 2012), and research on sourcing strategies exploring the power of communities for creating business value (Carillo, Huff, et al., 2017; Morgan et al., 2013).

Given the voluntary, open, and collaborative nature of the Joomla project (with its lack of corporate ownership and control), Joomla is a relatively unique case in the realm of open source CMSs, which makes the single-case study approach the more appropriate (Darke et al., 1998).

I saw my role as a researcher mainly as that of an outside observer, as opposed to being an involved researcher who conducts action-research-like methods. According to Walsham (1995), the role of an outside observer ensures a certain distance between the researcher and the study subjects, with the merit "that the researcher is seen as not having a direct personal stake in various interpretations and outcomes, and thus personnel [or participants] will often be relatively frank in expressing their views, provided a rapport of trust can be established" (Walsham, 1995, p. 77). Given the broad analytical lens of ecology that is employed in this thesis, an insider perspective could have increased the likelihood of being caught up in espoused views and could potentially have made the analysis more myopic.

According to Walsham (1995), a major disadvantage of being an outsider is that the researcher does not gain a direct insider experience of the case organisation and may not always have access to relevant data (such as confidential or sensitive data). Another potential problem with outsider views is that the understanding of insiders may be interpreted from inappropriate outsider perspectives. In order to mitigate the disadvantage of not having a direct insider experience by taking the role as an outside observer, I participated in two international Joomla community events, which not only enabled me to talk to community participants and get to know more about their experiences and insights, but also gave me a firsthand experience of what it is like to be with other people in the community. Section 5.5.2 elaborates more on these conference visits.

\subsection{Units of analysis}

The unit and scope of analysis usually follow from the research questions (Darke et al., 1998). The sub-studies in this thesis employ different methodological approaches, data collection methods, and analytical approaches, which are described in the respective sub-studies. Overall, in 
this thesis there is one primary unit of analysis and three subunits. This nested approach of defining units of analysis is also referred to as embedded design (Meyer, 2001).

One subunit of analysis is the self-employed people and small businesses that run on the back of Joomla (referred to as Joomla businesses in the context of this thesis).

Another subunit of analysis is the community. There is no unified definition of an open source community, but there are several characteristic traits that are often emphasised in the literature in connection with open source communities, such as the collaborative and distributed nature of interaction, collective production as a common goal, and particular values associated with open source (e.g., freedom, openness, transparency) (Markus, 2007, p. 200; O'Mahony \& Ferraro, 2007; von Krogh et al., 2012). In the context of this thesis, the open source community can be understood as the people who jointly contribute to an open source project and/or involve themselves in the activities around an open source project. These activities can be diverse, such as contributing code, providing help and support to others online or offline, organising user groups and events, and more (cf. Section 2.2.3).

Finally, the third subunit of analysis is the ecosystem; this can be seen as the wider context within which diverse sets of actors collaborate and compete. Both the community and the Joomla businesses are embedded in this ecosystem. The primary unit of analysis refers to the connections between the Joomla businesses and the community. Figure 14 provides a visual overview of the units of analysis in this thesis. 


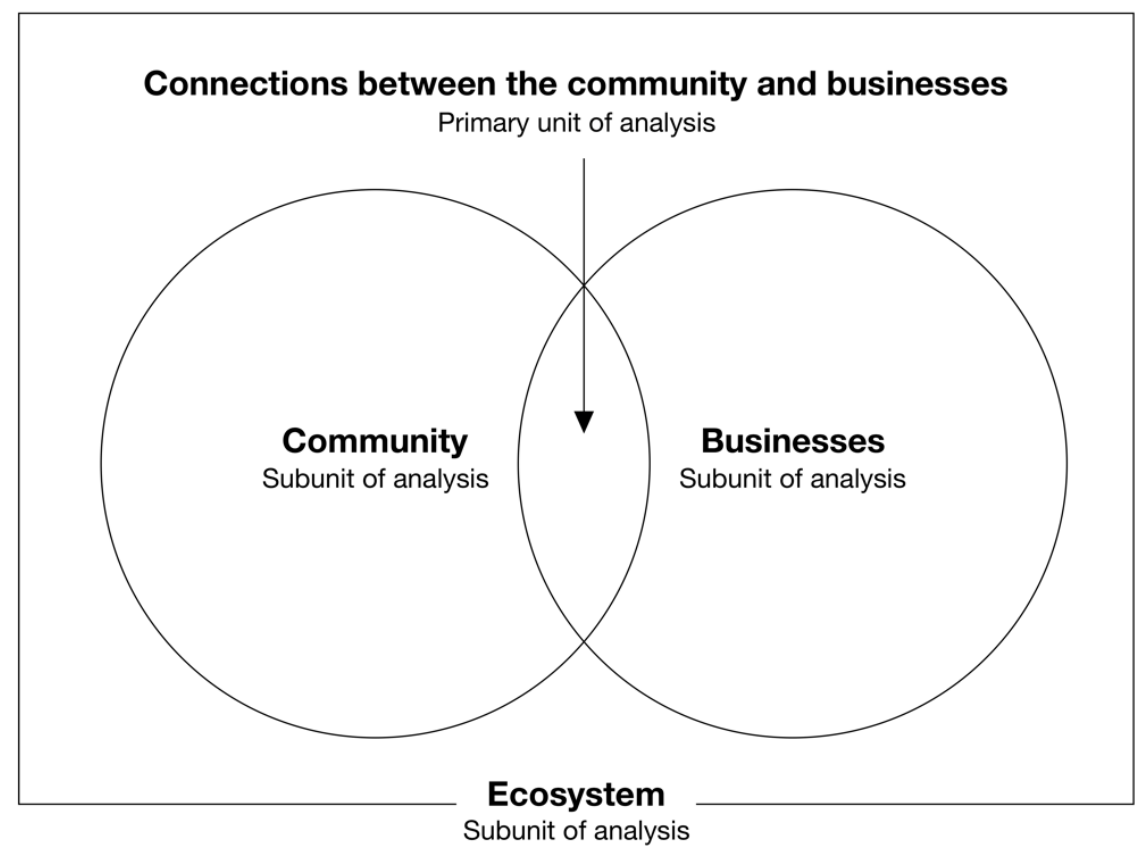

Figure 14: The units of analysis and their relationships in the context of this thesis.

\subsection{The role of theory}

Case study research is typically guided by the use of conceptual terms and theoretical propositions (Meyer, 2001). The knowledge of theories, models, and conceptual terms provides the basic preunderstanding without which the research runs the risk of becoming directionless (Meyer, 2001). In the early stages of the research, theory can inform the building of a theoretical framework, which can serve as a sensible theoretical guide when approaching the topic (Walsham, 1995). A preliminary analytical framework may consist of articulated preconceptions in the beginning and gradually develop into something coherent based on discoveries, analysis and interpretation (Dubois \& Gadde, 2002). However, as Gummesson (2000) points out, the use of conceptual terms and theories does not imply being their slave. Also Walsham (1995) cautions that a too-rigid use of theory can stifle the exploration of new issues and interesting avenues, which is the reason why he recommends a certain degree of openness and curiosity when approaching the field data. As he points out, with interpretive research, the researcher should be receptive to surprising findings and be prepared to modify any assumptions and theories throughout the research process. According to Walsham (1995, p. 76), this openness results in an "iterative process of data collection and analysis, with initial theories being 
expanded, revised, or abandoned altogether". In further illustrating his point, he uses the metaphor of scaffolding for raising a building, "where the scaffolding is removed once it has served its purpose" (Walsham, 1995, p. 76).

Set against this background, theory in this thesis was used more as an exploratory device rather than a testing device. It would therefore be wrong to classify this thesis as purely deductive, since the empirical data was not used to test theory in a strict sense, nor was the primary intention of using theory to make predictions. It would also be wrong to classify this thesis as purely inductive, since the empirical data was not used to establish general law-like premises based on samples of observations. Rather, it is more appropriate to label this thesis as abductive with reference to the fundamental methods of reasoning.

Bryman and Bell (2015) explain abduction as follows. In their conception, abduction is devised as a way to overcome the weaknesses of purely inductive or deductive approaches. One weakness of purely deductive approaches is the strict focus on theory-testing, which creates the problem of having to select a suitable theory to be tested. One weakness of purely inductive approaches is that the conclusions will remain vulnerable because the amount of empirical data is always limited. Instead, abduction, as a form of pragmatic logical reasoning, is a way of devising reasonable explanations for observed phenomena, patterns, and anomalies. Abduction requires continuous iterating back and forth between the data and the theory (or multiple theories) in order to make logical inferences that are plausible. Since there may be several competing interpretations of the data, the researchers' role is to feature what he or she considers to be the most plausible explanation(s), corroborated with arguments and logical reasoning.

Bryman and Bell (2015) emphasise that abductive reasoning is anchored in the interpretive tradition and closely related to the hermeneutic circle (Klein \& Myers, 1999). Similarly, Timmermans and Tavory (2012) describe abduction as a creative imaginative thinking process with the ultimate goal of explaining intriguing or surprising findings. According to them, abduction is a form of reasoning that is based on continuous conjecturing, thereby inviting the exploration of new relations among phenomena, observations, and theory. Knowledge and insights gained from abductive reasoning are regarded as socially constructed, susceptible to the researcher's personal positions and views, and contextually and historically situated (Timmermans \& Tavory, 2012; van Maanen, Sørensen, \& Mitchell, 2007). From this point of view, the researcher's understanding of a phenomenon evolves as a 
consequence of the interaction between different research activities, such as engaging in empirical observations or theorising (Dubois \& Gadde, 2002).

\subsection{Data collection}

An essential tactic in case study research is the use of multiple data sources, such as interviews, secondary sources of data, and observations (Meyer, 2001; Yin, 2009). The use of multiple sources of evidence can be a means to counteract any potential bias in the researcher's procedures for collecting and analysing data (Darke et al., 1998); it allows for a deeper understanding of the research problem, including historical and attitudinal issues, and provides a stronger foundation for the substantiation of hypotheses and claims through the triangulation of evidence (Meyer, 2001; Yin, 2009). Multiple data sources can provide corroborating information and strengthen the study's results by demonstrating the convergence of information from these different sources; furthermore, the use of multiple data sources can add greater depth to the overall understanding, especially when participants' accounts are conflicting (Darke et al., 1998).

When using abduction, the researcher should work with sufficiently detailed and rich data in order to conjecture, understand, explain, and render plausible one's arguments (van Maanen et al., 2007). The data that was collected throughout the research process for this thesis was quite diverse. For instance, data was collected through interviews, forums, expert talks and online lectures, online product offerings, blogs, magazine articles, web statistics, conference participation and participant observations. These data sources complemented each other in various ways; for instance, in a corroborative fashion. This can be illustrated by the example of factors that inform pricing practices in this open source setting. Utterances and statements that were made in interviews I conducted and in online video interviews of Joomla experts that I discovered and watched later on, both reflected and emphasised the importance of value-based pricing over pricing based on competitor price.

Figure 15 provides an overview of the key empirical data sources and how they informed the different constituent parts in this thesis. The key empirical data sources comprised two interview sets (more details about the interviews are given in the next section), online offerings of extension providers, online video interviews of Joomla experts, and other types of web sources (e.g., blogs, forums, statistics, firm websites). 


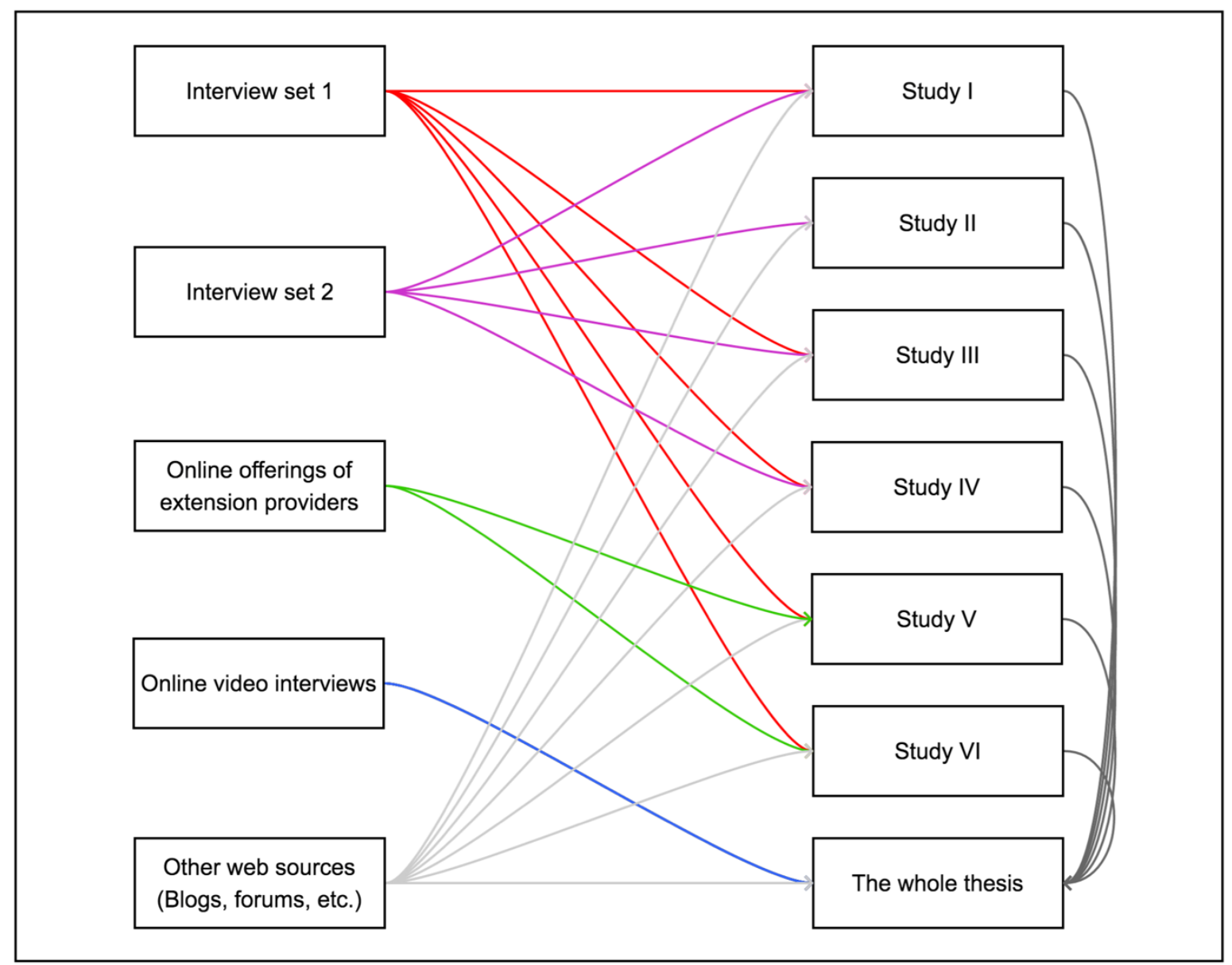

Figure 15: The key empirical data sources and how they informed the different constituent parts of this thesis.

\subsubsection{Interviews and sampling strategy}

Basically, interviews can be seen as the primary data source when carrying out interpretive case studies because they provide rich information through which researchers can best access and examine the interpretations, views, and experiences of the participants (Darke et al., 1998; Walsham, 1995).

A sampling procedure typically focuses on participants who can potentially provide the researcher with valuable and study-relevant knowledge, experience, and insights (Andrade, 2009). Furthermore, it is desirable to compile samples that contain multiple perspectives and pluralistic views, which can be useful for validating information or for resolving potential discrepancies among participants' interview accounts (Meyer, 2001).

The overall sampling procedure was conducted in two stages, leading to two sets of interviews (Interview set 1, Interview set 2). The first stage focused on providers of commercial Joomla extensions that where top-rated on the 
JED. The second stage focused particularly on people who had a visible affiliation with the Joomla project (e.g., on the Joomla website). Detailed information regarding the sampling procedures for these interview sets is given in the subsequent sections. More generally, the sampling approach led to many insightful interviews and accounts from many different viewpoints and perspectives; it also ensured that the interview data were relevant with respect to the units of analysis in this thesis, as described in Section 5.3.

In total, 47 interviews were conducted (the sum of both interview sets). Special care was taken to protect the identities of the interviewees. For instance, information that could reveal the identities of particular interviewees was excluded from any interview excerpts in the thesis, such as the name, age, gender, nationality, place of residence, workplace, brands and product names. Furthermore, the sequence of interviewee IDs is randomised for each sub-study that includes interview excerpts. This means that Interviewee \#10 in one sub-study, for instance, is not the same person as Interviewee \#10 in a different sub-study. This ensures that the collection of sub-studies does not provide cumulative information about a particular person's identity.

\subsubsection{Interview set 1}

The first set of interviews consisted of 21 providers of commercial Joomla extensions. These interviews were conducted between summer 2015 and spring 2016. The interview data mainly served as an input for the sub-studies on pricing (Study V), and bundling and versioning (Study VI). However, due to the richness of the data, they also informed the sub-studies on stakeholders (Study I), organisational identity (Study III), and economic incentives (Study IV).

The interview sample was compiled based on vendors whose extensions were top-rated on the JED. Top-rated commercial extensions could be interpreted as representative of vendors whose products are successful. The advantage of this method of sampling is that it is rather straightforward to compile a sample with the search functionality on the JED. It could also be argued that this method of sampling can introduce a bias considering the possibility that the popularity rankings could be skewed (e.g., by fake ratings). An alternative sampling strategy could have been based on the number of extensions that vendors offered. However, a broad product palette does not necessarily have to be representative of dominant business (or pricing) practices. It can be argued that focusing on the top-rated commercial extensions makes sense because potential customers are 
primarily exposed to the top-rated extensions on the JED (i.e., these extensions are featured in terms of visibility on this platform). When conducting the interviews based on this sample, it turned out that many of the participants were also active contributors to the Joomla community.

As of June 2015, the JED hosted more than 9,000 extensions and organised them into 34 main categories (e.g., access and security, administration, multimedia, financial). To attain a middle ground between feasibility and representativeness, it was decided to focus on the providers of the three top-rated commercial extensions in each category. The choice to focus on the top-rated paid extensions is based on the assumption that high user ratings can signal the commercial success of a product. One JED category was omitted from the sample procedure because it included no commercial extensions. Given the remaining 33 categories, 99 different extensions were selected (three in each category). Because there were some vendors that were top-rated in multiple categories, the final result set consisted of 66 vendors that were represented with one extension, 11 vendors with two extensions, two vendors with three extensions and one vendor with five extensions. In total, this amounted to 80 different vendors that accounted for these 99 extensions.

Interview requests were sent to all 80 vendors in summer 2015. The vendors were asked to suggest a day and time in case they were willing to submit to a personal interview. Alternatively, they were given the opportunity to respond to the interview questions via email. Sending out reminders in spring 2016 increased the response rate slightly. As already mentioned, the final interview repository consisted of 21 interviewees, corresponding to a response rate of approximately $26 \%$. All but one of these interviewees were located in Europe.

Seventeen of these 21 interviews were conducted via email, amounting to a total of 14,954 words. The other four interviews were conducted orally via Skype or Google Hangouts. These four interviews lasted 76 minutes on average (the shortest was 45 minutes, the longest took 124 minutes). The oral interviews were semi-structured, which gave the interviewees more freedom to elaborate upon issues that they deemed important; they were not recorded but notes were taken during the conversations.

In contrast, the email interviews had a structured format, whereby the interviewees were provided with a list of questions to which they could add their answers. According to Cassell and Symon (2004), one potential advantage of email interviews and asynchronous communication is a greater opportunity for reflexivity among interviewees. While there might also be potential drawbacks, such as decreased control for the interviewer and a 
lack of immediacy, the joint application of mail and personal interviews led to a rich set of accounts of different practices, opinions and views.

The questions for the first set of interviews revolved around motivations for developing Joomla extensions, the transition from non-commercial to commercial extension development, questions on pricing, bundling, and signalling based on the pricing framework created by Iveroth et al. (2013), and questions related to community aspects. The interview guide for this first set of interviews is attached in the appendix in Section 20.1.

\subsubsection{Interview set 2}

The second set of interviews consisted of 26 community participants. This interview set mainly served as input for the sub-study on organisational identity (Study III). However, because of the richness of the data, it also informed the sub-studies on key stakeholders (Study I), governance (Study II), and economic incentives (Study IV). These interviews were conducted between winter 2016 and spring 2017.

The sampling procedure started off by sending interview requests to organisers of user groups all around the world. The contact information of these people was listed on the Joomla website. At the time of sending the interview requests, the distribution of Joomla groups looked as follows: Africa (11), Asia (14), Caribbean (2), Europe (99), Middle East (3), North America (27), Oceania (5), South America (16). This means that 177 interview requests were sent. 18 people responded to these interview requests, which corresponds to an initial response rate of approximately $10 \%$.

The final interview sample also included people that I met during the first of two conference visits (see Section 5.5.2). The first conference visit led to five more interviews with community participants. Subsequently, the sampling procedure continued in a snowball fashion, whereby interviewees recommended further people for doing interviews. In this manner, interviews with three more community participants were conducted. Due to time constraints and the breath of the data collected I decided to confine myself to 26 respondents, even though interviewees provided further recommendations regarding potential interview partners. It turned out that most of the people who were contacted through this procedure also had a business connected to the community's software product(s). Some of the respondents occupied or had occupied positions in different organisational layers, such as work groups, or the leadership teams. 
Oral interviews with 24 community participants were conducted over Skype or Google Hangout. Two community participants were met and interviewed in person.

On average, the interviews lasted for 83 minutes (the shortest was 35 minutes, the longest took 134 minutes). With informed consent, these interviews were recorded. The second set of interviews amounted to 33 hours of interview data. This data was transcribed and anonymised, which amounted to a total of 190,228 words. The interviews were designed in a semi-structured format, essentially giving the interviewees ample opportunity to explain their views. Figure 16 shows the world-wide distribution of interview participants for this second set of interviews.

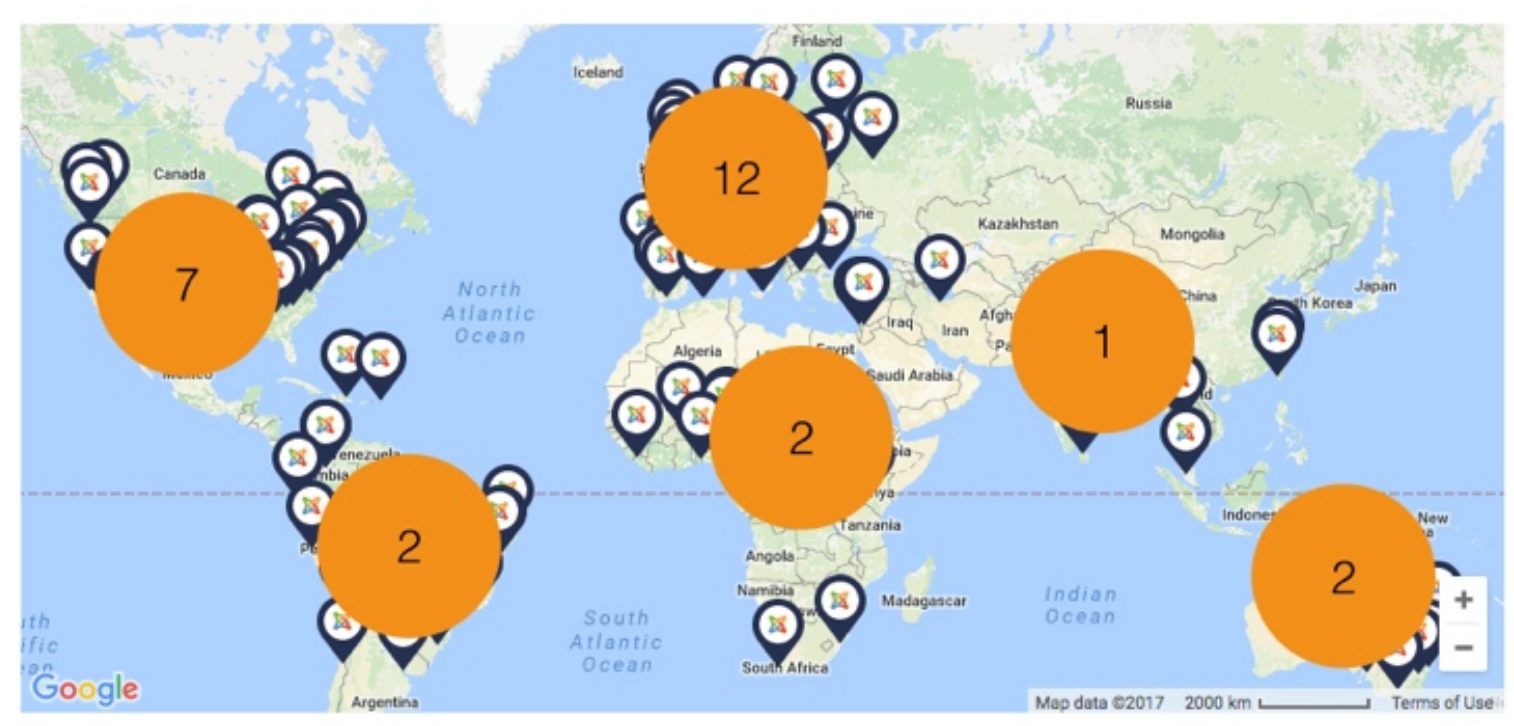

Figure 16: Distribution of interview participants for the second set of interviews on a map of Joomla user groups.

The main part of these interviews revolved around issues of governance and organisational identity. The interview guide for these interviews is attached in the appendix in Section 20.2. A second part of the interview questions revolved around business aspects. These questions were only brought up in cases where the interviewees had a commercial business connected to Joomla, which applied to most interviewees. The questions on business aspects mainly served the purpose of increasing my contextual understanding of business conduct in relation to Joomla. The interview questions on business aspects were inspired by the business model canvas 
(Osterwalder \& Pigneur, 2010) and roughly revolved around its conceptual themes. The interview guide addressing the business aspects is attached in the appendix in Section 20.3.

\subsubsection{Conference participation}

During my research, I attended two community events. The first one took place in December 2016, the second one in May 2018.

In December 2016, I had the opportunity to participate in a two-day Joomla conference in Vienna, a so-called JoomlaDay event. At JoomlaDay events all kinds of Joomla-related matters are discussed and presented. Furthermore, participants are able to network with others in the community. This conference was an opportunity to get in touch with community members but also to conduct participant observations. Participant observations are usually unobtrusive and can increase the rigour of studies when combined with other sources and methods (Meyer, 2001).

There were around 60 conference participants and a total of 27 speakers presenting and discussing a broad range of Joomla-related topics over a twoday period. For instance, the presentations revolved around responsive web design, security, copyright and cookie policies, website accessibility, the Joomla certification program, search engine optimisation, the presentation of all kinds of case studies, the current status of upcoming Joomla releases, backup strategies, and business model automation.

For me, this conference participation was valuable insofar as it gave me the opportunity to gain a first-hand experience of the activities in the community. The conference offered plenty of opportunities to socialise with others, which was a chance for me to contact potential interview partners. Interviews with some of the conference participants were conducted within the following weeks after the conference (see previous section). Conference participants also provided tips about who else to contact for further interviews. Finally, I was given the opportunity to present my work-inprogress to the conference audience, which resulted in interesting discussions (e.g., about licensing and business aspects).

In May 2018, I participated in an international Joomla event in Cologne, the so-called JAndBeyond conference. This event was organised as a threeday conference. My best guess is that there might have been around 200 people participating during these three days. There were 47 different conference slots (i.e., keynotes, presentations, and seminar sessions) distributed over the three days. More than 40 speakers talked about a broad range of Joomla-related topics and issues, such as security, upgradeability, resource management, cloud server infrastructures, extensions, scaling and 
performance, business models and strategy, web design and story-telling, new regulations and laws, the community's ability to attract volunteer workers, and more.

Apart from being an observer and active conference participant (e.g., involved in discussions, asking questions), this conference participation was valuable insofar as it gave me the opportunity to present my research informally in conversations with others. Although I could not acquire an official conference slot to present my research (all conference slots were already fully booked), individual conversations and conversations in small groups gave me the opportunity to gauge how different people react to some of the preliminary results that I had come up with. For instance, in one of the conversations I talked about the different challenges in commercialising community-driven OSS that I had identified. On the one hand, I could see that my presentation of the preliminary results triggered intense discussions. For instance, these discussions revolved around conflicts and competing lobbies in the community, marketing and the positioning of Joomla, alignment between the needs of developers and business people, and different revenue sources (e.g., customisation and value-added services). However, I also noticed that my presentation of the results probably needed to be more focused, concrete, and pointed in order to be useful from a practitioner's point of view. I tried to keep this insight in mind throughout the remaining work on this thesis.

\subsubsection{Online data-gathering}

Unsurprisingly, the Internet was a useful source of information throughout the research process. Data collection methods based on information on the Web have become increasingly popular amongst social scientists (Burns, 2010). A considerable proportion of communication within the Joomla community occurs through online means. Much of this communication is publicly available, such as on forums, email lists, and social media. The information gathered on the Web mainly served the purpose of painting a rich context against which areas of interests could be studied. The amount of Joomla-related information that is available on the Web is vast. Information can be found in forums, blogs, magazines, on the Joomla website, different social media channels, websites of firms and their product offerings, in previous interviews with community members, policy documents, leadership blogs, sites of user groups, information on collaborative platforms such as the GitHub repository, information on the issue tracker, YouTube videos of Joomla conference presentations, and Joomla-related podcasts. Most of the information from these sources was not 
used in a systematic fashion but more on-demand to verify, corroborate, or complement certain arguments and claims.

However, there were two types of online sources from which data was collected in a more systematic fashion. First, data was collected and analysed from online offerings that were available on the websites of commercial Joomla extension providers. In particular, this data set served as input for Study V (Pricing) and Study VI (Bundling and versioning). Analogous to the first interview set (see Section 5.5.1.1), the set of online offerings was compiled based on vendors whose extension were top-rated on the JED, leading to a set of 99 online offerings that were examined. More details of how these data have been analysed can be found in the respective sub-studies (Study V: Pricing, Study VI: Bundling and versioning).

The second online source that was used in a more systematic fashion was video interviews with Joomla experts ${ }^{87}$, conducted and hosted by Sarah Watz, a former president of OSM (the non-profit organisation behind Joomla), and a business owner offering Joomla-related services. Essentially, these talks revolved around Joomla, its community, and all sorts of businessrelated matters. Typically, known people in the community shared their insights and knowledge on all kinds of aspects of running a Joomla business. As emphasised by the host, the proclaimed motto of these talks was to "help Joomla businesses grow". The host started these talks in June 2017. By February 2018, this had amounted to 25 talks. Usually, they lasted for about an hour.

The conversations in these talks were coded for any kind of ecologyrelevant information. For instance, in one episode, the host emphasised that the Joomla ecosystem is fragile in the sense that it relies on a great and diverse number of people, which is the reason why she wants to encourage others to work with Joomla. The information gathered from these talks served to complement and validate some of my conclusions. For instance, as I observed from the interviews that I conducted myself, much of the information in these talks confirmed the important role of the community for the Joomla businesses (e.g., the community as a source of inspiration, knowledge sharing, best practice, support, and information about strategies and trends that are relevant in the business world).

\subsection{Analytical process}

In qualitative research, the analysis and data collection are intertwined in significant ways (Myers, 1997). This is due to frequent interactions between the data and the theory (Dubois \& Gadde, 2002; Eisenhardt, 1989). For instance, the researcher's presuppositions can affect the data-gathering; in 
turn, the data can also suggest new avenues for research (Myers, 1997). The overlapping of data collection and data analysis provides the researcher with flexibility in the sense that it allows for the consideration of new ideas during the research and data collection procedures (Darke et al., 1998). With interpretive approaches, the findings literally evolve in parallel with the ongoing investigation (Andrade, 2009) - they are a product of gaining a deeper understanding of the subject matter over time.

One suitable way to describe the process of gaining understanding is a model by Westelius (1996, p. 13), which is depicted in Figure 17. Westelius (1996) describes the process of gaining understanding as a spiral movement that is characterised by three parameters: input, reflection, and time. The input in this thesis basically includes all the information that was gathered and processed throughout the research process (e.g., interview data, information from diverse online channels, observations, feedback from supervisors and colleagues, the literature). The input continuously informed and triggered reflection processes. As a result, a richer understanding of the research subject gradually emerged as time went on. This model highlights that the process of understanding is never complete. Rather, the researcher's understanding of a particular problem evolves and changes over time. Given the limits of human attention, researchers can only ever achieve a partial understanding of a particular phenomenon, as opposed to being able to achieve an understanding that represents any sort of ultimate truth. 


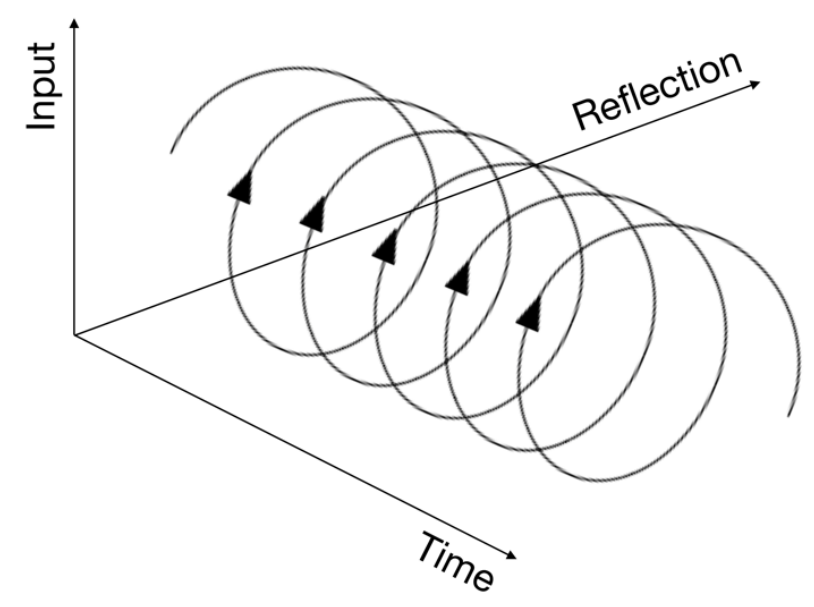

Figure 17: A model for describing the process of gaining understanding (Westelius, 1996, p. 13).

The goal of interpretive studies is to produce understanding by means of interpretation and sense-making (Darke et al., 1998). The process of gaining understanding involves continuously moving back and forth between empirical observations and theory, which is also called theory-matching (Dubois \& Gadde, 2002). This process is inherently abductive and involves theoretical concepts, data, and contextual information (van Maanen et al., 2007).

In order to make the analytical process more traceable, the following provides more details and illustrative examples. Dubois and Gadde (2002) conceive of the analysis in case study research as a nonlinear and pathdependent process of 'systematic combining', in which different elements and activities of the research are interrelated (e.g., the data collection and the emerging theoretical framework). The non-linearity and pathdependence in my research process can be illustrated by the fact that the idea for this thesis basically started with what became Study V (Pricing) in the end. From there, the path roughly continued to the ideas present in Study VI (Bundling and versioning), followed by Study II (Governance framework), Study III (Collective identities), Study I (Stakeholders), and Study IV (Economic incentives). Furthermore, a lot of work for the sub-studies in this thesis was done in parallel, which meant that the interview data could crossfertilise the work of the different sub-studies. For instance, interview data that was specifically collected for the pricing study (Study V) also fruitfully informed the study on governance and collective identities (Study III), and the study on stakeholders (Study I). Therefore, the work on this thesis should 
not be imagined as strictly iterative or linear. Rather, working on this thesis felt more like carving a story out of heaps of data, where the metaphorical hammer and chisel were guided by theory, discussions, feedback, and interesting stories and findings. For instance, the work on the pricing study rendered salient the connections between dominant forms of pricing and platform policy on the JED (an aspect of community governance), which in turn made me look into open source community governance. This interest eventually triggered ideas for two new studies, about governance dimensions (Study II), and a little later the interaction between governance and collective identities (Study III). While working on Study II (Governance framework), trying to log the most important dimension in open source community governance, I happened to read Westelius (2006), an article theorising the relationships between governance and organisational identity. This reading reminded me of the difficulty of defining membership in this community setting, and the enigma of exercising governance in the context of a global community of volunteers. This inspired the thought that the interaction between governance and organisational identity in the Joomla case might help me to better understand not only what holds this community together, but also governance and its effects in this particular context.

Due to the hermeneutic nature of the interpretive approach, the theory sometimes stimulated thinking in alternative explanatory patterns. For instance, the ecology lens cast the issues discussed in the individual substudies into a different perspective - looking at the individual motivations for community engagement discussed in Study IV through the ecology perspective (Hearn \& Pace, 2006; lansiti \& Levien, 2004; Moore, 1993; Olve et al., 2013; Westelius \& Lind, 2016) gave rise to the impression that one primary goal of community engagement amongst firms is to ensure collaboration amongst actors in order to maintain, sustain, and protect the ecosystem that is the basis for their (economic) survival.

While this would be an example of a more hermeneutic and theoryinspired style of analysis, some of the analysis was more driven by the data (albeit theory-guided). In particular, this applies to the second interview set. Analysing these interviews involved coding for salient themes. The software MAXQDA was particularly useful during this coding process because the amount of data was large (the second interview set consisted of a total of 190,228 words). Over a period of several months, a total of 1,137 codes were assigned to these interview data. Throughout the coding process, the codes were arranged and rearranged into hierarchical structures. MAXQDA, like other comparable tools, allows for the structuring of codes into hierarchies. The final top-level hierarchy consisted of 11 codes: 'identities', 'business models', 'CMS system qualities', 'interrelations between the 
community and the commercial realm', 'core values', 'education', 'governance and change', 'HR and recruiting', 'motivation', 'project success', and 'stakeholders'. This coding process helped me to make a variety of different relationships in the interview data more visible (e.g., openness, togetherness, passion, fun, sharing, generosity, and learning as important features of the core values of the community). In particular, the contents of Study I (Stakeholders), Study III (Collective identities), and Study IV (Economic incentives) were informed by this style of analysis.

\subsection{Validity and generalisability}

In qualitative research, the "researcher is the primary instrument of data collection and analysis" ${ }^{\prime 8}$. Both the data collection and analysis can be subject to influence from the researcher's interpretations, preferences, and background - this means that there is a potential for bias, which may decrease the validity of the findings (Darke et al., 1998). According to Andrade (2009), one measure for increasing the validity of case studies is the use of multiple sources of evidence to strengthen and corroborate one's claims and arguments. He argues that this can make the researcher's accounts more persuasive and trustworthy. This thesis draws upon many different information sources. For instance, information regarding business practices in the realm of Joomla was obtained not only from the interview data, but also from discussions on email lists, forums, social media, video talks, vendors' websites, and the JED.

Furthermore, a search for rival explanations and a general sensitivity to differences in interpretation can add more rigour to the overall research (Andrade, 2009; Klein \& Myers, 1999). In an attempt to follow this recommendation, I tried to be attentive to both similarities and differences in people's experiences and opinions in the data (e.g., the different opinions and views about the future of Joomla). I also tried to preserve an openness towards the possibility that there may exist multiple interpretations and explanations of events, attitudes, and practices (e.g., the founding story of Joomla, ideology versus economic interests, the meaningfulness of certain pricing practices). Thankfully, the comments and critique from my colleagues supported me in this respect. For instance, sometimes, the feedback from my colleagues suggested that my analysis might have become too myopic. The recommendations of my colleagues also helped to enhance the fit and appropriateness regarding the use of theory in relation to the empirical setting and the research goals (often also referred to as construct validity). 
My work has not only been subject to continuous scrutiny by my supervisors and colleagues at our division but also, over a period of five years, my work in progress was presented, discussed and critiqued at two annual conferences of the research school 'Management and IT' based in Uppsala. The interactions with my colleagues at our research school was a crucial part of the whole research process. Especially, at the beginning, but also during later stages of my research, these interactions led to the adding, revising, refinement, or abandoning of ideas.

Another problem in research is the generalisability of the results. With single-case studies, the generalisability of the results may be limited. However, single-case studies may be generalised to theoretical propositions (i.e., analytical generalisation in contrast to statistical generalisation) (Yin, 2009). As Klein and Myers (1999) argue, while interpretive research studies emphasise the subjective nature of knowledge, the basis for their generalisation is the transitioning from contextualised data to abstract categories. Klein and Myers (1999) emphasise that unique instances are relatable to abstract concepts; and abstract concepts in turn can be applicable in other settings. However, it is important, as the authors elucidate, to make the process of transitioning from empirical details to theoretical abstractions transparent and traceable for the reader. Bearing this in mind, I have tried to provide thick descriptions of case-relevant information, my reasoning, and my arguments throughout this thesis.

Finally, the validity and generalisability of research can be enhanced if the results are linked and compared to existing theory (Meyer, 2001). In a sense, theory-matching is similar to analytical generalisation. As explained by Meyer (2001), in analytical generalisation the results are compared with existing theory. As a result of the comparisons with existing theory, one starts to recognise which parts of the results are similar, dissimilar, or contradictory in relation to existing theories, concepts, or hypotheses. The key then is to explain and discuss the consequences of similarities, dissimilarities, and contradictory findings in light of existing theory (van Maanen et al., 2007). This process can lead to theoretical contributions in the form of refinements of concepts or conceptual frameworks, or new propositions and theories (Walsham, 1995). The discussions in the respective sub-studies (Chapters 6 - 11) and the final discussion of this thesis (Chapter 13) expand on such comparisons with the existing literature and draw upon the potential consequences and implications of the findings for theory.

While all these measures can enhance the validity and generalisability of the research, they cannot guarantee its success. Therefore, the reader of this thesis is encouraged to preserve a critical attitude, not only towards the contents and results that are presented in this thesis, no matter how 
Chapter 5: Methodological approach

persuasive, convincing, trustworthy, or accurate they may appear, but towards research in general. 


\section{A multi-stakeholder perspective on community-driven open source (Study I)}

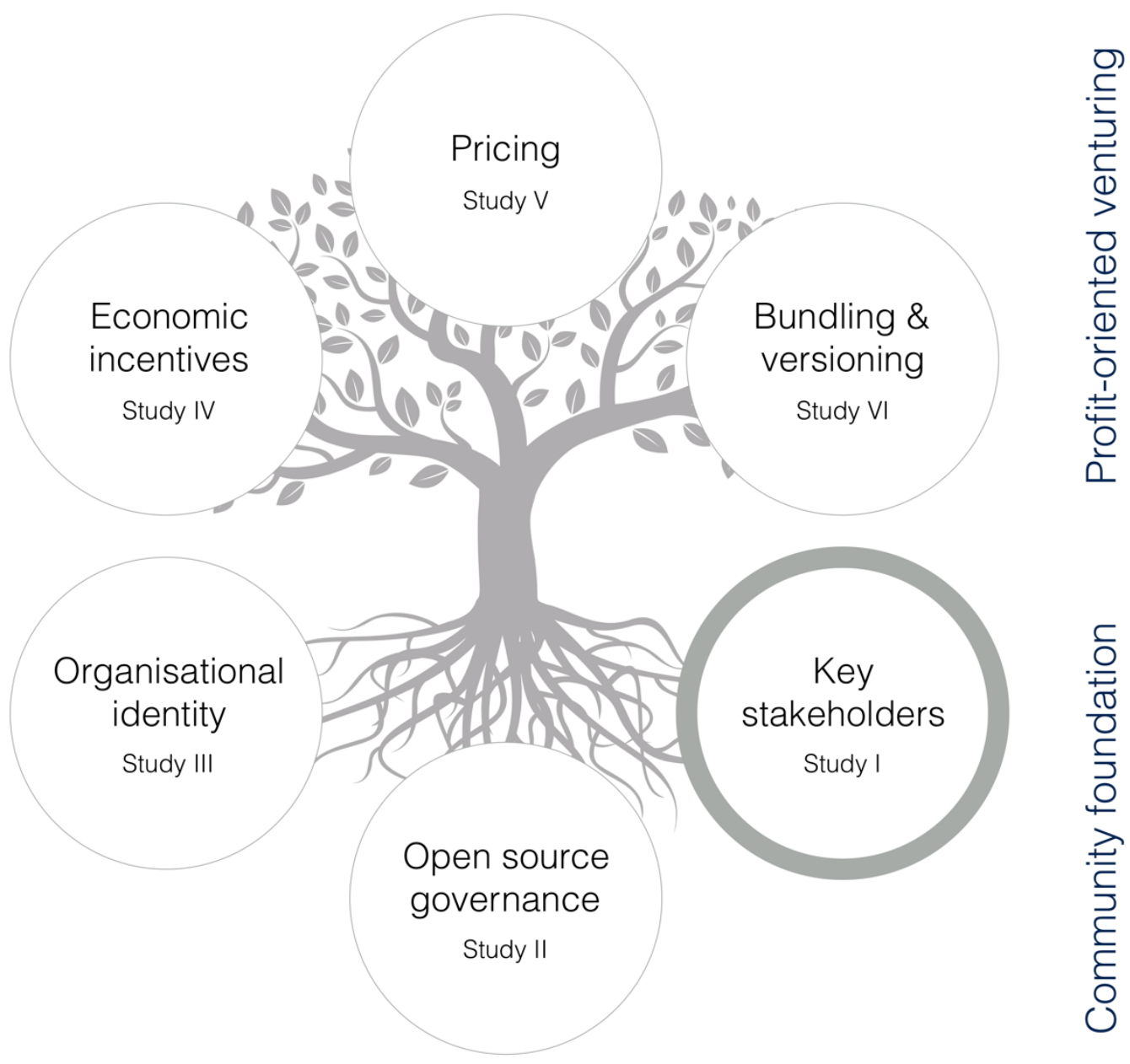




\subsection{Short summary}

Open source projects increasingly involve diverse sets of sponsors and stakeholders. For both open source communities and firms, this raises questions regarding how interests and interest groups shape and influence the development, organisation, and strategic orientation of open source projects. Stakeholder interests may also shape and influence the conditions for the commercialisation of open OSS in particular ways. In the literature, stakeholder relationships are portrayed as the fundamental drivers of value. Stakeholder analysis can therefore be a valuable information base for assessing the costs, risks, and benefits of investing in the development of OSS.

From a theoretical point of view, Study I addresses the lack of specificity regarding the concept of community in stakeholder theory. By identifying stakeholders in and around a worldwide community of volunteers, it helps to unbox the concept of community in stakeholder theory. Building on empirical insights, it proposes a two-dimensional model for identifying and categorising stakeholders in a community setting. This two-dimensional model builds on the core-periphery dichotomy, which is a widely-accepted model for the general structure of open source communities. The proposed classification provides a broad compass for identifying stakeholders in and around open source communities and may therefore facilitate a more nuanced understanding concerning who open source communities are and what they do. 


\subsection{Introduction}

The communities that account for the production of OSS often exhibit traits that are not easily reconciled with traditional business conduct. For instance, this relates to ideological tenets (Aksulu \& Wade, 2010), the absence of traditional forms of control (Nakakoji et al., 2002), the dominance of social gratification over financial rewards (Scacchi, Feller, Fitzgerald, Hissam, \& Lakhani, 2006), a reliance on dispersed communities of volunteers (Stewart \& Gosain, 2006), undefined project lifespans (Aksulu \& Wade, 2010), the absence of corporate budgets and schedules (von Hippel \& von Krogh, 2003), a lack of rigid organisational structures (Mateos-Garcia \& Steinmueller, 2008), self-appointed roles by community members (De Laat, 2007), or bazaar-like working styles that incorporate open exchange, differing agendas, and multiple approaches (Bird, Pattison, D'Souza, Filkov, \& Devanbu, 2008; Raymond, 1999b).

A recipe for the executive's nightmare? Yet, many businesses, professionals, and governments value the claimed benefits that come with open source. These benefits are widely recognised in terms of improved code quality, security, architectural design, customisability, and, last but not least, reduced cost. Further frequently cited benefits include the promotion of innovation, the spillover of knowledge, and the diffusion of cutting-edge technologies (Lerner, 2010). Virtually all software that is produced today includes OSS (Franch et al., 2013). Because many organisations have become dependent on OSS, they may increasingly recognise the need to interact with open source communities. As a consequence, open source projects increasingly entail diverse sets of sponsors and stakeholders (Crowston, 2016; Morgan \& Finnegan, 2014; O'Mahony, 2007). However, this raises questions regarding how interests and interest groups shape and influence the development, organisation, and strategic orientation of open source projects. Moreover, it raises the question how stakeholder interests shape the conditions for the commercialisation of open OSS.

Ongoing diversification of stakeholder interests in and around open source projects can be termed a contemporary challenge for professional management (both for community managers and actors who seek to interact with communities), which can be fruitfully linked to a theoretical problem in the literature. According to Dunham, R.E. Freeman, and Liedtka (2006), community as a concept is often treated as a monolith in stakeholder theory. They suggest that much more particularised work needs to be done to unbox the concept of community in stakeholder theory. Although they theorise different variants of communities (i.e., communities of place, communities of interest, virtual advocacy groups, and communities of practice), their 
classification may not offer much guidance on how to identify and analyse the stakes in and around open source projects. According to Perrault (2017), one problem may be the use of inadequate generic categories for stakeholder identification (e.g., customers, employees, shareholders, and suppliers) and a lack of guidance "for understanding the heterogeneity of stakeholder interests" (Perrault, 2017, p. 25).

Stakeholder theory often departs from (more or less well-defined) organisational operations and activities, which can affect stakeholders or can be affected by stakeholder interests. In this regard, this sub-study broadly focuses on the operations and activities of an open source project, which can affect various stakeholders, and, in turn can be affected by different stakeholder interests. Against this backdrop, Study I attempts to contribute with a more nuanced picture regarding the different interests and interest groups that may be involved in shaping the operations and activities in and around open source projects.

Stakeholder analysis may be of special interest in the context of serviceoriented open source projects. According to Nakakoji et al. (2002), such projects provide stable and robust solutions to a potentially large number of stakeholders - a population that can be way larger than the open source community itself. They further conjecture that service-oriented open source projects are more conservative towards rapid changes because they have to carefully consider changes that could disrupt the service provided to the population of stakeholders.

From an empirical point of view, Study I takes a close look at the Joomla community (for a detailed description of the empirical context see Chapter 4). Because stakeholder intent stands in mutual relationship with the environment that it produces (Mintzberg, 1978), Study I looks at open source in its larger context. This means that the level of analysis focuses on the ecosystem (Olve et al., 2013), rather than on the community, individual, group, organisational, or firm level. Stakeholder analysis is treated as a way to take stock of the ecosystem's inventory, as it were. This means that, while the community receives special attention due to the particularities of the setting, there may be actors outside the community who matter nonetheless. By taking into account the salient values, alliances, interests, and technologies that are involved, Study I provides a bird's eye view on important stakeholders in the Joomla case. The following research question is pursued: what is the configuration of stakeholders, their salient relationships and the interests that constitute the Joomla ecosystem?

Although scholars have accumulated a mass of research on stakeholder identification (Mitchell et al., 2017), particularised work in the realm of open source communities remains to be done. By unboxing stakeholders in the 
context of an open source community, Study I also offers insights for practitioners, such as community managers or firms who seek to interact with open source communities.

The remainder of Study I is structured as follows. The next section provides a theoretical background on stakeholder theory. This section is followed by a description of the methodological approach. The study then continues with a presentation of salient stakeholders in the Joomla case. Finally, prior to the concluding remarks, the discussion provides an interpretation of the findings in the light of existing theory, and presents a two-dimensional model for stakeholder classification in community settings.

\subsection{Theoretical background}

At the heart of stakeholder theory is the question of which stakeholders deserve or require management's attention, and which do not (Mitchell et al., 1997). The interests and claims of stakeholders beyond the profit maximisation function of an organisation have been argued as a core concern in stakeholder analysis (Mitchell et al., 1997). Stakeholder theory rests on the inseparability of ethics and business conduct (R. E. Freeman, Harrison, Wicks, Parmar, \& De Colle, 2010). From a moral perspective, power comes with responsibility (Westelius, Westelius, \& Brytting, 2013).

A prominent definition of stakeholders is provided by R.E. Freeman (2010, p. 46): "any group or individual who can affect or is affected by the achievement of the organisation's objectives". To narrow down the problem of stakeholder identification, extant research has proposed focusing on salient attributes, most notably power, legitimacy, and urgency (Mitchell et al., 1997). Still considered a good standard, this framework has influenced much research on stakeholder identification (Mitchell et al., 2017). Power derives from actors' ability to exert influence, legitimacy derives from the notion that stakeholders bear some sort of risk (e.g., capital, human, financial, valuables), and urgency derives from the immediacy of stakes and the priority they are given by managers' attention (Mitchell et al., 1997). However, single stakeholder concepts may fail to guide us satisfactorily during the identification process. For instance, there may be stakeholders within an ecosystem without power who matter nevertheless (Mitchell et al., 1997). Therefore, a whole range of other important concepts have been leveraged to guide the stakeholder identification process, such as social status (Perrault, 2017), or social responsibility (Mitchell et al., 2017).

Crane and Ruebottom (2011) propose identifying stakeholders in terms of their enacted social identities, ideologies, and values. They argue that such an approach could be of special help in the context of communities 
where it is often difficult to differentiate between organisational and societal stakes. They further conjecture that a consideration of social identities can account for the social glue that binds stakeholders based on shared values.

However, arguing with Kivits (2011), there is no single best stakeholder analysis tool, but we can aim at a combination of concepts and methods, on the one hand, to alleviate the weaknesses of single-method approaches, and, on the other hand, to form a framework that suits practical applicability. This interpretive research adopts a pragmatic stance and applies a lens that combines R.E. Freeman's (2010) definition (i.e., groups or individuals who can affect or are affected by organisational objectives) with other key attributes that may characterise salient stakeholders, such as power, legitimacy, and urgency (Mitchell et al., 1997), ideology, values, social responsibility (Crane \& Ruebottom, 2011), and social status (Perrault, 2017).

\subsection{Research approach}

To collect relevant data for stakeholder identification, one needs to scan the environment and try to capture important relationships, salient interests, and activities (Ballejos \& Montagna, 2008; Kivits, 2011). The stakeholder identification and analysis in this sub-study was informed by data that had been gathered from a variety of sources, including the relevant literature on open source communities, online data (e.g., web articles, blogs, video blogs, the Joomla website), and 47 interviews that were conducted with community participants (for more details regarding the data collection procedure, the reader is referred to Chapter 5). In order to cope with the breadth of the data, the software MAXQDA was used to code the interview data for stakeholder-relevant characteristics (e.g., power, legitimacy, urgency, social responsibility, social status). The online data sources were mainly used to validate, or if necessary, complement the interpretations that were drawn from the interview data.

An advantage of including online data is that it allows for unobtrusive access and that it enriches the data with historical episodes and everyday dynamics that may help to decipher who and what effectively counts (Bergquist \& Ljungberg, 2001; Parent \& Deephouse, 2007). Using multiple data sources is likely to reduce a potential bias that may stem from a lack of stakeholder views in the data (Kivits, 2011). Following recommendations by Kivits (2011), the analysis both followed a bottom-up reconstructive approach and a top-down analytical approach that was guided by the theoretical criteria and concepts of interest (e.g., power, legitimacy, urgency, social responsibility, social status). By iterating between the data and the theory, a set of salient stakeholders gradually emerged as a result of 
the interpretive work of the researcher (Klein \& Myers, 1999). The method employed excluded the ranking of stakeholders because stakeholder prioritisation may depend upon individual perspectives tied to different roles within an organisation (Parent \& Deephouse, 2007).

\subsection{Stakeholders in the Joomla case}

To start with, it should be noted that the salience of stakeholders can change over time and may vary from issue to issue (Mitchell et al., 1997; Imre, 2017). Because the pace of developments around web technologies is fast, there is a continuous encroachment of new technological frameworks, architectural designs, and business practices. As expressed by an interviewee, it can only be speculated how the landscape of web technologies might look ten years from now. This uncertainty also has implications for stakeholder analysis. Stakeholders at the present time (e.g., communities that develop external software on which the Joomla CMS builds) could decrease in terms of significance within only a few years. Furthermore, new stakeholders might enter the stage. Keeping this in mind, the following presents the status quo of salient stakeholders who currently shape and influence the activities in and around the Joomla community.

\subsubsection{The core community}

Membership in open source communities is often informal and loosely defined, which is the reason why the organisational boundaries appear to be fuzzy, at least to some extent. However, one can identify people who have a visible affiliation with the Joomla project (e.g., people registered on Joomla's volunteer portal, people with particular roles, people who can be associated with certain contributing activities, and official representatives).

The people who proactively work on keeping the Joomla project alive (often with high degrees of commitment) can be considered the core community; they are an important stakeholder group within the community. Without these dedicated people at the community's core, there would not be a functioning Joomla at all. Essentially, these people are responsible for the development and management of the Joomla project and its community. However, the core community should be seen as more of a fluid entity, rather than a coherent group. Although there is an official leadership structure with different representatives, such as the Team Leaders, Department Leaders, and Officers, the leadership structure is characterised by flat hierarchies and voluntary modes of participation. Furthermore, the contribution activities of team members can fluctuate. 
Just as the community as a whole cannot be seen as a homogeneous entity of actors, within the core community there can be different (clanlike ${ }^{\mathrm{XVII}}$ ) groups or cliques that collaborate, cooperate, and sometimes also compete in pushing the Joomla project in certain directions. The fact that there are many different views and perspectives within the Joomla community also extends to the core of people who essentially maintain and drive the Joomla project. For instance, there can be groups of people who are more commercially oriented, but also people who are more motivated by altruism, fun, and ideology. Conflicts between these groups can revolve around the goals, purpose, and direction of the Joomla project. According to an interviewee, power issues and conflicting interests between dominant groups of people can sometimes resemble a tug of war.

The people at the community's core also actively manage and maintain relationships with community-external parties (such as community partners, relevant businesses, or other communities that produce software the Joomla CMS relies upon). They also play a crucial role in coordinating and managing different community-internal entities such as user groups, departments, teams, or the legal entity behind Joomla $\left(\mathrm{OSM}^{89}\right)$.

The people in the core community essentially manage the fortunes of the Joomla project. They are attentive to all kinds of issues that affect the community and the Joomla CMS (e.g., monitoring state-of-the-art technology, trends, problems, and users' wishes). Often, but not always, people in the core community also have a business connected to the Joomla platform. According to the empirical data, many ideas and contributions stem from people in the core community, less so from peripheral users.

\subsubsection{Veterans}

Governance-wise, the Joomla community can be seen as a blend of meritocratic, bureaucratic and democratic elements. Although the community has gradually introduced more democratic means of decisionmaking over time, according to the interview data, there are certain people who are heard more than others. These people have also been termed 'alpha-members' in the community - in this sub-study, they are referred to as veterans.

These key people are often cherished for the competence that they possess. They have achieved high levels of status and reputation and therefore enjoy extensive support from others in the community. On

xxVII A clan is understood as a "group of people with a strong common interest" (Oxford Dictionary). 
average, these people have more influence over community matters than the rest of the community. Hence, the veterans can be seen as stakeholders.

\subsubsection{Representatives, leaders, volunteer workforce}

The Joomla community is also a large bureaucratic entity. Joomla relies on a relatively large volunteer workforce. Some of the volunteer workers serve as bureaucratic leaders and elected community representatives.

Different departments, teams, groups, and sub-groups work on diverse matters. The Joomla volunteer portal ${ }^{90}$ provides a good overview of the range of tasks, activities and problems dealt with by the volunteer workforce. For instance, they engage in software development and design, software testing, bug fixing, legal and financial matters, maintenance and user support, marketing, communication and social media, the community magazine, documentation, event management, administration of the website and the forums, to name but a few.

Governance decisions within the community can also create new potential stakeholders. For instance, potentially new stakeholders may have been brought to life after introducing a special-purpose program in 2016, called the Joomla certification program. This program enables people to become community-certified Joomla professionals. According to the Joomla website, the goals of the certification program are to ensure a qualified Joomla workforce and to establish standards for the level of skills and knowledge amongst Joomla professionals ${ }^{91}$. The actual exams for these certifications are offered by so-called Joomla learning partners, who can be seen as new community-internal stakeholders because they invest their time and provide the necessary infrastructure for conducting the exams. While providing a valuable service to the community, Joomla learning partners are given the opportunity to present themselves as official learning partners in their professional profile, and they have the opportunity to sell training and educational material to people who are interested in preparing for the certification exams $^{92}$.

\subsubsection{Domestic communities}

Joomla is a worldwide community of volunteers, but in some regions of the world, there can be more activity and participation than in others. As an example, consider the countries with 10 or more local user groups ${ }^{93}$ : there are strong local communities in France, Germany, Italy, the Netherlands, the United Kingdom, and the USA. But there are also countries with fewer local user groups where strong interactions among community members can be observed. Some of these local communities also operate forums in their 
own language. Of course, there is a lot of interaction across national borders, cultures, and language areas; however, each domestic community may bring a culturally unique perspective into the Joomla community, and the cultivation of these perspectives seems to be an important stake within the community.

\subsubsection{User groups}

Joomla user groups are local congregations organised by Joomla enthusiasts in different regions, towns, and cities all across the globe. The Joomla website hosts a directory of all user groups worldwide. At the time of writing, the distribution of user groups was as follows ${ }^{94}$ : Africa (11), Asia (15), Caribbean (1), Europe (97), Middle East (3), North America (25), Oceania (5), South America (15). In total, there were 172 user groups.

At user group meetings, people are given the opportunity to discuss all kinds of Joomla-related matters. Organisers of user groups often also organise so-called JoomlaDay events that attract participants from beyond regional and national borders. Events such as the JoomlaDay (and other transregional events) are not only a way to share Joomla-related knowledge and experiences, but they are also occasions to gain first-hand experiences of the cultural pluralism within the community.

For the local communities, user group meetings are opportunities to meet people in person. The Joomla community cannot be termed a 'virtual community' in the sense that people mainly interact through online communication (although a lot of interaction does happen through online means of communication). On the contrary, as the interview data show, the personal contact in the Joomla community is very important for the people in the community, which is one reason why the user groups are so important to the Joomla community.

The user groups can also provide opportunities for recruiting new people for volunteer work. Sometimes, new people actively engage in community work after meeting people through the local user groups. User groups provide support and knowledge exchange on a variety of different topics (not only Joomla-related but also Web-related topics and issues in general). Last but not least, user group meetings are opportunities to have a good time with like-minded others, especially for self-employed developers who mainly work on their own. 


\subsubsection{Extension providers}

Extension providers have a special place in the Joomla ecosystem. The term extension refers to software that can be used to extend the functionality of the Joomla CMS. Joomla hosts extensions on a platform called the JED. There are several thousand extensions, both free and commercial, available on the JED. Extensions are an important resource for users in the Joomla ecosystem. Some of the more popular extensions are used by thousands of people.

Extension providers often have tremendous experience and knowledge of the Joomla platform; they monitor the opinions within the community and provide feedback to the core development teams. Especially commercial extension providers may have a vested interest in the Joomla platform. Community decisions that affect future releases of the Joomla CMS (e.g., inclusion of features in upcoming Joomla releases) can affect the businesses of commercial extension providers. For instance, the business models of extension providers can sometimes be at risk because the functionalities that these providers offer through their commercial extensions can become integrated into the Joomla CMS, which can endanger an extension provider's business model. This risk especially applies to extensions that become highly popular. This is because popular extensions can be a sign of functionality that is widely needed amongst Joomla users but that is missing in the Joomla CMS.

While the Joomla leadership may not wish to threaten the economic viability of extension providers' business models, it has happened several times that popular extensions were integrated into the Joomla CMS. For instance, this was the case with version control, which was originally not a core feature but was provided by third-party extension providers. The products of these providers were no longer needed after version control was integrated into the Joomla CMS. Other examples include the 'custom fields' functionality that was introduced recently and could potentially make a whole set of extensions redundant. There is a range of features that have been added to the core of the Joomla CMS over time that were initially provided by third-party extensions.

However, extension providers do not always see it as a threat when parts of their functionality are integrated into the Joomla CMS. In some cases, they even offer their support and help the core team to accomplish just this. According to one interviewee, extension providers just have to be a bit resourceful and creative, and think about how profits can be made by offering new features on top of existing products in case their extensions become integrated. 
From this perspective, Joomla's plugin-architecture and the activities by extension providers can also be seen as a motor for platform innovation. This is because extensions can be a laboratory for people who seek to occupy certain niches in the Joomla ecosystem. Furthermore, commercial extension providers are dependent on the JED in terms of marketing and the generation of leads because they get the bulk of their customer traffic from the JED. However, Joomla not only affects extension providers, the work of extension providers can also affect the Joomla platform. For instance, the interview data show that extension providers can affect the image of the Joomla platform amongst users. A wide range of extensions can make the Joomla platform more attractive to the user base. On the other hand, if an extension developer delivers bad quality to the user base or customers, this can also backfire on Joomla's image as a valuable and robust CMS platform, as was reported.

\subsubsection{Users and end users}

Unsurprisingly, users and end-users are important stakeholders in the Joomla case. Users can be roughly divided into private users and organisational users. Users can be affected by Joomla in various ways. Backwards compatibility can be mentioned as an example. In the past, the Joomla community had to deal with some severe compatibility issues, especially, when moving from Joomla version 1.5.x (2008-2012) ${ }^{95}$ to 2.5 (2012), with the consequence that it lost a lot of users. According to interviewees, there was outrage amongst users when they realised that the upgrades were breaking their installations. After this 'disaster' (as it has been termed by an interviewee), the community decided to emphasise compatibility as an outspoken commitment. The new policy meant that all release cycles within a major version had to be compatible with each other. New features that would break existing installations would be introduced in the next major release. Furthermore, the community guarantees a minimum of four years of support for major Joomla releases ${ }^{96}$.

For the community leadership, having to go through past issues concerning compatibility was a learning process in which the interests of users were recognised more clearly. A broad and diverse user base comes at a price, which is the burden of having to weigh carefully which features to add or remove in upcoming releases. Because of the intricacies involved in preserving backward compatibility, Joomla release cycles tend to be slow.

Compatibility problems can also affect extension providers. New releases of Joomla can potentially conflict with or prevent the functioning of extensions, which can force extension providers to adapt or re-develop their 
code. The community leadership therefore has to consider a variety of factors and interests when working on new software releases.

\subsubsection{Private users}

According to the interview data, for some years, Joomla has been seen as the choice of people running private websites or blogs. However, this image is also changing. The past few years have brought many new competitors in the segment of private users. Services such as WIX ${ }^{97}$ and others enable people to design very simple websites in a what-you-see-is-what-you-get (WYSIWYG) manner without needing to have coding skills. As the interview data show, these days, the Joomla community is more outspoken in stating that Joomla is moving towards serving users who have more complex requirements and make elaborate demands on their websites. What makes the Joomla CMS appealing to both private users with elaborate needs and organisational users is the large ecosystem around the Joomla platform (including extensions and the range of professional services that are offered).

\subsubsection{Organisational users}

Organisational users can be broadly divided into charitable organisations (such as foundations, associations, clubs, and non-governmental organisations), commercially oriented organisations (such as small and medium-sized enterprises and corporations), and governmental organisations (such as schools or universities). According to interviewees, Joomla is a flexible and scalable tool, enabling it to serve the needs of businesses and organisations with more complex work processes, too. For instance, during the data collection, two cases of educational institutes with more than 100 Joomla installations were brought up as examples of Joomla usage in larger organisational settings.

Over the years, Joomla has become an increasingly complex system with a broad set of core features. As a consequence, it has also found its way into the IT portfolios of small and medium-sized enterprises. On the Web, there are also reported cases of large corporations that use Joomla, or have used it in the past, such as eBay, General Electric, IKEA, Holiday Inn, and Harvard University ${ }^{98}$, but also LINUX, and the United Nations Regional Information Centre for Western Europe (UNRIC) ${ }^{99}$.

\subsubsection{Providers of value-added services}

The range of professional and commercial services around the Joomla platform is broad (e.g., web development and design, customisation, 
consulting, hosting, training, maintenance and support, SaaS, Internet marketing, search engine optimisation, extensions, e-commerce).

Joomla professionals offer their services to a broad range of customers. The customers of these businesses can range from clients running small business websites, to corporations with dozens of websites that have to be coordinated across a global network of servers, and anything in between.

Joomla professionals can be an important source of feedback and inspiration to others in the community. A lot of input comes from the people who work with Joomla in their professional lives. Providers of value-added services are important stakeholders also for other reasons as well; they can market and recommend Joomla to their clients, which can increase the overall penetration rates of the Joomla platform. However, for providers of value-added services, building a business based on Joomla also introduces dependencies that can sometimes be difficult to manage. As the interview data show, one critique is that there is too little stakeholder thinking from the community leadership. A further critique is that the Joomla community should attend more to the needs of businesses in general.

Similar to extension providers, the quality delivered by Joomla professionals can affect the reputation of the Joomla platform as a whole. For instance, if a customer is dissatisfied with a Joomla solution, this can backfire on Joomla's reputation. According to one interviewee, Joomla professionals should invest enough time to make Joomla projects unique, distinct, and intuitive, because their work can affect the standing of the entire profession and the image of the Joomla project. Furthermore, web hosts can be seen as stakeholders, too. Many of them make Joomla available together with their hosting packages in order to help customers to create their websites quickly.

\subsubsection{Learners, trainees, and rookies}

Amongst the diverse set of motives for participating in the Joomla community, one is the opportunity to make the world a better place. The strong sense of social responsibility ingrained into the ideals of open source also surfaces in the interview data. In a nutshell, open source ideals are about freedom, sharing, education, open exchange, and non-excludability. Because the code can be studied by anyone, open source facilitates the diffusion of knowledge about cutting-edge web technologies. From this vantage point, open source also contributes to social and economic development worldwide.

The Joomla community not only produces free and open source code, community members also provide much free support, education, and 
training to community peers. Some people in the community go into schools to teach kids how to code using the example of Joomla, or they try to promote Joomla in university curricula. From a community point of view, these initiatives could also be seen as investments to increase the pool of potential users and volunteers who might contribute to the Joomla project in the future.

Joomla also provides opportunities to jobless people who are interested in enhancing their skills. For instance, through people in the community, they can acquire new skills and learn how to pivot into a career as a web developer. Finally, as expressed by interviewees, the community should also become better at communicating the image and value of social responsibility more clearly in order to increase the user base and to appear more attractive to potential volunteers.

\subsubsection{Sponsors, partners, and advertisers}

Joomla collaborates with a range of different partners, as can be seen from its website ${ }^{100}$. These partners are mainly businesses, such as providers of digital content, cloud services, hosting and storage, custom development, collaborative tools, security solutions, and legal counselling. Partners support the Joomla project and its community in various ways. Sponsors and partners may encourage their employees to do community work during working hours, they provide the community with specific services and solutions (e.g., translation services, search engine optimisation), infrastructure (e.g., hosting and server clusters), expert knowledge, and advice.

Partners often sponsor or attend community events, where they also give lectures and hold presentations. The Joomla world conference of 2017 in Rome was sponsored by 19 different vendors ${ }^{101}$ (seven different sponsorship packages were available ranging from 1,500 USD to 15,000 USD). Many of the sponsors had a particular focus on Joomla in their businesses (e.g., commercial extension providers).

Besides community events, the community also offers different sponsorship packages ${ }^{102}$ to interested parties who want to support the Joomla project financially. The available sponsorship packages range from 1,000 USD to 25,000 USD per year. At the time of writing, the Joomla website listed three official global sponsors ${ }^{103}$. Bluehost, one of the world's largest web hosts ${ }^{104}$, was listed as a 'platinum' sponsor, supporting Joomla with 25,000 USD per year. Then, there were two other hosting companies that supported the Joomla project with a 'bronze' sponsorship package, each donating 5,000 USD per year. 


\subsubsection{The wider Internet community}

Both the Joomla CMS and its community are part of a wider ecosystem. The Joomla CMS builds on many other important web technologies, such as PHP, JavaScript, and others. Within this technological landscape, there are continuous changes that people in the Joomla community monitor and, if necessary, react to (e.g., releases of new PHP features). Basically, the Joomla community has to align its activities with the developments around the key technologies that the Joomla CMS builds upon (e.g., runtime environment, front-end libraries, databases). In this sense, the Joomla community is entangled with other technologies and communities. However, most of these technologies can be seen as an environmental condition for Joomla; they can affect the activities around Joomla, but Joomla probably affects them to lesser extents. Although, it could be argued that Joomla also contributes in promoting the use of particular technological infrastructures, such as PHP and supported databases.

The Joomla project is not only affected by technological change; the ways in which websites are used and built also change over time (e.g., responsive designs, mobile first). Therefore, monitoring the trends within the wider Internet community is essential for the people in the community, especially for those who have a commercial business connected to Joomla. According to the interview data, the core teams in the Joomla community always have to find a balance between following recent trends and maintaining support for existing sites. Extensions are one way of mitigating this problem. For instance, extensions can be used to provide specific functionality without having to change the basic Joomla system.

\subsubsection{PHP}

Joomla is written in PHP, which is a "widely-used open source generalpurpose scripting language that is especially suited for web development" ${ }^{\prime 105}$. Many people in the Joomla community monitor the activities in the PHP community in order to be aware of any upcoming changes that could affect the Joomla platform (e.g., upcoming PHP releases, security fixes, new features).

According to the interview data, there are cross-sections of people in the Joomla community who are also active in the PHP community and in the JavaScript community. There can be controversial debates within the community about whether and to what extent Joomla should employ the most recent updates of these key technologies. Some of the latest releases of PHP have brought great performance improvements and new features. The Joomla platform can benefit from these improvements if it adopts and 
supports the new standards quickly. However, another concern is how quickly users upgrade the software that is needed to run Joomla. Many users are running Joomla on outdated PHP versions, which means that they cannot take full advantage of performance improvements. As expressed by an interviewee, sometimes, the community would like to be much further along, but it cannot progress, because the users are stuck with outdated technologies.

\subsubsection{Front-end libraries}

The Joomla CMS depends on libraries that provide all kinds of front-end functionality (user interface functionality), such as JavaScript libraries and Bootstrap. JavaScript is a programming language and a set of libraries for making websites interactive ${ }^{106}$. Joomla previously used the MooTools ${ }^{107}$ library as its standard JavaScript library; however, it switched over to using jQuery ${ }^{108}$ instead, following a general trend in web development. According to one interviewee, Joomla was an important stakeholder to the MooTools project. However, MooTools might have lost a lot of users after Joomla's decision to switch to jQuery. Joomla is also dependent on the Bootstrap ${ }^{109}$ framework, which provides a library of front-end components that are utilised by the Joomla platform.

\subsubsection{Databases}

Users' most popular choice of database for Joomla is MySQL ${ }^{110}$. But Joomla also provides support for other databases, such as PostgreSQL ${ }^{111}$ or Microsoft SQL Server. As a popular CMS platform, Joomla supports the most popular database solutions. An actor that has entered the stage more recently is the MariaDB ${ }^{112}$ project. The MariaDB project is a fork of the MySQL project; it was initiated by some of the original MySQL developers after the MySQL project was acquired by Oracle in 2010 (as reported by an interviewee, the founding story of the MariaDB project seems similar to Joomla's founding story). Joomla users also started to use MariaDB for their Joomla installations.

According to the interview data, within the Joomla community there was growing concern about MySQL after it was acquired by Oracle. MySQL is currently available as both a free community version and as a paid enterprise edition. The concern with MySQL is whether it is going to stay free and open, and whether the Joomla project should continue to place its faith in it. People in the community are carefully monitoring the developments around MySQL carefully, also because MySQL seems to be less integrated into the open source idea of thinking, unlike other software that Joomla relies on, such as from Apache, PHP and others. 


\subsubsection{Web servers}

Another environmental condition for the Joomla CMS concerns web servers. The primary functions of web servers are to ensure the communication and content delivery between clients and servers. Currently, the Joomla CMS officially supports three popular web servers: the Apache web server ${ }^{113}$; Nginx, which is a "free, open source, high-performance HTTP server"114; and a web server owned by Microsoft, called Internet Information Services. People in the community also monitor trends in the realm of web servers.

\subsubsection{Open source CMS community}

Joomla is also part of the wider open source CMS community (e.g., including Drupal, WordPress, Contao, and many others). There is some interaction going on between the communities in this realm. For instance, people can give presentations at community events of a "rival" CMS platform. Some people in the Joomla community also contribute or have contributed to WordPress or Drupal. However, according to the interview data, the interaction is not very intense. It seems that people tend to be protective of their platforms and communities.

People in the Joomla community monitor what their competitors are doing. The comparison with competing CMS platforms often triggers discussions about the features that should be included in the Joomla CMS. People in the Joomla community try to analyse what competitors are doing better and what can be learned from them. For instance, a shared opinion in the interview data is that Joomla has to improve in terms of user experience. Because the WordPress community is one of the largest communities in the world, it is not only seen as a competitor, but also as a great source of inspiration to people in the Joomla community.

More generally, within the CMS segment, a lot of new platforms have emerged in recent years. For instance, handy modelling kits, such as WIX or Squarespace, provide users with WYSIWYG editors for designing simple websites. This trend has also affected the positioning of Joomla. Joomla is claimed by interviewees to have moved more towards serving websites with elaborate needs and functionality.

Many businesses in the Joomla community also work with WordPress. This is because a lot of the Joomla market share has gone over from Joomla to WordPress during the past few years. This is the reason why many Joomla extension providers also offer their extensions for the WordPress platform because the user base, and consequently the potential customer base, is much bigger there. 


\subsubsection{Google and other trend setters}

Google often sets trends when it comes to web technologies. It also operates the world's most popular search engine. A hot topic within the Joomla community is search engine optimisation. In order to achieve higher rankings in search engine results, one goal of the Joomla project is to optimise the content structure, metadata descriptions, and keywords in ways that enable users' content to be optimally indexed by search engines. Especially for businesses and marketers, search engine optimisation is an important topic. There are also special extensions that offer the optimisation of Joomla websites for increased visibility on search engines.

For a couple of years now, Joomla has also been part of the Google summer of code (GSoC), which is a Google-sponsored program that gives students and young developers the chance to delve into challenges in open source development ${ }^{115}$, such as Joomla development.

There are also other important stakeholders that are part of the wider Internet environment that can affect the activities around the Joomla community; Facebook and Twitter can be mentioned as examples. According to one view that emerged in the interview data, people tend more and more to post their content on social network platforms rather than on private websites or blogs, which might negatively affect the penetration rates of Joomla (and that of other CMS platforms). However, some people in the community believe that Joomla is less affected by this trend because it has moved towards users and clients with more elaborate needs anyway. The social media hype may have also brought opportunities for people who work with Joomla; for instance, for extension providers who offer extensions for social integration (i.e., synchronisation of data across websites and social media sites).

Finally, there are many other platforms that are relevant to the developers working with Joomla. Websites are often designed to interact with diverse platforms in order to deliver rich content, including platforms such as MailChimp, Pinterest, Linkedln, Flickr, Spotify, and many more. Particularly for extension providers, these platforms provide opportunities to supply integrative solutions and services tailored to Joomla.

\subsubsection{Policy makers and standard setters}

Policy makers and standard setters can also affect the Joomla community and the activities around it, too. Standard setters are organisations that develop and maintain technical standards for industry adoption. For instance, the World Wide Web Consortium (W3C) ${ }^{116}$ is an important international standards organisation for the WWW. Amongst other 
standards, the W3C accounted for the introduction of the HTML5 $5^{117}$ standard. This standard provides improved support for multimedia content and has introduced various new syntactic features that affect web development in general. Also, the standards for cascading style sheets (CSS) are revised and updated, not every year, but from time to time.

Furthermore, policy makers and regulatory instances, such as the EU legislation, can affect web development in general. As an example, cookie policies are mentioned. The EU legislation on cookies "requires websites to get consent from visitors to store or retrieve any information on a computer, smartphone or tablet" ${ }^{\prime 118}$. Furthermore, the recently introduced EU General Data Protection Regulation might affect the people and businesses in the Joomla ecosystem in various ways. At the time of writing, this was a hot topic in the community. Generally, being active in the community and attending community events enables people to stay on top of the regulatory changes that affect their businesses and to learn how to deal with them.

\subsection{Discussion}

Stakeholder relationships can be seen as the fundamental drivers of value (R. E. Freeman et al., 2010). From this perspective, the Joomla case shows how different parts of a jigsaw puzzle interlock to form a particular value constellation (Normann \& Ramirez, 1993). While perceptions of stakeholder salience may depend upon individual perspectives (Parent \& Deephouse, 2007), a bird's-eye view can be the starting point for a more focused analysis. Figure 18 unboxes the stakeholders in the Joomla case. The arrowheads in this figure indicate the directionality of influence. Some relationships tend to be more unidirectional (or non-reciprocal), others are more bidirectional (or reciprocal). 


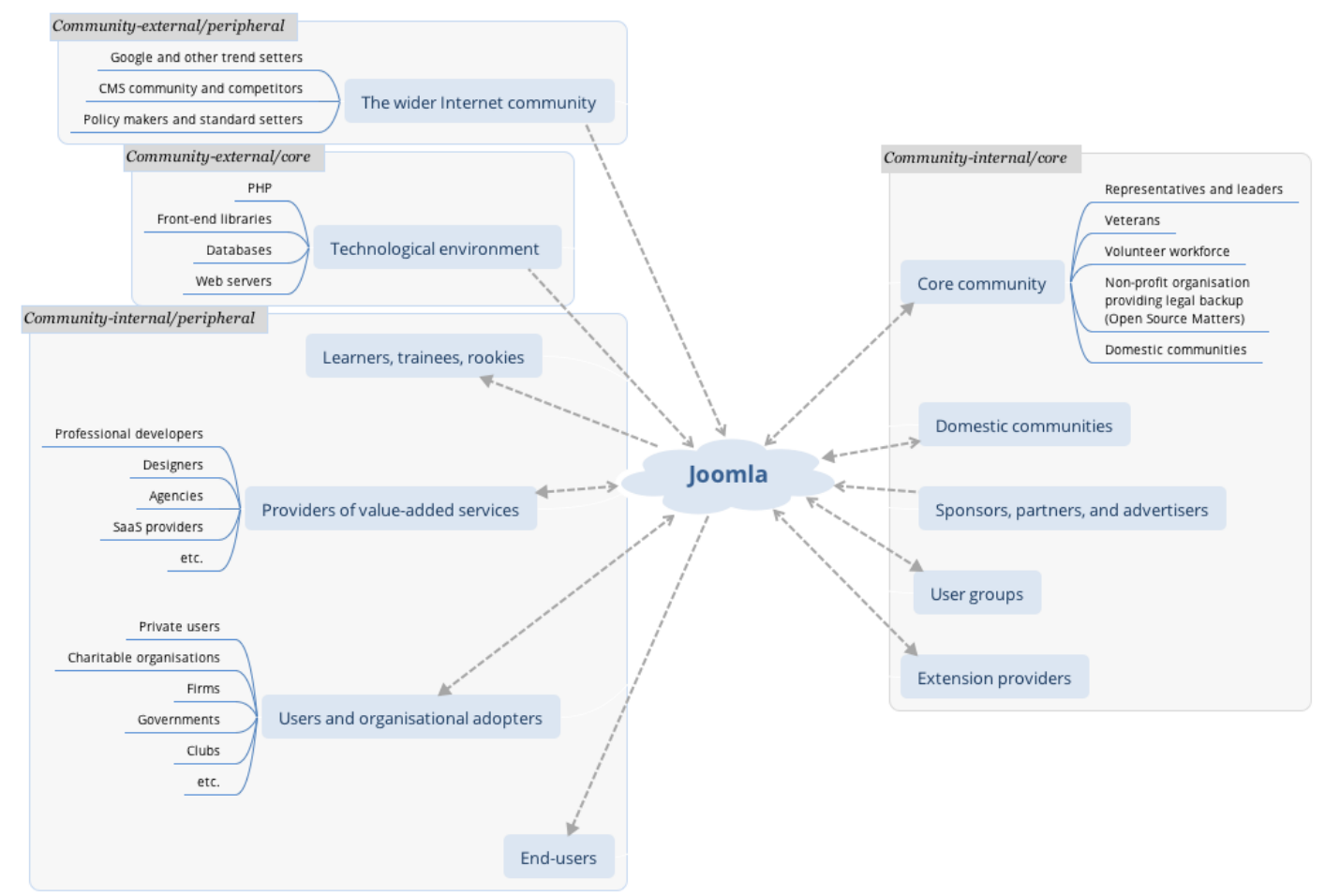

Figure 18: Overview of stakeholders in the case of the Joomla community.

In order to transform a cluttered map of stakeholders into more understandable chunks of information for stakeholder analysis, Study I proposes a two-dimensional categorisation of stakeholder relationships. Inspired by a widely accepted model for the general structure of open source communities (Crowston \& Howison, 2006; Crowston \& Shamshurin, 2017; Nakakoji et al., 2002), the first dimension concerns the immediacy of influence, which runs the gamut from core to periphery. From a stakeholder perspective, the idea is that influence exerted at the community's core can have more immediate effects. For instance, decisions and actions taken by core members (e.g., leaders, production teams) can have immediate consequences for the actors at the community's periphery (e.g., users, end users, businesses, private and organisational adopters). Conversely, the influence of actors at the periphery is less immediate but can be resounding nevertheless if the level of arousal, concerning issues that appear to be legitimate or urgent (e.g., compatibility, or security breaches), exceeds a certain threshold. For instance, as previously mentioned, Joomla faced severe criticism from its users when rolling out upgrades that broke existing Joomla installations. Apparently, the repercussions of this incident were 
quite strong, with the consequence that the leadership decided to explicitly commit themselves to compatibility for future releases.

The other' dimension concerns the scope of the influence; this is inspired by R.E. Freeman's (2010) distinction between internal and external stakeholder groups. Internal stakeholders in this sense refer to organisational members, organisational units, responsibilities and powers that dominantly shape organisational life. By external stakeholders, R.E. Freeman (2010) is referring to groups and organisations that more clearly reside outside the organisation's boundaries (e.g., competitors and governments). The boundaries between internal and external stakeholders in the Joomla ecosystem might also be blurred; however, making this distinction can still be useful. The sphere of influence runs the gamut from community-internal to community-external. Issues that arise within the internal sphere of influence are more accessible and manageable. In contrast, communityexternal stakeholders are more like an environmental condition for Joomla; they are scarcely affected by decisions or activities in the Joomla community. For instance, Joomla release cycles do not affect PHP release cycles; however, PHP release cycles do affect Joomla. Although there are people who are active in both communities, the possible range of stakeholders around the PHP project is vast (i.e., the majority of all websites build on PHP). This is why Joomla might have limited means to influence the release cycles of the PHP project. On the other hand, popular CMS systems, such as Joomla, WordPress, and Drupal might be important stakeholders for PHP too since they contribute to the diffusion of PHP technology. The fact that PHP discloses benchmark tests and performance improvements for new PHP releases by the example of popular CMSs ${ }^{119}$ supports this argument. Figure 19 shows how the stakeholders in the Joomla case can be categorised by use of the discussed dimensions: the immediacy of influence (core and periphery) and the scope of their influence (community-internal and community-external). 


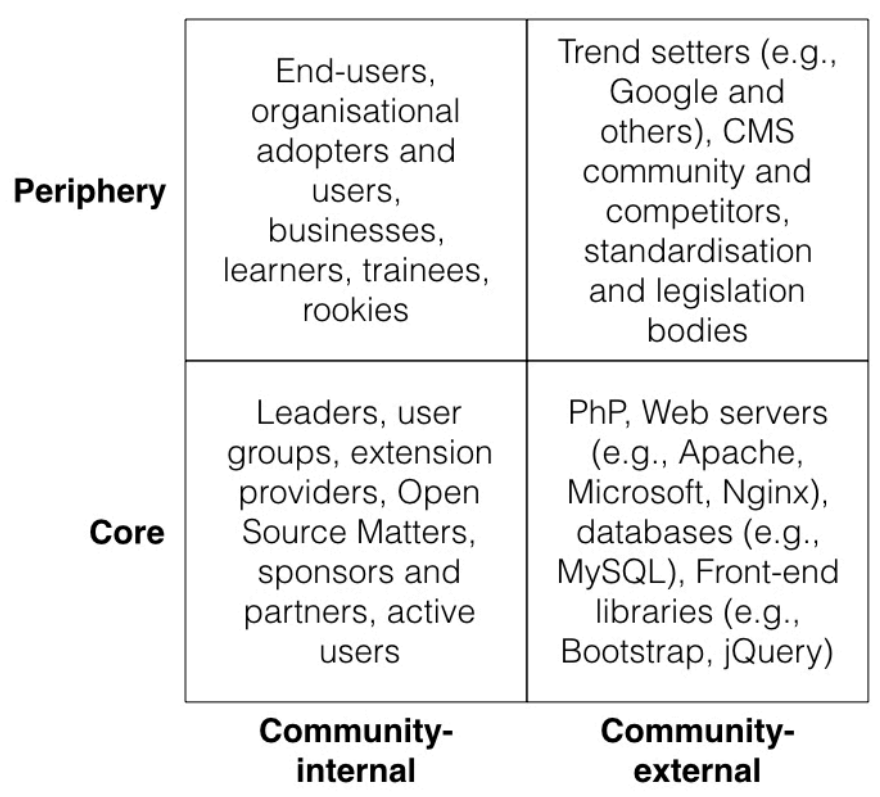

Figure 19: A two-dimensional model for stakeholder classification in a community setting.

The following example illustrates the interconnectedness of stakeholders. It comes back to the connection between the quality of professional services delivered by Joomla businesses and the image and reputation of the Joomla platform. References are made to the corresponding relationships in Figure 20. As mentioned before, the image and reputation of the Joomla platform can be affected by the work of Joomla professionals. When a Joomla business delivers badly designed web projects to one of its clients (1), it is likely to negatively affect the satisfaction of the client and its end users (2). However, according to the interview data, this situation can also negatively affect the client's perception of the Joomla project as a whole (3). As a consequence, clients may prompt the supplier to switch to a different platform (e.g., WordPress), or the client might abandon the contractual relationship with the supplier entirely (1). Conceivably, all this could also have negative consequences for extension providers (4) since they rely on a broad user base to be able to sell their offerings to a large enough number of customers. The community's decision to introduce a certification program to ensure the competence of the Joomla workforce could be seen as a measure to counter the potentially negative effects described in this example (5). 


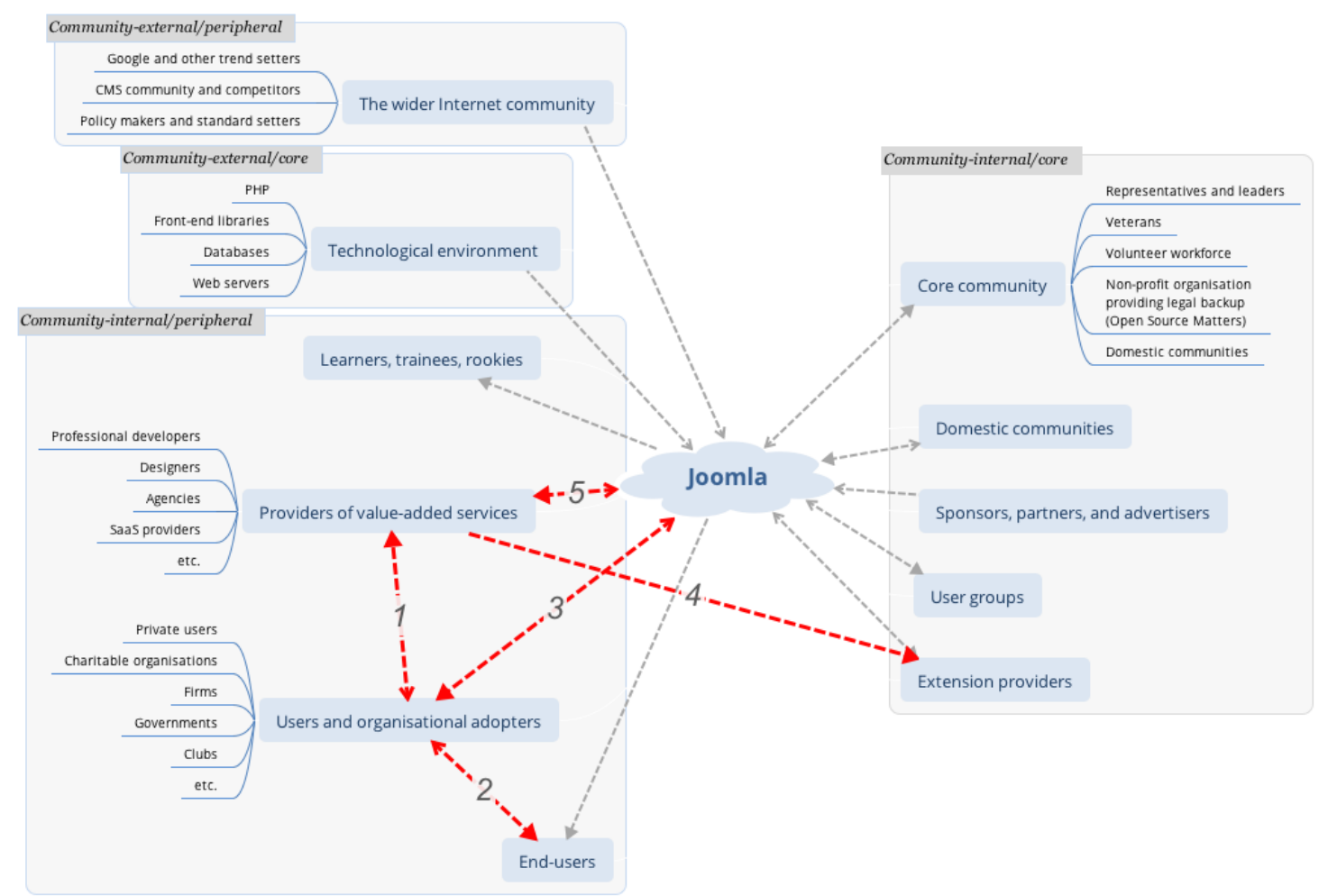

Figure 20: Interconnectedness of stakeholders in the example of image and reputation of the Joomla platform.

Finally, the discussion comes back to Dunham, R.E. Freeman, and Liedtka (2006), who advocated for the metaphors of communities of place (physical proximity), communities of interest (centred around a common purpose), community as virtual advocacy group (oppositional and issue centred), and communities of practice (work groups sharing interests, values, and purpose) for identifying legitimate stakeholders. The Joomla case prompts the question of how meaningful these four sub-categories are in the context of an open source community. Joomla seems to fit all these categories almost equally well; it is a community of place (e.g., the user groups, community events), a community of interest (e.g., the joint interest of sharing ideas and code for the common good, businesses having a vested interest in the continuation of Joomla), and a community of practice (e.g., Joomla as a distributed production environment) at the same time. It may even qualify as a virtual advocacy group (e.g., people advocating for and defending the open source ideals, protecting Joomla from corporate ownership). Study I shows that community as a concept in stakeholder theory does not have to be a residual category where insufficiently differentiated interest groups are lumped together, as Dunham et al. (2006) bewailed. However, their 
classification of communities of place, communities of interest, community as virtual advocacy group, and communities of practice may not offer suitable guidance for stakeholder identification in the context of open source communities. Rather, the empirical investigation suggests that it might be more appropriate to view the Joomla community as a community of communities (J. S. Brown \& Duguid, 1991; Boland Jr \& Tenkasi, 1995), within which aspects of place, interest, practice, and advocacy might emphasise different community facets. However, looking at the Joomla case, it does not seem reasonable to claim that these categories would be indicative of a particular community.

By contrast, Study I proposes a simple two-dimensional model for identifying and categorising stakeholders in a community setting based on a widely-accepted model for the general structure of open source communities (Crowston \& Shamshurin, 2017; Nakakoji et al., 2002), and by considering the scope of stakeholder influence (R. E. Freeman, 2010; Mishra \& Mishra, 2013). The generality of this model also makes it applicable in other community contexts (e.g., communities that may differ in terms of governance structures and target audiences). The proposed classification provides a broad compass for identifying stakeholders in and around open source communities and may therefore facilitate a more holistic understanding concerning who open source communities are and what they do.

However, the pragmatic stance adopted in this research highlights the importance of applying multiple perspectives when identifying stakeholders. Some stakeholders may be more salient when applying the concepts of power, legitimacy, and urgency (Mitchell et al., 1997). Other stakeholders may come to the fore when applying different concepts, such as social responsibility (Crane \& Ruebottom, 2011) and social status (Perrault, 2017).

For instance, learners, trainees, and rookies may not necessarily feature as an important stakeholder group when considering power, urgency, or legitimacy as a lens for identification. However, when applying social responsibility as a lens (Crane \& Ruebottom, 2011), these groups become more visible, given community members' passion for helping others in the community, and given the values that are emphasised by the open source ideals (e.g., freedom, sharing, education, open exchange, and nonexcludability). As mentioned previously, learners, trainees, and rookies also constitute an important pool for recruiting talents and volunteers who might contribute to the community in the future. Therefore, failing to identify this stakeholder group might limit the community's ability to cater to the needs of these constituencies, and to grow as a community. 
Furthermore, applying the lens of social status (Perrault, 2017) makes veterans, who possess a sort of interpretational sovereignty over issues that affect the community, more central. When considering R.E. Freeman's (2010) stakeholder definition of groups or individuals who can affect or are affected by the organisation's objectives, the focus shifts again. R.E. Freeman's (2010) definition makes peripheral actors, such as users and organisational adopters (who are obviously affected by the community's ability to produce and maintain quality software products) more important. But also, actors that are external to the community, such as communities that account for the technological environment without which Joomla could not function, become more visible when applying R.E. Freeman's (2010) definition.

Finally, for practitioners, stakeholder analysis in and around open source communities can be a valuable information base for assessing the costs, risks, and benefits of investing in the development of OSS. This research encourages practitioners to adopt a pragmatic stance when identifying stakeholders in and around open source communities by combining multiple lenses. Having followed such an approach, the insights provided in Study I may also be of use for actors engaged in stakeholder work (Mitchell et al., 2017), such as community managers, or firms that seek to interact with communities.

\subsection{Preliminary conclusions}

Study I has presented an analysis of stakeholders in the context of an open source community. By identifying stakeholders in and around a worldwide community of volunteers, it shows that stakeholders in the context of open source can be usefully categorised along two dimensions. The first dimension concerns the immediacy of influence, ranging from core to periphery. The second dimension concerns the scope of influence, which runs the gamut from community-internal to community-external. The proposed classification provides a broad compass for those who seek to identify, classify, and analyse legitimate stakeholders in the context of open source. This approach may facilitate a more holistic understanding concerning the heterogeneity of stakeholder interests in the context of open source communities. However, this research encourages practitioners to adopt a pragmatic stance when identifying stakeholders by combining multiples lenses. Finally, Study I questions the usefulness of the concepts of communities of place, communities of interest, community as virtual advocacy group, and communities of practice as suitable means for 
Chapter 6: Stakeholders (Study I)

identifying legitimate stakeholders in the context of open source communities. 



\section{An integrative framework for open source governance (Study} II)

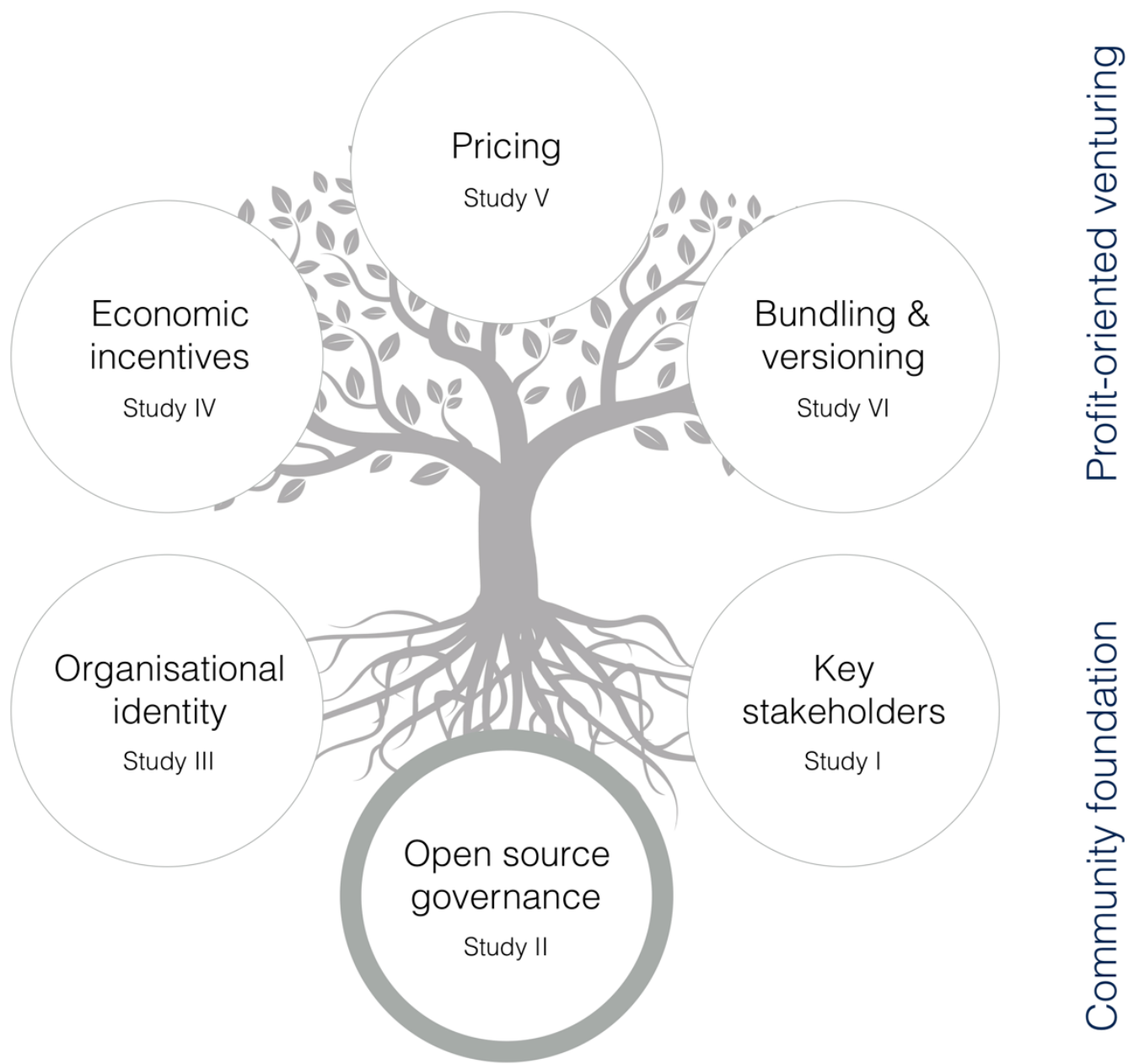




\subsection{Short summary}

The study of open source governance has emerged in response to the increased importance of OSS as an infrastructural resource and the significance of open source development methodologies in today's business practices. Academic research has proposed different frameworks and key dimensions that are deemed central to the study of open source governance. However, scholars have also criticised that open source governance dimensions have predominantly been studied in isolation. As has been argued in the literature, the study of governance effects is likely more meaningful when the key dimensions are considered collectively.

Research has considered governance configurations as a way forward in the analysis of open source governance. However, because the intellectual output on this topic has expanded rapidly, theorisation on the key dimensions and governance configurations may appear to be fragmented in the literature. Following on from this, the purpose of Study II is to review and integrate previously identified key dimensions of open source governance into a meaningful whole in order to further the study of open source governance configurations. Based on a review of the relevant literature on key dimensions in open source governance, a tentative, integrative framework for the study of open source governance (and corresponding governance configurations) is proposed. The proposed framework is applied to the Joomla case. 


\subsection{Introduction}

Governance in the context of open source communities has received increased scholarly attention in recent years. There are different reasons for that. Open source communities have flourished and attracted millions of advocates and users all around the globe. OSS has become a viable choice for a wide range of actors across industry sectors who rely on its use for offering their services (Perens, 2005). And, a growing number of large-scale, reliable and adaptive open source projects are challenging their proprietary alternatives (Jensen et al., 2010). Because open source governance can affect a wide range of stakeholders who place faith in OSS technologies, it has become more important to critically assess the qualities of governance in open source settings (Martínez-Torres \& Diaz-Fernandez, 2014; Perens, 2005).

Markus (2007, p. 152) defines open source governance as "the means of achieving the direction, control, and coordination of wholly or partially autonomous individuals and organisations on behalf of an open source development project to which they jointly contribute". Previous research has revealed that open source projects and their governance structures can look quite diverse (Lerner \& Tirole, 2002). In order to further the study of open source governance, previous research has called for greater attention to the varieties of community forms, the corresponding governance configurations, and the kind of institutional pillars that lend support to their functioning (Di Tullio \& Staples, 2013; Franck \& Jungwirth, 2003; Markus, 2007; O'Mahony, 2007). In particular, the search for governance configurations is regarded as a way forward in the analysis of open source governance (De Laat, 2007; Di Tullio \& Staples, 2013; Markus, 2007).

Connected to this agenda, research has studied governance in a variety of open source settings and proposed a range of key dimensions critical to the study of open source governance (De Noni, Ganzaroli, \& Orsi, 2011, 2013; Di Tullio \& Staples, 2013; Jensen et al., 2010; Lattemann \& Stieglitz, 2005; Midha \& Bhattacherjee, 2012; O'Mahony \& Ferraro, 2007; Schaarschmidt, Walsh, \& von Kortzfleisch, 2015; Shah, 2006; von Krogh et al., 2012). However, because the intellectual output on this topic has expanded rapidly, theorisation on key dimensions of open source governance appears to be fragmented in the literature. While Di Tullio and Staples (2013) review some of the most frequently studied open source governance dimensions, their study focuses on the effectiveness of combinations of governance mechanisms, rather than on integrating previous findings. However, governance effects are likely to be more meaningful when key dimensions are considered collectively (Di Tullio \& 
Staples, 2013). It may therefore be useful to further the integration of previous findings in this particular realm.

Study II sets out to review and integrate important key dimensions of open source governance into a unified and meaningful whole. Possibly, such a venture may hold the promise of advancing a generic framework for comparative analysis of open source governance configurations and the detection of ideal types.

The remainder of this sub-study is organised as follows. First, the theoretical background on open source governance is provided. This is followed by the methodology section which briefly describes the overall research approach in this sub-study. Subsequently, the relevant key dimensions of open source governance that could be identified in the literature are discussed. A tentative, integrative framework for open source community governance is presented and applied to the Joomla case.

\subsection{Theoretical background on open source governance}

Open source projects could be seen as a form of community-based innovation; they provide a social, organisational, and institutional environment for people to participate productively (Shah, 2006). These production communities, as they are equally labelled, are often characterised by principles of democratic participation, an absence of authoritative divisions of labour, volunteerism, and a lack of formal contracts (Crowston et al., 2012; O'Mahony \& Ferraro, 2007). Further characteristic traits are the global, multicultural, distributed and asynchronous nature of work and coordination practices (Sharma, Sugumaran, \& Rajagopalan, 2002).

Research on open source governance has most notably dealt with the emergence and persistence of authority, licensing issues, the distribution of roles and responsibilities, organisational structures (e.g., non-profit versus for-profit), decision-rights, code control, norms, representation within the community, incentive mechanisms and motivations of community participants, rules, monitoring and sanctions, communication processes, membership management, life-cycle stages, and more technical processes in open source development, such as requirement engineering, code inspection, or release coordination (Lattemann \& Stieglitz, 2005; Shah, 2006; O'Mahony \& Ferraro, 2007; Markus, 2007; von Krogh et al., 2012; Di Tullio \& Staples, 2013; Crowston et al., 2012).

Open source communities are often described as meritocratic systems. From a governance perspective, merit can be rewarded with greater status and responsibility, thereby reinforcing members' willingness to invest time 
and effort. However, research has also revealed that the interpretation of merit is context specific and can change over time ( $\mathrm{O}^{\prime}$ Mahony \& Ferraro, 2007). The widely held belief that technical contributions are valued the most has also been questioned. For instance, O'Mahony and Ferraro (2007) show that conceptions of leadership can change from technical merit, at the inception of an open source project, towards social skills and organisational competence as the project matures. They call this an "evolving and contextdependent notion of meritocracy" (O'Mahony \& Ferraro, 2007, p. 1083).

According to De Laat (2007), hierarchies in open source communities work in different ways from hierarchies in traditional organisations. He refers to them as hierarchies of esteem that grant participants certain privileges, such as influence, access to files and systems, decision rights, and ownership over inspection processes for code inclusion.

Sagers (2004) argues that open source communities are governed by sets of informal social systems with a lack of bureaucratic structure and formal contractual relationships. Due to a lack of command and control structures, open source communities can sometimes suffer from chaos and political infighting, which can have a negative impact on their projects' success (Sharma et al., 2002). While the need to manage conflict has been identified as a major issue in open source communities (Crowston et al., 2012; de Joode \& Egyedi, 2005), researchers have also been surprised about the extent to which open source projects manage to ensure order and discipline (Markus, Manville, \& Agres, 2000). Markus, Manville, and Agres (2000) think that successful open source projects rely on the interplay of different governance mechanisms that build on a shared culture.

Markus' (2007) work has been particularly influential in this literature stream. She argues that research on open source governance has been circling mainly around four types of issues. First, the relative importance of open source governance structures in relation to open source governance processes. Second, the extent to which open source governance is informal (e.g., norms and social control), formal (e.g., stipulated through policies and bylaws), or whether governance is what she calls 'encoded' in technology such as through online means of communication and administration (e.g., version control). With her third point, she is referring to the extent to which the sources of control are external to individuals or internal (i.e. incentive structures). And the fourth type of issues she identifies relates to the relative importance of trust in relation to monitoring and control in governance.

Furthermore, Markus (2007) has revealed three main purposes of open source governance. The first relates to governance as a solution to collective action dilemmas. As vivid examples, Markus (2007) mentions the tragedy of the commons and the problem of free riding. 
According to Markus (2007), the second main purpose of open source governance focuses on the effects of coordination problems on participation patterns. This view highlights problems created by a lack of hierarchical power and the struggle to generate productive collective outcomes (De Noni et al., 2011). However, in order to make up for the lack of operational control in distributed work and decision environments, communities can be creative in inventing suitable management techniques (Markus, 2007).

The third main purpose of open source governance discussed by Markus (2007) refers to the organisational climate and how institutional pillars invite participation. This view highlights the strategic importance of attracting skilled volunteers and the social atmosphere that a community's culture breeds (De Noni et al., 2011; Sharma et al., 2002). The organisational climate seems also important because volunteers' switching costs of moving to a different community, in case their experience is unsatisfactory, are probably low (De Noni et al., 2011).

Furthermore, a literature review by Crowston et al. (2012) reveals four different types of coordination mechanisms for open source governance: 'mechanisms to control the number of developers', 'modularity and division of labour', 'task assignment mechanisms', and 'instructive materials and standardisation initiatives'. The first of these refers to the restriction of access to development teams. Restricted access to development teams can be a means to improve the quality of coordination (Crowston et al., 2012; Sagers, 2004). With 'modularity and division of labour', Crowston et al. (2012) emphasise the fact that modular software architectures allow for massive parallelism in software development, which reduces coordination costs. With 'task assignment mechanisms', Crowston et al. (2012) are referring to self-assignment as the predominant mode of task-assignment in open source communities. Their fourth coordination mechanism, 'instructive materials and standardisation initiatives', refers to the use of development guides and policies that enable independent work.

The underlying idea in research on open source governance dimensions is that governance is a multi-dimensional phenomenon rather than a monolithic one; however, this raises the questions of what these dimensions are, in which ways they interrelate, whether they can be reduced to a small number of configurations, and how they are linked to community performance (De Noni et al., 2011; Markus, 2007). The following presents a cross-section through the diversity of governance frameworks in the literature.

According to De Noni, Ganzaroli, and Orsi (2011), open source governance can be reduced to two latent factors: "leadership and decisionmaking distribution, and reciprocity of the appropriation regime" (De Noni 
et al., 2011, p. 2). Building on these factors, De Noni, Ganzaroli, and Orsi (2013) proposed four governance configurations: 'open source based', 'sponsored', 'tolerant dictatorship', and 'collective'. With 'open source based', they are referring to communities that favour pragmatic types of licences, democratic leadership, and open membership. With 'sponsorbased', they are referring to communities that are driven by firms. In their view, these communities are characterised by pragmatic licensing, centralised and autocratic leadership, and gated membership. With tolerant 'dictator-based', they are referring to communities that are characterised by radical types of licences, centralised and individual-based leadership, and a lack of formal memberships. And finally, with 'collective', they are referring to communities that are characterised by radical types of licences, collective leadership, meritocratic rule, and informal membership.

Markus (2007) also proposed a framework for the study of open source governance; this framework comprises the categories 'ownership of assets', the 'chartering of the project', 'community management', 'software development processes', 'conflict resolution and rule changing', and the 'use of information and tools'. By 'ownership of assets', she means "intellectual property licences and formal legal organisational structures (e.g., foundations)" (Markus, 2007, p. 158). By 'chartering of the project', she is referring to "statements of vision about the goals of the project" (Markus, 2007, p. 158). By 'community management', she means "rules about who can be members, how their identity will be verified, what roles they can play, [and] how they can change roles" (Markus, 2007, p. 158). By 'software development processes', she is referring to "structures and rules that address the important operational tasks of development, such as requirements elicitation, assignment of people to tasks, processes for managing software changes, [and] release control" (Markus, 2007, p. 158). By 'conflict resolution and rule changing', she is referring to "rules and procedures for resolving conflict and for creating new rules" (Markus, 2007, p. 158). Finally, the 'use of information and tools' refers to "rules about how information will be communicated and managed and how tools and repositories will be used" (Markus, 2007, p. 158).

De Laat (2007) takes on a life-cycle perspective and studies three different types of governance: 'spontaneous governance', 'internal governance', and 'governance towards outside parties'. 'Spontaneous governance' refers to communities that exhibit low degrees of formal institutionalisation. In his view, this type of governance is particularly relevant for younger and emerging open source projects.

With 'internal governance', he covers larger projects and projects that have existed for a longer time. In his view, these kinds of projects have 
developed a variety of explicit and formal coordination and control mechanisms enabling them to achieve optimal outcomes. In relation to 'internal governance', De Laat (2007) discusses a variety of tools that enable coordination and control, such as "modularisation, division of roles, delegation of decision-making, training and indoctrination, formalisation, and autocracy/democracy" (De Laat, 2007, p. 167).

De Laat's (2007) third governance type is termed 'governance towards outside parties'. This type describes increased institutionalisation as open source projects move towards greater levels of maturity. In this case, firms, corporations, governments, and non-governmental organisations increasingly begin to adopt OSS solutions, which makes them dependent upon the future course of the corresponding open source project. According to De Laat (2007), open source communities try to respond to such situations by creating legal shells around the project, such as foundations that manage copyright issues, trademarks, and brand names. Or, they nominate spokespersons who manage the relationships with important external stakeholders. Adopting organisations then also increasingly tend to donate money, hardware, and other resources to secure the maintenance and future of the open source project. Obviously, this has consequences for open source governance; sometimes, open source communities reserve board memberships for external supporters. As an example, De Laat (2007) mentions the Linux Foundation, which attracts external partners (e.g., firms or universities) with memberships that grant them a voice in community management, although at high entry fees. De Laat (2007) concludes that, "larger OSS projects are in danger of ending up being governed like a mirror image of hierarchical firms" (De Laat, 2007, p. 173), with little or no democratic participation.

There are others who have also proposed open source governance frameworks (Sharma et al., 2002), but it is believed that those discussed above broadly cover the current state of the art in this area.

\subsection{Research approach}

Based on a stock of relevant articles in the literature, a tentative, integrative framework for open source governance was developed. Following recommendations by Dunne (2011), a literature review was conducted to capture and take stock of a variety of key dimensions in open source governance. The stages of the literature review align with procedures proposed by Cooper (1998), who sees a literature review as consisting of a problem formulation, the data collection, data evaluation, analysis, and the presentation of results. The purpose of the literature review was to arrive at 
a fairly good understanding of the key dimensions in open source governance (rather than to compile a complete picture of the breadth and scope of discussions on open source governance).

Relevant literature was searched for using Google Scholar and Web of Science. The following keyword combinations were used in the searches: 'open source' plus 'governance', and 'open source' plus 'control'. In combination with backward searching (screening the reference list of an article) and forward searching (looking at articles that cited a particular article), a final selection of 33 relevant articles was compiled. These articles were read fully and analysed for key dimensions by looking for important dimensions of open source governance (e.g., licensing and decisionmaking). Special attention was paid to the different typologies and frameworks that have been proposed in the literature. Frameworks and typologies were of special interest insofar as they provided insights on the conceptual differentiation in open source governance (Fiss, Cambré, \& Marx, 2013). Configuration theory suggests that governance dimensions should combine practically into relative small numbers of groups (Di Tullio \& Staples, 2013). The information gathered through the review of the literature informed the formation of logical groupings of governance dimensions into more or less coherent sets and subsets.

The resulting tentative, integrative framework for open source governance was then applied to the Joomla case. The application of the framework was also informed by the empirical data that had been gathered throughout the course of this thesis (see Section 5.5). In particular, the second set of interviews revolved around the focal governance dimensions in this sub-study, such as decision-making and conflict resolution (see Appendix A2).

\subsection{Key dimensions in open source community governance}

Based on the review of the literature, eight basic governance dimensions were discerned. These are: the collaborative type, patronage and sponsorship, membership, licensing, rules and policies, decision-making and conflict resolution, sanctioning, and life-cycle stages. For each of these dimensions, descriptive attributes are discussed. Figure 21 provides a visual overview of the tentative, integrative framework for open source governance.

\subsubsection{Collaborative type}

Nakakoji et al. (2002) propose to classify open source projects into 'exploration-oriented', 'utility-oriented', and 'service-oriented' types. To 
include the general purpose of the OSS in an open source governance framework makes sense because there is reason to believe that governance configurations can vary across these three types. The purpose of an open source project also gives clues about the target audience, their demands, claims, and requirements.

With the 'exploration-oriented', Nakakoji et al. (2002) are referring to open source projects that aim to push the frontiers of software development (e.g., scientific endeavours). These communities are highly innovative, creative, and experts in a certain field (e.g., computer graphics). They see the software as a learning resource and a way to study code structures and system architectures. Nakakoji et al. (2002) suggest that, project leaders maintain tight control over the projects in order to meet the original design goal. They further conjecture that these kinds of projects are more likely to be forked because the project leader's vision may easily come into conflict with the majority of community members.

By 'utility-oriented' OSS, Nakakoji et al. (2002) are referring to open source projects that target any kind of void in functionality. As an example, they mention device drivers. The primary use here is not scientific exploration but development that serves any kind of practical need. Nakakoji et al. (2002) think that this type is a prime example of the bazaar style of developing OSS. There is no centralised control, many users download a solution, modify it according to their needs, and then republish it, which leads to a proliferation of different, often incompatible, variants of the code. As they further explain, many of these projects may exist within larger open source communities, but created by peripheral developers, such as is the case with device drivers for Linux.

By 'service-oriented' OSS, Nakakoji et al. (2002) are referring to projects that aim to provide a stable and robust solution to a wider collection of stakeholders. One prime example in this category is the Apache web server, one of the most popular web servers. Another example that they mention is the PostgreSQL project. According to Nakakoji et al. (2002), with serviceoriented OSS, the population of stakeholders is much larger than the actual population of open source community members. Leaders or leading groups within this type may be very careful when introducing changes to the software because possible errors may cause a wide range of complications for numerous stakeholders and end-users. According to the authors, these kinds of projects are led more conservatively. 


\subsubsection{Patronage and sponsorship}

The distinction between community-managed and firm-sponsored forms of open source projects is common in the literature (Capra \& Wasserman, 2008; Di Tullio \& Staples, 2013; Riehle, 2012; West \& O'Mahony, 2008). This distinction is important because it gives clues about some fundamental aspects regarding the distribution of the decision-power in a community. In total, four types of patronage and sponsorship could be discerned: 'individual/group', 'community', 'single-vendor', and 'multi-vendor'.

Besides communities and firms, open source projects can be hosted, maintained, and controlled by single individuals and small groups of people. Furthermore, open source projects can be community-managed and be more or less independent from corporate control (Di Tullio \& Staples, 2013). With this type, the governing bodies of an open source project are typically operated by volunteers who do not get monetary compensation for doing community work (Riehle, 2012).

Open source projects can also be firm-sponsored. There are basically two types of firm-sponsorships: single-vendor and multi-vendor sponsorship (Riehle, 2012; Skerrett, 2011). The type of single-vendor sponsorship refers to open source projects that are governed and controlled by a single corporate sponsor that is the main economic beneficiary of the respective open source project (Riehle, 2012). Finally, multi-vendor sponsorship, refers to open source projects that are jointly steered and sponsored by multiple firms (Skerrett, 2011).

\subsubsection{Membership}

West and O'Mahony (2008) observed that open source communities rely on both formal and informal social structures to manage membership. Because it is generally difficult to define boundaries around open source communities it can be difficult to define membership (Sharma et al., 2002). However, membership can be strongly linked to participants' conception of their personal and professional identities (Markus et al., 2000). While membership is often conceived of in terms of core and peripheral membership (Nakakoji et al., 2002), some open source projects also offer formal and paid memberships. All in all, four approaches to membership could be discerned: 'open', 'vetted', 'voted/elected', and 'paid'.

Often, membership is open to anyone who wants to take over tasks and engage in community activities (e.g., software development, support, organisation of events). However, the group of core members that are curating open source projects is typically small (Crowston et al., 2012). Communities, and in particular core members, often design and maintain 
mechanisms (e.g., rules and institutions) to restrict access for unqualified workforce (Markus et al., 2000). Sagers (2004, p. 427) argues that "restricted access to the development team improves coordination within the project and safeguards exchanges among project members". Especially, when a project moves towards higher level of maturity, and when a division of roles gradually emerges, the formulation of entry requirements is often a necessity (De Laat, 2007).

Vetting and restricted access to core groups can be considered a governance mechanisms (Di Tullio \& Staples, 2013). Membership can be granted on the basis of merit, this means, to those who "provide major contributions in terms of quantity, quality, and continuity to the development of the community" (De Noni et al., 2011, p. 8). Core groups often have vetting processes in place to assess the skills, dedication and commitment of potential entrants to privileged groups (Di Tullio, 2012; Sharma et al., 2002).

For instance, Von Krogh, Spaeth, and Lakhani (2003) have shown that new participants follow join scripts, demonstrating their skills and technical expertise in order to become a member of a core team. De Laat (2007) mentions that vetting can also require prospective entrants to demonstrate their familiarity with the open source philosophy (De Laat, 2007).

Membership can entitle to certain decision-making power and it can be a precondition for being elected into the community's governing bodies (De Noni et al., 2011). There are also cases of open source projects where formal membership is decided upon via vote among privileged groups (Sharma et al., 2002). Formal memberships can entitle entrants to have a voice in decisions about governance matters (West \& O'Mahony, 2008). Finally, there are also examples of paid memberships. For instance, the Linux Foundation offers memberships to partners based on entry fees (De Laat, 2007).

\subsubsection{Licensing}

In the literature, licensing is considered to be an important open source governance mechanism (De Noni et al., 2011; Di Tullio \& Staples, 2013). Licensing refers to all "rights and obligations associated with open source software" (Markus et al., 2000, p. 18). Licensing is believed to have an impact on a variety of crucial aspects of open source development, including community members' motivation, coordination practices, and approaches to commercialisation (Crowston et al., 2012).

Shah (2006) argues that community members participate by following norms that are based on reciprocity. She conjectures that licensing terms are 
instrumental in the reinforcement of these norms. Licensing then also connects to ideology. Ideology can be conceived of as "shared, relatively coherently interrelated sets of emotionally charged beliefs, values, and norms that bind some people together and help them make sense of their worlds" (Trice \& Beyer, 1993, p. 33).

According to De Laat (2007), in the realm of open source, there is a more radical camp of ideology and a pragmatic one (also see the historical evolution of open source in Section 2.1). He thinks that the radical camp is concerned with regulatory frameworks that ensure that the software can be used, modified and (re)distributed freely, whereas the more pragmatic or moderate camp cherishes the practical benefits that come with open source code (e.g., opportunities for source inspection and the improvement of software quality).

De Laat's (2007) view suggests that the two camps also differ in their preferred choice of licence types. Whereas the first camp may appreciate $\mathrm{GPL}$, the other may prefer more permissive models, such as the BSD. From a slightly different angle, Markus (2007) conjectures that licensing is one of the means to overcome motivational problems in open source communities because it gives users and participants control over the ownership of the software and its benefits.

On all accounts, there is a plethora of open source licences (e.g., GPL, LGPL, BSD licence, Apache licence, MIT licence). To be recognised as such, an open source licence should be in line with the ten requirements stipulated by the OSI (De Noni et al., 2011).

De Noni, Ganzaroli, and Orsi (2011) distinguish between four types of licences: 'recursive/viral', 'partially recursive, 'permissive', and 'pragmatic/dual'. Essentially, recursive/viral licences enforce the openness of the code (e.g., GPL), partially recursive ones are slightly more permissive (e.g., LGPL), and permissive licences generally remove any restrictions upon the code (e.g., BSD). With the pragmatic/dual licencing approach, typically a free community version of the code is released together with a paid, and more sophisticated, version that ships under a proprietary licence (e.g., MySQL) (Comino \& Manenti, 2011).

\subsubsection{Rules and policies}

This dimension concerns the extent to which rules are typified through informal agreements and formal means. More generally, there can be informal rules (e.g., institutions, social norms) and formal rules (Schweik \& English, 2012). 
Especially in the beginning, at the inception of an open source project, work is mainly conducted on the basis of informal agreements. According to Schweik and English (2012), much of the exchanges among community participants builds on mutual understanding and the outlook of being rewarded when following social norms (e.g., social approval, learning benefits, reciprocity). They emphasise that these informal social contracts reduce uncertainty, help overcome coordination problems, and enable people to develop trusted relationships with their community peers.

However, when a project matures, participants increasingly see the need for formalisation in order to ease coordination and collaboration. Successful projects may be associated with higher degrees of formal governance (Di Tullio \& Staples, 2013). The formalisation of rules is often achieved via policy documents, guides, bylaws, the formulation of a code of conduct $(\mathrm{CoC})$, coding conventions, procedures for testing and error reporting, and strategy documents about the community's long-term vision and goals. For instance, rules and policies can be a way to formalise the division of labour (Lattemann \& Stieglitz, 2005). Such rules and policies can be modified and changed on an ongoing basis to meet a project's unique requirements (Sharma et al., 2002).

Schweik and English (2012) distinguish between rules at the operational level, the collective choice level, and the constitutional level. With rules at the operational level they refer to rules and norms that guide the everyday decisions in community work. For instance, this can include rules and policies regarding development processes, support activities, and release procedures. With rules at the collective choice level they refer to rules and norms that oversee rules and structures at the operational level. For instance, such rules can specify the distribution of authority for making code changes, but also the authority of changing the rules at the operational level (e.g., changes in development processes). With rules at the constitutional level they refer to rules and norms that specify the authority and procedures for changing collective choice rules. As an example, the authors mention the rules that specify who takes over important positions and responsibilities in case someone leaves a project. Rules at the constitutional level also cover licensing. The bylaws of the foundations that back open source projects can be seen as an example for rules and norms at the constitutional level, too.

Based on the work by Ostrom (2005), Schweik and English (2012) discuss seven rule categories in open source contexts: position rules (that specify the roles that people play), boundary rules (that narrow down the eligibility for certain positions), choice rules (that specify what can, cannot, and must be done), aggregation rules (that specify the course of action for resolving conflicts in decision-making), information rules (that specify the 
information flows between project members and external parties), payoff rules (that specify rewards and sanctions for particular outcomes and actions), and scope rules (that specify the outcomes that should/must be attained in given situations). As Schweik and English (2012) argue, these rule categories may be found at the operational level, the collective choice level, and the constitutional level.

\subsubsection{Decision-making and conflict resolution}

Generally, the literature makes a distinction into centralised and more decentralised decision-making styles (Crowston et al., 2012). However, all open source projects may have to rely on vertical components, involving some form of decision authority, in order to integrate work efforts (MateosGarcia \& Steinmueller, 2008). Sharma, Sugumaran, and Rajagopalan (2002) argue that most decisions in open source communities are reached via consensus, especially when a project's size is manageable and in case decision authority is delegated according to a project's modular structure.

During the initiation phase of an open source project, there are often charismatic leaders that coordinate others' contributions, provide a vision of the project, attract new developers, and keep the project together (Crowston et al., 2012). Often, these leaders are the ones who have the final say on important decisions in the community. A widely cited example of such more autocratic decision-styles is the Linux projects in its early days. Decisionmaking, leadership and authority are closely related (Crowston et al., 2012). However, leaders and their authority typically emerge on the basis of their sustained efforts and their technical expertise (Crowston et al., 2012). Through their contributions, community participants demonstrate knowledge, merit, values, and skills, for which they are rewarded with reputation and the right to exercise authority in turn (Mateos-Garcia \& Steinmueller, 2008).

A study by O'Mahony and Ferraro's (2007) provides insights into how open source communities develop a shared basis of positional authority. They argue that an inability to do so has disrupted many collectivist groups in the past. However, they also point out that more democratic forms of participation tend to exacerbate a community's ability to manage the production environment, which may ultimately compromise its long-term goals. They conclude that communities over time develop a blend of meritocratic, bureaucratic, and democratic rule, which the authors interpret as enabling rather than coercive.

They found positional authority to be limited in four ways. First, by constitutional requirements that members with positional power "defer to 
the wishes of the collective" (O'Mahony \& Ferraro, 2007, p. 1089). Second, leaders' authority is often limited to the function of consensus building and conflict resolution where persuasion skills and the deference to democratic norms are key in order to exert influence and to accomplish goals. Third, constitutional designs often allow members "to propose a general resolution that can counter a leader's actions" (O'Mahony \& Ferraro, 2007, p. 1089). And fourth, positional authority can be constrained by further countervailing sources of authority, such as by splitting up decision-making power among several leadership positions (e.g., project leader, technical committee).

The design and distribution of decision-making and authority may depend upon a project's adaption to unique circumstances (Markus et al., 2000) and on innate political tensions (Mateos-Garcia \& Steinmueller, 2008). This may help explain why there can be different governance configurations across different open source projects. Amongst others, such differences can explain the star-shaped governance structure of Linux, or the team-based model that emerged with the BSD Unix project (Mateos-Garcia \& Steinmueller, 2008).

More democratic styles of decision-making are often implemented through voting procedures over the Internet (Markus et al., 2000). However, as Sharma, Sugumaran, and Rajagopalan (2002) point out, this raises the issue of voting rights. Not all members of a community may have the right to vote. Sharma, Sugumaran, and Rajagopalan (2002) discuss an example where members of an email list were allowed to vote, but only core members' votes were binding. Based on such a mechanism, they conclude that a community may be able to measure the temperature on certain issues, while preserving the decision authority and the capacity to act.

All in all, open source governance mechanisms should enable transparent decision processes in order to motivate community members and to preserve a sense of fairness within the community (Sharma et al., 2002). A lack of transparency may alienate those who are not consulted, and may erode the sense of community (Crowston et al., 2012; Jensen \& Scacchi, 2005)

Based on the review of the literature, in total, five salient decision-styles are discerned: 'autocratic decision-making', 'delegated decision-making', 'tolerated decision-making', 'consensual decision-making', and 'democratic decision-making'.

\subsubsection{Sanctions}

The social mechanisms of sanctioning improper behaviour may chiefly be based on participants' concern for reputation but also on their access to 
important resources or groups (Markus et al., 2000; Sagers, 2004). Behavioural norms may only be of value "if there is a credible threat of sanction" (Gallivan, 2001, p. 296). Sanctions may be required in order to "to guarantee that those who voluntarily comply with [social] contracts are not taken advantage of by those who do not" (Sagers, 2004, p. 429).

Online communication channels provide plenty of means to observe participants' behaviour and to ensure compliance (Sharma et al., 2002). In case community participants lack the ability to observe behaviour or if they lack the means to ensure compliance, a community and its institutional foundations may be vulnerable to decay (Markus et al., 2000).

Sanctions can induce community participants to change their behaviour but sometimes they may also leave the community as a consequence (Sharma et al., 2002). Social pressure is particularly applied to those who undermine the community norms and the project's progress (Sharma et al., 2002). Sanctioning thereby safeguards the communication and the compliance with norms, and ensures the collaborative output in a community (Di Tullio \& Staples, 2013).

Markus and Agres (2000) identified three types of sanctions in open source communities: 'flaming', 'spamming', and 'shunning'. Flaming refers to angry or hostile messages that are sent and exchanged online. Spamming means the flooding of someone's mailbox with unsolicited content, while shunning refers to acts where people refuse to respond or withdraw from a conversation entirely. For instance, someone who violates the rules runs the risk of being taken less seriously or ignored entirely on email list conversations (Gallivan, 2001).

Drawing from Sagers (2004), expulsion can be added to the list of sanctions. He regards expulsion as the most drastic form of punishment for project members. Expulsion, e.g., through a no confidence vote, can serve to disempower someone in a leadership position, and to revoke other kinds of privileges (Di Tullio \& Staples, 2013).

As the empirical data suggest, threating to leave the community as a consequence of experiencing undue behaviour can be a further sanctioning mechanism. This type of sanctioning does not seem to play a prominent role in the literature, but should be added to this dimension nonetheless.

\subsubsection{Life-cycle stages}

Based on their study of the Debian project, O'Mahony and Ferraro (2007) identify four phases of governance evolution: 'de facto governance', 'designing governance', 'implementing governance', and 'stabilising governance'. With 'de facto governance' they are referring to the initiation 
phase of an open source project. At the inception of an open source project, it usually lacks formal governance. The founders often have the final say on important decisions and pass on the project leadership to a trusted person in case they leave the project (O'Mahony \& Ferraro, 2007).

As O'Mahony and Ferraro (2007) argue, when community leaders experience pressure from other community members, questioning the legitimacy of their positional authority, the transition to a next phase is triggered, which they call 'designing governance'. During this phase, community members start to develop a shared idea of formal governance structures, such as democratic mechanisms and procedures for elections, formulation of constitutions that stipulate the definition of roles and authority, and countervailing sources of authority such as the distribution of decision-making (O'Mahony \& Ferraro, 2007).

In a next phase, which they call 'implementing governance', a constitution is ratified and project leaders are elected for a limited period. Throughout this phase, previously designed governance mechanisms are finally put into practice (O'Mahony \& Ferraro, 2007). Finally, their model proposes a fourth phase, called 'stabilising governance', in which governance is adapted and aligned according to the members changing conception of the project's vision and goals. As O'Mahony and Ferraro (2007) emphasise, in this phase, the organisational leaders focus on organisation building, which involves communicational, cultural, relational, and persuasive skills, rather than knowledge on technical development processes.

To some extent, the typology by O'Mahony and Ferraro's (2007) seems to overlap with De Laat's (2007) life-cycle perspective ('spontaneous governance', 'internal governance', and 'governance towards outside parties). De Laat's (2007) 'spontaneous governance' seems to correspond to O'Mahony and Ferraro's (2007) 'de facto governance'. 'Internal governance' (De Laat, 2007) seems to correspond to both 'designing governance' and 'implementing governance' (O'Mahony \& Ferraro, 2007), whereas 'governance towards outside parties' (De Laat, 2007) seems to correspond to 'stabilising governance' (O'Mahony \& Ferraro, 2007).

However, both the models by O'Mahony and Ferraro (2007) and De Laat (2007) neglect that governance may also decline over time. By contrast, a life-cycle model by Lattemann and Stieglitz (2005) also includes the possibility of decline. Their model incorporates four life-cycle stages: 'introduction', 'growth', 'maturity', and 'decline or revival'.

Based on the review of the literature, the conceptual plurality around life-cycle stages of open source governance is integrated using the following typology of life-cycle stages: 'initiation', 'evolving', 'stabilising', 'maturity', 
and 'decline'. The 'initiation' phase essentially captures the ideas of 'defacto' governance (O'Mahony \& Ferraro, 2007), 'spontaneous governance' (De Laat, 2007), and 'introduction' (Lattemann \& Stieglitz, 2005). The 'evolving' phase of governance, captures the ideas expressed in 'designing governance' and 'implementing governance' (O'Mahony \& Ferraro, 2007), but also 'growth' (Lattemann \& Stieglitz, 2005) and 'internal governance' (De Laat, 2007). The phase of 'stabilising' governance is taken over from O'Mahony and Ferraro (2007). It can be regarded as a consolidation stage for implemented governance initiatives. 'Stabilising' governance is complemented with the idea of organisational 'maturity' (Lattemann \& Stieglitz, 2005), where governance has advanced to a more consistent and persistent state. Finally, the possibility for decline of governance is taken over from Lattemann and Stieglitz (2005).

Finally, the resulting tentative, integrative framework for open source governance is depicted in Figure 21. The next chapter applies this framework to the Joomla case. 
Chapter 7: Governance framework (Study II)

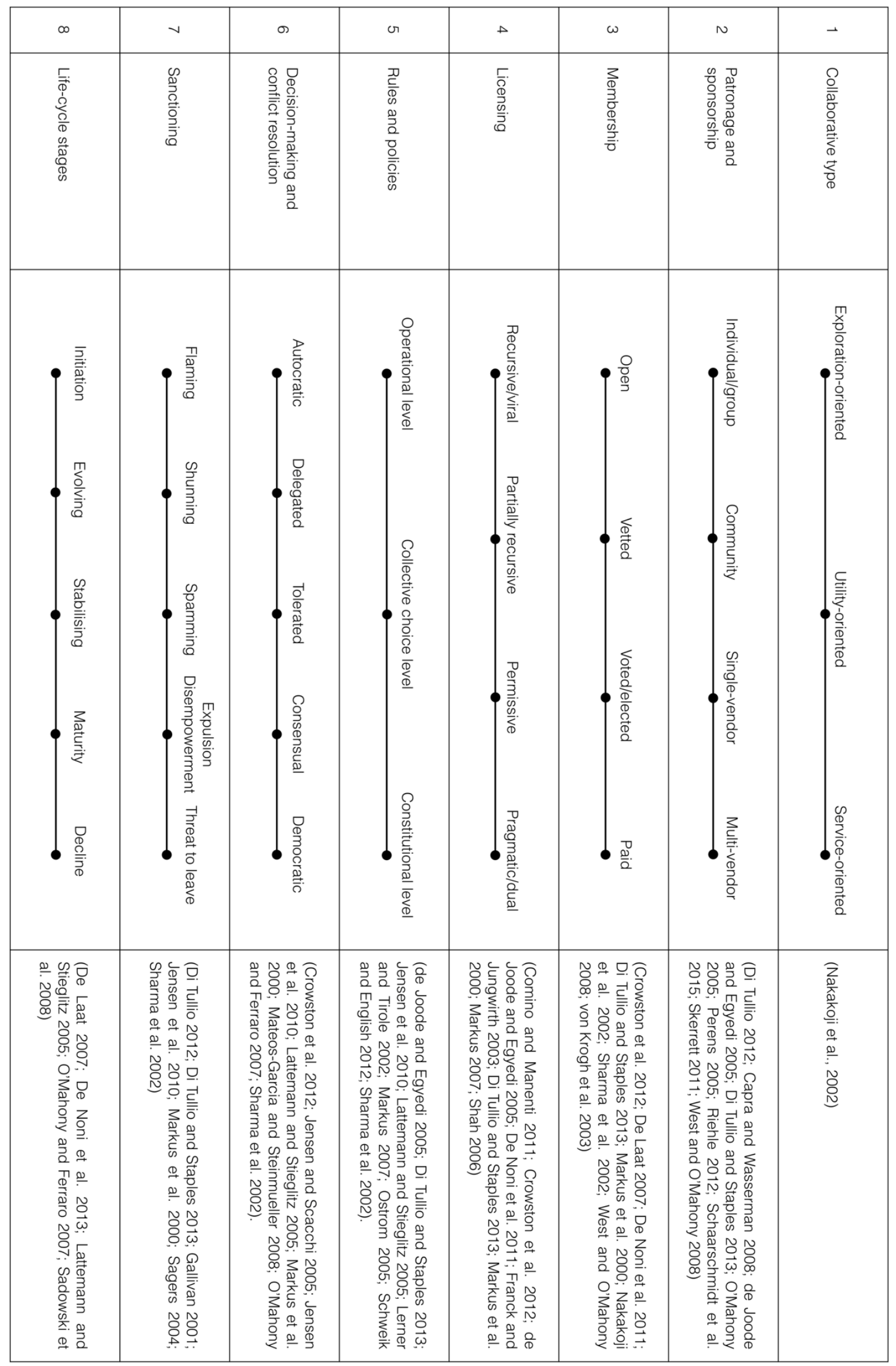

Figure 21: A tentative, integrative framework for open source governance. 


\subsection{Discussion}

The discussion applies the tentative, integrative framework for open source governance, which was presented in the previous chapter, to the Joomla case. Each of the dimensions and its attributes of the framework are used to explore and explain community governance in the Joomla case.

\subsubsection{Collaborative type}

In terms of the typology by Nakakoji et al. (2002), the Joomla case clearly falls into the category of service-oriented open source projects. Joomla provides an open source CMS solution to a large user base. There are millions of Joomla installations all around the globe. The population of users is much larger than the actual population of open source community members. Possible problems with the Joomla CMS can affect a wide range of stakeholders, such as users, end-users, and providers of value-added services around the Joomla platform. Nakakoji et al. (2002) argue that service-oriented open source projects are more conservative towards change. Due to the large population of users, the Joomla leadership may be relatively conservative towards change, too. For instance, according to interviewees, as a consequence of past compatibility issues in shipping upgrades (which negatively affected many users), the community has become more careful in introducing changes to the software.

\subsubsection{Patronage and sponsorship}

In terms of patronage and sponsorship, Joomla qualifies as a communitymanaged, community-steered, and community-driven open source project. There are no single corporate entities that have a prerogative in governance matters. All work in the Joomla community is done on a voluntary basis (including OSM), without direct monetary gratification for doing community work.

In contrast to Joomla, WordPress (one its major rivals) is a single-vendor open source project. The WordPress project is backed by the WordPress foundation, a public charity organisation that was founded by the creator of the WordPress software. The principal officer of this foundation is the founder himself. The founder of the WordPress project also leads a company called Automattic, which generates substantial revenue via a WordPresscentric business model (offering Web-hosting and enterprise services). In 2012, Automattic was estimated to generate 45 million USD in revenue ${ }^{120}$. In 2016, their revenue has been estimated to be 50 million USD, and the company had been valued at around 1.2 billion USD ${ }^{121}$. The WordPress 
core development team is led by its founder. Although Automattic has transferred the ownership of the WordPress trademark to the foundation, there is a strong interlinkage between leadership and staff across WordPress, Automattic, and the core development team that governs all aspects of development ${ }^{122}$.

The Linux project and the Apache project are examples of the type of multi-vendor open source projects. Both open source projects develop and distribute critical infrastructure software and are therefore of importance to a wide spectrum of stakeholders, such as big software corporations (e.g., Google, Microsoft, Facebook, IBM). Apache, for instance, provides external stakeholders with the opportunity to exert influence via memberships. Members have the right to elect the board and to propose new projects for incubation $^{123}$.

\subsubsection{Membership}

In the Joomla case, membership can be open, vetted, and voted depending on the kind of roles and groups one focuses on. In the Joomla case, there are no paid memberships. Membership is generally open at the periphery of the community. Basically, anyone can engage in activities such as providing support in forums, and organising/joining user group meetings, testing the software, and reporting bugs. One does not need to be a member of a team in the community in order to engage in such activities.

However, membership for specific teams is vetted. One has to contact the team leader in case one wishes to join a particular team. It is then upon the team leader to initiate a dialogue about the skills and intentions of a prospective entrant. The team leader has the responsibility to coordinate the work within a team, and to manage dependencies with other teams. The team leader is elected by the team members on an annual basis.

The community leadership in the Joomla case consists of the Team Leaders, the Department Coordinators, and the Officers (President, Vice President, Secretary and Treasurer). The Department Coordinators are elected by the Team Leaders of the respective departments. The Officer positions are elected together by all Department Coordinators, Team Leaders, and the existing Officers.

In a sense, the core of the Joomla community can be imagined as gated groups of people that rely on (informal) vetting when accepting new team members. Being accepted as a team member then opens the door for becoming a Team Leader, Department Coordinator, or an Officer. This organisational design solves the problem of voting rights in a large community of volunteers. Essentially, only people within the core leadership 
structure are eligible to vote. For instance, in a recent election for Officer positions, 43 people had the right to vote (all the Team Leaders, Department Coordinators and Officers) ${ }^{124}$. Figure 22 visualises the three types of membership that exist in the Joomla case from a core-periphery perspective. This particular way of restricting access to the core teams may facilitate the coordination in the community (Sagers, 2004).

open

vetted

voted

Figure 22: A three-stage model of membership levels from a coreperiphery perspective.

\subsubsection{Licensing}

In terms of licensing, the Joomla project clearly qualifies as a project with a recursive/viral type of licence. This is because Joomla is published under GPL terms. The Joomla case shows that licensing is closely tied to the core mission and values of the open source project ${ }^{125}$. People who use Joomla have the right to use and modify the Joomla code in whatever way they see fit, except that they have the obligation to respect the authorship of the code, and, in case they are distributing the code or modifications thereof, they have to maintain the original licensing terms. For the users of Joomla, the 
viral clause of the GPL ensures that no one can condition or claim property rights on the source code; and, it ensures that the knowledge-sharing of the code base is perpetuated (De Noni et al., 2011).

A further important aspect brought forth by interviewees is that the GPL creates trust by enforcing the openness of the code. This aspect is also acknowledged in the literature (Stewart \& Gosain, 2006). Essentially, the argument is that people can trust in the software because they can look under its hood and study its wiring and behaviour. The openness of the code may also maintain standards of professionalism in software development and encourage people's participation, given the attribution of creators and contributors in the copyright of the source files.

Looking at the Joomla case, the delineation between what previous literature (De Laat, 2007; Franck \& Jungwirth, 2003) referred to as the radical and pragmatic camp of open source ideology appears somewhat artificial. As has been mentioned, De Laat's (2007) view suggests that the two camps differ in their preferred choice of licence types - the radical camp preferring viral licences (e.g., GPL), and the pragmatic camp preferring permissive licences (e.g., BSD). In addition, Franck and Jungwirth (2003) argued that the radical camp embraces anti-capitalist attitudes (Franck \& Jungwirth, 2003).

However, while the Joomla project has adopted a viral licence, there is a variety of commercial activities around the Joomla platform. In a similar fashion, there are further GPL-based open source projects (e.g., WordPress, Drupal) that can be associated with a diverse range of commercial activities. Furthermore, as the empirical data show, the freedom of the code (often associated with the radical camp of open source ideology), and the practical benefits that come with the openness of the code, such as the opportunities for source code inspection and the improvement of software quality (often associated with the pragmatic camp of open source ideology), can be cherished at the same time.

\subsubsection{Rules and policies}

There is a whole range of rules and policies in place that safeguard the coordination practices in the Joomla case. At the operational level, the following rules can be identified. According to Schweik and English (2012), rules at the operational level guide the everyday decisions and actions in the community. To mention but a few, in the Joomla case, such rules and policies can refer to instructions on how to report a bug ${ }^{126}$, procedures for testing Joomla patches ${ }^{127}$, guidelines for committing code ${ }^{128}$, rules on how to behave in the forums ${ }^{129}$, information about coding standards ${ }^{130}$, how to 
register user groups and submit events ${ }^{131}$, how to become a contributor ${ }^{132}$, and how to submit extensions.

At the collective choice level, the following rules can be identified. According to Schweik and English (2012), rules at the collective choice level define and oversee rules and structures at the operational level. For instance, this can include the distribution of authority for making code changes. Rules at the collective choice level particularly refer to position rules, choice rules, information rules, payoff rules, and scope rules.

Although everyone can submit pull requests (i.e., submitting proposed changes and code contributions), there are only a few people who have the right to commit code changes to the Joomla code repository. Furthermore, there are only few people who possess the authority to act as moderators and administrators (position rules).

As an example for choice rules the current release strategy and support cycle can be mentioned. As was mentioned before, choice rules specify what can, cannot, and must be done. In 2014, the community leadership published a new release strategy that specifies the support and release cycles $^{133}$. Each major version of the Joomla CMS is developed and supported for specified amounts of time (currently a minimum of two years for development and four years for support). The release strategy also stipulates that all minor software releases for a given major version have to be backward compatible.

As an example for scope rules the overall development strategy of Joomla can be cited. As was mentioned before, scope rules specify the outcomes that should/must be attained in given situations. As published on the Joomla website, in a broad sense, the development strategy sets out what users can expect from the Joomla project. The development strategy is a rather extensive and long document; it deals with issues such as release policies, backward compatibility, support policy, upgrade policy, security policy, contributor policy, the mission, goals, and principles of the development teams. A short excerpt about the purpose of the development strategy, taken from the Joomla website, can be cited.

"This is primarily about how we approach and manage change: how we adapt, develop and grow our products in an ever-changing technological landscape; how we communicate to our users and contributors what to expect from our products as they change from one release to the next; and how we guide our contributors towards making the future changes that we want as a community"134. 
There are also information rules (that specify the information flows among project members and teams) and payoff rules (that specify rewards and sanctions for particular outcomes and actions). As example for payoff rules the $\mathrm{CoC}$ and the conflict resolution team can be mentioned. For instance, the conflict resolution team has the mandate to report and document breeches of the $\mathrm{CoC}$, and to propose sanctions to the leadership team ${ }^{135}$.

At the constitutional level, the following rules can be identified. According to Schweik and English (2012), rules at the constitutional level specify the authority and procedures for changing collective choice rules, and comprise of other constitutional rules and norms (e.g., licensing, bylaws, strategy documents about the community's long-term vision and goals). The bylaws ${ }^{136}$, for instance, regulate boundary rules that narrow down the eligibility of who can vote and who can be nominated for elections. For instance, the bylaws in the Joomla case define three classes of memberships who are eligible to take part in elections (Class 1 members comprise of Department Coordinators and Officers. Class 2 members comprise of the Team Leaders, and Class 3 members comprise of all the Team Members).

\subsubsection{Decision-making and conflict resolution}

In a nutshell, the decision-making in the Joomla case seems to revolve around 'delegated', 'moderated', 'consensual', and 'democratic' decisionmaking. No form of autocratic decision-making could be identified. Generally, decision-making in the Joomla case seems relatively decentralised. As was mentioned before, most decisions in open source communities may be reached via consensus (Sharma et al., 2002). As argued by an interviewee, the consensus model dominates the decision-processes in the community, even if votes are carried out. This means that consensus among a majority of decision-makers in governing bodies is often (but not always) achieved before decisions are put to a vote.

Interviewees argued that Joomla's decision processes are somewhat slow. Unlike WordPress, where decision-making is more centralised, in the Joomla community there is no central authority that can dictate decisions. As an interviewee expressed, "no one is the boss". Hierarchies in the Joomla case are practically flat, even though there are formal positions of authority such as the Team Leaders, Department Leaders, and Officers. As an interviewee expressed, due to the voluntary nature of the Joomla project, giving orders is no option to get work done. Rather, leadership and authority may be characterised by a need to convince others and to engage in 
dialogue. A mix of charisma, reputation, and persuasion skills may help leaders in such dialogues.

It was beyond the scope of this sub-study to take a deeper look at how decision authority is delegated within the community. However, it is reasonable to assume that the decision authority is delegated according to the project's modular structure. For instance, the teams in the Production Department have the authority to decide which features to include in upcoming versions of the Joomla $\mathrm{CMS}^{137}$. Typically, there is a Release Lead (i.e., a main responsible) that manages the most important aspects of upcoming Joomla releases. Even though important decisions may be delegated to the Release Lead, a person in such a role may find it crucial to preserve an open mind towards other opinions in community. The following quote illustrates this. In 2018, in an interview for the Joomla community magazine, George Wilson, a Release Lead for an upcoming Joomla version said the following:

"I'm trying to keep an open mind and listen to as many people and their opinions as possible - because the Joomla community is so large as you said it's important to remember I've only experienced a small percentage of it - but I have to make decisions for the whole community"138.

All in all, this suggests that decision authority in this case may be both delegated and tolerated (within bounds). The authority of a Release Lead seems accepted as long as there is ongoing consensus building that involves the diversity of opinions in the community.

Similar to the findings by O'Mahony and Ferraro's (2007), the Joomla community has developed a blend of meritocratic, bureaucratic, and democratic rule. While consensus-based in essence, there are also delegated, tolerated, and democratic mechanisms of decision-making.

\subsubsection{Sanctions}

Looking at a community of volunteers, the sanctioning of behaviour mainly targets the reputation of community participants and their access to important resources and groups (Markus et al., 2000; Sagers, 2004). For instance, a credible threat of sanction may be the revoking of rights to commit changes to the community-internal code repository (and access to other systems). Recently, the Joomla community temporarily banned a highly active member from community activities due to undue behaviour. This ban was decided via a majority vote in the community leadership. The decision was justified with reference to the importance of a "healthy, safe 
and non-toxic environment" ${ }^{139}$ for community participants. Looking at the interview data, this justification makes sense, given that participants generally value and cherish that people are predominantly nice to each other in the community. In terms of the framework in Figure 21, this ban can be interpreted as a temporary disempowerment of a community member. However, the empirical data show that formal sanctions seem a rarity in the Joomla case.

The empirical data further show that there can be flaming between different people and groups on social media channels. Few instances in the empirical data could be interpreted as shunning, except the ignoring of pull requests. However, there may be different reasons why pull requests may be ignored by other people (e.g., due to a lack of time). The empirical data show no indications of spamming. Finally, the empirical data show that people can also threaten to leave the community during conflict situations (e.g., in user groups, or on social media channels).

\subsubsection{Life-cycle stages}

Joomla was initiated in 2005 when being forked from the Mambo project (see Section 4.1). In its initiation phase, it lacked many formal governance structures that it has today. In the beginning, a few people led the project in a more informal manner. However, over time, the governance structures evolved and more formal means of governance and additional means of democratic participation were introduced. As required by US law, there were elections for the board of the non-profit organisation (OSM) that provides legal and organisational backing to the Joomla project early on.

While it is beyond this sub-study to attend to the breadth of communityinternal governance changes that occurred since 2005, several recent governance initiatives can be highlighted. In 2017, a new governance structure had been implemented in order to encourage contributors and to make work more efficient. This governance initiative reshaped and integrated previously existing formal organisational structures into a flatter and somewhat sleeker organisational design. Furthermore, a new voting procedure has been introduced so that team leaders are no longer appointed by the leadership, but elected by the team members. Together with its Board of Directors (see Section 4.3), after this transition, Joomla's top-level governance structure consists of several departments (i.e., Production department, Legal and Financial department, Marketing and Communication department, Events department, Operations department, and Programs department) instead of a community leadership team and a production leadership team, as was the case before. There is a number of 
different teams that are housed under these departments, specialising on all kinds of organisational and production-related matters (see Section 4.3).

A further recent governance change is the introduction of an Advisory Board $^{140}$ that has the right to add important items onto the meeting agendas of the Board of Directors. A further recent change is the inception of a socalled Ombudsman ${ }^{141}$ whose purpose is to serve as an appeal option to people who feel treated unjustly during conflict situations.

All in all, in terms of the framework in Figure 21, governance in the Joomla case could be seen as a mix between evolving governance and stabilising governance. As has been expressed by an interviewee, governance-wise, Joomla is growing up and about to move beyond puberty. Even if speculative, in a governance sense, many of the recent governance changes could take Joomla in a direction towards organisational maturity into the coming years ahead.

\subsection{Preliminary conclusions}

Based on a review of the literature, Study II integrated previous findings into a tentative, integrative framework for studying open source governance (and corresponding governance configurations). The applicability of the framework was demonstrated by the case of Joomla. This framework could be a start for further conceptual development in this particular area. However, it needs further work in order to assess the usefulness of this approach for comparative analysis. Future research could evaluate whether there are other dimensions that should be considered for integration and whether the proposed framework can be reduced to a more parsimonious representation. 

Chapter 8: Collective identities (Study III)

8 Collective identities and governance in the context of community-driven open source (Study III)

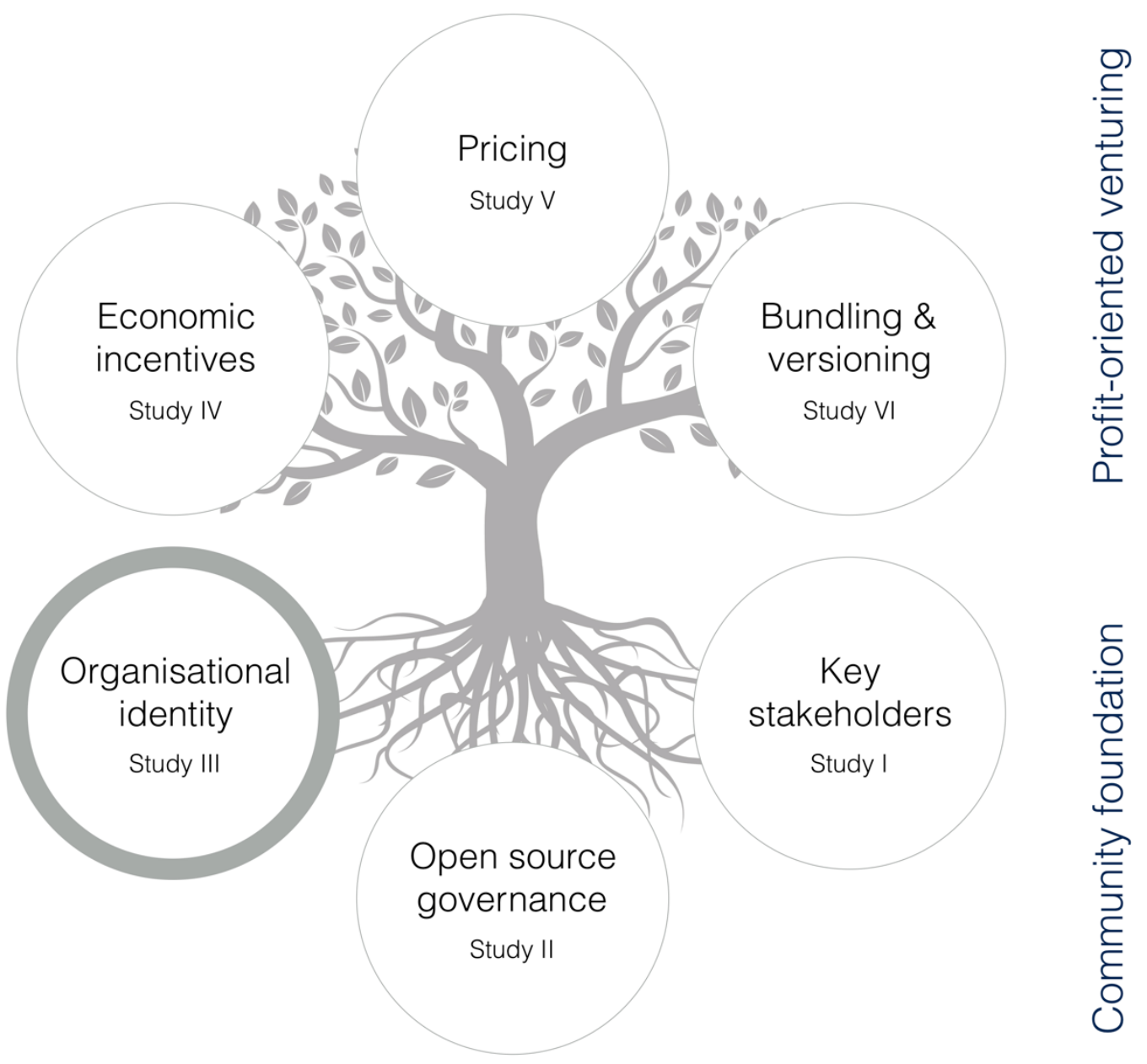




\subsection{Short summary}

Little research on open source has studied the multiplicity of organisational images that can exist because of the various interpretations that community participants can have of their community and their affiliation with it. However, in the literature, the multiplicity of organisational images and the plurality of identities are depicted as valuable information sources for managing conflict, coordination, and change. Therefore, the diversity of organisational views held by community participants, and the plurality of identities these imply, can potentially also inform governance practices in open source community settings.

As is argued in the literature, governance and organisational change can affect organisational members in different ways, depending on which organisational identities they subscribe to. For instance, governance can create, support, interfere with, or threaten members' conceptions of organisational identity and membership. Conversely, members' conceptions about who they are as an organisation can give rise to particular forms of governance and change. Against this backdrop, Study III examines the dynamic interplay between governance and collective identities. As this sub-study shows, this dynamic interplay can serve to explain a variety of consequences and outcomes produced by the collective efforts and actions of community participants. 


\subsection{Introduction}

The collectives that account for the production of OSS have been studied from numerous angles and perspectives, including governance (Di Tullio \& Staples, 2013; Jensen et al., 2010; Markus, 2007; O'Mahony \& Ferraro, 2007), motivation and participation patterns (Fang \& Neufeld, 2009; Roberts et al., 2006; von Krogh et al., 2012), and organising processes and collective outcomes (O'Mahony \& Lakhani, 2011; Stewart \& Gosain, 2006).

While this strand of research has illuminated many interesting facets of open source communities, it has neglected the multiplicity of organisational images that can exist due to the various interpretations that community participants can have of their community and their affiliation with it (Westelius, 2006). However, in the literature, multiplicity of organisational images and plurality of identities are depicted as valuable information sources for managing conflict, coordination, and change (Alvesson \& Willmott, 2002; Foreman \& Whetten, 2002; He \& Brown, 2013; Westelius, 2006). Therefore, the diversity of organisational views held by community participants and plurality of identities can potentially also inform governance practice in open source community settings.

Governance and organisational change can affect organisational members in different ways, depending on which organisational identities they ascribe to (Westelius, 2006). For instance, governance can create, support, interfere with, and threaten members' conception of organisational identity and membership (Elsbach \& Kramer, 1996; Westelius, 2006). Conversely, members' conceptions about who they are as an organisation can give rise to particular forms of governance and change (Kogut \& Zander, 1996; Stimpert et al., 1998). As is shown in this sub-study, the dynamic interplay between governance and collective identities can serve to explain a variety of consequences and outcomes produced by the collective efforts and actions of community participants.

From an empirical point of view, Study III takes a close look at the Joomla case (for a detailed description of the empirical context see Chapter 4). Joomla is an interesting case in the context of this sub-study for at least four reasons. First, governance practice seems to be of particular relevance in the context of service-oriented open source projects (Nakakoji et al., 2002) that serve as a stable and robust infrastructural resource for a wide range of stakeholders ${ }^{\mathrm{XXVII}}$. The Joomla CMS powers millions of websites across the globe.

xxvIII Such as operating systems, databases, web servers, content management systems, and more. 
Second, governance-wise, Joomla is an interesting case because it is community-owned, community-run, community-controlled, and purely based on voluntary participation, unlike its two main rivals, WordPress and Drupal, which are corporately controlled.

Third, "concerns about identity are just as profound as concerns about survival" (Whetten, 1998, p. viii). The realm of open source CMSs seems particularly affected by increased competition for users and volunteers. A surge in new projects and ongoing diversification can currently be observed in this realm. Joomla has faced increased competition for volunteers and users throughout the past few years. Its popularity (like that of other CMSs) is increasingly also challenged by a flood of new, although as-yet less popular, open source CMSs. Joomla still has millions of users and thousands of active followers across the world. However, it seems that it has continuously lost ground to one of its main competitors, WordPress. A loss of market share can in many ways be interpreted as an identity threat.

Fourth, since its foundation in 2005, Joomla has seen a series of governance changes. These changes were put into place to improve coordination practices, to appear more attractive to volunteers and users, to lower the entry barriers for new volunteers, to improve the organisational climate, and to increase the efficiency of production processes. Against this backdrop, Study III asks how governance and collective identities interact in the Joomla case.

From a theoretical point of view, it should be added that research on open source communities lends itself to generalisation to other organisational domains (Crowston et al., 2012; Markus et al., 2000). Theorists have argued that community forms of organising (such as open source production communities) are suitable grounds for analysing overall changing workplace realities (e.g., distributed work environments, lack of vertical hierarchies) and changing occupational identities (O'Mahony \& Lakhani, 2011; Soenen \& Moingeon, 2002). Scholars have also argued that competition for labour increasingly resembles modes of competition for volunteers, which is due to the greater mobility of workers and the lower costs they experience in switching workplaces (Collins \& Drucker, 1999; Crowston et al., 2012). Therefore, the results of this sub-study could also be of value in light of changing workplace realities.

The remainder of Study III is structured as follows. First, the necessary theoretical background is established. This is followed by a description of the methodological approach and the epistemological assumptions that are made. Subsequently, the analysis illustrates different examples that explain how governance and collective identities interact in the Joomla case. Prior to the concluding remarks, the implications of these findings are discussed. 


\subsection{Theoretical framework}

Essentially, identity relates to the set of beliefs and meanings that provide answers to the questions, "Who am I?" (at an individual level), and, "Who are we?" (at an organisational level) (Foreman \& Whetten, 2002). Organisational identity has been defined in different ways. For instance, as the set of claims about what is central, distinctive, and enduring about an organisation (Albert \& Whetten, 1985), "the theory that members of an organisation have about who they are" (Stimpert et al., 1998, p. 87), or "the combinative construal of firm culture, history, structure, characteristics, status and reputation" (Martin, Johnson, \& French, 2011, p. 576). According to Hatch and Schultz (1997, p. 357), organisational identity "refers broadly to what members perceive, feel and think about their organisations. It is assumed to be a collective, commonly-shared understanding of the organisation's distinctive values and characteristics". Organisational identity may also be interpreted as the images that members hold about their organisation and membership. While in the literature on organisational identity image is mostly treated as externally construed, i.e., how organisational members think their organisation appears in the eyes of an imagined external audience (He \& Brown, 2013), this chapter mainly focuses on internal manifestations of image and identity.

\subsubsection{Collective identities}

Along with organisational identity, scholars have also championed the term collective identities (Brewer \& Gardner, 1996; A. D. Brown, 2006; Dutton, Dukerich, \& Harquail, 1994; Pratt, 2003; Soenen \& Moingeon, 2002). The idea is to emphasise the multiplicity of organisational images that can exist due to the various interpretations that people may have of an organisation and their affiliation with it (Gioia, 1998; He \& Brown, 2013; Pratt \& Foreman, 2000; Westelius, 2006). Said differently, there are multiple individual images inscribed into what we often concisely refer to as 'the' organisation (Hedberg, Dahlgren, Hansson, \& Olve, 1997). Hence, the emphasis on the plural use of the term, collective identities. Multiple organisational identities can be seen as the "properties of a collective" (Pratt \& Foreman, 2000, p. 19). Pratt and Foreman (2000, p. 20) argue that "organisations have multiple organisational identities when different conceptualisations exist regarding what is central, distinctive, and enduring about the organisation".

From a conceptual point of view, scholars have used a variety of attributes to characterise organisational identities. For instance, a nomenclature developed by Albert and Whetten (1985) discerns between 
individuals' conceptions of an organisation's identity that coexist, possibly even throughout the entirety of an organisation (so-called holographic identities), and those that are particular to certain groups, roles, or individuals (so-called ideographic identities). Both ideographic and holographic identities have implications for governance. For instance, in his study of a large Swedish non-profit organisation promoting outdoor activities, Westelius (2006) problematised the issue of managing the multiplicity of organisational views held by its members. Building on Pratt and Foreman (2000), he suggested that the plurality of identities and their compatibility is an important source for managing conflict and change. For instance, he argues that the plurality of identities and the degree of synergy is valuable depending upon the diversity of tasks and environments with which people have to cope.

Scholars have also highlighted the fluid and adaptive nature of organisational identities. While Albert and Whetten (1985) have described organisational identity as the characteristics that are central, enduring, and distinct about an organisation, Gioia, Schultz, and Corley (2000) have called for greater attention to the dynamic and fluid nature of the identity concept.

Because organisational members may look to the past, the present, and the future to make sense of themselves, their organisational membership, their organisation and their affiliation with it, research has made further distinctions between historical identities, current identities, and future identities $^{\mathrm{XXIX}}$ (Pratt, 2003). This line of argument reinforces and complements the idea of the dynamic and fluid nature of the identity concept (Gioia et al., 2000).

From a governance perspective, the kind of tensions between the creation, durability, and adaptivity of identities has implications for an organisation's capacity to manoeuvre through turbulent environments and change (Gioia et al., 2000). In this regard, identity can have enabling or constraining effects, with both positive and negative consequences (Gustafson \& Reger, 1995; Kogut \& Zander, 1996). For instance, identity can serve as an important psychological anchor that can spur organisational members to seek solutions to identity threats (Gustafson \& Reger, 1995). Furthermore, it can promote perceptual patterns that affect issue interpretation (Gustafson \& Reger, 1995), the direction of learning and search (Kogut \& Zander, 1996), organisational control practices and decision-making (Foreman \& Whetten, 2002; He \& Brown, 2013).

xxIx E.g., "who do we want to become?" (He \& Brown, 2013). 


\subsubsection{Open source community governance}

A widely cited definition of open source community governance is provided by Markus (2007). She defines it as "the means of achieving the direction, control, and coordination of wholly or partially autonomous individuals and organisations on behalf of an open source development project to which they jointly contribute" (Markus, 2007, p. 152). The basic intentions behind open source community governance could also be recapped as the continuous efforts to foster a climate that attracts participants, and to manage policies, procedures, and decision rights to coordinate the work efforts of community members (Di Tullio \& Staples, 2013; Midha \& Bhattacherjee, 2012; von Krogh et al., 2012).

However, as O'Mahony and Ferraro (2007) note, developing authority and governance seems to be a particular problem for social groups where participation is voluntary and where reward mechanisms are predominantly non-financial. A lack of face-to-face interaction may place further strains on governance in open source settings (De Laat, 2007; Di Tullio \& Staples, 2013).

Previous findings show that open source community governance has direct effects on patterns of participation by community members, which means that governance mechanisms can be seen as a precursor for a community's vitality, productivity, and long-term success (Shah, 2006). The relationships between community governance and collective identities may be reciprocal, just as individual behaviour can affect organisational identities and the other way around (Pratt \& Foreman, 2000).

For instance, governance can provide regulatory signals regarding legitimate behaviour, practices and values (Fang \& Neufeld, 2009), thereby engendering particular perceptions of identities. Conversely, identities can inform and influence governance, such as resource allocation processes, decision-making, organisational agendas, and routines (Gioia, 1998; Stimpert et al., 1998).

\subsubsection{Analytical model}

Figure 23 provides a visual depiction of the analytical model that is applied in Study III. Drawing from the above, the epistemological assumption is that collective identities can give rise to particular forms of community governance (1), and that community governance can create, support, interfere with, or threaten collective identities (2). This interplay is the basis upon which qualities of collective outcomes are evaluated in this sub-study. Collective outcomes are assessed by community participants' perceptions of 
the vitality of their community and their perception of the impact of governance.

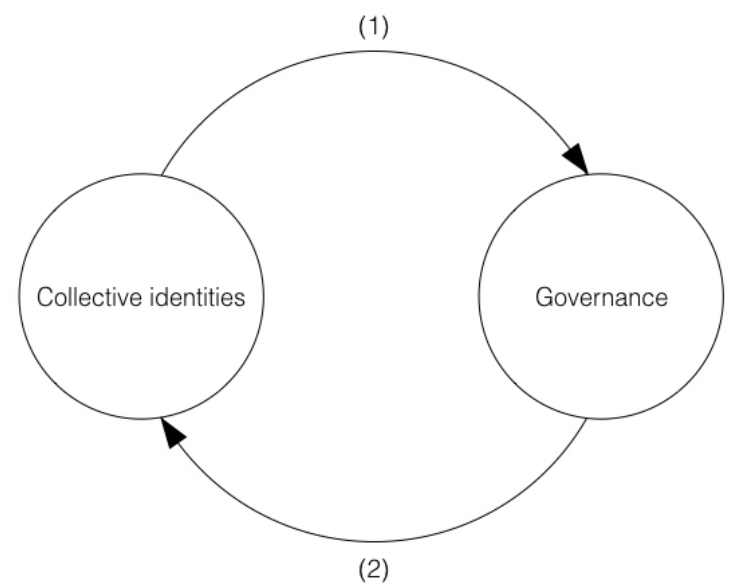

Figure 23: An analytical model that depicts the dynamic interaction between collective identities and governance.

\subsection{Research approach}

Providing answers to identity-related questions requires qualitative and narrative approaches that are able to do justice to the complexity and affectladen nature of identity (Albert, 1998). From a narrative perspective, organisations' identities can be seen as the identity-relevant stories expressed by individuals in order to make sense of a collective entity that they identify with (A. D. Brown, 2006). Naturally, these stories can share common characteristics, but they can also differ depending on individuals' biographies, roles, intentions, or goals (Gioia, 1998). Harvesting these stories can lead to an aggregate model of narratives and themes that reflect the polyphonic, heteroglossic ${ }^{x x x}$, and cacophonic nature of organisational images (A. D. Brown, 2006). The properties of collective identities could then be seen to reside in the aggregate subjective identity-related stories expressed by community participants (Whetten, 2006).

Study III builds mainly on the second set of interviews conducted in the course of this thesis (which consists of interviews with 26 community participants), but also partly draws on the first set of interviews. Data was collected through semi-structured interviews. For further information xxx "The presence of two or more expressed viewpoints in a text or other artistic work" (Oxford
Dictionary). 
regarding the data collection procedure, the reader is referred to Section 5.5.1 of this thesis.

Study III follows an interpretive research approach and builds on recommendations by Pratt (2003). This means that the data-gathering focused on stimulating inward-focused sensemaking that oscillates between the questions "who am I, in relation to organisational membership?", and "who are we as a collective?" Pratt (2003) emphasises that important events, like initiations, crises, issues, and changes are good candidates for stimulating identity-related sensemaking. Therefore, the interview participants were given the opportunity to elaborate upon impactful events in relation to their experiences as community participants. A particular focus in the analysis was directed towards episodes and instances when governance potentially conflicted with members' conception of identity. Incidents and events in the past were relevant insofar as they provided additional layers of understanding for describing the interplay between collective identities and governance.

To approximate a faithful picture of identities at a collective level, the interview questions touched not only upon aspects of personal experience in relation to organisational membership but also upon aspects of interpersonal experience and the immersion within the larger collective (Brewer \& Gardner, 1996; Brickson, 2000). Conversations at the personal level were intended to stimulate sensemaking that revolved around the question "Who am I in relation to my community membership?" Conversations at the interpersonal level were intended to stimulate sensemaking that revolved around the question "Who am I in relation to others in the community?" And, finally, conversations at the collective level were intended to stimulate sensemaking that revolved around the question "Who are we as a collective?" Further questions concerned community participants' perceptions of governance and governance impact. These questions revolved around aspects of open source community governance (Di Tullio \& Staples, 2013; Lattemann \& Stieglitz, 2005; Markus, 2007; O'Mahony, 2007; Shah, 2006; von Krogh et al., 2012), such as open source ideology, licensing, sponsorship, roles and responsibilities, decisionmaking, membership, accountability, sanctioning, and the organisational climate. These questions were in part inspired by Study II (Governance framework) in Chapter 7.

From an epistemological standpoint, the identity-related stories were projected from the individual level (the stories expressed by individuals) onto the collective level (the aggregate picture). Different collective identities were constructed based on salient identity-relevant traits present in the interview material and the degree to which they were shared. For 
instance, salient identity-relevant traits and stories can refer to common characteristics, similar and dissimilar perceptions, or matching episodes. The analysis draws on both mutual dependencies between these collective identities and how they interact with governance.

For the purpose of this sub-study, the interviews were analysed in a bottom-up fashion (Dye, Schatz, Rosenberg, \& Coleman, 2000) using the software MaxQData. Since identity is an elusive and context-dependent concept, and in an attempt to deal with the richness of the data, an inductive approach seemed more appropriate. However, while inductive approaches may offer more opportunities for discovery, the generalisability of the results may often be limited (Gioia, 1998). Where appropriate, Study III draws on information gathered from different web sources (e.g., the Joomla website, forum entries, statistics) in order to facilitate a holistic understanding of the empirical case.

Finally, it is important to note that the analysis is not intended to trace the historical evolution of effects between governance and collective identities. Rather, the episodes and events in the empirical data are used for illustrative purpose.

\subsection{Analysis}

The following discusses the set of salient collective identities that emerged from the analysis. The seven collective identities and the labels used for them were chosen by me, and are intended to be descriptive of the meanings associated with particular clusters of codes. For each of these collective identities, the text provides illustrative examples that show how governance and identity interact.

\subsubsection{Independent collective}

The distinct and interesting story connected with the initiation of Joomla was told in more detail in Section 4.1. This story is still vividly reflected in the interview material and contributes much to an understanding of one of Joomla's enduring and holographic identities, which is that of an independent collective. In short, the Joomla project was initiated in 2005 when a group of developers forked the code from the Mambo project, a CMS that was initially developed and made open source by the Australian company Miro. The project was forked due to a dispute between volunteer developers and Miro, who controlled the Mambo project. From a community perspective, after having harnessed the collective efforts of volunteer developers contributing to the Mambo project, Miro decided to take on a governance change that would exclude key community 
representatives from the governing body of the Mambo Foundation. As people in the community argued, this move was to have more control over the Mambo project and to be able to reap commercial benefit from the software exclusively for themselves.

This conflict with Miro caused outrage amongst the growing base of volunteer developers who had contributed to the Mambo project back then. A widely-shared opinion in the community was that it was unfair that a single commercial actor should control the Mambo project or be able to exclusively reap financial benefits out of the fruits that the community of volunteers had helped creating. Many community participants shared the frustration and anger over, what they perceived as a company trying to strip them of their accomplishments as a collective.

\begin{abstract}
"And then, then of course, people started saying, hey, what's going on here, what's about open source? Then they [the volunteer developers] took the code and this was the beginning of Joomla 1.0. So, they [the volunteer developers] said, not with us, um, well that is not open source. And, this basic thought, that the software is free, in the sense of freely accessible, but also in the sense that everyone can contribute, and there is not just one person or one firm or instance that owns this thing, that is something that is definitely borne by or cherished in the Joomla community" (Interviewee \#16).
\end{abstract}

From an identity perspective, Miro's decision severely conflicted with the community's shared belief in the ideals of open source, but it also violated participants' sense of fairness (see Figure 24). During the days of Mambo, the identity of an independent collective may have been a latent identity (Pratt \& Foreman, 2000) that was already slumbering within the community but that Miro's management may have failed to recognise. One could argue that the conflict with Miro triggered a transition in which the community developed a more tangible sense of its identity as an independent collective. 


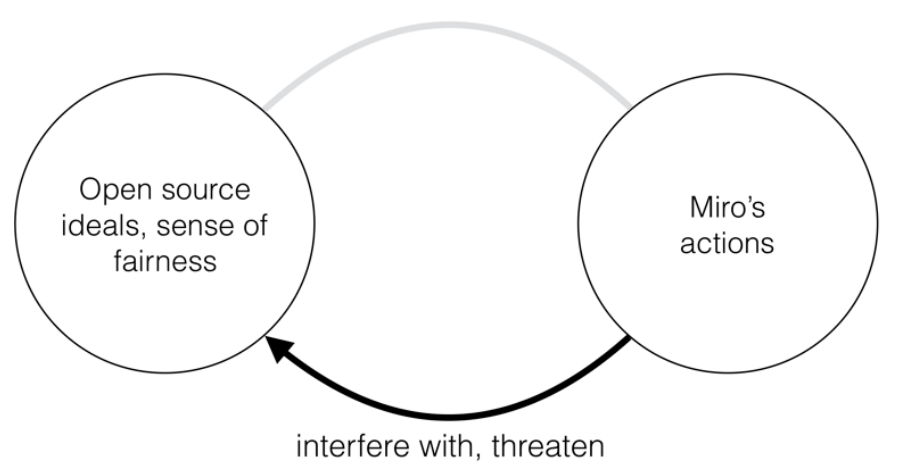

Figure 24: By community participants, Miro's actions were perceived to be in conflict with the community's shared belief in the ideals of open source and fairness. In particular, Miro's decision of excluding key community representatives from the Board of the Mambo Foundation caused indignation among people in the community.

Ultimately, the trust in Miro was destroyed on the volunteer developers' side. As a consequence, all of Mambo's core developers left the project and forked the Mambo code. Shortly after that, the Joomla project was initiated, as described in Chapter 4. The name 'Joomla' is a "phonetic spelling for the Swahili word 'Jumla', which means 'all together' or 'as a whole'"142. This aspect of togetherness often surfaced in the stories by the interviewees, both implicitly and sometimes explicitly.

"I think that there are a lot of people who are dedicated to Joomla, and that is the reason why we have a very humane, interactive, and also, yes, well a bit like the meaning of the word Joomla: all are one, all together. Either consciously or subconsciously everything runs in that spirit. We're doing this together" (Interviewee \#7).

In 2005, the Joomla project quickly gained traction and became the most popular CMS, with millions of users and followers, a position that it was able to hold onto for a few years ${ }^{\mathrm{xx} \mathrm{x}}$. The Joomla project was organisationally and legally backed by a foundation called OSM. One interviewee mentioned that this foundation was deliberately designed so as to keep the authority of the board over community matters and production decisions weak. One could argue that this particular form of governance was established as a

xxxI If we believe that Google Trends reflects a truthful picture of relative popularity. Therefore, this statement should be treated with care. 
consequence of the developers' previous experiences with corporate ownership and control, but also due to the emerging identity as an independent collective (see Figure 25).

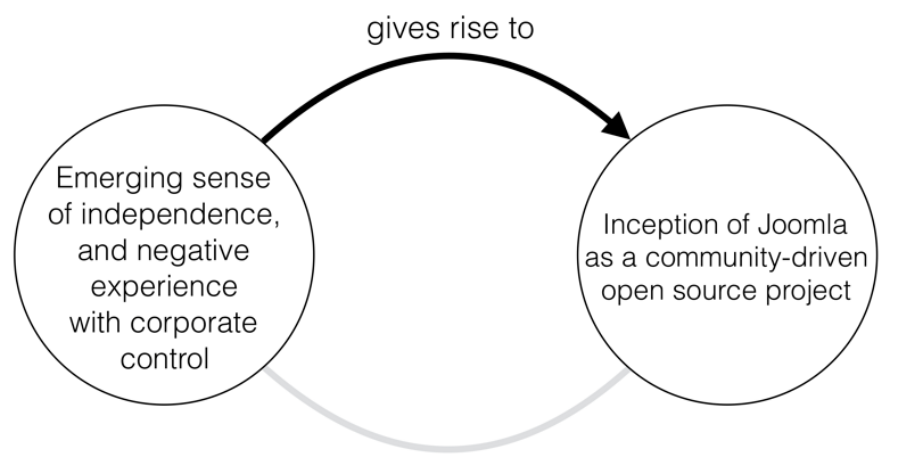

Figure 25: The inception of Joomla in 2005. The emerging sense of independence and the negative experiences with single-vendor corporate control led to the inception of Joomla as a community-driven open source project. The governance structures and the newly founded non-profit organisation were (and still are) characterised by flat hierarchies and decentralised decision-structures.

This story explains why many people in the Joomla community are sensitive towards ideas of introducing forms of corporate sponsorship via having the Joomla project run by a firm (as is the case with WordPress). Rather, people in this community are proud of their identity as an independent, communityowned and community-run open source project.

"... the pride in being completely open source and volunteer-driven, so for Joomla, I would say that stands out above all" (Interviewee \#6).

Not only would people in the community object to corporate sponsorship and control, but some people would even argue in favour of turning down donations from companies entirely in order to protect the project from corporate influence.

"I'd be like ... we need money to pay for the trademark ... we have to take these donations... but they were like, no, it'd be undue influence..." (Interviewee \#12). 
According to an interviewee, there were also ideas and experiments with paid development in order to be able to meet deadlines with upcoming Joomla release (remember that all Joomla community work is done on a voluntary basis). However, these ideas were met with (great) resistance in the community. Although there are community voices claiming that Joomla should be organised like WordPress in order to increase efficiency, these voices are often met with great resistance and references to the idea of togetherness. All in all, the repercussions of the negative experiences with Miro were deep, such that the identity trait of an independent collective evolved into an enduring identity.

\subsubsection{Open society}

As the empirical data show, further values and characteristics that are central, distinct and enduring in the Joomla case are supportiveness, helpfulness, openness, voluntariness, a passion for open source ideals, and a general spirit of generosity. The Joomla community embraces cultural pluralism and fosters a culture of sharing. In a nutshell, these identity-related aspects can be encapsulated as an open society (Lessig, 1999). The identity of an open society is a holographic one; the empirical data suggest that it exists throughout the entirety of the organisation. This particular value mix also engenders an appealing and stimulating environment that facilitates learning.

"... one thing I noticed particularly ... is how willing people were to help and how willing people were to share their own learning lessons, and their wisdom, and how freely they were willing to share their experiences, meaning like, I was new into the business ... at that time I had just left a corporate job, ... that was highly competitive ... and so what I really noticed was how friendly people were and willing to share ... 'these are the tools what I'm using, this is what works, for me, these are the things that I have done that haven't worked well', and I found that very striking compared to being in a corporate setting where people were competitive amongst each other, and I didn't find that within that open source environment, where even to the point where, you know, here I was, I am coming into web design and I am talking to other people who are making a living as web designers, and yet they were willing to say, you know, 'my recommendation is, you do this and that, and be careful with this', and I don't think that is common, you know, like people typically view you as a threat, and I didn't experience that at all [in the Joomla community]" (Interviewee \#1). 
Governance-wise, the community strives towards making organisational decisions in a democratic, consensual, and transparent manner. It could be argued that the particular mix of salient values (e.g., togetherness, open source ideals, generosity, voluntariness) gives rise to a governance model that favours collective decision-making, open exchange, and flat hierarchies at its heart (see Figure 26).

"... the open exchange model ... where not just one person can make decisions easily, ... because one person's mistake cannot be ... the future of a big project such as Joomla, it will be subject to the views and influences of all those who have a chance to participate ... open exchange is really a good thing. I think it ensures that this community sticks together. ... in terms of adopting features or dealing with issues ... that all happens through open exchanges ... I don't know whether other open source platforms do that, but for me, that is cool for Joomla" (Interviewee \#25).

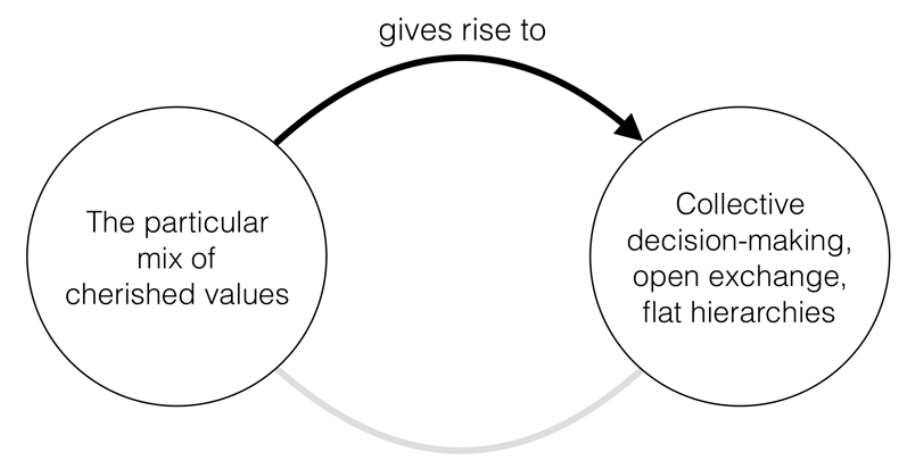

Figure 26: A salient value mix favours a particular governance model that is characterised by collective decision-making, open exchange, and flat hierarchies.

However, among interviewees, there are different opinions about the degree to which the decision-making structures in the Joomla community are effective. While Joomla's governance encourages participation on a rather broad scale, it may also promote organisational inertia regarding production and decision processes, as was expressed by many interviewees. As a consequence of its collective nature, decision-making can be subject to various interests tugging in different directions. As the empirical data 


\section{suggest, collective decision-making and volunteerism can lead to organisational inertia and chaos (see Figure 27).}

"[This] is how this project succeeds, you know, because at some points it is very hectic, you know, it's not like, ok, we are doing this in one month, it never works like that, or if you notice, for example, with every release, it's planned for one day and then probably it will release two months later, one month later, it's never, I don't remember any time there was ever a release that was launched on time ... because everyone is contributing, they don't get anything paid for, it's not a job ... and I don't feel that there is anything that I really dislike, because I understand there are limitations ... (Interviewee \#3).

"Joomla is run by anybody, so nobody can take a decision and say, ok for version 4 and 5 we want to go there and do that ... For Joomla, one of the drawbacks is great, because no one is the boss, it's anybody in the community can participate, but then, ok, you have discussions, some people may have this view and may think that this is important and some other parts are not important, other people, rightfully, have other ideas, and so on, but who decides, it's really difficult ... then you can have people not happy, and making a bad buzz, because they are very influential and not happy with the direction of Joomla 4, but that's a community and nobody decides. It has, it's good, I find it better, I like it better, but it also has drawbacks, that nobody can say, 'stop playing with the code guys now, this is the decision', ok, there are plus, there are minus, but globally we take this direction, point. Now, go and work. So that's the good thing and also the bad thing about Joomla" (Interviewee \#22).

"... everything does not need to be run by a corporate company, but the way it is maintained, it needs to change, or speed up, where there is taking time to take decisions, where they are not talking with the thirdparty developers, and, you know, everything is connected with business. If there is no business, not all people are connected to them, ... Suppose a new design trend was introduced like two or three years ago, like UX,... other things are moving so fast, but they are much too slow" (Interviewee \#4).

"... everything is very messy ... I think Joomla is an example of the chaos theory, because if you take a look at it and ask yourself, 'how can this be working?', you know, because there are people from all over the world, people who speak different languages, and there is no one telling them what to do, and that's a fact. There is no one saying, you have to do this, at least on the community side, I cannot tell you exactly, maybe it would be nice to have the perspective from the production leadership 
team, but on the community side you don't see people giving orders, normally. I know some people who try to and they wind up a long [way], yes, if you start giving orders, it's somebody, people stop listening to you, and um, so but anyway, I feel that even in the production leadership team, it's still very messy, you know, I mean it looks like chaos" (Interviewee \#3).

"I mean, few people know how much goes on in that project, like I have said that many times, you think you know everything that is going on, and then you find out there is some group with 15 people working on, you know, some really particular detail on accessibility [or the like] ... " (Interviewee \#12).

"... despite all this chaos and stuff like that, we have a great tool in our hands ... [however,] ... things take a long time to happen, and people talk a lot, there are the different time-zones, so it's not like, 'oh, let's meet anytime of the day', ... we have people from all over the world ... it's very funny, and it works, you know, there is an organic thing in the Joomla project that makes it work, and the only thing that comes to my mind, is 'organic', it's like a water that falls through the cracks of a rock, you know, it finds the best way ..." (Interviewee \#3).

"... I would say that is probably a very big weakness within Joomla, or maybe just the open source nature of it, because people are all volunteers, ... there can be some real dropouts, you know, you know gaps in consistency, or the project's gonna move forward and then they don't move forward some aspect of the project, you know, or something falls on its face, um, or I would probably say, ... that's a real weak point in dealing with volunteers" (Interviewee \#1).

"Well, I think in order for a community to be successful, in terms of IT projects, it has to deliver a good quality product, of course, um. But it has to be a community that does not succumb to in-fighting and struggles for power, that is ultimately counter-productive. Let's not forget that this community is centred around a piece of software, the thing that people use to build websites. And in order for it to be successful, it has to be used by a lot of people, and to be used by a lot of people, it has to be improved constantly, and in order to improve constantly, it has to progress. It can't be focused on, oh he said that, and then we do this ... It has to have clear goals forward and it has to accomplish them in a given period. I don't know if you know but the release of Joomla 3.5 was delayed seven or eight times because of complete chaos of the project" (Interviewee \#7). 
"Regarding the programming part, I have the feeling that in the top-level leadership they lack a bit of structure, I don't like that in the sense of, well everyone can participate, which is a cool thing, but it lacks a control structure that monitors whether everything makes sense. I would say that it lacks quality management, and I don't like that" (Interviewee \#10).

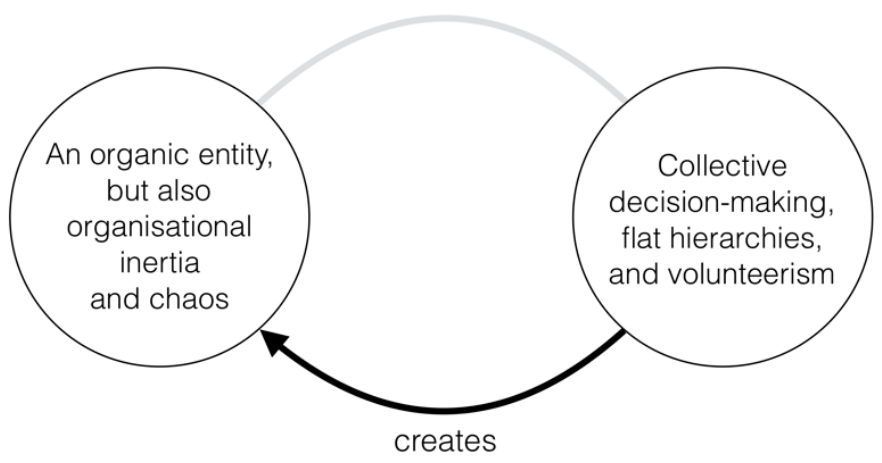

Figure 27: While collective decision-making, flat hierarchies, and volunteerism are cherished in the community, organisational inertia and chaos can come as the flip side of Joomla's governance model.

\subsubsection{Conflict space}

Although most interviewees emphasised that Joomla is a friendly and open space for people interested in exchanging support, knowledge, and ideas, it can sometimes also be a harsh environment for community participants. As much as the values of openness and transparency are cherished and perceived as stimulating factors by interview participants across the whole sample, the same values may also amplify another phenomenon that Joomla is known for: open disputes and a culture of open conflict (see Figure 28). These identity-related aspects could be considered as a conflict space, an ideographic identity. This means, while consensus-seeking seems to dominate in the community, sometimes, there can be more serious conflicts between particular people or small groups of people ('clubs' or 'clans', as they have been termed by interviewees), but not community-wide. Several interviewees emphasised that they prefer to stay out of these kinds of conflicts ("stay out of this kinda crap"). Although interviewees uttered disapproval of certain types of behaviour that they have seen in the past, conflicts in the community do not seem to have a crucial effect on the way in which interviewees see the community as a whole. 
"[Regarding conflicts and disputes], it doesn't affect how I see Joomla, how I use Joomla, and how I will give back to Joomla or anything. There will always be issues with people who want to go a different path" (Interviewee \#21).

A culture of open conflict also seems to be cherished and valuable.

"To be open, so to simply openly approach other people. And maybe also to criticise openly, not to do it behind other people's backs. I think, those who I have to do with would very much agree with that, to treat conflicts openly" (Interviewee \#24).

"I don't see a conflict as a weakness, I see it only, if you don't solve the problems, that's the weakness ... there will always be problems. If you solve them well, then you have a strong community ..." (Interviewee \#21).

However, from a governance perspective, the Joomla leadership has implemented several measures to ensure that community participants meet each other with respect, especially when they disagree. A CoC was put into place, likely with the intention of attenuating the negative side-effects of the core values of openness and transparency by emphasising on the values of respect and fairness ${ }^{143}$.

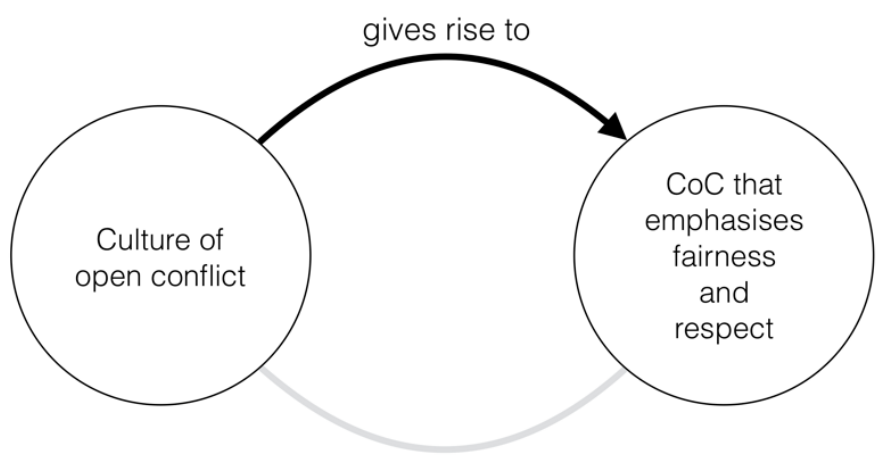

Figure 28: A culture of open conflict gives rise to the implementation of a code of conduct that emphasises fairness and respect.

However, the CoC alone proved not to be effective enough. This led the leadership teams to more drastic measures in dealing with issues of 
disrespectful utterances, flaming, and bashing. In the autumn of 2016, the community introduced a conflict resolution team that received the authority to initiate an election among leadership teams to ban community members who breach the $\mathrm{CoC}$. This formal bureaucratic mechanism allowed teams to sanction inappropriate behaviour towards other community peers.

"...the way that Joomla is going now, they have developed structures that ensure that you don't have to tolerate everything" (Interviewee \#10).

In conjunction with the voting procedure of banning people, the leadership introduced a non-disclosure agreement ${ }^{144}$ to protect the identities of the parties involved, including the leadership team voters and the banned community member. Not long after its inception, the new policies and procedures were applied for the first time, and with quite mixed results. The leadership informed the community that a high-standing and respected community member had received a temporary three-month ban from all community activities because of continuous breaches of the $\mathrm{CoC}$. The leadership announced the following:

\begin{abstract}
"We regret that today we had to ban someone with an outstanding track record as contributor and volunteer to our project. However, as leadership we cannot keep turning our heads away when this same person keeps breaching our CoC. This ban is meant to be a temporary measure to get the message across that as leadership we also attach great importance to a safe and healthy community ${ }^{\prime \prime 145}$.
\end{abstract}

However, according to interviewees, this decision caused a great buzz in the community, especially on different social media channels. Many criticised the lack of transparency and openness in the way in which this decision had been taken.

"... it wasn't talked about by the leadership team because of some nondisclosure agreement was signed to protect I guess the identity and the discussion of what happened. And I think that is a bad thing. I think that there should not ever be a non-disclosure agreement, and it should always be transparent because that is what Joomla is all about, community and openness" (Interviewee \#13).

"... if something was done that was against the governance and against what was signed for, then absolutely, the person should be banned, um, and that's totally fine with me, but again, I think the lack of 
communication, um, made it seem a lot worse than it was" (Interviewee \#14).

"... it's a huge drama. Um, basically someone was banned from the community for three months. Um [struggles to find words]. Um, it's a huge conflict and a struggle for power. There have been people who sort of came to the project and started to gain more and more responsibilities. And, they had some fundamental issues with other members of the community, um, that's one big problem with projects centred around communities, you tend to have in-fights. It's just our nature to struggle over things" (Interviewee \#7).

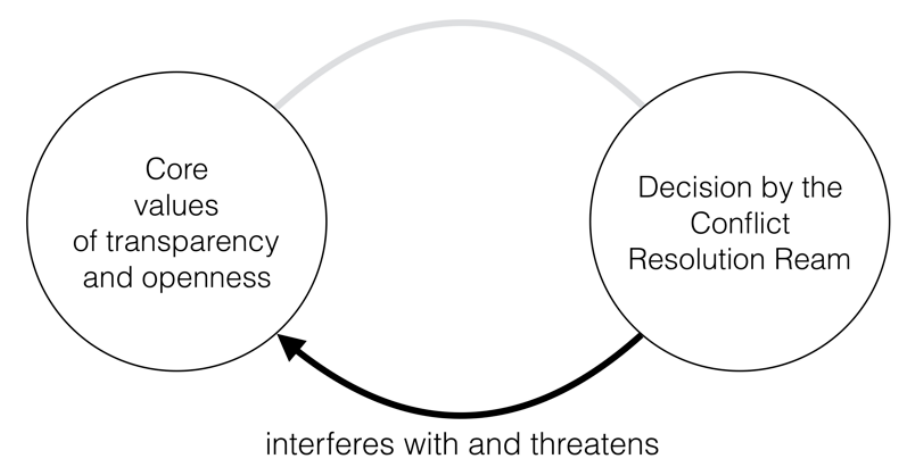

Figure 29: Newly implemented policies and procedures to deal with breaches against the $\mathrm{CoC}$ conflict with some of the core community values.

\subsubsection{Professionals}

Most of the interviewees had a professional business connected to the Joomla $\mathrm{CMS}^{\mathrm{XXXI}}$, or used it as a tool in their daily work with clients. These interviewees emphasised the flexibility, stability, scalability, robustness, extendibility and versatility of the Joomla CMS. There is a shared opinion amongst these interviewees that the Joomla CMS is well coded, top-notch in terms of security and that it is well suited for small, big and complex projects alike.

For these interviewees, Joomla and its community are important for their professional identities. In turn, these people infuse the community with business know-how, and entrepreneurial and strategic thinking. This makes

xxx॥ E.g., web developers, designers, extension providers, marketers, consultants. 
the Joomla community also a community of professionals. However, not everyone in the community has a business connected to Joomla. The identity of professionals is therefore an ideographic identity.

"It's just always weird to me that Joomla is seen as more of a commercial project than other projects" (Interviewee \#12).

"Everyone knows me as Joomla Boy. The fact that you are a reference and subject matter expert counts a lot for your professional success. Today I work exclusively with Joomla" (Interviewee \#9).

"... I do web development, I do websites only with Joomla, I do nothing else any longer like WordPress or others. And because I specialised in Joomla, I think that I have developed sort of expert status in that area ... and I think that I am also recognised for that" (Interviewee \#24).

"Well, in my profession everything basically revolves around Joomla. So, it has a rather big role in my life. It's a hobby and a profession, I work with Joomla, I also actively try to increase its popularity, so it parallels my whole life" (Interviewee \#10).

The interplay between identity and governance in this section can be illustrated by drawing on the ban of non-GPL code from the JED ${ }^{\mathrm{XXXII}}$ in 2009. Before 2009, the community also accepted non-GPL code on the JED. This means, before 2009, extension developers could distribute their code under alternative licensing options (both open source and proprietary). Furthermore, they could protect the source of their extensions by encrypting it. However, in 2009, the community leadership decided that all extensions on the JED had to be GPL compliant. The community leadership justified this decision with reference to the core values and the mission of the Joomla project (see Figure 30). In the community, this incident and the conflicts around it were also termed the 'GPL war'. As was announced on the Joomla website:

"Starting on 1 March 2009 only Joomla extensions licensed under the GNU GPL will be accepted into the JED. After another three months, from 1 July 2009, such extensions will no longer be listed in the JED. Under the same schedule, all encrypted or encoded extensions, whether

xxxIII Extensions are pieces of software through which the functionality of a basic Joomla installation can be extended in order to tailor the system to particular needs. Developers can market their extensions to users and customers on a platform called JED. This platform is operated by the Joomla community. 
or not they are GPL licensed, will also be excluded. Third party developers are a valued part of our community and in order to make this transition as easy as possible for them we selected a long notification period. This change is designed to strengthen the project's active commitment to its core mission, vision and values as articulated in September $2008^{\prime \prime 146}$.

"Well, I think, the Joomla community is very ideological about the idea of open source, in the sense of, it is open source, and you also have to distribute it open source. That has also led to that in the extension directory all extensions were removed that were not GPL licensed. It cannot be really followed up in all cases, but I would say it is a bit outlawed in the community when you take open source and then violate the licence terms. In case it happens, this is strongly decried in the community" (Interviewee \#10).

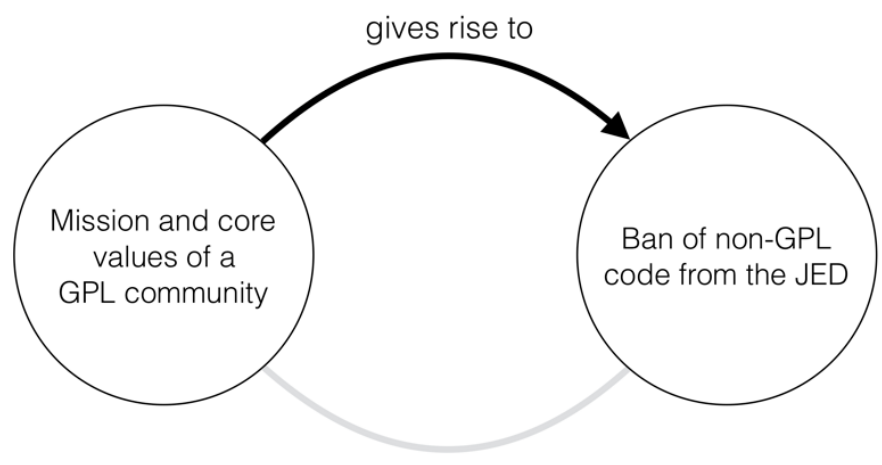

Figure 30: The community leadership justified the ban of non-GPL code from the JED with reference to the mission and core values of the Joomla project.

For some extensions providers, the new JED policies had the consequence that they could no longer charge for their software on a per-site basis. Nor could they any longer encrypt the source code of their extensions. As a consequence, many extension providers had to transition to a subscriptionbased support model for selling extensions.

"Actually, another business model a few years ago before they had the GPL wars in about 2008, something like that. Before that, there was not a requirement for extensions on the JED to be GPL licensed, so you had people who were selling extensions that had encrypted source code and 
you had to, when you buy it you gotta have this ionCube, or something like that running on your computer to run the extensions, and what people tended to do was to restrict the number of sites you could install it on, and basically a per/site fee for the software. Since the GPL enforcement came in, and I think it was 2009 or 2010, I'm not exactly sure. But basically, there was a big drama in the Joomla community, but they made a decision, so ok, from now on we are only going to list GPL extensions on the extension directory. And if you don't provide GPL code, you get unlisted and you won't get any traffic. So, of course a lot of drama, and some people were very annoyed ... under the GPL ... when you sell your software, you have to provide all the source code, so you can't really restrict someone from installing that one piece of software that they buy on a hundreds of sites or thousands of sites..." (Interviewee \#13).

All in all, the GPL policy change affected the ways in which extension providers interacted with their customers. In particular, it affected the way in which extension providers could effectively charge for their software products (see Figure 31). Furthermore, not being able to encrypt the source code, but having to deliver their extensions as GPL code to customers instead, may have enhanced the sensibility for software quality and coding standards among extension providers, since the code is available for study.

"I am personally not gonna read through anybody's code, because I am not a developer, but it makes, it makes the code developers to stand by their work, because people gonna get into it, so they can't hide behind it, so I think that is good" (Interviewee \#25). 


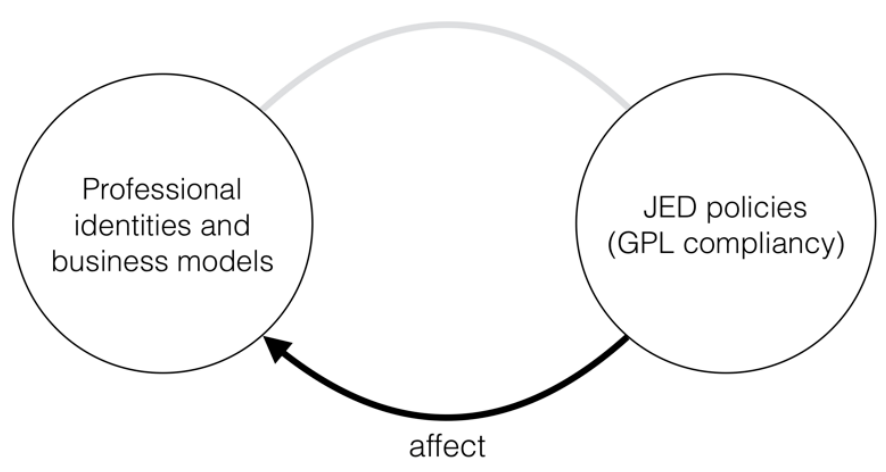

Figure 31: The banning of non-GPL code from the JED affected business owners around the Joomla platform and their professional identities. In particular, it affected the ways in which extension providers could effectively charge for their software products.

\subsubsection{Technological experts}

The Joomla CMS is a complex software product that is built and maintained by people who are technological experts in their respective fields. The identity of technological experts could be seen as an ideographic identity. Most users may be experts in working with the Joomla CMS, however not everyone may get in touch with its code under hood.

The identity of technological experts is shared by the people who account for the production of the Joomla CMS. They attend to all kinds of technical and production-related issues, such as security, user interface design, bugs, extensions, system design, and the Joomla framework. By interviewees, these people were referred to as the 'hardcore programmers'. The identity of technological experts also belongs to people who are not directly involved with the production of the Joomla CMS, such as people who are more peripherally involved in the community but nevertheless possess profound coding skills and in-depth knowledge of the Joomla framework.

"I really love the code, I love how Joomla is built how it is written" (Interviewee \#18).

"...we have a very, very strong coded CMS, and there we are very strong, and we are very flexible, where other CMSs are very strict on what they may do" (Interviewee \#2). 
The following discusses the interaction of governance and identity by the example of production teams and meritocratic governance. Although democratic participation has been gradually increasing over the years, when it comes to the production of Joomla, what effectively counts is an ability to demonstrate merit, skills, and technical expertise. Joomla's governance model is characterised by flat hierarchies, openness, volunteerism and a lack of hierarchical control, which favours meritocracy as a governing principle (see Figure 32).

"Yes, that's the hierarchy with us. So, if you are known, there are different Google groups, different chats. It's a bit like, you have to know people, and then you can say, well I have an interest in that ... [but] you have to be active, and say that you want to help, and then I think there are no hurdles, to become a leader" (Interviewee \#24).

"... it's more like the ones who invest time, they are the ones who have an influence ... so it's actually the people who invest time, they set trends ... what Joomla's future direction looks like" (Interviewee \#24).

"If someone contributes a lot to the project then I think it's ok if they also dominantly shape the direction" (Interviewee \#5).

"... sometimes this [i.e., development] can eat up a lot of time over months or weeks, and you program only for the sake of improving the software ... you really have to pay respect to these people for investing so much time. So, of course it needs the community to make everything work, but in the end, it is a small number of people in the core team who implement stuff. The feedback from the community is of course important. But it depends upon this small number of people who do stuff that the project actually runs" (Interviewee \#11).

"There are certain people whose opinion is very important, simply because they have demonstrated their skills and knowledge in the past, they have developed certain things, and have proved that they are experts, and therefore they are perceived differently by community members, and they are highly respected" (Interviewee \#11).

"... the people who show up and get work done, definitely stand out from the people who don't" (Interviewee \#17). 


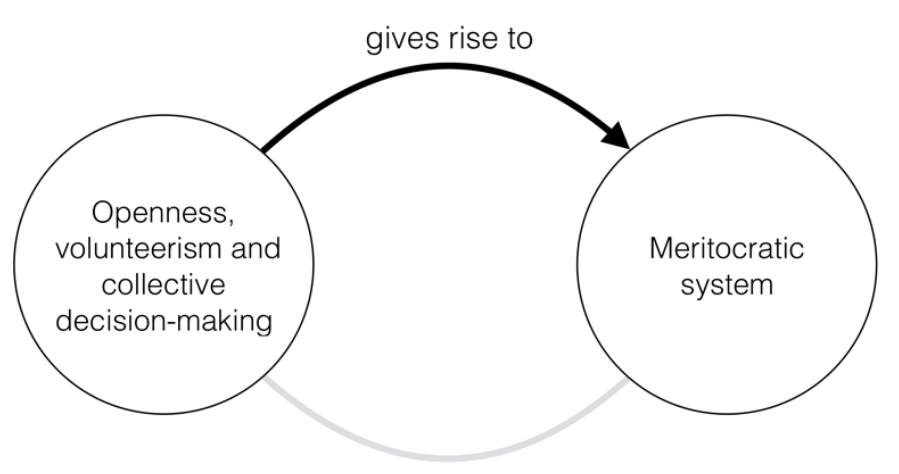

Figure 32: Openness, volunteerism, and collective decision-making favour the emergence of meritocracy as a governing principle. However, it should be added that democratic participation has been gradually increasing over the years. For instance, a recent governance change stipulated that all Team Leaders have to be elected by team members ${ }^{X X X N}$.

The impact of governance on identity can be illustrated by the example of mentoring activities and the on-boarding process for developers. According to one interviewee, the on-boarding process prescribes that new developers are given small tasks that they have to complete before they are assigned bigger tasks. It can be argued that such a policy, together with mentoring, helps to preserve the technical excellence and knowledge within the community (see Figure 33). The proven experts influence recruitment and initiation, guaranteeing that a culture of excellence survives.

"... somebody wants to volunteer, assign them a task, a small task, and see if they complete it, and if they complete it, you assign them another one, and then progressively assign them bigger tasks, but make sure that any task that you assign to them is something that they can complete. And never assign something bigger that they cannot complete. And this way it gives them a sense of contribution, and a sense of ownership but don't take somebody brand new, who comes with perhaps big credentials and put them in charge of other people who have been contributing for a while, that would be a mistake. So, that's the generally the gist of this on-boarding document" (Interviewee \#8).

xxxIV It was beyond the scope of this sub-study to take possible effects of the recently introduced Team Leader elections into account. Future studies could pick up on this. 
"I would say the last years, I was very active in development, but I am currently moving more towards giving speeches, to inspire people. So, I moved a bit away from general support to more specific support. It has become something more like mentoring" (Interviewee \#10).

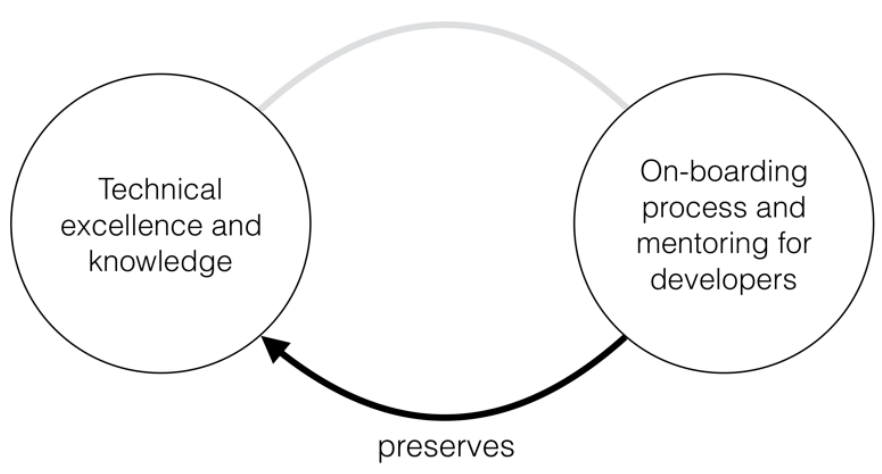

Figure 33: The on-boarding process and a focus on mentoring are measures that preserve the technical excellence and knowledge in the community.

\subsubsection{Family}

The Joomla community can also be seen as a family. Essentially, the identity as a family may hold the community together. In the context of Joomla, local congregations (e.g., user groups), personal contact, and offline meetings are of great importance. While much interaction between community participants necessarily occurs via online communication, face-to-face interaction and offline gatherings provide a human touch and are essential for building and strengthening emotional bonds.

"If this whole project would exclusively be online and impersonal, then it would not be something for me. So, for me, the personal thing, so actually meeting other people, is important" (Interviewee \#16).

"... the feeling of having it be an active community, is very important, that just saying, it's a community and having a list of names is not as powerful as having people who are actually communicating back and forth with each other, meeting, staying in touch, being involved in the project" (Interviewee \#6). 
"There is always money going with it, but if I look at the communityside, it's my heart that goes with Joomla and not the money. The money goes in when I have to travel, the costs, and for one night and the travel, and how to be an attendee at the events, the money in Joomla is in the companies not in the communities" (Interviewee \#2).

"The Joomla community means something very important to me because there is a strong family bond. In the community, there is mutual help and I believe it is helping others that we can achieve our results" (Interviewee \#9).

"For me the identity that Joomla passes is really a working community. A brotherhood, something that helps people improve in some way" (Interviewee \#9).

"Well, for me, Joomla is 'THE' project where the community is equally as important as the continuous development and prospering of the CMS system. I don't know other CMS communities that have a similar spirit in that sense. If the community is dead, then the project is dead, there is no corporate body behind Joomla, where you would have some employees doing the work, everything in Joomla is voluntary" (Interviewee \# 16).

For community participants, the identity of a family may also amplify the sense of obligation and commitment in light of the resources that have already been invested in getting to know people in the community and the Joomla CMS. Cultivating and experiencing a sense of family may reinforce feelings of social responsibility or the obligation to contribute back to the project or for the benefit of society at large.

"... it gets very emotional and passionate ... I saw that I was part of something bigger than me, and that I was helping it be maintained. So, this is something that is very, um, interesting because when, I saw, I realised that I was in the project that was helping other people, um, have their livings, make their livings, because a lot of people make their livings out of Joomla. In a way it touches people's lives for the better ..." (Interviewee \#3).

"... really, it kind of means everything to me right now, I mean, I'm so invested in it, um, you know, I don't know if it is weird, I kinda got swept away in it, I mean, really, what it means to me now, I work with people 
all over the world, and they are my friends, and I have gotten so many great opportunities out of it" (Interviewee \#15).

Early on, the Joomla community promoted the idea of local user groups. User groups are local congregations all around the world who organise meetings and events for people who work with Joomla. Local user groups are important offline forums for discussions among users on all skill levels. Typically, people get together in order to help each other in building websites (for both private and commercial purposes). However, besides working on technical problems these local congregations are also places to make friends, to have fun, and to talk to like-minded others. The empirical data suggest that the local user groups are an important vehicle for facilitating, reinforcing, and fostering the sense of family in the community (see Figure 34).

"What still makes you feel affiliated with Joomla, given all the circumstances that you just described and the setbacks? What still makes you feel positive towards it?] My local user group ... we get together. They are wonderful people, they are wonderful people. And people come to me, to join that user group because they have Joomla websites" (Interviewee \#26).

"... we are there for the friendship, and for learning something from each other, um, so it's just, it's not, um, I mean, people come there as a community thing ... I mean, they don't really expect to go home with a whole bunch of new knowledge" (Interviewee \#3). 


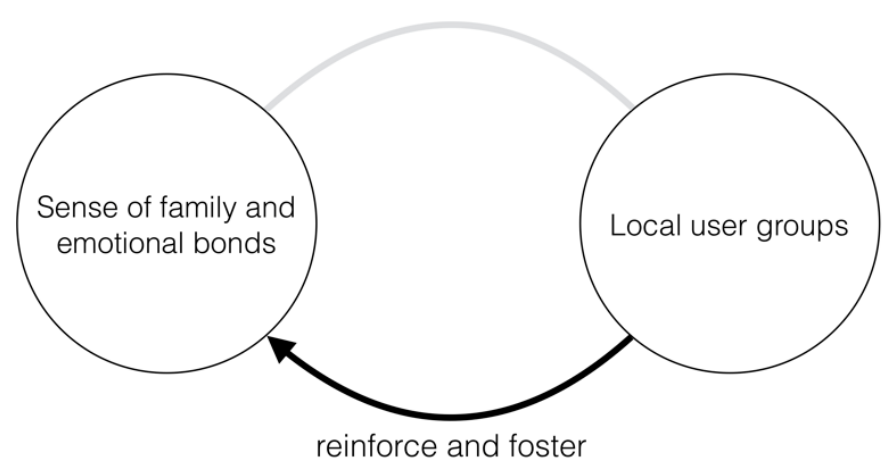

Figure 34: The local user groups reinforce and foster the identity of a family.

In many ways, the Joomla community can be seen as a community of communities $^{\mathrm{XXXV}}$. For instance, interviewees used the labels local communities, national communities, and the global community when talking about the Joomla community. These communities are all interconnected in some way. While user group meetings are more of local and regional relevance, many national communities organise so-called JoomlaDay events that have a more conference-like character and also attract and stimulate participation across countries and language borders. The JoomlaDay concept was taken over from the MamboDay concept ${ }^{\mathrm{xx} \times \mathrm{V}}$ early on. Although JoomlaDays are open to anyone, it is interesting to observe that it took a couple of years until the community began to organise global community events. In 2010, that means five years after Joomla's inception, the so-called "J and Beyond"147 event was organised as an international conference in Wiesbaden, Germany. According to the organisers, 190 people attended from 27 countries $^{148}$. In 2012, the community organised its first Joomla World Conference in San Jose, California $^{149}$. Both events still take place annually at different locations around the world.

"JoomlaAndBeyond ... has become a great conference because ... it's just very intimate, and it's all the Joomla people go and have a really good time, and conversations, I love that conference actually, um, it's

xxxv Just like 'family' may refer to one's immediate and local family, and to relatives further away.

xxxvı Gatherings in the Mambo community. 
one of my, you know, it's really fun, it's never in a big city, it's always in a smaller place, people are like focused on a group" (Interviewee \#12).

From an identity perspective, it could be argued that a growing sense of being part of a global family (e.g., increased exchange across national borders and continents) gave rise to the desire to organise community gatherings at a global level (see Figure 35).

"... sometimes you feel like you are in a global family. You know, when I go to events, I really feel like, ohhh, I really feel like home with my family, you know, because it's people that I've known for 5 years or even more. Some of them, it took me years to meet them in person, some of them I have never met in person, but we are in contact. So, when you are attending an event, the greatest thing for me, attending an event is just to be closer to both people that I either meet once a year, or that I may never have met ..." (Interviewee \#3).

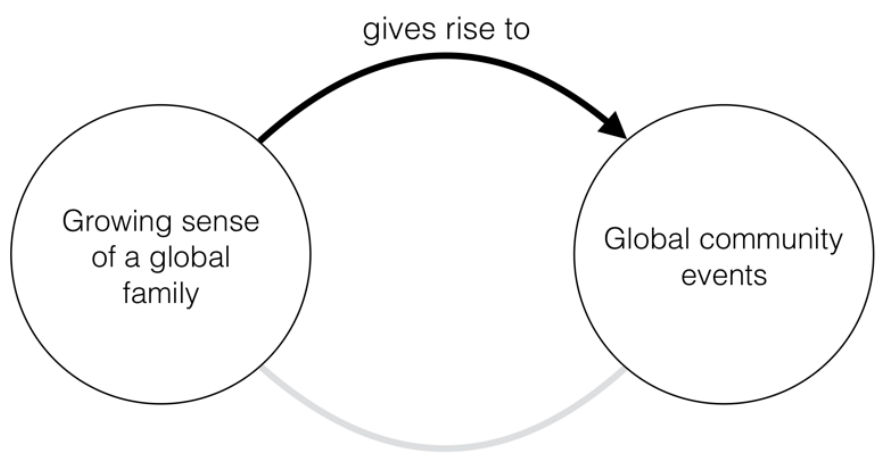

Figure 35: From an identity perspective, a growing sense of a global family gave rise to the organisation of global community events.

\subsubsection{Maturing organisation}

This section focuses on aspects of increased platform competition in order to illustrate the maturing of Joomla as an organisation. Different statistics on the Web indicate that Joomla has lost 'market share' over the past few years. However, the reliability of this data is difficult to assess. For instance, usage statistics provided by W3Techs ${ }^{150}$ only look at the top ten million websites (popularity ranking based on website traffic). However, the interview data indicate that Joomla seems a popular choice amongst smaller organisations. Given that the total number of websites has surged throughout the past ten 
years ${ }^{151}$, just looking at the top 10 million websites may not paint an accurate picture of Joomla usage. Given the steep rise in the total number of websites, it may even be the case that the absolute number of websites that are powered by Joomla has increased over time even though Joomla may have declined in the W3Techs statistics.

A 2015 article on builtWith.com ${ }^{\mathrm{XXXVII}}$ is entitled 'WordPress vs Joomla vs Drupal - The Battle Of The CMS'. The author, Chris Walker, observes the following:

"Although WordPress has the majority no matter which way you look at it, its lead is cut when we only look at the top 10,000 sites (instead of all sites on the Internet). Joomla also has a bigger share of the market when we're looking at the entire Internet (9\%), which fades when considering only the top 10,000 sites (1\%). Drupal on the other hand is more of a CMS of choice for the bigger sites out there. Drupal can be found on $9 \%$ of the top 10,000 sites, but only $2 \%$ of all of the sites on the Internet"1152.

Walker further observes:

"While all of these platforms [i.e., he is referring to WordPress, Joomla, and Drupal] are growing in absolute terms, there is a clear flow of users moving from and to each platform. WordPress looks like the entry-point tool, and doesn't gain many users from either Drupal or Joomla. It seems that once people have used either Drupal or Joomla, it's unlikely that they'll move over to WordPress. The same is not the case in the opposite direction though. Year upon year, WordPress is losing more users to Drupal and Joomla"153.

On the other hand, Google Trends statistics show a substantial relative decline in search-term frequency of the word 'Joomla' compared to 'WordPress' (see Figure 8 in Section 4.2.2). But also, this figure should be taken with care, not least because there was an enigmatic peak in 'WordPress' search frequency in 2014, which raises questions about how reliable this data really is. As mentioned earlier, it is at least conceivable that search term frequencies in Google Trends could be skewed by the use of automated robots on the Web.

Another concern with the representativeness of Google Trends is that Joomla developers seem to be more inclined to seek help from their personal networks, including colleagues, community peers, Joomla forums, and in

xxxvII BuiltWith is a profiler tool that analyses what kind of tools and frameworks a website is built with. 
different Facebook groups. This kind of search activity is not reflected in the Google Trends graph. It could be argued that the same may apply to WordPress. However, in the interview material, there is a shared opinion that the level of technical expertise amongst Joomla users is generally above that amongst users of WordPress. This could mean that WordPress users may be less inclined to immerse themselves in the relevant forums for technologists, that they have fewer people with pertinent skills in their personal networks whom they can ask for advice, and that they therefore may be more inclined to consult the Google search engine for help. If this is true, it would shed a different light on the Google Trends statistics. This interpretation basically rests on differences in technical proficiency amongst users of Joomla and WordPress; it seems to be further corroborated by the more general opinion amongst interviewees that WordPress targets users seeking a simple and easy solution for publishing content quickly without having to think about technical details. Some interviewees do not even see WordPress as a CMS (nor is it marketed as such, but as a blogging platform $\left.{ }^{\mathrm{XXXVIII}}\right)$.

However, what speaks against this interpretation is the potential for bias in the interview material. Interviewees' association with and preference for Joomla may influence their judgements in this respect. Another argument that speaks against this interpretation is that WordPress seems to be the market leader amongst the most popular ten million websites, where one would probably expect to find firms with more sophisticated demands on their websites.

Objectively, it is difficult to assess whether Joomla is losing market share or not. However, considering all the evidence, amongst interviewees there seems at least to be a shared perception that Joomla has lost market share in recent years. Arguably, this may have implications for community participants' perception of the vitally of their community.

Further data point in a similar direction. In June 2016, the Joomla community magazine released an article by John Hooley, a community contributor. The title of this article was somewhat alarming: "The Fall of Joomla"154. Hooley proposes three reasons for why Joomla has lost market share. First, he argues that the target audience has increasingly moved from developers to marketers. Second, he identifies a lack of positioning of Joomla. And third, he points to political issues that have hampered the progress of Joomla. Hooley's article concludes on a positive note, however,

xxxvIII On WordPress.org, WordPresss is marketed as an "open source software you can use to create a beautiful website, blog, or app". 
which resonates with the majority of beliefs in the interview material that Joomla will be able to increase its market share in the future.

From an identity perspective, a loss of market share can in many ways be interpreted as an identity threat. It can be argued that this perceived threat to Joomla's identity as a popular CMS solution for the masses has triggered a series of governance changes.

"First, the hard facts, the penetration of Joomla on the Internet, that was in decline over several years, and WordPress is the leader now. There is of course the success that we managed to stop this negative trend, I think that is a strong criterion. But also, the community, if you look at how many new things have been created, like JoomlaDays. All of a sudden you see that people come together through JoomlaDays, and they start projects" (Interviewee \#10).

"I think, a lot of people find it difficult to start with Joomla, where WordPress really has a much easier learning curve than Joomla, and also, five years ago and more, there was a huge difference between WordPress and Joomla, WordPress was not as professional as it is today, and Joomla was way ahead, five years ago, but WordPress has really caught up, and I think that they are equal in terms of professionalism today" (Interviewee \#21).

"I guess there is more competition, and also, um, systems, very small, like drag-and-drop, if you wanna make a website, just drag-and-drop, you don't need any programming, so that appeals to a lot of people, where you can make a website, you don't need any skills, you know, so many people will start there" (Interviewee \#21).

"With Joomla itself, when I say Joomla I don't mean the system but Open Source Matters [OSM], they recognised that the trend goes towards 'I only want to administrate content', and WordPress has quite an edge in that respect. I think that is also the reason for why WordPress is so strong, they say 'we take care of everything, you get your system with one click and can start working with it', and here Joomla is trying to pick up on that as well, slowly, with special offers. With Joomla.com, um, I think that Joomla has recognised these trends, and is trying to close the gap, which also relates to the transition process that you alluded to before, with Open Source Matters and so the signs of the times have been recognised, and now they just have to be implemented" (Interviewee \#10).

"Right, but the issue that I was talking about with the 1.6 fiasco that happened, I really think that killed us, but I guess that was from maybe 
2009 or 2010 or something, to 2012, these two years before 2.5 came out, I think that killed us, I saw it happen. Um, yes we have to be more competitive now but we are adding, for the Joomla 3.7, they are finally adding 'custom fields', which is going to be tremendous, my only hope is that they do it correctly" (Interviewee \#14).

From an identity perspective, it can be argued that the perceived threat to Joomla's identity as an open source CMS with a significant market share (relative to its competitors) has led to a series of governance changes within the community (see Figure 36). As examples, the following governance changes are discussed: the leadership transition, elections for Team Leaders, the certification program, and marketing initiatives.

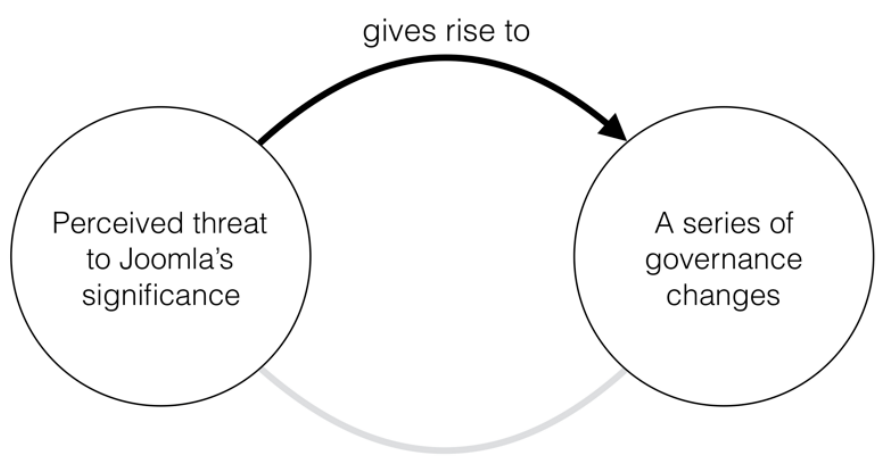

Figure 36: From an identity perspective, a perceived threat to Joomla's identity as a CMS for the masses triggered a series of governance changes.

In 2015, Joomla began to develop ideas for moving into a new organisational structure in order to make the community's decision structures sleeker and more effective. A transition team was put into place to guide and monitor the change. The actual structural change took full effect in early 2017. According to information in the community magazine, the goals of the new organisational structure were described as follows.

"The main goal of the new structure is to encourage contributors, bring together fragmented leadership teams and processes, involve more global communities, and to have a voting process where leaders are not appointed by leadership itself. It sets a road map for organised conflict resolution and a code of conduct"155. 
In autumn 2016, the certification program was introduced. The ideas for this program were already growing in $2012^{156}$. According to the Joomla website, the certification program had the following goals ${ }^{157}$ :

"The Joomla Certification Program has been created to ensure the competence of Joomla professionals through documented measurement of skills and knowledge. The program aims to establish a certain standard whilst promoting a qualified workforce. Professional certification can play an important role in the decision of a company or business owner when hiring skilled individuals for specific roles."

The Joomla website further emphasised that the certification program intended to establish a standard for professional Joomla skills. These measures could be seen as an attempt to strengthen Joomla's image as a platform for business developers.

With the leadership transition, Joomla also introduced elections for Team Leaders in order to make the selection process more transparent. Under the new organisational structure, Team Leaders have to be re-elected at the end of each year.

"Well, so far there were some people in the leadership team, and you knew each other, and then someone asked, can I join you, and then some people said, yes, you got the job. And that's all it took [laughs out loud]. So that was partly, or maybe it still is, non-transparent, so how do these people come to hold these leadership positions, who has a say in what, can someone also be deselected from that position again, and momentarily, we are in a transition process. So, the current structure is somewhat undemocratic, and in this transition process, or the final goal of that, is that the leadership positions in respective teams, are tied to a democratic process where you can apply for a position, and where people are also elected by others. So, the intention is that people are elected. Who is going to have the right to vote here, this is something that is not clear to me yet. So, not everyone that has written a simple patch, should be able to vote, so it is not that simple. So, it is a transition process that is currently under way, that is not finished yet, but we basically also noticed that because of the conflicts we had, that we have to go through this process. So, we cannot say that just because there are people who have done particular jobs for the past 10 years, that they should simply stay there, this is not justifiable any longer" (Interviewee \#16).

The newly implemented leadership structure also recognises the need to improve marketing efforts. Under the new leadership structure, a marketing 
and communication department was installed. Several interviewees mentioned that there is a need to enhance and rectify the image of the Joomla CMS and its community.

\begin{abstract}
"But I think the other thing, that's a big thing for Joomla to attract new talent, is to polish up its reputation because out there, out here in the wild, even though Joomla is still thriving within, the reputation here is that it is dying, and that is something propagated by the people in WordPress, especially. They say 'oh, Joomla is dying, and Joomla is dead', and now there is hundreds of CMSs out there, and Joomla is still thriving, for a while its market share was decreasing, and perhaps it lost some sites to WordPress, but I wouldn't say that it is dying, you know, but it has that reputation. And that's the biggest impediment towards its growing, is that is has a reputation of not being able to polish up" (Interviewee \#8).
\end{abstract}

It could be argued that, with the recent governance changes, Joomla is seeking to mature as an organisation. As one interviewee expressed it, organisation-wise Joomla could be seen as being in its final phase of puberty. It is still too early to assess the effects of the recent governance changes. However, all recent governance changes may, in one way or another, influence and shape Joomla's future identities (see Figure 37).

"I would rather say that Joomla has read the signs of the times, and that it actually has taken a strong positive development over the past two recent years. In earlier days it was rather unstructured, there were a few lighthouses that pointed the way, and in the meantime, it has been democratised a lot, the community has more rights to speak. And, one has the feeling, that one [the community] is about to grow up, one is not fully grown up yet, but I would say, one is in the final phase of puberty. So we have already survived a lot of big bangs, but there are still a few downshifts, but a lot of upshifts, so the trends is definitely pointing up" (Interviewee \#10).

"If we are able to deal with these kinds of problems, I really see a very bright future. Also in terms of flexibility, in the past, Joomla has been seen as more like the typical CMS for clubs, if it's more professional you use Typo3, for others you use WordPress, and if it's a cheap club you use Joomla. I think Joomla is moving away from this image, which is very positive too" (Interviewee \#10). 
"I hope the future of Joomla will be very prosperous! There are already several significant changes happening and this tends to improve. Joomla has already been shown to be the best CMS of the present time. It's just a matter of time to get ahead of the other CMSs in relation to the number of websites" (Interviewee \#9)

"There is still a little prejudice about Joomla. Some believe that Joomla is hard to work with, does not work well with SEO [i.e., search engine optimisation], and so on. But these are paradoxes that are being broken. It's just a matter of time ... Joomla 3.7 and 4.0 have just announced it is coming with everything. It will leave all competitors eating dust!" (Interviewee \# 16)

"Well, I mean, everybody says that the CMS as a product is just going away, it's not really necessary anymore for people to have that ... because there are so many, well both, the app world, which is outside the Web, so the world outside the Web is so much bigger, and then, even on the Web, there are so many more, for a simple website, there are so many more options, it's not really, people don't need this big thing, um, and, I don't know. I think, there will always be the need for some people to have a CMS" (Interviewee \#1).

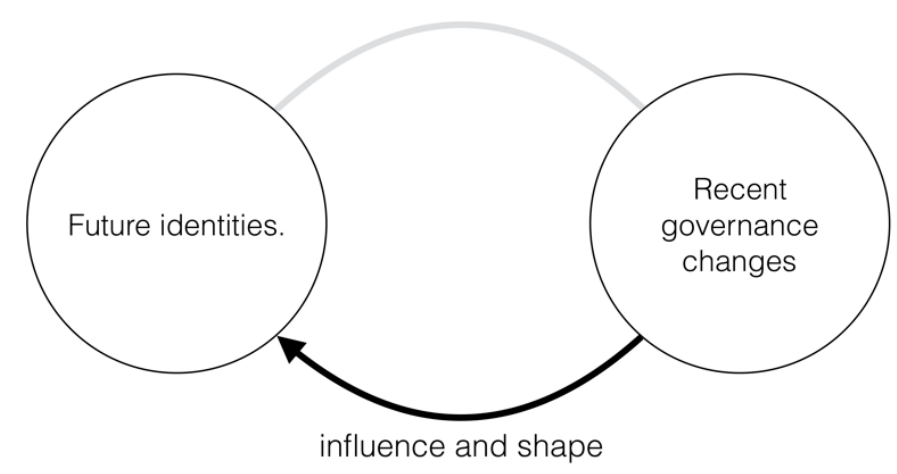

Figure 37: Recent governance changes will influence and shape Joomla's future identities.

\subsection{Discussion}

The analysis in Study III has focused on seven discernible identities, along with a description of characteristic traits. These seven identities should be seen as the result of the interpretative work of the researcher, rather than an 
exhaustive and complete picture of Joomla's identities. Table 4 presents an overview of these collective identities, along with the identity-related attributes that can be assigned to them.

\begin{tabular}{|l|l|l|l|}
\hline $\begin{array}{l}\text { Collective } \\
\text { identity }\end{array}$ & \multicolumn{2}{|c|}{ Identity-related attributes } \\
\hline $\begin{array}{l}\text { Independent } \\
\text { collective }\end{array}$ & Holographic & Stable and enduring & $\begin{array}{l}\text { Latent prior to Joomla's } \\
\text { inception }\end{array}$ \\
\hline Open society & Holographic & Stable and enduring & $\begin{array}{l}\text { Innate prior to Joomla's } \\
\text { inception }\end{array}$ \\
\hline Conflict space & Ideographic & Fluid & $\begin{array}{l}\text { Innate prior to Joomla's } \\
\text { inception }\end{array}$ \\
\hline Professionals & Ideographic & Fluid & $\begin{array}{l}\text { Innate prior to Joomla's } \\
\text { inception }\end{array}$ \\
\hline $\begin{array}{l}\text { Technological } \\
\text { experts }\end{array}$ & Ideographic & Stable and enduring & $\begin{array}{l}\text { Innate prior to Joomla's } \\
\text { inception }\end{array}$ \\
\hline $\begin{array}{l}\text { Family } \\
\text { incom }\end{array}$ & Holographic & Stable and enduring & $\begin{array}{l}\text { Innate prior to Joomla's } \\
\text { inception }\end{array}$ \\
\hline $\begin{array}{l}\text { Maturing } \\
\text { organisation }\end{array}$ & Holographic & Fluid & $\begin{array}{l}\text { Latent prior to Joomla's } \\
\text { inception }\end{array}$ \\
\hline
\end{tabular}

Table 4: Overview of collective identities in the Joomla case.

As can be seen from Table 4, the identity of an independent collective has been attributed as a holographic identity. The identity of an independent collective arose as a consequence of the fork from the Mambo project and since then has been a stable and enduring identity.

The identity of an open society has also been classified as holographic. Open exchange among community participants may encourage participation and hold the community together. In contrast to the identity of an independent collective, it could be argued that the identity of an open society was already innate to the Mambo community, prior to the inception of Joomla.

The identity of the conflict space has been attributed as an ideographic identity. While there can be fierce conflicts between different people and groups in the community at times, most community participants are probably not aware that these conflicts exist. The identity of a conflict space may be a more fluid identity (rather than a stable or enduring identity) because the nature of the conflicts is unpredictable and mutable. This identity may have already been innate to the Mambo community, prior to Joomla's inception. As was emphasised by interviewees, conflicts are not 
necessarily a negative thing. To the contrary, conflicts can also create momentum in guiding important decisions that affect the community as a whole, such as the fork from the Mambo project, future releases, and governance change.

The identity of professionals has been attributed as an ideographic identity. While there are many people who have a business connected to Joomla (especially people in the core community), this does not apply to the community as a whole. This identity is fluid because of the changing nature of the business environment (e.g., changing technological landscapes, platform competition, changing nature of business practices). This identity may have already been innate to the Mambo community prior to Joomla's inception, because back then people in the Mambo community were already offering commercial products and services in connection to the Mambo platform.

The identity of a family has been identified as a holographic identity. The identity as a family facilitates interpersonal bonds, meetings with likeminded others, helping behaviour, and long-term relationships. This identity can be regarded as stable and enduring. While much interaction in the community occurs via online channels, the stability of the identity of a family may essentially rest on people's ability and willingness to meet each other offline. This identity was already innate in the Mambo community, prior to Joomla's inception (the Mambo community had been described by interviewees as a strong and loyal community).

The identity of a maturing organisation has been attributed as a holographic identity. Governance decisions and governance change can affect the entire community. However, this identity is in constant flux, and should therefore be seen as a fluid identity, not least because governance constantly deals with emerging challenges and problems. Many governance changes over time have helped Joomla to mature as an organisation. This identity may have been latent in the Mambo community, prior to Joomla's inception, because the Mambo project was essentially controlled and governed by a corporate actor.

\subsubsection{Impact of identity}

As mentioned previously, identity can have both enabling and constraining effects, with both positive and negative consequences (Gustafson \& Reger, 1995; Kogut \& Zander, 1996). A commitment to volunteerism may appeal to people who value openness and helping behaviour. However, it brings about distinct challenges for the management of the Joomla project with regard to timeliness, commitment to tasks, and the continuity of the open 
source project. Open exchange and collective decision-making produce a system that was described as chaotic by one interviewee. However, chaos in this sense should not be seen as confusion, disorder or randomness but rather as a lack of predictability and the existence of complex orders ${ }^{158}$. Imagining the community as a chaotic and complex system, identity is probably better understood as an emerging bottom-up process rather than something that is imposed by top-down decision-makers, which it is often assumed to be in managerial perspectives on identity in the literature (Pratt \& Foreman, 2000). Although Study III assumes causal links between identity and governance, Joomla's governance is not characterised by hierarchical top-down decision-making. In a chaotic system, identities may be created, reproduced, negotiated and transformed based on open exchange and collective decision-making. A culture of open conflict may even fuel these processes in a lively way rather than obstruct them.

The literature suggests that multiple identities can be in conflict with one another, but also that repercussions of identity conflicts can be mitigated if identities are closely related (Pratt \& Foreman, 2000). It could be argued that the identity of an open society (characterised by open information exchange and collective decision-making) is crucially linked to the identities of professionals, technological experts, and the family. Open exchange promotes learning, the sharing of expertise, and the development of competencies, which also benefits the professionals who have a business connected to Joomla. At the same time, open exchange may foster the emotional bonds that hold the community together. This could be a reason why a culture of open conflict never seriously endangered the project's existence as a whole after it forked from the Mambo project (even though there were attempts of forking the Joomla project, as was reported by one interviewee).

\subsubsection{Requisite variety}

Pratt and Foreman (2000) argue that multiple identities can have both positive effects (e.g., increased response flexibility) and negative effects (e.g., organisational inaction, impeded strategic decision-making). Furthermore, they argue that too few identities can lead to a lack of adequate response strategies when organisations face turbulent times and change. They think that the level of multiplicity of identities should provide for enough requisite variety in order to cope with problems and change in complex social environments.

It could be argued that the multiplicity of identities in the Joomla case is likely to maintain a high level of requisite variety. Joomla is a worldwide 
community within which there is a diversity of skills, interests, capabilities, and cultural and professional backgrounds. This diversity may ensure a high degree of requisite variety, which in principle should increase the community's ability to cope with adverse conditions, turbulent times, and the challenges posed by the environment.

However, as the empirical data show, the reaction times to challenges are slow. One reason for this could be that the coordination costs in an open exchange model are high. Whether high coordination costs really diminish the benefits of this particular organisational form (e.g., the opportunity to source the creativity and competencies of crowds) is, however, questionable. Although the Web may be developing at a fast pace, it cannot be reinvented every year. Slow reaction times towards trends may even have positive effects if resources are spared that would otherwise have been wasted on hastily following trends that could later on turn out to be fads.

Essentially, from an identity perspective, open exchange and collective decision-making may favour the strengthening of profound value foundations (i.e., open source ideals, fairness, togetherness, transparency) over efficiency (i.e., timeliness, top-down decision-making, predictably). The art, it seems, in this particular case, may be to find the sweet spot between governance that improves efficiency, and governance that is in harmony with profound community values (e.g., collective decisionmaking, openness, transparency, cultural pluralism, helping behaviour, togetherness). With Joomla, the journey might be the true destination - the maturing organisation should keep that in mind.

\subsection{Preliminary conclusions}

Study III has analysed the interplay between governance and collective identities in the context of an open source community. The analysis identified seven discernible identities in the Joomla case. The interaction between governance and identity was described and illustrated based on identity-relevant narratives and characteristics, key incidents, impactful events, and change initiatives. The results show how collective identities and governance interact in the context of a worldwide community of volunteers. Furthermore, the enabling and constraining effects of identity were discussed with respect to open exchange, collective decision-making, and requisite variety. From an identity perspective, open exchange and collective decision-making may favour the strengthening of profound value foundations (i.e., open source ideals, fairness, togetherness, and transparency) over efficiency (i.e., timeliness, top-down decision-making, and predictably). 

9 Relationships between volunteer work and economic interests in the context of community-driven open source (Study IV)

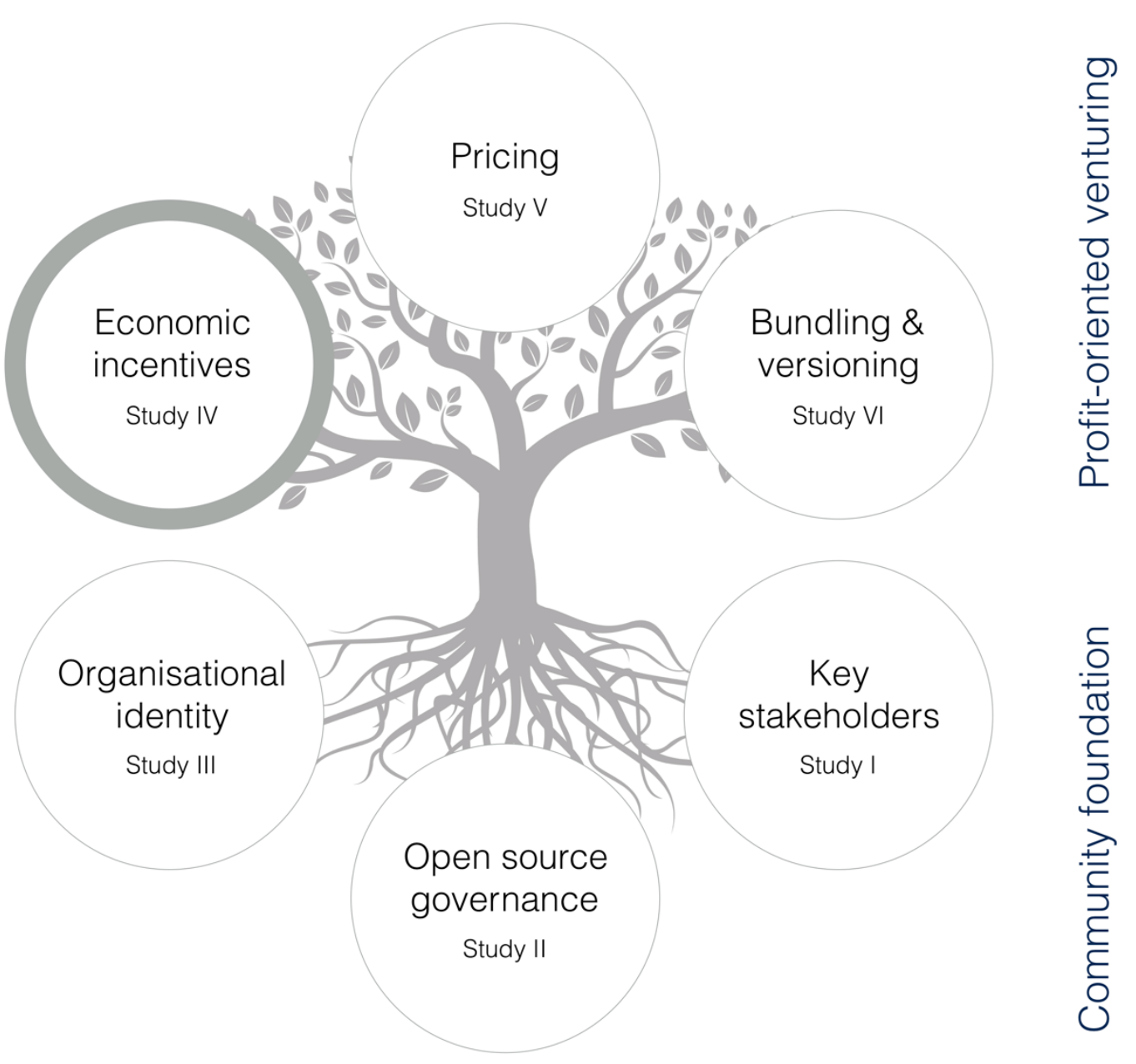




\subsection{Short summary}

Study IV explores the ways in which open source community engagement can support volunteers in pursuing economic goals. Following a call in the literature for more research on the relationships between community work and commercial activities, it applies a motivation perspective in order to illuminate how different motivations for community engagement are connected to community participants' abilities to pursue economic goals based on their community's software product(s). While the previous literature has focused on determining whether some types of motivation for community engagement dominate over others, Study IV focuses on the interrelatedness of motivations. Unlike other studies that exclusively rely on person-oriented motivations, this sub-study also concedes weight to incentives that are provided by the social and macro-institutional context. The results show how salient motivational drivers in the context of a community of volunteers (openness, supportiveness, identity, learning, reputation, use value) are connected to participants' abilities to advance their economic and career concerns. 


\subsection{Introduction}

The economic incentives in open source community engagement have received comparatively less attention than other types of motivation (Hertel, 2007; Mollick, 2016), and they have primarily been studied in settings with corporate sponsorship where paid development is solicited by firms that own an open source project. In contrast to this, diverse open source business models can be observed around community-driven open source projects that are based on purely voluntary modes of participation. In this latter case, community participants can only reap indirect economic rewards by employing business models that are centred around their community's software product(s) rather than being paid by a corporate sponsor that owns the open source project. These business models can only be sustained as long as voluntary work efforts are invested in order to sustain and maintain the open source project. Thus, whoever runs a business based on the community's software product(s) depends on what motivates voluntary community engagement.

From this vantage point, voluntary community engagement and economic concerns can become entangled. Although the literature acknowledges the heterogeneous, complex, and interrelated nature of motivations for community engagement (Bitzer et al., 2007; S. Freeman, 2007; Roberts et al., 2006), a review by Crowston et al. (2012) found that only a few studies have addressed how motivational factors interact to stimulate participation in open source communities.

Moreover, there has been a recent call for greater attention to relationships between community forms of organising and commercial activities, in order to explain how community engagement facilitates entrepreneurial venturing and commercialisation attempts (Mollick, 2016). This sub-study attempts to address this gap in the literature by exploring how different motivations for community engagement are connected to participants' abilities to pursue economic goals and career concerns. For instance, while the outlook of monetary rewards is a frequently cited motivational driver for community engagement, others such as learning, reputation, reciprocity, and joy may also contribute to the realisation of economic goals in particular ways.

Drawing on self-determination theory (SDT) (Ryan \& Deci, 2000) and on social practices (Erden, Schneider, \& von Krogh, 2014), Study IV considers person-oriented motivations but also the incentives provided by the social and macro-institutional context. Because human motivations do not exist in a vacuum but emerge as a consequence of interaction in social and cultural contexts (Fang \& Neufeld, 2009; S. Freeman, 2007), both social and 
psychological factors may be necessary to explain participation behaviour (Bagozzi \& Dholakia, 2006).

Furthermore, incentives for open source community engagement have been mainly restricted to discussions about software development and the contribution of code (cf. Section 2.2.3). However, apart from software development, open source communities also rely on many other roles and activities that require effort, skill, and dedication from community participants (e.g., official representation, recruiting, administrative tasks, marketing and external communication, legal issues, finance issues, tax issues, trademark issues, translation, user support and diagnosis, the planning of events, testing and documentation, lectures, mentoring, presentations, and speeches). Given the prevalence of community-oriented contributions (Rossi, 2006; Rozas \& Gilbert, 2015), the importance of leadership and organisation-building (O'Mahony \& Ferraro, 2007), and the role of users in open source innovation process ${ }^{\mathrm{xxxIx}}$, this ongoing 'codecentrism' (Rozas \& Gilbert, 2015) in the literature is surprising. One explanation for this may be the often taken for granted assumption that the sole purpose of activities in open source communities derives from a community's goal to produce working code.

When taking into consideration non-commercial sponsorship with a lack of opportunity for direct monetary compensation, and when going beyond the activity of software development as a primary mode of participation, there is reason to believe that participation patterns follow a more sophisticated logic than the literature suggests. In this respect, the question of how volunteer work aids community participants in deriving economic benefit from their community engagement might yield a more differentiated picture than what is currently assumed.

The remainder of this sub-study is organised as follows. First, the methodological approach is described. Thereafter, the theoretical framework is presented, together with an analytical model that builds on SDT and social practices. This is followed by a review of relevant articles on motivations for community engagement in open source contexts with a specific focus on findings regarding economic incentives. Subsequently, an analysis of the empirical findings is provided. Finally, prior to the conclusions, the results are discussed in light of existing theory.

xxxix E.g., provision of feedback, beta-testing, bug reporting, knowledge support between experienced and inexperienced individuals. 


\subsection{Research approach}

To gain a better understanding of how motivation and economic incentives in open source settings have been addressed in the literature, Study IV started off with a literature review ${ }^{\mathrm{XL}}$. The review focused on findings in relation to economic incentives. Appendix A4 presents an overview of the articles that were screened along with summaries of the relevant key findings. The next section provides a more detailed discussion on this relevant stock of literature. This first assessment of the literature served as an interpretive guide for making sense of how different types of motivations may support community participants in pursuing economic goals.

From an empirical point of view, Study IV again takes a close look at the Joomla community. For a more detailed description of the empirical context the reader is referred to Chapter 4 in this thesis.

Study IV draws on interviews with 47 community participants that have been conducted between 2015 and 2017. For more detailed information about the data collection procedure, the reader is referred to Section 5.5. in this thesis. As can be seen from the Joomla volunteer portal ${ }^{159}$, community members often use the Joomla CMS for work-related and professional purposes. Professional services offered by community participants are diverse, such as web development and design, customisation, extensions, templates, maintenance and support, staging services, system integration, web hosting, application development, security services (e.g., malware detection, intrusion detection, and recovery), training and consulting, analytics, Internet marketing, and content administration.

This sub-study is grounded in an interpretive research tradition (Klein \& Myers, 1999). Interview participants were given the opportunity to reflect and talk about their practices, to elaborate on the reasons why they engage in community work, to articulate practice dilemmas, and to elaborate upon important aspects of their community work (La Rocca, Hoholm, \& Mørk, 2017).

The analysis was mainly guided by abductive reasoning ${ }^{\mathrm{XL}}$. This means that the analysis was in part inspired by existing theory on how community engagement can support participants in reaping economic benefits. However, information on how community engagement can support

xL Similar to von Krogh et al. (2012), the search included terms like 'motivation', 'incentives' and 'open source'. Searches were conducted on Google Scholar and the Web of Science database. Backward and forward searches complemented the search strategy.

$\mathrm{xLI}$ For more information on abduction as a principle method of reasoning the reader is referred to Section 5.6 in this thesis. 
participants' in reaping economic benefits also emerged from the data, in a more bottom-up fashion.

\subsection{Theoretical framework}

This section discusses how the links between community engagement, practices, and motivations are understood within the context of this substudy. In short, community engagement manifests itself in the diversity of community-related practices. Motivational aspects in turn can serve to explain why people engage in such practices. The next section outlines the basic tenets of practice-based approaches. This is followed by a description of the basic tenets of SDT. Finally, an analytical model is proposed that connects community engagement, person-oriented motivations and incentives provided by the social and macro-institutional context.

\subsubsection{Social practices}

The origins of practice theory are often traced back to the works of Wittgenstein and Heidegger, who both embraced the idea that the interpretation and meaning of human activities form within the contexts that practices provide (Vaara \& Whittington, 2012). Practice theory is often described as an assortment or a family of theories that share some central concepts but also differ in terms of the ontological premises that they build upon as well as the vocabulary and accents that they speak (La Rocca et al., 2017; Miettinen, Samra-Fredericks, \& Yanow, 2009; Tavakoli \& Schlagwein, 2016).

Practice theories have been used and applied in a variety of different fields (La Rocca et al., 2017; Tavakoli \& Schlagwein, 2016). Because of the diversity of theories in this literature stream, practice-based approaches are often oriented and tailored towards the elements, themes, and challenges that theorists find most relevant in connection to a particular problem (Miettinen et al., 2009). It therefore stands to reason that researchers are well-advised to be pragmatic when adopting a practice perspective to study a particular problem that interests them.

Feldman and Orlikowski (2011) distinguish between three different foci in practice-based approaches: an empirical focus, a theoretical focus, and a philosophical focus. With reference to this categorisation, the practice lens in this sub-study has an empirical focus. This means that practices were understood as a lens to emphasise the range of activities that people engage in (e.g., routinised, irregular, formal, and informal activities) (Feldman \& Orlikowski, 2011). 
Practices can be seen as recurring patterns of human activity; said differently, practices are 'what' people actually do (Feldman \& Orlikowski, 2011; Miettinen et al., 2009). In the context of open source communities, 'what' people actually do, might refer to activities such as engaging in discussions, providing feedback, reporting bugs, developing and submitting code, attending events, leading teams, and more.

Human behaviour in practice theory is also partly explained as a consequence of the social and macro-institutional context within which practices are embedded (Vaara \& Whittington, 2012). Thus, practice perspectives generally confront "how social structures and human agency link together in the explanation of action" (Vaara \& Whittington, 2012, p. 4).

\subsubsection{Basic tenets of self-determination theory}

Motivation broadly refers to "the study of why people think and behave as they do" (Graham \& Weiner, 1996, p. 63). Research on motivation concerns people's attitudes, activities and goals with a specific focus on the reasons as to why these occur and manifest (Ryan \& Deci, 2000). The dichotomy of intrinsic and extrinsic motivations, most prominently associated with SDT, has been applied in numerous organisational settings (Deci \& Ryan, 1980; Gagné \& Deci, 2005, 2014).

SDT builds on the idea that there are three innate psychological needs that motivate individuals to initiate behaviours; these are the need for competence, autonomy, and relatedness (Deci \& Ryan, 2011; Ryan \& Deci, 2000). In SDT, these three psychological needs are seen as "innate psychological nutriments that are essential for ongoing psychological growth, integrity, and well-being" (Deci \& Ryan, 2000, p. 229). A further claim in SDT is that "each of these three needs plays a necessary part in optimal development so that none can be thwarted or neglected without significant negative consequences" (Deci \& Ryan, 2000, p. 229). In SDT, intrinsic and extrinsic motivations basically interoperate to satisfy these three basic psychological needs.

The concept of intrinsic motivation refers to behaviours and activities that provide inherent satisfaction and enjoyment, which means that behaviour is not stimulated by external promises, rewards, or sanctions; in turn, the concept of extrinsic motivation refers to behaviours and activities that are associated with either tangible rewards, separable consequences, or the avoidance of sanctioning (Ryan \& Deci, 2000; Ryan, Sheldon, Kasser, \& Deci, 1996). 
While extrinsic motivations are regulated based on external contingencies (i.e., externally controlled and instrumental motivation), SDT further suggests that extrinsic motivations can become internalised (Gagné \& Deci, 2005). "Internalisation is defined as people taking in values, attitudes, or regulatory structures, such that the external regulation of a behaviour is transformed into an internal regulation and thus no longer requires the presence of an external contingency" (Gagné \& Deci, 2005, p. 334). Internalised extrinsic motivations and self-regulation have also been treated by many studies on motivation in open source community engagement (Crowston et al., 2012; Mair et al., 2015; Roberts et al., 2006; von Krogh et al., 2012).

While there are other important tenets and sub-theories in SDT ${ }^{\mathrm{XLII}}$, essentially intrinsic, internalised extrinsic, and extrinsic motivation have been at the centre of attention in most studies on motivation in open source community engagement (Crowston et al., 2012; von Krogh et al., 2012).

\subsubsection{Analytical model}

Practice perspectives highlight how different factors of interest (such as knowledge, emotions, or motivations) become enacted in the context of practices (Erden et al., 2014; La Rocca et al., 2017). While practices provide answers as to 'what' people do, taking motivation on board provides complementary answers as to 'why' they do it (Deci \& Ryan, 2000). The combination of practices and motivation theory emphasises that the locus of motivation may reside not only within individuals but also within the social and macro-institutional context. The social context (e.g., the collaborative and distributed nature of work, interpersonal relationships, emotional bonds, the significance of events) as well as the macro institutional context (e.g., the ideological foundations of open source, cultural plurality, economic and competitive pressure) may encourage or discourage participation behaviour in particular ways (Stewart \& Gosain, 2006; Vaara \& Whittington, 2012).

As mentioned before, community engagement manifests itself in the diversity of community-related practices. Such practices are seen as analytical units in which individual motivation and the incentives provided by social and macro-institutional contexts coalesce. It is argued that charging practices with motivational aspects provides useful references points (i.e., the 'what' and 'why') for inferring coherent answers about 'how' volunteer work aids community participants in advancing their economic

XLII E.g., organismic integration theory. 
goals. Figure 38 visually depicts the relationships between community engagement, individual motivations, and the incentives provided by the social and macro-institutional context, as understood within the frame of this sub-study.

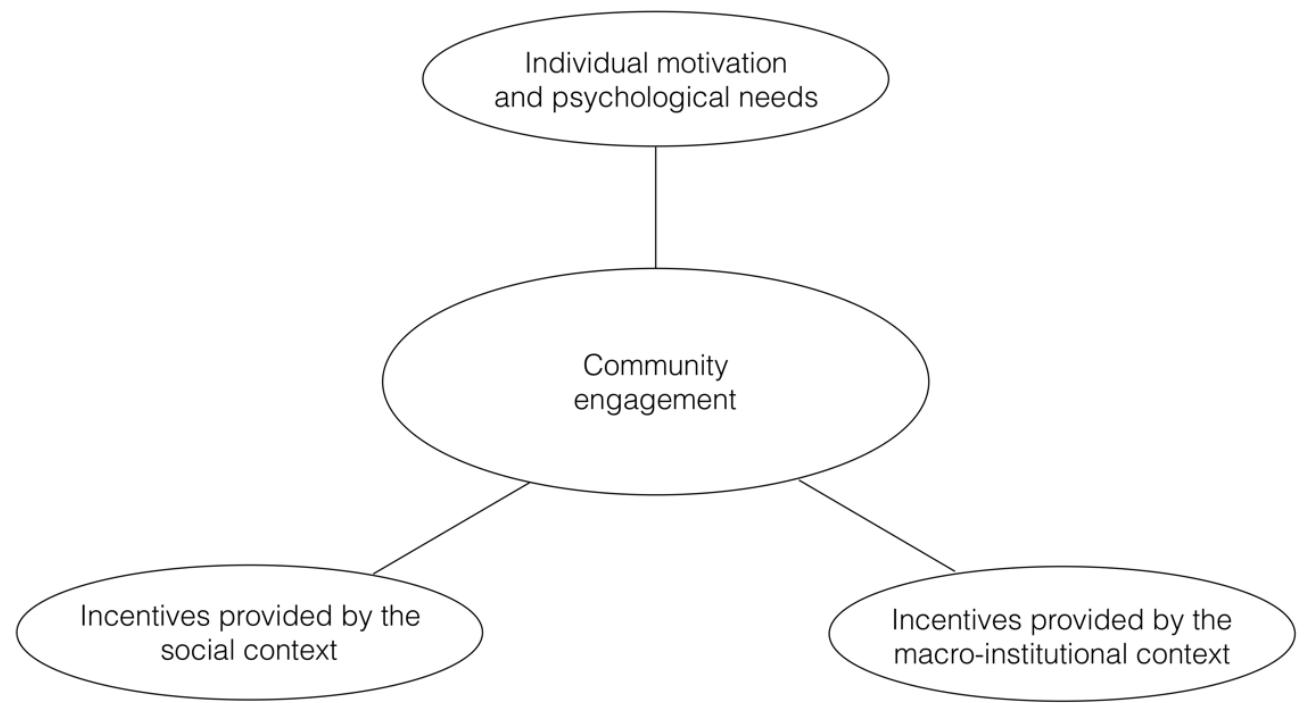

Figure 38: An analytical model that emphasises community engagement, the relationships to individual motivations, and the incentives provided by the social and macro-institutional context. Community engagement is reflected in a variety of different communityrelated practices (i.e., reoccurring activities), such as engaging in discussions, providing feedback, reporting bugs, developing and submitting code, attending events, leading teams.

\subsection{Literature review on motivations for community engagement}

Research on participants' motivation is a central theme in the literature on open source (Roberts et al., 2006). Because there are myriads of people, experts and novices alike, who contribute to open source projects (Hertel, 2007), there has been a wealth of research dedicated to studying patterns of motivation in open source communities. This research has identified a variety of intrinsic motivations (e.g., enjoyment, fun, altruism, reciprocity), internalised extrinsic motivations (e.g., user needs, use value, reputation, status, learning), and extrinsic motivations (e.g., economic rewards, career concerns, peer pressure) for community engagement (Bitzer et al., 2007; Crowston et al., 2012; Mair et al., 2015; Roberts et al., 2006; Shah, 2006; 
von Krogh et al., 2012). However, as von Krogh, Haefliger, Spaeth, and Wallin (2012) argue there has been a tendency to focus on intrinsic motivations to explain participation behaviour.

\subsubsection{Mixed results}

Research on motivation for community engagement has produced a range of mixed and controversial findings (Felin, Lakhani, \& Tushman, 2017; Ke \& Zhang, 2009). For instance, while some findings (Roberts et al., 2006) suggest that intrinsic motivation has no significant effect on participation, others suggest that it is a major driving force (Ke \& Zhang, 2009; Shah, 2006). Many have described the open source phenomenon as a gift culture within which altruism is the most important intrinsic motivation for participants and where social status is determined by one's willingness to give away (Wu, Gerlach, \& Young, 2007). By contrast, other research also suggests that developers are mainly driven by selfish interests rather than by altruistic motives (Hertel, 2007). Furthermore, there are also claims that developers are mainly motivated by ideological conviction (Bagozzi \& Dholakia, 2006).

Similarly disparate results can be observed for extrinsic motivations (Benbya \& Belbaly, 2010; Rossi, 2006). For instance, while some argue that extrinsic motivations undermine intrinsic motivations (the crowding-out effect, as it is often termed) (Osterloh \& Rota, 2007), there is also countervailing evidence against this claim (Roberts et al., 2006). Furthermore, there seems little agreement regarding the extent to which motivations are complementary, independent, or mutually reinforcing (Roberts et al., 2006). However, it seems generally accepted that community members participate out of combinations of intrinsic and extrinsic motivations. Because of the disparity of findings in this literature stream, scholars have suggested going beyond studying whether some motivational factors dominate over others, to consider the ways in which different motivational factors interact (Benbya \& Belbaly, 2010; Rossi, 2006). S. Freeman (2007) emphasises that the relationships between different motivational categories are still relatively unexplored in the literature. However, only a few studies seem to have pursued this particular thread in the meantime (Crowston et al., 2012).

\subsubsection{Complexity, plurality, and interrelatedness of motivation}

Many studies emphasise that motivation for participation is heterogeneous and that intrinsic and extrinsic motivations operate simultaneously (Benbya \& Belbaly, 2010; Bitzer et al., 2007; Roberts et al., 2006). Research also 
suggests that the plurality of motivating factors and the appeal to various types of contributors can in fact be considered a strength of open source in general (Hertel, 2007). Motivations can change over time (S. Freeman, 2007), differ across different types of open source projects (Bitzer et al., 2007; Shah, 2006), and depend on the personalities of participants (Hertel, 2007). Furthermore, research increasingly acknowledges that motivations may vary between different types of contributions (Benbya \& Belbaly, 2010; Rozas \& Gilbert, 2015; Santos, Kuk, Kon, \& Pearson, 2013). For instance, Bagozzi and Dholakia (2006) suggest that the motivations to take over unglamorous and mundane work cannot be reasonably explained by reputation enhancement, which is often depicted as a key motivational driver in community engagement.

Various kinds of evidence in the literature illustrate how motivations could be interrelated and reinforce each other. For instance, Roberts, Hann, and Slaughter (2006) found that status motivation can actually enhance intrinsic motivations. Wu, Gerlach, and Young (2007) found that opportunities for career advancement simultaneously enhance satisfaction and the willingness for long-term participation.

Especially for less skilled developers, open source communities provide ample opportunities and support for learning (Wu et al., 2007). Novices often initially consult the community because they need to solve a particular problem, but may subsequently experience the fun and joy of acquiring new skills and knowledge, reciprocate the support that they receive from others, build affective bonds with the community and its members over time (Bagozzi \& Dholakia, 2006; Fang \& Neufeld, 2009; Shah, 2006), refine their solutions through community help, and sometimes commercialise their innovations (Mollick, 2016).

\subsubsection{Criticism towards the dichotomy of intrinsic and extrinsic motivations}

Hertel (2007) criticised the strong focus on person-oriented motivational factors in studies on motivation for community engagement. Instead, he focused on job characteristics and the work context to explain motivation (by attending to factors such as skill variety, task identity, task significance, autonomy, and feedback).

S. Freeman (2007) and Benbya and Belbaly (2010) also criticised the framework of intrinsic and extrinsic motivations. For instance, S. Freeman (2007) argued that this dichotomy cannot account for the intricacy of human motivation and only reinforces prevalent discourses of hacker ethics and 'hobbyism'. She also rejects the idea that motivation can be quantified, as is 
the case in most survey-based research. She rather sees motivation as a complex quality of human life that is susceptible to subjective human interpretation. She also criticised the fact that SDT tends to treat motivation as an innate biological state rather than an emergent quality of human life.

Given the shortcomings that SDT may have in explaining participation behaviour, Study IV combines the framework of intrinsic and extrinsic motivations with a practice lens in order to concede weight to the social and macro-institutional context in which people's activities are embedded. Besides person-oriented motivational factors, this also highlights the ways in which social and institutional factors stimulate participation. Essentially, this approach is inspired by von Krogh et al. (2012).

\subsubsection{Economic incentives}

For businesses, both for adopters and suppliers ${ }^{\mathrm{XLIII}}$, OSS is appealing for several reasons. Many open source projects provide reliable, robust, and customisable solutions at a low cost (Rossi, 2006). From the perspective of individual contributors, there are several ways in which one can reap financial benefits out of community engagement. The following highlights three salient ways. First, individuals can be paid by firms that own an open source project. Second, there can be firms that pay their employees for contributing to open source projects (von Krogh et al., 2012). And third, individuals can be self-employed (Fang \& Neufeld, 2009) and contribute to open source projects because they have adopted business models that are centred around their community's software product(s). At the firm level, there are also, of course, other ways of earning money with OSS, such as dual-licensing, consulting, or support (Riehle, 2012).

Although Study IV focuses on motivations for community engagement at the individual level, it should be noted that, when looking at self-employed people who own small businesses, the nature of individual motivation for community engagement often resembles that of firm level motivation for investing resources in open source projects (Rossi, 2006). For instance, firms, freelancers, self-employed people, and owners of small businesses may be motivated to invest in open source projects in order to innovate and to source the skills, competencies, and efforts that are accessible through mass collaboration (Crowston et al., 2012). The metaphor of 'many eyeballs' (Raymond, 1999b, p. 29) is one example of the benefits of this type of collaboration.

xLIII Businesses can adopt OSS in order to provide specific services to their customers, or businesses can supply software that complements or extends particular OSS. 
According to Rossi (2006), firms and open source communities can form symbiotic relationships. She argues that commercial interests and firm engagement can bring a number of benefits to open source communities, such as an increase in the user base, greater popularity for the software, increased user friendliness, and an increased likelihood that tasks that are intrinsically less stimulating to volunteers are taken care of (Rossi, 2006).

S. Freeman (2007) argues that the boundaries between work and hobby for community participants can become blurred, which could also be seen as a consequence of symbiotic relationships between volunteerism and professionalism. She suggests that the widely-used distinction between work and hobby in open source communities seems artificial. As an example, she refers to professional development, which often involves the crossing of different social practices (across the community and the commercial realm). Because of blurred boundaries between work and hobby, she also questions the usefulness and validity of the concept of the 'volunteer' in the context of open source communities.

From an economic perspective, community engagement may be instrumental in many ways. For instance, community engagement may enable individuals to develop, improve, and maintain the tools that they need (use-value) (Crowston et al., 2012), to improve their skills (Hertel, 2007), to refine their thinking and gather new insights (Lakhani \& Wolf, 2005; Wasko \& Faraj, 2000), to stimulate their intellectual curiosity (Lerner \& Tirole, 2002), to receive performance feedback (Roberts et al., 2006), to stay in touch with trends (Wasko \& Faraj, 2000), to develop human capital and valuable relationships (S. Freeman, 2007; Hars \& Ou, 2002), and to realise entrepreneurial opportunities (Mollick, 2016).

Bagozzi and Dholakia (2006) argue that user groups in open source communities perform functions that are, in many respects, comparable to commercial software firms. As examples, they list activities such as installation support, user education, training, diagnoses, troubleshooting, consultancy, word-of-mouth referrals, and marketing. They argue that these functions at the grassroots level of open source communities "are crucial for the adoption, growth, and success of the open source projects" (Bagozzi \& Dholakia, 2006, p. 1110).

Wu, Gerlach, and Young (2007, p. 253) find that individuals' motivation to continue their community engagement "was influenced by both helping behaviour and economic incentives". Benbya and Belbaly (2010) suggest that participants' desire to further their career opportunities increases their motivation to contribute to open source projects. However, they find that the type of contribution seems to matter most to these individuals rather than the overall time and effort that they spend. Their explanation for this is that 
some types of contribution offer more opportunities for status enhancement than others. As an example, they mention the Apache meritocracy, where it seems impossible to advance one's status without having contributed substantially to the software code. Ke and Zhang's (2009) findings provide a complementary picture. Their results show that extrinsic motivations can stimulate continuous community engagement and lead to higher levels of commitment towards tasks.

Lerner and Tirole (2002) analysed motivation for open source community engagement from the perspective of labour economics. They emphasise that community members have to reap a net benefit out of their engagement. They define net benefit as the sum of immediate payoff ("current benefit minus current cost") and delayed payoff ("delayed benefit minus delayed cost") (Lerner \& Tirole, 2002, p. 213). This model essentially weighs opportunity costs against benefits such as improved performance and career opportunities. The authors argue that reputation and signalling incentives may not only lead to job opportunities but also ease the acquisition of venture capital. Crowston et al. (2012) argue that Lerner and Tirole's (2002) argument that "motivation is derived from indirect signalling about quality, with the payoff to come in higher career earnings" (Crowston et al., 2012, p. 14), has received little empirical support. However, Crowston et al. (2012) do not elaborate on possible reasons for this.

Finally, Mollick (2016) suggests that communities may play a crucial role in enabling participants to venture into entrepreneurial and commercial pathways. As he argues, through community engagement and community feedback, participants gradually begin to realise the value of their solutions. The help from their community peers often enables them to refine their solutions, which eventually can induce them to commercialise a particular innovation. Mollick (2016) highlights that the interplay between communities and for-profit entities is an important and potentially fruitful future research avenue. He suggests that research should explore the effects between community affiliation, innovation, and commercialisation attempts in more depth.

In summary, little research seems to have focused on the interrelatedness of motivations for community engagement. In particular, there seems little research on the systemic effects of interrelated motivations on community participant's abilities to advance their economic goals and career concerns.

\subsection{Findings}

This section presents the key motivational drivers in the Joomla case. The findings are structured by the different types of motivations that were salient 
in the interview material. There are different ways in which these types facilitate participants' ability to pursue economic goals. This section will explore them in more depth.

\subsubsection{Openness and altruism}

When people make contact with the community for the first time (e.g., through user groups, conferences, and friends), they are often impressed by the open, supportive and welcoming attitudes of people in the community. Even if there are interpersonal conflicts at times, and even though people sometimes leave the community because of these conflicts, interviewees predominantly enjoy the open culture that the community breeds, all over the world, both online and offline.

Openness belongs to the ideological foundation of open source, which is an important aspect of the macro-institutional context in this empirical setting. Especially for people who care about the open source philosophy, Joomla has its appeal. This philosophy promotes equal opportunities in the sense that everyone should be able to benefit from the source code, not only single individuals or firms. Openness in the Joomla community is not only reflected in sharing practices but also in attitudes when approaching other people. While there is a tendency in the open source literature to emphasise the openness of the code and its associated benefits ${ }^{\text {XLIV }}$, openness also materialises in other ways. For instance, the empirical data show that the cherished value of openness can also mean being open and honest towards others in the community. It can mean to show welcoming attitudes towards newcomers, and it can mean openness towards customers in order to build trust. For business owners, openness towards others in the community may also reduce the costs of accessing knowledge that could be of relevance for their businesses, and to get in contact with potential business partners.

Openness in this sense also connects to altruism, i.e., the selflessness of doing something for the welfare of others. From an SDT perspective, the voluntary act of doing something for the welfare of others satisfies all three basic psychological needs. Because participation is voluntary, individuals' decisions to contribute is highly self-determined (autonomy). By donating their time, skills and efforts to community work, participants can enhance their reputation and develop their skills (competence). Furthermore, through the act of giving (recall that open source communities are also referred to as gift-cultures), participants can reap the pleasure of having done something for others or society at large (relatedness).

XLIV E.g., software quality, security, modifiability, reduced cost. 
"I don't understand, it's almost like an obsession, but I mean, at this point, I have so much time invested in it, um, it's really kind of my outlet to make the world a better place, you know, because there are many Joomla users out there, you know, I can do something in the platform and the community that helps people, um, it helps a great number of people, you know, I can work from my office at home and have an impact on people's lives around the world in a positive way, I think that's amazing, it's really the only opportunity I ever had like that. That's not why I started using it, it just kind of turned into that, but it's very cool" (Interviewee \#25).

\subsubsection{Supportiveness, helping behaviour, reciprocity, and social responsibility}

Providing support, helping others, and answering questions is at the heart of the Joomla community. When helping behaviour and supportive attitudes are enacted within the context of different community practices, participation may be stimulated in particular ways. The appeal of doing community work may also stem from the fact that participants experience helping behaviour as a deeply ingrained normative component within the Joomla community. This could mean that the incentives that spur helping behaviour may reside in the macro-institutional context.

\footnotetext{
"Generally, the community is very cordial and supportive, well there are exceptions here and there, but there is a consensus that everyone should receive help, and if someone faces a problem, you can join, and if you want to participate, all doors are open. I never had the experience, when I faced problems, that I encountered any resistance" (Interviewee \#5).
}

Both reciprocity and helping behaviour in the community may support community members in pursuing their economic goals in more diffuse ways. Joomla user groups can serve as an example to illustrate this point. User group meetings can be opportunities to ask questions, discuss, and share ideas on specific feature requests and customer projects that professional developers are working on. Sometimes new work arises out of these meetings. Joomla user groups are also a way to maintain networks of professionals and to keep in touch with current trends that affect community members' businesses. But these friendship networks can be also be a means to collaborate on customer projects, be directed towards people with special skills, to pass on customer projects to others in case one cannot keep up with the workload, and to forward requests in forums to competent others. In particular, asking competent others in a network of friends within the community can save a lot of work time and reduce the time-to-market of 
participants' customer projects. The empirical data show that offline meetings in the community are of particular importance since they enable participants to discuss and solve problems more effectively.

The character of helping behaviour and reciprocation often resembles that of friendly turns, rather than that of formal business partnerships (although these do exist as well in this community setting). More colloquially, the ethos is "one hand washes the other". For example, a developer helps and works on a friend's customer project for free (even for weeks), and in turn reaps the benefit of getting competent advice from his friend who is technically much more proficient than himself and also gets the benefit of being able to use his friend's software solutions for free in his own customer projects. In other cases, participants help each other by simply logging into the back-end of each other's customer projects to fix problems, to structure the code properly, or to integrate their own code.

However, it cannot be maintained that there is a direct economic logic connected to reciprocity and helping behaviour in the sense that one person helps because it can benefit their own customer projects. This means that giving back to the community is triggered more by participants' sense of social responsibility and their ethical obligation to do something good for others and society at large, especially when one is able to sustain an economic career based on the Joomla CMS. This could mean that a sense of social responsibility possibly mediates the relationships between helping behaviour and reciprocity, on the one hand, and economic logics on the other.

\footnotetext{
"...Joomla has shown me the world in a lot of ways, you know, it's great, that's really awesome, but I never did it for that reason, I never did it to get something out of it, it was just my way of giving something back, because I made so much money using the Joomla platform" (Interviewee \#25).
}

\subsubsection{Use value and own need}

Use value and own need are well-known motivational drivers for community engagement. In the Joomla community, they are strong motivational drivers, too. From this point of view, participants engage in community work because of the practical benefits they reap from using the Joomla CMS (e.g., being able to use a feature-rich CMS platform). Participants engage in community work because they want to support the development, maintenance, and improvement of the Joomla CMS (e.g., by testing, reporting, and fixing bugs) because it has a particular value for them. 
The reasons why the Joomla CMS is of value to participants are manifold. The following illustrates this by the various attributes that interviewees used to characterise the value of the Joomla CMS: "especially well-written CMS", "love the code", "very, very strong coded CMS", "very flexible", "make[s] your life easier", "better tool for the job", "it will grow with the business", "the most flexible platform", "you can extend it very easily", "fits perfectly with what I'm gonna be doing", "scalable in all directions", "the stability with the Joomla community", "the range of functionality that is integrated in the CMS without having to install additional plugins or anything else", "security, or compatibility", "at least $80 \%$ out-of-the-box functionality", "you can build your own platforms", "from a simple blog to a mega portal or intranet". By contributing to the community, participants are able to protect and preserve these ascribed qualities, which are often of great importance in their daily work with customers.

Furthermore, the Joomla CMS is valuable and appealing because of its vast ecosystem of software extensions. In cases where the Joomla CMS does not provide a particular feature, there are many third-party plugins (both free and commercial) that address particular needs. In this regard, the Joomla CMS provides high degrees of freedom for the people who work with it.

Sometimes people contribute with code because they need particular features for themselves. While satisfying one's own need when contributing to the community may appear to be a selfish act, these contributions potentially also bring value to other people (to both community members and the whole user base) because the software is open and freely available. Therefore, selfish motives (i.e., one's own need) may also satisfy the psychological need for relatedness because contributors are aware that their contribution can potentially also bring value to other parties. Because of the openness of the platform, selfish interests may therefore often align with community interests. Contributing out of one's own need and use value often also entails having to deal with challenging tasks or to be engaged in creative problem-solving, which may satisfy the psychological need for competence.

\subsubsection{Influence, monitoring, and vested interests}

Further important motivational drivers are the ability to influence and shape the future course of the Joomla CMS, and the opportunity to keep up with trends that affect the Joomla platform, its community, and the businesses that are connected to it. From this point of view, community participants want to advocate for change and voice their concerns to other (influential) people in the community. The reasons why people want to exert influence are 
manifold. For instance, participants may have a vested interest in the continuation of Joomla when running a business model that builds on the Joomla CMS.

This can be illustrated by the example of extension providers. Extension providers can only sustain their business models as long as voluntary work efforts are invested to push the Joomla platform. The businesses of extension providers can be affected by community decisions in various ways. For instance, there could be compatibility issues between upcoming Joomla releases and particular extensions, which can require intervention from an extension provider's point of view. Due to changes in the Joomla CMS, they may sometimes have to adapt their code, but they could also opt to advocate against particular changes in the Joomla CMS.

"... you know, say in the case of an extension developer, and they are selling their products for let's say 50 [currency] with a subscription per year or something like that, you know, they are very invested in the community ... they are kinda building a product on top of the Joomla platform, so that's a whole different perspective, so they have a different set of motivations, you know, they are actually doing it to make money" (Interviewee \#25).

"... from a standpoint if your business depends on this, you don't wanna see your business going down, because all of a sudden Joomla becomes very unstable and has issues..." (Interviewee \#36).

"... somebody like myself who is using the product, using the software, and I am running a business with it, you know there is this aspect of wanting the software to continue because I have a lot invested in it ..." (Interviewee \#21).

"[What makes us participate] when it comes to Joomla itself, it is because we have a product centred around the community" (Interviewee \#2).

Reasons for trying to have an influence could also be functional needs or the dissatisfaction of having to work with cumbersome work-arounds in current Joomla versions.

"... e.g., you need Joomla for you and clients but you need that core [i.e., the Joomla core code] will include something [e.g., a particular feature]. So, this is one kind of motivation [to participate]" (Interviewee \#15). 
The urge to monitor community activities is a motivational driver too. Engaging with the people who are shaping and directing Joomla, helps businesses to stay on top of changes, see in which direction Joomla is evolving, keep in touch with state-of-the-art technology and web issues of all sorts, and to stay up-to-date on legal changes and requirements that affect web development in general (e.g., cookie policies, standardisation, EU General Data Protection Regulation). Monitoring the activities in the community is of particular importance for those who have a business connected to the Joomla platform.

\begin{abstract}
"... we have to be up to date with the newest issues because with products that are centred around, you know, different configurations of software, Joomla itself or plugins or extensions, there are a lot of weird problems that happen, so we have to be aware of them and try to solve them, be aware of Joomla itself because something is not working, not because of our system, but because of Joomla or some plugins, or an extensions ... So, we have to be aware of those issues and know how to fix them because fundamentally when something breaks for the client, they do not blame Joomla, they blame us because they use our product even though it is Joomla's fault" (Interviewee 41).
\end{abstract}

\title{
9.6.5 Sense of community, identity, and connectedness
}

The appeal of doing community work seems also strongly anchored in social factors, in particular, the interpersonal contact in the offline world. The social gatherings in the community may bring immediacy to the cherished values and also satisfy community members' psychological need for relatedness. From a social perspective, one particular aspect of being selfemployed seems to weigh heavily in this community setting. Being a selfemployed web developer often implies working alone, physically isolated from others. While being a self-employed developer may offer high degrees of autonomy, it may have detrimental effects because of people's psychological need for relatedness. With respect to these particular work realities, one important factor that stimulates participation may be that the community also provides a sense of identity and belonging ("being part of something bigger than yourself") and the opportunity to meet like-minded others in real life. The community has been described as a community with a very social attitude where strong family-like bonds develop between participants. Going to Joomla events can mean being closer to this family, to 'love' the Joomla community or being 'married' with it. 
"... for me it's the heart with Joomla, and the people around me that I know, it's the heart of Joomla and not other things" (Interviewee \#47).

In summary, the social life in the community and its related aspects (e.g., intercultural encounters, helping behaviour, spirituality) have appeal on its own, which makes the community attractive for participants.

\begin{abstract}
"... you get to help people. And you get to be helped by people. The interpersonal aspect of FOSS [free and open source software] is very strong and life-changing. It makes you a better person, more openminded and more thoughtful. I can't put a price on that life changing attribute of FOSS and would never trade it for all the money in the world" (Interviewee \#14).
\end{abstract}

\title{
9.6.6 Learning, knowledge exchange, and knowledgeable peers
}

The empirical data show that learning opportunities are important motivational drivers that stimulate community participation, which is also in line with the results of many previous studies. The motivation of learning belongs to the type of internalised extrinsic motivation. In the Joomla case, both the macro-institutional context and the social context in which community practices are embedded emphasise the importance of learning. It might be fair to say that education, as an important aspect of the macroinstitutional context, might have emphasised the importance of learning long before people consider themselves to be part of the community. This is because community members are typically well educated, ambitious, and have often gone through years of higher education.

Open source ideologies may facilitate learning by promoting sharing behaviour. While the open source literature often emphasises the sharing of code, the empirical data show that the sharing of ideas, opinions, feedback, knowledge, skills, and best practice is just as important. Sharing behaviour facilitates learning, which in consequence can help community members in furthering their professional careers. For instance, user group meetings and conferences are special occasions for sharing knowledge and insights. The empirical data show that user group meetings are places to receive and give installation support, training, diagnosis, troubleshooting, consultancy, and word-of-mouth referrals ${ }^{\mathrm{XLV}}$. At the same time, these user group meetings are

XLV Which confirms the findings by Bagozzi and Dholakia (2006) who have argued that user groups in open source communities perform functions that are in many respects comparable to commercial software firms. 
occasions to have fun and enjoy time with like-minded others, as was frequently mentioned by interviewees.

Sharing behaviour may not only help to speed up learning processes but, from an economic perspective, it may also help community members to reduce the time-to-market of their products, services, and solutions. Because Joomla is a complex software system with a steep learning curve, quick learning is highly valued. Furthermore, the exchange of ideas may help to shift attention to more creative aspects of the problems that community participants deal with in their professional work.

"I have always been motivated by learning opportunities ... there is always something that someone will add up to our composition, that will change your life for that day. For instance, ... someone will just mention the easy way to do it, probably using one page, and compressing some of the views, and all of a sudden you say, 'why didn't I think about that?', I mean, it now looks so simple ... And left alone, it would take an entire long thinking process to streamline this form, to make it simple, but it wouldn't click. So, through that exchange of ideas, I believe we all learn very fast, so instead of, one of the things that I have learned when I got into IT web development, is that there is always something new to learn, and if you are working on a solution, no matter how good you are, how fast you are to pick up on a new concept, you spend a lot of time trying to understand little things. But working in a group, you don't waste your time on aspects of projects or ideas that people have already invested time in, you reap the reward by exchange of knowledge, and then you also share what you have spent time on. That way we all pay attention to more creative aspects or designing business models, for those who run small companies, or how to engage more clients, or how to improve the look and view of Joomla sites in the country. So instead of us killing our time on technical details, ... we just learn to exchange knowledge, and then we pay attention to more creative things. So that's the main benefit I see in working in such a community. The exchange of ideas, and the possibility to learn very quickly." (Interviewee \#11)

There is another interesting aspect about learning that relates to individual curiosity. While curiosity may in many ways facilitate individual learning, sharing behaviour in the context of mass collaboration seems to elevate learning to a new level.

"... I went there [to his first user group meeting], but I was like a newbie, the guys were really pro and the guy organising it, but it was really interesting because the first time I was exchanging tips and tricks, and you can learn a lot by yourself if you are curious, I am curious, but it's 
another level when you share good practices or ideas, or security issues, and so on, this is how it all started because the organiser of the Joomla user group, [name of the user group] was really nice, so um, I started to help him with an extension he was building ..." (Interviewee \#12)

The presence of knowledgeable people is another motivational factor that spurs participation in the Joomla community. The Joomla community is populated by many experienced and knowledgeable people. Several interviewees stated that for them the Joomla community is on average more competent and proficient than communities producing comparable software products.

As the interview data show, participants often see the benefit of being able to get in touch with experienced and knowledgeable peers within the community. Especially for people who are seeking to develop their competencies, this might have great appeal. For instance, security is an important but also a complex topic that is often addressed at Joomla events. Domain experts share their insights on how to protect websites from malicious hacking attempts ${ }^{\mathrm{xLV}}$. Such topics are highly relevant for participants' commercial businesses, which makes it easier to see the benefits of attending community events.

Knowledge exchange occurs on all kinds of levels. Different community participants possess and share expert knowledge on different domains, including Internet marketing, search engine optimisation, database optimisation, and business development. The community provides a platform to find and contact these people through different channels. Knowledge exchange and collaboration may not only help to develop competencies but may also strengthen the cohesiveness of the community.

"I really like the spirit of community collaboration. In addition to the national and regional conferences because during these events there is a great exchange of knowledge and experiences, which greatly strengthens the community" (Interviewee \#34).

\subsubsection{Joy, fun, and enthusiasm}

In the interview material, the intrinsic motivations of joy, fun, and enthusiasm are frequently mentioned drivers for participating in the community. Especially the joy of meeting other people, the joy of learning, the pleasure of cultivating friendships and being exposed to new mind-sets are important motivations. Furthermore, as the interview data suggest,

XLVI E.g., monitoring the server, firewall configurations, identification of potential backdoors. 
participating out of joy may facilitate long-term commitment and the opportunities to gain recognition, which in further consequence can have reputation-enhancing effects.

"I think the great majority participates for intrinsic reasons, because it is fun, because when you do something over an extended period you also get recognition for that ..." (Interviewee \#27).

"... I mean, people who contribute to code do not do it for money, some do it for respect but that is just a nice plus. I think it's more the intrinsic values" (Interviewee \#2).

\title{
9.6.8 Reputation and status
}

In line with previous findings, reputation, status, and standing are important motivational drivers in the Joomla community. However, reputation can mean different things to different people in the community. For instance, some participants hold, or strive towards holding, official positions. For others, reputation refers to the esteem that derives from providing valuable contributions, comments and advice.

\begin{abstract}
"Some people want to have the reputation, because then you get a different status... you receive a different status, that's clear, you are seen differently, perceived differently, and you can discuss on a different level than someone who is less involved. That may be an incentive for many because they already work with Joomla and they like it, otherwise they would not do it" (Interviewee \#35).
\end{abstract}

"... the personal brand aspect, the reputation, there are some people who are motivated by that, you look at [community member] for instance, he is all about his reputation ... and he has built his whole business around it. People come to him, because he is ... the expert, and um, there are definitely people in the community and that is what they are looking for, and um, it serves that purpose" (Interviewee \#19).

Reputation is also connected to the norms within the community. To enhance one's reputation does not only mean to invest time and effort in community work, but also to subject one's behaviour to cherished and valued community norms (e.g., the open source philosophy).

"If someone engages in the community strongly, and maybe more than others, but maybe only insults others, or claims to help but in reality 
does not help at all, that exists as well; there are people, and sometimes it seems they only want to increase the number of their own entries in a forum. So, in a forum, you have these numbers that show you who has posted how much. I also know that from other forums, not only from Joomla, there are many people who contribute with lots of entries but never really are productive. Only because you are active within the community, this does not mean at all that you are effective or valuable to the community. I think this then depends a lot on how you help, and of course also your manners. We know from many stories, how you approach people, and how you write with them, makes a huge difference, as compared to having a sort of evil or snotty style. That makes a difference" (Interviewee \#35).

Given the fact that there is no direct monetary compensation for community, reputation may be one of the main currencies in the Joomla community. Seen as a currency, community members' reputation is also an asset within the macro-institutional context in which economic activities are embedded. For instance, reputation eases the building of professional networks but also the ability to exert influence in Joomla's meritocracy.

"And another reason may be, well yes, the fun of jointly developing something, whereby, it may also play a role that you can say, well this is something that ' $I$ ' developed, you can be proud of, that is surely a reason. Well, of course you are not paid for anything, so maybe you expect to be able to raise your own expert status, especially when you earn your money with Joomla or developing Joomla components. You could say that the network that you build through your reputation is something that you can utilise to earn a living because you delve into a big network where you in one way or another can get a new job, so that is another point that I would see" (Interviewee \#35).

"... it is more likely that your committed code will be ignored, compared to being a known figure who has already committed several times, and then this receives more attention from other people. So, it's really like that, the more active you get, and the more well-known you are, it gets easier... reputation is the right word, if you build reputation and show that you are capable, um, then it gets faster, the things will be tested quicker and looked at" (Interviewee \#5).

Furthermore, having a certain standing within the community can be a positive signal for potential customers but also for future employers. For instance, being able to show a track record as a community member can boost the credibility of community members' businesses and offerings, and increase the perceived competence among (prospective) clients. 
"... there is kind of a status kinda thing on there, it's kind of, for example, if you are Googling a Joomla developer in [home town], you're gonna come across my name at some point, because I am so involved in the community here, and it's all over my website, and what not, I mean, it definitely adds a level of credibility to my service. If someone asks, how well do you know Joomla, I say, I am one of the guys that makes it, you know, moving in with that, you don't have to try hard to convince them that I know what I am doing" (Interviewee \#25).

"And because I specialised in Joomla, I think that I have developed a sort of expert status in that area in [home country], and I think that I am also recognised for it" (Interviewee \#24).

"... especially probably in Europe where it is more popular, um, I am sure it does not look bad to have it on your resumé, and you know, that you contribute to the development of an open source, um, platform. I can see many motivations for that" (Interviewee \#36).

"... many customers have previous experience with Joomla, and for those it probably makes a difference when we can show that we are active within the community, or that we run our blog on Joomla. So, I think that we are perceived differently by just doing that, so not only as the one who offers a solution but someone who demonstrates competence and knowledge. That makes a completely different impression because then they see, aha, this is someone who knows his stuff" (Interviewee \#5).

\subsubsection{Commitment and perceived switching costs}

Further motivational aspects are the time and efforts that community participants have invested in learning Joomla and getting to know its community. Since Joomla is a complex software product, it can take time to develop the status of a Joomla expert. But it also takes time to get to know people in the community. The perception of these investments (e.g., time, effort, travel expenses) can be aspects that can increase the perceived switching costs to a different platform (or community) and at the same time increase participants' commitment to Joomla and its community.

"... not that you can't go and take this website and build it on another platform, but there are a lot of resources invested in the first build, and there will be a lot of resources required to go do it differently, so I think ultimately, I have just decided ...I am just gonna try to know Joomla as best as I can" (Interviewee \#12). 
When participants are committed to working exclusively with Joomla to deliver their solutions and services, they also try to promote Joomla. Familiarity with the Joomla platform and personal preferences play a role here. For instance, for business owners it makes sense to promote Joomla because they know that they have the competence to work with it effectively. Furthermore, participants who offer commercial extensions for the Joomla platform have an interest in helping increase the Joomla user base (which might help to increase the potential customer base). "... because I have a preference for Joomla, I promote it, ... I try to
promote Joomla as much as I can" (Interviewee \#11).

"... it's actually in his [referring to an extension developer] best interest for his business to survive to enrich other people's knowledge about Joomla so other people continue to use it and therefore buy his products" (Interviewee \#41).

\subsubsection{Intersubjective trust}

Having a business connected to Joomla can mean being dependent upon the updates, security fixes, bug fixes, and feature improvements that the Joomla community provides. However, it is a community of volunteers. In case of problems that are caused by a Joomla bug, there are no contractual agreements that would call community members into action to fix the problem. Running a business based on Joomla might therefore appear hazardous at times. However, there is a logic that might help explain how business owners can establish trust in the community's ability to deal with problems, such as security issues, swiftly. If someone has a business connected to Joomla, and they know that the core developers have a business connected to the Joomla platform too, they are more confident about Joomla's ability to provide security patches quickly, because those core developers are dependent on swift fixes of security problems themselves. This could mean that vested interests on the core developers' side can enhance other participants' trust in the community to deal with problems in a timely manner. While speculative, this form of intersubjective trust may stimulate overall participation in a positive way.

"[How does Joomla preserve a certain responsiveness concerning security issues?] Well, think of it this way, if you were a developer for the Joomla project, and you were alerted to the fact that there was a bug out there, something that could take down a Joomla site, and you probably have 10, 15, 20, 30 Joomla sites yourself, you're gonna want 
a solution, so, I think, they have, I haven't seen them delayed on getting anything patched, and again, I think, the community as a whole, as web developers, understand the security issues, and I think, they jump right on it ... From a programmer standpoint, I think, we are all in this boat together, and we, the people who are volunteers, if their businesses are dependent on Joomla, they are gonna be out there trying to fix it as quickly as they can, if they see a security issue. So, I have less worry about that" (Interviewee \#36).

\subsection{Discussion}

Even though plain economic and career concerns have been cited as motivational drivers by interviewees, they do not seem to play a dominant role when people make their initial contact with the community. Initial motivations for getting in contact with the community seem to be joy, fun, passion, use value, curiosity, an eagerness to learn, friends and social networks, rather than economic concerns.

However, economic opportunities are often realised after participants engage in the community. What starts as a passion can gradually turn into a real job and attempts at commercialisation. Similar to Mollick's (2016) observations, community engagement in this empirical setting can help participants to acquire useful inputs on how to work with Joomla in their professional lives, and how to develop and refine their software solutions and business models. Essentially, the community provides a platform where competencies are developed and traded. Being able to access the pool of expertise within the community can strengthen participants' abilities to pursue economic careers, and it can help them to pivot into new careers and ventures on the back of Joomla.

Due to the voluntary nature of the Joomla project, the economic incentives for participating in the community cannot be reasonably explained through extrinsic motivations alone. Rather, there may be both direct and indirect ways through which motivations for community engagement are connected to participants' ability to further their economic careers.

According to Deci and Ryan (2000, 230), "people will tend to pursue goals, domains, and relationships that allow or support their need satisfaction". While participants are often in for the fun, joy, and passion, the realisation of business opportunities can be important at the same time. The appeal of simultaneously engaging in community work and commercial activities could be explained by the high levels of autonomy that are involved. SDT suggests that, in order for people to maintain and enhance high levels of intrinsic motivation, "people must experience satisfaction of 
the needs both for competence and autonomy" (Ryan \& Deci, 2000, p. 58). Both voluntary community engagement and self-employment offer very high degrees of autonomy. Practices that span both the community and the commercial realm (e.g., asking for and giving advice on particular customer projects, scouting opportunities and trends, sharing best practices, collaborating on customer projects) may therefore enhance intrinsic motivations accordingly. An environment that stimulates intrinsic motivations may be conducive when dealing with complex issues. This is because intrinsic motivations are associated with increased individual effort when trying to overcome obstacles and complex tasks (Roberts et al., 2006).

Similarly, community engagement offers ample opportunities for enhancing and developing one's competence. In line with Roberts et al. (2006), Study IV finds that status motivations can boost intrinsic motivation (i.e., enhanced reputation can make it more fun to participate). While SDT predicts this relationship, competence may not only have reputationenhancing effects and make community engagement more pleasurable, it is simultaneously a valuable asset in the daily work with customers.

SDT further suggests that a sense of relatedness facilitates the process of internalisation of values, attitudes, and regulatory structures (Gagné \& Deci, 2005; Ryan \& Deci, 2000). While community engagement is a welcome vehicle for connecting to like-minded others, and in establishing a sense of belonging, it may also facilitate the internalisation of community values (e.g., helping behaviour, openness, supportiveness). This means that joy, satisfaction, and enthusiasm in the Joomla community derive not only from engaging in intrinsically stimulating activities (such as the fun of meeting other people or engaging in interesting and challenging programming tasks) but also from the fact that participants widely identify with the values and norms promoted by the open source philosophy (i.e., internalised values $^{\mathrm{XLVII}}$.

From this perspective, it could be argued that the behaviour that participants engage in "is an integral part of who they are" (Gagné \& Deci, 2005 , p. 335); that it emanates from participants' sense of self, with the effect that the behaviour is perceived to be self-determined and that the associated rewards are close to the joy and satisfaction one reaps out of engaging in more intrinsically stimulating activities (Gagné \& Deci, 2005).

While previous research has suggested that tangible rewards might have negative consequences for the provision of public goods (Wasko \& Faraj,

xLVII The open source philosophy relates to values and attitudes such as sharing, openness, and collaboration (Stewart \& Gosain, 2006). 
2000), the results of this sub-study provide a more nuanced picture of this. While tangible rewards in the form of direct financial gratification might indeed negatively impact upon participants' motivation to contribute ${ }^{\mathrm{XLVIII}}$, the empirical data suggest that tangible rewards in the form of one's own need (a form of self-interested behaviour) can positively stimulate participation if selfish interests are in line with community interests. For instance, if participants contribute with code because they need a particular feature for themselves (own need), and if these features are of value to the entire user base (i.e., selfish interests are in line with community interests), the selfish motivation to contribute can be reputation enhancing and at the same time positively impact the provision of the public good. Coming back to Lerner and Tirole (2002), the net benefits of engaging in community work materialise in various forms, especially when one has a business connected to the community's software product(s). Table 5 provides a condensed summary of this.

In summary, this research contributes to the literature on both motivation for open source community engagement (Ke \& Zhang, 2009; Mair et al., 2015; Roberts et al., 2006; von Krogh et al., 2012) and forms of communitybased innovation (V. Lee, 2011; Puranam, Alexy, \& Reitzig, 2014; Riehle, 2012; von Krogh \& von Hippel, 2006; West \& Lakhani, 2008; West, Salter, Vanhaverbeke, \& Chesbrough, 2014). In addressing a recent call for more research on the relationships between community forms of organising and commercial activities (Mollick, 2016), this research shows, from a motivation perspective, how voluntary community engagement can support participants in reaping economic benefit from their community engagement.

XLVIII E.g., one interviewee reported negative experiences and conflicts in relation to previous experiments with direct monetary compensation for community work. 


\begin{tabular}{|c|c|c|}
\hline$\#$ & Motivation & Relationships to economic goals and career concerns \\
\hline 1 & Openness & $\begin{array}{l}\text { For businesses, there are many benefits that come with } \\
\text { the openness of the software code (e.g., software quality, } \\
\text { security, modifiability, reduced cost, and more). } \\
\text { However, openness can also mean openness towards } \\
\text { customers in order to build trust. For participants, } \\
\text { openness may also reduce the costs for being able to } \\
\text { access knowledge that is of relevance for their } \\
\text { businesses, and to get in contact with potential business } \\
\text { partners. }\end{array}$ \\
\hline 2 & Altruism & $\begin{array}{l}\text { Donating efforts, skills, knowledge, and code for the } \\
\text { welfare of others facilitates reputation building. } \\
\text { Reputation, as a primary currency in volunteer work, } \\
\text { facilitates the formation of professional networks and can } \\
\text { enhance the credibility of participants' businesses. }\end{array}$ \\
\hline 3 & Social responsibility & $\begin{array}{l}\text { A sense of social responsibility and the ethical } \\
\text { obligations to do good for others and society at large may } \\
\text { mediate between helping behaviour and the realisation } \\
\text { of economic goals. }\end{array}$ \\
\hline 4 & $\begin{array}{l}\text { Supportiveness, } \\
\text { helping behaviour, } \\
\text { and reciprocity }\end{array}$ & $\begin{array}{l}\text { Because the Joomla CMS is a complex software product, } \\
\text { exchanging support can sometimes save a lot of work } \\
\text { time and reduce the time-to-market of web projects. }\end{array}$ \\
\hline 5 & $\begin{array}{l}\text { Use value and own } \\
\text { need }\end{array}$ & $\begin{array}{l}\text { Participants try to protect and preserve the value of the } \\
\text { Joomla CMS for their businesses and their daily work with } \\
\text { customers. Contributing out of use value and one's own } \\
\text { need potentially also brings value to the entire user base } \\
\text { (and other businesses), even if the initial motivation to } \\
\text { contribute may have been selfish. }\end{array}$ \\
\hline 6 & Influence & $\begin{array}{l}\text { Community participants want to actively influence and } \\
\text { shape the future of the Joomla CMS. Especially for } \\
\text { participants who have a business connected to the } \\
\text { Joomla CMS, the ability to influence the future course of } \\
\text { the community (e.g., governance-wise) and the software } \\
\text { platform (e.g., in terms of the functional features), is a } \\
\text { way to protect and maintain the value of the Joomla } \\
\text { platform for their businesses. }\end{array}$ \\
\hline 7 & $\begin{array}{l}\text { Monitoring and } \\
\text { following trends }\end{array}$ & $\begin{array}{l}\text { The ability to monitor community activities is of } \\
\text { particular importance when participants have a business } \\
\text { connected to the Joomla CMS. For instance, by } \\
\text { monitoring community activities, participants stay aware } \\
\text { of trends and Joomla-related problems that could affect } \\
\text { their customers and their businesses. Through } \\
\text { community engagement, participants have the ability to } \\
\text { stay on top of changes, see the direction in which Joomla } \\
\text { is evolving, keep in touch with state-of-the-art } \\
\text { technology and web issues of all sorts. }\end{array}$ \\
\hline
\end{tabular}




\begin{tabular}{|c|c|c|}
\hline 8 & Vested interests & $\begin{array}{l}\text { When participants have a commercial business } \\
\text { connected to Joomla, community engagement can be } \\
\text { stimulated because of vested interests in the Joomla } \\
\text { platform. In particular, participants who exclusively work } \\
\text { with the Joomla CMS to deliver their services and } \\
\text { solutions can only sustain their businesses as long as } \\
\text { voluntary work efforts are invested in order to develop } \\
\text { and maintain the Joomla project. }\end{array}$ \\
\hline 9 & $\begin{array}{l}\text { Sense of community, } \\
\text { identity, and } \\
\text { connectedness }\end{array}$ & $\begin{array}{l}\text { The (often neglected) work realities of self-employed } \\
\text { developers may have detrimental effects because of } \\
\text { participants' psychological need for relatedness. By } \\
\text { providing a sense of identity and belonging, the } \\
\text { community may enhance participants' psychological and } \\
\text { spiritual well-being, which can positively impact on } \\
\text { organisations' success and sustainability (Brytting, } \\
\text { Westelius, \& Westelius, 2013). }\end{array}$ \\
\hline 10 & $\begin{array}{l}\text { Learning, } \\
\text { knowledgeable peers, } \\
\text { and knowledge } \\
\text { exchange }\end{array}$ & $\begin{array}{l}\text { Community participants often have to deal with complex } \\
\text { issues and problems. The community enables } \\
\text { participants to learn quickly, with the effect that more } \\
\text { attention can be dedicated to creative aspects of } \\
\text { problem-solving (e.g., business design). Knowledgeable } \\
\text { peers, mass collaboration, and the competencies that are } \\
\text { embedded within the community can reduce the time- } \\
\text { to-market of web solutions. }\end{array}$ \\
\hline 11 & $\begin{array}{l}\text { Joy, fun, and } \\
\text { enthusiasm }\end{array}$ & $\begin{array}{l}\text { Participating out of joy and fun may facilitate long-term } \\
\text { commitment and the opportunities to gain recognition, } \\
\text { which in turn can enhance reputation. Arguing with SDT, } \\
\text { subjecting oneself to the shared norms promoted by open } \\
\text { source ideologies may be experienced as pleasurable in } \\
\text { itself. Said differently, participants may reap pleasure } \\
\text { from 'living' the open source philosophy. }\end{array}$ \\
\hline 12 & Reputation and status & $\begin{array}{l}\text { Community members' reputation facilitates the formation } \\
\text { of professional networks and can boost the perceived } \\
\text { credibility of participants' businesses and services on the } \\
\text { customers' side. }\end{array}$ \\
\hline 13 & $\begin{array}{l}\text { Commitment and } \\
\text { perceived switching } \\
\text { costs }\end{array}$ & $\begin{array}{l}\text { The perception of investments in getting to know the } \\
\text { Joomla CMS and its community (e.g., time, effort, travel } \\
\text { expenses) can be aspects that make participants stick } \\
\text { with the community. Especially when participants have } \\
\text { developed their status as a Joomla expert, they are more } \\
\text { inclined to stick with the community and promote the } \\
\text { Joomla platform in their professional businesses. }\end{array}$ \\
\hline 14 & Intersubjective trust & $\begin{array}{l}\text { Given the voluntary nature of the Joomla project, the fact } \\
\text { that many people in the community's core have a } \\
\text { business connected to the Joomla CMS can be an } \\
\text { important signal to other business owners in the } \\
\text { community that potential problems (e.g., security }\end{array}$ \\
\hline
\end{tabular}




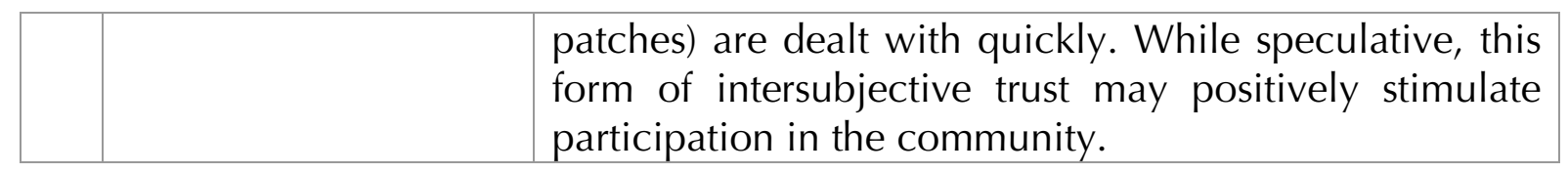

Table 5: The net benefits of engaging in community work materialise in various forms, especially when one has a business connected to the community's software product(s).

\subsection{Preliminary conclusions}

Study IV has explored the ways in which open source community engagement can support volunteers in advancing their economic goals and career concerns. It identified 14 salient motivational drivers for community engagement in this empirical setting. While these drivers are more or less well-known in the literature (except for intersubjective trust), the added benefit that comes with this sub-study is that it explains how each of these connect with community participant's ability to advance their economic goals and career concerns. Unlike previous studies in the literature that have tended to focus on determining whether some types of motivations for community engagement dominate over others, Study IV focuses on the interrelatedness of motivations. In doing so, it discussed various indirect ways in which community engagement can support individuals in pursuing their economic goals and career concerns. 



\section{Pricing of open source software extensions (Study V)}

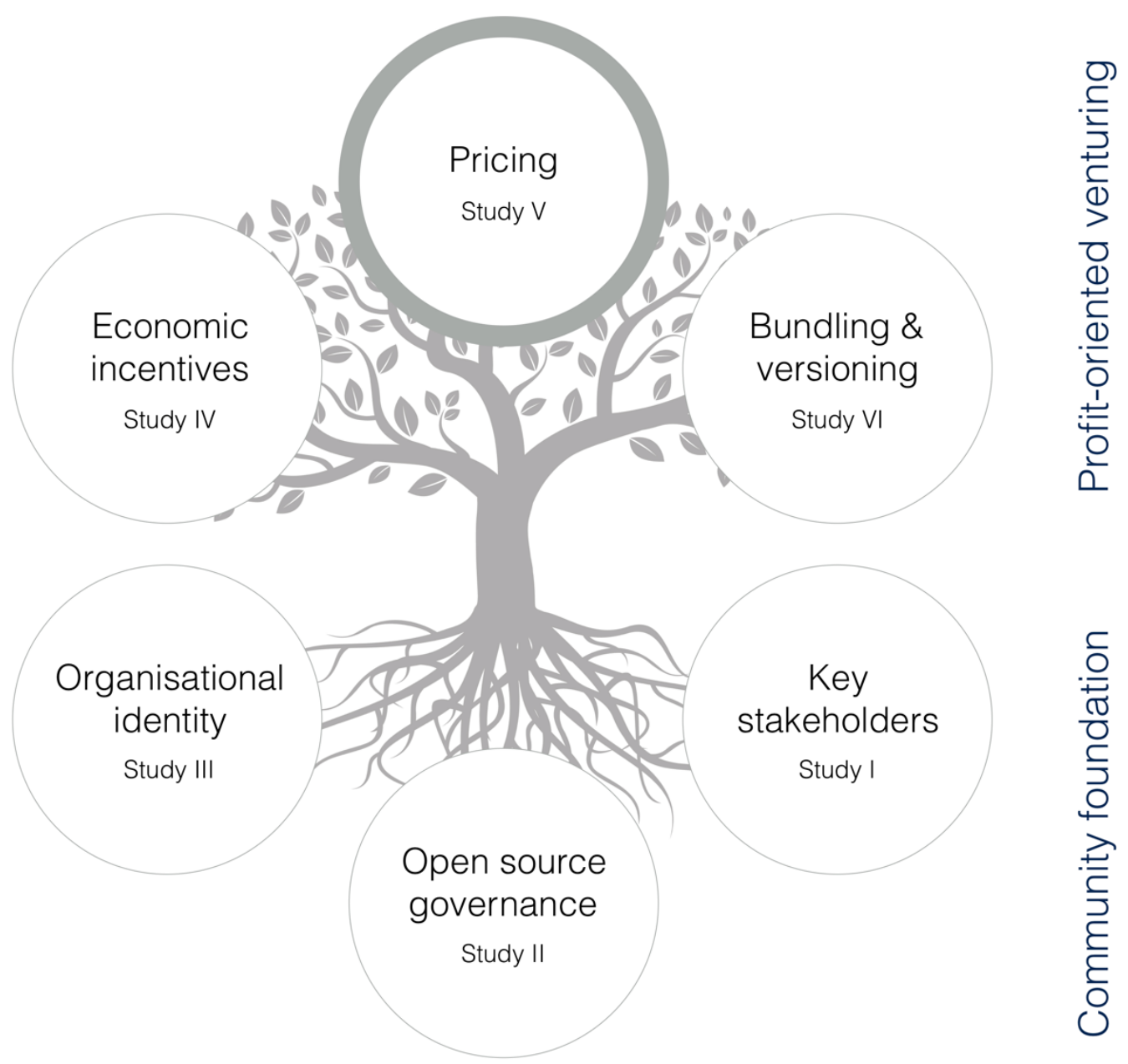




\subsection{Short summary}

The difficulty in stipulating acceptable prices for software and related services is a widely recognised problem in practice and in research. Due to the particular modes of software production and distribution, it is often laborious to predict development costs and future revenues. The growing popularity of OSS has added to the pricing problem. In particular, the area of extension markets (also called plugin or add-on markets) for open source CMSs has thus far been neglected by empirical pricing research. Extension markets provide users, administrators, developers and firms with the possibility of buying software that extends the functionality of their CMS. Study $\mathrm{V}$ evaluates pricing practices from the supplier perspective and proposes framing pricing strategies in such a context using a fivedimensional pricing model. The results provide insights into pricing as practised by vendors in an open source extension market and reveal the particular ways in which these practices cluster within the frame of the body of theory. The discussion expands on factors that inform vendors' pricing strategies for goal attainment. The results reveal the dominance of subscription models and salience of value-based pricing strategies. Furthermore, insights are presented into the utilisation of cross-subsidisation and lifetime support models as revenue generation strategies. Finally, Study $\checkmark$ refers to unexplored issues in the literature and suggests avenues for future research. 


\subsection{Introduction}

There is increasing scientific curiosity regarding inventive strategies and useful models for pricing software and related services. Previous research has emphasised the role of pricing as a powerful strategic capability (Dutta, Zbaracki, \& Bergen, 2003; Iveroth et al., 2013; Piercy, Cravens, \& Lane, 2010). Innate to a strategic perspective on pricing are the links among price, cost, value, and the strategic positioning of the firm. Above all, a commitment to value-based pricing has been argued to be essential for strategic pricing. This commitment, so the argument goes, would enable firms to occupy desirable market segments while at the same time allowing for sustainable price levels (Piercy et al., 2010).

While this might sound plausible, it can be difficult to achieve. Since there is no standard method for valuing intellectual capital and intangible assets, there is no generalisable approach to pricing information goods (Bontis \& Chung, 2000). Pricing of software and related services remains a challenge in many regards (Petri et al., 2018). One problem is the imbalance between the production and reproduction costs; i.e., virtually all production costs could be seen as part of the initial investment, whereas the costs of reproduction are virtually zero (Iveroth et al., 2013). While suppliers might face possible high upfront costs for development, operation on the buyers' side can incur substantial costs too (e.g., hardware and machinery, software, training, support). Furthermore, depending on the type of software, the sales and implementation cycles can vary in duration and labour intensity, eventually driving cost on the suppliers' side (Hajji, Pellerin, Léger, Gharbi, \& Babin, 2012).

Another difficulty relates to the general problem of translating the value of an intellectual product (such as software) into price ranges that are perceived as acceptable to both the supplier and the buyer. Vendors face the challenge of having to understand the value perceptions of their customers in order to develop appropriate price models that align with customers' willingness to buy, as well as with the business objectives of their ventures (Bontis \& Chung, 2000). Perceptions of value, however, are not easily measured (Hinterhuber, 2008); they can relate to performance, network effects, prevalence rates (Harmon, Demirkan, Hefley, \& Auseklis, 2009; Lehmann \& Buxmann, 2009), attributions of corporate success (Kittlaus \& Clough, 2009), qualities of agreements between buyers and sellers (e.g., support, maintenance, licensing), efficiency, novelty and other value drivers (Amit \& Zott, 2001).

Open source adds to the pricing problem because vendors are primarily reliant on indirect revenue generated by complementary services, such as 
support (Lehmann \& Buxmann, 2009; Petri et al., 2018; Riehle, 2009b). In addition to high upfront cost for development, support intensity can be difficult to predict and can increase variable costs for suppliers. Finally, although software vendors can create value through product improvements or lower costs, they might not always be capable of capturing this value in terms of economic rents (Docters, Tilstone, Bednarczyk, \& Gieskes, 2011; Dutta et al., 2003). Having outlined some major problems in the pricing of software and related services, theoretical, empirical, and methodological considerations are now discussed.

A pricing strategy could be seen as a reasoned choice among possible configurations of price, offering, competitors, customers and the market structure, with the aim of achieving profitability (Dixit, Whipple, Zinkhan, \& Gailey, 2008). Exploring these configurations in empirical settings can enhance our understanding of the challenges that software vendors face in pricing their products and services. As is echoed in the literature, there is a need for more empirical studies on pricing of software (B. C. Kim, 2013; Laatikainen et al., 2013; Lehmann \& Buxmann, 2009). Connected to that, there is a general lack of studies addressing the pricing of integrated solutions of goods and services (Kienzler \& Kowalkowski, 2017).

Study $\mathrm{V}$ attempts to address this gap by examining the pricing practices of vendors offering commercial OSS extensions for Joomla. In Joomla terms, extensions refer to plugins, components, modules, language packets, and design templates that are available for the Joomla platform ${ }^{\mathrm{xLI}}$. To the best of the author's knowledge, extension markets in the open source sphere have not yet been illuminated from a pricing perspective. To keep research informed about problems and challenges that vendors face in pricing their software and services, Study $V$ contributes with an exploratory study of pricing strategies devised by vendors active in the Joomla extension market ${ }^{\mathrm{L}}$.

Pricing is an area that requires consideration of both product and market characteristics (Lehmann \& Buxmann, 2009). Both product and market characteristics are implicit to a pricing model proposed by Iveroth et al. (2013), which this sub-study applies. Software licence requirements are considered as well because they enable and constrain businesses in particular manners (Fitzgerald, 2006).

XLIX Different software platforms promote different nomenclatures for software that allows for ad-hoc expansion of functionality, like extensions (Joomla, Safari), plugins (WordPress, Eclipse), modules (SAP, Drupal), add-ons (Firefox), or apps (Apple, Android). It is not the intention of this study to disambiguate these terms further. For reasons of consistency with the empirical setting, the term 'extension' will be used throughout this study.

$\mathrm{L} \quad$ This market is a B2C and B2B market. 
A strategy could be seen as a purposeful activity that employs an available repertoire of methods, plans, and skills to achieve a long-term goal. A pricing strategy in particular rests upon the available repertoire of methods, plans, and skills that facilitate the leveraging of price and pricerelated aspects to achieve stable revenues and long-term profitability. Against this backdrop, there are two research questions that guide Study V. First, what pricing patterns are prevalent in the extension market of the open source CMS, Joomla? And second, how can vendors' reasoning about pricing explain these patterns?

Study $\mathrm{V}$ mainly contributes to the literature on the pricing of software. It is possible that the results could also be of relevance for scholars and practitioners interested in strategy and open source business models. The remainder of this sub-study is structured as follows. First, the theoretical framework is presented. The subsequent section outlines the research approach. Then, the empirical results are presented, followed by a discussion of patterns of pricing strategy that could be discerned. Finally, Study $\mathrm{V}$ ends with a discussion of key aspects that affect pricing practices in this setting, and it provides recommendations for further research.

\subsection{Theoretical framework}

As a theoretical lens, Study $V$ applies the five dimensions of a pricing model proposed by Iveroth et al. (2013). The authors call their model "SBIFT", an acronym built from its five dimensions (scope, base, influence, formula, and temporal rights). SBIFT could be seen as a meta-model approach to describe or configure price models. A price model basically captures the fundamental price-related aspects of an agreement between a seller and a buyer (Diamantopoulos, 1991; Petri, 2014). The SBIFT model suggests that these agreements can be analysed by considering the granularity of the offering (scope), the information base from which a pricing decision is derived (base), the seller's and the buyer's abilities to influence the price (influence), how price is connected to volume (formula), and the timespan for which the price of the product gives the buyer rights to use it (temporal rights). The SBIFT model's explanatory power most clearly unfolds from a supplier perspective and in comparative approaches, which is the main reason why it is applied in this sub-study. The SBIFT model has been used in IT settings (Laatikainen et al., 2013) and non-IT settings (Petri, 2014). For instance, Laatikainen et al. (2013) used SBIFT to evaluate price models of cloud service providers, and they identified 73 different SBIFT model configurations in their sample.

The advantages of the SBIFT model are that it provides a granular view on essential price-related aspects. Furthermore, it derives its propositions 
from a synthesis of a variety of theories of pricing, strategy, marketing, and from the authors' long-standing experience in consultancy and academia. Laatikainen et al. (2013) emphasised the model's explanatory flexibility and regarded it as the "most integrative work in the current pricing literature" (Laatikainen et al., 2013, p. 119). Nevertheless, the model has its limitations. One important foundation for pricing lies in the relevant value drivers that impact customers' perceptions of benefits and trade-offs (Harmon et al., 2009). The SBIFT model does not account for any specifics regarding value drivers or their impact on prices. However, the current research might help to broaden the empirical base for future development of the SBIFT model. Figure 39 depicts the SBIFT model, along with short descriptions of its five dimensions.

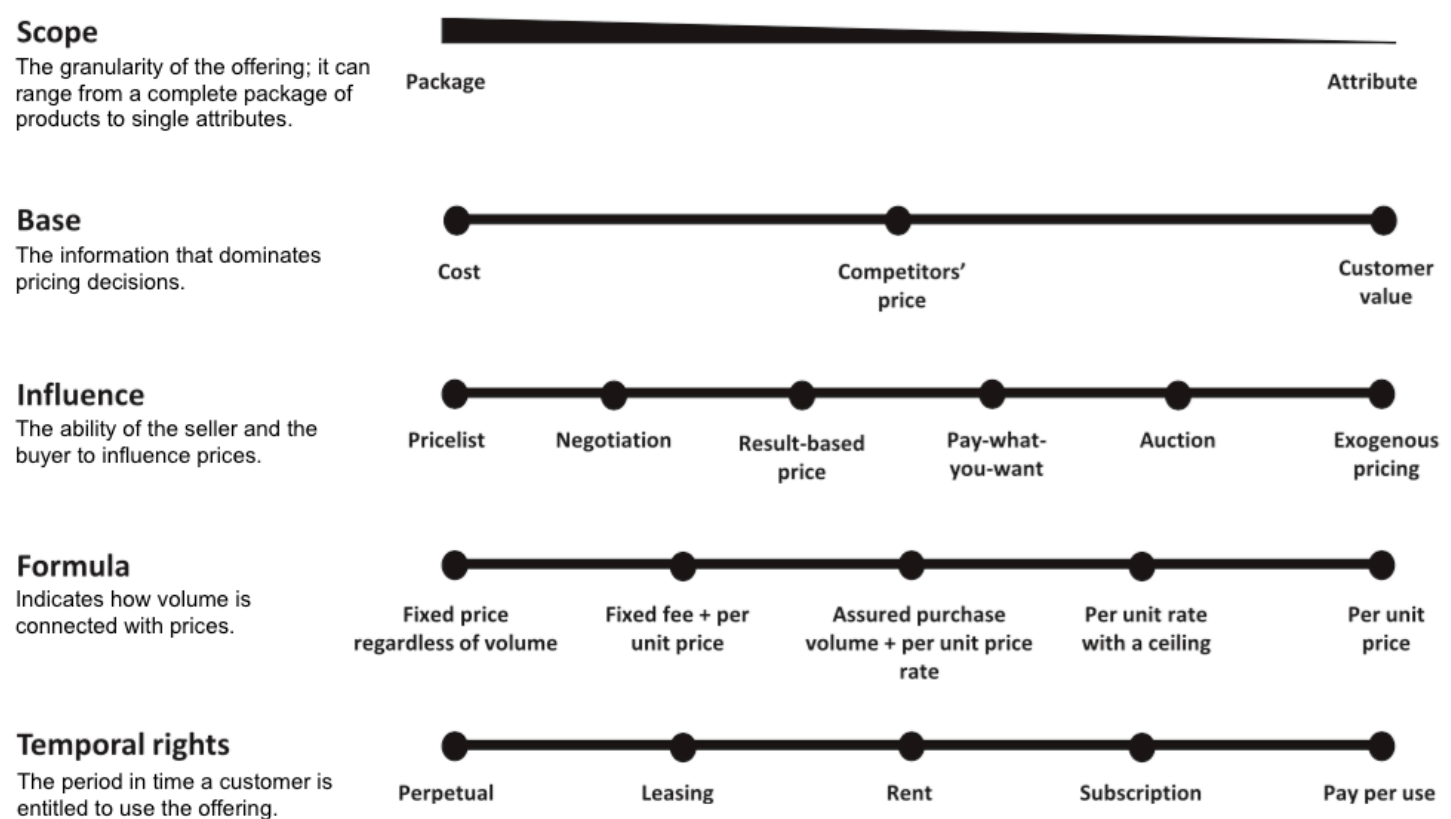

Figure 39: The five-dimensional SBIFT model (Iveroth et al. 2013).

\subsection{Empirical setting}

Joomla was introduced in Chapter 4. Its plugin architecture enables people to extend the Joomla CMS with custom functionality using software extensions, for which they may have to pay although Joomla itself is free. Joomla hosts a directory of extensions on a platform called the JED. This platform and the activities around it can be viewed as an extension market. In this market, the JED serves as an intermediary (Bailey \& Bakos, 1997) that provides vendors with the opportunity to advertise their extensions with a 
description of their features and merits. Users can rummage through the JED, but they must continue to vendors' websites to make purchases.

Joomla policies have only allowed for the publishing of GPL code on the JED since 2009 (Plummer, 2013). All extensions, whether free or commercial, must be published under the GPL, which basically states that everyone should have the right to modify and share the code, and that all modifications should be stated and published under the same licence. As mentioned earlier, this practice of cascading licence requirements down to all derivatives of the code is also called copyleft, which basically prohibits any restrictions on the code or its derivatives at any present or future time. The GPL was created in the 1980s (see Section 2.1.3); among the plethora of open source licences, it is amongst the most popular ones (Fitzgerald, 2006). As mentioned earlier, according to the information on the Joomla website, the GPL policy on the JED is to strengthen the core mission, the vision and the values of the whole project. However, Joomla's website explicitly emphasises that GPL allows developers to charge for their services and products.

\subsection{Research approach}

Study V pursued a qualitative approach that largely followed recommendations for case-oriented research (Eisenhardt, 1989; Eisenhardt \& Graebner, 2007). Essentially, the analysis was based on data from the JED, a sample of online offerings (i.e., 99 extensions), and a sample of interviews with vendor representatives (CEOs, founders, developers, owners, team members), which included 21 participants. The sampling procedure is described in more detail in Section 5.5.1.1.

The SBIFT model served as an initial lens to examine the pricing of online offerings within the sample of 99 extensions. This initial investigation yielded insights into dominant pricing patterns. The interviews were crucial insofar as they allowed for a deeper and more nuanced understanding of the rationales that inform vendors' pricing strategies. The interviews yielded information about SBIFT model dimensions that are not readily observed from vendors' online offerings, such as the information base on which pricing is based on, or parts of the influence dimension.

Cluster analysis (Namey, Guest, Thairu, \& Johnson, 2008) facilitated the attainment of insight regarding the relative importance of cost, competitor price, and customer value in vendors' pricing rationales. In doing so, a proxy measurement for the weights of attributes in the base dimension of the SBIFT model was retrieved. Overall, the analysis could be described as an iterative process of making sense of the data. Throughout this process, the 
interpretation of the data was subject to continuous revision and discussions with colleagues. This process helped in forming plausible explanations backed by the data.

\subsection{Findings}

This section presents the findings of the empirical investigation. Prior to an elaboration of the SBIFT model results, the ratio of paid versus free extensions on the JED is discussed briefly. Out of the total number of extensions on the JED, there was a slight majority of paid extensions $(51.43 \%$ paid). The more basic the functionality in an extension category was, the fewer paid extensions were found in that category, as with administration $(23.17 \%$ paid), site management $(25.80 \%$ paid), core enhancements $(26.81 \%$ paid $)$ and editing $(27.91 \%$ paid). The more tailored the functionality in an extension category was, the more paid extensions existed in that very category, as with vertical markets (69.46\% paid), e-commerce $(63.76 \%)$, and migration and conversion (64.29\%). Given these numbers, it seems more plausible to charge for niche functionality than for basic functionality. However, many vendors offered paid and free extensions alike. Therefore, it cannot be concluded that suppliers of niches versus elementary needs would congruently cluster into paid versus free extension providers. In applying the SBIFT model dimensions, the text makes references to the corresponding concepts in Figure 40, which provides a visual summary of the findings along with the SBIFT model dimensions.

\subsubsection{Scope}

This section presents findings concerning the granularity of the offerings. The findings from the sample of online offerings are presented first, followed by the findings from the interview data. As observed from the online offerings, the majority of vendors tied their extensions to a subscription that typically included technical support, free downloads, free updates and other benefits within the subscription period. The majority of extensions were available in multiple bundling options (1). For instance, there were special packages for developers, business users, or occasional users. Some vendors also offered packages with lifetime support, promising lifetime access to updates, documentation, or support. To a lesser extent, extensions were available as single subscription only (2), indicating that an extension is tied to a support subscription but a buyer cannot obtain the software through alternative bundling options. A minority of the extensions was offered as single download (3), indicating that buyers are charged a fee each time they want to acquire the software. 
The remainder of this section presents findings from the interview data. Table 6 provides examples of evidence from the interview data in relation to the scope dimension. Most interviewees stated that they use subscription models, and some even referred to it as a standard practice:

"I sell a yearly subscription for product updates and support. It is a common practice for Joomla extensions" (Interviewee \#14).

Software quality, support quality and customer experience are often at the forefront of vendors' thinking when discussing their offerings and their bundling options. Interviewees reported that their clients regard bundles as attractive offerings, especially when several extensions within a bundle complement one another in a useful fashion. Packaging the software with support is not only a means to ensure a good experience for customers but also to market the quality delivered by a vendor and to stimulate further purchases. This particular manner of packaging is seen as the easiest way to sell GPL code.

\begin{tabular}{|l|c|}
\hline Salience & Evidence from the interviews \\
\hline $\begin{array}{l}\text { Complements } \\
\text { of software } \\
\text { and support } \\
\begin{array}{l}\text { as a means to } \\
\text { ensure a }\end{array}\end{array}$ & $\begin{array}{l}\text { "We want to bundle support with the file downloads to ensure } \\
\text { a good experience for the user" (Interviewee \#10). }\end{array}$ \\
$\begin{array}{l}\text { good } \\
\text { customer } \\
\text { experience. }\end{array}$ & $\begin{array}{l}\text { "Given the wide range of users at different technical skills the } \\
\text { quality of the extension alone isn't enough. Users tend to skip } \\
\text { the product documentation and jump right into its usage. The } \\
\text { customer support service complements the extension and } \\
\text { facilitates the learning curve" (Interviewee \#4). } \\
\text { Product } \\
\text { affinity. }\end{array}$ \\
\hline $\begin{array}{l}\text { "We try to mix extensions that can be [a] good offer for the } \\
\text { customer + bundle them in packages where one extension } \\
\text { integrates with other [extensions]" (Interviewee \#2). }\end{array}$
\end{tabular}

Table 6: Examples of evidence from the interview data in relation to the scope dimension.

There are many different ways to design the scope of information goods offerings. In the literature, these practices have variously been referred to as bundling, versioning, windowing, customisation or discrimination (Akçura \& Altınkemer, 2010; Laatikainen et al., 2013; Lehmann \& Buxmann, 2009; Shapiro \& Varian, 1999; Stremersch \& Tellis, 2002). It is beyond the scope 
of this sub-study to pursue this topic in depth, but Study VI in Chapter 11 picks up on it.

\subsubsection{Base}

This section presents findings concerning the information base that dominates pricing decisions. Because this base cannot be readily observed by simply looking at online offerings, this section exclusively builds on the interview data. Table 7 provides examples of evidence from the interview data in relation to the base dimension.

In order to achieve a profitable business, the price must cover at least the cost of development, maintenance, support, and a profit margin. Development costs and support costs are of special importance. Support is an essential pillar of the business model; however, support can be a considerable cost driver. Each minute spent on support means less time for actual development. It is therefore revealing to examine the support cost per unit sold and whether it is new or existing customers incurring the cost. New customers ask more questions, which is why they accumulate more support costs. In turn, returning customers are less likely to file support requests, with positive effect on vendors' profit margins. Based on this insight, one strategy is to grant discounts equalling half of the additional profit margin to return customers. This practice is claimed to be a successful method to achieve a higher customer-retention rate, in turn increasing profits and allowing for the maintenance of stable prices for new customers.

Asking for whether the competitor price is part of the pricing decision, one would receive answers ranging from "yes, of course" to "no, never". Although low-price strategies serve a purpose (e.g., to increase sales in specific customer segments), undercutting competitor price was perceived to risk leading to a race to the bottom that effectively has only losers. Rather, a strengthened position in a more profitable segment of the market is seen as a means to ward off competition. This reasoning is based on the assumption that the products of competitors that undercut prices almost certainly decrease in quality. The same reasoning leads to the belief that lowering the price in an attempt to attract more customers does not necessarily produce the desired effect; it can even lead to fewer customers because potential buyers regard the product as less serious and hence less attractive.

When vendors perceive competitor prices as either extremely high or extremely low, they do not base their own prices on them. An approach to managing this problem is to consider customers' needs, customers' spending capacity and one's own financial needs to come to a fair price. The price 
base then also becomes a perception of fairness. Several interviewees mentioned fairness as a motive. The perception of fairness can also be linked to competitor prices or other software market prices as guidelines. For instance, observing Adobe charging a particular price for some application can guide thinking about reasonable and fair prices for particular extensions.

Vendors attempt to come close to a truly customer-centric approach in their businesses and even provide refunds to customers in case they are dissatisfied. However, reasoning about customer value can be delicate. One strategy to overcome these difficulties is to use value metrics in a more intuitive fashion, thinking about what is reasonable, desirable, and fair. One key concern pertains to how much people are willing to pay for having a particular problem solved or for receiving a feature that they want. This consideration is followed by reflection over what can be done to derive profits from these needs. A reservation price (i.e., the lowest possible price for a vendor) can be decided first. This price can also be linked to competitor prices. Based on this calculation, a package or a service can be designed to address customer demand, including complementary services that are relevant for the product (e.g., web hosting, consulting, customisation).

Focusing on customer value increases the likelihood of having satisfied customers who are tempted to renew their subscriptions or purchase other products. If vendors are able to cater to customers' 'real needs', they find it justifiable to charge more. Sometimes, customer feedback can even indicate that prices are too low rather than too high.

The importance of customer value is also reflected in statements that emphasise perfection as a driving force (e.g., to create a "software Porsche" with a "no matter what" attitude). Furthermore, the interview data show that vendors often do not keep track of the hours they spend on developing and improving their extensions, especially in the beginning when they start their businesses. Pricing is then mainly based on intuition, gut feeling, and customer feedback. Although developing towards customer value is more effortful, especially when having to bear flexibility in mind throughout development, the interview data suggest that cost (4) and competitor price (5) have a somewhat lower relative weight in vendors' pricing rationales than customer value (6). 


\begin{tabular}{|c|c|}
\hline Salience & Evidence from the interviews \\
\hline $\begin{array}{l}\text { Importance of } \\
\text { customer } \\
\text { value; } \\
\text { comparatively } \\
\text { low relevance } \\
\text { of competitor } \\
\text { price. }\end{array}$ & $\begin{array}{l}\text { - "I make [the pricing] decision based on the value my product } \\
\text { brings to the customer" (Interviewee } \# 13 \text { ). } \\
\text { - "I prefer that people say: "it was totally worth the price, and } \\
\text { saved me a lot of time'" (Interviewee } \# 3 \text { ). } \\
\text { - "The price of a competitor plays a minor part ... our higher } \\
\text { price is often competitive through fast and good support" } \\
\text { (Interviewee } \# 21 \text { ). } \\
\text {-We compare ourselves rarely with competitors, partly } \\
\text { because some competitors use extremely high pricing or use } \\
\text { extremely low pricing" (Interviewee \#5). }\end{array}$ \\
\hline $\begin{array}{l}\text { Comparatively } \\
\text { low relevance } \\
\text { of cost; } \\
\text { significance of } \\
\text { customer } \\
\text { feedback, } \\
\text { intuition, and } \\
\text { fairness. }\end{array}$ & $\begin{array}{l}\text { - "... I don't know the number of development hours and so the } \\
\text { costs. Pricing is mainly based on my feeling and customers' } \\
\text { feedback about the pricing. I actually increased the price ... } \\
\text { because the feedback of people [indicated] that they would be } \\
\text { happy to pay more [for newly introduced features]" } \\
\text { (Interviewee \#3). } \\
\text { "[We are] trying to match the customer needs with the } \\
\text { customers' pocket with our own financial needs with what } \\
\text { seems fair" (Interviewee \#5). } \\
\text { "I have tried pricing by the hour but found out that in } \\
\text { development it is very hard to predict how many hours a } \\
\text { feature will take to develop, test, debug, implement and } \\
\text { support afterwards, so I quickly abandoned this model ... } \\
\text { people have different development processes and spending } \\
\text { time coding/typing on the computer does not always equal } \\
\text { better end results. So, there is definitely a huge element of } \\
\text { subjectivity in pricing" (Interviewee \#20). }\end{array}$ \\
\hline
\end{tabular}

Table 7: Examples of evidence from the interview data in relation to the base dimension.

\subsubsection{Influence}

This section presents findings concerning the ability of the seller and the buyer to influence the price. The findings from the sample of online offerings show that all prices were communicated through pricelists (7). The remainder of this section presents findings from the interview data. Table 8 provides examples of evidence from the interview data in relation to the influence dimension.

Pricelists make it easier to plan for a viable budget. Although there are occasional negotiation attempts from the customers' side, most vendors 
want to stick with the pricelist, either because they believe that their prices are fair, or because prices on that list are already as low as they can be without causing a loss. Customers who want to negotiate the price are also seen as a factor driving support costs because they tend to be more demanding and also renew their subscriptions less often.

However, there are vendors, albeit a slight minority in the interview sample (8), that are willing to negotiate prices on a case-by-case basis. The motives underlying negotiations on the vendors' side can be larger purchases by customers, requests from non-government organisations, or customers who convince a vendor that they otherwise could not afford to pay the full price. The final deal can include other benefits than a lower price, e.g., additional extensions or templates. Vendors who negotiate are prepared to negotiate both the price and scope of the offering, an observation also made by Laatikainen et al. (2013).

Result-based pricing (e.g., revenue split until customers break even) does not play any role - neither the online offerings nor the interview data indicate it in any way. The problem referred to is one of measurement. It is difficult to assess whether an extension has allowed a customer to earn money. Customers' success relies on too many factors outside of vendors' control.

Pay-what-you-want or donation models are not viable alternatives either. Some vendors had prior experience with donation models (9), but these models were not viewed as a sustainable revenue source by anyone. A simple plugin that requires only a few hours per month of maintenance can be subject to a donation model, but anything more complex that requires reliable support and consulting is difficult to maintain on a donation basis. 


\begin{tabular}{|l|c|}
\hline Salience & Evidence from the interviews \\
\hline $\begin{array}{l}\text { No } \\
\text { willingness to } \\
\text { negotiate the } \\
\text { price. }\end{array}$ & $\begin{array}{l}\text { "There is no negotiation. The buyers who attempt to get lower } \\
\text { prices are usually the ones requiring also more support. We } \\
\text { simply state that our prices are fair already. Take it or leave it" } \\
\text { (Interviewee \#5). }\end{array}$ \\
\hline $\begin{array}{l}\text { Provision of } \\
\text { alternative } \\
\text { options. }\end{array}$ & $\begin{array}{l}\text { "We don't negotiate our pricing, but we do provide some } \\
\text { benefits for users that make larger purchases" (Interviewee \#4). } \\
\text { "Very rarely does a customer negotiate the price. The few times } \\
\text { that it happened, I offered the ability to buy more than one } \\
\text { extension for a discount, which has indeed worked once or } \\
\text { twice" (Interviewee \#14). }\end{array}$ \\
\hline
\end{tabular}

Table 8: Examples of evidence from the interview data in relation to the influence dimension.

\subsubsection{Formula}

This section presents findings concerning how volume is connected to price. The findings from the sample of online offerings show that practice within this dimension clusters between pure flat-rate pricing, i.e., fixed price regardless of volume (10), and pure transaction-based pricing, i.e., per unit pricing (11), with a vast majority of offerings in the former category.

The remainder of this section presents findings from the interview data. Table 9 provides examples of evidence from the interview data in relation to the formula dimension. An argument against charging on a per download basis is that customers are discouraged to upgrade to newer, more stable and more secure software. Furthermore, vendors could be accused of intentionally building bugs into the software to require customers to buy new versions of the software more often. Another disadvantage with perdownload payment is that Joomla has slow release cycles, so a downloaded extension could function for very long, resulting in lower revenues than a subscription, which would be renewed at intervals.

There were also two arguments against the provision of single support requests for non-subscribers. First, when clients are frustrated with a problem (even though it might be caused by their own actions), they tend to see the supplier as responsible for fixing the problem. From this perspective, it makes more sense to contract on a subscription basis, rather than on the basis of single support requests. Second, charging for single support requests can lead to many discussions about whether a particular customer question is a valid transaction, which is not worth the effort. Additionally, transaction- 
based pricing of downloads is believed by some interviewees to be in conflict with Joomla policies and the GPL requirements.

\begin{tabular}{|l|c|}
\hline Salience & Evidence from the interviews \\
\hline $\begin{array}{l}\text { Charging per } \\
\text { download is } \\
\text { not a viable } \\
\text { model. }\end{array}$ & $\begin{array}{l}\text { "Charging per download or per version is a very perverse } \\
\text { model. You are giving a disincentive for upgrades which means } \\
\text { that your clients will stick with old, buggy, vulnerable versions } \\
\text { of your software" (Interviewee \#1). } \\
\text { "[Charging on a per download basis is] not working with } \\
\text { Joomla. They [i.e., the customers] want an extension, and when } \\
\text { purchased they want to install it everywhere they want. Of } \\
\text { course, support for multiple sites can be paid additionally" } \\
\text { (Interviewee \#15). }\end{array}$ \\
\hline $\begin{array}{l}\text { Transaction- } \\
\text { based or per } \\
\text { unit pricing } \\
\text { may not be in } \\
\text { line with }\end{array}$ & $\begin{array}{l}\text { "Due the GPL, I won't charge per download, it's simply not in } \\
\text { GPL. }\end{array}$ \\
\hline
\end{tabular}

Table 9: Examples of evidence from the interview data in relation to the formula dimension.

\subsubsection{Temporal rights}

This section presents findings concerning the duration of time within which a customer is entitled to use the offering. The findings from the sample of online offerings show that all software remains functional after the subscription period has ended. As guaranteed by the GPL, the right to use the code is perpetual (12). For providers of closed-source software, it may be easier to restrict the usage of their software via authentication mechanisms or licence validation, but the GPL requires vendors to disclose the source code to their customers. The duration of support subscriptions is limited, typically between three months and 24 months (13). However, there were also some vendors that offered lifetime support (12).

Finally, the remainder of this section presents findings from the interview data. Table 10 provides examples of evidence from the interview data in relation to the dimension of temporal rights. The interview data confirm that leasing, rent and pay per use do not play any significant roles in this empirical setting; not only because these models can be difficult to implement, but also because they can encounter resistance from customers. 
Vendors have little means (and apparently also little desire) to actively control the 'life span' of their extensions. While SaaS models were regarded as a possibility, no one within this sample adopted such a model. One reason for refraining from SaaS models is that vendors would have to take care for the hosting environment, which can be too effortful for a single developer or a small firm. However, there are also other arguments for refraining from SaaS models, such as customers' privacy and security concerns. Furthermore, some interviewees believed that leasing is not in agreement with Joomla policies.

\begin{tabular}{|l|l|}
\hline Salience & Evidence from the interviews \\
\hline $\begin{array}{l}\text { Leasing is not } \\
\text { practicable } \\
\text { and too } \\
\text { effortful for } \\
\text { Joomla } \\
\text { extensions. }\end{array}$ & $\begin{array}{l}\text { "With Joomla, this makes little sense to us. Leasing } \\
\text { software would also mean that you either take care of the } \\
\text { hosting environment (so offer Joomla as a whole as a } \\
\text { service) or offer some kind of web service" (Interviewee } \\
\text { \#5). }\end{array}$ \\
\hline $\begin{array}{l}\text { Leasing may } \\
\text { be in conflict } \\
\text { with GPL and } \\
\text { Joomla rules. }\end{array}$ & $\begin{array}{l}\text { "[Leasing] is a good model, but we found no way to } \\
\text { implement it yet" (Interviewee \#2). }\end{array}$ \\
\hline
\end{tabular}

Table 10: Examples of evidence from the interview data in relation to the dimension of temporal rights. 


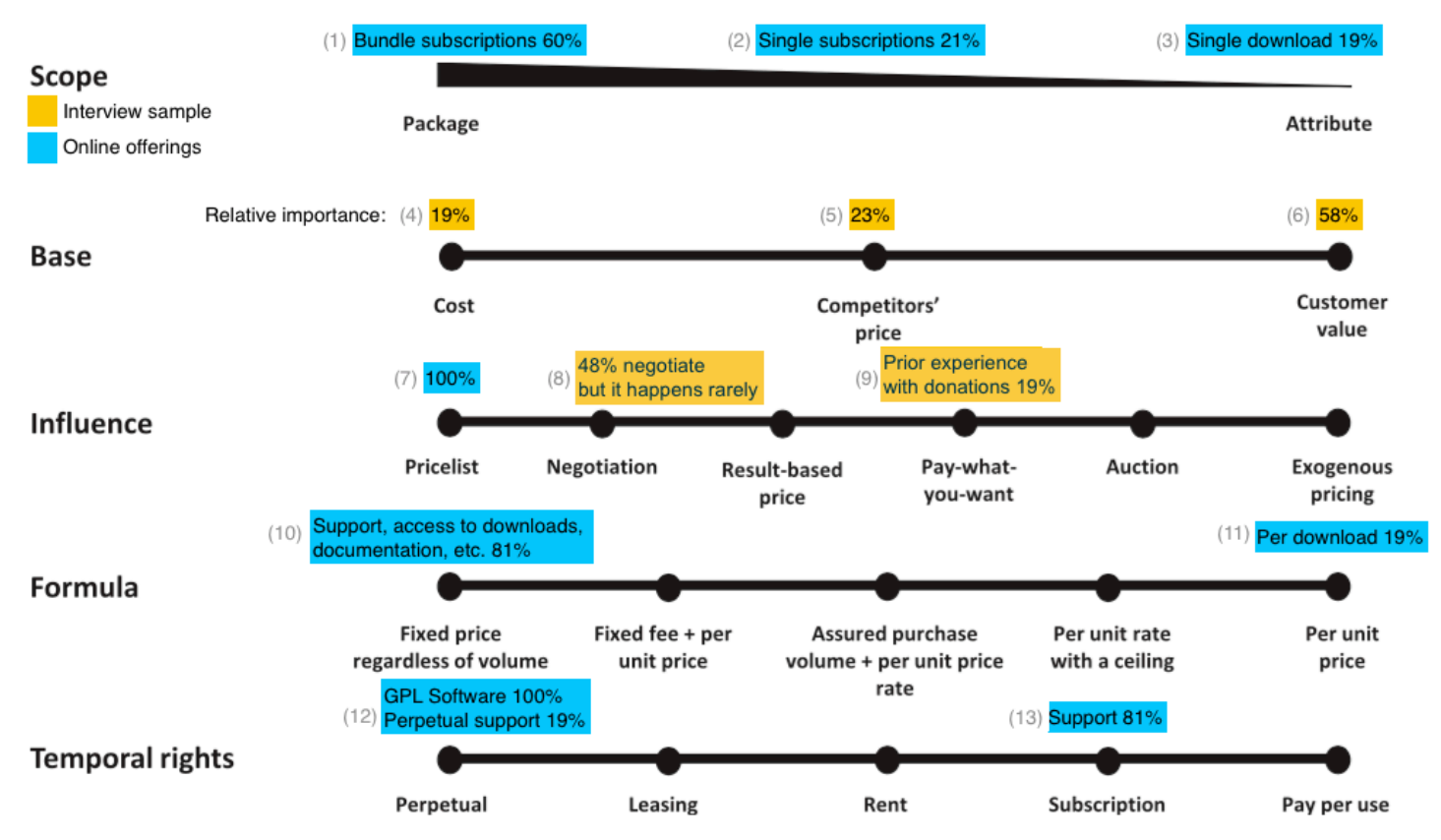

Figure 40: A visual summary of the quantitative SBIFT model results.

\subsubsection{Dominant pricing pattern}

The empirical investigation was a journey through a plurality of different practices, opinions and views. Nonetheless, there are particular ways in which emerging impressions cluster within the frame of the body of theory. Figure 41 provides a visual summary of the dominant pricing practice in this setting from a SBIFT model perspective. The package predominantly consists of two building blocks: software (A) and a support subscription (B). The GPL ensures that the software can be used perpetually. Within the subscription period, customers can download extensions or updates as often as they want. The support subscription is limited in duration and typically stipulates a fixed price regardless of volume (C). Within the subscription period, customers are entitled to file support requests. There were no communicated limits on the number of support requests that customers could file. However, because support drives vendor costs, it is reasonable to assume that support requests must follow a fair-use principle. There was no explicit mention of paying customers 'over-using' the possibility of support, which of course does not mean there were no cases. The package constitutes the basis for the customer value proposition (D). The information base for pricing includes cost (E), competitor price (F) and customer value $(G)$, with the last given relatively higher weight in vendors' pricing rationales. 


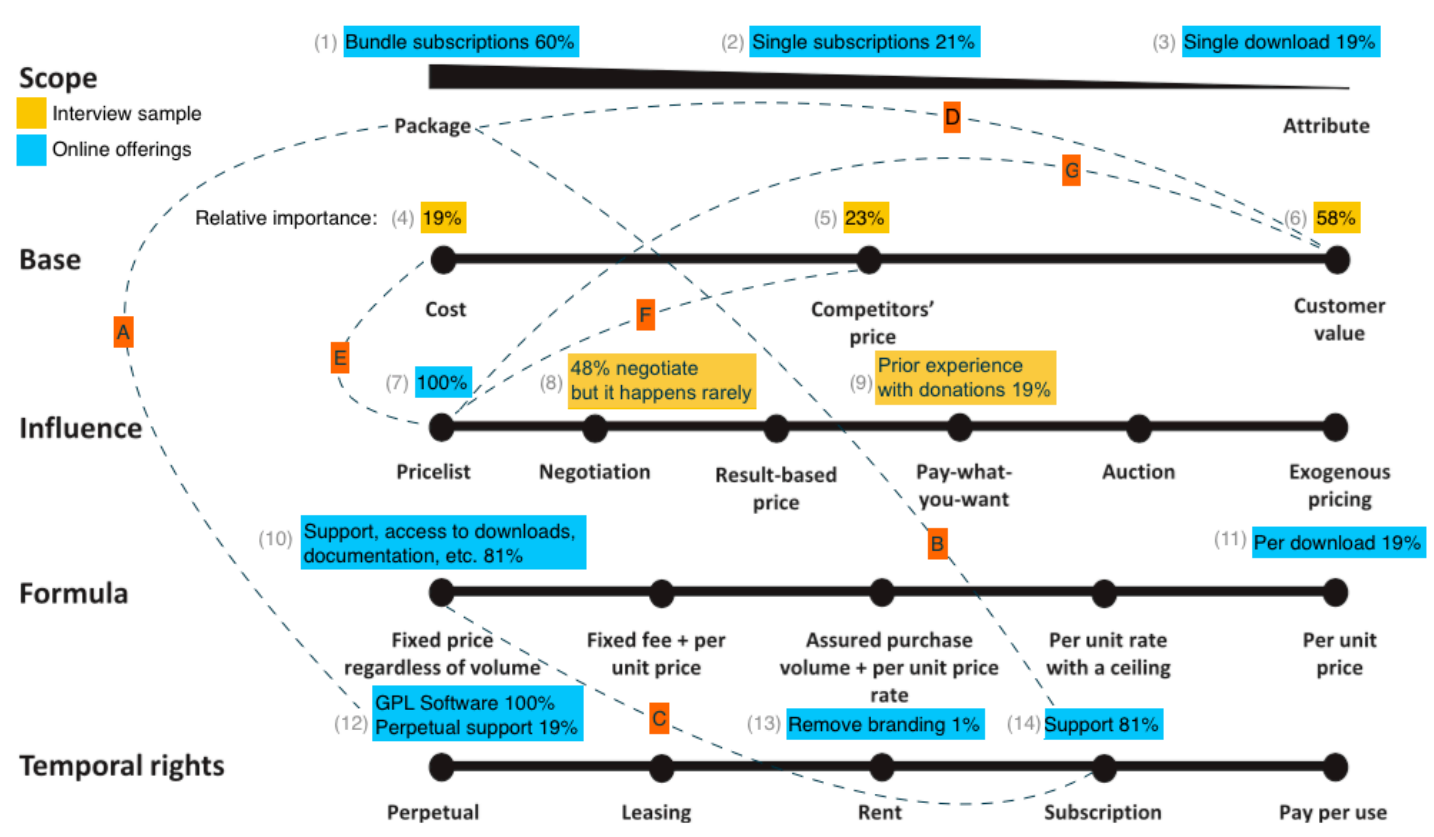

Figure 41: Dominant pricing practice from a SBIFT model perspective.

\subsection{Discussion}

In this section, the results are compared with the pricing literature. The main traits discussed are the dominance of subscriptions, of value-based pricing, the (unexpected) lifetime support offer, the cross-subsidisation practice, and the influence of platform policy on pricing practices. While price model configurations for Joomla extensions can be diverse (Petri et al., 2018), Study $\checkmark$ finds that there is a dominance of subscription-based price models within the studied sample. The dominance of subscriptions for software and related services has previously been observed (Harmon et al., 2009; Plummer, 2013) and is confirmed by this sub-study. The merits of subscription plans could be explained as follows. Subscription plans may allow for stable relationships between customers and vendors and for a fair distribution of risk. For vendors, subscription plans facilitate long-term planning because they allow for continuous and stable revenue streams. For customers, subscription plans may provide the safety of having someone in charge in case of problems arise. Since the majority of customers in this setting are small and medium sized businesses that are in great need of support, it makes sense to contract on a subscription basis. 
A subscription may also be a contractual vessel laying the grounds for the emergence and persistence of trust between vendors and customers: for vendors, because their customers commit to financing operational efforts, continuous product improvements, and the retention of professional services over a period of time; and for customers, because it implies being part of a strategic alliance from which timely support can be expected. Experiencing trust may also increase perceived switching cost on the customers' side and thereby create value through lock-in effects. Increased lock-in effects may also decrease the price elasticity of demand and provide vendors the benefit of enhanced flexibility in their pricing policies.

Furthermore, in addition to price, a customer perceives other costs (Christopher, 1982), for instance, costs for installation, maintenance, or diagnosis. A subscription may be a way of reducing the perception of these costs because it provides customers with the comfort of participating in a coalition that has their problems at heart.

\subsubsection{Dominance of value-based pricing}

Subscription plans may promote what Harmon et al. (2009) see as an intrinsic quality of value-based pricing strategies, i.e., the fostering of customer relationships to achieve financial and strategic objectives. Although competitor price and cost play non-negligible roles in vendors' reasoning about prices, they play minor roles compared to customer value. Even those vendors mentioning cost and competitor price as main impact factors, implicitly, explicitly, and often extensively elaborated on the importance of support quality, software quality, customer satisfaction, customer experience, customer needs and customer problems.

Software can be seen as an experience good (Lehmann \& Buxmann, 2009). In agreement with previous observations (DeLone \& McLean, 2003; Shapiro \& Varian, 1999), the empirical data suggest that customer experience not only derives from the use of the software but also from the integrated value of software and support. Therefore, being attentive to the anticipated consequences of software and service quality is imperative for vendors in this setting.

Another explanation for the dominance of customer value may be that profitability in digital economies is less reliant on single transactions than on long-term relationships between customers and suppliers (Ancarani, 2002). Vendors attempt to ensure a high-quality experience for customers throughout the subscription period, which not only makes customers more inclined not only to renew their subscriptions but also to purchase other products and services from the same vendor. 
Furthermore, vendors feel more confident to target higher-priced segments when they are convinced that they deliver superior value to customers. While inference of quality from price is a well-studied phenomenon (Cialdini, 2009; Obermiller, 1988), Piercy et al. (2010) referred to this value-centric pricing practices as a high-active pricing strategy. According to them, the suppliers' bet is that a higher price will appeal to customers' perception of quality and that it will increase dependability on the product. They further conjecture that this strategy could offer suppliers more protection against competitors, especially for highly differentiated products. In addition, a higher price can be a way to avoid attracting 'bad' or overly demanding customers.

Because of the high degree of subjectivity involved in pricing extensions, pricing is mainly guided by intuition, perceptions of fairness and customer feedback. Vendors set prices according to what they consider to be a fair compensation in relation to their efforts in creating and maintaining quality products and services. In line with Piercy et al. (2010), pricing in this setting should therefore be seen less as a 'quick fix' for adding value or alluring new customers. The data suggest that price sensitivity in this empirical setting is either low, i.e., adjusting the price of a product has little effect on sales, or that customer demand even decreases in reaction to lowered prices because it can signal inferior quality. A unique value proposition can set a vendor's offering apart from the competition, but the data suggest that lower prices are less able to do so. What aggravates the situation for commercial extension providers is that their products also compete with free extensions. In case a commercial extension competes with free extensions, it may not make too much sense to base the pricing decision on competitor prices. Rather, the value perceptions of customers as indicated through their feedback may serve as an orienting guide in pricing.

An alternative explanation for lower weighting of competitor price is based on customers' search costs for finding and comparing different products. The JED does not provide information on prices; hence, there is no convenient way for customers to list, filter and compare products based on price level. The vendors may be well aware that prices are not easily compared. According to Harmon et al. (2009), search costs can be a special burden for customers who highly value their time and opportunity costs, which may partly explain the low price sensitivity expressed in the interviews.

Furthermore, according to Lehmann and Buxmann (2009), competition depends upon product homogeneity and the market structure. Considering competitor price to a greater extent would make sense if there were plenty of homogenous competing products within the same niche. However, the 
bundling of extensions is widely practised. Bundling can render products less comparable and decrease customers' price sensitivity (Stremersch \& Tellis, 2002). Therefore, it could be conceded that a low relative weighting of competitor price in vendors' pricing rationales could in part also be explained by the wide-spread practice of bundling in this setting.

A potential explanation for the lower relevance of development costs expressed in the interviews can be derived from Harmon et al. (2009). According to them, pricing strategies based on customer value do not have cost recovery or timely returns on investment as a primary goal. This view is arguably supported by the interviewees who did not count the hours of development and who had software quality, support quality, and reputation at the forefront of their thinking. This is not to say that cost is irrelevant; it surely is not. Therefore, it is worth considering how cost is linked to customer experience and the commitments stipulated by the price model. As previously mentioned, the key cost drivers in this setting are development challenges and support requests. Poor software quality very likely increases support intensity on the vendors' side, in turn increasing support costs. In a similar fashion, poor support quality can increase support intensity and thereby increase support costs. From a strategic perspective, both poor software quality and poor service quality may endanger vendors' prospect of customers confirming their commitment (by prolonging their subscriptions or by posting good ratings on the JED).

Support costs can depend on the characteristics of problems that customers face. For instance, marginal costs for support could probably be kept low if customers' problems are homogenous, as when customers can resolve common problems by relying on online documentation or when the entire customer base benefits from a bug fix that is subsequently rolled out and published as a new software version. Marginal costs for support will likely increase if customers' problems are highly heterogeneous. Then, a vendor can expect little synergy in operational support by attending to one particular customer's problem.

\subsubsection{Lifetime support}

An unexpected price model configuration in this empirical setting is lifetime support. Lifetime support models entice customers to buy all-in-one bundles at higher prices with the promise of lifetime access to downloads, updates, and perpetual support. At first sight, it was not obvious how such an approach would allow for sustainable profit. However, there is a rationale for offering lifetime support that surfaced in the interviews, which is based on the assumption that a customer will use the product only for a few years 
before switching to a different solution or a different platform. Although lifetime offerings are typically marketed as to emphasise on the customers' ability to consume benefits throughout their entire lives, a vendor assumes that customers will use the product or the service for a rather limited period of time, for instance, fewer than five years. If the assumption is that customers move on after this period anyway and if there is continuous turnover of customers within this target segment, it makes sense to offer lifetime bundles. From this point of view, a lifetime offering could be seen as a valuable signalling strategy (Kirmani \& Rao, 2000), especially if it lays the ground for convincing customers about the benefits of other products and services offered by a vendor.

\subsubsection{Cross-subsidisation}

Another interesting practice observed in this setting is cross-subsidisation based on customer groups (i.e., new customer versus existing ones) and product groups (i.e., free extensions versus paid ones). Cross-subsidisation based on customer groups presumes that returning customers can subsidise prices for new customers. The reason is that repeat customers file fewer support requests because they are already familiar with the software. Repeat customers therefore increase the profit margin because they accumulate lower support costs. A percentage of this additional margin can then be given as discounts to them. This practice can boost profits through higher customer-retention rates and at the same time allow to keep prices for new customers at a stable level. This particular form of cross-subsidisation does not appear to be prominently discussed in the literature on the pricing of software and related services. A possible explanation for this finding could be the lack of empirical contributions in this area.

Cross-subsidisation based on product groups occurs when a vendor releases a variety of free extensions to spread word about its brand and product quality in order to generate leads and organic traffic. Paid extensions, in turn, subsidise the development of free extensions. Similar to the freemium business model (Kumar, 2014), releasing a variety of free extensions increases the likelihood of sales of commercial offerings. Lehmann and Buxmann (2009) would call this approach capitalisation on indirect network effects. Forty-five percent of all vendors in this sample offered both free and paid extensions. Free extensions typically have simple functionalities; they can be lightweight modules, additional files, plugins, or templates. 


\subsubsection{Software licence and the price model}

The dominance of subscriptions can in part also be explained by licence requirements and Joomla platform policies. Plummer (2013) emphasised that the JED accepted non-GPL and encrypted code before 2009, indicating that developers used a range of proprietary and open source licences to sell their extensions. However, the platform policy changed in 2009, and since then, the JED has only accepted GPL code, which may have left subscriptions as the only viable alternative for selling extensions. As the interview data show, subscriptions are the easiest and most effective way of commercialising GPL code. Because extension providers receive the bulk of their traffic from the JED, vendors have little leeway to pursue alternative pricing and licensing strategies when selling Joomla extensions. This is because vendors could run the risk of being banned from the JED in case they do not comply with the JED policies. Hence, this sub-study suggests that platform policy and the licensing that it promotes may in part explain the dominant forms of price model configurations for selling extensions. Finally, Figure 42 highlights the key aspects (classified into four categories) that affect pricing practices in the realm of commercial OSS extensions. 


\begin{tabular}{|l|}
\hline Integrated value of \\
software and support \\
\hline The quality of the \\
software alone is not \\
enough to satisfy \\
customers. \\
. Customer experience \\
derives from the \\
integrated value of \\
software and support. \\
Support facilitates the \\
learning curve and \\
complements the use \\
of the software. \\
In case of problems, \\
customers tend to see \\
suppliers in charge, \\
even when problems \\
are caused by \\
customers' own \\
actions. \\
Customers' experience \\
and their problems are \\
at the heart of the \\
commitments \\
stipulated via \\
subscription plans. \\
\\
\end{tabular}

\begin{tabular}{|l|}
\hline \multicolumn{1}{|c|}{ Cost drivers } \\
\hline Both poor software \\
quality and poor \\
support quality can \\
increase support cost \\
but also endanger \\
customers' willingness \\
to prolong their \\
commitments. \\
Homogeneity of \\
customer problems \\
can decrease support \\
cost. \\
Heterogeneity of \\
customer problems \\
can increase support \\
cost. \\
Cross-subsidisation is \\
a way to exploit \\
differences in support \\
intensity to keep prices \\
stable for new \\
customers. \\
Life-time support \\
models build on the \\
assumption that \\
customers use the \\
product for a limited \\
period of time (e.g., \\
less than five years). \\
\end{tabular}

\begin{tabular}{|l|}
\hline \multicolumn{1}{|c|}{ Platform policy } \\
\hline - Platform policy affects \\
the way in which \\
vendors can charge for \\
their products and \\
services. \\
- Non-GPL code is not \\
accepted by the JED. \\
Vendors receive the \\
bulk of traffic from the \\
JED, which is a strong \\
incentive to comply \\
with Joomla policies. \\
Subscriptions are the \\
most effective way to \\
sell GPL-licensed \\
code. \\
As interpreted by \\
some vendors, Joomla \\
policies may prohibit \\
leasing models. \\
\end{tabular}

\begin{tabular}{|l|}
\hline \multicolumn{1}{|c|}{ Fairness } \\
\hline Because of the \\
subjectivity in pricing \\
based on customer \\
value, prices are \\
determined in relation \\
to what vendors \\
consider a fair \\
compensation in \\
relation to their efforts, \\
and what value they \\
believe customers can \\
derive from the use of \\
their offering. \\
Customer feedback \\
informs pricing \\
policies. Sometimes \\
customer feedback \\
can indicate that prices \\
are too low rather than \\
too high. \\
Support requests \\
follow a fair-use \\
principle. \\
Subscription plans \\
facilitate a fair \\
distribution of risks \\
between suppliers and \\
buyers. \\
\\
\end{tabular}

Figure 42: A summary of key aspects affecting pricing practices in the realm of commercial OSS extensions.

\subsubsection{Limitations and opportunities for further research}

While Study $\vee$ draws on rich interview material and an analysis of 99 extensions, the generalisability of the results may be limited due to the comparatively small sample size. Furthermore, a focus on the top-rated extensions might yield specific pricing patterns that might not be generalisable to the entirety of extensions in the JED. However, the insights from this qualitative study could serve as an input for follow-up quantitative survey studies on the basis of large-scale data. Future research could also study extension markets for other CMS platforms, such as WordPress ${ }^{\mathrm{Ll}}$ or other (non-CMS) software platforms. Considering multiple extension markets and cross-comparisons could further our understanding of pricing practices in this realm. Finally, because two interviewees reported positive

LI While there are myriads of commercial plugins for WordPress, one problem in investigating WordPress is that it does not currently host plugins with paid functionality in its official plugin directory. 
experiences of experimenting with financing extensions through crowdfunding initiatives, future research could explore the significance of crowd funding in the context of software extensions.

\subsection{Preliminary conclusions}

Study $V$ focused on pricing strategies pursued by vendors offering commercial extensions for the Joomla platform. The results showed a prevalence of subscription models that grant access to downloads, support, updates, documentation and other benefits within the subscription period. Given the idiosyncrasies of OSS, subscriptions facilitate stable relationships between customers and vendors, long-term planning, and a fair distribution of risk. Compared to cost and competitor prices, customer value is judged to have a relatively higher weight in vendors' pricing rationales. For extension providers, focusing on customer value is a strategy to cater to customers' 'real needs', to ward off competition more effectively and to decrease support costs at the same time. This sub-study also highlights the effects of platform policy on the dominant forms of pricing patterns. Further insights were provided regarding how vendors utilise cross-subsidisation and lifetime support models as revenue generation strategies. Study V followed calls for more empirical research on the pricing of software and related services; it links to unexplored issues in the literature and highlights avenues for future research. 

11 Bundling and versioning of open source software extensions (Study VI)

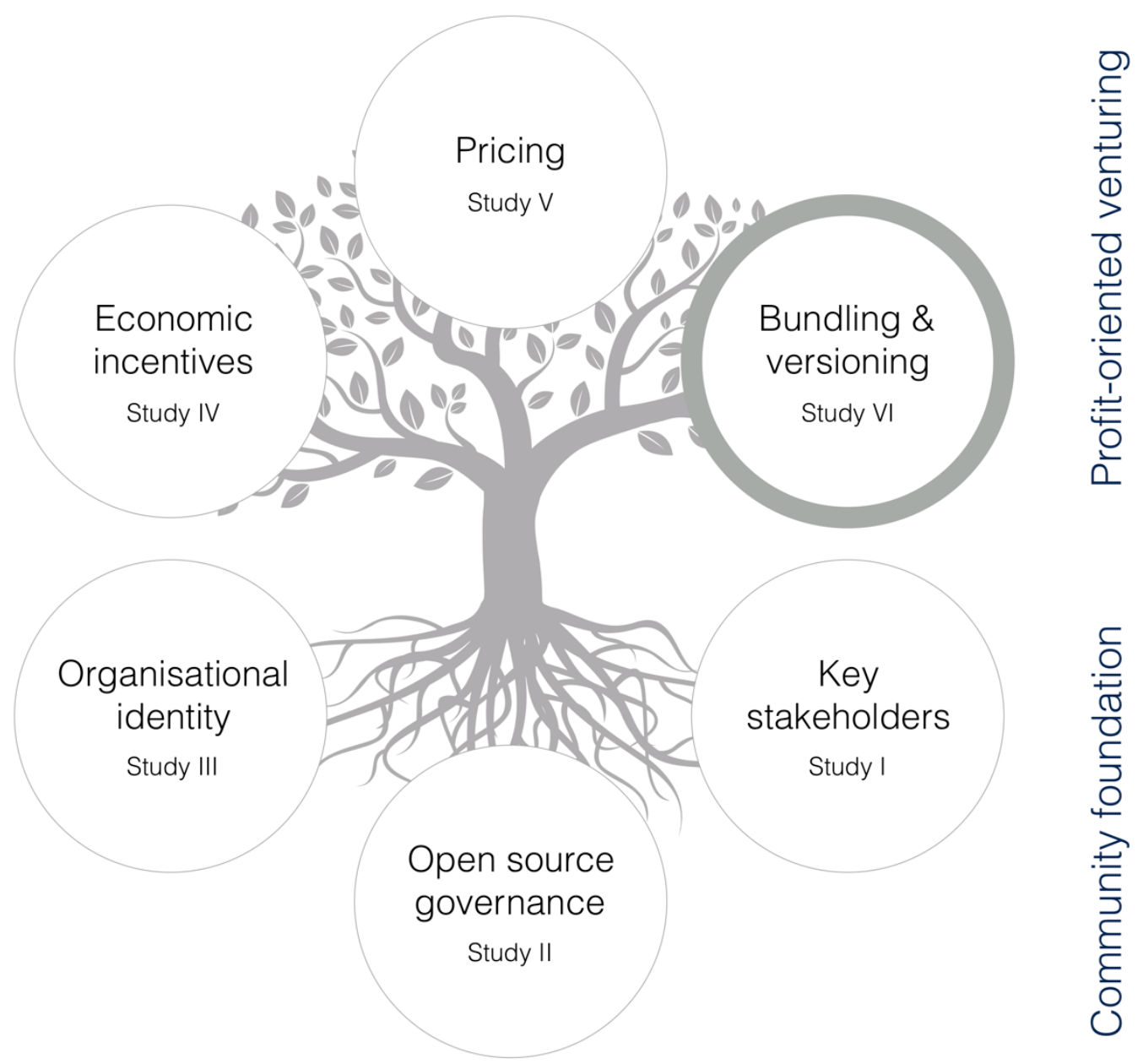




\subsection{Short summary}

Study VI examines bundling and versioning practices employed by vendors offering software extensions for Joomla. Firms employ bundling and versioning for a variety of reasons, such as appealing to customers' value perceptions in more favourable ways, exploiting the willingness to buy among different customer segments, or binding customers via lock-in through integrated product suits. Bundling and versioning are of particular importance in the context of information goods; however, vendors may struggle to bundle and version their offerings because of the manifold approaches that information goods afford. In an attempt to address this problem, Study VI takes on a design-oriented approach towards bundling and versioning, analysing compositions of offerings and the specific product attributes that they consist of. The results show that vendors bundle and version their offerings based on diverse sets of capabilities, competencies, resources, and differentiation criteria. Vendors utilise a surprising number of product attributes and differentiation criteria to compose and structure their offerings. Drawing on empirical insights, this sub-study proposes a generic model for analysing bundling and versioning both in a descriptive and prescriptive sense. The findings of Study VI may not only be relevant to academic research but possibly also serve as inspiration to practitioners in such areas as software product management or marketing. 


\subsection{Introduction}

Study VI problematises bundling and versioning in the context of OSS and related services. Though bundling and versioning of information goods ${ }^{\mathrm{LII}}$ has been subject to increased scholarly attention in recent years, studies on bundling and versioning in the realm of software and related services are scarce. This is surprising for at least three reasons.

First, the literature suggests that bundling and versioning is fundamentally linked to competitive strategy (Iveroth et al., 2013; Lehmann \& Buxmann, 2009; Olve et al., 2013), which would justify greater managerial and academic mindfulness towards bundling and versioning practices in the realm of software and related services.

Second, as stated in the literature, bundling and versioning are of significant importance in marketplaces for software (Miceli, Ricotta, \& Costabile, 2007). Despite steady economic growth for information goods in general and the software industry in particular, signified by ongoing trends in digitalisation (Cöster \& Westelius, 2016) and diffusion of new digital products and services (De Sordi, Reed, Meireles, \& da Silveira, 2016), we do not see these trends equally reflected in the number of empirical studies about bundling and versioning of software and related services.

And third, as has been pointed out by Bakos \& Brynjolfsson (2000), providers of information goods (such as software) generally struggle with how to package and price their products. One challenge may be the malleability of information goods and the various approaches towards bundling and versioning it affords. Product variety created through bundling and versioning constitutes an important information base upon which customers evaluate purchase decisions, which justifies greater attention to the ways in which product attributes are composed, structured, and configured to form an offering (Miceli et al., 2007).

The context of open source may be of special interest in respect thereof. In a sense, product design for OSS is challenging because it is typically not the software that is sold but the services around it. That means open source vendors typically pursue indirect revenue generation strategies based on support, maintenance, licence agreements, or customisation (Riehle, 2012). The increasing popularity of open source has sparked great creativity in designing business models, pricing and delivery schemes that align with the idiosyncrasies of open source; however, it has also made pricing more complex (August, Shin, \& Tunca, 2013; Cusumano, 2007; von Krogh \& von

LII Examples of information goods are "books, journals, computer software, videos, etc." (Varian, 2000, p. 1). 
Hippel, 2006). Against this backdrop, it may be of value to focus on bundling and versioning practices employed by open source vendors.

From an empirical point of view, analogous to Study V, Study VI looks at vendors offering OSS extensions for Joomla. A particular focus lies on the kind of product attributes and differentiation criteria that these vendors utilise to compose and structure their offerings. Because open source vendors compete on a global market, they may be receptive to approaches that hold the promise of stimulating sales and mitigating entrepreneurial risk, such as bundling and versioning.

It is believed that more empirical accounts on bundling and versioning in this area can expose salient patterns of practice and reveal potential problems that open source vendors face. Evidence from interviews is presented to provide complementary insights on the motives that inform vendors' bundling and versioning practices in this empirical setting.

Study VI speaks to both scholars and practitioners in the management fields who have an interest in pricing issues, strategy, and open source business models. The question that guides this research concerns how open source vendors bundle and version their offerings to stay competitive. The findings reveal a surprising variety of product attributes and differentiation criteria that open source vendors utilise to compose and structure their offerings. Essentially, vendors combine and integrate diverse sets of capabilities, competencies and resources on a product level to differentiate the scope of their offerings.

The remainder of this sub-study is structured as follows. The next section accounts for the strategic relevance of bundling and versioning in the realm of information goods. This is followed by a presentation of relevant concepts and theories on bundling and versioning in the literature, which serves as a theoretical guide for the empirical investigation. Then, the empirical setting and the methodological approach are described. The findings are presented and analysed in the subsequent section. Prior to the concluding remarks, a discussion of the results is offered along with a generic model for analysing bundling and versioning both in a descriptive and prescriptive sense.

\subsection{Background and strategic aspects}

Bundling and versioning are widely practised techniques intended to stimulate sales based on integration and differentiation strategies. Both techniques complement one another and appear to be closely intertwined on a conceptual level.

In the literature, product differentiation and price discrimination are not only seen as effective means to increase profitability (Bhargava \& 
Choudhary, 2001) but also as strategic vehicles. Both practices are potential means to ward off competitors' attempts to enter a marketplace while reinforcing innovation due to prospects of capturing higher market shares (Bakos \& Brynjolfsson, 2000; Venkatesh \& Mahajan, 2009). Bundling and versioning are also implicit in the recent literature (Iveroth et al., 2013) that highlights pricing as a source of innovation. This means that how a firm defines the scope of what is effectively charged for is not only an inherent quality of a particular value proposition, but also a source for price model innovation, i.e., the reconfiguration of price model parameters for maintaining a competitive edge $\mathrm{LIII}^{\text {. }}$

Bundling and versioning seem particularly apt in the realm of information goods because of their characteristic features. As commonly acknowledged, information goods can account for high production costs while the cost for reproduction is negligible (Bakos \& Brynjolfsson, 1999; Shapiro \& Varian, 1998). Consequently, software vendors face the risk of having to ponder whether future revenue will make up for high initial investments (e.g., development costs) and whether cost will be recouped over the whole lifecycle of a software product. As stated by Bakos and Brynjolfsson (1999), particularly in the case when marginal costs for reproduction and distribution converge towards zero, bundling and versioning can yield firms more profit than selling their products separately.

However, as Venkatesh and Mahajan (2009) argue, marginal costs for information goods are often assumed to be zero for analytical convenience, which in their eyes downplays the profound impact of variances in marginal costs regarding the choice of alternative bundling strategies.

Information goods are thought to be well-suited for bundling and versioning because of another characteristic trait, that of high transmutability. Transmutability refers to the ease of modification and the ease of manipulation. Because software is customisable, suppliers can in principal tailor a software product to differing customer needs (Lehmann \& Buxmann, 2009; Viswanathan \& Anandalingam, 2005). However, designing software towards increased flexibility may also be associated with higher development costs. Nevertheless, the flexibility that comes with bundling and versioning of information goods can be considered a source for value creation in itself because it facilitates innovative reconfigurations of functional features, resources, and capabilities on a product level (Amit \& Zott, 2001).

From a strategic perspective, bundling and versioning require consideration of a product's key properties and how fundamental they are

LIII Important aspects of this were discussed in Chapter 10. 
in different customer segments (Olve et al., 2013). However, in order to help explain vendors' success in commercialising OSS, we need to know what these key properties are, how they are interconnected, and how they can be configured to create a viable offering.

\subsection{Theoretical framework}

This section presents and discerns the relevant concepts on bundling and versioning in the literature. Already Stremersch and Tellis (2002) bewailed the confusion in the bundling literature regarding inconsistent use of terms and the lack of accepted definitions. This problem has not necessarily vanished in the meantime. It requires some effort to disentangle the various different notions of bundling and differentiation discussed in the literature. In doing so, a research model is developed and used as a theoretical lens and an interpretive guide.

\subsubsection{Package}

The term package can be understood as the top-level unit of analysis of an offering. Looking at different dictionary definitions ${ }^{\mathrm{LIV}}$, the traits of a package can be synthesised as follows. There are essentially two underlying metaphors: the package as a container, and as a wrapper. A package as a container can hold a multitude of related things (e.g., items, services, products), but conceptually appears as a single unit that can be offered and sold to a customer. A package as a wrapper is to cover something and emphasises the presentational aspects of the package but also its protection. The purpose of a package is to attract attention, ease promotion, impart vital product information, and enable utilisation. The package is therefore a useful analytical proxy for what could be seen as the identity of the product.

The terms package and bundle are often used synonymously. However, in contrast to a package, the term bundle emphasises that something is tied together, whereas a package emphasises that something is wrapped or kept in a container. Figure 43 outlines the structural relationships between the terms package, wrapper, container, and bundle. 


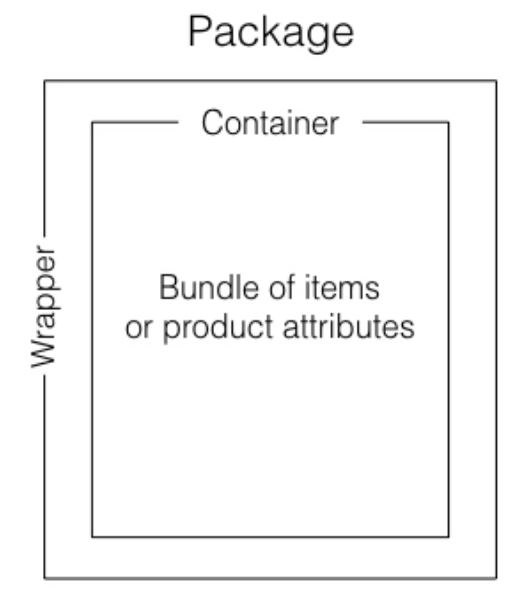

Figure 43: The structural relationships between the terms package, wrapper, container, and bundle.

\subsubsection{Bundling}

One popular definition of bundling is provided by Stremersch and Tellis $(2002,55)$, who refer to it as "the sale of two or more separate products in a package". With products, they basically refer to any kind of goods or services. Bundled elements can be complements, substitutes or independently valued products (Venkatesh \& Mahajan, 2009).

However, when it comes to information goods like software, perceptions on what constitutes a package can differ. This means that the extent to which a package is perceived to consist of distinct or discernible entities can be subjective. Because bundled elements may not always be recognisable as distinct products, it makes sense to complement the definition by Stremersch and Tellis (2002) with a slightly different notion. Iveroth et al. (2013) place analytical emphasis on the granularity of the offering with respect to its scope. The scope of an offering is devised as a spectrum that ranges from an individual product or product attribute (that could be sold separately) to a mix of products or product attributes that come as a package. Given the malleability of information goods, this definition allows for more interpretive flexibility in describing the scope of an offering.

Bundling is a form of price discrimination (Linde, 2009). From a strategic perspective, bundling strategies can be a means of avoiding price or product comparisons on individual items (Ancarani, 2002). The rationale is that a single price for a bundle can lower price sensitivity and make a purchase more likely (Pan, Ratchford, \& Shankar, 2004; Stremersch \& Tellis, 2002). However, bundling may also be a heuristic that simplifies decision making 
for customers, e.g., when recognising prospective bargains (Arora, 2008). From a practical point of view, Lehmann and Buxmann (2009) also mention decreased administrative cost (e.g., invoicing) for vendors as an argument in favour of bundling.

Borrowing from Lehmann and Buxmann (2009), a bundle price can in principle be determined in three ways: 'additive', 'superadditive', or 'subadditive'. They call it 'additive' when the bundle price corresponds to the sum of prices for individual items, 'superadditive' when the actual price is higher than the sum of prices for individual items, and 'subadditive' when discounts are given for bundled products. For customers to accept superadditive pricing, a collection of items in a bundle has to be compiled or integrated in ways that adds value for customers beyond the reservation prices of individual items.

Previous research has proposed further distinctions into price bundling, product bundling, pure bundling, mixed bundling, unbundling, and customised bundling (Laatikainen et al., 2013; Lehmann \& Buxmann, 2009; Stremersch \& Tellis, 2002; Olderog \& Skiera, 2000). These terms will be briefly described to shed some more light on the conceptual thicket.

\title{
11.4.2.1 Price bundling
}

Stremersch and Tellis (2002) define price bundling as:

\begin{abstract}
"the sale of two or more separate products in a package at a discount, without any integration of the products. Because the products are not integrated, the reservation price for the price bundle is, by definition, equal to the sum of the conditional reservation prices of the separate product. In other words, bundling itself does not create added value to consumers, and thus a discount must be offered to motivate at least some consumers to buy the bundle" (Stremersch \& Tellis, 2002, p. 56).
\end{abstract}

Price bundling therefore corresponds to subadditive pricing practice. The literature describes price bundling as a promotional tool because it is easily applied to differentiate variants of price-package combinations (Stremersch \& Tellis, 2002). The discounts are often important signals for customers who consider a purchase but are not interested in buying all the items in a bundle (Monroe, 2011). As Lehmann and Buxmann (2009) explain, price bundling is of particular relevance in the software industry because it can enable vendors to reap benefits of potential network effects through a wide circulation of their products. 


\subsubsection{Product bundling}

In contrast to price bundling stands product bundling. Here, Stremersch and Tellis (2002) emphasise the added value that comes with integrated products and services, which can justify a higher price. They define product bundling as:

"the integration and sale of two or more separate products or services at any price. This integration provides at least some consumers with added value" (Stremersch \& Tellis, 2002, p. 57).

This means that product bundling could be seen to correspond to superadditive pricing practice. Because product bundling builds on customers' willingness to pay for added value, it is seen as a suitable longterm differentiation strategy (Stremersch \& Tellis, 2002). Lehmann and Buxmann (2009) emphasise that different degrees of integration can be achieved through product bundling. However, they add that not all parts of a bundle must be complementary or integrated to be recognised as a product bundle; some elements in a bundle may be independent of another, while others may integrate or complement one another.

\subsubsection{Pure bundling}

With a pure bundling approach, only bundles are made available for purchase (Stremersch \& Tellis, 2002). Pure bundling corresponds to the leftmost type 'package' in the 'scope' dimension of the pricing model proposed by Iveroth et al. (2013).

Pure bundling is sometimes referred to as 'tying' in the economics and legal literature (Stremersch \& Tellis, 2002). Tying occurs when the sale of one product is conditional upon the sale of another product (Whinston, 1990). This means that even if a customer wants to purchase only one of two products, the offering only makes the purchase of both products available. In that sense, bundling can be a means to leverage monopoly power in a market through foreclosure and exclusion, as explicated by Bakos \& Brynjolfsson (2000). Pure bundling as a strategy may be prohibited in certain cases when foreclosure or exclusion are alleged aims to create monopoly-like market situations (Whinston, 1990). As a frequently cited example, the case of Microsoft can be mentioned where the tying of Microsoft Windows and Internet Explorer led to court proceedings that ultimately pledged Microsoft to ensure that users could choose their web browser (Apon, 2007). 


\subsubsection{Mixed bundling and customised bundling}

According to Lehmann and Buxmann (2009), mixed bundling occurs when customers have the choice of whether to buy a product in a bundle or as an individual item. The literature mentions customised bundling as a special variant of mixed bundling (Laatikainen et al., 2013; Lehmann \& Buxmann, 2009). Customised bundling allows a customer to compose a bundle out of predesigned specifications devised by a vendor (Lehmann \& Buxmann, 2009). Customised bundling also has been termed buyer-driven bundling (as opposed to seller-driven bundling) (Adomavicius, Bockstedt, \& Curley, 2015).

Laatikainen et al. (2013) make a two-way distinction regarding the scope of customised bundling. Their first variant refers to bundling based on predefined options. This is when the bundle can be composed of certain predefined options. Their second variant refers to bundling based on freely chosen numbers of items. This is when the selection of items in a bundle is completely up to the buyer. Wu, Hitt, Chen, and Anandalingam (2008) find that customised bundling may outperform other bundling strategies under certain conditions, for instance, when customer heterogeneity varies significantly.

\subsubsection{Pure component and unbundling}

The pure component approach means that vendors offer items only in a standalone form (Venkatesh \& Mahajan, 2009). Similar to that, unbundling occurs when bundles of products or product suits are broken apart and made available as individual items (Stremersch \& Tellis, 2002). In the pricing model by Iveroth et al. (2013), unbundling would refer to a transition from the sale of a package of products or product attributes to the sale of single products or product attributes. The terms pure component and unbundling are often used synonymously in the literature, although strictly speaking, unbundling is the strategic uncoupling of pre-existing composite products or bundles, whereas the term pure component signifies a product's 'natural' separation from other products (Venkatesh \& Chatterjee, 2006; Venkatesh \& Mahajan, 2009).

\subsubsection{Versioning}

Versioning is the differentiation of products with the purpose of targeting specific customer segments, each at a favourable price (Varian, 1997). For instance, products can be differentiated in terms of quality, scope, or performance, with the aim of creating different "versions" of the product 
(Lehmann \& Buxmann, 2009). Different product versions and their corresponding price tags are then supposed to appeal to aggregate preferences in specific customer segments.

For instance, cutting down on features of a product to provide a slimmer version can appeal to customer segments with a lower willingness to buy without cannibalising on more profitable customer segments with a higher willingness to buy (Bhargava \& Choudhary, 2008; Olve et al., 2013; Raghunathan, 2000; Shapiro \& Varian, 1998).

In the literature, bundling is also seen as a special form of versioning (Shapiro \& Varian, 1999), possibly because different configurations of products or product attributes can lead to a range of differentiated packages that vendors can sell. Because software can be offered in different packages that vary in functional scope or in combination with services that vary in scale and quality, versioning and bundling are closely interlinked (Shapiro \& Varian, 1999).

Similar to bundling, versioning is a way to configure different value propositions; hence, it is a particular form of price discrimination, i.e., socalled second-degree price discrimination (Bakos \& Brynjolfsson, 2000; Bhargava \& Choudhary, 2001). For a detailed discussion on forms of price discrimination, interested readers are referred to the literature (Bhargava \& Choudhary, 2001; Lehmann \& Buxmann, 2009; Linde, 2009; Pigou, 2013). In brief, drawing on Lehmann \& Buxmann (2009), these three forms of price discrimination can be summarised as follows. First-degree price discrimination builds on individual differentiation and personalised pricing, second-degree price discrimination builds on the principles of customer segmentation and self-selection, and third-degree price discrimination builds on market segmentation without the possibility of customer selfselection. According to Lehmann \& Buxmann (2009), second-degree price discrimination is of particular importance when it comes to digital goods. When customers replicate the rank order of versions through their purchase decisions, the qualities that differ across available versions can then be termed vertically differentiated (Christopher, 1982). Differentiating multiple versions of an offering may maximise the consumer surplus in each customer segment (Bhargava \& Choudhary, 2001). This strategy is especially useful when consumer valuations are known for different customer segments (Bhargava \& Choudhary, 2001).

As illustrated by Olve et al. (2013), the strategic question is deliberation on how different kinds of product features are valued among different customer segments. The particular ways in which versioning is implemented can also be a tool to entice customers to upgrade to more expensive highspec versions. Here, the rationale is to limit the functionality of software 
such that users with low-end versions begin to experience inconvenience or disutility over time, which possibly causes them to upgrade to more expensive high-end versions later on (Shivendu \& Zhang, 2015).

In connection with that, a special form of versioning is the freemium pricing strategy, where the offering is divided into a free scaled-down version of the product, and a premium, feature-rich version that customers have to pay for. This strategy can increase market penetration of a product or a brand and therefore facilitates potential network effects for firms (Lehmann \& Buxmann, 2009).

\subsection{Research approach}

Study VI builds upon a sample of 99 online offerings that was compiled from the JED (see Section 5.5.3), and a set of 21 interviews conducted with extension providers (see Section 5.5.1.1). The JED serves as an intermediary for vendors offering free and commercial OSS extensions for the Joomla CMS. As mentioned before, to keep the sample size manageable, the three top-rated commercial extensions in 33 different categories on the JED were examined. As acknowledged in the literature (Eisenhardt, Graebner, \& Sonenshein, 2016), sampling across diverse relevant categories has the benefit of enhanced theoretical generalisability of the data.

Venkatesh and Mahajan (2009) classify two broad types of methodological approaches towards bundling: design-oriented approaches (i.e., analysis of the composition of the offering and the specific attributes it consists of), and pricing-oriented approaches (i.e., analysis of reservation prices for particular price/bundle combinations). With respect thereto, Study VI takes on a design-oriented approach in a qualitative research tradition with a specific focus on the product attribute level. To develop an understanding of how vendors in this setting bundle and version their offerings, a two-way approach was undertaken.

First, a qualitative content analysis was conducted, which looked at vendors' websites to get a deeper sense of how their offerings were composed and structured (Hsieh \& Shannon, 2005). Content analysis requires successive matching of the target material using a coding frame that defines the categories of interest relevant to the research question (Schreier, 2014). The coding process placed special emphasis on the kind of product attributes and differentiation criteria vendors used to bundle and differentiate their offerings.

Second, interviews were conducted with vendors in an attempt to infuse more clarity on the motives that guide vendors' bundling and versioning practices. According to the literature, consideration of multiple data sources 
in the analysis can be one way to enhance validity (Eisenhardt, 1989). A total of 21 interviewees provided accounts regarding their motives and strategies for bundling and versioning their offerings.

The analytic procedure started together with the data collection, which involved the search for patterns, meanings, and the matching of theory with empirical observations (Kohlbacher, 2006). The ultimate goal of the analytic procedure was to develop a satisfactory and coherent understanding of observed structures, patterns, and statements.

\subsection{Results and analysis}

Bundling and versioning of extensions is practised in diverse ways. From a conceptual point of view, bundling and versioning in this setting occur in all varieties (e.g., pure bundling, pure component, mixed bundling, customised bundling), although the frequencies vary. For instance, selling the software as a pure component without subscription and support is rare. The bulk of vendors tie and package software with subscriptions and support (cf. Study V). This configuration could be seen as a basic package in this setting. However, in total, 56 different product attributes and differentiation criteria were observed that can serve to refine and differentiate the granularity of the offering (see Appendix A5 for an overview). The range of product attributes and differentiation criteria that vendors utilise to compose and structure their offerings appears to be surprisingly versatile in relation to what is commonly thought of as a typical OSS offering (i.e., software and support in a package). The range of observed product attributes can be broadly categorised into nine groups: 'core product', 'terms and compliance', 'supplementary service', 'supplementary content', 'entitlements', 'guarantees and assurance', 'functional scope and technical specification', 'ancillary incentives', and 'signalling'.

The 'core product' basically refers to the software extension. Although the software as such is not sold, only the services around it, the core of the offering is the software; all other product attributes depend on it and are supplementary in nature.

Attributes under 'terms and compliance' basically define and stipulate the scope of the service agreement. For instance, this includes the subscription length or the number of websites for which support is provided.

The category 'supplementary service' encompasses all additional services beyond the basic package. For instance, this can include installation services, priority support, migration support, and more. 
'Supplementary content' refers to varieties of complementary files and add-ons that can be included, for instance, templates, plugins, configuration files, and more.

The category 'entitlements' lists different types of benefits and selfservices that do not require immediate interaction between customers and suppliers, for instance, access to updates, access to documentation, and access to support forums.

Vendors also pack various 'guarantees and assurances' that can differ in quality and scope on top of a basic package. For instance, vendors may guarantee that their extensions are compatible with third-party extensions, or promise guaranteed response times for support.

The category 'functional scope and technical specification' basically refers to the ways in which integral features of an extension can be limited and differentiated to version the offering.

'Ancillary incentives' are a further means to differentiate the offering and to stimulate purchase decisions. This can include loyalty discounts, tying items, upgrade discounts, or discounts based on upgrade timing (see Appendix A5 for more details).

Finally, the category 'signalling' comprises all attributes that communicate further important characteristics about the offering. For instance, perpetual use of the software or the availability of the source code. Strictly speaking, however, these attributes cannot be used to differentiate the offering in this open source setting. Because vendors deliver GPL code $^{160}$, it follows by definition that customers can use the software perpetually and it entails that they have access to the code. These attributes are listed nevertheless for two reasons. First, they are often used and presented alongside other product attributes in the sample of online offerings. Second, it is easily imagined that these attributes could be versioned in other contexts, such as with dual-licensing approaches (Valimaki, 2003), where the offering is differentiated based on whether customers use the software for commercial or non-commercial purposes.

The variety of package names that have been observed will be discussed briefly. This is relevant when looking at the package as a wrapper (cf. Section 11.4.1). The range of names used to denominate packages is quite diverse (see Appendix A6). These package names have been categorised into six groups based on what they signify, i.e., 'target audiences, professions or occupations' (e.g., agency, business, developer), 'performance and levels of expertise' (e.g., advanced, core, power pack), 'service duration' (e.g., annual bundle, lifetime bundle), 'product type, content, and function' (e.g., all-inone, integration package), 'scope of value' (e.g., basic, normal, lite, plus), and 'abstract types' (e.g., blue level, green level, pink level). 
As Shapiro and Varian (1998b) suggest, product differentiation and price discrimination builds on the idea that different users exhibit different valuations for a product (e.g., home users versus power users). A proliferation of package names could signal a focus on value-based differentiation and pricing in this setting, which would be in line with the findings of Study V (cf. Section 10.7.1).

\subsubsection{Motives for bundling and versioning}

This section elaborates on findings from the interview material to provide complementary insights on the motives that inform vendors' strategies for bundling and versioning their offerings.

The regulatory framework of the GPL has a decisive impact on how a package is designed in its basic form. Software extensions in this setting ship as GPL code, which means that the software can be easily (and legally) shared. As a consequence, OSS cannot be sold directly but associated services can be. However, rather than seen as the ideal way, subscriptions and support services have been described as the simplest way to commercialise OSS extensions. The drawback with this particular way of packaging is that it increases variable costs for vendors (i.e., support intensity is not always easy to predict) and somewhat deprives vendors from taking full advantage of low marginal costs of reproduction for software and its associated scalability effects.

This finding is interesting because it partly runs counter to the idea of highly scalable business models for information goods due to low marginal costs. While information goods may be reproduced at low marginal cost, obligations are created for each new copy that is distributed to customers (e.g., the obligation to handle support requests). As a consequence, low marginal costs for information goods are of little value when associated services require direct assistance from the supplier side (such as support).

The evidence shows an important link between bundling and the use of software, which is customers' experience. Bundling has been described as a means of ensuring a quality experience for users. A high quality of extensions alone does not seem to be enough to keep customers satisfied. The argument is that the degree of technical expertise amongst customers can vary considerably. Problems often arise when customers integrate extensions into their systems. It is exacerbating that customers often do not read manuals or online documentation when they face problems. Bundling the software with timely and helpful support then complements its use, ensuring a good experience for customers and facilitating their learning curve. 
It can be argued that the particular value that comes with a combination of software and support is a base upon which customers evaluate their experience and further their decisions of prolonging their commitments by renewing their subscriptions. From this perspective, it is the integrated value of software and support that returns customers or entices them to buy higherspec bundles at a higher price.

The evidence shows that product affinity is a further important motive for combining several extensions in a bundle. By customers it can be perceived as a powerful signal when several extensions in a bundle complement one another or integrate in a useful way. This strategy requires a commitment to interoperability at the heart of a vendor's business strategy, while it can be realised in practice through platform thinking, whose ultimate goal is to develop a range of complementary and integrable products that serve as a platform that customers can select.

It has been further argued that related extensions within a package can lower customers' need for support, because customers tend to become familiar with the intent of the software designer. This means that when customers have developed a sense of how to use and troubleshoot one extension, they may find it easier to do the same for other related extensions offered by the same vendor. For vendors, this can have the pleasant side effect of lowered support intensity, and therefore a reduction of support cost.

It is common practice to give discounts for bundled items in this setting. Reportedly, bundles of extensions are usually well received and considered good value for money by customers. Discounts may trigger impulse purchases on the customers' side. The literature recognises this aspect: the prospect of making a bargain by choosing a bundle seems a strong signal in customers' evaluation of price (Arora, 2008). Further research could explore the effects of particular price/bundle combinations in this setting.

An alternative approach to bundling, which is not prominently discussed in the literature, is to simply give discounts for multiple individual extensions within the same order. Discounts can be automatically drawn from the total price when adding additional extensions to an order. Alternatively, discounts can be given if customers previously bought other extensions. This practice is seen as a workaround for customers who desire customised bundling (i.e., self-compiled bundles); it is positively received by customers and can boost sales. In essence, this approach could be seen as a simple implementation of joint customised bundling and price bundling. Customers in this particular case did not have to choose from predefined options but could choose their extensions freely. While this may be an effective way to address possible variances in customer heterogeneity (Wu et al., 2008), it 
may also reduce administrative costs for invoicing (Lehmann \& Buxmann, 2009).

Further evidence shows that vendors work on the continuous redesign of their offerings. Similar to what the literature suggests (Olve et al., 2013), bundle design can be guided by analysis of common use case scenarios and reflection about the kind of features that ensure good customer experience. This is often complemented by studying the market and how competitors bundle and version their offerings. While the subscription period may be an obvious target for differentiation, over time vendors develop a sense for other possible ways to differentiate their offerings (the range of product attributes and differentiation criteria in Appendix A5 provides an account thereof).

However, not all identified product attributes and differentiation criteria make equal sense for all vendors. For instance, providing compatibility support for older Joomla versions was described as harmful by one vendor, while it was used as a differentiation criterion by others. The reason for not providing compatibility support was that it is too effortful to maintain and support legacy versions of an extension. For vendors, the inclusion or use of specific product attributes and differentiation criteria could therefore be based upon their cost-benefit assessment when designing the offering.

From a strategic perspective, bundling and versioning in this setting can be instrumental in enticing customers to upgrade to available higher-spec versions. As an example, the versioning of subscription lengths can be mentioned. When customers have little idea of how long they plan to use the product, and when they have no prior experience of an extension's quality or a vendor's integrity, they may be hesitant to opt for longer subscription periods when buying for the first time. Reportedly, customers often convert to yearly subscriptions after having settled for shorter terms in the first place. From that perspective, it can make sense to make the purchase of short-term subscriptions available as an alternative low-risk offering for customers. As reported, converting short-term subscriptions into longer-term subscriptions can be achieved by demonstrating high quality support standards. As an ancillary incentive, customers can receive discounts relative to the standard price of the mainstream product when upgrading to longer-term subscriptions.

In a similar fashion, versioning based on a freemium strategy is used to trigger purchase decisions at some later point in time. This type of versioning gives customers the opportunity to test the quality of an extension with a scaled-down version of the mainstream product and leaves them the option of buying a full-feature version of the product later on, which is reportedly a successful strategy. 
To mention a final point, vendors' conception of fairness can influence their stance towards bundling and versioning. The evidence shows that it can make sense to deliberately refrain from bundling or tying. One vendor reported that he does not want to obligate customers to buy 'things' that they do not need. When a customer intends to buy exactly one extension, this vendor does not like the idea of trying to make them buy more through alternative bundling options. From this perspective, fairness is seen as an important signal to customers that may influence their purchase decisions.

\subsection{Discussion}

When examining the data, there is no unified view of how a package should be conceived. The varieties of package names and their associated significations (see Appendix A6) could be taken as a further sign that vendors have different notions about what they actually sell. It seems plausible that a basic package, i.e., the particular configuration of software, support, and subscription could be seen as a form of integrative bundling because it is an integral part of the business model. This argument can be linked to the degrees of cohesion among bundled items that Adomavicius et al. (2015) alluded to. They define cohesion "as the degree to which the items in a bundle of goods provide some value as a group aside from the simple additive value derived from each individual item, for example, due to complementarity, inseparability, or some other perceived connection among the items" (Adomavicius et al., 2015, p. 185). In this open source setting, the particular configuration of software, support, and subscriptions seems to be an inseparable cohesive unit. However, generally speaking, the cohesiveness of product attributes is context dependent. Software, support and subscriptions may very well be complementary or independent product attributes in other settings.

In Figure 44, a generic model for analysing bundling and versioning is proposed. This model regards bundling as the process of configuring combinations of product attributes within a package. Versioning is depicted as the process of differentiation across packages. This model incorporates the idea that product attributes and combinations thereof can be complementary, integrative, substitutionary, or versioned (Adomavicius et al., 2015; Stremersch \& Tellis, 2002; Varian, 1997; Venkatesh \& Mahajan, 2009). For practitioners, Appendix A5 (product attributes and differentiation criteria) and Appendix A6 (package names and significations) can serve as an inspirational source for designing an offering using this generic model. 


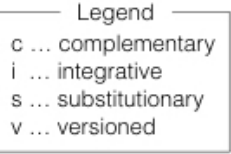

Package 1

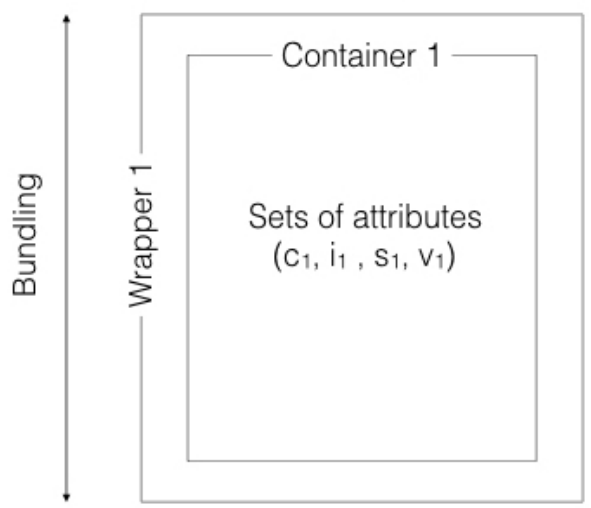

Package $n$

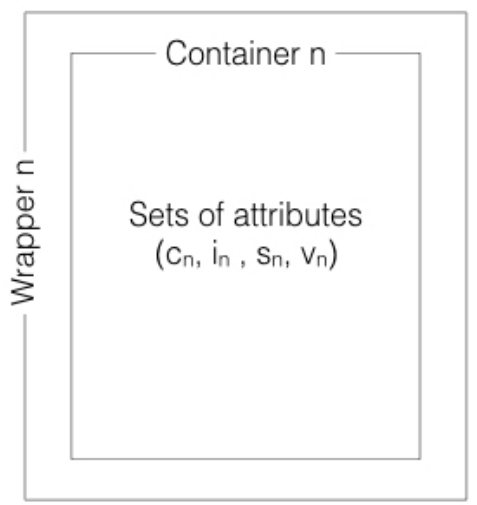

Versioning

Figure 44: A generic model for analysing bundling and versioning both in a descriptive and prescriptive sense.

To illustrate the application of the generic model proposed in Figure 44, the text proceeds with a detailed discussion of a concrete example that is deemed representative for how bundling and versioning occurs in this setting.

\subsubsection{The example of LOGMan}

LOGMan $^{\mathrm{LV}}$ is an extension for the Joomla platform that is developed by Joomlatools, a small firm with a team of 11 people from seven different countries. 'LOGman' provides user analytics, advanced filtering, dashboard modules, and activity streams for the Joomla platform ${ }^{161}$. This extension is available in four different package configurations: 'Personal', 'Business', 'Agency', and simply 'LOGman' ${ }^{162}$. Figure 45 provides a visual summary of these package configurations based on the generic model in Figure 44.

The package 'LOGman' costs €59. Seen as a container, it includes the extension 'LOGman', six months of support, six months of updates, one Joomla site for which support is provided, and a guaranteed response time

Lv The data for the LOGMan example were retrieved from the vendor's website and have been last checked on 4 April 2017. 
of 72 hours during weekdays for support requests. The package as a wrapper places communicative emphasis on a single extension rather than on a specific target audience.

The package 'Personal' costs €99. Seen as a container, it includes the extension 'LOGman' and three other extensions, 12 months of support, 12 months of updates, one Joomla site for which support is provided, and a guaranteed response time of 72 hours during weekdays for support requests. The package as a wrapper specifically addresses owners of personal websites, as is communicated on the vendor's website.

The package 'Business' costs €199. Seen as a container, it includes the extension 'LOGman' and three other extensions, 12 months of support, 12 months of updates, five Joomla sites for which support is provided, a guaranteed response time of 48 hours during weekdays for support requests, additional web services like indexing and thumbnail generation, and special support for developers who wish to modify Joomlatools extensions. Seen as a wrapper, the package addresses small businesses with multiple websites, as is communicated on the vendor's website.

The package 'Agency' costs €399. Seen as a container, it includes the extension 'LOGman' and three other extensions, 12 months of support, 12 months of updates, support for an unlimited number of sites, a guaranteed response time for support requests of 24 hours including weekends, additional web services like indexing and thumbnail generation, special support for developers who wish to modify Joomlatools extensions, and finally, third-level client support, which means that direct support will be provided to customers' clients. Seen as a wrapper, the package targets developers and integrators who resell Joomlatools extensions to their customers, as is communicated on the vendor's website.

In this particular case, the following product attributes are versioned: the number of extensions available in a package, the number of sites that support is provided for, guaranteed response times for support, and the availability of additional services (e.g., web services, developer support, and third-level client support). Third-level client support could be seen as a tying element because it is only available in the high-spec configuration. For web developers in particular, third-level client support could be a lucrative product attribute, since they would not have to support their clients directly in the event of problems with LOGman.

'LOGman' can be seen to be offered in a mixed bundling approach (i.e., it is offered as a single extension but also in combination with other extensions and product attributes). In this example, no discounts are communicated for higher-spec packages, which could mean that the prices 
for packages are calculated in an additive or superadditive way; however, this is purely speculative.

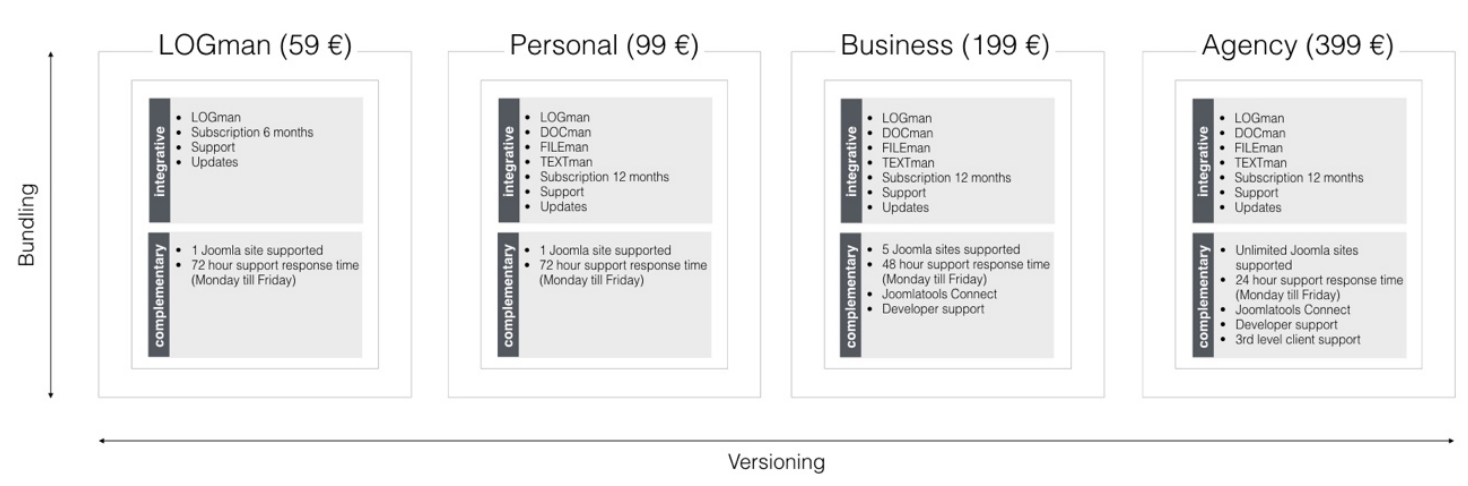

Figure 45: Bundling and versioning by the example of LOGman (a Joomla extension).

It is easy to imagine how this illustrative example could be differentiated further and extended as desired by utilising any of the product attributes and differentiation criteria listed in Appendix A5 and the package names listed in Appendix A6. For instance, it could be extended by a substitutionary product attribute, such as a Joomla template that is supposed to serve as a more sophisticated replacement of existing default design templates.

By considering the signification of package names, and the range of product attributes and differentiation criteria identified in this sub-study, this generic model can serve as an inspirational source for practitioners when designing an offering. As Study $\mathrm{VI}$ shows, based on diverse sets of capabilities, competencies, and resources, a wide variety of product attributes and differentiation criteria can serve to compose and structure an offering.

However, for a sustainable business model, product design requires deliberation on how configurations of products and product attributes are linked to marginal and variable costs. As alluded to by Venkatesh and Mahajan (2009), the benefits of low marginal costs for reproduction for information goods may be overstated. The economies of aggregation for information goods, as explicated by Bakos and Brynjolfsson (2000) and others, may not apply equally to all types of information goods and configurations of product attributes. For instance, this empirical setting shows that the regularity framework of an open source licence can have a constraining effect on the scalability benefits frequently ascribed to 
information goods. This is because open source vendors can effectively only charge for support services that are tied to the software; however, support can incur substantial variable costs.

More research is needed to evaluate the viability of different bundling and versioning configurations in the realm of software and related services. Potential subjects of investigation could be how different bundling and versioning configurations are connected to vendors' success in selling software and services, how these configurations are linked to firm strategy, and when to increase or decrease the number of available bundling options.

\subsection{Preliminary conclusions}

Study VI took on a design-oriented approach to show how open source vendors bundle and version their offerings. The results indicate that vendors bundle and version their offerings based on diverse sets of capabilities, competencies, resources, and differentiation criteria. This sub-study provides an account of the creative potential that is unleashed in bundling and versioning of OSS extensions. Vendors utilise a whole range of product attributes and differentiation criteria to compose, structure, and configure their offerings. However, bundling configurations in this open source setting can increase variable costs on the vendors' side. Therefore, this research suggests that the benefits of low marginal costs for reproduction of information goods may not equally materialise in all settings. For instance, the regulatory framework of an open source licence may have a constraining effect on the scalability benefits frequently ascribed to information goods. Finally, based on empirical data, Study VI proposes a generic model for bundling and versioning both in a descriptive and prescriptive sense. 


\section{Findings and analysis}

This chapter elaborates on the findings concerning the research questions that were stated in Section 1.2 (RQ1 and RQ2). First, the relevant findings with respect to RQ1 are presented, followed by a presentation of relevant findings with respect to RQ2. The theoretical angle in this discussion is informed by the theoretical framework presented in Chapter 3.

\subsection{RQ1: What are the challenges in commercialising community-driven OSS and how do firms cope with them?}

RQ1 asked about challenges and how firms cope with them. Challenges are broadly understood as the major difficulties that firms need to overcome in order to be successful in commercialising community-driven OSS. Common such challenges revolve around nine distinct factors: the global operating environment, the pace of change, the cannibalisation of ideas, platform policy, platform image, the voluntary nature of the open source project, the blurring of boundaries between private and professional lives, the difficulty of estimating costs, and firm dependencies. While these nine factors have emerged in a bottom-up fashion, they roughly cluster around three domains: the ecosystem, the community, and the firm. These domains are congruent with the units of analysis discussed in Section 5.3. More detailed explanations of these nine factors are given below in Sections 12.1.1 to 12.1.9. Table 11 provides an overview of the distinct factors around which challenges revolve, along with the assignment of the respective domains. The discussion in Chapter 13 theorises the relationships between these three domains (i.e., ecosystem, community, firm). 


\begin{tabular}{|l|l|}
\hline Domain & Key factors around which challenges revolve \\
\hline Ecosystem & - Global operating environment \\
& - Pace of change \\
\hline Community & - Cannibalisation of ideas \\
& - Platform policy \\
& - Platform image \\
\hline Firm & - Boluntary nature of the open source project \\
& - Difficulty of estimating costs \\
& - Firm dependencies. \\
\hline
\end{tabular}

Table 11: A categorisation of the challenges in commercialising community-driven OSS.

\subsubsection{Global operating environment}

While a global operating environment provides many opportunities (e.g., access to a worldwide pool of competencies, volunteers, and customers), it may also pose challenges to firms in the Joomla ecosystem. Here, the discussion focuses on three aspects of the global operating environment: the large pool of competitors, reputation in Internet-enabled markets, and differences in spending capacity across the globe.

While the majority of interviewees were mainly serving customers in their local vicinity (i.e., regional, supra-regional, national), many Joomla businesses also offered their services to a global customer base. Competition and price pressure at a global scale can be fierce, especially in the market for extensions. But also with other types of products and services (e.g., web design and development), firms face an abundance of competitors.

The global operating environment around Joomla is essentially an Internet-enabled market, which means that exposure on online channels is key to firms. For instance, the JED provides a built-in rating and review system where customers can exchange information about the trustworthiness of extension providers and the quality of their products and services. For extension providers, having a reputable presence on the JED is important because they receive a considerable proportion of their traffic from this site. According to interviewees, good reviews are usually triggered by good service quality. However, good reviews are difficult to get. And whether reviews are always authentic is questionable. According to interviewees, sometimes people use unfair means to push reviews and ratings. However, while this problem is known in the community, it might 
be difficult to tackle. Future research could explore this problem in more depth.

For Joomla businesses, a global operating environment with a large pool of competitors is likely to reduce the switching costs of their clients. For Joomla businesses, one way of coping with this challenge refers to bundling and versioning practices. As discussed in Study VI (Bundling and versioning), bundling and versioning are particularly useful tools for stimulating sales in global marketplaces for software. With bundling and versioning, Joomla businesses can creatively take advantage of the malleability of information goods when designing their products and services. These practices may reduce the comparability of their offerings, and increase the perceived switching costs for clients at the same time (Bakos \& Brynjolfsson, 2000; Iveroth et al., 2013).

Connected to this, extension providers often pursue pricing strategies that emphasise customer value and longer-term contracts based on subscriptions (Study V: Pricing). This particular method of pricing may offer more protection against unsustainable price wars. While Study V (Pricing) specificially focused on providers of commercial extensions, the same pattern may apply to other types of products and services around the Joomla platform (such as web development, consulting, maintenance, and marketing). This conjecture is corroborated by statements made by community members in online video interviews, who depict pricing based on competitor price as unviable for professional services around Joomla.

A further problem in a global operating environment is that the spending capacity of clients can vary considerably across the globe. Location-based pricing, the tailoring of prices based on regional properties, may be a way to alleviate this problem ${ }^{\mathrm{LV}}$. While there was curiosity in location-based pricing among interviewees, there were no clear indications in the empirical data that this would be a viable avenue. Location-based pricing may also be a challenge due to differing perceptions of prices across cultures (Meng, 2011). This topic was beyond the scope of Study V (Pricing), but it could be worthy of the attention of future research endeavours.

From an ecology perspective, the dominant pricing practices in the Joomla case (Study V: Pricing) may be in line with the arguments by Moore (1993), who suggests that the sustainability of the ecosystem may be enhanced when pricing prevents self-destructive infighting that leads to plummeting and unsustainable price levels.

LVI Location-based pricing was brought up by an interviewee in relation to negotiation attempts for buying extensions. 


\subsubsection{Pace of change}

The business practices and technologies in the Joomla case are affected by a relatively fast pace of change (as is the case with other web-related technologies and business models). Since Joomla's inception in 2005, new technologies and frameworks for web development have sprung up almost like mushrooms, and existing technologies have gone through evolutionary stages. The growth of open source projects on the Web (as was mentioned in the introduction in Chapter 1) can be indicative of the pace of change around web technologies.

Since Joomla's inception, the related business practices have seen many changes, too. Some of these changes are reflected in trends around digitalisation, social media, responsive design, the shift towards mobile computing, the emergence of cloud services, and developments in ecommerce and Internet marketing, to name but a few. Many other trends loom on the horizon, or are pushing into the mainstream (e.g., big data, artificial intelligence, virtual reality, Internet of things), with as-yet unpredictable consequences for Joomla, its community, and the ecosystem around it.

The pace of change poses a variety of challenges to Joomla businesses. For instance, making forecasts regarding the market situation has become more difficult. This is because the means of publishing, distributing, and consuming information on the Web are constantly evolving, and so are the demands of firms (and prospective clients) on their websites. Many small firms may even no longer see a need to operate their own websites or CMSs because they can use social media services to publish their content free of charge.

On the other hand, there are still plenty of opportunities. Websites today are no longer self-contained and static systems, they have to interact and communicate with a variety of different systems, which increases their complexity and, likewise, the demand for professional development and support.

The following highlights two response strategies that Joomla businesses utilise in order to cope with a fast-changing environment. The first concerns their interaction with the community, while the other relates to product design and the interaction with the clients.

For Joomla businesses, their interaction with the community is valuable for dealing with the uncertainties of a fast-changing environment. The community provides a platform for staying informed about technological trends and new business practices (Study IV: Economic incentives). People in the community help each other by sharing ideas on a variety of business- 
related matters, including ideas on how to acquire new customers, how to scope customer projects more effectively, how to manage customers' expectations, how to spot market opportunities, and how to engage existing customers.

The other response strategy concerns product design and the interaction with clients. As the empirical data suggest, in order to cope with a fastchanging environment, businesses can move from offering single services (such as web development) to more integrated packages that address the customer's needs and experience in a more holistic manner. For instance, these services can include the initial development of a website, configuration and customisation, integration with other systems that the client uses, web hosting, maintenance (e.g., software upgrades and continuous security updates over a period of time), marketing and real-time analysis of user behaviour, strategic consulting, monitoring, security audits, and content administration.

As a consequence of this holistic approach to product and service design, the providers of value-added services increasingly become a part of their clients' organisation. This means that the boundaries between the providers and the clients become blurred (as do the boundaries between private and professional lives, which will be discussed below). The importance of the client's success is increasingly reflected in the thinking of the business owners. Partly, they regard themselves as a part of their clients' organisations and want to help them grow their business. With these shifts, the service providers become more involved in the client's processes; they increasingly do not work for their clients, but with them. The focus is on growing together with the client, and to benefit from each other's ideas.

As perspectives on business ecology suggest, a blurring boundary between firms and their clients may have the consequence that the future of firms will be more closely tied to the success and future of their clients (Iansiti \& Levien, 2004; Olve et al., 2013; Westelius \& Lind, 2016). Whether future pricing practices might also see a noticeable shift towards result-based arrangements as a consequence remains to be seen. Currently, result-based pricing does not seem to play a prominent role in the Joomla case (Study V: Pricing).

\subsubsection{Cannibalisation of ideas}

Unsurprisingly, the interview data show that the openness of the code is highly cherished in the Joomla case. However, as a consequence of this openness there is also a tendency to cannibalise good ideas. This can be illustrated by the example of extension providers. In cases where an 
extension becomes too popular, it runs the risk of being integrated into the Joomla platform, which can eventually threaten the business model of an extension provider (Study I: Stakeholders). If an upcoming Joomla release makes extension providers' current products redundant, they are forced to be creative in developing new product features on top of a revised Joomla CMS.

These dynamics could be seen as a particular mode of innovation, with a redistribution of value based on a product that moves from niche popularity (offered as a commercial extension) to mass popularity (ending up being integrated into the host platform). This mode of innovation may prevent single actors from becoming a dominant force over an extended period of time. This observation is potentially interesting given the attributed importance of network effects in the context of information goods and ecosystems in the literature (lansiti \& Levien, 2004; Lehmann \& Buxmann, 2009; Shy, 2001). As this example shows, the extent to which single commercial actors can reap potential network effects may be limited by the community's interests and decisions.

As the empirical data show, the community leadership can also opt not to integrate a popular extension. One reason for doing this links to perceptions of fairness - community leaders may not want to threaten the business models of the affected extension providers. The empirical data further show that the community can opt against integrating a popular extension when it requires reliable and timely support, which can be difficult for a community of volunteers to maintain. Generally, an extension might not easily be integrated into the Joomla platform; however, it has happened several times in the past (Study I: Stakeholders). The criteria that govern these decisions might be popularity (which can signal a broad need amongst the user base), perceptions of fairness, and the need for professional support.

From an ecology perspective, the cannibalisation of ideas may favour community welfare over individual gain under certain threshold conditions (e.g., when an extension becomes increasingly popular). Whether the effects of cannibalisation can create significant disincentives for would-be participants in the ecosystem (e.g., for extension providers and other actors) could be a subject for further investigation. Possibly, for actors with a stronger sense of community, i.e., those who strongly subscribe to an identity that emphasises collaboration, togetherness, and generosity (Study III: Collective identities), the utility of openness and transparency might outweigh its potentially negative effects (e.g., the cannibalisation of ideas). Said differently, under conditions of openness and transparency, experiencing collaboration, togetherness, and generosity as cherished 
community values may help to explain why many actors see others as a source of learning and inspiration, rather than as a threat.

\subsubsection{Platform policy}

A policy can be understood as a "course or principle of action adopted or proposed by an organisation"163. In the context of this thesis, platform policy can be understood as the principle of action that the community adopts in relation to the technological platform that it provides (i.e., the Joomla CMS).

As the empirical data show, platform policy can affect the commercial actors within an ecosystem in different ways. For instance, it can affect the ways in which open source vendors can effectively charge for their products and services (Study V: Pricing). This can be illustrated by the example of Joomla extensions. Joomla policies have prohibited the publishing of nonGPL extensions on the JED since 2009 (Plummer, 2013). Prior to that, extension providers used a variety of licensing alternatives (open source and proprietary licences) to sell their products. However, the community's decision to ban non-GPL code from the JED left subscriptions as the only viable option for selling commercial extensions (Study V: Pricing, Study VI: Bundling and versioning).

Being required to release GPL code to their customers limited vendors' ability to restrict the life-span and the modifiability of their products (e.g., through authentication mechanisms and source code encryption). The fact that Joomla operates its own intermediary platform for extensions provides the community with a governance lever for encouraging extension providers' compliance with the GPL. This is because the JED generates considerable traffic for commercial extension providers, which boosts their sales. Therefore, commercial extension providers might have a strong incentive to comply with JED policies; otherwise, they run the risk of being banned from the JED, which can cut them off from valuable revenuegenerating web traffic.

It could then also be argued that the dominant form of pricing of extensions (i.e., subscription-based offerings) is a consequence of the community's commitment to cherished values and norms, such as openness and transparency (Study III: Collective identities). This is because the community's decision to ban non-GPL code from the JED was justified with reference to the core mission and values of the entire Joomla project ${ }^{164}$.

It could further be argued that, in order to compensate for the limited possibilities in pricing, extension providers have become more creative in designing product packages and bundle alternatives. As Study VI (Bundling 
and versioning) shows, extension providers utilise quite a broad range of product attributes and differentiation criteria to design their offerings.

As discussed in Study III (Collective identities), governance (e.g., as reflected in platform policy) interacts with identity-relevant community characteristics (e.g., open source values). This interaction has consequences for dominant business and pricing practices (Study V: Pricing, Study VI: Bundling and versioning). The connections between governance, identity, and business practices are apparent in different examples. For instance, licensing is an important governance dimension in the context of open source (Study II: Governance framework). The GPL requires extension providers to disclose the source code of their products to prospective customers. However, GPL code can be legally shared with anyone on the Web, which could be seen as another challenge for commercial actors in the Joomla case. Basically, anyone could take the code and make it their own business by applying a few modifications (it might not need modifications at all). However, although there have been reported cases of people who attempted to resell commercial extensions and people who shared extensions on 'warez channels' ${ }^{\mathrm{LVII}}$, the evidence suggests that this does not seem to be a major problem in the Joomla case. There are several reasons that could explain this.

For instance, there are ethical concerns that may prevent this practice from occurring at a larger scale. It might be perceived as unfair to engage in such practices. Actors who violate the established sense of fairness by behaving unethically (e.g., by reselling another provider's extensions) may garner a bad reputation, with the effect that their ability to run a successful and sustainable business may be diminished. Connecting to this idea from an ecology perspective, lansiti and Levien (2004) suggest that actors within an ecosystem are interconnected and strongly dependent on each other for effectiveness and survival. This could imply that the actors within an ecosystem might have disincentives to behave in unethical or opportunistic ways in order to avoid the negative consequences of a bad reputation. Unethical behaviour might have the consequence of being banned from the JED. A bad reputation might have the consequence of being excluded from the continued collaboration with people in the community. All in all, the anticipated social costs of behaving unethically might safeguard the interaction among commercial actors and their clients, thereby facilitating the overall health of the ecosystem.

LVII I.e., channels through which pirated software is distributed. 


\subsubsection{Platform image}

Before elaborating on the empirical findings, the intended meanings of the terms 'platform', 'image', and 'competition' are briefly explained. A platform can be understood as "a group of technologies that are used as a base upon which other applications, processes or technologies are developed"165. As an example, consider the Joomla platform. Platform competition is understood as the rivalry among different platforms. Different platforms compete for diverse resources, such as users and market share, developers and volunteers, sponsors, and providers of value-added services. In the realm of CMSs, Joomla competes with diverse CMS platforms, such as WordPress, Drupal, and others.

Platform image is understood as an important proxy through which platform competition occurs. Platform image refers to the shared impressions that a public audience holds about a particular platform. Naturally, these shared impressions can be comprised of both positive and negative qualities.

The Joomla businesses have been increasingly affected by platform competition within the CMS segment. The past few years have brought a fairly steep rise in alternative software platforms for publishing web content, including both proprietary and open source solutions. In addition, easy to use cloud-based services for creating simple websites such as WIX ${ }^{166}$ and Squarespace ${ }^{167}$ are reducing the potential customer base for Joomla-based businesses, but also for other popular open source CMS platforms (e.g., WordPress and Drupal).

In response to these trends, many Joomla businesses are trying to promote Joomla as much as they can, and they encourage other community members to do the same. Those businesses that work exclusively with Joomla are particularly vulnerable to the potential effects of a shrinking market share for their preferred platform. For instance, extension providers depend on high penetration rates of the Joomla platform in order to be able to sell their products and services to a large enough number of customers.

More generally, the penetration rates of software platforms and the distribution of market share among such platforms may be difficult to assess objectively. Although Joomla might have lost market share in relative terms compared to its main competitors (as was indicated by interviewees), in absolute terms Joomla's market share might even grow, given the overall growth of the Internet. If the market growth outpaces the relative shrinkage of market-share, the Joomla market size would still be expanding.

The empirical data show that many Joomla-based businesses have extended their product portfolio to other platforms. This may be a 
consequence of increased platform competition. For instance, many extension providers offer their solutions for both Joomla and WordPress. Moreover, many web developers work with Joomla, WordPress, and other software frameworks at the same time. For individual firms, this strategy may reduce the exposure to platform competition. However, it may also be costlier to develop and retain competence across diverse (though similar) platforms. From a provider's point of view, it can make sense to focus on one particular platform in order to be more efficient.

As mentioned before, platform image is understood as an important proxy through which platform competition occurs. Although Joomla has been described as a robust and flexible CMS by the interviewees, they also mentioned that there can be perceptions amongst prospective customers that Joomla has a bad reputation. According to interviewees, these perceptions can stem from past compatibility issues or relate to the perceived ease of use of the system. As the empirical data suggest, platform image may also be affected by negative campaigning by individuals and firms that engage around competing platforms.

For Joomla businesses, a negative platform image can be problematic for several reasons. This applies in particular to those who work exclusively with Joomla and even decline customer requests if they insist on a different choice of platform. A negative platform image might make it more difficult for these businesses to sell their services. In addition, a negative platform image might reduce the attractiveness of both the platform and the community in the eyes of (prospective) users and volunteers.

Platform image is not only affected by platform-specific characterisations but also by higher-level attributes, such as general preconceptions about open source. According to interviewees, there are still prospective customers who believe that everything that ships under the label of open source should come free of charge. Or, there are preconceptions that there are few development or implementation costs associated with value-added services around OSS. Vendors cope with this problem by trying to educate their customers and users in this regard (e.g., by emphasising the efforts that are going into customisation, maintenance, development, and support).

From an ecology perspective, enhancing both the image of open source and the image of the host platform are necessarily collective efforts. However, in the Joomla ecosystem, there is no central authority that instructs others to engage in image campaigns. Awareness of trends around platform competition and image might percolate slowly through the community. Years might pass until a shared perception of these problems creates momentum, if at all. Even if shared perceptions of problems exist, the 
response and decision structures in the community are slow (as was reported by interviewees).

From an ecology perspective, a negative image of the host platform may not only be a problem for single Joomla businesses, it could also corrode the viability of the ecosystem around Joomla. The image of the host platform seems to be an outspoken issue at the community level. The importance of this issue is also reflected in recent governance changes through which the community introduced a marketing department. Moreover, the interview data show that poor-quality products and services delivered by commercial actors in the Joomla ecosystem can negatively affect the image of the Joomla platform (Study I: Stakeholders). In response, people in the community try to encourage others to deliver high quality to their clients, which is in line with lansiti and Levien (2004), who argue that actors within an ecosystem have strong incentives to support others in enhancing their own performance, which in turn can strengthen the entire ecosystem.

\subsubsection{Voluntary nature of the open source project}

The voluntary nature of the Joomla project is a deliberate choice. People in the community are proud of running this project on a voluntary basis. The reasons why the Joomla community operates through volunteerism are rooted in its history, which is described in both Chapter 4.1 and in Study III (Collective identities).

The voluntary nature of the Joomla community affects the businesses working around the Joomla platform in different ways. For instance, there can be fluctuations in community activities (e.g., support activity, development activity). People engage in community activities alongside their professional and personal obligations (e.g., jobs, clients, family), and they are not paid for doing community work. If there are problems with the Joomla CMS, there is no guarantee that anyone will answer questions in the forums in a timely manner. Nor are there contractual agreements that would obligate community members to provide support.

Another challenge that might stem from the voluntary nature of the project is a lack of continuity in the release cycles of Joomla. Interviewees mentioned that Joomla releases are usually delayed. However, they also mentioned that they have become used to that. Nevertheless, delayed releases may displease commercial actors around Joomla; for instance, when waiting for promised features that may ease their work with clients. Delayed release cycles might also negatively affect the image of Joomla, which in turn can indirectly affect Joomla businesses in negative ways (as discussed in Section 12.1.5). 
The voluntary nature of Joomla mainly pertains to the collaborative dimension of coopetition. In the case of community-driven open source (e.g., Joomla), this collaborative dimension is likely to be more fundamental than with firm-driven open source (e.g., WordPress). In the case of Joomla, without the community there would not be any useable software products. By contrast, in the case of WordPress, there is one single firm, called Automattic, that mainly pushes the development of the platform. In addition, Automattic offers a range of WordPress-related products and services ${ }^{168}$, making it the main beneficiary of the ecosystem around WordPress. By contrast, Joomla has remained a volunteer project in order to prevent a constellation that has one principal commercial beneficiary at the centre of the community (as is the case with WordPress and others). Drawing on Study III (Collective identities), this could mean that choosing Joomla over WordPress is also an ethical choice ${ }^{\mathrm{LVIII}}$; a choice which may be rooted in salient community values and the conviction that there should be equal opportunities in commercialising the community's software product(s).

While firm-driven open source might offer higher degrees of efficiency in community governance (e.g., more continuity in release cycles and support activities, quicker response and decision structures), seen as a moral choice, people around Joomla might approve of the uncertainties that may stem from the voluntary nature of their open source project. In return, they get equal opportunities to participate in the community's governing bodies and equal opportunities in commercialising the community's software product(s).

\subsubsection{Blurring boundary between private and professional lives}

More than ten years ago, S. Freeman (2007) observed the blurring boundaries between the private and professional lives of individuals in the context of open source communities. In the Joomla case, there can be a considerable overlap between private and professional lives, too.

For instance, the work of self-employed people and business owners in the Joomla case is usually not bound to a particular physical location, they can basically work from anywhere. This means that the laptop and customer projects are often constant companions when going on vacation. Trips are often planned to combine personal and work-related purposes (e.g., going on a holiday and visiting clients, employees, or partners at the same time).

Furthermore, many self-employed people and business owners in the Joomla case often work in isolation, physically separated from their peers,

LVIII Besides other reasons that people cite for choosing one over the other (e.g., technical superiority). 
employees, partners, and customers. The community provides a platform for these people to socialise with like-minded others, and to establish a sense of belonging (Study III: Collective identities). However, at the same time, the community is a space for talking about business matters and for building professional networks, thus reinforcing the blurring of boundaries between private and professional lives.

Moreover, there are a number of Joomla businesses that are operated by couples. Seen as an advantage, couples can have their offices and private lives under one roof, which for instance provides them with some more flexibility in caring for their kids (e.g., flexible working hours, proximity). However, this intertwining of people's marital and working lives can also be challenging for the individuals involved. For instance, people could bring up work-related matters in situations that are perceived to be private, intimate, or romantic by their spouses (and the other way around). According to the empirical data, one key in dealing with blurred boundaries between private and professional life seems to be an active desire and the discipline to separate private and work-related matters as much as possible.

Another factor that makes the boundaries between private and professional lives unclear is that business owners often try to remain available to their employees, business partners, and customers during their private time. This problem might apply to self-employment in general, but the combination of self-employment and volunteer work in this open source setting might amplify it. This means that, while the workload as a selfemployed person can be quite high and leave little room for private life, so can volunteer work. Being both a volunteer and an entrepreneur/business owner can be highly intrinsically stimulating (Study IV: Economic incentives), with the consequence that people can lose their work-life balance more easily and risk burnout in the longer term. In fact, some of the interviewees reported that they had to cut down the time they spent on doing community work because of this problem.

A blurred boundary between private and professional lives may have both advantages and drawbacks. From an ecology perspective, it could be argued that it may strengthen the ties and relationships amongst community members, thereby strengthening the ecosystem. A negative side effect may be that individuals are more prone to burnout, which could also lead to a loss of productivity within the ecosystem (e.g., a loss of valuable volunteers from the community). 


\subsubsection{Difficulty of estimating costs}

Another great challenge that Joomla businesses face is the difficulty in estimating the costs for development and operational support. As is elaborated in Study V (Pricing), there is a huge subjective element in the pricing of value-added services for OSS. The time it takes to develop a specific product can often be only roughly considered. It is very difficult to predict the hours it will take to develop and support a product. As one interviewee pointed out, going by the hours can be misleading because different developers work in different ways, and the time spent on coding does not always translate into better end results. Although charging by the hour is difficult, sometimes it can make sense; for instance, with simple and straightforward tasks or when customers want to start a project where the specifications and scope of the project are only loosely defined at the beginning. This is essentially a matter of who should bear the risk of how long a task will take: the supplier or buyers.

In the realm of extensions, time spent on operational support can substantially reduce the time needed for working on improvements to the product, which eventually drives up costs (Study V: Pricing). In order to reduce costs, or make them more predictable, business owners rely on synergies and automation. For instance, development costs can be reduced when tailored solutions can be applied and reused in other contexts, such as for other customer projects (synergy). A further factor that can reduce costs is the degree of automation in operational support (e.g., automating routines for backup, monitoring, or updates). As emphasised by one interviewee, automation not only makes work more efficient, it also enhances the scalability of the entire business model. Process automation for increased business model scalability is well-discussed in the literature on IT-based businesses (Stampfl, Prügl, \& Osterloh, 2013).

A further factor that can reduce costs is the outsourcing of parts of the development (and support) to lower-wage regions. As the empirical data indicate, some Joomla businesses have outsourced parts of their development to low-wage regions. The precise extent to which this is happening, and what the consequences may be, was beyond the focus of this thesis. Future studies could pick up on this.

Essentially, for Joomla businesses, the community can be a valuable source of inspiration on how to control costs more effectively and how to make their business model more scalable. For instance, people in the community often exchange experiences on estimating the costs for development and operational support, how to charge customers, and how to scope customer projects more effectively in order to control costs. 
Furthermore, the community provides a platform for hiring competent people all over the world, which some business owners might also see as an opportunity to get in contact with contractors and freelancers in lower-wage regions of the world.

\subsubsection{Firm dependencies}

This section discusses firm dependencies in the Joomla ecosystem. Commercial actors depend on the community and its software product(s) when building a business around the Joomla platform. In turn, the community depends on voluntary work efforts in order to create productive outputs. Often, these efforts and useful inputs come from the commercial actors around Joomla because they have a vested interest in the continuation of the platform. Commercial actors' dependence on the community has a range of implications. Some of these implications have been discussed in Section 12.1.6 in relation to the voluntary nature of the Joomla project.

A major source of dependence are the decisions and decision structures within the community. Decisions in the community can relate to platform policy (see Section 12.1.4), release cycles, the inclusion and abandonment of features with new releases, compatibility, and more. Interviewees stated that the decision structures in the Joomla community are too slow to keep up with a fast-changing environment. For instance, according to several interviewees, there can be hesitancy in the community around decisions related to adapting to recent versions of technologies that Joomla builds on. Decision processes can also be hampered by conflicting interests, infighting, and power struggles (Study III: Collective identities). Reportedly, decisionmaking processes can sometimes resemble a tug of war, in which different interests pull in different directions, complicating and delaying decisions. While difficulties in decision-making processes are not specific to community settings, the non-hierarchical and non-authoritarian decision structures, plus the open participation architecture, make the decisionmaking a more multi-interest process in the Joomla case than elsewhere.

Moreover, interviewees complained that community decisions can sometimes be myopic, failing to take into account different stakeholder interests around the Joomla project. In particular, business owners suggested that the community should pay more heed to the needs and realities of Joomla businesses. According to interviewees, community decisions can sometimes be in conflict with the demands and interests of Joomla businesses. A frequently used example by interviewees to illustrate possible disparities between development activities in the community and business interests around Joomla was past compatibility issues. 
Past compatibility issues between Joomla releases made it apparent just how dependent commercial actors are on the continuity of the Joomla project. Such compatibility issues caused many customer installations to fail, creating trouble, discomfort, and extra working hours for many Joomla businesses. Having to deal with upgrade problems on numerous customer installations can become a considerable and costly burden for small business owners.

Reportedly, there were many problems in upgrading and transitioning from Joomla version $1.5^{\mathrm{LIX}}$ to $2.5^{\mathrm{LX}}$ and from version 2.5 to $3^{\mathrm{LXI}}$. These compatibility issues caused outrage in the community. According to several interviewees, many users and commercial businesses turned their backs on Joomla as a result of these problems. As a consequence of these experiences, there is a much stronger commitment towards compatibility within the community today (Study III: Collective identities).

However, sometimes the community faces a dilemma in aligning community decisions with user needs. For instance, Internet service providers might use outdated versions of PHP or database technologies, which can impede the spread of new Joomla versions. This means that, even if the community would like to move on, it sometimes cannot do so because a large proportion of the users may be stuck with an outdated technological infrastructure.

Another problem is that the bulk of community work is often carried out by a few people, which might slow down the overall progress around the open source project. This observation may run somewhat counter to the prevailing image that open source provides more hands and eyes, and thus good chances of keeping up with a fast-changing environment. Suitable governance may be a key in leveraging available resources more effectively. The community implemented a series of governance changes in 2017; however, it is too early to evaluate the effects of these changes. Future studies could pick up on this.

Furthermore, there are not only mutual dependencies between commercial actors and the community, there can also be dependencies between the commercial actors in the Joomla ecosystem. For instance, many Joomla businesses rely on the use of third-party Joomla extensions in order to create and maintain their clients' websites. Some of the interviewees mentioned that they use a number of extensions by default on each of their clients' projects because they have become an integral part of their

Initially released in January 2008.

Initially released in January 2012.

Initially released in September 2012. 
workflows. However, sometimes these extensions can cause problems. Or, there may be compatibility issues between these extensions, which can lead to complex and costly trouble-shooting operations. As mentioned earlier, longer-term commitments between providers and clients, as facilitated through support subscriptions, may partly reduce the perception of these costs (Paper V: Pricing).

For commercial actors, one major coping strategy to reduce the planning uncertainties that may stem from the various dependencies discussed in this section is to engage in community activities themselves. In particular, their dependence on the open source project is a reason why many commercial actors opt to support it and influence its activities. Community engagement enables commercial actors to push their own agendas, voice their concerns, advocate for compatibility, vote for functionality that eases their work, and keep up to date with rumours and trends that can affect the Joomla project (Study IV: Economic incentives). In addition, the community provides a forum for establishing alignment among third-party developers.

The dependencies between commercial actors and the community might appear to lessen the distinction between community-driven and firmdriven open source. However, in the Joomla case, there is no single commercial actor who has a final say in governance matters, as is the case with firm-driven open source (e.g., WordPress). Nor does Joomla compare well with syndicate-like governance approaches, where decision-making belongs to somewhat closed groups of firms and corporations, as is the case with the Linux project. Governance in the Joomla case invites participation by both hobbyists and professional actors, without formal exclusionary barriers (such as membership fees).

From an ecology perspective, both the community and the OSS could be seen as a public good and a crucial collective resource in the ecosystem. While commercial actors depend on these collective resources, they can cope better with the uncertainties around this dependence by engaging in voluntary community work themselves. Therefore, community engagement and profit-oriented venturing could be seen as intertwined. The next section specifically focuses on different aspects of this intertwining.

\subsection{RQ2: How are volunteer community engagement and profit- oriented venturing intertwined in the context of community- driven open source?}

RQ2 asked how volunteer community engagement and profit-oriented venturing are intertwined in the context of community-driven open source. As mentioned, this theme connects with recent research on the relationships 
between community forms of organising and entrepreneurial activities (Mollick, 2016; Rosenfall, 2012), and research on sourcing strategies exploring the power of communities for creating business value (Carillo, Huff, et al., 2017; Morgan et al., 2013). However, none of these sources specifically discusses intertwining. Below, four aspects of intertwining are discussed: reinforcement, complementarity, synergy, and reciprocity (Robey et al., 2003). Both the positive and negative facets of intertwining are considered, since they are both important for a balanced analysis (Lundmark \& Westelius, 2008; Valiente \& Westelius, 2007).

Before discussing different aspects of intertwining, the following provides summary statistics for the intersection of community engagement and profit-oriented venturing in the interview samples. The interview samples showed a considerable intersection of participants who both contributed to the Joomla community and had a business that was in some way connected to Joomla. First, the summary statistics for the first set of interviews are presented, followed by the summary statistics for the second set of interviews. Thereafter, the discussion continues with a presentation of findings concerning aspects of intertwining.

\subsubsection{Summary statistics on the first set of interviews}

As described in Section 5.5.1, the first set of interviews was based on a sample of 21 commercial extension providers. Within this set, there were 14 people who actively contributed to the Joomla project. These contributions included activities as diverse as code contributions, the dissemination of knowledge on using Joomla, mentoring and support, sponsoring, participating at Joomla events, the provision of free extensions, work with sponsors, writing blogs about Joomla, participating in different teams, reporting bugs, writing documentation, organising user groups, filing pull requests, answering questions in forums, and administrating the JED.

Participants also utilised the community as a platform for promoting their own products (e.g., at community events). Furthermore, while 14 interviewees were active contributors, another four said that they were currently not contributing, but that they had done so in the past. One of these four emphasised that he had contributed in numerous areas. A shortage of time was the main reason for being inactive.

One interviewee mentioned that he would like to contribute but had not done so yet. Two interviewees provided no answers regarding their community engagement. Table 12 provides an overview of the contribution activities of commercial extension providers within the first set of interviews. 


\begin{tabular}{|l|l|}
\hline $\begin{array}{l}\text { Number of } \\
\text { interviewees }\end{array}$ & Answers regarding contribution activities \\
\hline 14 & $\begin{array}{l}\text { Actively contributed to the Joomla project (e.g., code contributions, the } \\
\text { dissemination of knowledge about using Joomla, mentoring and } \\
\text { support, sponsoring, participating at Joomla events, provision of free } \\
\text { extensions, work with sponsors, writing blogs about Joomla, } \\
\text { participating in different teams, reporting bugs, writing documentation, } \\
\text { organising user groups, filing pull requests, answering questions in } \\
\text { forums, administrating the JED). }\end{array}$ \\
\hline 4 & $\begin{array}{l}\text { Were currently not contributing to the community but had done so in } \\
\text { the past. }\end{array}$ \\
\hline 1 & Would like to contribute but had not done so yet. \\
\hline 2 & Provided no answer regarding their community involvement ${ }^{\text {LXII }}$ \\
\hline
\end{tabular}

Table 12: Contribution activities of commercial extension providers in the first set of interviews.

\subsubsection{Summary statistics on the second set of interviews}

The proximity of volunteer community engagement and profit-oriented venturing was also apparent in the second set of interviews. As described in Section 5.5.1, this second set of interviews was compiled based on community affiliation and consisted of 26 participants.

Within this set, only two interviewees did not have a business dealing with Joomla, two more interviewees used Joomla in their jobs as employees, and three interviewees reported that they had a business connected to Joomla but only as a side business. For the rest (19 interviewees), Joomla played a more or less significant role in their business, which meant that their business was a major source of income, and that they were either offering products and services for the Joomla platform (e.g., Joomla extensions, Joomla-specific development and services) or that these products and services were related to or based on Joomla in some way (e.g., web development, design, marketing, consulting, integration, training).

LXII Of course, it is not necessary to be involved in the community in order to sell extensions and related services such as support. In addition, having provided no answer on this specific question does not necessarily mean that the respective interviewees are (or were) not involved in the community. 


\begin{tabular}{|l|l|}
\hline $\begin{array}{l}\text { Number of } \\
\text { interviewees }\end{array}$ & $\begin{array}{l}\text { Answers regarding their commercial activities in relation to the } \\
\text { community's software product(s) }\end{array}$ \\
\hline 19 & $\begin{array}{l}\text { For these interviewees, Joomla played a more or less significant role } \\
\text { in their business. Their business was a major source of income; they } \\
\text { were either offering products and services for the Joomla platform } \\
\text { (e.g., Joomla extensions, Joomla-specific development and services) } \\
\text { or products and services that were related to or based on Joomla in } \\
\text { some way (e.g., web development, design, marketing, analytics, } \\
\text { consulting, integration, training). }\end{array}$ \\
\hline 3 & Had a business connected to Joomla but only as a side business. \\
\hline 2 & Worked with Joomla in their jobs as employees. \\
\hline 2 & Had no business connected to Joomla. \\
\hline
\end{tabular}

Table 13: Commercial activities of people affiliated with the community as evident from the second set of interviews.

\subsubsection{Reinforcement}

As described in the theoretical framework, by 'reinforcement', Robey et al. (2003) emphasise the strengthening of a relationship by adding more elements to it. In an abstract sense, the idea is that one element can strengthen the effect of others, thereby increasing redundancy. From an ecology perspective, redundancy may increase the resilience of an ecosystem. For instance, a large pool of volunteers may increase the redundancy around the Joomla project by each being able to contribute to the project, thereby providing more stability to the community foundations on which the businesses of commercial actors rely.

The additive effects of the ideas and inputs from large numbers of volunteers and businesses around Joomla may stimulate productivity within the community, and strengthen the image of the Joomla project (e.g., by signalling vitality) and the ecosystem around it (e.g., by disseminating knowledge about using Joomla in efficient ways when working with customer projects).

Redundancy in the Joomla case may be facilitated through low barriers to access and participation. Although there are also limits as to what one can do in the community, basically anyone can participate in it, or run a business based on Joomla.

However, as Valiente and Westelius (2007) suggest, reinforcement may also increase inconsistencies and costs. Due to low participation barriers and voluntarism, there may be higher costs for coordination and conflict resolution. As the empirical data show, many governance issues in the 
community essentially revolve around these aspects (Study III: Collective identities).

The effects of reinforcement between volunteer community engagement and profit-oriented venturing can also be illustrated by the keystones in the Joomla ecosystem. As mentioned in Chapter 3, keystones are firms that are valued for their long-standing experience and the proven products and services that they offer (e.g., extensions, but also other types of products and services). These keystones occupy profitable niches within the ecosystem. In doing so, they demonstrate that they can be of value to others in the ecosystem, which also raises their status in the community. The keystones can only sustain their Joomla-based businesses as long as the technological platform is of significance and value to a large enough number of users. The keystones strengthen the community by sponsoring community events, by providing inspiration and direction, and by engaging in all kinds of community-related activities.

For the keystones, the community is not only a space for knowledge exchange, it is also a marketing platform for presenting their products. As the empirical data suggest, products, brands, and services are predominantly (though not exclusively) endorsed in more informal ways, such as through referrals, word-of-mouth, and community events. The community provides the space and channels for these more informal means of marketing.

Drawing on Valiente and Westelius (2007), while keystones may provide more stability to the ecosystem, stability and robustness may come at the cost of increased inertia. Keystones may have a disincentive to induce change once they have found and occupied a profitable niche in the Joomla ecosystem. Change may imply a possible threat to their established positions in the ecosystem. For instance, extension providers might have little incentive to advocate for change that could undermine their business models (see Section 12.1.3). Interviewees stated that, compared to other communities, the Joomla community is comparatively slow in adapting to new technologies and trends. This keystone-based systemic inertia may partly explain why.

In summary, a large and active community can strengthen the businesses that flourish around community-driven open source projects. Conversely, profitable businesses can strengthen and reinforce the vitality of the community. Reinforcement between volunteer community engagement and profit-oriented venturing may also provide stability and robustness to the ecosystem. However, as a side-effect, there may be increased systemic inertia, which may require governance and strategy interventions in order to increase the responsiveness to environmental change. 


\subsubsection{Complementarity}

As described in the theoretical framework, by 'complementarity', Robey et al. (2003) emphasise that elements with different characteristics can compensate for each other's strengths and weaknesses.

A major strength of the community is that it provides a potentially large pool of expertise - a pool that by far exceeds the capabilities of any single actor in the ecosystem. This pool of expertise is especially useful when dealing with complex customer solutions. The learning benefits offered by the community enable commercial actors to grow their business and to become better solution providers. Commercial actors can have their code and ideas reviewed and discussed (especially if intended as a community contribution), and they can receive free support on tricky issues. Furthermore, the community provides a platform for professional networking through which commercial actors can meet potential business partners.

A weakness that single commercial actors may have is the problem of working in isolation at their day jobs, often disconnected from their employees, colleagues, contractors, partners, and customers. According to the empirical data, self-employed people, freelancers, and small business owners sometimes tend to think that they are on their own, but when they recognise all the people and activities in the community, they often realise that they have support. The problem of working in isolation seems to be often, if not entirely, neglected in discussions on the commercialisation of OSS. The community compensates for these often-neglected work realities by providing a space for connecting with like-minded others and by providing a sense of identity and belonging. As Study IV (Economic incentives) showed, an important motive for engaging in the community is the desire to be part of something bigger than oneself. In this sense, the community facilitates psychological health and spiritual well-being in the ecosystem (Study III: Collective identities, Study IV: Economic incentives).

A major strength of commercial actors is that they have the experience of working with Joomla on their clients' installations. This experience, and the problems that arise throughout their work with clients, can be of great value to the community. Without the experience of commercial actors, it would be more difficult to collect reliable information on the usefulness and reliability of the Joomla CMS.

Commercial actors also play a crucial role in spreading information about trends within the community. Not only the community but the entire ecosystem around Joomla benefits from this infusion of knowledge and experience. As argued by Moore (2006), a business ecosystem needs to 
incorporate customer feedback in order to stay relevant. Connected to this, the community provides an important platform through which feedback from customers can be exchanged and disseminated.

Unsurprisingly, one weakness of a community of volunteers is that it is notoriously underfunded. Commercial actors often compensate for this weakness by providing the necessary funding to the Joomla project. Funding is needed for events and other community-related expenses (e.g., trademark, legal counselling, hosting, marketing).

Another weakness of a project that is based purely on voluntary participation is that the levels of activity and commitment can vary, which has consequences for the continuity and stability of the open source project. In part, commercial actors may be able to make up for this because they often take over official responsibilities and show perseverance in light of challenging community tasks. Vested interests in the Joomla project may partly explain the commitment from the side of commercial actors (Study IV: Economic incentives).

As suggested by Valiente and Westelius (2007), complementarity can carry an increased risk of failure due to interdependencies. Applying this premise to the Joomla case, the interdependencies between the community and commercial actors can involve competing interests and uncertainties. Either of these cases may lead to efficiency losses and increased costs for commercial actors. For instance, they have to bear the costs of fixing broken customer installations when facing compatibility issues with Joomla upgrades. Or, commercial actors might not receive timely answers in support forums to questions concerning their customer installations. The businesses of commercial actors may also be affected by communityinternal bickering on production-relevant matters.

Furthermore, volunteers might face the risk of burnout when investing too much time and energy in community work. This might particularly apply to those volunteers who have a business connected to the Joomla project, and those who aim to build and maintain a reputable presence within the community.

In summary, commercial actors can infuse strengths into the community that compensate for the weaknesses that a community of volunteers necessarily grapples with. Many of the attitudes, skills, and competencies that are cultivated in professional contexts might come to the benefit of the community in the form of inspiration and experience. In turn, the pool of expertise and resources accessible through the community makes up for a possible lack thereof on the part of the commercial actors. To some extent, exposure to risks that stem from complementarity (e.g., competing interests, uncertainties, burnout and self-exploitation) may be minimised through 
personal and professional networks of community peers, enabling instant contact with knowledgeable, supportive, or influential people in the community.

\subsubsection{Synergy}

As mentioned in the theoretical framework, by 'synergy', Robey et al. (2003) emphasise that a combination of elements can create new properties (e.g., performance effects) that surpass the effects of the individual elements.

One of the most important synergistic effects between volunteer community engagement and profit-oriented venturing may be learning. As mentioned in Study IV (Economic incentives), learning is a well-known motivational driver for community engagement, both at an individual and an organisation level. Essentially, the community breeds a culture that facilitates sharing and learning. For commercial actors, a variety of learning benefits accrue from engaging in the community.

For instance, they can learn how to defend their value propositions in light of increased platform competition, price pressure, and global competition. They can also learn how to solve particular problems more effectively, thereby reducing the time-to-market of their client projects (Study IV: Economic incentives). The continuous exchange among participants also facilitates the joint development of ideas in the community. As emphasised by interviewees, the interaction within the community essentially enables more purposeful learning, rather than having to learn from trial and error (Study IV: Economic incentives).

Besides learning, another such synergistic effect (i.e., a new property that arises as a result of the intertwining of volunteer community engagement and profit-oriented venturing) refers to the confidence of commercial actors in the community's ability to deal with Joomla-related issues in a suitable and timely manner. As was discussed in Study IV (Economic incentives), no contractual agreements force anyone to provide support for Joomla businesses if they face problems that are caused by the Joomla CMS. One such problem could be security vulnerabilities. The Joomla project, just like any popular software platform, relies on the continuous fixing of security vulnerabilities. However, given the voluntary nature of the project, how can commercial actors be sure that security vulnerabilities will be dealt with in a suitable and timely manner, if at all?

As discussed in Study IV (Economic incentives), a form of intersubjective trust may provide an answer to that. From a synergy point of view, intersubjective trust arises as a consequence of the intertwining of volunteer community engagement and profit-oriented venturing. That is to say, 
commercial actors can be confident that bugs will be fixed quickly when they know that the people in the core development teams have a business connected to Joomla themselves. This demonstrates that, in the absence of monetary compensation and formal contracts, the experience of shared fate may help overcome problems of trust and confidence within an ecosystem.

From an ecology perspective, intersubjective trust as an emergent property, and the experience of shared fate may function as stabilising factors in the ecosystem. The salient value of togetherness in the Joomla case (Study III: Collective identities) may help to foster the experience of shared fate.

From an ecology perspective, the productive outputs of an ecosystem can be understood as a result of the synergistic effects that emerge through the interactions among its actors. Low access barriers and the value of openness may amplify a culture of open participation and exchange. However, there can also be negative effects arising as a consequence of this interaction, such as conflicts and the formation of competing cliques. A culture of openness may equally amplify a culture of open conflict (Study III: Collective identities), which may need suitable governance responses. However, as Study III suggests, in order to channel conflicts in constructive and productive ways, governance should not violate fundamental community values (e.g., openness, transparency, togetherness).

\subsubsection{Reciprocity}

Unlike Robey et al. (2003), Valiente and Westelius (2007) do not regard reciprocity as a distinct aspect of intertwining. They argue that reciprocity (and the interdependence to which it refers) is inherently fundamental to the other aspects of intertwining (i.e., reinforcement, complementarity, synergy). However, a separate discussion of reciprocity may be justified for the following reason.

As mentioned in Section 3.7, by 'reciprocity', Robey et al. (2003) emphasise the interdependence of intertwined relationships. This interdependence implies that both elements are more or less equally important in producing the reciprocal effects. This type of intertwining evokes a resemblance to mutualistic symbiotic relationships (Dahlander \& Magnusson, 2005). Symbiosis can be described as "a relationship between people or organisations that depend on each other equally"169. Because of the resemblance to ecology (i.e., symbiosis), reciprocity deserves its own independent consideration in the context of this thesis.

The empirical data suggest that voluntary community engagement and profit-oriented venturing in the context of community-driven open source 
can coexist in a mutualistic symbiotic form. This complements findings by Dahlander and Magnusson (2005) who have previously reported symbiotic relationships between firms and open source communities. However, their study focused on firm-driven open source projects, where communities were initiated and established by focal firms in close relation to their products, standards, and commercial operations. In the context of community-driven open source, the symbiotic relationships between firms and communities are probably less obvious, thus more difficult to spot. However, as this thesis shows, they do exist, but under different conditions and with different dynamics (e.g., due to the absence of corporate ownership and central control, a lack of funding, and unpredictable fluctuations in community activities).

Commercial actors depend on the continuous development, maintenance, and improvement of the Joomla platform. On the other hand, the community depends on the input and experience of the commercial actors. Many code contributions and voluntary work efforts come from these commercial actors. The resources and contributions of these people are essential for the community to prosper. These aspects of mutualism are repeatedly expressed in the empirical data. In a nutshell, Joomla businesses can effectively only grow and prosper if the community grows and prospers, and vice versa.

However, there may also be risks associated with reciprocity. Taking symbiosis as a starting point, reciprocal relationships may not only be of a mutualistic character, but also commensalistic and even parasitic (Dahlander \& Magnusson, 2005). Translated into this open source setting, the phenomenon of free-riding could be classified as an example of a commensalistic type of interaction. This is to say, anyone can run a business based on Joomla without ever contributing back to the community. According to von Hippel and von Krogh (2003), most users actually are freeriders. Although the empirical data show that the mere use of the software can be seen as a contribution in itself (e.g., by increasing the penetration rate of Joomla), commercial actors might face the risk that too little community engagement from the users' side could stifle the development and maintenance of the open source project.

For reciprocal relationships of a parasitic character, consider the case of a highly skewed workload distribution in the community. There may be situations and periods when the bulk of the workload in the community is shouldered by only a few volunteers, which, from an ecology perspective, could possibly lead to parasitic effects in the sense that users (including commercial actors) may benefit from the fruits of these few volunteers' work, but the affected individuals may be harmed in the long run by risking 
burnout. Although it cannot be termed parasitic if high-contributing volunteers really enjoy their activities and the fruits of being a significant contributor, from a theoretical standpoint, it seems basically possible that single volunteers overwork themselves and risk burnout in case the workload distribution in the community remains uneven over an extended period of time. Furthermore, high-contributors may not realise at first that their strong commitment and the experience of their achievements over time have led to feelings of being emotionally trapped (Westelius, 2008). A fair distribution of the workload may be desirable, but may not be easily achieved in a community of volunteers, both from a motivation and coordination point of view.

Mutual encouragement is another example that can serve to illustrate aspects of reciprocity and interdependence in the Joomla case. Among the different motivations for community engagement (Study IV: Economic incentives), firms might also be motivated to be active in the community in order to motivate others to do voluntary community work. For instance, firms might want to motivate volunteers by showing respect and appreciation. While this particular aspect did not feature clearly in Study IV (Economic incentives), it became more evident from a business ecology perspective, based on the premise that actors have strong incentives to support others in enhancing their own performance (lansiti \& Levien, 2004).

In the Joomla case, encouraging others to engage in community work can mean encouraging both people who pursue commercial interests based on Joomla, and people who do not. This means that Joomla businesses are not only dependent on other volunteers who have a Joomla business themselves, but also on volunteers who do something else in their day job, but who do crucial community work nevertheless. For instance, at the Joomla World Conference in 2017, a lead developer for an upcoming Joomla release gave a presentation about the release plan of the software and the current state of affairs ${ }^{170}$. However, this lead developer's day job was not connected to Joomla. In order to motivate individuals who are more intrinsically motivated to do community work, firms with a vested interest in the Joomla platform might encourage them by paying them respect, showing appreciation and gratitude, and by enacting their commitment towards shared values (e.g., by demonstrating that "open source matters" ${ }^{171}$ ). Official recognition and public appreciation are shown not only at community events, but also on the Joomla website (e.g., honour roll, articles, news, stories, team memberships, mentions of contributing activities and achievements), and in all kinds of online channels (e.g., social media, the forums, blogs, GitHub, issue tracker). 
From an ecology perspective, there are reciprocal relationships between an organisation's health and the health of the entire ecosystem in which it participates, which is why organisations have strong incentives to preserve the overall stability and health of any ecosystem in which they participate (lansiti \& Levien, 2004). This could help explain the importance of helping behaviour in the Joomla case (Study III: Collective identities, Study IV: Economic incentives). The interview data show that the interpersonal aspects, and supportive attitudes within the community in particular, can be experienced as strong and even as life-changing by the people in the community. In a sense, the community provides a shared space where the importance of helping behaviour becomes visible and reinforced. Experiencing supportive behaviour within the community may also facilitate trust among community members, which in turn may facilitate the formation of professional networks.

In summary, from an ecology perspective, commercial actors in the ecosystem might have strong incentives to help and encourage others not only because it is a valuable strategy (Mars et al., 2012), but also because it ensures the collective health of the ecosystem (lansiti \& Levien, 2004). However, mindful intertwining (Valiente \& Westelius, 2007) requires consideration of both positive and negative effects. In the context of community-driven open source, the reciprocal relationships between community engagement and profit-oriented venturing may not only be of mutualistic character, but might also take on the form of commensalistic and even parasitic character. 


\section{Discussion and contributions}

Before beginning this discussion, it should be noted that an important type of contributions associated with interpretive research is contributions containing rich insight, which refers to information that is not easily captured (Walsham, 1995). The present thesis has contributed a wealth of rich empirical insights of potential value for subsequent research. For instance, one such type of information that is not easily captured is participants' motivation for community engagement, but also identity-relevant information. This thesis has provided thick descriptions of such caserelevant matters, often corroborated with anonymised excerpts from the interview material. Furthermore, the sub-studies in this thesis (Chapter $6-$ 11) make individual contributions on their own that are elaborated in the corresponding chapters.

The remainder of this section discusses the theoretical implications of the findings, and the contributions they make. The next section starts off by discussing the metaphor of communities as superorganisms. The subsequent section proposes a framework for analysing community-based value creation in business ecosystems. This is followed by a generic representation of community-based value creation utilising organismic metaphors.

Thereafter, a model for classifying community types is proposed. This model provides a four-way distinction between open source communities based on the degree of firm control and democratisation in community governance. This is followed by a discussion of spiritual well-being, the sense of belonging, and the psychological health of community participants, which is a discussion that is somewhat neglected in the open source literature.

Then, the discussion turns to a particular form of intersubjective trust that facilitates commercial actors' confidence in the community's ability to deal with critical issues. Penultimately, issues in relation to the transitioning of community members from a community-based self-identity to an entrepreneurial self-identity are discussed. Finally, this chapter ends with a broader discussion of the implications for value-based, strategic, and ecology perspectives on open source.

\subsection{Communities as superorganisms}

During the final stage of working on this thesis, my attention was drawn to the metaphor of superorganisms. Inspired by ecology terminology and the metaphor of intertwining (e.g., reciprocal and symbiotic relationships), open 
source communities can be imagined as superorganisms. The idea to conceive of peer-production communities as living organisms is expressed in Carillo, Marsan, and Negoita (2017). However, more specifically, these communities could be viewed as superorganisms. A superorganism is an association of a large number of individual 'organisms' that behave as an organic whole ${ }^{172}$. Examples of superorganisms in nature are colonies, swarms, or herds of animals ${ }^{\text {LXIII. }}$

Inwardly, such superorganisms may facilitate the health of individual 'organisms' and provide protection and care (e.g., via constitutional values and norms in organisational contexts). If we adopt the term for the Joomla community and draw on the findings from this thesis, superorganisms may provide a sense of orientation, identity, and belonging. Outwardly, such superorganisms may be vehicles for navigating a confusingly complex and global organisational terrain. Drawing on Westelius and Lind (2016), superorganisms may enable commercial actors to extend their myopic field of vision, their area of activity, and the environmental impact for which they are aiming.

There may be both collaboration and competition among superorganisms (Carillo, Marsan, et al., 2017). For instance, platforms and related communities may compete for valuable resources (e.g., volunteers, experts, developers) and market share (i.e., living space). At the same time, there may be an ongoing exchange of ideas and practices among communities $^{\text {LXIV }}$. The various dependencies among technological platforms may necessitate coordination, cooperation, and collaboration among superorganisms. While communities mutually observe each other, there can be intersections of people who engage in two or more of these communities. Future research could explore the role of such boundary-spanning brokers among competing and collaborating superorganisms.

From an ecology perspective, new superorganisms may emerge while others may fade, and some may manage to adapt to changing environmental conditions. Future research could explore the role of firms and communities in such evolving constellations of superorganisms. In summary, conceptualising the community as a superorganism contributes to the nascent literature stream on ecology perspectives that conceive of peerproduction communities as living organisms (Carillo, Marsan, et al., 2017).

The metaphor of superorganisms has also been applied and used in other fields, such as psychology (Seeley, 2001) and political science (Corning,

LXIII E.g., ants, termites, birds, fish.

LXIV As the empirical data show, to some extent, there is ongoing exchange between Joomla, WordPress, and Drupal. Exploring the scale and extent of this exchange was beyond the focus of this thesis. Future research could pick up on the exchange relationships between open source communities. 
2008). For instance, the European Union could be seen as a superorganism. Inwardly, it provides legal and institutional foundations for economic exchange, conflict resolution, and identification. Outwardly, it may be a vehicle for having a (more impactful) voice in an evolving, and confusingly complex, global terrain. Possibly, ecology research in the management fields can draw inspiration from these literature streams.

\subsection{A framework for analysing community-based value creation in business ecosystems}

In Section 12.1, the challenges in commercialising community-driven OSS were summarised in nine factors clustered into three domains: the ecosystem, community, and firm. Based on these insights, a framework for analysing community-based value creation in business ecosystems is proposed. Visually, this framework is depicted as a Venn diagram in Figure 46. Venn diagrams are useful for depicting the relations between sets of entities. Moore (2006) suggests that business ecosystems may in part be understood through Venn diagrams. His idea is that mapping the landscape of participants by overlapping sets can facilitate the understanding of interdependencies within an ecosystem. The framework that I propose builds on the three constituents: ecosystem, community, and firm. The following briefly explains the meanings of these constituents.

As stated in Section 3.1, the ecosystem delineates a specific 'living space', its structural characteristics, and the population of 'organisms' whose relationships and interactions are at the centre of attention. As an example, consider the Joomla ecosystem, which is the focus of the present thesis. As discussed in Study I (Stakeholders), the boundaries that make up this particular 'living space' include the Joomla community, users, end-users, businesses, diverse technological platforms (e.g., web servers, databases, PHP, front-end libraries), trend setters (Google and others), the wider CMS community and competing CMS platforms, and standardisation and legislation bodies.

As stated in Section 5.3, an open source community is broadly understood as the set of people who involve themselves in the activities around an open source project. As noted before, the range of these activities can be broad (see Section 2.2.3). In the case of Joomla, people in the community band together around the common goal of collective production and shared values, such as freedom, openness, transparency, and togetherness (Study III: Collective identities).

The domain of the firm can be characterised by drawing on recent research that seeks to extend Coase's (1937) classical theory of the firm to 
the domain of peer production. Central to Coase's (1937) theory is that firms emerge due to transaction costs in markets, and that the entrepreneur sits at the interface between price-based coordination mechanisms prevalent in markets and hierarchical coordination practices within firms. However, with plummeting transaction costs, new coordination practices have emerged, making organisational boundaries more permeable, thus challenging classical theories of the firm (Benkler, 2017).

Felin, Lakhani, and Tushman (2017) have criticised classical theories of the firm for their lack of sociality. In contrast, they highlight the role of sociality in extending firms' rationality (e.g., by harnessing the knowledge embedded in networks and communities), sociality as sensing and signal (e.g., by facilitating bottom-up sensing among employees, fostering of collective wisdom, flattened organisational structures, self-selection onto projects), and sociality as a means of fostering identity (e.g., relations to social movements, ideologies, and the intermingling of personal and professional identities). In a nutshell, in Figure 46 and the following text, the term 'firm' ought to be interpreted by use of these characterisations ${ }^{\mathrm{LXV}}$, rather than by classical depictions of the firm.

Having outlined the meanings of the terms 'ecosystem', 'community', and 'firm', the following continues by drawing on their intersections in the Venn diagram. The conceptual labels for the intersections in the Venn diagram emerged in a bottom-up style, although guided by the theory. This means that the relationships between the overlapping circles (i.e., ecosystem, community, firm) were analysed in view of the challenges and aspects discussed in Chapter 12. From an analytical point of view, this approach corresponds to abductive reasoning, discussed in Section 5.4. One aim of this analysis was to find descriptive labels for the corresponding intersections in the Venn diagram.

The choice of conceptual labels for the intersections in Figure 46 is elaborated in the following sections. In summary, the intersection of the domains ecosystem and community was subsumed under the umbrella of 'collective innovation'. The intersection of the domains community and firm was subsumed under the umbrella of 'community engagement'. The intersection of the domains firm and ecosystem was subsumed under the umbrella of 'value capture'. Finally, the intersection of 'collective innovation', 'community engagement', and 'value capture' was subsumed under the umbrella of 'community-based value creation'.

Lxv In the Joomla case, examples of firms are extension providers, web developers, and marketers. 


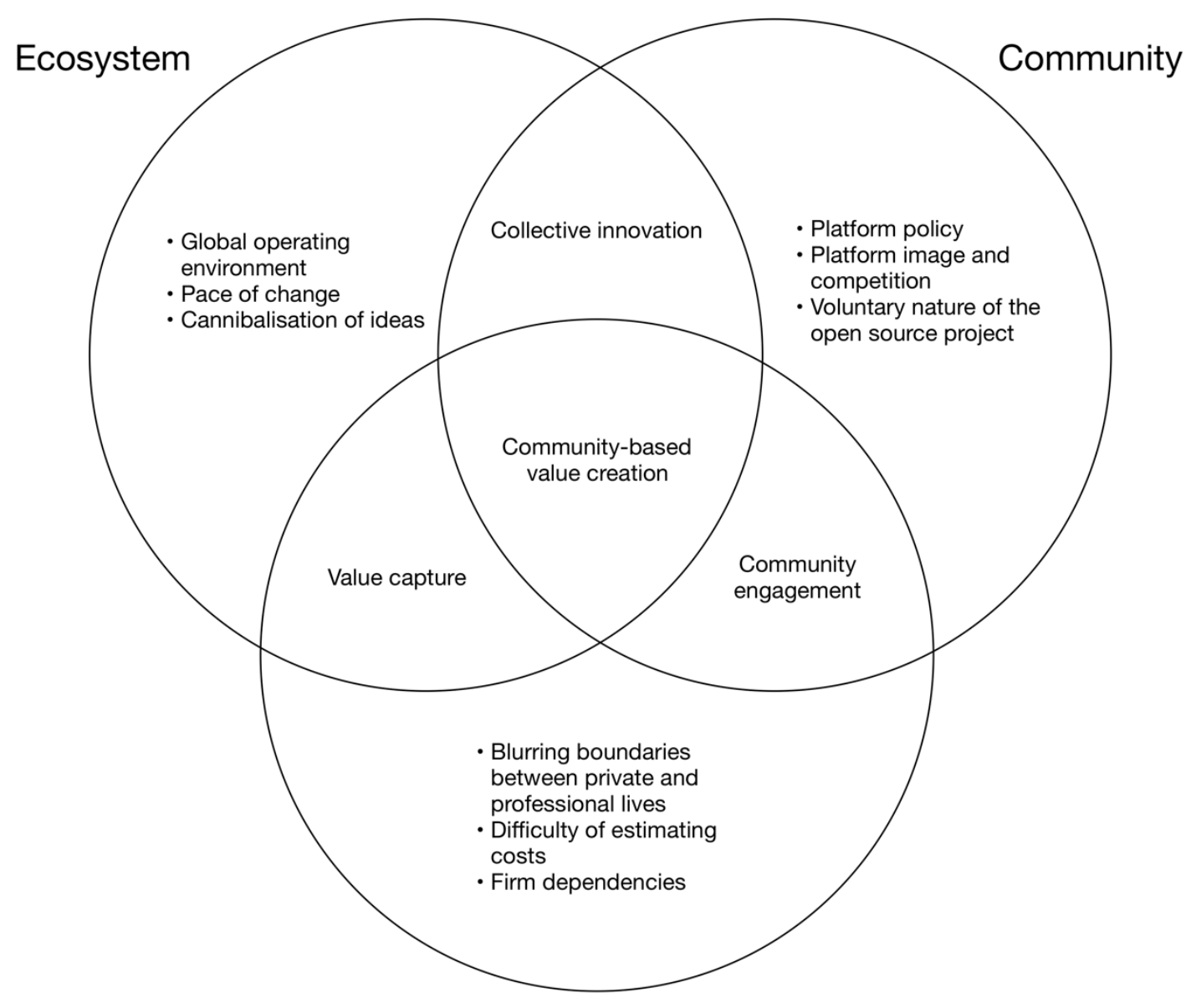

Firm

Figure 46: A Venn diagram depicting the essential conceptual relations among the three constituents: ecosystem, community, and firm.

The non-intersecting regions in Figure 46 emphasise that each of the individual constituents (i.e., ecosystem, community, firm) consists of more than just their intersections. For instance, even though a firm may be part of an ecosystem and a community, it consists of more than that (e.g., its relationships with firms that are not part of the ecosystem). Even though a community may be associated with an ecosystem and commercial actors, a community consists of more than that (e.g., volunteers who participate purely for fun). And, even though an ecosystem may include particular communities and firms, it is always more than that (e.g., characterised by evolving constellations of actors, communities, and firms). 


\subsubsection{Collective innovation (ecosystem and community)}

With the term 'collective innovation', the proposed framework emphasises that community-based value creation in ecosystems depends on the productive outputs, innovativeness, and sustainability of communities.

The community-based open source production paradigm is often portrayed as the archetype of collective innovation (Christian, 2015; von Hippel, 2005). Essentially, collective innovation sources the ideas and creativity of potentially massive numbers of people, sometimes also referred to as crowds (Kozinets, Hemetsberger, \& Schau, 2008). The ecosystem provides this vast and diverse pool of resources. In turn, the outputs of collective innovation come to the benefit of the entire ecosystem. For instance, these benefits come in the form of OSS (which comes as a public good), or as ideas and solutions that emerge as a consequence of the activities around open source projects. In essence, the productive outputs of communities (e.g., software, ideas, and solutions) can be regarded as the raw materials that are used, refined, and extended in commercial contexts (O'Reilly, 1999).

There are both opportunities and challenges around collective innovation. For instance, seen as an opportunity, the global operating environment provides access to a large and diverse pool of potential volunteers, experts, communities, and technologies. Seen as a challenge, it may involve fierce competition for talented people, coordination problems, increased uncertainties, and interdependencies between technological platforms.

Likewise, seen as an opportunity, platform policy may protect the openness of the code and safeguard the interactions among community participants. Seen as a challenge, it may make it more difficult to commercialise and price OSS (Study V: Pricing, Study VI: Bundling and versioning). Likewise, seen as an opportunity, the cannibalisation of ideas may provide the necessary inspiration that drives innovation. Seen as a challenge, it may make it more difficult to develop a unique value proposition.

\subsubsection{Community engagement (firm and community)}

Drawing on Section 2.2.5, interacting with communities can offer a variety of benefits to firms. In the literature, the knowledge, skills, networks, and resources accessible through open source communities are depicted as potential sources of value creation, innovation, and competitive advantage (Daniel \& Stewart, 2016; Lakhani \& Panetta, 2007; Mollick, 2016; Morgan et al., 2013; Morgan \& Finnegan, 2014; Weber, 2004). The literature further 
suggests that the strategic benefits for firms may unfold as a consequence of their interaction with the community (Androutsellis-Theotokis et al., 2011; Carillo, Marsan, et al., 2017; Valença et al., 2014).

The findings of this thesis point in a similar direction. As discussed in Chapter 12, the relationships between firms and communities can be of symbiotic character. However, while firms can benefit from their interaction with communities, and vice versa, this thesis stresses that firm participation in communities can entail challenges for both firms and communities. For instance, seen as an opportunity, platform policy and governance may enable firms to actively participate in community committees, governing bodies, and work groups in order to voice their concerns and to protect their interests. Seen as a challenge, it may involve exposure to competing interests, and fluctuations in the continuity of community activities. Likewise, seen as an opportunity, the blurring of boundaries between private and professional lives may lead to synergistic effects (e.g., joint socialising with like-minded others and professional networking). Seen as a challenge, it may entail increased exposure to stress, and risk of burnout due to high degrees of intrinsic stimulation or strong feelings of obligation and commitment (cf. Sections 12.1.7 and 12.2.6). Previous research has shown that the sense of duty and obligation among people in communities can be strong (Bagozzi \& Dholakia, 2006), however, without expanding on the negative aspects of strong commitment, such as the feeling of being trapped, and a sense of fatigue (Westelius, 2008). Future research can pick up on this.

\subsubsection{Value capture (firm and ecosystem)}

Value capture explains how firms generate revenue from value creation (Morgan et al., 2013). With system-based views of value creation, such as with business ecosystems, value capture has to be seen in terms of the bigger picture (Amit \& Han, 2017). For instance, from an ecology perspective, value capture can involve complex coordination across multiple firms (Bharadwaj, El Sawy, Pavlou, \& Venkatraman, 2013). Value capture can also involve significant sacrifices, such as upfront investments or continuous efforts to ensure ecosystem participation (West \& Wood, 2013).

Typically, the value capture strategy comprises the revenue model, the cost structure, the relationships with third parties and customers, and nonmonetary gains such as reputation and tacit knowledge (Amit \& Zott, 2001; Morgan et al., 2013). Pricing and bundling strategies should be added to this list (Study V: Pricing, Study VI: Bundling and versioning) because they regulate the commitments and payment flows between firms, customers, and partners (Iveroth et al., 2013). 
In reality, firms face many challenges in capturing value, which is particularly true in the realm of open source (West, 2007). In addition to more general difficulties in pricing software, such as high upfront costs for development and the difficulty of predicting support intensity (Study V: Pricing), compared to proprietary software, the appropriability of OSS is limited. This is because the source code is usually available as a public good, which is at odds with traditional frameworks for value capture that are based on ownership and control (Morgan et al., 2013).

Seen as an opportunity, value capture within ecosystems may enable firms to reduce the costs of development and maintenance by employing the existing expertise and knowledge among complementors and partners (Morgan et al., 2013). Seen as a challenge, value capture may become more difficult around platforms that are affected by reputation loss (see Section 12.1.5). Likewise, seen as an opportunity, ecosystems may provide firms with the opportunity to reap gains through potential network effects. Seen as a challenge, firms may fail to capture the value of their innovations due to the briskness of imitators.

\subsubsection{Community-based value creation (collective innovation, community engagement, and value capture)}

System-based views on value creation, such as ecology perspectives, consider multiple loci and targets of value creation (Amit \& Han, 2017). This holistic way of thinking pays heed to the bigger picture in which the valuecreating logics are embedded (Olve et al., 2013).

In a broad sense, the framework that I propose suggests that the loci of community-based value creation reside in the ecosystem, the community, and the firm. In a narrower sense, the loci of value creation are rooted in value capture strategies (such as the aforementioned price model configurations, and relationships with third parties and customers), community engagement, and collective innovation. Bearing in mind a more unitary conception of value, the proposed framework suggests viewing value in ecosystems as an emergent property that is fed and governed by collective innovation, community engagement, and firms' ability to capture value.

Ideas related to coopetition and value co-creation are implicit in the proposed framework. As mentioned in Section 2.2.6, coopetition emphasises the strategic interdependence among actors (Dagnino, 2009; Duc et al., 2017). Actors may collaborate in collective innovation processes, but at the same time compete for the same customer segments. However, in contrast to the concept of coopetition, which somewhat neglects the diversity of configurations, motivations, strategies, and interests that drive 
the value creation logics, the proposed framework offers a holistic and system-based view of value creation in ecosystems.

The proposed framework also partially captures ideas implicit in value co-creation. In a broad sense, in co-creation, the consumers and users are viewed as creative agents in the production process (Kozinets et al., 2008; Prahalad \& Ramaswamy, 2004; Zwass, 2010). Especially in the realm of open source, users are involved in the production process (or they actively support the community in other ways), which makes them co-creators of value.

Figure 47 shows the final framework for analysing community-based value creation in business ecosystems. This framework may be useful for analysing value creation in contexts of firm-community interaction. According to Havemo's (2018) typology of visualisation logics, Figure 47 highlights the fundamental relationships of community-based value creation in business ecosystems; however, it neglects the processes and transactions that lead to value creation. Future research could focus on developing models that emphasise the processes and transactions that occur between these three fundamental domains (Havemo, 2018). 


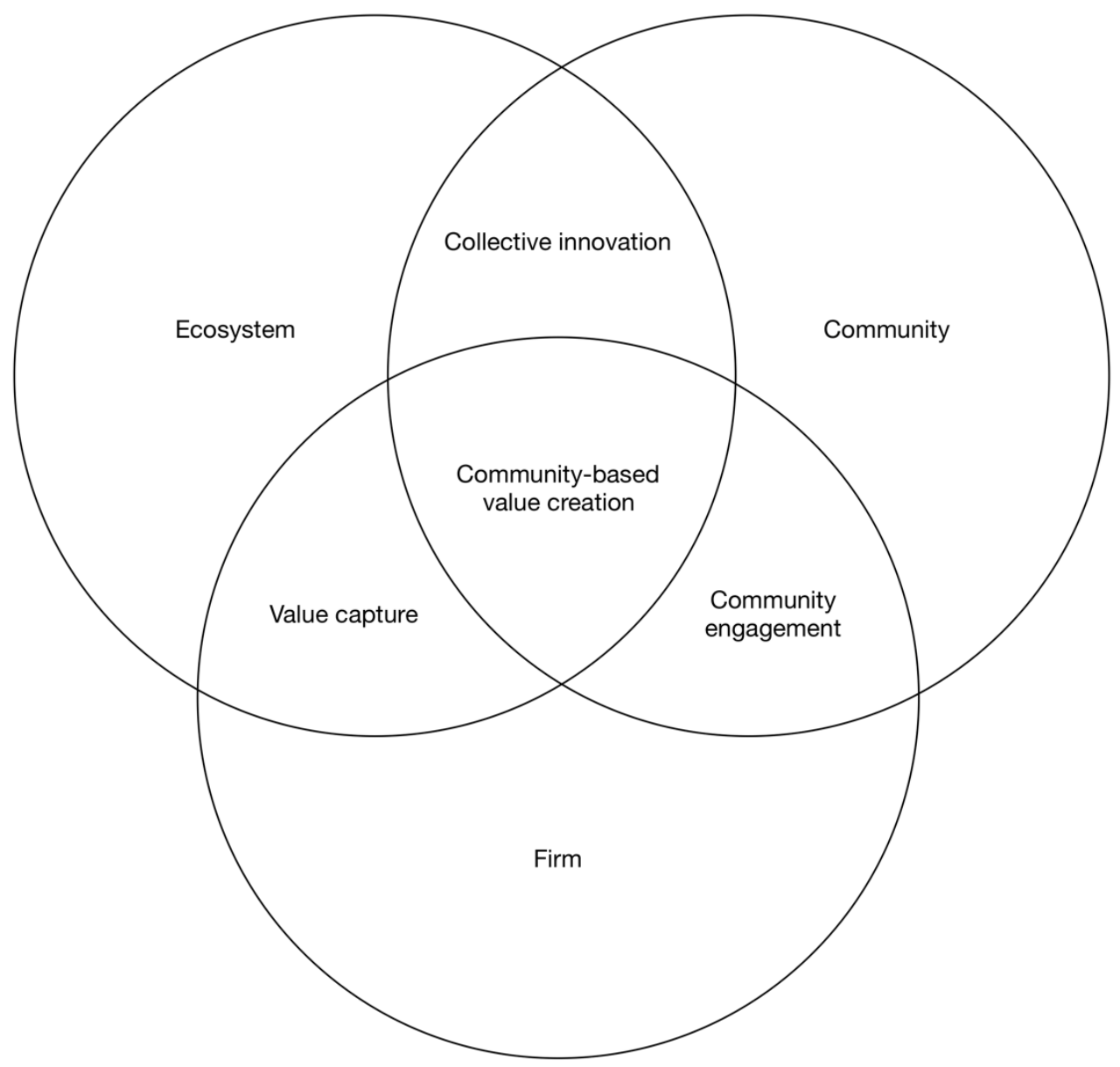

Figure 47: A framework for analysing community-based value creation in business ecosystems.

\subsubsection{Applying the framework to the Joomla case}

This section applies the framework presented in the previous section to the Joomla case. The intention is to illustrate briefly how the framework can be applied, rather than to provide a comprehensive evaluation.

\subsubsection{Ecosystem}

In a nutshell, the Joomla ecosystem consists of a variety of actors, including diverse communities, users, and commercial actors. Partly, these have been discussed in Study I (Stakeholders). For instance, there are different communities that produce software which Joomla builds upon (e.g., PHP, database technologies, web servers). There are communities that produce competing platforms (most notably, WordPress and Drupal, but also others). The ecosystem is populated by trend-setters, such as the big Internet giants 
(i.e., Google, Facebook) and regulatory bodies that can affect web development in general (e.g., standard-setters). The ecosystem further includes the millions of Joomla users. Most of them are likely passive users. This means that they use the software to build their websites, but only a fraction of them may actively involve themselves in community activities. Furthermore, the ecosystem is populated by a variety of commercial actors (e.g., small firms, freelancers) that offer Joomla-related products and services that are of relevance to others in the ecosystem.

\subsubsection{Community}

The Joomla community can be understood as the set of people who are involved in the activities around the Joomla project. The range of activities can be broad and diverse (cf. Section 2.2.3 and Chapter 4). In short, people in the Joomla community band together around a common purpose (e.g., collaborative production, mutual support) and shared values, such as openness and togetherness (cf. Study III: Collective identities). The Joomla community is populated by people from all over the world, with diverse motivations, skills, cultural backgrounds, and interests.

\subsubsection{Firm}

As stated in Section 5.3, the Joomla businesses were understood as the selfemployed people and (small) firms that run a business on the back of Joomla. More generally, these actors can be addressed via the domain of the firm ${ }^{\mathrm{LXV}}$. A Joomla business in this sense may provide all sorts of products and services in connection to the Joomla platform (e.g., web development, hosting, consulting, customisation, marketing, extensions, support and maintenance).

In line with the above-presented depiction of the firm (cf. Section 13.2), Joomla businesses are more characterised by diffuse and permeable boundaries. This is reflected in blurring boundaries between service providers and clients (cf. Section 12.1.2), blurring boundaries between private and professional lives (cf. Section 12.1.7), and in blurring boundaries between firms and the community (cf. Section 12.2).

In line with the depiction of the firm by Felin, Lakhani, and Tushman (2017), Joomla businesses leverage the knowledge and networks embedded in the community to extend their rationality; they utilise the community for sensing and signalling regarding trends, and for establishing a sense of identity and belonging (cf. Study IV: Economic incentives). In essence, firms

Lxvı Even though most of them are small firms. 
both benefit from and contribute to the Joomla project and its community (cf. Section 12.2).

\subsubsection{Collective innovation (ecosystem and community)}

The ecosystem around Joomla provides crucial resources to the community. This can include volunteers who involve themselves in community activities. While peripheral Joomla users engage in discussions and provide impulses and ideas, volunteers at the community's core have more influence over production-related, administrative, and managerial matters of the Joomla project. Firms support the community financially in order to secure the continuous operations of the Joomla project.

With collective innovation, the costs of production and maintenance of the Joomla CMS are distributed globally, to a volunteer workforce that is likely unknown to most users, which applies to open source settings more generally (Ågerfalk \& Fitzgerald, 2008). Joomla users and providers of complementary products and services depend on the innovativeness and productivity of this volunteer workforce. In turn the Joomla community depends on the ideas and skills of the people, firms, and organisations that populate the Joomla ecosystem.

While the Joomla community sources the skills of talented people worldwide, within the Joomla ecosystem, communities also compete for talented people and market share. As was mentioned earlier, particularly the segment of open source CMSs is affected by increased platform competition (cf. Study III: Collective identities). There is competition for both users and volunteers. From an ecology perspective, they both provide fundamental nutrients that feed the production processes and activities within the community. Taking even more distant areas of interaction into account (Westelius \& Lind, 2016), at the periphery of the Joomla ecosystem, one may also recognise competition from the vast number of open source communities that seek to attract the attention of interested, young, or talented people. This wider horizon may also comprise standard-setters, lawmakers and tax authorities (who may impact how goods and services can be traded), academics and business people debating open source, and device producers who make the equipment that Joomla runs on.

\subsubsection{Community engagement (firm and community)}

A considerable portion of this thesis was dedicated to exploring and explaining the ways in which community engagement and profit-oriented venturing are intertwined in the context of community-driven open source (cf. Study IV: Economic incentives, and Section 12.2). 
The gist of this discussion was that the Joomla community offers a variety of benefits (both operational and strategic) to the businesses that engage in community activities. For the Joomla businesses, the knowledge, skills, networks, and resources accessible through the Joomla community are a potential sources of value creation, innovation, and competitive advantage.

In turn, the Joomla community benefits in various ways from the involvement of the Joomla businesses (cf. Section 12.2.4). The Joomla businesses provide direction to the Joomla project and often take on important responsibilities and tasks. They infuse the community with business know-how and strategic thinking (Study III: Collective identities). They show perseverance in dealing with challenging tasks and provide feedback on the usability and performance of the Joomla CMS in professional contexts. Furthermore, the community benefits from the donations by the Joomla businesses, which help cover community-related expenses (e.g., for trademark fees and legal counselling). The Joomla businesses also facilitate the organisation of community events (e.g., through sponsorships enabling lower entry fees for conference participants).

The intersection of the community and firm emphasises both competitive and collaborative dynamics. While the relationships between Joomla businesses and the Joomla community can be of symbiotic character, they can also carry a potential for friction, such as exposure to competing interests and fluctuations in the continuity of community activities (cf. Section 12.1.6).

\subsubsection{Value capture (firm and ecosystem)}

Joomla businesses pursue diverse strategies in order to capture value. For instance, Study $\mathrm{V}$ (Pricing) shows how longer-term relationships with customers are facilitated via subscription plans. Furthermore, the empirical data show that a focus on customer value and reliable support facilitates positive customer experiences, which in turn entices customers to prolong their commitments. Related to that, Study VI (Bundling and versioning) shows how diverse sets of capabilities, competencies, resources, and differentiation criteria are creatively combined to create sets of product bundles that are intended to appeal to different customer segments.

With a system-based view of value creation, value capture strategies have to be seen in terms of the bigger picture. For Joomla businesses, value capture can involve significant sacrifices, such as upfront investments in development, the fostering of networks, and the development of a reputable presence in the community. Furthermore, value capture can involve the coordination among several suppliers, contractors, and partners. 
Value capture among Joomla businesses seems particularly impeded by the difficulties to predict the costs of development and support (cf. Paper V: Pricing). Value capture may also be affected by the popularity and image of the Joomla platform (cf. Section 12.1.5). For instance, extension providers rely on a high penetration rate of the Joomla platform in order to be able to sell their products and services to a large enough number of customers. Increased platform competition within the ecosystem may diminish the abilities of Joomla businesses to capture value based on Joomla-related products and services. In turn, a high penetration of the Joomla CMS may enable Joomla businesses to reap the benefits of network effects.

\subsubsection{Community-based value creation (collective innovation, community engagement, and value capture)}

System-based views on value creation consider multiple loci and targets of value creation (Amit \& Han, 2017). The framework that I propose provides a template for analysing how value is created for multiple such targets, including users, firms and their customers, communities, and societies at large, by considering collective innovation processes, firm-community interactions, and firms' ability to capture value.

The Joomla CMS has been referred to by interviewees as a robust and versatile tool for web publishing and application development. Users across the globe reap the benefit of being able to use this tool free of charge. They are able to access the source code, study it, and tweak it in whatever way they want to. Furthermore, they reap the benefit of being able to direct questions to people in the Joomla community when facing problems. As a side effect, they make themselves dependent upon a volunteer workforce whose intentions and goals may appear opaque at times.

Similarly, firms reap the benefit of having a robust and stable software platform that facilitates their work with clients. The costs of development for the Joomla CMS are distributed among volunteers across the globe (e.g., hobbyists and enthusiasts, students, business owners and firms, freelancers and entrepreneurs). The distributed costs of development may come to the benefit of firms' clients in the form of a faster time-to-market of their web solutions. While the ability to capture value enables Joomla businesses to sustain their value propositions to clients and partners, their ability of doing so also creates value for the entire Joomla project because it demonstrates and signals the viability of the Joomla CMS in professional contexts.

To firms, the Joomla ecosystem may provide an opportunity space in which profitable niches can be found, developed, and occupied. However, consistent with the overall purpose of this thesis, ecosystems are not only 
spaces of opportunities, they also pose challenges that firms need to overcome in order to be successful. For instance, the viability and profitability of niches are affected by trends, platform competition, community decisions, and evolving constellations of actors, which can increase uncertainty for firms. As argued in Section 12.1.2, community engagement and interaction with community peers is one way of dealing with such uncertainty. This could mean that, besides identity and a common purpose, also uncertainty may be a factor that partly explains why actors band together around a community, even if they sometimes may face each other as rivals in a competitive environment.

Finally, the interplay among the actors within the Joomla ecosystem leads to value creation for societies at large, all around the globe. The community preserves and protects the openness of the code and cultivates the knowledge that led to its creation. The community supports people in learning and in realising business opportunities, thereby facilitating productivity across the globe. By providing a sense of belonging, the community may in part facilitate the well-being and psychological health of community participants all around the globe. While speculative, all this may also facilitate the sense of social responsibility among community participants. Social responsibility is often implicit in both the interviews that I conducted and discussions on open source in the literature, but seldomly treated and spelled out in more explicit ways.

\subsubsection{A generic representation of community-based value creation utilising organismic metaphors}

As previously discussed in Section 13.1, communities can be conceived of as superorganisms. These were characterised as associations of large numbers of individual 'organisms' that behave as an organic whole. The above-presented framework for community-based value creation in business ecosystems (cf. Figure 47) can be transferred into a more generic form by featuring organismic metaphors. Making such a translation can be of use to the emerging research that utilises ecological and organismic metaphors to study the health and sustainability of peer production communities (Carillo, Marsan, et al., 2017). This can be achieved by substituting the terms 'community' and 'firm' in Figure 47 with the ecology-related terms 'superorganism' and 'individual organism'.

In further consequence, the terms 'collective innovation', 'community engagement', and 'value capture' in Figure 47 were replaced with equivalents that seemed appropriate from an ecology perspective. These are explained in the following. The resulting model is depicted in Figure 48. 
'Collective innovation' was substituted with the term 'impact'. To an individual organism (e.g., firms and volunteers), a superorganism (i.e., a community) may be a vehicle for extending its myopic field of vision, its area of activity, and the environmental impact that it aims for. Conversely, the ecosystem can impact on a superorganism in different ways, such as through trends, platform competition, and regulatory changes (Study I: Stakeholders; Study III: Collective identities).

'Community engagement' was substituted with the term 'leverage'. To an individual organism (e.g., firms and volunteers), a superorganism (i.e., a community) may provide leverage for realising its individual goals (Study IV: Economic incentives). A superorganism may facilitate the protection and care of associated individual organisms (Study III: Collective identities, Study IV: Economic incentives). Conversely, a superorganism may leverage the abilities, resources, and skills of individual organisms (e.g., firms and volunteers) for increasing environmental impact and dealing with turbulent times.

'Value capture' was substituted with the term 'nutrients'. To an individual organism (e.g., firms and volunteers), the ecosystem may provide the nutrients that are essential for prosperity and survival. For instance, for firms, contractual relationships with customers could be such nutrients (Study V: Pricing, Study VI: Bundling and versioning). Conversely, individual organisms may provide nutrients to others in the ecosystem, such as products, services, and resources.

'Community-based value creation' was substituted with the term 'health'. In ecology speak, a conducive interplay between ecosystem, superorganisms, and individual organisms may be necessary in order to facilitate the health, sustainability, and prosperity of an ecosystem, and its population of superorganisms and individual organisms. Perhaps, the model in Figure 48 can aid future research in developing theoretical foundations for studying the complex interactions in and around peer production communities by the use of organismic metaphors (Carillo, Marsan, et al., 2017). 


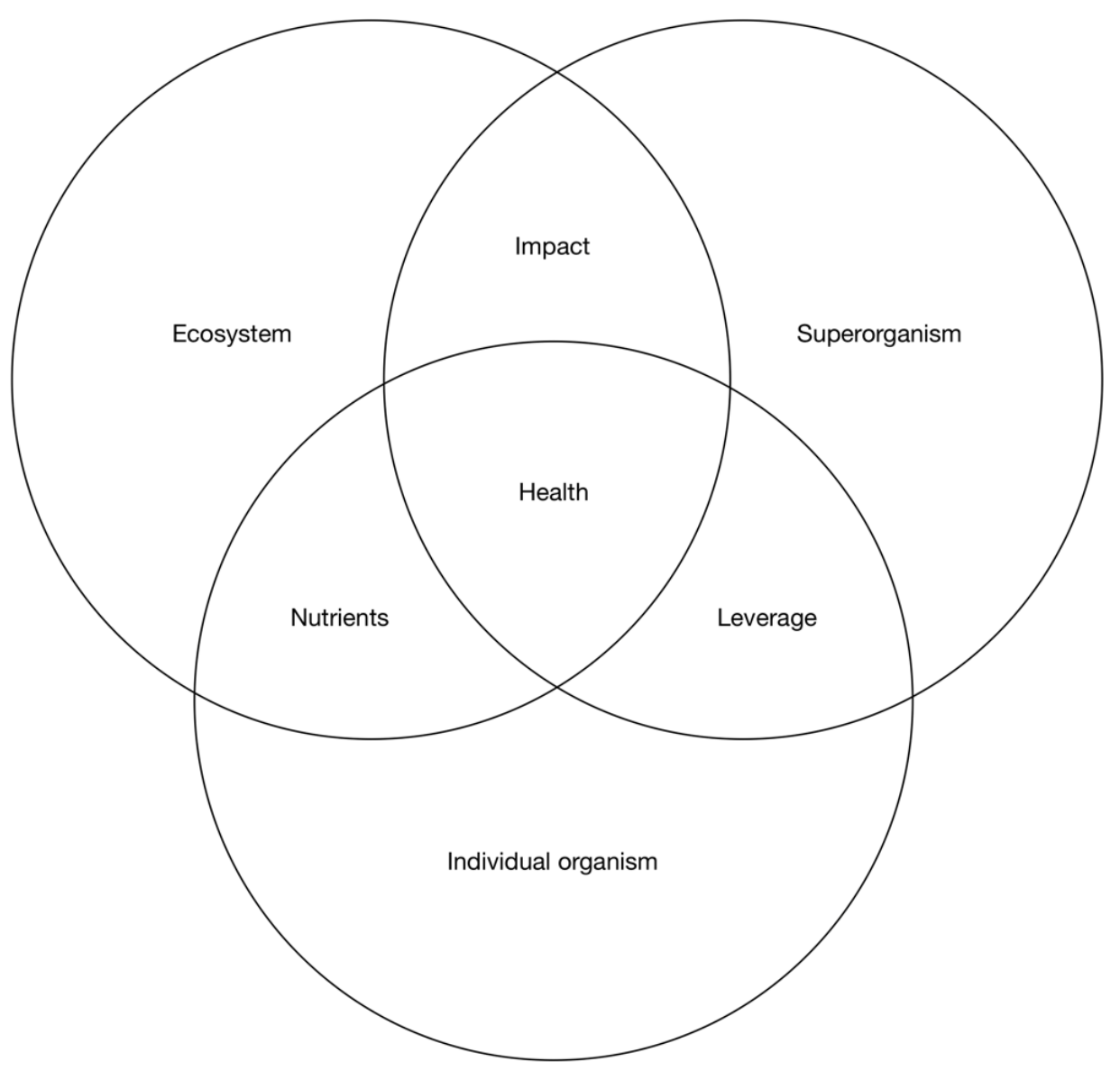

Figure 48: A generic representation of community-based value creation utilising organismic metaphors.

\subsection{A model for classifying community types}

After having studied Joomla and the relevant literature, it became clearer that community-driven open source could be one of four different types of open source projects. I found that existing classifications of community types are somewhat narrow. For instance, the dichotomy of single-vendor versus multi-vendor open source (Riehle, 2012; Skerrett, 2011) neglects community-driven open source. The dichotomy of community versus commercial open source (Capra \& Wasserman, 2008) neglects that there can be commercial activities around community-driven open source project. The idea emerged to integrate and revamp known community types into a slightly different, unified whole. The result led to a four-way classification of open source communities based on the degree of firm control and democratisation in community governance. 
Figure 49 depicts this four-way distinction along with the resulting community types: clan-driven open source, community-driven open source, firm-driven open source, and syndicate-driven open source. The dotted lines in this diagram symbolise that the boundaries between these four categories are permeable.

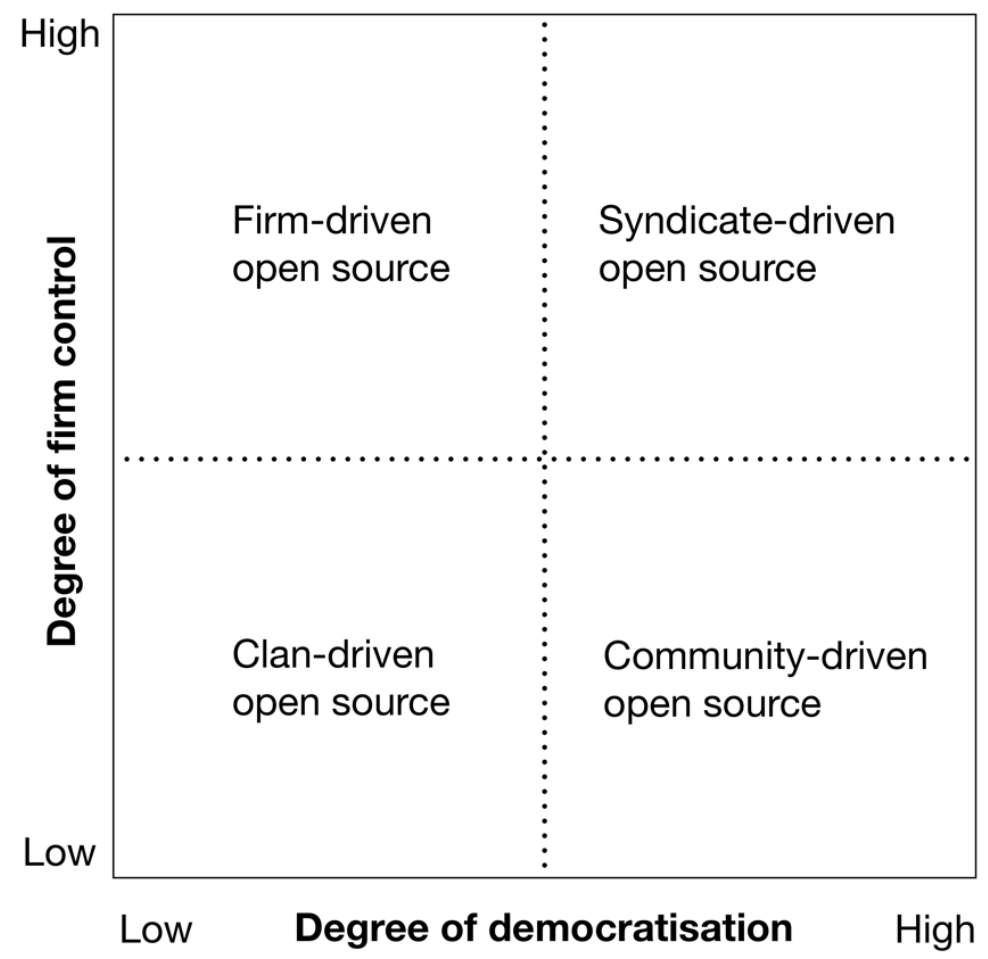

Figure 49: A four-way classification of open source communities based on the degree of firm control and democratisation in community governance.

In a broad sense, this model contributes to the literature stream on open source community governance (Blekh, 2015; Capra, Francalanci, \& Merlo, 2008; De Laat, 2007; De Noni et al., 2011; Jensen et al., 2010; Markus, 2007; Matei \& Irimia, 2014; O'Mahony, 2007; O'Mahony \& Ferraro, 2007; Sagers et al., 2004; Schaarschmidt, Bertram, \& von Kortzfleisch, 2011).

In a narrower sense, the proposed model provides an alternative view to Schaarschmidt, Walsh, and von Kortzfleisch (2015) who differentiate between firm-initiated versus community-initiated open source projects, and open source projects with one participating firm and multiple participating firms. However, as will be argued, their differentiation is problematic, too. 
For instance, their model classifies open source community types based on whether they are initiated by firms or communities. However, open source projects can also be initiated by single individuals and small clan-like groups (Skerrett, 2011).

Many (if not the majority) of important open source projects have been initiated by single individuals and clan-like groups of people, rather than by firms or communities. Furthermore, the model by Schaarschmidt, Walsh, and von Kortzfleisch (2015) somewhat neglects that community governance and community types can change over time. For instance, even if an open source project is initiated by a firm, it can transition into a community-driven open source project over time $\mathrm{LXVII}^{\mathrm{LX}}$. The Joomla case is one example of such a transition (see Section 4.1).

Schaarschmidt, Walsh, and von Kortzfleisch (2015) classify the Linux project as a multi-vendor project that was initiated by a community. However, it could be argued that in the very beginning, the Linux project was initiated by single individuals and clan-like groups of people (although over time it involved the contributions of massive numbers of people). The Linux project transitioned into a community-driven open source project over time, and eventually, into a project that is sponsored by an entire industry.

A further problem with the model by Schaarschmidt, Walsh, and von Kortzfleisch (2015) is their differentiation into open source projects with one participating firm versus multiple participating firms. This differentiation somewhat suggests that there cannot be multiple participating firms around, what they term, single-vendor open source projects. However, considering an example, there may be hundreds, if not thousands, of participating firms around the WordPress project, although it is mainly governed, steered, and controlled by one single firm.

In order to offer an alternative view, this thesis proposes a four-way distinction of open source communities based on the degree of firm control and democratisation in community governance. The following discusses the resulting four community types, which are clan-driven open source, community-driven open source, firm-driven open source, and syndicatedriven open source.

In clan-driven open source, the degree of firm control and democratisation in community governance is low. Clan-driven open source is typically governed in more informal ways by small groups and charismatic leaders. As mentioned earlier in this thesis, a clan is understood as a (small) "group of people with a strong common interest" ${ }^{173}$. Such small and socially

LXVII Connected to that, O'Mahony and Ferraro (2007) provide insights into how community governance can evolve and change over time. 
cohesive groups rely upon informal and value-based connections for maintaining control and productivity (Ouchi, 1979). The frequently-cited benevolent dictator model (Shah, 2006) and the lieutenant model (Androutsellis-Theotokis et al., 2011) can be seen as forms of clan-driven open source. In particular, the early days of the Linux project could be seen as an example for clan-driven open source. However, over time, the Linux project evolved into a syndicate-driven open source project, which will be explained below.

In community-driven open source, the degree of firm control in community governance is low, and the degree of democratisation is high. However, low degrees of firm control do not preclude the possibility of firm influence in governance and production matters. The Joomla case, treated in this thesis, is an example of community-driven open source. The Joomla project was created after forking from a firm-driven open source project (Mambo). While there can be strong connections between community engagement and profit-oriented venturing in the context of communitydriven open source (as this thesis shows), in community-driven open source, no single commercial actor has a prerogative in governance matters. Rather, a pronounced sense of community and togetherness may characterise this community type (Study III: Collective identities).

In firm-driven open source, the degree of firm control in community governance is high, and the degree of democratisation is low. Typically, there is a single firm that acts as a patron of the open source project. This firm can be regarded as the main commercial beneficiary in the ecosystem around the open source project (although there can be diverse commercial activities by other firms in the ecosystems around such open source projects). This community type is equivalent to what Riehle (2012) refers to as single-vendor commercial open source. WordPress and MySQL are examples of firm-driven open source.

In syndicate-driven open source, the degree of firm control and democratisation in community governance is high. A syndicate refers to a group of firms that band together in order to "promote a common interest"174 and to "share the cost of a particular business operation for which a large amount of money is needed"175. This community type is equivalent to what Schaarschmidt et al. (2011) refer to as multi-vendor open source. Syndicatedriven open source is mainly driven and funded by a broader range of firms (often large corporations). Syndicate-driven open source has to pay heed to a variety of stakeholders and corporate interests in community governance. Democratic participation among firms is typically ensured via boards, committees, and other governing bodies. Today, the Linux project and the Apache Software Foundation are examples of syndicate-driven open source. 
As discussed in Section 2.1.6, over time, the Linux project has become the collaborative pursuit of an entire industry, as its list of members and sponsors shows. In retrospect, even the SHARE user group, created by industry leaders in 1955 (discussed in Section 2.1) could qualify as syndicate-driven open source (although, the term 'open source' did not exist back then).

\subsection{Governance and strategic open source}

This section briefly discusses the connections between community governance and the notion of strategic open source. Morgan and Finnegan, (2014, p. 226) define strategic open source as the "use of open source software and processes in a manner that leverages both the peer-produced and open innovation qualities of such software and processes in order to create business value". They further argue that "the governance process for strategic open source is very much a top-down process" (Morgan \& Finnegan, 2014, p. 235).

However, there may be a need for differentiation. The view that governance in open source settings is a top-down process seems to be difficult to square with the findings of this thesis. Governance may be a largely top-down process within certain community types (e.g., with firmdriven open source). However, this thesis suggests that governance in the context of community-driven open source is an interactive process between business owners, community members, and other interest groups such as users and third-party developers (Study I: Stakeholders, Study II: Governance framework, Study III: Collective identities). In the context of communitydriven open source, it seems more reasonable to view governance as an ongoing process of negotiation amongst stakeholders, rather than as a topdown process (as may be the case with other community types).

Future research could study the similarities and differences in governance forms and configurations (cf. Study II: Governance framework) between the four community types described in the previous section (i.e., clan-driven open source, community-driven open source, firm-driven open source, and syndicate-driven open source).

\subsection{Spiritual well-being, sense of belonging, and psychological health}

The empirical data suggest that the community provides a space that facilitates the spiritual well-being, sense of belonging, and hence the psychological health and productivity of community participants (Study IV: Economic incentives). This is important due to the particular work realities of self-employed people and small-business owners in this open source 
setting. People often work as 'lonesome warriors', physically isolated from their colleagues and peers, with detrimental effects on their well-being and, potentially, on their productivity as well.

However, as the findings suggest (Study III: Collective identities, Study IV: Economic incentives), the community can partly compensate for the lack of social support that people face in their own surroundings. By providing a space for socialising with like-minded others, the community, in part, makes up for detrimental work realities. Social relations and care are preconditions for human health and productivity (Westelius et al., 2013). Therefore, by facilitating the well-being of community participants, the community may also indirectly facilitate their productivity.

It is surprising to see that issues around spiritual well-being, a sense of belonging, and psychological health are somewhat neglected in the open source literature. At least, one would expect that the effects of the particular work realities that people face would feature more in the literature; for instance, in the literature on motivations for community engagement (Bagozzi \& Dholakia, 2006; Hars \& Ou, 2002; Mair et al., 2015; Oreg \& Nov, 2008; Shah, 2006; von Krogh et al., 2012). Although there are studies that touch upon an individual sense of belonging, identification, and sense of community as important factors encouraging community participation (Lakhani \& Wolf, 2005; von Krogh, 2003; Ye \& Kishida, 2003), often these studies do not treat issues around spiritual well-being, a sense of belonging, or psychological health in a more comprehensive manner. Furthermore, these studies usually neglect the role and effects of people's work realities.

There is a need for more research exploring the factors that facilitate community participants' spiritual well-being, sense of belonging, and psychological health, along with the related effects on individual and organisational productivity (at both a firm and a community level).

\subsection{Intersubjective trust}

The discussion in Section 12.2.5 picked up on trust in relation to commercial actors' dependence on the community's software product(s). The core of this discussion concerned the question of how commercial actors deal with the uncertainties stemming from the voluntary nature of the open source project. More to the point, the question is: how can commercial actors trust in the community's ability to deal with critical issues (e.g., vulnerabilities, bugs) in a timely and adequate manner, given the implications of volunteerism (e.g., lack of corporate control, lack of monetary compensation, fluctuations in the continuity of community activity)? 
Trust is complex, multidimensional, and carries a variety of meanings (Castaldo, 2003); however, there is an emerging consensus that trust can generally be defined as the "willingness to be vulnerable based on the trustor's positive expectations of the trustee" (Pytlik Zillig \& Kimbrough, 2016, p. 18). The study of trust typically involves uncertainties, risk, vulnerability, past experiences, intentions, and learning (e.g., about trustworthiness) (Pytlik Zillig \& Kimbrough, 2016).

From this point of view, the commercial actors in this open source setting can be seen as the trustors, and the people in the core development teams as trustees. In part, commercial actors may learn from past experience that they can trust in the community's ability to deal with critical issues. However, in addition, the findings suggest that a form of intersubjective trust may alleviate commercial actors' perceptions of being dependent on the open source project (Study IV: Economic incentives). The argument is that commercial actors can be more confident that the community will deal with critical issues when they know that people in the core development teams have a business connected to the open source project themselves. This form of intersubjective trust emerges as a consequence of the intertwining of community engagement and profit-oriented venturing. In a sense, it resembles the experience of shared fate (i.e., the perception of being in the same boat altogether).

From a business ecology perspective, this may show that, in the absence of monetary compensation and formal contracts, the experience of shared fate may help overcome problems of trust and confidence in a large and confusingly complex system of interacting 'organisms'.

This finding may also add to the literature stream on intersubjective trust whose diversity and multifaceted nature still remains to be explored to a fuller extent (Frederiksen, 2012). In particular, how trust overcomes uncertainty is still being debated (Frederiksen, 2014). Shared fate may be one aspect to consider in this debate. The particular form of intersubjective trust discussed in this thesis seems to connect to Frederiksen's (2014) phenomenological view of trust. He considers trust to be an alternative way of perceiving managerial uncertainty, rather than a way of reducing uncertainty through risk calculation (as contemporary trust research tends to do). In his view, having concerns about trust already means to have entered a state of risk, as opposed to a state of trusting. In his view, trust is maintained as long as there is no need to reflexively consider the trustworthiness of others, otherwise trust is lost. Frederiksen (2014) argues that trust may not require a translation of experience into decision-grade knowledge; rather, it is comparable to a phenomenological attitude that is informed by collectively shared experiences. In a sense, this view of trust corresponds to 
fate because fate is a contiguous concept in which the emotional dimension dominates and the cognitive dimension is virtually absent (Castaldo, 2003).

Arguing with Frederiksen (2014), based on past experience and the familiarity of risk situations, commercial actors (the trustors) may assess, in a more intuitive fashion, the incentives of people in the core development teams (the trustees) to take their interests into account. Trust in this case thus rests on the taken-for-granted assumption that the trustees are expected to suffer the same consequences if critical issues are overlooked. In light of the challenges connected with being economically dependent on a community of volunteers (see Section 12.1.6), this sense of shared fate may bestow serenity and faith upon the commercial actors within the ecosystem.

Although there have been studies on trust in open source settings, they have mainly focused on within-group perspectives on trust in development teams (De Laat, 2010; Gallivan, 2001; Lane, van der Vyver, \& Basnet, 2004; Ho \& Richardson, 2013; Stewart \& Gosain, 2001). Furthermore, the results of these studies are somewhat inconclusive. To some extent, they regard interpersonal trust as an antecedent to the effectiveness of open source communities (Lane, van der Vyver, Basnet, \& Howard, 2004). In other views the need for trust is obviated almost entirely. For instance, Gallivan (2001) argues that various control mechanisms in open source settings can ensure effective performance in the absence of trust. He conjectures that opens source communities may rely on trust only as a last resort when effective controls are not available or when there is a risk that controls undermine the working relationships among people in the community.

However, while formal rules and regulations are often necessary in order to manage the complexity and size of open source projects (De Laat, 2010), an open source project may not be able to function without trust as a glue to hold the community together (Stewart \& Gosain, 2001). Controls may never fully substitute for the need for trust (De Laat, 2010). In fact, too little trust may undermine people's willingness to join the community or to continue with their engagement (Ho \& Richardson, 2013). Or, they might participate less frequently (Stewart \& Gosain, 2001), all of which can harm open source projects because the level of community activity is a key determinant of their success and survival (Tsoy \& Staples, 2018). This in turn highlights the importance of trust. A cultivation of cooperative norms may engender trust and positively affect people's intention to continue with their community engagement (Ho \& Richardson, 2013). For participants in open source communities, the absence of corporate control and monetary compensation can even be factors that engender trust (Lane, van der Vyver, Basnet, et al., 2004). Given its historical roots and its evolution (see Section 4.1 ), the Joomla community is probably a prime example of distrust in 
centralised types of corporate control in community governance. Striking a balance between trust and control in community governance seems to be key.

From a business and strategy perspective, trust is important because it may decrease transaction costs, increase the efficiency of outcomes, and create business benefits such as loyalty among customers, suppliers, and users (Corallo, Passiante, \& Prencipe, 2007; Ebadazadeh Semnani \& Nord, 2017). Connected to that, this thesis elaborates upon one particular form of intersubjective trust that may facilitate bonds and loyalty between firms and communities. Future research could explore this particular form of trust in more depth. Furthermore, future research could study other forms of trust that facilitate bonds and loyalty in contexts of firm-community interaction. For instance, alongside intersubjective trust, this could include the role of systemic trust in the community as a whole, or trust in specific functions within the community.

More generally, it appears that there have been few attempts to study trust in contexts of business ecosystems or firm-community interaction. As was previously observed, the evolving dynamics of trust in open source settings are not well understood (Lane, van der Vyver, \& Basnet, 2004; Lane, van der Vyver, Basnet, et al., 2004). However, with some notable exceptions (De Laat, 2010), only few studies seem to have pursued this particular thread in the meantime,

All in all, there seems to be both an opportunity and a need to further the study of trust in the realm of business ecosystems and firm-community interaction. One interesting question is how trust affects the viability of an ecosystem in which firm-community interaction is embedded.

\subsection{Community-based self-identity versus entrepreneurial self- identity}

This section connects to Mollick's (2016) discussion on, what he terms, the transitioning of open source developers from a community-based selfidentity to an entrepreneurial self-identity when commercialising an open source solution. Mollick's (2016) work suggests that differences in individuals' propensity to commercialise an open source solution can be explained by the strength of their community-based self-identity ${ }^{\text {LXVIII }}$. His argument is that individuals are less likely to commercialise a solution when they have a strong community-based self-identity (referred to as the identity of an open source developer in his paper), which he assumes to be

LXVIII His conception of self-identity is based on Terry, Hogg, and White (1999), who conceive of it as the significance of behavioural and social aspects to a person's self-conception. 
inconsistent with an entrepreneurial identity. Furthermore, he argues that individuals transition from a community-based self-identity to a commercial/entrepreneurial identity when they commercialise a solution. However, this suggests that an individual's community-based self-identity as an open source developer would be somehow weakened or become less pronounced as a consequence of this transition, which seems to be difficult to square with the findings of this thesis.

Rather, the empirical data in this thesis suggest that individuals who run a business based on the community's software product(s) do have a strong sense of community, and that they strongly subscribe to the values of open source. The empirical data suggest that being part of the community and adhering to open source ways of thinking plays a significant role in participants' conceptions of who they are (Study III: Collective identities, Study IV: Economic incentives).

While Mollick (2016, p. 1473) concludes that there "appears to be a large gap between conceptualising oneself as an open source developer and viewing oneself as a money-making entrepreneur", the empirical data in this thesis suggest that participants' conceptions of professional identity and their conception of community membership can be closely related and interdependent. This could mean that viewing oneself as an open source developer and as a business owner/entrepreneur go together rather well. Different arguments in the literature may support this claim.

For instance, the private-collective innovation model suggests tight connections between developers' activities around open source projects and their ability to appropriate returns from running open-source-based business models (von Hippel \& von Krogh, 2003). As discussed in Study IV (Economic incentives), there are a variety of (indirect) economic benefits associated with the attitudes and behaviours that are rooted in what can be broadly referred to as open source ideology (e.g., sharing practices, helping behaviour, openness, collaboration, fairness, learning). Open source approaches and proprietary approaches are often mixed, which is particularly valuable to entrepreneurs (Fosfuri, Giarratana, \& Luzzi, 2008). This mixing of open source and proprietary approaches suggests a blurring of the distinction between community and commercial/entrepreneurial activities. In a similar fashion, the boundaries between firms and communities in open source settings are regarded as weak (Grand, von Krogh, Leonard, \& Swap, 2004). This is accompanied by blurred boundaries between private and professional lives (see Section 12.1.7), which, to some degree, suggests close connections between community values and professional values. 
Furthermore, the open source movement has built not only on a confluence of hackerdom and enthusiasm, but also on professionalism, competence, and commercial interests (West \& Gallagher, 2006b). The historical roots of open source and its evolution corroborate this (see Section 2.1). Moreover, for entrepreneurs and business owners, the resources embedded in open source communities may be more easily accessible when community peers can infer compatibility with community values and norms (Sadowski, Sadowski-Rasters, \& Duysters, 2008).

One problem with Mollick's (2016) study may be his conception of the identity of an open source developer, which mainly emphasises traits of hackerdom and the 'free work' that open source developers do. However, these stereotypes of open source are also contested (Carillo \& Okoli, 2008).

As my empirical data show, even when participants are money-making business owners/entrepreneurs, they still do a lot of 'free' community work. An identity as a hacker generally refers to attitudes related to creative problem-solving, helping, and sharing behaviour (Lakhani \& Wolf, 2005). As this thesis suggests, these attributes are crucial for people involved in commercial activities around an open source project (Study IV: Economic incentives).

All in all, Mollick's (2016) study remains vague about what exactly it is that changes when individuals allegedly move from the identity of an open source developer to that of an entrepreneur. The results of this thesis suggest that more theoretical refinement may be needed in studying the process of commercialising an open source solution. As this thesis suggests, both identities (of an open source developer and of a business owner/entrepreneur) may coexist in a mutually supportive way.

\subsection{Value-based, strategic, and ecology perspectives on open source}

More broadly, this thesis also contributes to the literature stream on open source that investigates the role of communities in firms' ability to create value and competitive advantage (Carillo, Huff, et al., 2017; Morgan et al., 2013; Morgan \& Finnegan, 2014). As mentioned previously, there is a lack of theoretical understanding about firm-community interaction (Carillo, Marsan, et al., 2017; Mollick, 2016). Connected to this, this thesis shows that there are demonstrable effects of reinforcement, complementarity, synergy, and reciprocity in the intertwining of volunteer community engagement and profit-oriented venturing (cf. Section 12.2). By showing that this intertwining can be strong in empirical cases where commercial activities are often implicitly assumed to be absent (Capra, Francalanci, 
Merlo, \& Lamastra, 2009), this thesis provides a more nuanced view of firm involvement in the context of open source.

Morgan and Finnegan (2014) conjecture that one reason for the lack of studies on value creation and value capture in the realm of open source is that dominant views on value creation have mainly focused on the value created for customers rather than alternative targets for value creation, such as users, communities, and society at large. The findings of this thesis emphasise the importance of such alternative targets for value creation. By considering such alternative targets, this thesis integrates collective innovation, community engagement, and value capture into a unified model of community-based value creation in business ecosystems (see Section 13.2). Having done so, it responds to calls for more research on how the value-creating logics of firm-community interactions are embedded in the bigger picture within which they occur (Daniel \& Stewart, 2016; Morgan \& Finnegan, 2014).

Moreover, studies on open source have tended to be developer-centric (see Section 2.2.3), which might be another reason for a lack of studies on firm involvement in the realm of open source (Linåker et al., 2016). However, the topic of firm-community interaction has increasingly become of strategic relevance to organisations (Carillo, Marsan, et al., 2017). Connected to this, this thesis shows, from an ecology perspective, how the diversity of actors and activities around open source projects contribute to value creation within an ecosystem. By widening the scope beyond the confines of software development, this thesis does justice to the multiformity and diversity of the open source phenomenon.

While in a broad sense, this thesis connects with the literature on ecology perspectives in the management fields, which emphasise the social nature of business ecosystems (Iansiti \& Levien, 2004; Moore, 2006; Olve et al., 2013; Westelius \& Lind, 2016), in a narrower sense, this thesis also connects with the nascent literature stream on ecology perspectives in the context of open source (Duc et al., 2017; Teixeira et al., 2016). Studies on coopetition in ecosystems are generally scarce (Bengtsson \& Kock, 2014; Linåker et al., 2016), which may explain the lack of understanding of value creation within ecosystems (Teixeira et al., 2016).

As previously mentioned in Section 2.2.6, coopetition in an ecosystem can carry a potential for friction stemming from differing needs (Valença et al., 2014), conflicting values (Jansen et al., 2009), and incongruent interests among actors (Duc et al., 2017). This means that business ecosystems are not only spaces of opportunity, they may also pose a variety of challenges to participating firms. In order to allow for a more balanced assessment of firm participation in ecosystems, research should pay attention to both the 
opportunities and challenges that firms face (Linåker et al., 2016). In order to overcome the one-sided nature of the discussions of opportunities in the literature, this thesis contributes with an empirical examination and discussion of the challenges that firms face in creating value within ecosystems, based on community interaction. In addition, it shows how commercial actors cope with these challenges. In total, nine factors were identified around which challenges revolve (see Section 12.1). Based on these factors and the domains into which they cluster (i.e., ecosystem, community, firm), a framework for analysing community-based value creation in business ecosystems was developed (see Section 13.2). Furthermore, the concept of superorganisms was suggested for analysing interactions and dependencies among constellations of communities in ecosystems (see Section 13.1).

As the findings suggest, the firm level benefits of community participation not only accrue from direct engagement in the breadth of activities in open source communities, such as learning benefits and support (Study IV: Economic incentives) but they also emerge as a consequence of the collective interaction within an ecosystem and the intertwining of volunteer community engagement and profit-oriented venturing. Open source communities could be seen as hotbeds for cultivating such collective interaction, through which valuable resources emerge and evolve (e.g., both material and immaterial assets) (Christian, 2015; Kozinets et al., 2008; O'Reilly, 1999; von Hippel, 2005).

From an ecology perspective, attention is shifted towards the emergent qualities of a system. For instance, drawing on Daniel and Stewart (2016), effective knowledge exchange could be seen as an emergent quality of interactive dialogue. In a similar fashion, the different aspects discussed in this thesis could be interpreted as emergent qualities of an ecosystem, such as the sense of belonging and feelings of togetherness, intersubjective trust, ethical conduct, and learning. This has also importance for the dynamic properties of an ecosystem. Members' shared history - in this community or others - may, for good or worse, be an even stronger determinant of its future than it is in traditional firms, since coordination is largely voluntary and relies more on informal processes and less on formalised governance.

As this thesis suggests, emerging qualities can facilitate the coping with a challenging environment. For instance, intersubjective trust facilitates commercial actors' confidence in light of the uncertainties that stem from the voluntary nature of the open source project (see Section 13.6). Feelings of togetherness and a sense of belonging, which emerge as a consequence of the interaction and bonding within the community, can make up for the detrimental effects of individual work realities (see Section 13.5). And, 
interaction in the community enables more purposeful learning (see Section 12.2.5), which can reduce the time-to-market of solutions that are provided by commercial actors.

From this point of view, emergent qualities facilitate the productivity of ecosystems in both direct and indirect ways. They may spawn important incentives that encourage participation in ecosystems and communities, which in turn may facilitate their viability. Future research could study the connections between the emergent qualities of ecosystems and the related effects on productivity at different levels of analysis (e.g., ecosystem, community, firm). Future research may also reveal other types of challenges in ecosystems and novel ways in which firms cope with them. This research avenue may further the understanding of suitable organisational response strategies for developing environmental congruence, which is a determinant of organisational survival and success (Carillo, Marsan, et al., 2017). 


\section{Conclusions}

Having adopted a business ecology perspective, this thesis pursued two overarching themes. The first concerned the challenges faced by firms in commercialising community-driven OSS, in light of the diverse goals and interests of the various players, and the conditions and restrictions imposed by the environment. In summary, the findings show that these challenges revolve around nine distinct factors, which roughly cluster into three domains: the ecosystem, the community, and the firm (see Section 12.1).

Challenges relating to the global operating environment, the pace of change, and the cannibalisation of ideas roughly belong to the domain of the ecosystem. Challenges relating to platform policy, platform image, and the voluntary nature of the open source project roughly belong to the domain of the community. And finally, challenges relating to the blurring of boundaries between private and professional lives, the difficulty of estimating costs, and firm dependencies roughly belong to the domain of the firm.

The second theme concerned firm-community interaction and explored the ways in which community engagement and profit-oriented venturing are intertwined in the context of community-driven open source. This intertwining was explored by focusing on four aspects of intertwining that are theorised in the literature: reinforcement, complementarity, synergy, and reciprocity. The findings reveal demonstrable effects of all four factors in the intertwining of volunteer community engagement and profit-oriented venturing (see Section 12.2). By showing that such intertwining can be strong in empirical cases where commercial activities are often implicitly assumed to be absent, this thesis provides a more nuanced understanding of firm involvement in the realm of open source.

Drawing on the findings, a number of theoretical implications were discussed. Section 13.1 discussed the applicability of the metaphor of superorganisms in the context of open source. When this metaphor is employed, communities are viewed as an association of a large number of individual 'organisms' that behave as an organic whole. This metaphor may be applicable in a variety of organisational contexts, beyond open source (e.g., innovation communities, crowdsourcing, collaborative and participatory platforms). Future research could explore the roles that firms and boundary spanners ought to play in evolving constellations of superorganisms. 
Based on the results, a framework for analysing community-based value creation in business ecosystems was developed (see Section 13.2). Bearing in mind a more unitary conception of value, this framework regards value creation as an emergent property that is fed and governed by the collaborative and competitive dynamics within ecosystems. More specifically, this framework integrates collective innovation, community engagement, and value capture into a unified model of value creation that is applicable in contexts of firm-community interaction. In doing so, this research responds to the lack of understanding in the literature about how the value-creating logics of firm-community interactions are embedded in the bigger picture within which they occur.

In Section 13.3, a model for classifying open source communities was proposed. This model suggests a four-way classification of open source communities based on the degree of firm control and democratisation in community governance. The resulting four community types are: clandriven open source, community-driven open source, firm-driven open source, and syndicate-driven open source. This model may help future studies to be more specific about the community-idiosyncratic attributes and effects that they study and observe.

Section 13.4 argued for a more differentiated view of governance in connection with strategic open source. While previous research has argued that governance for strategic open source is a top-down process, the results of this thesis suggest a more nuanced picture. While governance may be a top-down process in the context of firm-driven open source, the results of this thesis suggest that this does not hold for community-driven open source. Rather, governance in community-driven open source may be an interactive process of negotiation amongst various stakeholders (e.g., business owners, community members, users, third-party developers).

Section 13.5 highlighted issues in relation to community participants' spiritual well-being, sense of belonging, and psychological health. Such issues are somewhat neglected in the literature; however, they seem to be important given the particularities of the work realities that people face (e.g., working in isolation). By stimulating social relations, care, and support among community participants, communities may facilitate the well-being, sense of belonging, and psychological health of community participants. Future research could study the connections between well-being, sense of belonging, the psychological health of community participants, and productivity at different levels of analysis (e.g., individual, firm, community, ecosystem).

Section 13.6 highlighted a particular form of intersubjective trust in relation to the uncertainties faced by commercial actors when they are 
dependent on the community's software product(s). In short, commercial actors can be more confident that the community will respond to critical issues (e.g., security vulnerabilities and bugs) when they know that the people in the core development teams have a business connected to the open source project themselves. This particular form of intersubjective trust may emerge as a consequence of the intertwining of community engagement and profit-oriented venturing. In light of the voluntary nature of the open source project, it may alleviate commercial actors' perception of being dependent on the open source project by imbuing them with a sense of serenity. In short, the experience of shared fate may help to overcome problems of trust and confidence in ecosystems. Shared fate, in the articulated sense, may be one aspect to consider in academic debates on how trust overcomes uncertainty.

Section 13.7 discussed issues regarding the transitioning of open source developers from a community-based self-identity to an entrepreneurial selfidentity when commercialising open source solutions. In contrast to previous research, which suggests a weakening of a community-based selfidentity as a consequence of this transitioning, the findings of this thesis suggest that a community-based and an entrepreneurial self-identity may coexist in mutually supportive ways. As the empirical data show, open source ways of thinking can play a significant role in participants' conceptions of who they are as a business owner. The findings suggest that more theoretical refinement may be needed around this issue, which could be the subject of future studies.

As highlighted in Section 13.8, in a broad sense, this thesis contributes to the literature streams on the commercialisation of OSS, the business value and strategic aspects of open source, the interrelationships between community forms of organising and entrepreneurial activities, and the nascent research on ecology perspectives on peer-production communities. This thesis highlights that ecosystems are not only spaces of opportunity, they also pose challenges and risks that firms need to overcome in order to be successful. While this thesis discusses a number of responses and coping strategies towards such challenges, future research may also disclose other types of challenges in ecosystems and novel ways in which firms can deal with them.

In summary, by attending to the diversity of actors and activities within the ecosystem around an open source project, this thesis does justice to the multiformity and diversity of the open source phenomenon. A variety of opportunities for future research have already been highlighted. Finally, the reader is reminded that each of the six sub-studies upon which this thesis builds make individual contributions and suggestions for future research on 
their own, which are discussed in the respective sub-studies that make up Chapters $6-11$. The next chapter reflects on the limitations of this thesis, followed by a discussion of further opportunities to deepen the study of the Joomla case. 


\section{Limitations}

Every research has its limitations, and this thesis is no exception. One such limitation concerns the generalisability of the results. Although this research draws on rich empirical data based on a small, purposeful sample of community participants and firms, the potential target population within a global community, such as that surrounding Joomla, is vast. The drawing of boundaries will necessarily impact upon what is found (Dubois \& Gadde, 2002). For instance, there are some countries where the Joomla community is more active. Focusing on particular countries in the sampling procedure might have directed the examination in a different way, or possibly led to other interesting findings. Furthermore, this thesis does not consider cultural aspects, neither in the sampling procedure nor as a theoretical focus. This may, for instance, lead to a neglect of the role of language and language barriers in people's ability to take advantage of the resources that are embedded within the community.

Moreover, while the subjectivity of interpretive research is considered an advantage, because it allows the researcher to gather deep insights into a research problem, it also creates problems (Andrade, 2009). The subjectivity of the researcher always shapes the investigation (Darke et al., 1998). While the trail of evidence in this thesis is grounded in thick descriptions of contextual information, events, values, and practices, the results may nevertheless be subject to bias. There could be alternative interpretations that were not considered in this thesis. The results are therefore not only limited in terms of the sample size and generalisability, but also in terms of objectivity. People employing different theoretical lenses might be able to illuminate the Joomla case in other ways. For instance, due to resource limitations, the power dynamics within the community remained one such theoretical and empirical blind spot. However, this issue deserves the attention of future research because there is reason to believe that the power dynamics within the community play a role in the intertwining of volunteer community engagement and profit-oriented venturing. For instance, power dynamics might affect people's ability or willingness to commercialise community-driven OSS. 



\section{Future work}

There are plenty of approaches and angles that could deepen the study of the Joomla case. In addition to the variety of opportunities for future research that have already been mentioned and discussed, the following provides some more inspiration on potentially study-relevant subjects. The suggestions for future work are grouped by three categories: the market domain, community domain, and client domain.

\subsection{Market domain}

This section highlights opportunities for future work that revolve roughly around the domain of the market, such as intermediary market places for software components, crowdfunding, and location-based pricing.

\subsubsection{Intermediary market places for extensions, plugins, components, and add-ons}

One focus of study could be the role of the JED as an intermediary marketplace for extensions. To extension providers, the JED is an important platform for presenting their products to potential clients. One potential subject of study is the information supply on the JED. For instance, as mentioned in Study V (Pricing), the JED does not provide information on prices. Future research could study the effects of a lack of information supply regarding prices on extension providers' ability to attract clients through the JED.

Other potential topics of investigation could be vendors' strategies in competing for users' attention on this platform, the significance of the JED as a marketing channel for extension providers (compared to other channels, such as Google, adverts, fairs, social media, conferences, word-of-mouth referrals, community engagement), and the effectiveness and potential flaws of the ratings system on the JED.

Future research could conduct similar investigations into other software markets, such as markets for add-ons and plugins (e.g., WordPress, Drupal, Magento). These investigations could also extend into markets other than the CMS market. There are plenty of examples of software platforms, both open source and proprietary, that have commercial markets for extensions, components, add-ons, plugins, and apps. For instance, the Eclipse Marketplace, Matlab, Microsoft Office, MySQL, the Apple store, and plugin markets for digital audio workstations such as Logic and Pro Tools. There 
should be myriads of examples of software platforms out there waiting to be discovered and studied more systematically.

\subsubsection{Crowdfunding and location-based pricing}

As mentioned in Study V (Pricing), some extension providers had experience of acquiring funds for the development of extensions through crowdfunding. Although these vendors reported positive experiences with these attempts, there needs to be more research on the significance and viability of crowdfunding in the realm of open source. Future research could delve into this potentially rewarding research avenue.

Furthermore, some extension providers expressed curiosity about location-based pricing. However, this may be difficult to implement for a variety of reasons. Future research could explore the feasibility and significance of location-based pricing in the realm of open-source-based products and services.

\subsection{Community domain}

This section highlights opportunities for future work that revolve roughly around the domain of the community, such as the effects of fragmentated online communication, free-riding, disincentives for community engagement, and the transitioning of developers from offering noncommercial to commercial extensions.

\subsubsection{The fragmentation of online communication}

The proliferation of online communication channels (e.g., social media) may have led to a fragmentation of public communication around the community. The Joomla project was founded in 2005. In its early days, the main sources of public communication amongst community members were likely to be the official email list and the forum. However, today, there are many different public communication channels that people use to exchange Joomla-relevant information. For instance, there are many different Joomla groups registered on Facebook and Twitter. According to interviewees, the community also uses a collaborative platform called Glip ${ }^{176}$ for communityinternal communication and coordination. Community-related communication also occurs on the Joomla issue tracker and on GitHub. And there may be many other channels utilised by community members. A possible consequence is that a lot of attention has moved from the email lists and forums to other channels, creating the perception that communication within the community has become increasingly fragmented. This 
phenomenon may not be Joomla-specific, but also apply to other organisational settings.

The ongoing fragmentation of online communication might make it more difficult for individuals to get a good sense of the breadth of activities within the Joomla community. It may also have consequences for the image of the platform and its community. A decline of communication over the traditional community channels (e.g., the email list, forum) might give the impression that community activities have decreased over time, whereas in fact communication may just have become more fragmented.

The visibility of online communication is an important characteristic in the context of open source. However, fragmented communication might undermine this visibility to some extent. Drawing on Stewart and Gosain (2001), one potentially negative effect of this may be a decrease of trust on the part of contributors, users, and adopters. However, trust may be an important foundation of people's willingness to engage in community work. Future research could explore the consequences of fragmented communication in more depth.

\subsubsection{Free-riding and disincentives for community engagement}

A further subject of future research could be the role of free-riding. Freeriding refers to the practice of utilising the community's software product(s) without contributing back to the community. In this sense, most users could probably be seen as free-riders. An interesting question is whether the use of the software alone can be considered a contribution. The empirical data show this to be the case as it helps to increase the penetration rates of the software, which benefits both the community and the commercial actors around the Joomla platform.

A further interesting subject of study could be why some firms with a business connected to the community's software product(s) do not engage in community work, in spite of the many benefits that firms can reap. Exploring their reasons might also help communities to become more effective in their recruiting and engagement strategies. As the interview data show, there may be different reasons for why business owners refrain from engaging in community activities. For instance, as mentioned by one interviewee, there might be a fear that someone else could steal customers if customer projects are discussed collectively at community events. Protective and competitive attitudes could attenuate people's willingness to attend community events. Exploring such issues could help resolve the problem of why some people (or firms) contribute to the community while others refrain from doing so. 


\subsubsection{The transitioning from non-commercial to commercial extensions}

As the empirical data show, many developers shared their extensions for free before they began to offer commercial extensions. Individual developers may only gradually start to realise the commercial opportunities of their software over time. Facing the choice between spending considerable amounts of spare time in developing free extensions or turning their work into a commercial business, it seems understandable why some choose the latter. However, there may also be other reasons why people transition to offering commercial extensions when they have offered non-commercial extensions before. Future research could explore the hurdles that developers face when moving from developing non-commercial extensions to commercial ones. There may be diverse challenges in making this transition (e.g., developing features that justify the price, convincing users to pay for something that previously came for free). This theme connects with the literature stream on user entrepreneurship (Mollick, 2016; Shah \& Tripsas, 2016).

\subsection{Client domain}

This section highlights opportunities for future work that revolve roughly around the domain of the client, such as the perceived benefit components of open source offerings, negotiation strategies, signalling strategies, and the scoping of client projects.

\subsubsection{Focus on the clients' perspective}

This thesis has mainly focused on the providers' perspective; however, examining open source offerings from the clients' perspective could be insightful, too. Future research could explore in more depth the perceived benefit components (Christopher, 1982) of open source offerings on the clients' side. For instance, clients' perceptions regarding switching costs and lock-in for value-added products and services around OSS may inform firms' pricing and bundling strategies in a fruitful way. In addition, the negotiation strategies of prospective clients could be a subject for further exploration. This could aid providers of value-added products and services to develop more effective strategies for finding acceptable solutions during negotiations (e.g., by suggesting particular product/price/bundling configurations). 


\subsubsection{Signalling strategies and the scoping of projects}

Future research could explore the effectiveness of the signalling strategies of extension providers who attempt to attract customers. This could include investigations into how providers of value-added services want to be seen by potential customers, what signals they try to avoid, and the extent to which their signals are effective means of attracting (the right) customers. In a broad sense, signalling strategies connect to the efforts to avoid negative perceptions on the clients' side by generating expectations that cannot be met. As the empirical data suggest, one strategy to generate positive perceptions among clients is to under-promise and over-deliver. Another strategy is a humble attitude with respect to one's own capabilities when dealing with clients. A related topic is the problem of scoping customer projects. Badly scoped projects may engender false expectations and dissatisfaction among clients or lead to uncontrollable costs on the providers' side. Future research can pick up on these issues. 



\section{List of figures}

Figure 1: A structural overview of this thesis. This thesis builds on six sub-studies. For analytical convenience, the six sub-studies can be roughly divided into two realms: the realm of the community foundations and the realm of profit-oriented venturing.

Figure 2: Inspired by Androutsellis-Theotokis et al. (2011), this timeline provides a condensed summary of the genesis and evolution of open source, with a focus on web technologies and significant events.

Figure 3: The core-periphery structure of open source communities, an onion-like model (Androutsellis-Theotokis et al., 2011; Crowston \& Shamshurin, 2017; Nakakoji et al., 2002).

Figure 4: The structure of the theoretical framework of this thesis. The business ecology perspective is complemented with ideas from other relevant theoretical areas, such as stakeholder theory, community governance, organisational identity, motivation theory, pricing, and bundling...............................50

Figure 5: The Joomla logo. The Joomla logo symbolises togetherness and unity as important community values.

Figure 6: Penetration rates of the three most popular open source CMSs, as shown by statistics on W3Techs in December 2017.

Figure 7: Total number of websites for the years $2000-2017 \ldots \ldots \ldots \ldots \ldots . . .67$

Figure 8: A comparison of Joomla (blue) with WordPress (red) on Google Trends, compiled in November 2017 ........................68

Figure 9: Worldwide distribution of Joomla user groups, as of

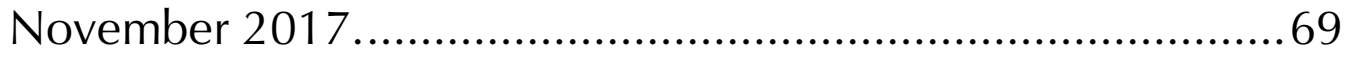

Figure 10: The top-level organisational structure of Joomla as depicted by OSM. The number of teams in this diagram is illustrative. 
Figure 11: Departments together with an overlay of their teams, as of December 2017 (at the time of writing, there were no teams assigned to the Local Communities Department).

Figure 12: Distribution of team memberships among volunteers, as of December 2017.

Figure 13: The categories in the Joomla resources directory provide a glimpse of the breadth of commercial services that are offered in connection with the Joomla platform.

Figure 14: The units of analysis and their relationships in the context of this thesis.

Figure 15: The key empirical data sources and how they informed the different constituent parts of this thesis.

Figure 16: Distribution of interview participants for the second set of interviews on a map of Joomla user groups.

Figure 17: A model for describing the process of gaining understanding (Westelius, 1996, p. 13).

Figure 18: Overview of stakeholders in the case of the Joomla community.....

Figure 19: A two-dimensional model for stakeholder classification in a community setting.

Figure 20: Interconnectedness of stakeholders in the example of image and reputation of the Joomla platform.

Figure 21: A tentative, integrative framework for open source governance.

Figure 22: A three-stage model of membership levels from a coreperiphery perspective.

Figure 23: An analytical model that depicts the dynamic interaction between collective identities and governance.

Figure 24: By community participants, Miro's actions were perceived to be in conflict with the community's shared belief in the ideals of open source and fairness. In particular, Miro's decision of excluding key community representatives from 
the Board of the Mambo Foundation caused indignation among people in the community.

Figure 25: The inception of Joomla in 2005. The emerging sense of independence and the negative experiences with singlevendor corporate control led to the inception of Joomla as a community-driven open source project. The governance structures and the newly founded non-profit organisation were (and still are) characterised by flat hierarchies and decentralised decision-structures.

Figure 26: A salient value mix favours a particular governance model that is characterised by collective decision-making, open exchange, and flat hierarchies.

Figure 27: While collective decision-making, flat hierarchies, and volunteerism are cherished in the community, organisational inertia and chaos can come as the flip side of Joomla's governance model.

Figure 28: A culture of open conflict gives rise to the implementation of a code of conduct that emphasises fairness and respect. ..175

Figure 29: Newly implemented policies and procedures to deal with breaches against the $\mathrm{CoC}$ conflict with some of the core community values.

Figure 30: The community leadership justified the ban of non-GPL code from the JED with reference to the mission and core values of the Joomla project.

Figure 31: The banning of non-GPL code from the JED affected business owners around the Joomla platform and their professional identities. In particular, it affected the ways in which extension providers could effectively charge for their software products

Figure 32: Openness, volunteerism, and collective decision-making favour the emergence of meritocracy as a governing principle. However, it should be added that democratic participation has been gradually increasing over the years. For instance, a recent governance change stipulated that all Team Leaders have to be elected by team members. 
Figure 33: The on-boarding process and a focus on mentoring are measures that preserve the technical excellence and knowledge in the community.

Figure 34: The local user groups reinforce and foster the identity of a family.....

Figure 35: From an identity perspective, a growing sense of a global family gave rise to the organisation of global community events.

Figure 36: From an identity perspective, a perceived threat to Joomla's identity as a CMS for the masses triggered a series of governance changes.

Figure 37: Recent governance changes will influence and shape Joomla's future identities.

Figure 38: An analytical model that emphasises community engagement, the relationships to individual motivations, and the incentives provided by the social and macroinstitutional context. Community engagement is reflected in a variety of different community-related practices (i.e., reoccurring activities), such as engaging in discussions, providing feedback, reporting bugs, developing and submitting code, attending events, leading teams................209

Figure 39: The five-dimensional SBIFT model (Iveroth et al. 2013),......240

Figure 40: A visual summary of the quantitative SBIFT model results. ...251

Figure 41: Dominant pricing practice from a SBIFT model perspective.

Figure 42: A summary of key aspects affecting pricing practices in the realm of commercial OSS extensions.

Figure 43: The structural relationships between the terms package, wrapper, container, and bundle.

Figure 44: A generic model for analysing bundling and versioning both in a descriptive and prescriptive sense. 
Figure 45: Bundling and versioning by the example of LOGman (a Joomla extension).

Figure 46: A Venn diagram depicting the essential conceptual relations among the three constituents: ecosystem, community, and firm.

Figure 47: A framework for analysing community-based value creation in business ecosystems......................................... 320

Figure 48: A generic representation of community-based value creation utilising organismic metaphors...............................327

Figure 49: A four-way classification of open source communities based on the degree of firm control and democratisation in community governance. 



\section{List of tables}

Table 1: An overview of the sub-studies on which this thesis builds upon.

Table 2: Four aspects of intertwining: reinforcement, complementarity, synergy, and reciprocity (Robey et al., 2003).

Table 3: An overview of numbers and facts about the Joomla project.

Table 4: Overview of collective identities in the Joomla case. 196

Table 5: The net benefits of engaging in community work materialise in various forms, especially when one has a business connected to the community's software product(s)....

Table 6: Examples of evidence from the interview data in relation to the scope dimension.

Table 7: Examples of evidence from the interview data in relation to the base dimension.

Table 8: Examples of evidence from the interview data in relation to the influence dimension.

Table 9: Examples of evidence from the interview data in relation to the formula dimension.

Table 10: Examples of evidence from the interview data in relation to the dimension of temporal rights.

Table 11: A categorisation of the challenges in commercialising community-driven OSS.

Table 12: Contribution activities of commercial extension providers in the first set of interviews.

Table 13: Commercial activities of people affiliated with the community as evident from the second set of interviews......302 



\section{References}

Aarikka-Stenroos, L., \& Ritala, P. (2017). Network management in the era of ecosystems: Systematic review and management framework. Industrial Marketing Management, 67, 23-36.

Adomavicius, G., Bockstedt, J., \& Curley, S. P. (2015). Bundling effects on variety seeking for digital information goods. Journal of Management Information Systems, 31(4), 182-212.

Ågerfalk, P. J., \& Fitzgerald, B. (2008). Outsourcing to an unknown workforce: Exploring opensourcing as a global sourcing strategy. MIS Quarterly, 32(2), 385-409.

Akçura, M. T., \& Altınkemer, K. (2010). Digital bundling. Information Systems and E-Business Management, 8(4), 337-355.

Akera, A. (2001). Voluntarism and the fruits of collaboration: The IBM user group, Share. Technology and Culture, 42(4), 710-736.

Aksulu, A., \& Wade, M. (2010). A comprehensive review and synthesis of open source research. Journal of the Association for Information Systems, 11(11), 576-656.

Albert, S. (1998). The Definition and Metadefinition of Identity. In D. A. Whetten \& P. C. Godfrey (Eds.), Identity in Organizations: Building Theory Through Conversations (pp. 1-13). SAGE Publications.

Albert, S., \& Whetten, D. A. (1985). Organizational identity. Research in Organizational Behavior, 7, 263-295.

Alvesson, M., \& Willmott, H. (2002). Identity regulation as organizational control: Producing the appropriate individual. Journal of Management Studies, 39(5), 619-644.

Amit, R., \& Han, X. (2017). Value creation through novel resource configurations in a digitally enabled world. Strategic Entrepreneurship Journal, 11(3), 228-242.

Amit, R., \& Zott, C. (2001). Value creation in e-business. Strategic Management Journal, 22(6-7), 493-520.

Ancarani, F. (2002). Pricing and the Internet: Frictionless commerce or pricer's paradise? European Management Journal, 20(6), 680-687.

Andrade, A. D. (2009). Interpretive research aiming at theory building: Adopting and adapting the case study design. The Qualitative Report, 14(1), 42-60.

Androutsellis-Theotokis, S., Spinellis, D., Kechagia, M., \& Gousios, G. (2011). Open Source Software: A Survey from 10, 000 Feet. Foundations and Trends in Technology, Information and Operations Management, 4(3-4), 187-347. 
Apon, J. (2007). Cases against Microsoft: similar cases, different remedies. European Competition Law Review, 28(6), 327.

Arora, R. (2008). Price bundling and framing strategies for complementary products. Journal of Product \& Brand Management, 17(7), 475-484.

August, T., Shin, H., \& Tunca, T. I. (2013). Licensing and competition for services in open source software. Information Systems Research, 24(4), 1068-1086.

August, T., Shin, H., \& Tunca, T. I. (2018). Generating value through open source: Software service market regulation and licensing policy. Information Systems Research, 29(1), 186-205.

Bagozzi, R. P., \& Dholakia, U. M. (2006). Open source software user communities: A study of participation in Linux user groups. Management Science, 52(7), 1099-1115.

Bailey, J. P., \& Bakos, Y. (1997). An exploratory study of the emerging role of electronic intermediaries. International Journal of Electronic Commerce, 1(3), 7-20.

Bakos, Y., \& Brynjolfsson, E. (1999). Bundling information goods: Pricing, profits, and efficiency. Management Science, 45(12), 1613-1630.

Bakos, Y., \& Brynjolfsson, E. (2000). Bundling and Competition on the Internet. Marketing Science, 19(1), 63-82.

Ballejos, L. C., \& Montagna, J. M. (2008). Method for stakeholder identification in interorganizational environments. Requirements Engineering, 13(4), 281-297.

Benbya, H., \& Belbaly, N. (2010). Understanding developers' motives in open source projects: A multi-theoretical framework. Communications of the AIS, 27(Article 30), 589-610.

Bengtsson, M., \& Kock, S. (2014). Coopetition - Quo vadis? Past accomplishments and future challenges. Industrial Marketing Management, 43(2), 180-188.

Benkler, Y. (2017). Peer production, the commons, and the future of the firm. Strategic Organization, 15(2), 264-274.

Bergquist, M., \& Ljungberg, J. (2001). The power of gifts: organizing social relationships in open source communities. Information Systems Journal, 11(4), 305-320.

Bharadwaj, A., El Sawy, O. A., Pavlou, P. A., \& Venkatraman, N. (2013). Digital Business Strategy: Toward a Next Generation of Insights. MIS Quarterly, 37(2), 471-482.

Bhargava, H. K., \& Choudhary, V. (2001). Information goods and vertical differentiation. Journal of Management Information Systems, 18(2), 89-106. 
Bhargava, H. K., \& Choudhary, V. (2008). Research Note - When Is Versioning Optimal for Information Goods? Management Science, 54(5), 1029-1035.

Bianchi, A. J., Kang, S. M., \& Stewart, D. (2012). The organizational selection of status characteristics: Status evaluations in an open source community. Organization Science, 23(2), 341-354.

Bird, C., Pattison, D., D'Souza, R., Filkov, V., \& Devanbu, P. (2008). Latent social structure in open source projects. In Proceedings of the 16th ACM SIGSOFT International Symposium on Foundations of software engineering (pp. 24-35). ACM.

Bitzer, J., Schrettl, W., \& Schröder, P. J. (2007). Intrinsic motivation in open source software development. Journal of Comparative Economics, 35(1), 160-169.

Blekh, A. (2015). Governance and organizational sponsorship as success factors in free/libre and open source software development: An empirical investigation using structural equation modeling. Nova Southeastern University.

Boland Jr, R. J., \& Tenkasi, R. V. (1995). Perspective making and perspective taking in communities of knowing. Organization Science, 6(4), 350372.

Bontis, N., \& Chung, H. (2000). The evolution of software pricing: From box licenses to application service provider models. Internet Research, 10(3), 246-255.

Borgh, M., Cloodt, M., \& Romme, A. G. L. (2012). Value creation by knowledge-based ecosystems: Evidence from a field study. $R \& D$ Management, 42(2), 150-169.

Bosch, J. (2009). From software product lines to software ecosystems. In Proceedings of the 13th International Software Product Line Conference (pp. 111-119). Carnegie Mellon University.

Brandenburger, A. M., \& Nalebuff, B. J. (1997). Co-Opetition. 1. A revolution mindset that combines competition and cooperation. 2. The game theory strategy that's changing the game of business. Currency Doubleday.

Bretthauer, D. (2001). Open Source Software: A History. University of Connecticut Library.

Brewer, M. B., \& Gardner, W. (1996). Who is this 'We'? Levels of collective identity and self representations. Journal of Personality and Social Psychology, 71(1), 83-93.

Brickson, S. (2000). The impact of identity orientation on individual and organizational outcomes in demographically diverse settings. Academy of Management Review, 25(1), 82-101. 
Brown, A. D. (2006). A narrative approach to collective identities. Journal of Management Studies, 43(4), 731-753.

Brown, J. S., \& Duguid, P. (1991). Organizational learning and communities-of-practice: Toward a unified view of working, learning, and innovation. Organization Science, 2(1), 40-57.

Bryman, A., \& Bell, E. (2015). Business research methods. Oxford University Press.

Burns, E. (2010). Developing email interview practices in qualitative research. Sociological Research Online, 15(4), 1-12.

Capra, E., Francalanci, C., \& Merlo, F. (2008). An empirical study on the relationship between software design quality, development effort and governance in open source projects. IEEE Transactions on Software Engineering, 34(6), 765-782.

Capra, E., Francalanci, C., Merlo, F., \& Lamastra, C. R. (2009). A survey on firms' participation in open source community projects. In C. Boldyreff, K. Crowston, B. Lundell, \& A. I. Wasserman (Eds.), Open Source Ecosystems: Diverse Communities Interacting (pp. 225-236). Springer.

Capra, E., \& Wasserman, A. I. (2008). A framework for evaluating managerial styles in open source projects. In B. Russo, E. Damiani, S. Hissam, B. Lundell, \& G. Succi (Eds.), Open Source Development, Communities and Quality (pp. 1-14). Springer.

Carillo, K., Huff, S., \& Chawner, B. (2017). What makes a good contributor? Understanding contributor behavior within large Free/Open Source Software projects - A socialization perspective. The Journal of Strategic Information Systems, 26(4), 322-359.

Carillo, K., Marsan, J., \& Negoita, B. (2017). Exploring the biosphere Towards a conceptualization of peer production communities as living organisms. In SIGOPEN Developmental Workshop for Research on Open Phenomena. Seoul: Association for Information Systems.

Carillo, K., \& Okoli, C. (2008). The open source movement: A revolution in software development. Journal of Computer Information Systems, 49(2), 1-9.

Cassell, C., \& Symon, G. (2004). Essential guide to qualitative methods in organizational research. Sage.

Castaldo, S. (2003). Trust variety - Conceptual nature, dimensions and typologies. Presented at the 19th IMP-conference, Lugano.

Checkland, P. (2000). Soft Systems Methodology: A thirty year retrospective. Systems Research and Behavioral Science, 17(1), 11-58.

Christian, J. (2015). The User Organisation: Structure and Governance in an Open Source Project. University of Brighton. 
Christopher, M. (1982). Value-in-use pricing. European Journal of Marketing, 16(5), 35-46.

Cialdini, R. B. (2009). Influence (Rev. edn). HarperCollins e-books.

Ciesielska, M., \& Westenholz, A. (2016). Dilemmas within commercial involvement in open source software. Journal of Organizational Change Management, 29(3), 344-360.

Clarysse, B., Wright, M., Bruneel, J., \& Mahajan, A. (2014). Creating value in ecosystems: Crossing the chasm between knowledge and business ecosystems. Research Policy, 43(7), 1164-1176.

Coase, R. H. (1937). The nature of the firm. Economica, 4(16), 386-405.

Collins, J., \& Drucker, P. (1999). A Conversation between Jim Collins and Peter Drucker. Drucker Foundation News, 7(2), 4-5.

Comino, S., \& Manenti, F. M. (2011). Dual licensing in open source software markets. Information Economics and Policy, 23(3-4), 234-242. https://doi.org/10.1016/j.infoecopol.2011.07.001

Cooper, H. M. (1998). Synthesizing research: A guide for literature reviews (Vol. 2). Sage.

Corallo, A., Passiante, G., \& Prencipe, A. (2007). The digital business ecosystem. Edward Elgar Publishing.

Corning, P. A. (2008). Holistic Darwinism: The new evolutionary paradigm and some implications for political science. Politics and the Life Sciences, 27(1), 22-54.

Cöster, M., \& Westelius, A. (2016). Digitalisering. Liber.

Crane, A., \& Ruebottom, T. (2011). Stakeholder theory and social identity: rethinking stakeholder identification. Journal of Business Ethics, 102(1), 77-87.

Crowston, K. (2016). Open Source Technology Development. In W. S. Bainbridge \& M. C. Roco (Eds.), Handbook of Science and Technology Convergence (pp. 475-486). Springer.

Crowston, K., Feller, J., Mols, C.-E., \& Wasserman, A. I. T. (2016). The Future of Open Source Research: A Panel Discussion. In IFIP Advances in Information and Communication Technology (pp. 201-203). Gothenburg: Springer.

Crowston, K., \& Howison, J. (2006). Assessing the health of open source communities. Computer, 39(5), 89-91.

Crowston, K., \& Shamshurin, I. (2017). Core-periphery communication and the success of free/libre open source software projects. Journal of Internet Services and Applications, 8(1), Article 10.

Crowston, K., Wei, K., Howison, J., \& Wiggins, A. (2012). Free/Libre open source software development: What we know and what we do not know. ACM Computing Surveys, 44(2), Article 7. 
Cusumano, M. A. (2007). The changing labyrinth of software pricing. Communications of the ACM, 50(7), 19-22.

Dagnino, G. B. (2009). Coopetition strategy: a new kind of interfirm dynamics for value creation. In G. B. Dagnino \& E. Rocco (Eds.), Coopetition Strategy (pp. 45-63). Routledge.

Dahlander, L. (2005). Appropriation and appropriability in open source software. International Journal of Innovation Management, 9(3), 259285.

Dahlander, L., \& Magnusson, M. G. (2005). Relationships between open source software companies and communities: Observations from Nordic firms. Research Policy, 34(4), 481-493.

Daniel, S., \& Stewart, K. (2016). Open source project success: Resource access, flow, and integration. The Journal of Strategic Information Systems, 25(3), 159-176.

Darke, P., Shanks, G., \& Broadbent, M. (1998). Successfully completing case study research: combining rigour, relevance and pragmatism. Information Systems Journal, 8(4), 273-289.

de Joode, R. van W., \& Egyedi, T. M. (2005). Handling variety: The tension between adaptability and interoperability of open source software. Computer Standards \& Interfaces, 28(1), 109-121.

De Laat, P. B. (2007). Governance of open source software: State of the art. Journal of Management \& Governance, 11(2), 165-177.

De Laat, P. B. (2010). How can contributors to open source communities be trusted? On the assumption, inference, and substitution of trust. Ethics and Information Technology, 12(4), 327-341.

De Noni, I., Ganzaroli, A., \& Orsi, L. (2011). The Governance of Open Source Software Communities: An Exploratory Analysis. Journal of Business Systems, Governance \& Ethics, 6(1), 1-18.

De Noni, I., Ganzaroli, A., \& Orsi, L. (2013). The evolution of OSS governance: a dimensional comparative analysis. Scandinavian Journal of Management, 29(3), 247-263.

De Sordi, J. O., Reed, E. N., Meireles, M., \& da Silveira, M. A. (2016). Development of digital products and services: Proposal of a framework to analyze versioning actions. European Management Journal, 34(5), 564-578.

Deci, E. L., \& Ryan, R. M. (1980). Self-determination theory: When mind mediates behavior. The Journal of Mind and Behavior, 1(1), 33-43.

Deci, E. L., \& Ryan, R. M. (2000). The 'what' and 'why' of goal pursuits: Human needs and the self-determination of behavior. Psychological Inquiry, 11(4), 227-268. 
Deci, E. L., \& Ryan, R. M. (2011). Self-determination theory. In P. A. M. Van Lange, A. W. Kruglanski, \& E. T. Higgins (Eds.), The handbook of theories of social psychology (pp. 416-433).

DeLone, W. H., \& McLean, E. R. (2003). The DeLone and McLean model of information systems success: A ten-year update. Journal of Management Information Systems, 19(4), 9-30.

Di Tullio, D. (2012). The Governance of Open Source Software Development Projects. Queen's University.

Di Tullio, D., \& Staples, D. S. (2013). The governance and control of open source software projects. Journal of Management Information Systems, 30(3), 49-80.

Diamantopoulos, A. (1991). Pricing: theory and evidence - a literature review. In M. J. Baker (Ed.), Perspectives on Marketing Management (Vol. 1, pp. 63-192). Wiley.

Dixit, A., Whipple, T. W., Zinkhan, G. M., \& Gailey, E. (2008). A taxonomy of information technology-enhanced pricing strategies. Journal of Business Research, 61(4), 275-283.

Docters, R., Tilstone, L., Bednarczyk, S., \& Gieskes, M. (2011). Pricing in the digital world. Journal of Business Strategy, 32(4), 4-11.

Dubois, A., \& Gadde, L.-E. (2002). Systematic combining: An abductive approach to case research. Journal of Business Research, 55(7), 553560.

Duc, A. N., Cruzes, D. S., Hanssen, G. K., Snarby, T., \& Abrahamsson, P. (2017). Coopetition of software firms in Open source software ecosystems. In A. Ojala, H. Holmström Olsson, \& K. Werder (Eds.), Software Business. ICSOB 2017. Lecture Notes in Business Information Processing (pp. 146-160). Springer.

Dunham, L., Freeman, R. E., \& Liedtka, J. (2006). Enhancing stakeholder practice: A particularized exploration of community. Business Ethics Quarterly, 16(1), 23-42.

Dunne, C. (2011). The place of the literature review in grounded theory research. International Journal of Social Research Methodology, 14(2), 111-124.

Dutta, S., Zbaracki, M. J., \& Bergen, M. (2003). Pricing process as a capability: A resource-based perspective. Strategic Management Journal, 24(7), 615-630.

Dutton, J. E., Dukerich, J. M., \& Harquail, C. V. (1994). Organizational images and member identification. Administrative Science Quarterly, 39(2), 239-263. 
Dye, J. F., Schatz, I. M., Rosenberg, B. A., \& Coleman, S. T. (2000). Constant comparison method: A kaleidoscope of data. The Qualitative Report, $4(1), 1-10$.

Ebadazadeh Semnani, S., \& Nord, T. (2017). The relational factors affecting the transition to new business models. In R. J. Baumgartner, M. Fuellsack, U. Gelbmann, \& R. Rauter (Eds.), Exploring a changing view on organizing value creation: Developing new business models. Institute of Systems Sciences, Innovation and Sustainability. University of Graz.

Eisenhardt, K. M. (1989). Building theories from case study research. Academy of Management Review, 14(4), 532-550.

Eisenhardt, K. M., \& Graebner, M. E. (2007). Theory building from cases: opportunities and challenges. Academy of Management Journal, $50(1), 25-32$.

Eisenhardt, K. M., Graebner, M. E., \& Sonenshein, S. (2016). Grand challenges and inductive methods: Rigor without rigor mortis. Academy of Management Journal, 59(4), 1113-1123.

Elsbach, K. D., \& Kramer, R. M. (1996). Members' responses to organizational identity threats: Encountering and countering the Business Week rankings. Administrative Science Quarterly, 41(3), 442-476.

Erden, Z., Schneider, A., \& von Krogh, G. (2014). The multifaceted nature of social practices: A review of the perspectives on practice-based theory building about organizations. European Management Journal, $32(5), 712-722$.

Fang, Y., \& Neufeld, D. (2009). Understanding sustained participation in open source software projects. Journal of Management Information Systems, 25(4), 9-50.

Feldman, M. S., \& Orlikowski, W. J. (2011). Theorizing practice and practicing theory. Organization Science, 22(5), 1240-1253.

Felin, T., Lakhani, K. R., \& Tushman, M. L. (2017). Firms, crowds, and innovation. Strategic Organization, 15(2), 119-140.

Feller, J., \& Fitzgerald, B. (2000). A framework analysis of the open source software development paradigm. In Proceedings of the 21st international conference on Information systems (pp. 58-69). ACM.

Fershtman, C., \& Gandal, N. (2007). Open source software: Motivation and restrictive licensing. International Economics and Economic Policy, $4(2), 209-225$.

Fiss, P. C., Cambré, B., \& Marx, A. (2013). Configurational theory and methods in organizational research (Vol. 38). Emerald Group Publishing. 
Fitzgerald, B. (2006). The transformation of open source software. MIS Quarterly, 30(3), 587-598.

Foreman, P., \& Whetten, D. A. (2002). Members' identification with multiple-identity organizations. Organization Science, 13(6), 618635.

Fosfuri, A., Giarratana, M. S., \& Luzzi, A. (2008). The penguin has entered the building: The commercialization of open source software products. Organization Science, 19(2), 292-305.

Franch, X., Susi, A., Annosi, M. C., Ayala, C. P., Glott, R., Gross, D., ... Thomas, C. (2013). Managing risk in open source software adoption. In Proceedings of the 8th International Joint Conference on Software Technologies (pp. 258-264).

Franck, E., \& Jungwirth, C. (2003). Reconciling rent-seekers and donators The governance structure of open source. Journal of Management and Governance, 7(4), 401-421.

Frederiksen, M. (2012). Dimensions of trust: An empirical revisit to Simmel's formal sociology of intersubjective trust. Current Sociology, 60(6), 733-750.

Frederiksen, M. (2014). Trust in the face of uncertainty: A qualitative study of intersubjective trust and risk. International Review of Sociology, 24(1), 130-144.

Freeman, R. E. (2010). Strategic management: A stakeholder approach. Cambridge University Press.

Freeman, R. E., Harrison, J. S., Wicks, A. C., Parmar, B. L., \& De Colle, S. (2010). Stakeholder theory: The state of the art. Cambridge University Press.

Freeman, S. (2007). The material and social dynamics of motivation. Science Studies, 20(2), 55-77.

Gagné, M., \& Deci, E. L. (2005). Self-determination theory and work motivation. Journal of Organizational Behavior, 26(4), 331-362.

Gagné, M., \& Deci, E. L. (2014). The History of Self-Determination Theory in Psychology and Management. In M. Gagné (Ed.), The Oxford handbook of work engagement, motivation, and self-determination theory (pp. 1-9). Oxford University Press.

Gallivan, M. J. (2001). Striking a balance between trust and control in a virtual organization: a content analysis of open source software case studies. Information Systems Journal, 11(4), 277-304.

Gioia, D. A. (1998). From individual to organizational identity. In D. A. Whetten \& P. C. Godfrey (Eds.), Identity in Organizations: Building Theory Through Conversations (pp. 17-31). SAGE Publications. 
Gioia, D. A., Schultz, M., \& Corley, K. G. (2000). Organizational identity, image, and adaptive instability. Academy of Management Review, 25(1), 63-81.

Gousios, G., Vasilescu, B., Serebrenik, A., \& Zaidman, A. (2014). Lean GHTorrent: GitHub data on demand. In Proceedings of the 11th working conference on mining software repositories (pp. 384-387). ACM.

Graham, S., \& Weiner, B. (1996). Theories and principles of motivation. In D. C. Berliner \& R. C. Calfee (Eds.), Handbook of educational psychology (pp. 63-84). Routledge.

Grand, S., von Krogh, G., Leonard, D., \& Swap, W. (2004). Resource allocation beyond firm boundaries: A multi-level model for open source innovation. Long Range Planning, 37(6), 591-610.

Gummesson, E. (2000). Qualitative methods in management research. SAGE Publications.

Gustafson, L. T., \& Reger, R. K. (1995). Using organizational identity to achieve stability and change in high velocity environments. Academy of Management Proceedings, 464-468.

Hajji, A., Pellerin, R., Léger, P.-M., Gharbi, A., \& Babin, G. (2012). Dynamic pricing models for ERP systems under network externality. International Journal of Production Economics, 135(2), 708-715.

Harmon, R., Demirkan, H., Hefley, B., \& Auseklis, N. (2009). Pricing strategies for information technology services: a value-based approach. In 42nd Hawaii International Conference on System Sciences (pp. 1-10). IEEE.

Hars, A., \& Ou, S. (2002). Working for free? Motivations of participating in open source projects. International Journal of Electronic Commerce, 6(3), 25-39.

Hatch, M. J., \& Schultz, M. (1997). Relations between organizational culture, identity and image. European Journal of Marketing, 31(5/6), 356-365.

Havemo, E. (2018). A visual perspective on value creation: Exploring patterns in business model diagrams. European Management Journal, (36), 441-452.

He, H., \& Brown, A. D. (2013). Organizational identity and organizational identification: A review of the literature and suggestions for future research. Group \& Organization Management, 38(1), 3-35.

Hearn, G., \& Pace, C. (2006). Value-creating ecologies: understanding next generation business systems. Foresight, 8(1), 55-65.

Hedberg, B., Dahlgren, G., Hansson, J., \& Olve, N.-G. (1997). Virtual organizations and beyond: discover imaginary systems. John Wiley. 
Hertel, G. (2007). Motivating job design as a factor in open source governance. Journal of Management \& Governance, 11(2), 129-137.

Hinterhuber, A. (2008). Customer value-based pricing strategies: why companies resist. Journal of Business Strategy, 29(4), 41-50.

Ho, S. Y., \& Richardson, A. (2013). Trust and distrust in open source software development. Journal of Computer Information Systems, 54(1), 84-93.

Hsieh, H.-F., \& Shannon, S. E. (2005). Three approaches to qualitative content analysis. Qualitative Health Research, 15(9), 1277-1288.

Iansiti, M., \& Levien, R. (2004). Strategy as ecology. Harvard Business Review, 82(3), 68-81.

Imre, Ö. (2017). Learning by negotiation: Stake and salience in Implementing a journal management system. In H. Bilgin, H. Danis, E. Demir, \& U. Can (Eds.), Financial Environment and Business Development (pp. 369-383). Springer.

Iveroth, E., Westelius, A., Petri, C.-J., Olve, N.-G., Cöster, M., \& Nilsson, F. (2013). How to differentiate by price: proposal for a five-dimensional model. European Management Journal, 31(2), 109-123.

Jansen, S., Finkelstein, A., \& Brinkkemper, S. (2009). A sense of community: A research agenda for software ecosystems. In 31st International Conference on Software Engineering. IEEE.

Jensen, C., \& Scacchi, W. (2005). Collaboration, leadership, control, and conflict negotiation and the netbeans. org open source software development community. In Proceedings of the 38th Annual Hawaii International Conference on System Sciences. IEEE.

Jensen, C., Scacchi, W., Ågerfalk, P., Boldyreff, C., González-Barahona, J. M., Madey, G. R., \& Noll, J. (2010). Governance in open source software development projects: A comparative multi-level analysis. In Open Source Software: New Horizons (pp. 130-142). Springer.

Jones, C., Hesterly, W. S., \& Borgatti, S. P. (1997). A general theory of network governance: Exchange conditions and social mechanisms. Academy of Management Review, 22(4), 911-945.

Joshua, J. V., Alao, D. O., Okolie, S. O., \& Awodele, O. (2013). Software Ecosystem: Features, Benefits and Challenges. International Journal of Advanced Computer Science and Applications, 4(8), 242-247.

Ke, W., \& Zhang, P. (2009). Motivations in open source software communities: The mediating role of effort intensity and goal commitment. International Journal of Electronic Commerce, 13(4), 3966.

Kienzler, M., \& Kowalkowski, C. (2017). Pricing strategy: A review of 22 years of marketing research. Journal of Business Research, 78, 101110. 
Kim, B. C. (2013). Optimal pricing strategies for open source support providers. Asia Pacific Journal of Information Systems, 23(1), 1-19.

Kim, H., Lee, J.-N., \& Han, J. (2010). The role of IT in business ecosystems. Communications of the ACM, 53(5), 151-156.

Kirmani, A., \& Rao, A. R. (2000). No pain, no gain: A critical review of the literature on signaling unobservable product quality. Journal of Marketing, 64(2), 66-79.

Kittlaus, H.-B., \& Clough, P. N. (2009). Software product management and pricing: Key success factors for software organizations. Springer.

Kivits, R. A. (2011). Three component stakeholder analysis. International Journal of Multiple Research Approaches, 5(3), 318-333.

Klein, H. K., \& Myers, M. D. (1999). A set of principles for conducting and evaluating interpretive field studies in information systems. MIS Quarterly, 23(1), 67-93.

Kogut, B., \& Zander, U. (1996). What firms do? Coordination, identity, and learning. Organization Science, 7(5), 502-518.

Kohlbacher, F. (2006). The use of qualitative content analysis in case study research. Forum: Qualitative Social Research, 7(1), 1-30.

Kozinets, R. V., Hemetsberger, A., \& Schau, H. J. (2008). The wisdom of consumer crowds: Collective innovation in the age of networked marketing. Journal of Macromarketing, 28(4), 339-354.

Krishnamurthy, S. (2005). An analysis of open source business models. In J. Feller, B. Fitzgerald, S. Hissam, \& K. R. Lakhani (Eds.), Perspectives on Free and Open Source Software (pp. 279-296). MIT Press.

Kumar, V. (2014). Making 'freemium' work. Harvard Business Review, 92(5), 27-29.

La Rocca, A., Hoholm, T., \& Mørk, B. E. (2017). Practice theory and the study of interaction in business relationships: Some methodological implications. Industrial Marketing Management, 60, 187-195.

Laatikainen, G., Ojala, A., \& Mazhelis, O. (2013). Cloud services pricing models. In G. Herzwurm \& T. Margaria (Eds.), Software Business. From Physical Products to Software Services and Solutions. ICSOB 2013. Lecture Notes in Business Information Processing (pp. 117-129). Springer.

Lakhani, K. R., \& Panetta, J. A. (2007). The principles of distributed innovation. Innovations: Technology, Governance, Globalization, 2(3), 97-112.

Lakhani, K. R., \& Wolf, R. G. (2005). Why hackers do what they do: Understanding motivation and effort in free/open source software projects. In J. Feller, B. Fitzgerald, S. Hissam, \& K. R. Lakhani (Eds.), Perspectives on Free and Open Source Software (pp. 3-22). MIT Press. 
Lakka, S., Stamati, T., Michalakelis, C., \& Martakos, D. (2011). The ontology of the OSS business model: An exploratory study. Open Source Software Dynamics, Processes, and Applications, 3(1), 39-59.

Lane, M., van der Vyver, G., \& Basnet, P. (2004). Trust in virtual communities involved in free/open source projects: An empirical study. In ACIS 2004 Proceedings. AIS Electronic Library.

Lane, M., van der Vyver, G., Basnet, P., \& Howard, S. (2004). Interpretative insights into interpersonal trust and effectiveness of virtual communities of open source software (OSS) developers. In Proceedings of the 15th Australasian Conference on Information Systems (ACIS 2004). AIS Electronic Library.

Lattemann, C., \& Stieglitz, S. (2005). Framework for governance in open source communities. In Proceedings of the 38th Annual Hawaii International Conference on System Sciences. IEEE.

Lee, S. H. (1999). Open source software licensing. Harvard Law School. Retrieved from http://eon.law.harvard.edu/openlaw/gpl.pdf

Lee, V. (2011). How firms can strategically influence open source communities. Technische Universität Hamburg-Harburg.

Lehmann, S., \& Buxmann, P. (2009). Pricing strategies of software vendors. Business \& Information Systems Engineering, 1(6), 452-462.

Lerner, J. (2010). The comingled code: Open source and economic development. MIT Press.

Lerner, J., \& Tirole, J. (2002). Some simple economics of open source. The Journal of Industrial Economics, 50(2), 197-234.

Lerner, J., \& Tirole, J. (2005). The scope of open source licensing. Journal of Law, Economics, and Organization, 21(1), 20-56.

Lessig, L. (1999). Open code and open societies: Values of Internet governance. Chicago Kent Law Review, 74(3), 1405-1420.

Levine, S. S., \& Prietula, M. J. (2013). Open Collaboration for Innovation: Principles and Performance. Organization Science, 25(5), 1526-5455.

Li, Y., Tan, C.-H., \& Teo, H.-H. (2012). Leadership characteristics and developers' motivation in open source software development. Information \& Management, 49(5), 257-267.

Linåker, J., Rempel, P., Regnell, B., \& Mäder, P. (2016). How firms adapt and interact in open source ecosystems: Analyzing stakeholder influence and collaboration patterns. In M. Daneva \& O. Pastor (Eds.), Requirements Engineering: Foundation for Software Quality (pp. 6381). Springer.

Linde, F. (2009). Pricing information goods. Journal of Product \& Brand Management, 18(5), 379-384. 
Lundmark, E., \& Westelius, A. (2008). Internet-based changes in organizational communication. In Y. K. Dwivedi, A. Papazafeiropoulou, \& J. Choudrie (Eds.), Handbook of research on global diffusion of broadband data transmission (pp. 637-654). IGI Global.

Mair, P., Hofmann, E., Gruber, K., Hatzinger, R., Zeileis, A., \& Hornik, K. (2015). Motivation, values, and work design as drivers of participation in the R open source project for statistical computing. Proceedings of the National Academy of Sciences, 112(48), 14788-14792.

Markus, M. L. (2007). The governance of free/open source software projects: Monolithic, multidimensional, or configurational? Journal of Management \& Governance, 11(2), 151-163.

Markus, M. L., Manville, B., \& Agres, C. E. (2000). What makes a virtual organization work? MIT Sloan Management Review, 42(1), 13-26.

Mars, M. M., Bronstein, J. L., \& Lusch, R. F. (2012). The value of a metaphor: Organizations and ecosystems. Organizational Dynamics, 41(4), 271280.

Martin, K. D., Johnson, J. L., \& French, J. J. (2011). Institutional pressures and marketing ethics initiatives: The focal role of organizational identity. Journal of the Academy of Marketing Science, 39(4), 574-591.

Martínez-Torres, M. R., \& Diaz-Fernandez, M. C. (2014). Current issues and research trends on open source software communities. Technology Analysis \& Strategic Management, 26(1), 55-68.

Matei, A., \& Irimia, S. I. (2014). Open Source Governance - A More Ambitious Cousin of Collaborative Governance. International Journal of Public Administration, 37(12), 812-823.

Mateos-Garcia, J., \& Steinmueller, W. E. (2008). The institutions of open source software: Examining the Debian community. Information Economics and Policy, 20(4), 333-344.

McCulloch, R. D. (1981). Putting it on the line. Oak Ridge National Laboratory Reviews, 14(3), 16-21.

Mehra, A., Dewan, R., \& Freimer, M. (2011). Firms as incubators of open source software. Information Systems Research, 22(1), 22-38.

Meng, J. (2011). Understanding cultural influence on price perception: Empirical insights from a SEM application. Journal of Product \& Brand Management, 20(7), 526-540.

Messerschmitt, D. G., \& Szyperski, C. (2005). Software ecosystem: Understanding an indispensable technology and industry. MIT Press.

Meyer, C. B. (2001). A case in case study methodology. Field Methods, 13(4), 329-352. 
Miceli, G., Ricotta, F., \& Costabile, M. (2007). Customizing customization: A conceptual framework for interactive personalization. Journal of Interactive Marketing, 21(2), 6-25.

Midha, V., \& Bhattacherjee, A. (2012). Governance practices and software maintenance: A study of open source projects. Decision Support Systems, 54(1), 23-32.

Miettinen, R., Samra-Fredericks, D., \& Yanow, D. (2009). Re-turn to practice: An introductory essay. Organization Studies, 30(12), 13091327.

Mintzberg, H. (1978). Patterns in strategy formation. Management Science, 24(9), 934-948.

Mishra, A., \& Mishra, D. (2013). Applications of stakeholder theory in information systems and technology. Engineering Economics, 24(3), 254-266.

Mitchell, R. K., Agle, B. R., \& Wood, D. J. (1997). Toward a theory of stakeholder identification and salience: Defining the principle of who and what really counts. Academy of Management Review, 22(4), 853886.

Mitchell, R. K., Lee, J. H., \& Agle, B. R. (2017). Stakeholder Prioritization Work: The Role of Stakeholder Salience in Stakeholder Research. In D. M. Wasieleski \& J. Weber (Eds.), Stakeholder Management (pp. 123-157). Emerald Publishing Limited.

Mollick, E. (2016). Filthy Lucre? Innovative Communities, Identity, and Commercialization. Organization Science, 27(6), 1472-1487.

Monroe, K. B. (2011). Some personal reflections on pricing research. Review of Marketing Research, 8(Special Issue), 209-241.

Moore, J. F. (1993). Predators and prey: A new ecology of competition. Harvard Business Review, 71(3), 75-83.

Moore, J. F. (1996). The death of competition: Leadership and strategy in the age of business ecosystems. Harper Business.

Moore, J. F. (2006). Business ecosystems and the view from the firm. The Antitrust Bulletin, 51(1), 31-75.

Moore, J. F. (2013). Shared purpose: A thousand business ecosystems, a connected community, and the future. Createspace Independent.

Morgan, L., Feller, J., \& Finnegan, P. (2013). Exploring value networks: Theorising the creation and capture of value with open source software. European Journal of Information Systems, 22(5), 569-588.

Morgan, L., \& Finnegan, P. (2014). Beyond free software: An exploration of the business value of strategic open source. The Journal of Strategic Information Systems, 23(3), 226-238. 
Myers, M. D. (1997). Qualitative research in information systems. MIS Quarterly, 21(2), 241-242.

Nakakoji, K., Yamamoto, Y., Nishinaka, Y., Kishida, K., \& Ye, Y. (2002). Evolution patterns of open source software systems and communities. In Proceedings of the International Workshop on Principles of Software Evolution (pp. 76-85). ACM.

Namey, E., Guest, G., Thairu, L., \& Johnson, L. (2008). Data reduction techniques for large qualitative data sets. In G. Guest \& K. M. MacQueen (Eds.), Handbook for team-based qualitative research (pp. 137-162). AltaMira Press.

Normann, R., \& Ramirez, R. (1993). From value chain to value constellation: designing interactive strategy. Harvard Business Review, 71(4), 65-77.

Obermiller, C. (1988). When do consumers infer quality from price? Advances in Consumer Research, 15, 304-310.

Okoli, C., \& Nguyen, J. (2015). Business Models for Free and Open Source Software: Insights from a Delphi Study. SSRN Working Paper Series.

Olderog, T., \& Skiera, B. (2000). The benefits of bundling strategies. Schmalenbach Business Review, 52(2), 137-159.

Olve, N.-G., Cöster, M., Iveroth, E., Petri, C.-J., \& Westelius, A. (2013). Prissättning: Affärsekologier, affärsmodeller, prismodeller. Studentlitteratur AB.

O'Mahony, S. (2007). The governance of open source initiatives: What does it mean to be community managed? Journal of Management \& Governance, 11(2), 139-150.

O'Mahony, S., \& Ferraro, F. (2007). The emergence of governance in an open source community. Academy of Management Journal, 50(5), 1079-1106.

O'Mahony, S., \& Lakhani, K. R. (2011). Organizations in the shadow of communities. Research in the Sociology of Organizations, 33, 3-36.

Oreg, S., \& Nov, O. (2008). Exploring motivations for contributing to open source initiatives: The roles of contribution context and personal values. Computers in Human Behavior, 24(5), 2055-2073.

O'Reilly, T. (1999). Lessons from open source software development. Communications of the ACM, 42(4), 32-37.

Orlikowski, W. J., \& Baroudi, J. J. (1991). Studying information technology in organizations: Research approaches and assumptions. Information Systems Research, 2(1), 1-28.

Osterloh, M., \& Rota, S. (2007). Open source software development - Just another case of collective invention? Research Policy, 36(2), 157-171. 
Osterwalder, A., \& Pigneur, Y. (2010). Business model generation: a handbook for visionaries, game changers, and challengers. John Wiley \& Sons.

Ostrom, E. (2005). Understanding institutional diversity (Vol. 241). Princeton University Press Princeton.

Ouchi, W. G. (1979). A conceptual framework for the design of organizational control mechanisms. Management Science, 25(9), 833-848.

Pan, X., Ratchford, B. T., \& Shankar, V. (2004). Price dispersion on the Internet: A review and directions for future research. Journal of Interactive Marketing, 18(4), 116-135.

Parent, M. M., \& Deephouse, D. L. (2007). A case study of stakeholder identification and prioritization by managers. Journal of Business Ethics, 75(1), 1-23.

Perens, B. (2005). The emerging economic paradigm of open source. First Monday, Special Issue \#2: Open Source.

Perrault, E. (2017). A 'Names-and-Faces Approach'to Stakeholder Identification and Salience: A Matter of Status. Journal of Business Ethics, 146(1), 25-38.

Petri, C.-J. (2014). Using an innovative price model to leverage the business model - the case of price model innovation in the largest Swedish taxi company. Journal of Business Models, 2(1), 56-70.

Petri, C.-J., Radits, M., \& Iveroth, E. (2018). Prissättning. In E. Iveroth, J. Lindvall, \& J. Magnusson (Eds.), Digitalisering och styrning. Studentlitteratur.

Piercy, N. F., Cravens, D. W., \& Lane, N. (2010). Thinking strategically about pricing decisions. Journal of Business Strategy, 31(5), 38-48.

Pigou, A. C. (2013). The economics of welfare. Routledge.

Plummer, T. (2013). Learning Joomla! 3 Extension Development. Packt Publishing.

Ponelis, S. R. (2015). Using interpretive qualitative case studies for exploratory research in doctoral studies: A case of information systems research in small and medium enterprises. International Journal of Doctoral Studies, 10, 535-550.

Prahalad, C. K., \& Ramaswamy, V. (2004). Co-creation experiences: The next practice in value creation. Journal of Interactive Marketing, 18(3), 5-14.

Pratt, M. G. (2003). Disentangling collective identities. In J. Polzer (Ed.), Identity issues in groups (pp. 161-188). Emerald Group Publishing. 
Pratt, M. G., \& Foreman, P. O. (2000). Classifying managerial responses to multiple organizational identities. Academy of Management Review, 25(1), 18-42.

Puranam, P., Alexy, O., \& Reitzig, M. (2014). What's 'new' about new forms of organizing? Academy of Management Review, 39(2), 162-180.

Pytlik Zillig, L. M., \& Kimbrough, C. D. (2016). Consensus on conceptualizations and definitions of trust: Are we there yet? In E. Shockley, T. M. S. Neal, \& L. M. PytlikZillig (Eds.), Interdisciplinary perspectives on trust (pp. 17-47). Springer.

Raghunathan, S. (2000). Software editions: An application of segmentation theory to the packaged software market. Journal of Management Information Systems, 17(1), 87-113.

Raymond, E. (1999a). A brief history of hackerdom. In C. DiBona, S. Ockman, \& M. Stone (Eds.), Open sources: Voices from the revolution (pp. 19-30). O'Reilly Media. Retrieved from https://immagic.com/eLibrary/ARCHIVES/GENERAL/AUTHOR_P/R00 0825P.pdf

Raymond, E. (1999b). The cathedral and the bazaar. Knowledge, Technology \& Policy, 12(3), 23-49.

Raymond, E. (1999c). The revenge of the hackers. In C. DiBona, S. Ockman, \& M. Stone (Eds.), Open sources: Voices from the revolution (pp. 207220). O'Reilly Media.

Riehle, D. (2009a). The business model of commercial open source software. Technical report, SAP Research.

Riehle, D. (2009b). The commercial open source business model. In M. L. Nelson, M. J. Shaw, \& T. J. Strader (Eds.), Value Creation in E-Business Management (pp. 18-30). Springer.

Riehle, D. (2012). The single-vendor commercial open course business model. Information Systems and E-Business Management, 10(1), 5-17.

Roberts, J. A., Hann, I.-H., \& Slaughter, S. A. (2006). Understanding the motivations, participation, and performance of open source software developers: A longitudinal study of the Apache projects. Management Science, 52(7), 984-999.

Robey, D., Schwaig, K. S., \& Jin, L. (2003). Intertwining material and virtual work. Information and Organization, 13(2), 111-129.

Rosenfall, T. (2012). Open Source Vendors' Business Models. Linköping University Electronic Press.

Rossi, M. A. (2006). Decoding the 'free/open source (F/OSS) software puzzle', a survey of theoretical and empirical contributions. In J. Bitzer \& P. J. Schröder (Eds.), The Economics of Open Source Software Development (pp. 15-55). Emerald Group Publishing. 
Rozas, D., \& Gilbert, N. (2015). Talk is silver, code is gold? Contribution beyond source code in free/libre open source software communities. Presented at the British Sociological Association Annual Conference 2015.

Ryan, R. M., \& Deci, E. L. (2000). Intrinsic and extrinsic motivations: Classic definitions and new directions. Contemporary Educational Psychology, 25(1), 54-67.

Ryan, R. M., Sheldon, K. M., Kasser, T., \& Deci, E. L. (1996). All goals are not created equal: An organismic perspective on the nature of goals and their regulation. In P. M. Gollwitzer \& J. A. Bargh (Eds.), The psychology of action: Linking cognition and motivation to behavior (pp. 7-26). Guilford Press.

Sadowski, B. M., Sadowski-Rasters, G., \& Duysters, G. (2008). Transition of governance in a mature open software source community: Evidence from the Debian case. Information Economics and Policy, 20(4), 323332.

Sagers, G. (2004). The influence of network governance factors on success in open source software development projects. In ICIS 2004 Proceedings (pp. 427-438). AIS Electronic Library.

Sagers, G., McLure-Wasko, M., \& Dickey, M. (2004). Coordinating efforts in virtual communities: Examining network governance in open source. In AMCIS 2004 Proceedings (pp. 2695-2698). AIS Electronic Library. Salus, P. H. (1994). A quarter century of UNIX. Addison-Wesley Publishing. Santos, C., Kuk, G., Kon, F., \& Pearson, J. (2013). The attraction of contributors in free and open source software projects. The Journal of Strategic Information Systems, 22(1), 26-45.

Scacchi, W., Feller, J., Fitzgerald, B., Hissam, S., \& Lakhani, K. (2006). Understanding free/open source software development processes. Software Process: Improvement and Practice, 11(2), 95-105.

Schaarschmidt, M. (2012). Firms in open source software development: managing innovation beyond firm boundaries. Springer.

Schaarschmidt, M., Bertram, M., \& von Kortzfleisch, H. F. (2011). Exposing differences of governance approaches in single and multi vendor open source software development. In M. Nüttgens, A. Gadatsch, K. Kautz, I. Schirmer, \& N. Blinn (Eds.), Governance and sustainability in information systems. Managing the transfer and diffusion of IT (pp. 1628). Springer.

Schaarschmidt, M., Walsh, G., \& von Kortzfleisch, H. F. (2015). How do firms influence open source software communities? A framework and empirical analysis of different governance modes. Information and Organization, 25(2), 99-114. 
Schreier, M. (2014). Qualitative content analysis. In U. Flick (Ed.), The SAGE Handbook of Qualitative Data Analysis (pp. 170-183). SAGE Publications.

Schwandt, T. A. (1998). Constructivist, interpretivist approaches to human inquiry. In N. K. Denzin \& Y. S. Lincoln (Eds.), The landscape of qualitative research: Theories and issues (pp. 221-259). Sage Publications.

Schwarz, A., \& Jax, K. (2011). Etymology and Original Sources of the Term 'Ecology'. In A. Schwarz \& K. Jax (Eds.), Ecology Revisited (pp. 145147). Springer.

Schweik, C. M., \& English, R. C. (2012). Internet success: A study of open source software commons. MIT Press.

Seeley, T. D. (2001). Decision making in superorganisms: How collective wisdom arises from the poorly informed masses. In G. Gigerenzer \& R. Selten (Eds.), Bounded rationality: The adaptive toolbox (pp. 249261).

Severance, C. (2014). Andrew S. Tanenbaum: The Impact of MINIX. Computer, 47(7), 7-8.

Severdia, R., \& Crowder, K. (2009). Using Joomla: Building powerful and efficient Web sites. O'Reilly Media.

Shah, S. (2006). Motivation, governance, and the viability of hybrid forms in open source software development. Management Science, 52(7), 1000-1014.

Shah, S., \& Tripsas, M. (2016). When do user innovators start firms? A theory of user entrepreneurship. In D. Harhoff \& K. R. Lakhani (Eds.), Revolutionizing innovation: Users, communities and open innovation (pp. 285-307). MIT Press.

Shapiro, C., \& Varian, H. R. (1998). Versioning: The smart way to sell information. Harvard Business Review, 76(6), 106-115.

Shapiro, C., \& Varian, H. R. (1999). Information rules: A strategic guide to the network economy. Harvard Business School Press.

Sharma, S., Sugumaran, V., \& Rajagopalan, B. (2002). A framework for creating hybrid open source software communities. Information Systems Journal, 12(1), 7-25.

Shivendu, S., \& Zhang, Z. (2015). Versioning in the software industry: Heterogeneous disutility from underprovisioning of functionality. Information Systems Research, 26(4), 731-753.

Shy, O. (2001). The economics of network industries. Cambridge University Press.

Skerrett, I. (2011). Best practices in multi-vendor open source communities. Technology Innovation Management Review, (January), 11-14. 
Soenen, G., \& Moingeon, B. (2002). The five facets of collective identities. In B. Moingeon \& G. Soenen (Eds.), Corporate and Organizational Identities. Routledge.

Spinellis, D. (2017). A repository of Unix history and evolution. Empirical Software Engineering, 22(3), 1372-1404.

Stampfl, G., Prügl, R., \& Osterloh, V. (2013). An explorative model of business model scalability. International Journal of Product Development, 18(3-4), 226-248.

Stewart, K. J., \& Gosain, S. (2001). An exploratory study of ideology and trust in open source development groups. In ICIS 2001 Proceedings (pp. 507-512).

Stewart, K. J., \& Gosain, S. (2006). The impact of ideology on effectiveness in open source software development teams. MIS Quarterly, 30(2), 291-314.

Stimpert, J. L., Gustafson, L. T., \& Sarason, Y. (1998). Organizational identity within the strategic management conversation: Contributions and assumptions. In D. A. Whetten \& P. C. Godfrey (Eds.), Identity in organizations: Building theory through conversations (pp. 83-98). SAGE Publications.

Stremersch, S., \& Tellis, G. J. (2002). Strategic bundling of products and prices: A new synthesis for marketing. Journal of Marketing, 66(1), 5572.

Tansley, A. G. (1935). The use and abuse of vegetational concepts and terms. Ecology, 16(3), 284-307.

Tavakoli, A., \& Schlagwein, D. (2016). A review of the use of practice theory in information systems research. In PACIS 2016 Proceedings. AIS Electronic Library.

Teixeira, J., Mian, S., \& Hytti, U. (2016). Cooperation among competitors in the open source arena: The case of openstack. Presented at the International Conference on Information Systems (ICIS 2016), AIS Electronic Library.

Terry, D. J., Hogg, M. A., \& White, K. M. (1999). The theory of planned behaviour: Self-identity, social identity and group norms. British Journal of Social Psychology, 38(3), 225-244.

Thomas, L. D., \& Autio, E. (2014). The fifth facet: The ecosystem as an organizational field. In DRUID Society Conference.

Timmermans, S., \& Tavory, I. (2012). Theory construction in qualitative research: From grounded theory to abductive analysis. Sociological Theory, 30(3), 167-186.

Tozzi, C., \& Zittrain, J. (2017). For Fun and Profit: A History of the Free and Open Source Software Revolution. MIT Press. 
Trice, H. M., \& Beyer, J. M. (1993). The cultures of work organizations. Prentice Hall.

Tsay, J., Dabbish, L., \& Herbsleb, J. (2014). Influence of social and technical factors for evaluating contribution in GitHub. In Proceedings of the 36th International Conference on Software Engineering (pp. 356-366). ACM.

Tsoy, M., \& Staples, D. S. (2018). Role of reputation cues in trust formation for a developer's decision to join Open Source Software projects.

Vaara, E., \& Whittington, R. (2012). Strategy-as-practice: Taking social practices seriously. Academy of Management Annals, 6(1), 285-336.

Valença, G., Alves, C., Heimann, V., Jansen, S., \& Brinkkemper, S. (2014). Competition and collaboration in requirements engineering: $A$ case study of an emerging software ecosystem. In 2014 IEEE 22nd International Requirements Engineering Conference (pp. 384-393). IEEE.

Valiente, P., \& Westelius, A. (2007). Sustainable Value of Wireless ICT in Communication with Mobile Employees. In P. Andersson, U. Essler, \& B. Thorngren (Eds.), Beyond Mobility (pp. 130-151). Studentlitteratur.

Valimaki, M. (2003). Dual licensing in open source software industry. Systemes D'Information et Management, 8(1), 63-75.

Valkokari, K. (2015). Business, innovation, and knowledge ecosystems: How they differ and how to survive and thrive within them. Technology Innovation Management Review, 5(8), 17-24.

van Maanen, J., Sørensen, J. B., \& Mitchell, T. R. (2007). The interplay between theory and method. Academy of Management Review, 32(4), 1145-1154.

Varian, H. R. (1997). Versioning information goods. University of California. Varian, H. R. (2000). Buying, sharing and renting information goods. The Journal of Industrial Economics, 48(4), 473-488.

Venkatesh, R., \& Chatterjee, R. (2006). Bundling, unbundling, and pricing of multiform products: The case of magazine content. Journal of Interactive Marketing, 20(2), 21-40.

Venkatesh, R., \& Mahajan, V. (2009). The design and pricing of bundles: A review of normative guidelines and practical approaches. In Handbook of pricing research in marketing (pp. 232-257). Edward Elgar Publishing.

Viswanathan, S., \& Anandalingam, G. (2005). Pricing strategies for information goods. Sadhana, 30(2), 257-274.

von Hippel, E. (2001). Innovation by user communities: Learning from open source software. MIT Sloan Management Review, 42(4), 82-86. 
von Hippel, E. (2005). Democratizing innovation. MIT press.

von Hippel, E., \& von Krogh, G. (2003). Open source software and the "private-collective" innovation model: Issues for organization science. Organization Science, 14(2), 209-223.

von Krogh, G. (2003). Open source software development. MIT Sloan Management Review, 44(3), 14-18.

von Krogh, G., Haefliger, S., Spaeth, S., \& Wallin, M. W. (2012). Carrots and rainbows: Motivation and social practice in open source software development. MIS Quarterly, 36(2), 649-676.

von Krogh, G., Spaeth, S., \& Lakhani, K. R. (2003). Community, joining, and specialization in open source software innovation: A case study. Research Policy, 32(7), 1217-1241.

von Krogh, G., \& von Hippel, E. (2006). The promise of research on open source software. Management Science, 52(7), 975-983.

Walsham, G. (1995). Interpretive case studies in IS research: nature and method. European Journal of Information Systems, 4(2), 74-81.

Walsham, G. (2006). Doing interpretive research. European Journal of Information Systems, 15(3), 320-330.

Walsham, G., \& Sahay, S. (1999). GIS for district-level administration in India: Problems and opportunities. MIS Quarterly, 23(1), 39-65.

Wasko, M. M., \& Faraj, S. (2000). 'It is what one does': Why people participate and help others in electronic communities of practice. The Journal of Strategic Information Systems, 9(2-3), 155-173.

Wasserman, A. I. (2013). Community and commercial strategies in open source software. Information Technology, 55(5), 181-188.

Watson, R. T., Boudreau, M.-C., York, P. T., Greiner, M. E., \& Wynn Jr, D. (2008). The business of open source. Communications of the ACM, $51(4), 41-46$.

Weber, S. (2004). The success of open source. Harvard University Press.

Weiss, M. (2015). The business of open source: Missing patterns. In Proceedings of the 20th European Conference on Pattern Languages of Programs. ACM.

West, J. (2007). Value capture and value networks in open source vendor strategies. In 40th Annual Hawaii International Conference on System Sciences (HICSS'07). IEEE.

West, J., \& Bogers, M. (2014). Leveraging external sources of innovation: A review of research on open innovation. Journal of Product Innovation Management, 31(4), 814-831.

West, J., \& Dedrick, J. (2001). Open source standardization: The rise of Linux in the network era. Knowledge, Technology \& Policy, 14(2), 88-112. 
West, J., \& Gallagher, S. (2006a). Challenges of open innovation: The paradox of firm investment in open source software. $R \& D$ Management, 36(3), 319-331.

West, J., \& Gallagher, S. (2006b). Patterns of open innovation in open source software. In H. Chesbrough, W. Vanhaverbeke, \& J. West (Eds.), Open Innovation: Researching a new paradigm (pp. 82-108). Oxford University Press.

West, J., \& Lakhani, K. R. (2008). Getting clear about communities in open innovation. Industry and Innovation, 15(2), 223-231.

West, J., \& O'Mahony, S. (2008). The role of participation architecture in growing sponsored open source communities. Industry and Innovation, 15(2), 145-168.

West, J., Salter, A., Vanhaverbeke, W., \& Chesbrough, H. (2014). Open innovation: The next decade. Research Policy, 43(5), 805-811.

West, J., \& Wood, D. (2013). Evolving an open ecosystem: The rise and fall of the Symbian platform. In R. Adner, J. E. Oxley, \& B. S. Silverman (Eds.), Collaboration and Competition in Business Ecosystems (Vol. 30, pp. 27-67). Emerald Group Publishing.

Westelius, A. (1996). A study of patterns of communication in management accounting and control projects. Stockholm School of Economics.

Westelius, A. (2006). Images and imaginators in virtual organising - The NPO Friluftsfrämjandet and www. frilufts.se. International Journal of Public Information Systems, 2(1), 11-37.

Westelius, A. (2008). Energirådgivning 2.0: Läge och möjligheter. Linköping Electronic Articles in Computer and Information Science, 12(1).

Westelius, A., \& Lind, J. (2016). Painting the relevant organisation. In F. Nilsson, C.-J. Petri, \& A. Westelius (Eds.), Strategic management control: With a focus on dialogue. Studentlitteratur.

Westelius, A., Westelius, A.-S., \& Brytting, T. (2013). Meaning, authority, rationality and care as MARCs of sustainable organisations. Cross Cultural Management: An International Journal, 20(2), 161-185.

Whetten, D. A. (1998). Why organizational identity and why conversations? In D. A. Whetten \& P. C. Godfrey (Eds.), Identity in Organizations. SAGE Publications.

Whetten, D. A. (2006). Albert and Whetten revisited: Strengthening the concept of organizational identity. Journal of Management Inquiry, 15(3), 219-234.

Whinston, M. D. (1990). Tying, foreclosure, and exclusion. The American Economic Review, 80(4), 837-859.

Williams, S. (2002). Free as in freedom: Richard Stallman's crusade for free software. O'Reilly Media. 
Wu, C.-G., Gerlach, J. H., \& Young, C. E. (2007). An empirical analysis of open source software developers' motivations and continuance intentions. Information \& Management, 44(3), 253-262.

Wu, S., Hitt, L. M., Chen, P., \& Anandalingam, G. (2008). Customized bundle pricing for information goods: A nonlinear mixed-integer programming approach. Management Science, 54(3), 608-622.

Ye, Y., \& Kishida, K. (2003). Toward an understanding of the motivation open source software developers. In Proceedings of the 25th international conference on software engineering (ICSE 03) (pp. 419429). ACM.

Yin, R. K. (2009). Case study research: Design and methods (4th ed.). SAGE Publications.

Zahra, S. A., \& Nambisan, S. (2012). Entrepreneurship and strategic thinking in business ecosystems. Business Horizons, 55(3), 219-229.

Zwass, V. (2010). Co-creation: Toward a taxonomy and an integrated research perspective. International Journal of Electronic Commerce, 15(1), 11-48. 



\section{Appendices}

\subsection{Appendix A1 - interview guide for the first set of interviews}

\section{Basics}

Vendor

- Where is your company legally based? How would you describe your position(s) in the company?

- How many employees/team members do you have? In which countries are they located?

- Could you please tell us your annual revenues generated by extensions and complementary services?

- How would you describe the segment to which your main customers belong?

- Can you describe the competition in your area? Is there anything salient?

Motivation

- What are your motivations for developing Joomla extensions?

- How did you come to start doing this work?

- When did you start to offer commercial extensions?

- Did you offer free extensions before doing so?

- Do you still offer free extensions? If so, why the combination of free and commercial?

Non-commercial to commercial

- What kind of difficulties have you faced/do you face in offering commercial Joomla extensions?

- What obstacles do you face when pricing your products/extensions?

- How do you cope with these obstacles? 


\section{Pricing}

Scope

- In what ways do you try to package your offering?

- What is the reasoning behind this?

Price base

- What kind of information dominates your pricing decisions? (e.g., cost of developing, producing, distributing, and selling the products and services, competitor price, others?)

- Are your competitors' prices part of the base for the pricing decisions?

- How does customer value impact upon the pricing decision?

\section{Influence}

- To what extent do buyers have the power to influence the price? Are there negotiation attempts? How do you react to negotiation attempts?

- In what ways can result-based pricing be a viable alternative? (e.g., revenue split until your customer breaks even)

- As a vendor, what is your experience with donation systems or 'paywhat-you-want' models?

\section{Formula}

- In what ways can it make sense to charge per customer system transaction? (e.g., per request, per registration, etc.)

Temporal rights

- In what ways can it make sense to offer the leasing of software? (e.g., through web services, etc.)

- Have you considered selling your extensions as a product (e.g., the customer pays once and acquires the perpetual right of use) - what speaks for and what speaks against it?

Bundling and Signalling 
- How do you want your customers to view you?

- What kind of signals do you want to send to potential buyers?

- What kind of signals have proven to be effective means to attract customers?

- What kind of signals do you try to avoid? (e.g., promises or expectations that cannot be fulfilled, etc.)

- How would you describe your bundling strategies? How are they received by customers and other team members?

- What is your most popular bundling option? Why do you think so?

- What is the reasoning behind bundling?

\section{Community aspects}

- What do you like about Joomla? (e.g., platform, community, architecture, future development, etc.)

- What do you dislike about it? (e.g., platform, community, architecture, future development, etc.)

- Are there any tensions/conflicts between your strategies/activities as an extension provider and the strategies/activities of the Joomla core team?

- In what ways are you active in the Joomla community?

- What are potential growth strategies for Joomla as a platform and what are your ambitions as an extension developer?

\section{Other questions}

- What other aspects (not mentioned so far) impact upon pricing?

- Is there anything else that you want to say? 


\subsection{Appendix A2 - interview guide for the second set of interviews with a focus on governance and organisational identity}

\section{Demographic information}

- What is your age?

- What is your profession?

- What is your highest level of education?

- What is your nationality?

\section{Collective identities}

\section{Individual}

- In what ways are you active within the Joomla community? (And since when?)

- On a spectrum from core to peripheral participation, where would you see yourself and your activities?

- What does Joomla mean to you? What do you like about the community? What do you dislike about the community?

- What do you like about Joomla as a tool? What do you dislike about it?

- In what ways do you identify with Joomla and/or its community? Is it also important for your professional identity?

- What made/makes you participate in the community (and how did your participation level change over time)?

- Do you use Joomla to pursue economic goals? (E.g., do you have a business that is in some way related to Joomla?)

\section{Interpersonal}

- How would you characterise your collaboration/work/interaction with your community peers?

- In what ways is it important to have interpersonal ties within the community?

- What typical conflicts arise in your interaction/work with your community peers?

- What are your strategies to deal with these conflicts? 
Collective

- How would you describe your sense of the community as a whole? Or, how would you describe Joomla's identity?

- What are the purposes of Joomla and its community?

- What kind of problems does Joomla and its community face? (Also try to explain why.)

- What values are commonly cherished within the community?

- What do people (commonly) disagree about? And why?

- Who or what is (dominantly) shaping the activities and opinions within the community, and how?

\section{Project success and innovative capabilities}

Project success

- Concerning Joomla, how would you define project success? What enables/hinders it?

- How would you define community success? What enables/hinders it?

- How would you define community performance? What enables/hinders it?

- How would you characterise Joomla's productivity?

- Why are people leaving the community? Why are new people coming in?

Innovative capabilities

- How would you describe the community's ability to innovate?

- What facilitates/hinders innovation within the community?

- How is Joomla affected by general trends (E.g., societal, technological)? What are the consequences of this?

\section{Governance perspective}

\section{Ideological foundations}

- Do you think there is an ideology and/or ideological foundation behind Joomla that created or holds the community together (like an open source ideology, or a software engineering ethos, or others)? If so, can you describe it? 
Collaborative type

- In what ways do users' demands, needs, requirements, and claims affect activities within the community?

Patronage and sponsorship influence

- How does Joomla's organisational structure impact upon community activity?

- What role do sponsors play?

Licensing

- What is the role of licensing (e.g., the terms and ideas stipulated by the GPL)?

Roles and Responsibilities

- How does the division of labour, role structure, and the assignment of roles and responsibilities work in the community?

Membership

- How can we think about membership of the community (e.g., levels of participation, formal versus informal membership)?

Monitoring

- How is compliance with guides and policies ensured? What facilitates members' compliance with rules, guidelines, and policies?

Sanctions

- What kinds of behaviour can be subject to sanctions by community members? What kinds of sanctioning can be observed?

Incentive Structure

- What drives people in the community (e.g., intrinsic versus extrinsic motivations)? 
Decision-making and authority

- How can we think about decision-making and authority within the community (e.g., distribution of authority, delegation mechanisms, leadership and vision, conflict resolution, transparency of decisionmaking processes, decisions about strategy and future courses of action)?

Life-cycles

- What can you say about Joomla's future and the future of its community? What can you say about the maturity of Joomla's organisational structure and governance systems?

Organisational climate

- How would you describe Joomla's organisational climate?

Communication tools

- What are the community's dominant means of communication?

Leadership

- How would you interpret and describe leadership in the context of Joomla?

Stakeholders

- Who are important stakeholders for Joomla and its community (e.g., who is affected by Joomla and its community and, conversely, who or what affects Joomla and its community)?

Others

- If you could change anything about Joomla (or its community), what would that be?

- Is there anything else you want to say? 


\subsection{Appendix A3 - interview guide for the second set of interviews with a focus on business aspects}

- What kinds of products or services (related to Joomla) are you offering?

- How would you describe the competition in your business segment?

- How would you describe your value propositions?

- What makes your value proposition attractive to customers?

- How would you describe your core capabilities?

- How can customer relationships be managed and maintained?

- What are your typical customer segments?

- Through what channels do you find your customers (or how do they find you)?

- How would you describe the key activities that enable you to develop your value proposition?

- How do you interact with your key partners? Or, what kind of relationships are crucial in your business models?

- What are the key resources that enable you to develop your value proposition?

- What are the main cost drivers?

- How do you price your products and services?

- What other business models do you see in Joomla? (e.g., support, maintenance, development, others)

\subsection{Appendix A4 - a review of the literature on open source community engagement with a focus on economic incentives (Study IV)}

\begin{tabular}{|c|c|c|c|c|}
\hline Authors & $\begin{array}{l}\text { Research } \\
\text { design }\end{array}$ & $\begin{array}{l}\text { Relevant findings with respect } \\
\text { to extrinsic motivations }\end{array}$ & Perspective & Community \\
\hline $\begin{array}{l}\text { (Bagozzi \& } \\
\text { Dholakia, } \\
\text { 2006) }\end{array}$ & $\begin{array}{l}\text { Quantitative } \\
\text { (statistical } \\
\text { analysis). }\end{array}$ & $\begin{array}{l}\text { Voluntary Linux user groups } \\
\text { fulfil equivalent functions } \\
\text { found in proprietary software } \\
\text { development. They serve as } \\
\text { marketing agents, provide } \\
\text { customer support, and discuss } \\
\text { strategic opportunities for } \\
\text { business development. } \\
\text { Through their activities and } \\
\text { work, user groups help } \\
\text { increasing the adoption rates of } \\
\text { the software and thereby } \\
\text { contribute to the growth and } \\
\text { success of the open source } \\
\text { platform. }\end{array}$ & $\begin{array}{l}\text { Theory of planned } \\
\text { behaviour, goal- } \\
\text { directed behaviour, } \\
\text { motivation theory, } \\
\text { social identity } \\
\text { theory, and } \\
\text { philosophy of } \\
\text { collective } \\
\text { intentionality. }\end{array}$ & $\begin{array}{ll}\text { Linux } & \text { user } \\
\text { groups. } & \end{array}$ \\
\hline
\end{tabular}




\begin{tabular}{|c|c|c|c|c|}
\hline $\begin{array}{l}\text { (Benbya \& } \\
\text { Belbaly, } \\
2010)\end{array}$ & $\begin{array}{l}\text { Quantitative } \\
\text { (statistical } \\
\text { analysis). }\end{array}$ & $\begin{array}{l}\text { Career expectations and the } \\
\text { development of professional } \\
\text { opportunities are significantly } \\
\text { linked to the type of } \\
\text { participation (e.g., submitting } \\
\text { and reviewing source code) } \\
\text { rather than the overall time } \\
\text { spent on working for a project. }\end{array}$ & $\begin{array}{l}\text { Social exchange } \\
\text { theory, goal } \\
\text { orientation, } \\
\text { expectancy theory. }\end{array}$ & $\begin{array}{l}\text { Sample of } \\
\text { projects } \\
\text { registered on } \\
\text { SourceForge. }\end{array}$ \\
\hline $\begin{array}{l}\text { (Bianchi, } \\
\text { Kang, \& } \\
\text { Stewart, } \\
\text { 2012) }\end{array}$ & $\begin{array}{l}\text { Quantitative } \\
\text { (statistical } \\
\text { analysis). }\end{array}$ & $\begin{array}{l}\text { The level of formal education } \\
\text { and age are not associated with } \\
\text { social status in open source } \\
\text { communities unlike in many } \\
\text { other social settings. Status in } \\
\text { open source communities } \\
\text { derives from demonstrating } \\
\text { commitment and dedication to } \\
\text { tasks. Such meritocratic reward } \\
\text { systems span boundaries } \\
\text { around groups of people where } \\
\text { internal status characteristics } \\
\text { are activated and where } \\
\text { society-level status } \\
\text { characteristics are deactivated. }\end{array}$ & $\begin{array}{l}\text { Status } \\
\text { characteristics } \\
\text { theory. }\end{array}$ & Advogato. \\
\hline $\begin{array}{l}\text { (Crowston } \\
\text { et al., 2012) }\end{array}$ & $\begin{array}{l}\text { Qualitative } \\
\text { and } \\
\text { quantitative } \\
\text { (literature } \\
\text { review). }\end{array}$ & $\begin{array}{l}\text { They argue that empirical work } \\
\text { has provided little evidence for } \\
\text { Lerner and Tirole's (2002) } \\
\text { hypothesis that "motivation is } \\
\text { derived from indirect signalling } \\
\text { about quality, with the payoff } \\
\text { to come in higher career } \\
\text { earnings" (Crowston et al., } \\
2012 \text {, p. 14). However, the } \\
\text { authors do not further elaborate } \\
\text { on this specific claim. They cite } \\
\text { reputation and career } \\
\text { development as frequently } \\
\text { mentioned extrinsic } \\
\text { motivations, whereas fun, } \\
\text { sharing and learning } \\
\text { opportunities are mentioned as } \\
\text { the most frequent intrinsic } \\
\text { motivations discussed in the } \\
\text { literature. They argue that } \\
\text { recent literature has also started } \\
\text { to explore motivations for } \\
\text { sustained participation. } \\
\text { However, they find that only } \\
\text { few studies have addressed } \\
\text { how intrinsic and extrinsic } \\
\text { factors interact to stimulate } \\
\text { participation. }\end{array}$ & $\begin{array}{lr}\text { Literature } & \text { review } \\
\text { with a general } \\
\text { focus } \\
\text { development } \\
\text { processes. }\end{array}$ & $\begin{array}{l}\text { Apache, Bind, } \\
\text { Eclipse, } \\
\text { Gnome, } \\
\text { Mozilla } \\
\text { Firefox, Linux, } \\
\text { MySQL, } \\
\text { Sendmail, Perl, } \\
\text { Python, } \\
\text { OpenOffice. }\end{array}$ \\
\hline $\begin{array}{l}\text { (Fang \& } \\
\text { Neufeld, } \\
\text { 2009) }\end{array}$ & $\begin{array}{l}\text { Qualitative } \\
\text { and } \\
\text { quantitative } \\
\text { (longitudinal } \\
\text { case study). }\end{array}$ & $\begin{array}{l}\text { Their study emphasises situated } \\
\text { learning and identity } \\
\text { construction as important } \\
\text { antecedents for long-term } \\
\text { participation. Though use } \\
\text { value explains initial }\end{array}$ & $\begin{array}{l}\text { Theory of } \\
\text { legitimate } \\
\text { peripheral } \\
\text { participation. }\end{array}$ & phpMyAdmin. \\
\hline
\end{tabular}




\begin{tabular}{|c|c|c|c|c|}
\hline & & $\begin{array}{l}\text { participation, situated learning } \\
\text { and identity construction are } \\
\text { determinants for long-term and } \\
\text { esteem-oriented participation. }\end{array}$ & & \\
\hline $\begin{array}{l}\text { (Fershtman } \\
\text { \& Gandal, } \\
\text { 2007) }\end{array}$ & $\begin{array}{l}\text { Quantitative } \\
\text { (statistical } \\
\text { analysis). }\end{array}$ & $\begin{array}{l}\text { Being listed as a contributor is } \\
\text { an important incentive to } \\
\text { contribute. The authors suggest } \\
\text { that output per contributor } \\
\text { (measured in source lines of } \\
\text { code) is higher with less } \\
\text { restrictive open source } \\
\text { licences. They further contend } \\
\text { that open source projects with } \\
\text { less restrictive licensing are } \\
\text { more commercially oriented. }\end{array}$ & $\begin{array}{l}\text { Motivation theory } \\
\text { and open source } \\
\text { licensing. }\end{array}$ & $\begin{array}{l}71 \text { SourceForge } \\
\text { projects. }\end{array}$ \\
\hline $\begin{array}{l}\text { (S. Freeman, } \\
2007)\end{array}$ & $\begin{array}{l}\text { Qualitative } \\
\text { (interviews } \\
\text { and archival } \\
\text { data). }\end{array}$ & 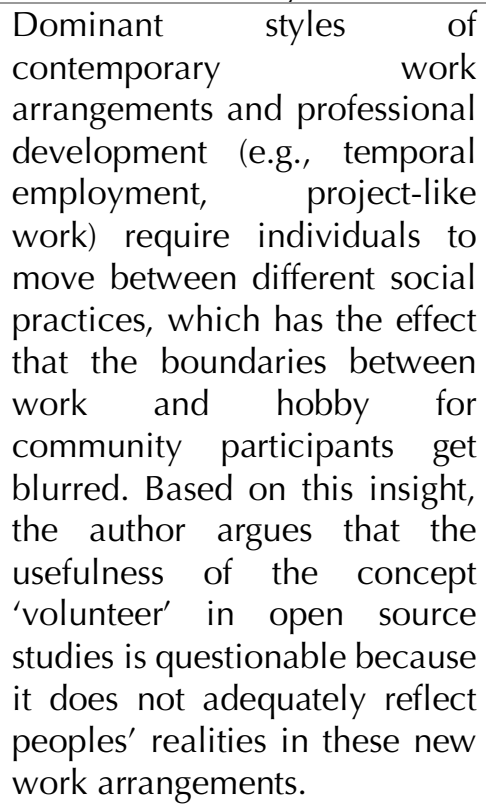 & $\begin{array}{l}\text { Cultural } \\
\text { psychology, critical } \\
\text { psychology and } \\
\text { activity theory. }\end{array}$ & OpenOffice. \\
\hline $\begin{array}{l}\text { (Hertel, } \\
2007)\end{array}$ & $\begin{array}{l}\text { Qualitative } \\
\text { (conceptual). }\end{array}$ & $\begin{array}{l}\text { In contrast to person-oriented } \\
\text { aspects of motivation, research } \\
\text { should also consider the ways } \\
\text { in which job characteristics } \\
\text { motivate community } \\
\text { engagement. Amongst others, } \\
\text { the author suggest that job } \\
\text { characteristics like task } \\
\text { complexity, opportunities for } \\
\text { learning, social support, or } \\
\text { individual autonomy and } \\
\text { responsibilities are promising } \\
\text { for such endeavours. The } \\
\text { results of this article are } \\
\text { relevant to economic } \\
\text { incentives insofar as the author } \\
\text { suggest that this research } \\
\text { avenue could potentially shed } \\
\text { more light on possible benefits } \\
\text { and drawbacks of adopting } \\
\text { traits of open source } \\
\text { development into corporate }\end{array}$ & $\begin{array}{l}\text { Work psychology, } \\
\text { job characteristics. }\end{array}$ & $\begin{array}{l}\text { Reference to } \\
\text { Linux, Apache, } \\
\text { Mozilla and } \\
\text { WikiPedia. }\end{array}$ \\
\hline
\end{tabular}




\section{Chapter 20: Appendices}

\begin{tabular}{|c|c|c|c|c|}
\hline & & $\begin{array}{l}\text { and closed } \\
\text { development. }\end{array}$ & & \\
\hline $\begin{array}{l}\text { (Ke \& } \\
\text { Zhang, } \\
\text { 2009) }\end{array}$ & $\begin{array}{l}\text { Quantitative } \\
\text { (statistical } \\
\text { analysis). }\end{array}$ & $\begin{array}{l}\text { Extrinsic motivations lead to } \\
\text { strong individual commitment } \\
\text { to tasks but does not lead to } \\
\text { strong involvement in terms of } \\
\text { effort intensity (i.e., time } \\
\text { invested). }\end{array}$ & $\begin{array}{l}\text { Self-determination } \\
\text { theory. }\end{array}$ & $\begin{array}{l}\text { Sample of } \\
\text { participants } \\
\text { from } \\
\text { SourceForge } \\
\text { MySQL and } \\
\text { OpenOffice. }\end{array}$ \\
\hline $\begin{array}{l}\text { (Lerner \& } \\
\text { Tirole, } \\
\text { 2002) }\end{array}$ & $\begin{array}{l}\text { Qualitative } \\
\text { (Interviews } \\
\text { and } \\
\text { secondary } \\
\text { sources). }\end{array}$ & $\begin{array}{l}\text { Career concern incentives as a } \\
\text { delayed reward scheme, e.g., } \\
\text { future job offers, shares in } \\
\text { commercial open-source- } \\
\text { based companies, future access } \\
\text { to venture capital. Signalling of } \\
\text { performance and reputation. }\end{array}$ & $\begin{array}{l}\text { Labour economics, } \\
\text { career concerns, } \\
\text { and industrial } \\
\text { organization } \\
\text { theory. }\end{array}$ & $\begin{array}{l}\text { Apache, Linux, } \\
\text { Perl, and } \\
\text { Sendmail. }\end{array}$ \\
\hline $\begin{array}{l}(\mathrm{Li}, \mathrm{Tan}, \& \\
\text { Teo, 2012) }\end{array}$ & $\begin{array}{l}\text { Quantitative } \\
\text { (statistical } \\
\text { analysis). }\end{array}$ & $\begin{array}{l}\text { Open source development } \\
\text { strategies are increasingly } \\
\text { considered by commercial } \\
\text { actors. Leadership is an } \\
\text { important antecedence for } \\
\text { motivating and attracting } \\
\text { contributions. Developer who } \\
\text { are more extrinsically } \\
\text { motivated prefer transactional } \\
\text { leadership styles (i.e., } \\
\text { leadership provides clear } \\
\text { structure that define rewards } \\
\text { and punishments). Developer } \\
\text { who are more intrinsically } \\
\text { motivated prefer } \\
\text { transformational leadership } \\
\text { styles (i.e., leaders provide } \\
\text { intellectual stimulation and } \\
\text { inspiration). }\end{array}$ & $\begin{array}{l}\text { Path-goal theory, } \\
\text { motivation theory, } \\
\text { leadership styles. }\end{array}$ & $\begin{array}{l}\text { Sample of } \\
\text { projects } \\
\text { registered on } \\
\text { SourceForge. }\end{array}$ \\
\hline $\begin{array}{l}\text { (Mair et al., } \\
\text { 2015) }\end{array}$ & $\begin{array}{l}\text { Quantitative } \\
\text { (statistical } \\
\text { analysis). }\end{array}$ & $\begin{array}{l}\text { Hybrid motivation as a crucial } \\
\text { determinant for participation. } \\
\text { No significant influence for } \\
\text { pure extrinsic motivations. }\end{array}$ & $\begin{array}{l}\text { Motivation theory } \\
\text { and work design } \\
\text { characteristics. }\end{array}$ & $\begin{array}{l}\text { R community } \\
\text { (software for } \\
\text { statistical } \\
\text { computing). }\end{array}$ \\
\hline $\begin{array}{l}\text { (Mollick, } \\
\text { 2016) }\end{array}$ & $\begin{array}{l}\text { Qualitative } \\
\text { (interviews) } \\
\text { and } \\
\text { quantitative } \\
\text { (longitudinal } \\
\text { survey). }\end{array}$ & $\begin{array}{l}\text { An anti-commercial attitude is } \\
\text { no significant predictor for the } \\
\text { commercialisation of OSS but } \\
\text { rather a pronounced } \\
\text { entrepreneurial self-image. }\end{array}$ & $\begin{array}{l}\text { Entrepreneurship } \\
\text { and innovation. }\end{array}$ & $\begin{array}{l}\text { Jailbreak } \\
\text { communities } \\
\text { and GitHub } \\
\text { projects. }\end{array}$ \\
\hline $\begin{array}{l}\text { (Roberts et } \\
\text { al., 2006) }\end{array}$ & $\begin{array}{l}\text { Quantitative } \\
\text { (longitudinal, } \\
\text { statistical } \\
\text { analysis). }\end{array}$ & $\begin{array}{l}\text { The pervasiveness of } \\
\text { commercial interests } \\
\text { connected to OSS has led to a } \\
\text { thriving open source industry. } \\
\text { Motivations are interrelated in } \\
\text { complex ways. They find no } \\
\text { evidence that extrinsic } \\
\text { motivations crowd out intrinsic } \\
\text { motivations. Being paid for } \\
\text { development enhances status } \\
\text { motivations whereas status } \\
\text { motivations enhance intrinsic } \\
\text { motivations. }\end{array}$ & Motivation theory. & Apache. \\
\hline
\end{tabular}




\section{Chapter 20: Appendices}

\begin{tabular}{|c|c|c|c|c|}
\hline $\begin{array}{l}\text { (Rossi, } \\
\text { 2006) }\end{array}$ & $\begin{array}{l}\text { Qualitative } \\
\text { (literature } \\
\text { review). }\end{array}$ & $\begin{array}{l}\text { Findings on motivation for } \\
\text { community engagement are } \\
\text { mixed (for instance, regarding } \\
\text { the salience of reputation or the } \\
\text { effects of monetary rewards). } \\
\text { Because people's motivations } \\
\text { are different, research should } \\
\text { focus on studying the } \\
\text { interaction of motivations } \\
\text { rather than the dominance of } \\
\text { one over the other. } \\
\text { Extrinsic motivations } \\
\text { (such as the pursuance of } \\
\text { commercial interests) can have } \\
\text { a positive impact on the } \\
\text { allocation of tasks that are } \\
\text { intrinsically less interesting. } \\
\text { When studying SMEs, the } \\
\text { nature of motivation resembles } \\
\text { that of individual motivation. } \\
\text { As important firm level } \\
\text { motivations they cite } \\
\text { standardisation, cost, strategic } \\
\text { considerations and } \\
\text { compatibility. }\end{array}$ & $\begin{array}{l}\text { Focus on } \\
\text { motivation, } \\
\text { governance and } \\
\text { intellectual } \\
\text { property rights. }\end{array}$ & $\begin{array}{l}\text { Apache, Linux, } \\
\text { Perl (also } \\
\text { examples of } \\
\text { firms investing } \\
\text { in OSS such as } \\
\text { Hewlett } \\
\text { Packard, IBM, } \\
\text { Oracle, Red } \\
\text { Hat are } \\
\text { provided). }\end{array}$ \\
\hline $\begin{array}{l}\text { (Rozas \& } \\
\text { Gilbert, } \\
\text { 2015) }\end{array}$ & $\begin{array}{l}\text { Qualitative } \\
\text { (participant } \\
\text { observation, } \\
\text { documentary } \\
\text { analysis, and } \\
\text { interviews). }\end{array}$ & $\begin{array}{l}\text { Community-oriented } \\
\text { contributions facilitate } \\
\text { economic sustainability (e.g., } \\
\text { sponsoring of events, donations } \\
\text { to crowdfunding campaigns } \\
\text { enabling the development of } \\
\text { core modules, memberships in } \\
\text { related associations). }\end{array}$ & $\begin{array}{l}\text { Affective labour, } \\
\text { commons-based } \\
\text { peer production. }\end{array}$ & Drupal. \\
\hline $\begin{array}{l}\text { (Shah, } \\
\text { 2006) }\end{array}$ & $\begin{array}{l}\text { Qualitative } \\
\text { (interviews } \\
\text { and archival } \\
\text { data). }\end{array}$ & $\begin{array}{l}\text { Differences in motivations may } \\
\text { account for differences } \\
\text { regarding the type of } \\
\text { innovation that is created by } \\
\text { developers. While hobbyists, } \\
\text { who are mainly driven by } \\
\text { enjoyment, tend to explore } \\
\text { uncharted territory and novel } \\
\text { functionality, individuals who } \\
\text { seek financial rewards mainly } \\
\text { invest their time and energy } \\
\text { into designs that are of interest } \\
\text { to large market segments. }\end{array}$ & $\begin{array}{l}\text { Governance, } \\
\text { innovation, and } \\
\text { motivation theory. }\end{array}$ & $\begin{array}{l}\text { Sample of } \\
\text { projects on } \\
\text { SourceForge. }\end{array}$ \\
\hline $\begin{array}{l}\text { (Tsay, } \\
\text { Dabbish, \& } \\
\text { Herbsleb, } \\
\text { 2014) }\end{array}$ & $\begin{array}{l}\text { Quantitative } \\
\text { (statistical } \\
\text { analysis). }\end{array}$ & $\begin{array}{l}\text { What can be derived from this } \\
\text { work is that the transparency in } \\
\text { open source projects that is } \\
\text { afforded by the use of online } \\
\text { collaborative tools (e.g., } \\
\text { GitHub), may provide valuable } \\
\text { signals and cues for evaluating } \\
\text { a project's progress, which may } \\
\text { increase planning reliability for }\end{array}$ & $\begin{array}{l}\text { Evaluation of } \\
\text { signals and } \\
\begin{array}{l}\text { cuessociated } \\
\text { contributions. }\end{array}\end{array}$ & GitHub. \\
\hline
\end{tabular}




\begin{tabular}{|c|c|c|c|c|}
\hline & & $\begin{array}{l}\text { people who reap economic } \\
\text { benefit from the software. }\end{array}$ & & \\
\hline $\begin{array}{l}\text { (von Krogh } \\
\text { et al., 2012) }\end{array}$ & $\begin{array}{l}\text { Qualitative } \\
\text { (literature } \\
\text { review). }\end{array}$ & $\begin{array}{l}\text { The majority of studies } \\
\text { discussing extrinsic } \\
\text { motivations report that career } \\
\text { opportunities and monetary } \\
\text { rewards are important and } \\
\text { significant motivations for } \\
\text { community engagement. } \\
\text { However, they also cite studies } \\
\text { that report weak support for } \\
\text { career concerns as a } \\
\text { motivation, e.g., Hemetsberger } \\
\text { (2002). }\end{array}$ & $\begin{array}{l}\text { Motivation theory } \\
\text { and social practice } \\
\text { theory. }\end{array}$ & $\begin{array}{l}\text { Apache, Linux } \\
\text { and others. }\end{array}$ \\
\hline $\begin{array}{l}\text { (Wasko \& } \\
\text { Faraj, 2000) }\end{array}$ & $\begin{array}{l}\text { Qualitative } \\
\text { and } \\
\text { quantitative } \\
\text { (content } \\
\text { analysis). }\end{array}$ & $\begin{array}{l}\text { For some participants, the } \\
\text { community is a resource to } \\
\text { enhance their professional } \\
\text { standing. } \\
\text { responses are means to } \\
\text { enhance status and reputation, } \\
\text { which can lead to consultancy } \\
\text { work. }\end{array}$ & $\begin{array}{l}\text { Knowledge } \\
\text { management. } \\
\text { Knowledge as a } \\
\text { public good that is } \\
\text { embedded in a } \\
\text { community. }\end{array}$ & $\begin{array}{l}\text { Usenet } \\
\text { newsgroups. }\end{array}$ \\
\hline $\begin{array}{l}\text { (C.-G. Wu } \\
\text { et al., 2007) }\end{array}$ & $\begin{array}{l}\text { Quantitative } \\
\text { (statistical } \\
\text { analysis). }\end{array}$ & $\begin{array}{l}\text { The realisation of career } \\
\text { opportunities enhances } \\
\text { community participants' } \\
\text { satisfaction and indirectly } \\
\text { reinforces } \\
\text { community engagement. }\end{array}$ & $\begin{array}{l}\text { Expectancy-value } \\
\text { theory. }\end{array}$ & $\begin{array}{l}\text { Random } \\
\text { sample from } \\
\text { SourceForge, } \\
\text { Debian and } \\
\text { OpenWebmail. }\end{array}$ \\
\hline
\end{tabular}

\subsection{Appendix A5 - product attributes and differentiation criteria (Study VI)}

\begin{tabular}{|l|l|l|l|}
\hline$\#$ & Product attribute & Description & Cersioning \\
\hline \multicolumn{2}{|c|}{ Core product } \\
\hline 1 & Commercial extension & $\begin{array}{l}\text { Commercial extensions are at } \\
\text { the core of the business model. }\end{array}$ & $\begin{array}{l}\text { Number of commercial } \\
\text { extensions available in a } \\
\text { package. }\end{array}$ \\
\hline 2 & Subscription & $\begin{array}{l}\text { Terms and compliance } \\
\text { Typically, services based on } \\
\text { subscription models are } \\
\text { offered. }\end{array}$ & $\begin{array}{l}\text { Subscription length (e.g., 6 } \\
\text { months, 12 months, 24 } \\
\text { months). }\end{array}$ \\
\hline 3 & Software licence & $\begin{array}{l}\text { Extensions in this setting are } \\
\text { typically offered under GPL } \\
\text { terms. } \\
\text { The number of sites (or } \\
\text { domains) the software can be } \\
\text { used for. }\end{array}$ \\
\hline 4 & Sites installed & $1-$ unlimited. \\
\hline
\end{tabular}




\section{Chapter 20: Appendices}

\begin{tabular}{|c|c|c|c|}
\hline 5 & Sites (or domains) supported & $\begin{array}{l}\text { The number of sites (or } \\
\text { domains) support is provided } \\
\text { for. }\end{array}$ & $\begin{array}{l}\text { Single site, multiple sites } \\
\text { (e.g., 5, 10, 20), unlimited } \\
\text { sites. }\end{array}$ \\
\hline \multicolumn{4}{|c|}{ Supplementary service } \\
\hline 6 & Additional web services & $\begin{array}{l}\text { The package includes } \\
\text { additional web services during } \\
\text { the subscription period (e.g., } \\
\text { file indexing or generation of } \\
\text { thumbnails) }\end{array}$ & $\begin{array}{l}\text { Number of additional web } \\
\text { services. }\end{array}$ \\
\hline 7 & Installation service & $\begin{array}{l}\text { Offers customers the benefit of } \\
\text { remote installation service. }\end{array}$ & $\mathrm{n} / \mathrm{a}$ \\
\hline 8 & Installation support & $\begin{array}{l}\text { Support for customers who } \\
\text { face problems during the } \\
\text { installation, integration, or } \\
\text { configuration of extensions } \\
\text { (e.g., compatibility problems } \\
\text { with Joomla or third-party } \\
\text { extensions). }\end{array}$ & $\mathrm{n} / \mathrm{a}$ \\
\hline 9 & Priority support & $\begin{array}{l}\text { Problems of customers who } \\
\text { have opted for priority support } \\
\text { are prioritised over problems of } \\
\text { customers who have not opted } \\
\text { for priority support. Sometimes } \\
\text { this is also called VIP ticket } \\
\text { support. }\end{array}$ & $\mathrm{n} / \mathrm{a}$ \\
\hline 10 & Third-level client support & $\begin{array}{l}\text { A supplier of extensions } \\
\text { provides direct support to } \\
\text { customers' clients (e.g., a } \\
\text { customer could be a developer } \\
\text { who in turn works for clients } \\
\text { who need support). }\end{array}$ & $\mathrm{n} / \mathrm{a}$ \\
\hline 11 & Developer support & $\begin{array}{l}\text { Special support for developers } \\
\text { who wish to modify an } \\
\text { extension that they purchased. }\end{array}$ & $\mathrm{n} / \mathrm{a}$ \\
\hline 12 & Email support & $\begin{array}{l}\text { Customers receive support via } \\
\text { email. }\end{array}$ & $\mathrm{n} / \mathrm{a}$ \\
\hline 13 & Migration service & $\begin{array}{l}\text { Customers receive support for } \\
\text { migrating their extensions to } \\
\text { new systems. }\end{array}$ & $\mathrm{n} / \mathrm{a}$ \\
\hline 14 & Skype support & $\begin{array}{l}\text { Customers receive live support } \\
\text { via Skype. }\end{array}$ & $\mathrm{n} / \mathrm{a}$ \\
\hline 15 & Ticket support & $\begin{array}{l}\text { The package includes support } \\
\text { through a ticket system. Ticket } \\
\text { support and forum support can } \\
\text { be distinct product attributes. } \\
\text { For example, while one } \\
\text { package provides forum } \\
\text { support, a higher-level } \\
\text { package can offer both. }\end{array}$ & $\mathrm{n} / \mathrm{a}$ \\
\hline 16 & Training & $\begin{array}{l}\text { Schooling and training for } \\
\text { Joomla beginners, extension } \\
\text { developers, or administrators. }\end{array}$ & $\mathrm{n} / \mathrm{a}$ \\
\hline 17 & Upgrade service & $\begin{array}{l}\text { Upgrading to newer versions of } \\
\text { a software can cause problems. } \\
\text { This service provides support }\end{array}$ & $\mathrm{n} / \mathrm{a}$ \\
\hline
\end{tabular}




\section{Chapter 20: Appendices}

\begin{tabular}{|c|c|c|c|}
\hline & & $\begin{array}{l}\text { for problems related to the } \\
\text { upgrading of customers' } \\
\text { extensions. }\end{array}$ & \\
\hline \multicolumn{4}{|c|}{ Supplementary content } \\
\hline 18 & Free extensions & $\begin{array}{l}\text { A package can include a } \\
\text { number of free extensions. }\end{array}$ & Number of free extensions. \\
\hline 19 & Additional components & $\begin{array}{l}\text { Number of additional } \\
\text { components available in a } \\
\text { package. }\end{array}$ & $\begin{array}{l}\text { Number of additional } \\
\text { components. }\end{array}$ \\
\hline 20 & Commercial add-ons & $\begin{array}{l}\text { Software that provides } \\
\text { integration or extra features for } \\
\text { extensions that a customer } \\
\text { bought previously. For } \\
\text { instance, payment gateways or } \\
\text { social integration. These add- } \\
\text { ons are only available to } \\
\text { customers who have an active } \\
\text { subscription and are similar to } \\
\text { in-app purchases. }\end{array}$ & $\begin{array}{l}\text { Number of commercial add- } \\
\text { ons accessible. }\end{array}$ \\
\hline 21 & Free add-ons & $\begin{array}{l}\text { The package includes free } \\
\text { access to configuration files, } \\
\text { themes, plugins, or } \\
\text { combinations thereof. }\end{array}$ & $\begin{array}{l}\text { Number of free add-ons } \\
\text { available. }\end{array}$ \\
\hline 22 & Icon sets & $\begin{array}{l}\text { A package includes additional } \\
\text { icon sets. }\end{array}$ & $\begin{array}{l}\begin{array}{l}\text { Number of icon sets } \\
\text { available. }\end{array} \\
\end{array}$ \\
\hline 23 & Language packs & $\begin{array}{l}\text { A package comes with } \\
\text { additional language packs. } \\
\text { E.g., the users can switch } \\
\text { between multiple languages in } \\
\text { the front-end or the back-end. }\end{array}$ & $\begin{array}{l}\text { Number of language-packs } \\
\text { available. }\end{array}$ \\
\hline 24 & Mobile adaptive templates & $\begin{array}{l}\text { A package comes with } \\
\text { templates for mobile versions } \\
\text { of a website. }\end{array}$ & $\begin{array}{l}\text { Number of templates } \\
\text { available. }\end{array}$ \\
\hline 25 & Mobile app available & $\begin{array}{l}\text { Means that an extension is also } \\
\text { available as a mobile app. }\end{array}$ & $\mathrm{n} / \mathrm{a}$ \\
\hline 26 & Modules & $\begin{array}{l}\text { The package comes with } \\
\text { additional modules. }\end{array}$ & $\begin{array}{l}\text { Number of additional } \\
\text { modules. }\end{array}$ \\
\hline 27 & Plugins & $\begin{array}{l}\text { The package comes with } \\
\text { additional plugins. }\end{array}$ & $\begin{array}{l}\text { Number of additional } \\
\text { plugins, compatibility with } \\
\text { Joomla versions. }\end{array}$ \\
\hline 28 & Premium rulesets & $\begin{array}{l}\text { Rulesets allow for processing } \\
\text { of content in particular ways. } \\
\text { They could be thought of as } \\
\text { processing templates that } \\
\text { dynamically transfer any input } \\
\text { text to a desired HTML output } \\
\text { according to the logics that } \\
\text { apply in the ruleset. }\end{array}$ & $\mathrm{n} / \mathrm{a}$ \\
\hline 29 & Quickstart configuration & $\begin{array}{l}\text { The package comes with pre- } \\
\text { configured themes and } \\
\text { configuration files. }\end{array}$ & $\mathrm{n} / \mathrm{a}$ \\
\hline 30 & Additional templates & $\begin{array}{l}\text { The package ships with } \\
\text { additional templates. }\end{array}$ & $\begin{array}{l}\text { Number of additional } \\
\text { templates available. }\end{array}$ \\
\hline
\end{tabular}




\section{Chapter 20: Appendices}

\begin{tabular}{|c|c|c|c|}
\hline 31 & Access to new products & $\begin{array}{l}\text { The package includes free } \\
\text { access to new products (e.g., } \\
\text { extensions or supplementary } \\
\text { content) that are released } \\
\text { within the subscription period. }\end{array}$ & $\mathrm{n} / \mathrm{a}$ \\
\hline 32 & Removable backlinks & $\begin{array}{l}\text { Customers can conveniently } \\
\text { remove advertisement and } \\
\text { backlinks through a back-end } \\
\text { switch. }\end{array}$ & $\mathrm{n} / \mathrm{a}$ \\
\hline 33 & Documentation & $\begin{array}{l}\text { Customers get access to } \\
\text { documentation during the } \\
\text { subscription period. }\end{array}$ & $\mathrm{n} / \mathrm{a}$ \\
\hline 34 & Downloads & $\begin{array}{l}\text { Customers are granted access } \\
\text { to specific download areas } \\
\text { during the subscription period. }\end{array}$ & $\mathrm{n} / \mathrm{a}$ \\
\hline 35 & Discount on renewal & $\begin{array}{l}\text { A package entitles customers } \\
\text { to discounts when they renew } \\
\text { the subscription before } \\
\text { expiration (e.g., } 10 \% \text {, } 20 \% \text {, } \\
30 \% \text {, in some cases up to } \\
50 \% \text { ). }\end{array}$ & $\begin{array}{l}\text { Percentage of discounts } \\
\text { given. }\end{array}$ \\
\hline 36 & Software updates & $\begin{array}{l}\text { Customers receive free } \\
\text { software updates during the } \\
\text { subscription period. }\end{array}$ & $\mathrm{n} / \mathrm{a}$ \\
\hline 37 & Support forum & $\begin{array}{l}\text { Customers are granted access } \\
\text { to support forums where they } \\
\text { can ask for help during the } \\
\text { subscription period. }\end{array}$ & $\mathrm{n} / \mathrm{a}$ \\
\hline 38 & Tutorials & $\begin{array}{l}\text { Customers are granted access } \\
\text { to online tutorials. For } \\
\text { instance, tutorials on coding, } \\
\text { marketing, search engine } \\
\text { optimisation, and more. }\end{array}$ & $\mathrm{n} / \mathrm{a}$ \\
\hline \multicolumn{4}{|c|}{ Guarantees and assurance } \\
\hline 39 & $\begin{array}{l}\text { Third-party } \quad \text { extension } \\
\text { compatibility }\end{array}$ & $\begin{array}{l}\text { A package guarantees } \\
\text { compatibility with third-party } \\
\text { extensions. }\end{array}$ & $\begin{array}{l}\text { Number of third-party } \\
\text { extensions for which } \\
\text { compatibility is guaranteed. }\end{array}$ \\
\hline 40 & Joomla version compatibility & $\begin{array}{l}\text { The package specifies for } \\
\text { which Joomla versions the } \\
\text { purchased extensions are } \\
\text { compatible. }\end{array}$ & $\begin{array}{l}\text { Different Joomla versions } \\
\text { (e.g., Joomla 1.5, Joomla 2.5, } \\
\text { Joomla 3.x) }\end{array}$ \\
\hline 41 & Cross-platform availability & $\begin{array}{l}\text { In addition to Joomla, a } \\
\text { package makes the software } \\
\text { (i.e., an extension) also } \\
\text { available for other CMS } \\
\text { platforms (e.g., WordPress). }\end{array}$ & The platforms supported. \\
\hline 42 & $\begin{array}{l}\text { Guaranteed response time for } \\
\text { support based on weekdays }\end{array}$ & $\begin{array}{l}\text { Specifies whether a difference } \\
\text { is made for guaranteed } \\
\text { response times for support on } \\
\text { weekdays and weekends. A } \\
\text { package can specify that } \\
\text { guaranteed response times } \\
\text { during weekends are only }\end{array}$ & Weekdays, weekends \\
\hline
\end{tabular}




\section{Chapter 20: Appendices}

\begin{tabular}{|c|c|c|c|}
\hline & & $\begin{array}{l}\text { available in higher priced } \\
\text { packages. }\end{array}$ & \\
\hline 43 & $\begin{array}{l}\text { Guaranteed response time for } \\
\text { support }\end{array}$ & $\begin{array}{l}\text { A package can guarantee faster } \\
\text { response times for support (at a } \\
\text { higher price) independent of } \\
\text { weekdays. }\end{array}$ & $\begin{array}{l}\text { Hours within which support } \\
\text { request are to be answered } \\
\text { (e.g., reply within } 12 \mathrm{~h}, 24 \mathrm{~h} \text {, } \\
48 \mathrm{~h} \text {, or } 72 \mathrm{~h} \text { ). }\end{array}$ \\
\hline \multicolumn{4}{|c|}{ Functional scope and technical specification } \\
\hline 44 & Features & $\begin{array}{l}\text { Refers to the set of features an } \\
\text { extension provides. For } \\
\text { example, private messaging, } \\
\text { invoices, advanced search, } \\
\text { payment options, order } \\
\text { management, notification } \\
\text { systems, analytic features, } \\
\text { expert modes, image editors, } \\
\text { and more. }\end{array}$ & Range and scope of features. \\
\hline 45 & Custom features & $\begin{array}{l}\text { The package includes } \\
\text { provision and development of } \\
\text { custom features. }\end{array}$ & $\mathrm{n} / \mathrm{a}$ \\
\hline 46 & Third-party integration & $\begin{array}{l}\text { A package includes integration } \\
\text { with external platforms and } \\
\text { systems, such as integration } \\
\text { with Mailchimp, social media } \\
\text { platforms (e.g., Facebook, } \\
\text { Twitter), Google, Amazon, etc. }\end{array}$ & $\mathrm{n} / \mathrm{a}$ \\
\hline \multicolumn{4}{|c|}{ Ancillary incentive } \\
\hline 47 & Loyalty discount & $\begin{array}{l}\text { Customers get discounts (e.g., } \\
15 \% \text { when renewing the } \\
\text { subscription after the first year, } \\
\text { and a higher discount (e.g., } \\
30 \% \text { ) when renewing after the } \\
\text { second year. }\end{array}$ & $\begin{array}{l}\text { Percentage of discounts, } \\
\text { periods after which discounts } \\
\text { are granted. }\end{array}$ \\
\hline 48 & Money back guarantee & $\begin{array}{l}\text { A package guarantees refunds } \\
\text { within a specified number of } \\
\text { days, for instance, in case } \\
\text { customers face problems or } \\
\text { when they are dissatisfied. } \\
\text { Valid causes or circumstances } \\
\text { for which refunds are granted } \\
\text { are often specified in policy } \\
\text { documents. }\end{array}$ & $\begin{array}{l}\text { Number of days within } \\
\text { which refunds are possible. } \\
\text { The percentage of refunds } \\
\text { could also be versioned; } \\
\text { however, this was not } \\
\text { observed in this setting. }\end{array}$ \\
\hline 49 & Tying items & $\begin{array}{l}\text { Items or product attributes } \\
\text { (e.g., extensions, } \\
\text { complementary content, or } \\
\text { complementary services) that } \\
\text { are only available in a specific } \\
\text { package but not as single items } \\
\text { or within other packages (e.g., } \\
\text { developer support). }\end{array}$ & $\begin{array}{l}\text { Number and qualities of } \\
\text { tying items. }\end{array}$ \\
\hline 50 & Upgrade Discount & $\begin{array}{l}\text { When upgrading from one } \\
\text { package to a higher spec } \\
\text { package, discounts are given. } \\
\text { As an example, consider the }\end{array}$ & $\begin{array}{l}\text { Percentage of discounts } \\
\text { given. Combination of } \\
\text { packages for which upgrade } \\
\text { discounts are granted. }\end{array}$ \\
\hline
\end{tabular}




\section{Chapter 20: Appendices}

\begin{tabular}{|c|c|c|c|}
\hline & & $\begin{array}{l}\text { availability of three different } \\
\text { packages (A, B, and C, from } \\
\text { low to high spec) where } \\
\text { package B includes an upgrade } \\
\text { discount to package C, } \\
\text { whereas package A would not } \\
\text { include any upgrade discounts. }\end{array}$ & \\
\hline 51 & Upgrade timing & $\begin{array}{l}\text { When upgrading to a high- } \\
\text { spec package, the full price of } \\
\text { the current package is given as } \\
\text { a discount in case the upgrade } \\
\text { occurs within a specified } \\
\text { number of days (e.g., } 60 \text { days), } \\
\text { otherwise a minimum discount } \\
\text { is guaranteed (e.g., } 25 \% \text { ). }\end{array}$ & $\begin{array}{l}\text { Number of days within } \\
\text { which upgrade discounts are } \\
\text { granted. }\end{array}$ \\
\hline \multicolumn{4}{|c|}{ Signalling } \\
\hline 52 & Open source code & $\begin{array}{l}\text { The package guarantees access } \\
\text { to the source code. Because } \\
\text { extensions in this setting are } \\
\text { typically delivered as GPL } \\
\text { code, this is granted anyway; } \\
\text { nevertheless, many vendors } \\
\text { use it as a signal. }\end{array}$ & $\mathrm{n} / \mathrm{a}$ \\
\hline 53 & Perpetual use of the software & $\begin{array}{l}\text { Perpetual use of the software } \\
\text { after the subscription has } \\
\text { expired. This is also implicit to } \\
\text { GPL code but often used as a } \\
\text { signal. }\end{array}$ & $\mathrm{n} / \mathrm{a}$ \\
\hline 54 & Download from trusted source & $\begin{array}{l}\text { Signals that customers are } \\
\text { provided with secure and } \\
\text { tested code. Could also be } \\
\text { interpreted as a measure to } \\
\text { discourage users from } \\
\text { obtaining the software from } \\
\text { other sources (e.g., warez } \\
\text { channels). }\end{array}$ & $\mathrm{n} / \mathrm{a}$ \\
\hline 55 & Platform integration & $\begin{array}{l}\text { Extensions offered by a vendor } \\
\text { can be usefully and seamlessly } \\
\text { integrated with one another. }\end{array}$ & $\mathrm{n} / \mathrm{a}$ \\
\hline 56 & Multilingual support & $\begin{array}{l}\text { Operational support is } \\
\text { provided in several languages } \\
\text { (e.g., English, Spanish, French). }\end{array}$ & $\mathrm{n} / \mathrm{a}$ \\
\hline
\end{tabular}

\subsection{Appendix A6 - package names and significations (Study VI)}

\begin{tabular}{|l|l|l|}
\hline$\#$ & Signification & Package names \\
\hline 1 & $\begin{array}{l}\text { Target audiences, } \\
\text { professions } \\
\text { Occupations }\end{array}$ & $\begin{array}{l}\text { Agency, Business, Dev, Developer, Developer licence, Geek bundle, } \\
\text { Membership plan Business, Membership plan Personal, Personal }\end{array}$ \\
\hline 2 & $\begin{array}{l}\text { Performance and } \\
\text { levels of expertise }\end{array}$ & $\begin{array}{l}\text { Advanced, Core, Joomla Pro pack, Power pack, Pro, Professional, Professional } \\
\text { Bundle, Starter, Starter bundle }\end{array}$ \\
\hline
\end{tabular}




\section{Chapter 20: Appendices}

\begin{tabular}{|c|l|l|}
\hline 3 & Service duration & $\begin{array}{l}\text { Annual bundle, Annual licence, Lifetime bundle, Lifetime subscription, } \\
\text { Perpetual licence (lifetime), X year/month subscription bundle (e.g., X=3 } \\
\text { months, 6 months, 1 year, 2 year) }\end{array}$ \\
\hline 4 & $\begin{array}{l}\text { Product type, content, } \\
\text { and function }\end{array}$ & $\begin{array}{l}\text { 1 Domain, All commercial extensions, All-in-one, Bundle, Bundle } \\
\text { subscription, Extension name (i.e. the name of an extension is used as a } \\
\text { package name), Integration package, Multi site subscription, Single licence, } \\
\text { Single product for Joomla version X (e.g., X=Joomla version 2.5 or 3.0), Single } \\
\text { site subscription, Single subscription, Unlimited bundle, Unlimited domains }\end{array}$ \\
\hline 5 & $\begin{array}{l}\text { Basic, Basic membership, Eco, Essentials, Essentials pack, Free, Full, Joomla } \\
\text { premium pack, Lite, Normal, Plus, Premium, Premium membership, Premium } \\
\text { help, Social bundle, Special deals, Standard }\end{array}$ \\
\hline 6 & Abstract types & Blue level, Bronze, Gold, Green level, Pink level, Silver \\
\hline
\end{tabular}





\section{Web links}

All web links were last accessed on 20 September 2018.

1 https://sourceforge.net/about

2 https://github.com/about

3 https://community.hds.com/community/innovation-center/hus-place/blog/2017/02/28/share-is-not- anacronym-it-s-what-we-do

4 https://www.share.org

5 http://hopl.info/showlanguage.prx?exp=136\&language=USE

6 https://www.computerhope.com/history/unix.htm

7 https://en.wikipedia.org/wiki/History_of_Unix

8 https://arstechnica.com/tech-policy/2011/07/should-we-thank-for-feds-for-the-success-of-unix/

9 https://networking.ringofsaturn.com/Unix/bsd.php

10 https://stallman.org/biographies.html

11 https://www.fsf.org

12 https://www.gnu.org/gnu/manifesto.en.html

13 https://www.gnu.org/philosophy/free-sw.en.html

$14 \mathrm{https}: / /$ networking.ringofsaturn.com/Unix/bsd.php

15 https://opensource.com/article/18/2/coining-term-open-source-software

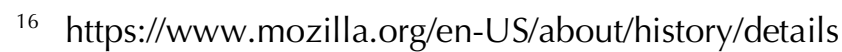

17 https://opensource.com/article/18/2/coining-term-open-source-software

18 https://opensource.org

19 https://opensource.org/osd

20 https://www.debian.org/social_contract

21 https://opensource.org/licenses/alphabetical

22 https://www.gnu.org/philosophy/floss-and-foss.en.html

${ }^{23}$ https://www.gnu.org/software/fsfe/projects/ms-vs-eu/halloween1.html

24 https://en.wikipedia.org/wiki/OpenOffice.org\#History

25 https://www.theguardian.com/technology/2002/oct/31/software.opensource

26 https://en.wikipedia.org/wiki/Linspire

27 https://w3techs.com/technologies/history_overview/web_server

28 https://www.facebook.com/notes/facebook-engineering/folly-the-facebook-open-sourcelibrary/10150864656793920

29 https://readwrite.com/2013/10/17/is-facebook-the-worlds-largest-open-source-company

30 https://www.economist.com/business/2017/03/16/what-satya-nadella-did-at-microsoft

31 https://news.microsoft.com/2014/11/12/microsoft-takes-net-open-source-and-cross-platform-adds-new -development-capabilities-with-visual-studio-2015-net-2015-and-visual-studio-online

32 https://www.toptal.com/dot-net/dotnet-core-going-wild-and-open-source-what-took-you-so-long

33 https://www.cio.com/article/3026664/open-source-tools/the-real-reason-microsoft-open-sourcednet.html

34 https://www.linuxfoundation.org/membership

35 https://www.linuxfoundation.org/membership/members

36 https://www.youtube.com/watch?v=-YdL7Hch78s

37 https://www.youtube.com/watch?v=XLAIMB7whdc 


\section{Chapter 21: Web links}$$
45
$$

72 https://resources.joomla.org/en/getting-started-on-the-jrd

73 https://volunteers.joomla.org

74 https://www.opensourcematters.org/organisation/faq.html\#13-is-open-source-matters-a-foundation

75 https://www.opensourcematters.org

76 https://community.joomla.org/blogs/leadership/project-budget-for-2017-18-finalised.html

77 https://community.joomla.org/blogs/leadership/dissolve-coc.html

${ }^{78}$ https://www.facebook.com/JoomlaWorldConference/videos/vl.326085097866880/14781912022761 62

${ }^{79}$ https://community.joomla.org/blogs/leadership/joomla-leadership-adopts-new-structure-amethodology.html

${ }^{80}$ https://community.joomla.org/blogs/leadership/a-new-organizational-structure-and-methodology-toempower-the-growth-of-joomla.html 


\section{Chapter 21: Web links}

${ }^{100}$ https://www.joomla.org/about-joomla/partners.html

101 https://conference.joomla.org/sponsors.html

102 https://www.joomla.org/sponsor.html

103 https://www.joomla.org/current-sponsors.html

104 https://visual.ly/community/infographic/computers/worlds-largest-web-hosts

105 http://php.net/manual/en/intro-whatis.php

${ }^{106}$ https://en.wikipedia.org/wiki/JavaScript

107 https://mootools.net

108 https://jquery.com

109 http://getbootstrap.com

$110 \mathrm{https} / / / \mathrm{www} . \mathrm{mysql.com}$

111 https://www.postgresql.org

112 https://mariadb.org

$113 \mathrm{https} / / / \mathrm{httpd}$.apache.org

114 https://www.nginx.com/resources/wiki

115 https://summerofcode.withgoogle.com

$116 \mathrm{https} / / / \mathrm{www} . w 3.0 \mathrm{~g}$

117 https://en.wikipedia.org/wiki/HTML5

118 https://www.cookielaw.org/the-cookie-law

119 http://www.zend.com/en/resources/php7_infographic

${ }^{120}$ http://allthingsd.com/20120425/automattic-grows-up-the-company-behind-wordpress-com-sharesrevenue-numbers-and-hires-execs

${ }^{121}$ http://www.investopedia.com/articles/markets/012716/automattic-ipo-candidate-2016.asp

122 https://make.wordpress.org/core/handbook/about/organization

${ }^{123} \mathrm{http}: / / w w w . a p a c h e . o r g / f o u n d a t i o n / h o w-i t-w o r k s . h t m l$ \#structure

124 https://community.joomla.org/blogs/leadership/joomla-elections-results-group-1-2018.html

${ }^{125}$ https://www.joomla.org/announcements/general-news/4410-free-as-in-freedom.html 
126 https://docs.joomla.org/Filing_bugs_and_issues

${ }^{127}$ https://docs.joomla.org/Testing_Joomla!_patches_QuickReferenceGuide

${ }^{128}$ https://docs.joomla.org/Joomla:Commit_Guidelines

129 https://forum.joomla.org/viewtopic.php?f=8\&t=65

${ }^{130} \mathrm{https} / / /$ github.com/joomla/coding-standards

131 https://community.joomla.org/events.html

132 https://docs.joomla.org/Portal:Participating_in_the_Community

133 https://docs.joomla.org/Release_and_support_cycle

${ }^{134}$ https://developer.joomla.org/news/586-joomla-development-strategy.html

135 https://community.joomla.org/blogs/leadership/handling-conflict-in-the-joomla-community.html

136 https://www.opensourcematters.org/organisation/by-laws-policies.html

${ }^{137}$ https://github.com/joomla/joomla-platform/wiki/Contributing-to-the-joomla-platform

$138 \mathrm{https} / / /$ magazine.joomla.org/issues/issue-jan-2018/item/3295-joomla-4-interview-series-georgewilson-release-lead

139 https://community.joomla.org/blogs/leadership/handling-conflict-in-the-joomla-community.html

$140 \mathrm{https} / / /$ volunteers.joomla.org/governance/advisory-board

${ }^{141}$ https://volunteers.joomla.org/governance/ombudsman

$142 \mathrm{http}: / /$ opensourcematters.org/joomla.html

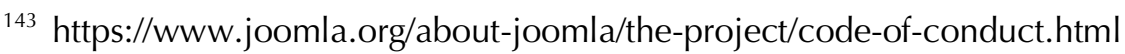

${ }^{144}$ https://community.joomla.org/blogs/leadership/3089-handling-conflict-in-the-joomla-community.html

145 https://groups.google.com/forum/\#!topic/joomla-leadership/a-yDIBU9Z1I

146 https://community.joomla.org/blogs/leadership/636-jed-to-be-gpl-only-by-july-2009.html

$147 \mathrm{http}: / /$ jandbeyond.org

148 http://jandbeyond.org/archive/52-j-and-beyond-2010.html

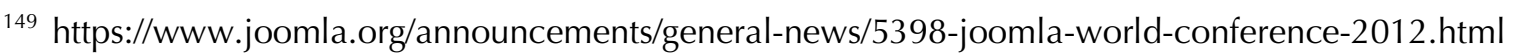

$150 \mathrm{https}: / /$ w3techs.com/technologies

$151 \mathrm{http}: / /$ www.internetlivestats.com/total-number-of-websites

152 https://blog.builtwith.com/2015/11/11/wordpress-vs-joomla-vs-drupal-the-battle-of-the-cms

153 https://blog.builtwith.com/2015/11/11/wordpress-vs-joomla-vs-drupal-the-battle-of-the-cms

154 https://magazine.joomla.org/issues/issue-june-2016/item/3057-the-fall-of-joomla

155 https://magazine.joomla.org/issues/issue-jan-2017/item/3198-2017-another-year-so-much-morejoomla

156 https://magazine.joomla.org/issues/issue-december-2015/item/2905-joomlacertification

${ }^{157}$ https://certification.joomla.org

158 http://dictionary.cambridge.org/dictionary/english/chaos-theory

159 https://volunteers.joomla.org

160 https://www.gnu.org/licenses/gpl-3.0.en.html

$161 \mathrm{https} / / / \mathrm{www}$.joomlatools.com/extensions/logman

$162 \mathrm{https} / / / \mathrm{www}$.joomlatools.com/pricing

163 https://en.oxforddictionaries.com/definition/policy

${ }^{164} \mathrm{https} / / /$ extensions.joomla.org/support/knowledgebase/item/the-gpl-and-the-jed

165 https://www.techopedia.com/definition/3411/platform

166 https://www.wix.com

$167 \mathrm{https}: / / \mathrm{www}$. squarespace.com

168 https://www.wpbeginner.com/showcase/20-most-influential-wordpress-businesses-and-companiestoday 


\section{Chapter 21: Web links}

169 https://dictionary.cambridge.org/dictionary/english/symbiosis

${ }^{170}$ https://www.facebook.com/JoomlaWorldConference/videos/1476071572488125

$171 \mathrm{https}: / /$ www.opensourcematters.org

172 https://en.oxforddictionaries.com/definition/superorganism

$173 \mathrm{https} / / / \mathrm{en}$. oxforddictionaries.com/definition/clan

$174 \mathrm{https} / / /$ en.oxforddictionaries.com/definition/syndicate

175 https://dictionary.cambridge.org/dictionary/english/syndicate

176 https://glip.com 



\section{THESES IN ECONOMIC INFORMATION SYSTEMS}

\section{DOCTORAL THESES}

1. Savén, Bengt, 1995, Verksamhetsmodeller för beslutsstöd och lärande - En studie av produktionssimulering vid Asea/ABB 1968-1993. Doktorsavhandling 371, IDAEIS, Universitetet och Tekniska Högskolan i Linköping.

2. Villegas, Jaime, 1996, Simulation Supported Industrial Training from an Organizational Learning Perspective - Development and Evaluation of the SSIT Method. Doktorsavhandling 429, IDA-EIS, Universitetet och Tekniska Högskolan i Linköping.

3. Nilsson, Fredrik, 1997, Strategi och ekonomisk styrning - En studie av hur ekonomiska styrsystem utformas och används efter företagsförvärv. Doktorsavhandling 475, IDA-EIS, Universitetet och Tekniska Högskolan i Linköping.

4. Moberg, Anna, 1997, Närhet och distans - Studier av kommunikationsmönster i satellitkontor och flexibla kontor. Doktorsavhandling 512, IDA-EIS, Universitetet och Tekniska Högskolan i Linköping.

5. Lindström, Jörgen, 1999, Does Distance Matter? On Geographical Dispersion in Organisations. Doktorsavhandling 567, IDA-EIS, Universitetet och Tekniska Högskolan i Linköping.

6. Tjäder, Jimmy, 2000, Systemimplementering i praktiken - En studie av logiker i fyra projekt. Doktorsavhandling 618, IDA-EIS, Universitetet och Tekniska Högskolan i Linköping.

7. Petri, Carl-Johan, 2001, Organizational Information Provision - Managing Mandatory and Discretionary Use of Information Technology. Doktorsavhandling 720, IDA-EIS, Universitetet och Tekniska Högskolan i Linköping.

8. Gäre, Klas, 2003, Tre perspektiv på förväntningar och förändringar i samband med införande av informationssystem. Doktorsavhandling 808, IDA-EIS, Universitetet och Tekniska Högskolan i Linköping.

9. Skåmedal, Jo, 2004, Telecommuting's Implications on Travel and Travel Patterns. Doktorsavhandling 869, IDA-EIS, Universitetet och Tekniska Högskolan i Linköping.

10. Askenäs, Linda, 2004, The Roles of IT - Studies of Organising when Implementing and Using Enterprise Systems. Doktors-avhandling 870, IDA-EIS, Universitetet och Tekniska Högskolan i Linköping.

11. Wang, Zhiping, 2004, Capacity-Constrained Production-Inventory Systems Modelling and Analysis in both a Traditional and an E-Business Context. Doktorsavhandling 889, IDA-EIS, Universitetet och Tekniska Högskolan i Linköping. 
12. Kald, Magnus, 2004, In the Borderland between Strategy and Management Control - Theoretical Frameworks and Empirical Evidence. Doktorsavhandling 910, IDAEIS, Universitetet och Tekniska Högskolan i Linköping.

13. Cäker, Mikael, 2005, Management Accounting as Constructing and Opposing Customer Focus - Three Case Studies on Management Accounting and Customer Relations. Doktorsavhandling 933, IDA-EIS, Universitetet och Tekniska Högskolan i Linköping.

14. Keller, Christina, 2007, Virtual Learning Environments in Higher Education - A Study of User Acceptance. Doktors-avhandling 1114, IEI-EIS, Universitetet och Tekniska Högskolan i Linköping.

15. Cöster, Mathias, 2007, The Digital Transformation of the Swedish Graphic Industry. Doktorsavhandling 1126, IEI-EIS, Universitetet och Tekniska Högskolan i Linköping.

16. Ahlström, Petter, 2008, Strategier och styrsystem för seniorboendemarknaden. Doktorsavhandling 1188, IEI-EIS, Universitetet och Tekniska Högskolan i Linköping.

17. Scheja, Mikael, 2009, Börsbolags redovisning av alternativa resultatbegrepp - En studie om hur, och varför, bolag noterade på Stockholmsbörsen redovisar 'NonGAAP measures'. Doktorsavhandling 1258, IEI-EIS, Universitetet och Tekniska Högskolan i Linköping.

18. Nilsson, Erik B., 2010, Strategi, styrning och konkurrenskraft - En longitudinell studie av Saab AB. Doktorsavhandling 1318, IEI-EIS, Universitetet och Tekniska Högskolan i Linköping.

19. Imre, Özgün, 2018, Adopting information systems - Perspectives from small organizations. Doktorsavhandling 1895, IEI-EIS, Universitetet och Tekniska Högskolan i Linköping.

20. Odar, Susanne, 2019, Managementinitiativ, mening och verksamhetsresultat - En retrospektiv studie av en teknikintensiv verksamhet. Doktorsavhandling 1970, IEIEIS, Universitetet och Tekniska Högskolan i Linköping.

21. Radits, Markus, 2019, A Business Ecology Perspective on Community-Driven Open Source: The Case of the Free and Open Source Content Management System Joomla. Doktorsavhandling 1937, IEI-EIS, Universitetet och Tekniska Högskolan i Linköping. 


\section{LICENTIATE THESES}

1. Larsson, Rolf, 1992, Aktivitetsbaserad kalkylering i ett nytt ekonomisystem. Licentiatavhandling 298, IDA-EIS, Universitetet och Tekniska Högskolan i Linköping.

2. Noghabai, Mehran, 1993, Värdering av strategiska datorinvesteringar - Med ett ledningsperspektiv på FMS- och KIS-investeringar. Licentiatavhandling 371, IDAEIS, Universitetet och Tekniska Högskolan i Linköping.

3. Moberg, Anna, 1993, Satellitkontor - En studie av kommunikationsmönster vid arbete på distans. Licentiatavhandling 406, IDA-EIS, Universitetet och Tekniska Högskolan i Linköping.

4. Carlsson, Peter, 1994, Separation av företagsledning och finansiering - Fallstudier av företagsledarutköp ur ett agentteoretiskt perspektiv. Licentiatavhandling 414, IDA-EIS, Universitetet och Tekniska Högskolan i Linköping.

5. Sjöström, Camilla, 1994, Revision och lagreglering - Ett historiskt perspektiv. Licentiatavhandling 417, IDA-EIS, Universitetet och Tekniska Högskolan i Linköping.

6. Poignant, Lars, 1994, Informationsteknologi och företagsetablering - Effekter på produktivitet och region. Licentiatavhandling 441, IDA-EIS, Universitetet och Tekniska Högskolan i Linköping.

7. Lind, Jonas, 1994, Creditor-Firm Relations: An Interdisciplinary Analysis. Licentiatavhandling 451, IDA-EIS, Universitetet och Tekniska Högskolan i Linköping.

8. Nilsson, Fredrik, 1994, Strategi och ekonomisk styrning - En studie av Sandviks förvärv av Bahco Verktyg. Licentiatavhandling 463, IDA-EIS, Universitetet och Tekniska Högskolan i Linköping.

9. Lagerström, Bo, 1995, Successiv resultatavräkning av pågående arbeten Fallstudier i tre byggföretag. Licentiatavhandling 476, IDA-EIS, Universitetet och Tekniska Högskolan i Linköping.

10. Andersson, Jörgen, 1995, Bilder av småföretagares ekonomistyrning. Licentiatavhandling 522, IDA-EIS, Universitetet och Tekniska Högskolan i Linköping.

11. Larsen, Kristina, 1996, Förutsättningar och begränsningar för arbete på distans Erfarenheter från fyra svenska företag. Licentiatavhandling 550, IDA-EIS, Universitetet och Tekniska Högskolan i Linköping.

12. Lindström, Jörgen, 1996, Chefers användning av kommunikationsteknik. Licentiatavhandling 587, IDA-EIS, Universitetet och Tekniska Högskolan i Linköping.

13. Larsson, Annika, 1996, Ekonomisk styrning och organisatorisk passion - Ett interaktivt perspektiv. Licentiatavhandling 595, IDA-EIS, Universitetet och Tekniska Högskolan i Linköping. 
14. Ollinen, Jan, 1997, Det flexibla kontorets utveckling på Digital - Ett stöd för multiflex? Licentiatavhandling 623, IDA-EIS, Universitetet och Tekniska Högskolan i Linköping.

15. Zetterlund, Per-Ove, 1998, Normering av svensk redovisning - En studie av tillkomsten av Redovisningsrådets rekommendation om koncernredovisning, RR01:91. Licentiatavhandling 668, IDA-EIS, Universitetet och Tekniska Högskolan i Linköping.

16. Tjäder, Jimmy, 1998, Projektledaren \& planen - En studie av projektledning i tre installations- och systemutvecklingsprojekt. Licentiatavhandling 675, IDA-EIS, Universitetet och Tekniska Högskolan i Linköping.

17. Wennestam, Christina, 1998, Information om immateriella resurser - Investeringar i forskning och utveckling samt i personal inom skogsindustrin. Licentiatavhandling 712, IDA-EIS, Universitetet och Tekniska Högskolan i Linköping.

18. Westin, Carl-Johan, 1998, Informationsförsörjning: En fråga om ansvar - Aktiviteter och uppdrag i fem stora svenska organisationers operativa informationsförsörjning. Licentiatavhandling 730, IDA-EIS, Universitetet och Tekniska Högskolan i Linköping.

19. Jansson, Åse, 1998, Miljöhänsyn - En del i företags styrning. Licentiatavhandling 731, IDA-EIS, Universitetet och Tekniska Högskolan i Linköping.

20. Bäckström, Anders, 1998, Värdeskapande kreditgivning - Kreditriskhantering ur ett agentteoretiskt perspektiv. Licentiatavhandling 734, IDA-EIS, Universitetet och Tekniska Högskolan i Linköping.

21. Ferntoft, Anders, 1999, Elektronisk affärskommunikation - Kontaktkostnader och kontaktprocesser mellan kunder och leverantörer på producentmarknader. Licentiatavhandling 751, IDA-EIS, Universitetet och Tekniska Högskolan i Linköping.

22. Alvehus, Johan, 1999, Mötets metaforer - En studie av berättelser om möten. Licentiatavhandling 753, IDA-EIS, Universitetet och Tekniska Högskolan i Linköping.

23. Skåmedal, Jo, 1999, Arbete på distans och arbetsformens påverkan på resor och resemönster. Licentiatavhandling 752, IDA-EIS, Universitetet och Tekniska Högskolan i Linköping.

24. Gäre, Klas, 1999, Verksamhetsförändringar i samband med ISinförande. Licentiatavhandling 791, IDA-EIS, Universitetet och Tekniska Högskolan i Linköping.

25. Björkegren, Charlotte, 1999, Learning for the Next Project - Bearers and Barriers in Knowledge Transfer within an Organisation. Licentiatavhandling 787, IDA-EIS, Universitetet och Tekniska Högskolan i Linköping.

26. Askenäs, Linda, 2000, Affärssystemet - En studie om teknikens aktiva och passiva roll i en organisation. Licentiatavhandling 808, IDA-EIS, Universitetet och Tekniska Högskolan i Linköping. 
27. Nilsson, Håkan, 2000, Informationsteknik som drivkraft i granskningsprocessen En studie av fyra revisionsbyråer. Licentiatavhandling 788, IDA-EIS, Universitetet och Tekniska Högskolan i Linköping.

28. Kald, Magnus, 2000, The Role of Management Control Systems in Strategic Business Units. Licentiatavhandling 842, IDA-EIS, Universitetet och Tekniska Högskolan i Linköping.

29. Cäker, Mikael, 2000, Vad kostar kunden? Modeller för intern redovisning. Licentiatavhandling 844, IDA-EIS, Universitetet och Tekniska Högskolan i Linköping.

30. Lindahl, Magnus, 2000, Bankens villkor i låneavtal vid kreditgivning till högt belånade företagsförvärv - En studie ur ett agentteoretiskt perspektiv. Licentiatavhandling 754, IDA-EIS, Universitetet och Tekniska Högskolan i Linköping.

31. Bergum, Svein, 2000, Managerial Communication in Telework. Licentiatavhandling 807, IDA-EIS, Universitetet och Tekniska Högskolan i Linköping.

32. Svarén, Stefan, 2001, Styrning av investeringar i divisionaliserade företag - Ett koncernperspektiv. Licentiatavhandling 894, IDA-EIS, Universitetet och Tekniska Högskolan i Linköping.

33. Sandell, Niklas, 2001, Redovisning i skuggan av en bankkris - Värdering av fastigheter. Licentiatavhandling 915, IDA-EIS, Universitetet och Tekniska Högskolan i Linköping.

34. Odar, Susanne, 2002, IT som stöd för strategiska beslut, en studie av datorimplementerade modeller av verksamhet som stöd för beslut om anskaffning av JAS 1982. Licentiatavhandling 916, IDA-EIS, Universitetet och Tekniska Högskolan i Linköping.

35. Hansson, Emma, 2001, Optionsprogram för anställda - En studie av svenska börsbolag. Licentiatavhandling 917, IDA-EIS, Universitetet och Tekniska Högskolan i Linköping.

36. Sevenius, Robert, 2002, On the Instruments of Governance - A Law \& Economics Study of Capital Instruments in Limited Liability Companies. Licentiatavhandling 956, IDA-EIS, Universitetet och Tekniska Högskolan i Linköping.

37. Berglund, Fredrika, 2002, Management Control and Strategy - A Case Study of Pharmaceutical Drug Development. Licentiatavhandling 958, IDA-EIS, Universitetet och Tekniska Högskolan i Linköping.

38. Nilsson, Peter, 2003, Svenska bankers redovisningsval vid reservering för befarade kreditförluster - En studie vid införande av nya redovisningsregler. Licentiatavhandling 1033, IDA-EIS, Universitetet och Tekniska Högskolan i Linköping.

39. Stoltz, Charlotte, 2004, Calling for Call Centres - A Study of Call Centre Locations in a Swedish Rural Region. Licentiatavhandling 1084, IDA-EIS, Universitetet och Tekniska Högskolan i Linköping. 
40. Sällberg, Henrik, 2004, On the Value of Customer Loyalty Programs - A Study of Point Programs and Switching Costs. Licentiatavhandling 1116, IDA-EIS, Universitetet och Tekniska Högskolan i Linköping.

41. Vascós Palacios, Fidel, 2005, On the Information Exchange between Physicians and Social Insurance Officers in the Sick Leave Process - An Activity Theoretical Perspective. Licentiatavhandling 1165, IDA-EIS, Universitetet och Tekniska Högskolan i Linköping.

42. Keller, Christina, 2005, Virtual Learning Environments in Higher Education - A Study of Students' Acceptance of Educational Technology. Licentiatavhandling 1167, IDA-EIS, Universitetet och Tekniska Högskolan i Linköping.

43. Ahlström,

Petter, 2005, Affärsstrategier

för seniorbostadsmarknaden. Licentiatavhandling 1172, IDA-EIS, Universitetet och Tekniska Högskolan i Linköping.

44. Cöster, Mathias, 2005, Beyond IT and Productivity - How Digitization Transformed the Graphic Industry. Licentiatavhandling 1183, IDA-EIS, Universitetet och Tekniska Högskolan i Linköping.

45. Horzella, Åsa, 2005, Beyond IT and Productivity - Effects of Digitized Information Flows in Grocery Distribution. Licentiatavhandling 1184, IDA-EIS, Universitetet och Tekniska Högskolan i Linköping.

46. Kollberg, Maria, 2005, Beyond IT and Productivity - Effects of Digitized Information Flows in the Logging Industry. Licentiatavhandling 1185, IDA-EIS, Universitetet och Tekniska Högskolan i Linköping.

47. Käll, Andreas, 2005, Översättningar av en managementmodell - En studie av införandet av Balanced Scorecard i ett landsting. Licentiatavhandling 1209, IDAEIS, Universitetet och Tekniska Högskolan i Linköping.

48. Mihailescu, Daniella, 2006, Implementation Methodology in Action - A Study of an Enterprise Systems Implementation Methodology. Licentiatavhandling 1233, IDA-EIS, Universitetet och Tekniska Högskolan i Linköping.

49. Park-Westman, Misook, 2006, Managing Competence Development Programs in a Cross-cultural Organisation - What are the Barriers and Enablers? Licentiatavhandling 1263, IDA-EIS, Universitetet och Tekniska Högskolan i Linköping.

50. Flodström, Raquel, 2006, A Framework for the Strategic Management of Information Technology. Licentiatavhandling 1272, IDA-EIS, Universitetet och Tekniska Högskolan i Linköping.

51. Fryk, Pontus, 2007, Beyond IT and Productivity - Effects of Digitized Information Flows in Health Care. Licentiatavhandling 1328, IEI-EIS, Universitetet och Tekniska Högskolan i Linköping.

52. Lundmark, Erik, 2008, Organisational Adoption of Innovations - Management Practices and IT. Licentiatavhandling 1352, IEI-EIS, Universitetet och Tekniska Högskolan i Linköping. 
53. Anjou, Annette, 2008, Scanias framgång - Betydelsen av strategisk kongruens och integrerad styrning. Licentiatavhandling 1364, IEI-EIS, Universitetet och Tekniska Högskolan i Linköping.

54. Fagerberg, Jesper, 2008, Occupational Fraud - Auditors' Perceptions of Red Flags and Internal Control. Licentiatavhandling 1369, IEI-EIS, Universitetet och Tekniska Högskolan i Linköping.

55. Arwinge, Olof, 2010, Internal Control - A Study of the Concept and Themes of Internal Control. Licentiatavhandling 1431, IEI-EIS, Universitetet och Tekniska Högskolan i Linköping.

56. Svensson, Martin, 2010, Routines for Engagement - Emotions and Routines when Communicating through ICTs. Licentiatavhandling 1444, IEI-EIS, Universitetet och Tekniska Högskolan i Linköping.

57. Gullberg, Cecilia, 2011, Puzzle or Mosaic? On Managerial Information Patterns. Licentiatavhandling 1483, IEI-EIS, Universitetet och Tekniska Högskolan i Linköping.

58. Styf, Elisabeth, 2011, Styrelsens ansvar för den interna koden. Licentiatavhandling 1491, IEI-EIS, Universitetet och Tekniska Högskolan i Linköping.

59. Granath, Malin, 2012, Kan professioner organiseras fram? - En fallstudie av den kommunala energi- och klimatrådgivningen. Licentiatavhandling 1519, IEI-EIS, Universitetet och Tekniska Högskolan i Linköping.

60. Eriksson, Emelie, 2017, Patterns of corporate visual self-representations in accounting narratives. Licentiatavhandling 1792, IEI-EIS, Universitetet och Tekniska Högskolan i Linköping. 



\section{The Swedish Research School of Management and Information Technology MIT}

The Swedish Research School of Management and Information Technology (MIT) is one of 16 national research schools supported by the Swedish Government. MIT is jointly operated by the following institutions: Blekinge Institute of Technology, Chalmers University of Technology, University of Gothenburg, Jönköping International Business School, Karlstad University, Linköping University, Linnaeus University Växjö, Lund University, Mälardalen University College, Stockholm University, Umeå University, Örebro University, and Uppsala University, host to the research school. At the Swedish Research School of Management and Information Technology (MIT), research is conducted, and doctoral education provided, in three fields: management information systems, business administration, and informatics.

\section{DISSERTATIONS FROM THE SWEDISH RESEARCH SCHOOL OF MANAGEMENT AND INFORMATION TECHNOLOGY}

\section{Doctoral theses (2003- )}

1. Baraldi, Enrico (2003), When Information Technology Faces Resource Interaction: Using IT Tools to Handle Products at IKEA and Edsbyn. Department of Business Studies, Uppsala University, Doctoral Thesis No. 105.

2. Wang, Zhiping (2004), Capacity-Constrained Production-Inventory Systems: Modelling and Analysis in both a Traditional and an E-Business Context. IDA-EIS, Linköpings universitet och Tekniska Högskolan i Linköping, Dissertation No. 889

3. Ekman, Peter (2006), Enterprise Systems \& Business Relationships: The Utilization of IT in the Business with Customers and Suppliers. School of Business, Mälardalen University, Doctoral Dissertation No 29.

4. Lindh, Cecilia (2006), Business Relationships and Integration of Information Technology. School of Business, Mälardalen University, Doctoral Dissertation No 28.

5. Frimanson, Lars (2006), Management Accounting and Business Relationships from a Supplier Perspective. Department of Business Studies, Uppsala University, Doctoral Thesis No. 119.

6. Johansson, Niklas (2007), Self-Service Recovery. Information Systems, Faculty of Economic Sciences, Communication and IT, Karlstad University, Dissertation KUS 2006:68.

7. Sonesson, Olle (2007), Tjänsteutveckling med personal medverkan: En studie av banktjänster. Företagsekonomi, Fakulteten för ekonomi, kommunikation och IT, Karlstads universitet, Doktorsavhandling, Karlstad University Studies 2007:9. 
8. Maaninen-Olsson, Eva (2007), Projekt $i$ tid och rum: Kunskapsintegrering mellan projektet och dess historiska och organisatoriska kontext. Företagsekonomiska institutionen, Uppsala universitet, Doctoral Thesis No. 126.

9. Keller, Christina (2007), Virtual learning environments in higher education: A study of user acceptance. Linköping Studies in Science and Technology, Dissertation No. 1114.

10. Abelli, Björn (2007), On Stage! Playwriting, Directing and Enacting the Informing Processes. School of Business, Mälardalen University, Doctoral Dissertation No. 46.

11. Cöster, Mathias (2007), The Digital Transformation of the Swedish Graphic Industry. Linköping Studies in Science and Technology, Linköping University, Dissertation No. 1126.

12. Dahlin, Peter (2007), Turbulence in Business Networks: A Longitudinal Study of Mergers, Acquisitions and Bankruptcies Involving Swedish IT-companies. School of Business, Mälardalen University, Doctoral Thesis No. 53.

13. Myreteg, Gunilla (2007), Förändringens vindar: En studie om aktörsgrupper och konsten att välja och införa ett affärssystem. Företagsekonomiska institutionen, Uppsala universitet, Doctoral Thesis No. 131.

14. Hrastinski, Stefan (2007), Participating in Synchronous Online Education. School of Economics and Management, Lund University, Lund Studies in Informatics No. 6.

15. Granebring, Annika (2007), Service-Oriented Architecture: An Innovation Process Perspective. School of Business, Mälardalen University, Doctoral Thesis No. 51.

16. Lövstål, Eva (2008), Management Control Systems in Entrepreneurial Organizations: A Balancing Challenge. Jönköping International Business School, Jönköping University, JIBS Dissertation Series No. 045.

17. Hansson, Magnus (2008), On Closedowns: Towards a Pattern of Explanation to the Closedown Effect. Swedish Business School, Örebro University, Doctoral Thesis No. 1.

18. Fridriksson, Helgi-Valur (2008), Learning processes in an inter-organizational context: $A$ study of krAft project. Jönköping International Business School, Jönköping University, JIBS Dissertation Series No. 046.

19. Selander, Lisen (2008), Call Me Call Me for some Overtime: On Organizational Consequences of System Changes. Institute of Economic Research, Lund Studies in Economics and Management No. 99.

20. Henningsson, Stefan (2008), Managing Information Systems Integration in Corporate Mergers \& Acquisitions. Institute of Economic Research, Lund Studies in Economics and Management No. 101.

21. Ahlström, Petter (2008), Strategier och styrsystem för seniorboende-marknaden. IEI-EIS, Linköping universitetet och Tekniska Högskolan i Linköping, Doktorsavhandling, Nr. 1188.

22. Sörhammar, David (2008), Consumer-firm business relationship and network: The case of "Store" versus Internet. Department of Business Studies, Uppsala University, Doctoral Thesis No. 137. 
23. Caesarius, Leon Michael (2008), In Search of Known Unknowns: An Empirical Investigation of the Peripety of a Knowledge Management System. Department of Business Studies, Uppsala University, Doctoral Thesis No. 139.

24. Cederström, Carl (2009), The Other Side of Technology: Lacan and the Desire for the Purity of Non-Being. Institute of Economic Research, Lund University, Doctoral Thesis, ISBN: 9185113-37-9.

25. Fryk, Pontus, (2009), Modern Perspectives on the Digital Economy: With Insights from the Health Care Sector. Department of Business Studies, Uppsala University, Doctoral Thesis No. 145.

26. Wingkvist, Anna (2009), Understanding Scalability and Sustainability in Mobile Learning: A Systems Development Framework. School of Mathematics and Systems Engineering, Växjö University, Acta Wexionesia, No. 192, ISBN: 978-91-7636-687-5.

27. Sällberg, Henrik (2010), Customer Rewards Programs: Designing Incentives for Repeated Purchase. Blekinge Institute of Technology, School of Management, Doctoral Dissertation Series No. 2010:01.

28. Verma, Sanjay (2010), New Product Newness and Benefits: A Study of Software Products from the Firms' Perspective, Mälardalen University Press, Doctoral Thesis.

29. Iveroth, Einar (2010), Leading IT-Enabled Change Inside Ericsson: A Transformation Into a Global Network of Shared Service Centres. Department of Business Studies, Uppsala University, Doctoral Thesis No. 146.

30. Nilsson, Erik (2010), Strategi, styrning och konkurrenskraft: En longitudinell studie av Saab $A B$, IEI-EIS, Linköpings universitet och Tekniska Högskolan i Linköping, Doktorsavhandling, Nr. 1318.

31. Sjöström, Jonas (2010), Designing Information Systems: A pragmatic account, Department of Informatics and Media, Uppsala University, Doctoral Thesis.

32. Numminen, Emil (2010), On the Economic Return of a Software Investment: Managing Cost, Benefit and Uncertainty, Blekinge Institute of Technology, School of Management, Doctoral Thesis.

33. Frisk, Elisabeth (2011), Evaluating as Designing: Towards a Balanced IT Investment Approach, IT University, Göteborg, Doctoral Thesis.

34. Karlsudd, Peter (2011), Support for Learning: Possibilities and Obstacles in Learning Applications, Mälardalen University, Doctoral Thesis.

35. Wicander, Gudrun (2011), Mobile Supported e-Government Systems: Analysis of the Education Management Information System (EMIS) in Tanzania, Karlstad University, Doctoral Thesis. Karlstad University Studies 2011:49.

36. Åkesson, Maria (2011), Role Constellations in Value Co-Creation: A Study of Resource Integration in an e-Government Context, Karlstad University, Doctoral Thesis. Karlstad University Studies 2011:36. 
37. Nfuka, Edephonce N. (2012), IT Governance in Tanzanian Public Sector Organisations, Department of Computer and Systems Sciences, Stockholm University, Doctoral Thesis.

38. Larsson, Anders Olof (2012), Doing Things in Relation to Machines: Studies on Online Interactivity, Department of Informatics and Media, Uppsala University, Doctoral Thesis.

39. Andersson, Bo (2012), Harnessing Handheld Computing: Framework, Toolkit and Design Propositions, Lund University, Doctoral Thesis.

40. Erixon, Cecilia (2012), Information System Providers and Business Relationships: A Study on the Impact of Connections, Mälardalen University, Doctoral Thesis.

41. Svensson, Martin (2012), Routes, Routines and Emotions in Decision Making of Emergency Call Takers, Blekinge Institute of Technology, Doctoral Dissertation Series No. 2012:04.

42. Svensson, Ann (2012), Kunskapsintegrering med informationssystem I professionsorienterade praktiker, Institutionen för tillämpad IT, Göteborgs universitet, Doktorsavhandling.

43. Pareigis, Jörg (2012), Customer Experiences of Resource Integration: Reframing Servicescapes Using Scripts and Practices, Karlstad University, Doctoral Thesis. Karlstad University Studies 2012:38.

44. Röndell, Jimmie (2012), From Marketing to, to Marketing with Consumers, Department of Business Studies, Uppsala University, Doctoral Thesis No. 155.

45. Lippert, Marcus (2013), Communities in the Digital Age: Towards a Theoretical Model of Communities of Practice and Information Technology, Department of Business Studies, Uppsala University, Doctoral Thesis No. 156.

46. Netz, Joakim (2013), Diffusa spänningar eller spännande tillväxt? Företagsledning $i$ tider av snabb förändring, Mälardalens högskola, Doktorsavhandling $\mathrm{nr} 135$.

47. Thorén, Claes (2013), Print or Perish? A Study of Inertia in a Regional Newspaper Industry, Karlstad University, Doctoral Thesis. Karlstad University Studies 2014:10 (Ny uppl.).

Stockhult, Helén (2013), Medarbetare $i$ dialog: en studie om viljan att göra mer än det formellt förväntade, Örebro universitet, Örebro Studies in Business Dissertations, 4.

48. Mihailescu, Daniela (2013), Explaining the Use of Implementation Methodology in Enterprise Systems Implementation Context: A Critical Realist Perspective, Lund University, Doctoral Thesis.

49. Ghazawneh, Ahmad (2012), Towards a Boundary Resources Theory of Software Platforms, Jönköping International Business School, Doctoral Thesis.

50. Shams, Poja (2013), What Does it Take to Get your Attention? The Influence of In-Store and Out-of-Store Factors on Visual Attention and Decision Making for Fast-Moving Consumer Goods, Karlstad University, Doctoral Thesis. Karlstad University Studies 2013:5.

51. Osowski, Dariusz (2013), From Illusiveness to Genuineness: Routines, Trading Zones, Tools and Emotions in Sales Work, Department of Business Studies, Uppsala University, Doctoral Thesis No. 160. 
52. Höglund, Linda (2013), Discursive Practises in Strategic Entrepreneurship: Discourses and Repertoires in Two Firms, Örebro University, Doctoral Thesis.

53. Persson Ridell, Oscar (2013), Who is the Active Consumer? Insight into Contemporary Innovation and Marketing Practices, Department of Business Studies, Uppsala University, Doctoral Thesis.

54. Kask, Johan (2013), On business relationships as Darwinian systems: An exploration into how Darwinian systems thinking can support business relationship research, Örebro University, Doctoral Thesis.

55. Paulsson, Wipawee Victoria (2013), The Complementary Use of IS Technologies to Support Flexibility and Integration Needs in Budgeting, Lund University, Doctoral Thesis.

56. Kajtazi, Miranda (2013), Assessing Escalation of Commitment as an Antecedent of Noncompliance with Information Security Policy, Linnaeus University, Doctoral Thesis.

57. Hasche, Nina (2013), Value Co-Creating Processes in International Business Relationships: Three empirical stories of co-operation between Chinese customers and Swedish suppliers, Örebro University, Doctoral Thesis.

58. Pierce, Paul (2013), Using Alliances to Increase ICT Capabilities, Lund University, Doctoral Thesis.

59. Mansour, Osama (2013), The Bureaucracy of Social Media: An Empirical Account in Organizations, Linnaeus University, Doctoral Thesis.

60. Osmonalieva, Zarina (2013), Factors Determining Exploitation of Innovative Venture Ideas: A study of nascent entrepreneurs in an advisory system, Mälardalen University, Doctoral Thesis.

61. Holmberg, Nicklas (2014), The Purity of Separation of Concerns: The Service Oriented Business Process - a Design Approach for Business Agility, Lund University, Doctoral Thesis.

62. Poth, Susanna (2014), Competitive Advantage in the Service Industry. The Importance of Strategic Congruence, Integrated Control and Coherent Organisational Structure: A Longitudinal Case Study of an Insurance Company, Department of Business Studies, Uppsala University, Doctoral Thesis.

63. Safari, Aswo (2014), Consumer Foreign Online Purchasing: Uncertainty in the ConsumerRetailer Relationship, Department of Business Studies, Uppsala University, Doctoral Thesis.

64. Sandberg, Johan (2014), Digital Capability: Investigating Coevolution of IT and Business Strategies, Umeå University, Doctoral Thesis.

65. Eklinder Frick, Jens (2014), Sowing Seeds for Innovation: The Impact of Social Capital in Regional Strategic Networks, Mälardalen University, Doctoral Thesis.

66. Löfberg, Nina (2014), Service Orientation in Manufacturing Firms: Understanding Challenges with Service Business Logic, Karlstad University, Doctoral Thesis. Karlstad University Studies 2014:30. 
67. Gullberg, Cecilia (2014), Roles of Accounting Information in Managerial Work, Department of Business Studies, Uppsala University, Doctoral Thesis No. 171.

68. Bergkvist, Linda (2014), Towards a Framework for Relational-Oriented Management of Information Systems Outsourcing: Key Conditions Connected to Actors, Relationships and Process, Karlstad University, Doctoral Thesis. Karlstad University Studies 2014:31.

69. Tavassoli, Sam (2014), Determinants and Effects of Innovation: Context Matters, Blekinge Institute of Technology, Doctoral Thesis No. 2014:10.

70. Högström, Claes (2014), Fit In to Stand Out: An Experience Perspective on Value Creation, Karlstad University, Doctoral Thesis. Karlstad University Studies 2014:44.

71. Jansson, Tomas (2015), Agila projektledningsmetoder och motivation, Karlstads universitet, Doctoral Thesis. Karlstad University Studies 2015:9.

72. Ryzhkova, Natalia (2015), Web-Enabled Customer Involvement: A Firms' Perspective, Blekinge Institute of Technology, Doctoral Thesis.

73. Sundberg, Klas (2015), Strategisk utveckling och ekonomistyrning: Ett livscykelperspektiv. Företagsekonomiska institutionen, Uppsala universitet, Doctoral Thesis No. 173.

74. Nylén, Daniel (2015), Digital Innovation and Changing Identities: Investigating Organizational Implications of Digitalization, Umeå University, Doctoral Thesis.

75. Chowdhury, Soumitra (2015), Service Logic in Digitalized Product Platforms: A Study of Digital Service Innovation in the Vehicle Industry, Gothenburg University, Doctoral Thesis.

76. Jogmark, Marina (2015), Den regionala transformationsprocessens sociala dimension. Karlskrona 1989-2002, Blekinge Tekniska Högskola, Doctoral Thesis.

77. Sundström, Angelina (2015), Old Swedish Business in New International Clothes: Case Studies on the Management of Strategic Resources in Foreign-Acquired Swedish R\&D Firms, Mälardalen University, Doctoral Thesis.

78. Öbrand, Lars (2015), Information Infrastructure Risk: Perspectives, Practices \& Technologies, Umeå University, Doctoral Thesis.

79. Brozović, Danilo (2016), Service Provider Flexibility: A Strategic Perspective, Stockholm University, Doctoral Thesis.

80. Siegert, Steffi (2016), Enacting Boundaries through Social Technologies: A Dance between Work and Private Life, Stockholm University, Doctoral Thesis.

81. Linton, Gabriel (2016), Entrepreneurial Orientation: Reflections from a Contingency Perspective, Örebro University, Doctoral Thesis.

82. Akram, Asif (2016), Value Network Transformation: Digital Service Innovation in the Vehicle Industry, Department of Applied Information Technology, Chalmers University of Technology and University of Gothenburg, Doctoral Thesis. 
83. Hadjikhani, Annoch (2016), Executive Expectation in the Internationalization Process of Banks: The Study of Two Swedish Banks Foreign Activities, Department of Business Studies, Uppsala University, Doctoral Thesis No. 177.

84. El-Mekawy, Mohamed (2016), From Theory to Practice of Business-IT Alignment: Barriers, an Evaluation Framework and Relationships with Organizational Culture, DSV, Stockholm University, Doctoral Thesis.

85. Salavati, Sadaf (2016), Use of Digital Technologies in Education: The Complexity of Teachers' Everyday Practice, Linnaeus University, Doctoral Thesis.

86. Pashkevich, Natallia (2016), Information Worker Productivity Enabled by IT System Usage: A Complementary-Based Approach, Stockholm Business School, Stockholm University, Doctoral Thesis.

87. Stone, Trudy-Ann (2016), Firms in Global Value Chains, Blekinge Institute of Technology (BTH), Doctoral Thesis.

88. Saarikko, Ted (2016), An Inquiry into the Nature and Causes of Digital Platforms, Umeå University, Doctoral Thesis.

89. Tona, Olgerta (2017), The Journey of Mobile Business Intelligence: From Vision to Use, Lund University, Doctoral Thesis.

90. Fredin, Sabrina (2017), History and Geography Matter: The Cultural Dimension of Entrepreneurship, Blekinge Institute of Technology, Doctoral Thesis.

91. Giovacchini, Elia (2017), Weaving the Symbiotic Relationship: A Longitudinal Study of a Firm-Sponsored Open Source Community Relationship Maintenance, Stockholm Business School, Stockholm University, Doctoral Thesis.

92. Gillmore, Edward (2017), Four Essays on Subsidiary Evolution: Exploring the Antecedents, Contexts and Outcomes of Mandate Loss, School of Business, Mälardalen University, Doctoral Thesis.

93. Crawford, Jason (2017), Regulation's Influence on Risk Management and Management Control Systems in Banks, Department of Business Studies, Uppsala University, Doctoral Thesis.

94. Von Schantz, Hanna (2017), Well, that makes sense! Investigating opportunity development in a technology start-up, Stockholm Business School, Stockholm University, Doctoral Thesis.

95. Wass, Sofie (2017), The Importance of eHealth Innovations: Lessons about Patient Accessible Information, Jönköping International Business School, Doctoral Thesis.

96. Imre, Özgün (2018), Adopting Information Systems: Perspectives from Small Organizations, Department of Management and Engineering (IEI), Linköping University, Doctoral Thesis.

97. Lövgren, Daniel (2017), Dancing Together Alone: Inconsistencies and Contradictions of Strategic Communication in Swedish Universities, Informatics and Media, Uppsala University, Doctoral Thesis. 
98. Charitsis, Vasileios (2018), Self-Tracking, Datafication and the Biopolitical Prosumption of Life, Karlstad University, Doctoral Thesis.

99. Lammi, Inti (2018), A Practice Theory in Practice: Analytical Consequences in the Study of Organization and Socio-Technical Change, Department of Business Studies, Uppsala University, Doctoral Thesis.

100. Leite, Emilene (2018), Complexity in the 'Extended' Business Network: A study of Business, Social and Political Relationships in Smart City Solutions, Department of Business Studies, Uppsala University, Doctoral Thesis.

101. Aasi, Parisa (2018), Information Technology Governance: The Role of Organizational Culture and Structure, Department of Computer and Systems Sciences, Stockholm University, Doctoral Thesis.

102. Servadio, Luigi (2018), Customer Rituals: Ethnographic Explorations of Wine Rituals with Families and Friends, Stockholm Business School, Stockholm University, Doctoral Thesis.

103. Ahlgren, Kajsa (2018), Travelling Business Models: On Adapting Business Models to New Contexts, Design Sciences, Faculty of Engineering, Lund University, Doctoral Thesis.

104. Markowski, Peter (2018), Collaboration Routines: A Study of Interdisciplinary Healthcare, Stockholm Business School, Stockholm University, Doctoral Thesis.

105.Zaffar, Fahd Omair (2018), The Value of Social Media: What Social Networking Sites Afford Organizations, Division of Informatics, Department of Applied Information Technology, University of Gothenburg, Doctoral Thesis.

106. Stendahl, Emma (2018), Headquarters Involvement in Managing Subsidiaries, Stockholm Business School, Stockholm University, Doctoral Thesis.

107. Fischer, Christian (2018), Business Intelligence through a Sociomaterial Lens: The Imbrication of People and Technology in a Sales Process, Department of Business Studies, Uppsala University, Doctoral Thesis.

108. Lagin, Madelen (2018), The Price We Pay: The Autonomy of Store Managers in Making Price Decisions, Department of Business Studies, Örebro University, Doctoral Thesis.

109. Odar, Susanne (2019), Managementinitiativ, mening och verksamhetsresultat: En retrospektiv studie av en teknikintensiv verksamhet, Department of Management and Engineering (IEI), Linköping University, Linköping Studies in Science and Technology, Doctoral Thesis.

110. Radits, Markus (2019), A Business Ecology Perspective on Community-Driven Open Source: The Case of the Free and Open Source Content Management System Joomla, Department of Management and Engineering (IEI), Linköping University, Linköping Studies in Science and Technology, Doctoral Thesis No. 1937. 